\title{
SERIES
}

Alpine Forschungsstelle Obergurgl

Band 1

innsbruck university press

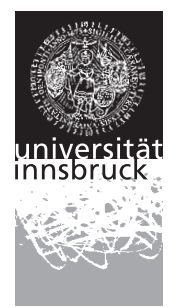


Dankesworte

Die Herausgeberinnen bedanken sich sehr herzlich bei allen Autorlnnen für die gute Zusammenarbeit und die spontane Bereitschaft, dieses Buchprojekt mitzutragen. Ein besonderer Dank ergeht an den Vizerektor für Forschung der Universität Innsbruck, Herrn Univ.-Prof. Dr. Dr.h.c.mult. Tilmann Märk, für die Finanzierung des Buches. Die Stiftung „Jubiläumsfonds der Leopold-Franzens-Universität Innsbruck“ unterstützte den Druck des Buches. 
Eva-Maria Koch, Brigitta Erschbamer (Hg.)

\section{Glaziale und periglaziale Lebensräume im Raum Obergurgl}




\section{Eva-Maria Koch}

Alpine Forschungsstelle Obergurgl, Universität Innsbruck

\section{Brigitta Erschbamer}

Institut für Botanik, Universität Innsbruck

Diese Publikation wurde mit finanzieller Unterstützung aus den Fördermitteln des Vizerektorats für Forschung der Leopold-Franzens-Universität Innsbruck gedruckt.

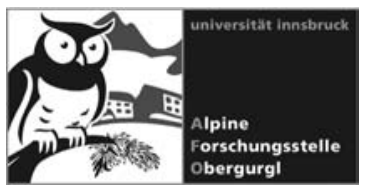

(c) innsbruck university press, 2010

Universität Innsbruck, Vizerektorat für Forschung

Alle Rechte vorbehalten.

Das Werk ist urheberrechtlich geschützt. Die Rechte für Nachdruck, Übersetzung sowie der Entnahme von Abbildungen und Bildern liegen bei den Herausgeberinnen bzw. bei den jeweiligen AutorInnen. Die in den Beiträgen geäußerten Meinungen müssen nicht mit denen der Herausgeberinnen übereinstimmen.

Umschlag: Gregor Sailer

Umschlagmotiv: Blick über die Hohe Mut in die Gletschervorfelder des Rotmoosferners (Vorderseite) und des Gaisbergferners (Rückseite), Obergurgl, Ötztal

Foto: Erich Schwienbacher (25.07.2008)

Layout: Carmen Drolshagen

Produktion: Fred Steiner, Rinn

www.uibk.ac.at/iup

www.uibk.ac.at/afo

ISBN 978-3-902719-50-8 


\section{Inhaltsverzeichnis}

Vorwort

Eva-Maria Koch, Brigitta Erschbamer

\section{Einleitung}

Das Ötztal -Topographische Kennzeichnung 9

Gernot Patzelt

Kapitel 1 I Historisches zum Thema Gletscher,

Gletschervorfeld und Obergurgl

Wolfgang Meixner, Gerhard Siegl

Kapitel 2 | Geologie und Geomorphologie von Obergurgl und Umgebung 31

Karl Krainer

Kapitel 3 I Klima und Gletscher in Obergurgl 53

Andrea Fischer

Kapitel 4 I Klima- und Vegetationsgeschichte

Das Rotmoostal im Wandel (1895-2009)

Eva-Maria Koch

Vegetationsgeschichte im Bereich des Rotmoostales

Sigmar Bortenschlager

Kapitel 5 I Die Böden eines alpinen Gletschertales 93

Erich Schwienbacher, Eva-Maria Koch 
Inhaltsvzerzeichnis

Kapitel 6 I Pflanzliche Sukzession im Gletschervorfeld

Vegetation und Besiedlungsstrategien

Fabian Nagl, Brigitta Erschbamer

Zur Kryptogamenflora im Rotmoostal

Georg Gärtner

Die Flechten im Gletschervorfeld des Rotmoosferners

Roman Türk, Brigitta Erschbamer

Kapitel 7 I Die tierische Besiedlung von Gletschermoränen

165

Eva-Maria Koch, Rüdiger Kaufmann

Kapitel 8 | Aquatische Lebensräume

Hochalpine Flusslandschaft Rotmoos

Leopold Füreder

Lebensraumtypen und Diversitätsgradienten

lotischer Algen in einem Gletschereinzugsgebiet

Eugen Rott, Doris Gesierich, Nico Binder

Kapitel 9 I Pilze und mikrobielle Gemeinschaften im Gletschervorfeld

Ursula Peintner, Regina Kuhnert

Kapitel 10 I Leben auf Schnee und Eis

Birgit Sattler, Daniel Remias, Cornelius Lütz,

Hieronymus Dastych, Roland Psenner

Anhang 


\section{Vorwort}

Nahe am Alpenhauptkamm, mitten im Herzen der Alpen, liegt die Alpine Forschungsstelle Obergurgl (AFO), eine Außenstelle der Universität Innsbruck. Sie ist seit Jahrzehnten eine Anlauf- und Koordinationsstelle für Hochgebirgsforschung in den Zentralalpen, bietet Unterkunft sowie Arbeitsräume und stellt wissenschaftliche Daten und Informationen zur Verfügung.

Die AFO wurde im Jahr 1951 von Prof. Wolfgang Burger gleichzeitig mit dem Bundessportheim Obergurgl ins Leben gerufen. Er wählte drei leerstehende Zollhäuser aus, um in den Österreichischen Zentralalpen eine allseitig naturforschende Stelle einzurichten, deren Aufgabe es sein sollte, Alpinismus, alpinen Skilauf, Wissenschaft im und vom Hochgebirge mit Gästen aus allen Ländern Europas und allen Erdteilen zu pflegen.

Die wissenschaftlichen Kuratoren und Leiter der Alpinen Forschungsstelle ließen die Forschung im Ötztal aufleben und widmeten sich im Laufe der kommenden Jahre zahlreichen verschiedenen Themen, wie der Sammlung von Tier- und Pflanzenarten, Untersuchungen von Lebensgemeinschaften sowie der Höhen- und Sportmedizin. Seit 1951 werden zudem mit Hilfe einer meteorologischen Station Wetterbeobachtungen durchgeführt.
Mit den Forschungstätigkeiten des gebürtigen Längenfelders Dr. Walter Moser wuchs der internationale Ruf der Alpinen Forschungsstelle. Walter Moser begann 1970 auf dem Hohen Nebelkogel (3.200 m) bei Sölden die Anpassungsstrategien von Pflanzen an die Umweltbedingungen des Hochgebirges zu untersuchen. Im Jahr 1973 wurde Obergurgl unter seiner Leitung als Fallstudie für ein MAB (Men and Biosphere)-Projekt der UNESCO ausgewählt. Gemeinsam mit den Dorfbewohnern versuchten WissenschaftlerInnen Daten für ein Computermodell zu generieren. Die ökologischen und ökonomischen Zukunftsoptionen der Region wurden damit modelliert und standen der lokalen Bevölkerung als Entscheidungshilfe zur Verfügung.

Von 1979 bis 1999 übernahm Prof. Gernot Patzelt die Leitung der AFO, die seinem Forschungsinstitut für Hochgebirgsforschung zugeordnet wurde. Er beschäftigte sich vor allem mit Gletscherund Klimageschichtsforschung, Massenbewegungen und historischer Natur- und Kulturlandschaftsentwicklung im alpinen Bereich.

Auch heute werden im inneren Ötztal zahlreiche Forschungsprojekte verschiedenster Fachrichtungen durchgeführt. Die AFO möchte die Ergebnisse in einer Buchserie „Lebensräume des inne- 
ren Ötztales“ veröffentlichen. In ihrem ersten Buch präsentiert sie die Arbeiten von WissenschaftlerInnen, die in glazialen und periglazialen Lebensräumen tätig sind. Die Kapitel spannen einen Bogen von Gletschern über rezent eisfreie Flächen bis hin zu älteren Moränen und Bereichen außerhalb des Gletschervorfeldes. Dieses Werk soll allen Interessierten breitgefächerte, wissenschaftliche Informationen über die Region liefern. Zudem wird aufgezeigt, welche Forschungsfragen bereits untersucht worden sind und welche Wissenslücken nach wie vor bestehen.

Warum die Forschungstätigkeit im Hochgebirge wichtig ist, lässt sich mehrfach verdeutlichen. Es handelt sich zumeist um Grundlagenforschung, die nicht unmittelbar auf praktische Anwendungen abzielt. Sie hilft uns, das Funktionieren von Ökosystemen unter den extremen Bedingungen des Hochgebirges besser zu verstehen, und zeigt auf, welche Umweltfaktoren die Entwicklung bestimmen, auf welche Veränderungen Ökosysteme empfindlich reagieren und gegen welche Einflüsse sie robust sind. Die gesammelten Erkenntnisse können in Zukunft aber auch für praktische Bereiche wichtig sein, wie beispielweise für die effektive Rekultivierung von erodierten Hängen im Hochgebirge oder für die Erstellung von Prognosen (Klimawandel,
Naturgefahren, Vegetationsentwicklung, Wasserhaushalt). Vor allem im Hinblick auf die weitläufigen Veränderungen des Klimas sind die Kenntnisse über glaziale und periglaziale Lebensräume von großer Bedeutung. Betrachtet man die Bilderserie vom Rotmoostal (Kap. 4, Koch), wird deutlich, welch rasche Entwicklungen diese Lebensräume beeinflussen.

Obergurgl und im Speziellen das Rotmoostal und seine Umgebung eignen sich ganz besonders für die Erforschung glazialer und periglazialer Lebensräume. Die Ötztaler Alpen sind einerseits die am stärksten vergletscherte Gebirgsgruppe Österreichs, unterschiedlichste Lebensräume treten in großer Dichte nebeneinander auf. Andererseits sind die alpinen Untersuchungsflächen leicht erreichbar. Auch der Rückzug der Gletscher ist im Rotmoostal anhand der Moränen gut ersichtlich und zeitlich datierbar. Die Natur selbst führt hier „ein Experiment" durch: die Besiedelung der eisfrei werdenden Moränen gibt uns die einmalige Möglichkeit, das Entstehen von neuen Lebensgemeinschaften unter den Bedingungen des Hochgebirges zu beobachten und zu analysieren.

Eva-Maria Koch \& Brigitta Erschbamer Alpine Forschungsstelle Obergurgl 


\section{Einleitung | Das Ötztal - Topographische Kennzeichnung}

Gernot Patzelt

Das Einzugsgebiet der Ötztaler Ache ist mit $893 \mathrm{~km}^{2}$ das flächengrößte der Stubaier-Ötztaler Alpen. Kennzeichnend ist die Höhenverteilung mit den großen Flächenanteilen im oberen Stockwerk des Gebirgsmassives, wie Abb. 1 zeigt. Rund 50 \% der Gesamtfläche des Einzugsgebietes (EZG) liegt über 2500 m Höhe. Die vier Höhenstufen zwischen 2500 und 2900 m umfassen rund 30 \% der EZGFläche. Das hat unmittelbaren Einfluss auf das Abflussregime der Ache, wenn z.B. im Frühsommer die Schneeschmelze diese Höhenstufe erreicht und zum alljährlichen Schmelzhochwasser führt. Für die Entwicklung von Schadenshochwassersituationen ist es entscheidend, ob spätsommerliche Niederschläge in Höhenlagen über $2500 \mathrm{~m}$ als Schnee oder als Regen fallen.

Die Gletscherfläche des EZG der Ötztaler Ache hat im Jahre $1969130 \mathrm{~km}^{2}$ betragen. Seither sind $15 \mathrm{~km}^{2}$ Eis abgeschmolzen. Im Gurgler Tal hat die Gletscherfläche von $28 \mathrm{~km}^{2}$ (1969) auf $24 \mathrm{~km}^{2}$ abgenommen. Seit dem letzten Gletscherhochstand um 1850/55 sind im EZG rund 95 $\mathrm{km}^{2}$ eisfrei geworden, das sind $45 \%$ der ehemaligen Gletscherfläche.
Diese seit rund 150 Jahren eisfrei werdenden Gebiete werden Gletschervorfelder genannt. Das sind Areale, in denen Prozesse der Wiederbesiedlung durch die Tier- und Pflanzenwelt gut studiert werden können. Im Vorfeld des Rotmoosferners werden exemplarisch Untersuchungen dieser Art durchgeführt. Die Vergrößerung der Gletschervorfelder beeinflusst aber auch das Abflussverhalten und den Sedimenttransport der Gletscherbäche maßgeblich, mit Folgen für die Siedlungsgebiete in tieferliegenden Talabschnitten.

Für das EZG wurde eine mittlere Höhenlage der potentiellen Waldgrenze in $2300 \mathrm{~m}$ festgelegt, was nicht ausschließt, dass auf begünstigten Standorten Waldbäume kleinflächig auch bis $2400 \mathrm{~m}$ aufkommen. Der aktuellen Waldfläche von $130 \mathrm{~km}^{2}$ steht eine potentielle von $290 \mathrm{~km}^{2}$ gegenüber. $160 \mathrm{~km}^{2}$ Wald wurde durch menschliche Tätigkeit in Kulturland umgewandelt, wobei seit jeher die Weidenutzung der Hochlagen vorherrscht. Im Gegensatz zu den naturgesteuerten Veränderungen in der Gletscherregion der letzten 150 Jahre ist der menschliche Einfluss auf die Waldverbreitung ein Jahrtausende zurückreichender 


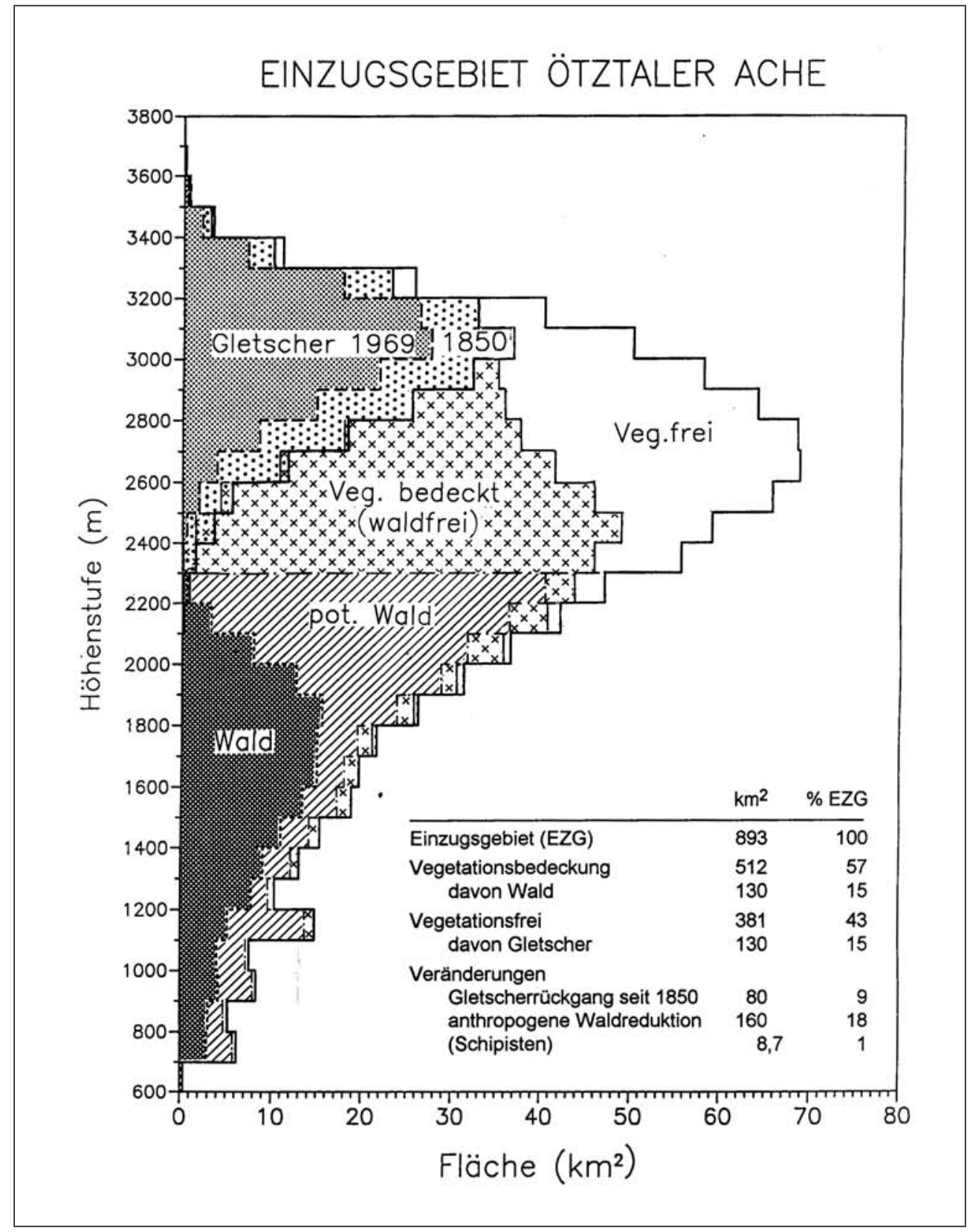

Abb. 1:

Flächenanteile in $100 \mathrm{~m}$ - Höhenstufen des Einzugsgebietes der Ötztaler Ache mit den Anteilen der Gletscherflächen von 1969 und 1850, der Vegetationsfläche sowie der aktuellen und potentiellen Waldfläche. 
Vorgang. Seit 6800 Jahren ist Weidewirtschaft im Ötztaler Gebirgsraum - speziell im Gurgltal am Beilstein - nachweisbar und zeigt in der Bronzezeit vor 3500 Jahren eine Ausbreitung bis in Höhen von $2500 \mathrm{~m}$. Danach folgt die weitere Nutzung mit wechselnder, aber nicht mehr unterbrochener Intensität und erreicht im Hochmittelalter mit dem Ausbau der Dauersiedlung bis über die Getreideanbaugrenze einen neuen Höhepunkt. Davon ist mit den großen, waldfrei gehaltenen Flächen das Landschaftsbild in den Hochlagen heute noch geprägt.

Mit dem Tourismus haben sich die Verhältnisse im Tal grundsätzlich geändert. Der Tourismus beansprucht zwar deutlich geringere Flächen als die traditionelle Landwirtschaft, doch werden die genutzten Areale durch Baumaßnahmen massiv umgestaltet. Das Gurgler Tal mit seinen drei Gurgl-Orten zeigt die Entwicklung deutlich: aus einer Grenzertragslage ist ein potenter Wirtschaftsraum entstanden, der sich allerdings schwer einschränken lässt. Für die glazialen und periglazialen Lebensräume im Nahbereich der Erschließungsgebiete bedarf es daher besonderer Schutzmaßnahmen.

\section{Literatur}

Patzelt, G. (1996) Modellstudie Ötztal Landschaftsgeschichte im Hochgebirgsraum. Mitt.d.Österr.Geogr.Ges. 138. Jg.: $53-70$

\section{Verzeichnis des Autors}

Gernot Patzelt

Universität Innsbruck

Institut für Geographie

Innrain 52, 6020 Innsbruck, Österreich

Gernot.Patzelt@uibk.ac.at 


\title{
Kapitel 1 | Historisches zum Thema Gletscher, Gletschervorfeld und Obergurgl
}

\author{
Wolfgang Meixner, Gerhard Siegl
}

\section{Zusammenfassung}

Der folgende Beitrag behandelt die wirtschaftliche und soziale Entwicklung Obergurgls vom 17. bis ins 20. Jahrhundert. Dabei wandelte sich der Ort von einem Bergbauerngebiet zu einer Tourismusdestination. Dem südlich von Obergurgl gelegenen Rotmoostal kommt dabei zwar keine besondere Bedeutung zu, es wird allerdings immer wieder im Zusammenhang mit alpinistischen Leistungen sowie ob seiner landschaftlichen (postglazialen) Gestalt gewürdigt.

\section{Abstract}

The following article outlines the economic and social development of the village Obergurgl from the 17 th to the 20th century. The economic character of the village changed from a mountain forming area into a tourism destination. South of the village the Rotmoos valley (Rotmoostal) is situated. It is mentioned in connection with alpinistic achievements as well as for its special postglacial landscape.

\section{Erste Erwähnungen von Gletschern im Ötztal}

Die Menschen im alpinen Raum haben sich seit Jahrtausenden im Um- und Vorfeld von Gletschern sowie auf denselben aufgehalten. ${ }^{1}$ Schriftliche Spuren der Begegnung mit Gletschern finden sich allerdings erst seit dem Mittelalter. Eine der frühesten Erwähnungen der Begegnung mit Schnee und Eis verdanken wir der Überquerung des Mont Cenis im Winter 1076/77 durch Kaiser Heinrich IV. (1050-1106) gemeinsam mit seiner Fami-

1 Zur frühesten Datierung menschlichen Aufenthaltes im Ötztal vgl. Leitner W. (1995) Der „Hohle Stein“ - eine steinzeitliche Jägerstation im hinteren Ötztal, Tirol (Archäologische Sondagen 1992/93). In: Spindler K., Rastbichler-Zissernig E., Wilfing E, zur Nedden D., Nothdurfter H. (eds.), Der Mann im Eis. Neue Funde und Ergebnisse, The Man in the Ice Vol. 2, Veröffentlichungen des Forschungsinstituts für Alpine Vorzeit der Universität Innsbruck 2, Wien New York, 209-213. Allgemein zu Tirol vgl. Forcher M. (2000) Als Tirol noch nicht Tirol hieß. Urgeschichte, Römerzeit und frühes Mittelalter in unserem Raum. In: Forcher M. (eds.), Tirols Geschichte in Wort und Bild. Mit Beiträgen von Franz Fliri zu Landesnatur und Kulturlandschaften, Innsbruck, 80-87. 
lie, um nach Canossa zu gelangen. Dabei wird erwähnt, dass Menschen und Tiere in Eis und Schnee auf Rinderhäuten zu Tal gefahren seien. ${ }^{2}$ Anselm von Lucca (1036-1086) beschrieb 1080 die Lage von Brixen in seiner Vita folgendermaßen ${ }^{3}$ : „In loco siquidem horrido et asperrimo, in mediis nivalibus Alpibus, ubi fames assidua et frigus pene semper continuum, locus ipse vicus est pro civitate, qui Brixanerium vocatur, altissimis circundatus scopulis, ubi etiam vix nomen obtinetur christianitatis." (Ein schrecklicher und ungemein rauer Ort, mitten in den schneebedeckten Alpen, wo unablässig Hunger und fast dauernd Kälte herrschen, ein Dorf anstelle einer Stadt [...] umschlossen von höchsten Bergspitzen, wo kaum der Name des Christentums bekannt ist.)

\section{Historische Erwähnungen von \\ Gletschern in Tirol}

Die erste Erwähnung eines Gletschers im Tiroler Raum finden wir rund 200 Jahre später, um 1260, in einer Schenkungsurkunde des Bischofs von Brixen für das Kloster Wilten bei Innsbruck. Dort wird die innere Grenze des übertragenen Territoriums folgend fixiert: „cacumen montis qui dicitur Fernaer“ (Spitze Berge, welche Ferner genannt werden). Das Gebiet dieser Schenkung umfasste die Hochtäler Senders und Liesens im Sellrain, mit dem „Spitzen Berg“ ist der Fernerkogl gemeint. ${ }^{4}$ Gletscher dienten, ebenso wie markante Bergspitzen, zur Grenzbezeichnung. „Ain perg, haizzet der Ferner“ lautet eine 1347 niedergeschriebene Lokalisierung im Stanzertal in der Gegend von Grins (vermutlich die Parseierspitze oder der Riffler). ${ }^{5}$ „Ferrner“ im „Stubaier Alpein“, „am Pfaffen“ und in der „Sulzenau“ werden 1500 im „Gejaidbuch Kaiser

2 Lamperti monachi Hersfeldensis opera (1894), Holder-Egger O. (ed.), Monumenta Germaniae Historica, Scriptores rerum Germanicarum in usum scholarum separatim editi (SS rer. Ger.), Hannover und Leipzig, 1-304, hier 286-287. Ich danke Herrn Univ.-Prof. i.R. Dr. Josef Riedmann für seine freundlichen Hinweise auf entsprechende Belegstellen.

3 Wilmans R. (ed.) (1856) Vita Anselmi Episcopi Lucensis Auctore Bardone Presbytero. In: Pertz G. H. (ed.), Historiae aevi Salici, Monumenta Germaniae Historica, Scriptores in folio (SS) 12, Hannover, 13-35, hier 19. Lucca wählte diese schaurige Darstellung auch deshalb, um damit den Ruf jener Versammlung, die 1080 Papst Gregor VII. abgesetzt hatte, auch von dieser Seite herabzuwürdigen.

4 S. Stolz O. (1928) Anschauung und Kenntnis der Hochgebirge Tirols vor dem Erwachen des Alpinismus: 2. Teil. Zeitschrift des Deutschen und Österreichischen Alpenvereins 59: 14-66, hier 14.

5 S. Stolz O. (1928) Anschauung und Kenntnis der Hochgebirge Tirols vor dem Erwachen des Alpinismus: 2. Teil. Zeitschrift des Deutschen und Österreichischen Alpenvereins 59: 14-66, hier 14. 
Maximilians I. erwähnt. ${ }^{6}$ In der drei Jahre später (1503) verfassten Oberstjägermeisterordnung Kaiser Maximilians I. werden „Verner“ in der inneren Ötztaler Gruppe und im Wetterstein erwähnt. ${ }^{7}$

Als früheste kartographische Darstellung eines Gletschers im Gebiet der Ötztaler Alpen gilt die des "Groß Verner - Glacies continua et perpetua“, auf der mit „Tirolis comitatus amplissimi regionumque finitimarum nova tabula" betitelten Holzschnittkarte, des Warmund Ygl von Volderthurn (1564-1611). Sie wurde 1605 in Prag und 1621 in München gedruckt und vor allem die Gletscherdarstellung diente späteren Karten als Vorbild. ${ }^{8}$ Bildliche Darstellungen von Fernern oder Gletschern finden sich erst in der Neu- zeit. Sie sind aber weniger als Darstellungen konkreter topographischer Gegebenheiten, denn als Erinnerungspraktiken des Mittelalters sowie der frühen Neuzeit zu lesen. Diese Darstellungen greifen meist den antiken literarischen Topos des locus terribilis auf: Berge sind nichts Erhabenes, sondern schaurig, abschreckend und hässlich. ${ }^{9}$ Diese Betrachtung ändert sich im Laufe des 17. und 18. Jahrhunderts und weicht einer Darstellung, die schlussendlich in die der Betrachtung der ,erhabenen“ Berge mündet. Ausgegangen war dieser Wandel von der niederländischen Gebirgsmalerei, die bereits im 17. Jahrhundert von einem pittoresken, unruhigen Reichtum zu einer monumentalen Schlichtheit gefunden hatte [etwa Hercu-

6 Michael Mayr (1901), Das Jagdbuch Kaiser Maximilians I., Innsbruck. Das Original des Gejaidpuechs (1500), zusammengestellt von Oberstforstmeister Karl von Spaur, geschrieben vom Schreiber der Jagdkanzlei Wolfgang Hohenleiter, befindet sich als Codex 5751-2 in der Königlichen Bibliothek, Brüssel. Eine nicht illustrierte Abschrift besitzt das Tiroler Landesarchiv, Innsbruck. 7 Stolz O. (1928) Anschauung und Kenntnis der Hochgebirge Tirols vor dem Erwachen des Alpinismus: 2. Teil. Zeitschrift des Deutschen und Österreichischen Alpenvereins 59: 14-66, hier 14.

8 Ygl war Hofkammerbuchhalter in Innsbruck, wurde 1600 Buchhalter der niederösterreichischen Kammer in Graz und schließlich 1603 Kammerbuchhalter und Rat am Prager Hof Kaiser Rudolfs II. Als Beamter hatte er Tirol auf seinen Reisen gut kennengelernt. 1962 wurde eine Facsimileausgabe in Innsbruck aufgelegt. Die älteste Karte Tirols wurde 1561 von Wolfgang Lazius (1514-1565) in der Kartensammlung Typi Chorographici provinciarum Austriae in Wien veröffentlicht. S. Rangger L. (1904) Warmund Ygl und seine Karte von Tirol. In: Forschungen und Mitteilungen zur Geschichte Tirols und Vorarlbergs 1, 183-207 sowie Kinzl H. (1962) Die Karte von Tirol des Warmund Ygl 1604/05. Begleitworte zur Neuausgabe der Karte anlässlich der Jahrhundertfeier des Österreichischen Alpenvereins im Jahre 1962, Innsbruck. Vgl. Beimrohr W. (2008) Warmund Ygl und seine Karte von Tirol, http://www.tirol.gv.at/fileadmin/www.tirol.gv.at/themen/kultur/landesarchiv/downloads/Ygl. PDF [geprüft 7.11.2009].

9 Garber K. (1974) Der locus amoenus und der locus terribilis. Bild und Funktion der Natur in der deutschen Schäfer- und Landlebendichtung des 17. Jahrhunderts, Literatur und Leben N.F. 16, Wien. Goethes Faust II greift diese Thematik ständig auf. So ist das erste Bild des ersten Aktes mit „Anmutige Gegend“ überschrieben, der erste Aufzug des vierten Aktes lautet „Hochgebirg“ und das Schlussbild des fünften Aktes „Bergschluchten“. S. Goethe J.W.v. (1831) Faust. Der Tragödie zweiter Teil, hier zitiert nach der Reclamausgabe von 1971, 3, 162-171 sowie 214-222. 
les Pietersz Segher (um 1590-um 1638) oder Roeland Roghman (1627-1692)]. ${ }^{10}$

\section{Gletscher im Ötztal}

Die erste bildliche Darstellung eines Gletschers, die noch dazu außergewöhnlich ist, verdanken wir einem Naturphänomen in den Ötztaler Alpen. Der Vernagtferner war immer wieder in das querliegende Rofental vorgestoßen und hatte dort einen Eisdamm gebildet. Der dadurch entstandene See führte immer wieder zu katastrophalen Ausbrüchen. Insgesamt vier solcher Eisseebildungen sind dokumentiert: um 1600, um 1680, nach 1770 sowie 1845/48. ${ }^{11}$ Die Seeaufstauung von 1600 hatte am 20. Juli des Jahres zu einem katastrophalen Ausbruch geführt. Aufgrund eines neuerlichen Aufstaues 1601 wurde ein umfangreicher Bericht an Kaiser Rudolf II. gesandt. In der Handschrift „Vom Gericht Sonnenburg etc. ... d.i. Michael Burglechners [15731642] Tirolischen Adlers Dritter Theil,
Dritte Abtheilung, Alle Städte des ganzen Landes" findet sich dieser Bericht des Hofbauschreibers Abraham Jäger, datiert zum 9. Juli 1601, wiedergegeben ${ }^{12}$ :

„Vom Schloß Juval hinein gegen Mitnacht [= Norden; W.M.] ist das Schnalser Tall, so sich bey drey meil hinein erströckht, gegen dem Otzhall zue, bis an den großen Ferner, so innerhalb zwayen Jaren als 1599 und 1600 sich dahin gesezt und weil die zuefliessenden Wasser nit auslaufen mügen hat Er sich dermaßen geschwölt das Er im Sommer des 1601 Jar lang gewesen 625. Brait 175. und 60 Claffter tieff, Als Er aber hernach Prichig worden, Ist Er one sonder warn schaden durch den Schnalser Pach in die Etsch, und dann durch die Ozthaller Achen in den Yhn allgemach abgesichen und ausgerunnen ./. Er hat anfangs bey den Underthonen so daselbst umb Ire Höf gehabt unnd volgendts in dem unndern Inthall ainen ser grosen ./. schröckhen Verursacht mit grosser andacht hat mann processiones gehalten und gebet täg angestellt; [...]“

10 Vgl. Ziak K. $\left(1981^{5}\right)$ Der Mensch und die Berge. Eine Weltgeschichte des Alpinismus, Salzburg, hier 28-30. Das Buch ist 1936 erstmals erscheinen. Wir folgen hier der 5. Auflage.

11 Vgl. Nicolussi K. (1990) Bilddokumente zur Geschichte des Vernagtferners im 17. Jahrhundert. Zeitschrift für Gletscherkunde und Glazialgeologie 26/2: 97-119. Kurt Nicolussi sei auch für die problemlose Überlassung einer Reproduktion der Abbildung des Eissees von 1600 gedankt. Vgl. auch Hirtlreiter G. (2004) Ewiges Eis? - Bewegtes Eis! Vom galoppierenden Ferner und vom „gewesten See“. In: Ritschel B. (2004) Ötztaler Alpen, München, 30-45.

12 Vom Gericht Sonnenburg etc. ... d.i. M. Burglechners Tirolischen Adlers Dritter Theil, Dritte Abtheilung, Alle Städte des ganzen Landes (vor 1636), Bibliothek des Tiroler Landesmuseums Ferdinandeums, FB 2099, 1033-1039, hier 1033.

Vgl. Beimrohr W. (2008) Mathias Burglechner (Burgklehner) - Beamter, Historiker und Kartograph, http://www.tirol.gv.at/fileadmin/www.tirol.gv.at/themen/kultur/landesarchiv/downloads/ Burglechner.PDF [geprüft 7.11.2009]. 
Dem Bericht als „Abriss D“ beigefügt war eine sehr realistische Abbildung des Vernagtgletschers sowie des durch diesen aufgestauten Sees. Diese später aquarellierte Federzeichnung (Abb. 1) war offenbar nach den „anzaigen“ des Abraham Jägers angefertigt worden, ob durch ihn selber, ist unklar, aufgrund seiner Tätigkeit könnte er zumindest eine Skizze dazu geliefert haben. ${ }^{13}$

Was diesen Bericht und die dazugehörige Abbildung so einzigartig macht, ist dessen realistische Darstellung. Etwa in der minutiösen Beobachtung der Gestalt des aufgestauten Eises:

„Selcher Ferner ist auch nit wie andere mit ganzen Eiß glatt gewaxen, sonder mit lauterm Karackh GstellsPizen Zynnen, Wasserstuben Zwerch Clüfften und selzamen farben, das man sich darob nit genuegsam verwundern khann $[\ldots]^{]_{14}}$

Vom Rotmoostal existieren keine solch frühen Quellen. Das Aquarell „nach der Natur" von A. Ziegler zeigt den Zustand von 1893 (Abb. 2). ${ }^{15}$ Zeitungsberichte existieren bereits ab der ersten Hälfte des 19. Jahrhunderts. 1844 wurde im Tiroler Boten über eine Höhenmessung im
Rotmoostal berichtet. ${ }^{16} 1858$ findet sich im selben Blatt eine Beschreibung des Zustandes der Ötztaler Ferner (auch des Gletschers im Rotmoostal). Vom beobachten Zuwachs der Gletscher zeigte sich der Autor überrascht. ${ }^{17}$ Ein Jahr später wird in der Volks- und Schützen-Zeitung erneut über die Entwicklung der Ötztaler Gletscher berichtet und auch auf die Ferner im Rotmoostal eingegangen:

„Die Wärme des verflossenen Sommers hat die Ferner des Oetzthals sehr stark angegriffen, was man wohl schon aus der bedeutenden Wassermasse, welche im Laufe des Sommers abgeflossen ist, mit Sicherheit schließen konnte. [...]

Die Ferner in Geisberg und Rothmoos hörten zwar am Ende des Juni auf zu wachsen, aber ihre Enden stehen noch an derselben Stelle, wo sie damals standen; ja vielmehr habe ich gegen das Ende Septembers wieder ein geringes Vorschieben bemerkt, und der Ferner in Geisberg war nie ganz ruhig. Diese beiden interessanten Ferner sind seit Menschengedenken fortwährend im Wachsen begriffen und haben im letzten Frühjahre jene alten Gränzen wieder erreicht, bis zu

13 Die Federzeichnung findet sich unter der Signatur F.B. 7218 in der Bibliothek des Tiroler Landesmuseums Ferdinandeum, Innsbruck, und ist mit Bildbeilage „D“ gekennzeichnet.

14 Bericht des Abraham Jäger. In: Vom Gericht Sonnenburg etc. ... d.i. M. Burglechners Tirolischen Adlers Dritter Theil, Dritte Abtheilung, Alle Städte des ganzen Landes (vor 1636), Bibliothek des Tiroler Landesmuseums Ferdinandeum, F.B. 2099, hier 1037.

15 Gurgl. Rotmoos-Ferner bei G[urgl]. Aquar[ell]. v. A. Ziegler. Stempelaufdruck: „Legat A. Ziegler 27 VI. 1893“. In Handschrift: „Rothmoos-Ferner bei Gurgl im Oetzthal. A. Ziegler n. d. Natur“. Aquarell. Bibliothek des Tiroler Landesmuseums Ferdinandeum, Innsbruck, F.B. 8752.

16 Rothmoosthal bei Gurgl. Höhenmessung. In: Tiroler Bote 1844: 336.

17 Über den Zustand der Ferner im Ötzthal. In: Tiroler Bote 1858: 751. 


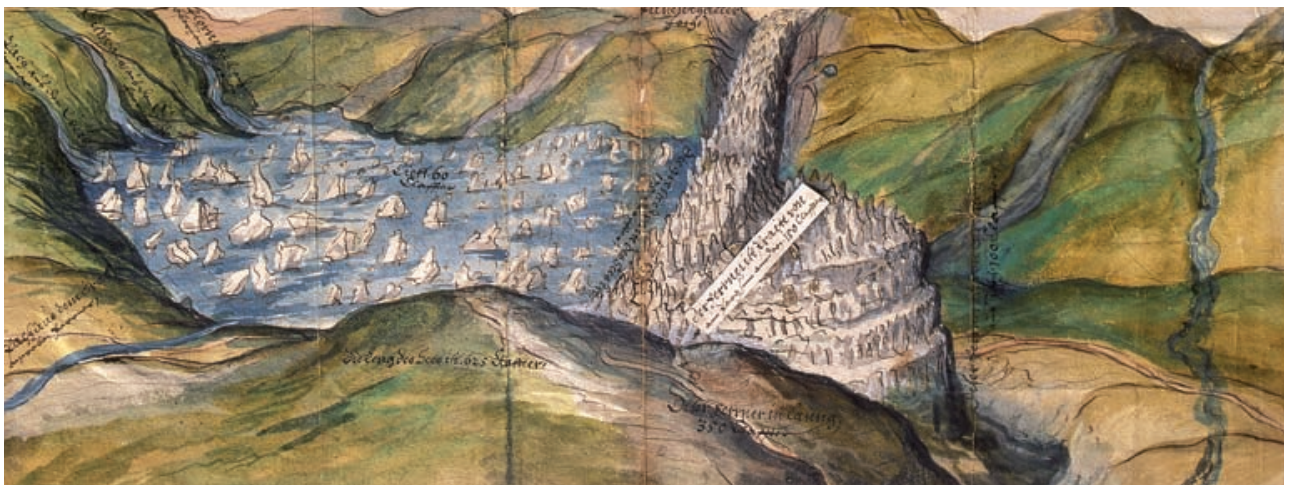

Abb. 1:

Darstellung des Vernagtferners und seines Eissees, 9. Juli 1601. Aquarellierte Federzeichnung, 200 x 525 mm. Bibliothek des Landesmuseums Ferdinandeum, FB 7218.

Photographie durch K. Nicolussi.

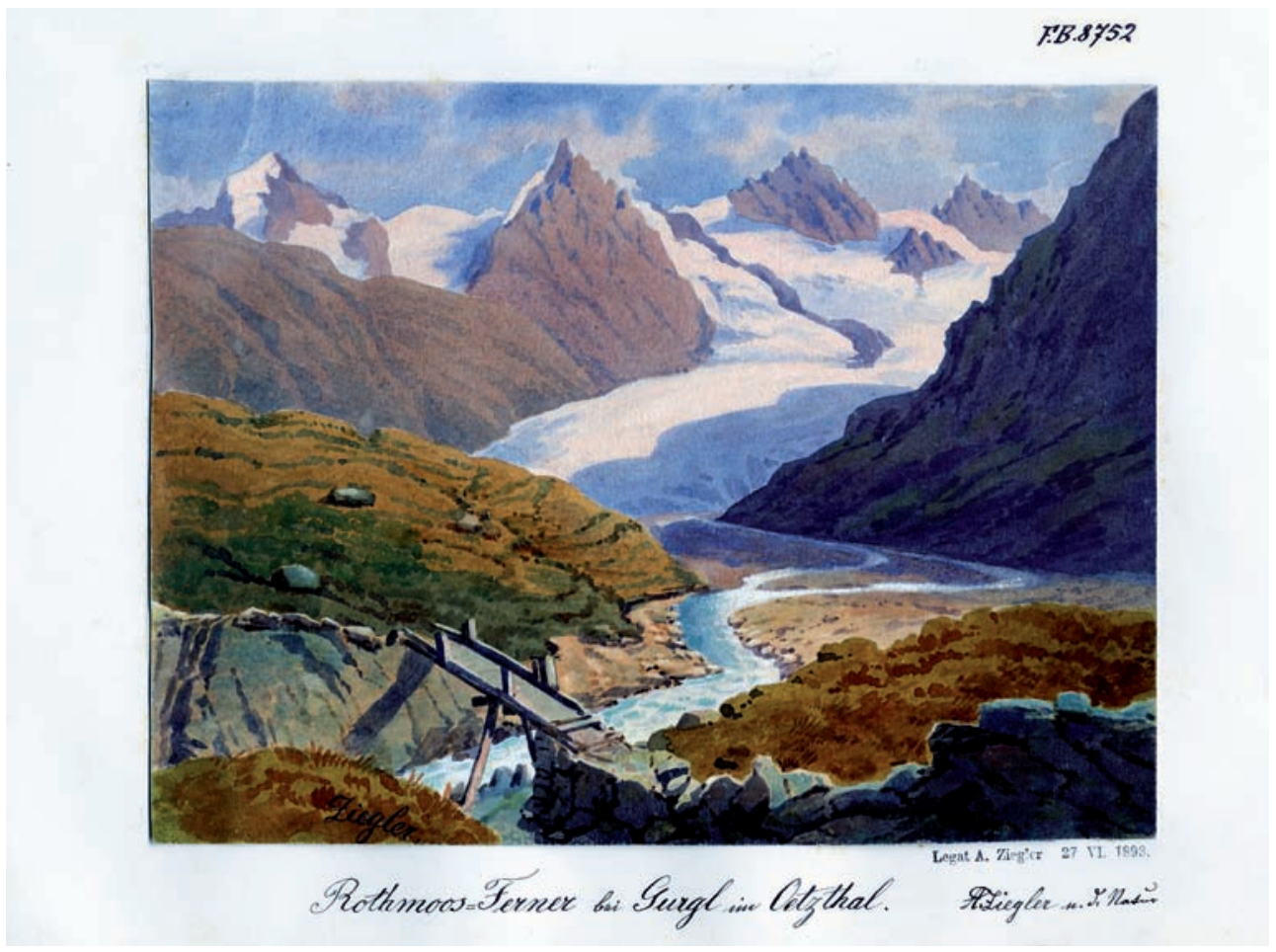

Abb. 2:

Rothmoos-Ferner bei Gurgl im Oetzthal. A. Ziegler n. d. Natur. Stempelaufdruck: „Legat A. Ziegler 27 VI. 1893“. Aquarell. Bibliothek des Landesmuseums Ferdinandeum, FB 8752. 
welchen sie in einer früheren Zeit schon einmal vorgerückt waren. Da hierüber weder eine Aufzeichnung, noch eine Sage vorhanden ist, so läßt sich nichts Näheres mehr angeben. Ein Ferner kündiget sein beginnendes Anwachsen dadurch an, daß er höher wird und stärker zerklüftet, und eben so ist es ein Zeichen beginnenden Abnehmens, wenn er niedriger wird und seine Klüfte sich schließen, wie es zum Theil heuer der Fall war. Eine Reihe von solchen Jahren wie das heurige würde sie ohne Zweifel zu schleunigem Rückzuge nöthigen. ${ }^{18}$

Auch der Kurat von Gurgl, Adolf Trientl (1817-1897), widmete sich der Beobachtung der Ferner im Ötztal. ${ }^{19}$ In einer undatierten, vermutlich 1869 erstellten Handschrift hielt er Bemerkenswertes „Über einige Gränzen der alten Gletscher im Ötzthale, insbesondere in Gurgl" fest. Zum Rotmoostal führte er darin aus:

„Auf der südlichen Seite gegen das Thal Rothmoos möchte man fast versucht sein, ganz nahe an der Höhe einige Andeutungen von Moränen des Rothmoosgletschers aus einer späteren Zeit zu vermuthen. Daß diese Vermuthung nicht aus der Luft gegriffen ist, beweisen einige sehr gut erhaltene Seitenmoränen des alten Gletschers in Geisberg, welche nur wenig niedriger als die Mut auf der anderen Seite des schmalen Thales am Roßkar vorbeiziehen."

Trientl referiert in diesem Manuskript aber nicht nur über seine glaziologischen Beobachtungen, sondern erweist sich auch als Kenner der Gesteinskunde, der nicht nur grundlegendes, sondern auch praktisches Wissen zu vermitteln wusste: „Jetzt liegen die Kalksteine sehr gelegen in der Nähe zum Kalkbrennen und liefern einen ausgezeichneten Kalk, besonders die etwas spärlichen Dolomite aus Rothmoos, welche weich und leicht zu brennen beim Löschen einen fetten und gelben Kalk geben, der durch seine feinen Beimischungen von Eisenoxyd, Thonerde und Kieselsäure manche Eigenschaft mit dem hydraulischen Kalk zu theilen scheint."

Seine Hauptaufmerksamkeit in diesem Text galt allerdings der Entwicklung und Zukunft der Gletscher und demgemäß spekulativ ließ er seine Ausführungen enden:

„Aber noch ein Frage sei mir zum Schluße erlaubt. Seit 300 Jahren bemerkt man in Tirol und in der Schweiz ein allmähliches Anwachsen der Gletscher. Deutet dieß etwa wieder auf den Anfang einer neuen

18 Aus dem Oetzthale. (Die Oetzthaler Gletscher im heurigen Sommer.) In: Volks- und SchützenZeitung, 14. Jhg., 3. Oktober 1859, Nr. 121: 1.

$19 \mathrm{Zu}$ Adolf Trientl vgl. Sauser E. (2001) Biographisch-Bibliographisches Kirchenlexikon. Band XVIII, Herzberg: 1395-1396 sowie Hofinger W. (eds.) (1992) Der Mistapostel. Ein Leben für den Bauernstand: Adolf Trientl (1817-1897), Innsbruck; darin u.a. Fliri F. (1992) Trientl als Naturforscher: 165-174. 
Eisperiode hin, oder ist es nur eine Rückzugsoscillation?" 20

Eine ausführliche Schilderung der Gletscher im Ötztal sowie des Rotmoosferners (Abb. 3) lieferte 1860 Karl Sonklar Edler von Innstädten. Sonklar war k.k. Oberleutnant sowie Professor für Geographie an der k.k. Militär-Akademie zu Wiener-Neustadt. Sonklar hatte die Gegend auf zwei Reisen, von denen er die letzte 1856 unternommen hatte, persön- lich erkundet. In mehreren Paragraphen beschreibt Sonklar das Rotmoostal, dessen Gletscher er als von „zierlicher Gestalt" bezeichnete. Demgemäß fand er auf dem Ferner „ausser einigen schönen Radialspalten am Gletscherende, einigen Längsspalten weiter oben und der Häufigkeit von Gletschermühlen [...] wenig interessantere Einzelheiten vor". Sonklar berichtet, dass der Rotmoosgletscher „seit einigen Jahren im Rückzug begriffen“ "sei,

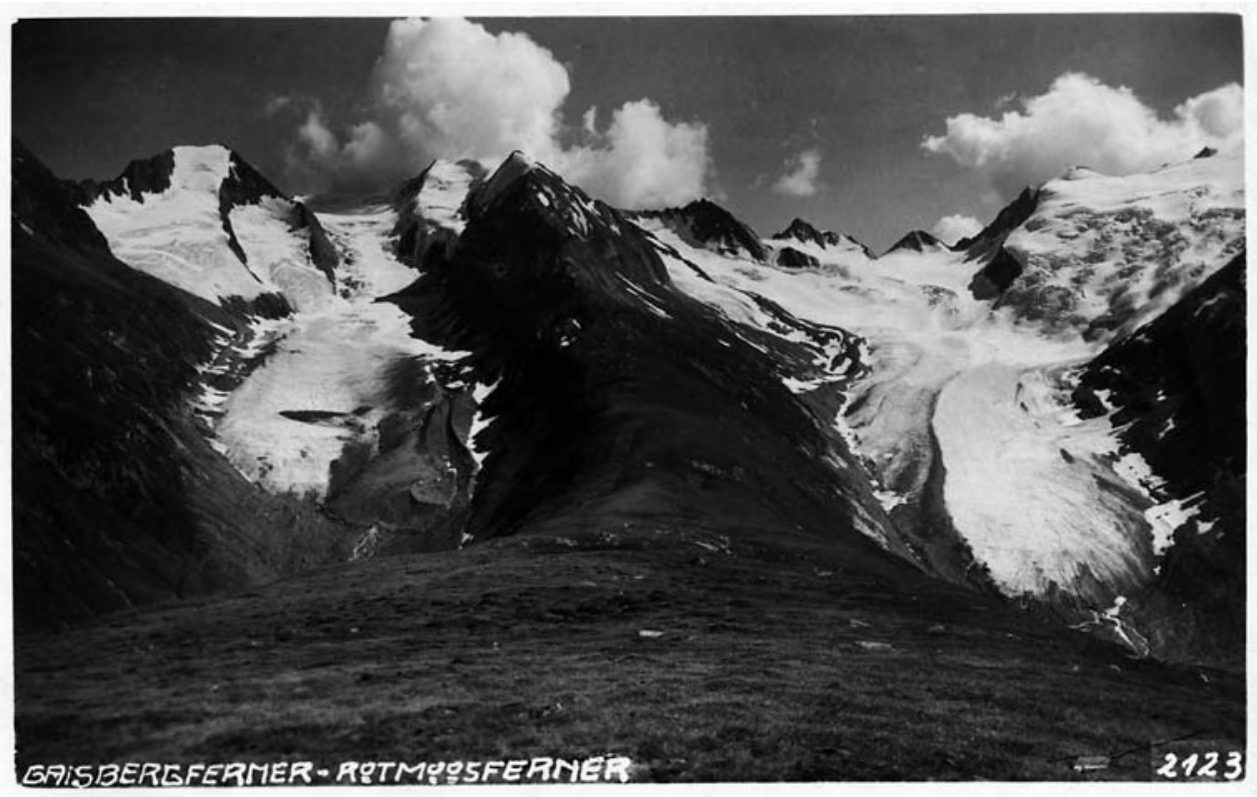

Abb. 3:

Gaisbergferner - Rotmoosferner. Fotopostkarte Nr. 2123. Much Heiss, Alpiner Kunstverlag, Innsbruck. Postkarten Sammlung der Bibliothek des Tiroler Landesmuseums Ferdinandeum, Stichwort „Obergurgl“.

20 Trientl A. (1869) Über einige Gränzen der alten Gletscher im Ötzthale, insbesondere in Gurgl. Handschrift. Bibliothek des Tiroler Landesmuseums Ferdinandeum, Innsbruck, F.B. 4344. Trientl hatte wiederholt in Tageszeitungen sowie in Fachzeitschriften seine naturkundlichen Beobachtungen dargelegt. Vgl. Fliri F. (1992) Trientl als Naturforscher. In: Hofinger W. (Hg.) Der Mistapostel. Ein Leben für den Bauernstand: Adolf Trientl (1817-1897), Innsbruck: hier 167. 
nachdem dieser „seit 26 bis 30 Jahren an Terrain ungemein gewonnen" hatte. Sein Führer berichtete ihm von „ergiebige[n] Bergmähder (Bergwiesen) “ auf dem Talgrunde, „den jetzt das Ende der Eiszunge bedeckt “. ${ }^{21}$

\section{Früher Alpinismus im Rotmoostal}

Nicht nur Naturkundliches findet sich über das Rotmoostal in Zeitungen und Zeitschriften, sondern auch Bemerkenswertes zum frühen Alpinismus und seinen Auswirkungen. 1874 veröffentlichte Guido Hammer eine ausführliche Beschreibung einer Wanderung von Gurgl nach Lazins über das Rotmoosjoch, die er ein Jahr zuvor unternommen hatte. Aufmerksam auf diese „interessante Partie“ war er durch den Kuraten Franz X. Senn gemacht worden. Hammer war trotz widriger Wetterverhältnisse mit seinem 17-jährigen Sohn und vier weiteren Bergkameraden zu dieser Tour aufgebrochen. Ihnen zur Seite standen drei Führer (Peter
Paul Gstrein, Alois Gstrein, Methodius Scheiber) sowie ein Proviantträger (Blasius Grüner). Ein weiterer Einheimischer, der damals älteste Gurgler Führer Tobias Santer, begleitete den Proviantträger bei seiner Rückkehr. ${ }^{22}$

Dass die Begehung des Rotmoosferners nicht ganz ungefährlich war, zeigt die Schilderung eines Bergunglücks durch Adolf Trientl aus dem Jahr 1863. Einer der beiden Führer zweier englischer Alpinisten war im August in eine Gletscherspalte gestürzt, woraus er nach vier Stunden Aufenthalt wieder herausgezogen werden konnte. Trientl vermerkte kritisch, dass das Unglück auch deshalb passiert sei, weil die beiden Führer, Hirten der Alpe Lazins, sich noch nie auf dem Gletscher aufgehalten hätten. ${ }^{23}$

Das südlich des Dorfes Obergurgl gelegene und unbewohnte Rotmoostal zieht sich südöstlich als markantes Trogtal zu den Gipfeln des Ötztaler Hauptkammes (Scheiber-, Trinker- sowie Heuflerkogel) hinauf. Das Tal wurde, wo möglich, zur Beweidung genutzt. Weiters lieferte das

21 Sonklar K. Edler von Innstädten (1860) Die Oetzthaler Gebirgsgruppe, mit besonderer Rücksicht auf Orographie und Gletscherkunde, nach eigenen Untersuchungen, Gotha: hier 68 sowie 75. Die Paragraphen 81-84 befassen sich mit dem Rotmoostal.

22 Hammer G. (1874) Rothmoosjoch. Ein Uebergang von Gurgl über das Rothmoosjoch nach Lazins und über das Spronserjoch nach Meran am 12. August 1873. In: Der Alpenfreund. Blätter für Verbreitung von Alpenkunde unter Jung und Alt in populären und unterhaltenden Schilderungen aus dem Gesammtgebiet der Alpenwelt und mit praktischen Winken zur genußvollen Bereisung derselben. Amthor E. (eds.) VII. Band, Gera: 139-146. Zu Franz Xaverius Senn (1831-1884) vgl. Schöpf W. G. (2005) Biographisch-Bibliographisches Kirchenlexikon. Band XXIV, Nordhausen: 1336-1348.

23 Trientl, A. (1863) Das Unglück auf dem Rothmoosferner. In: Volks- und Schützen-Zeitung 18. Jhg.: 610. 
dort befindliche Hochmoor Torf zum Heizen sowie Marmor und Kalkgestein, das gebrannt wurde. ${ }^{24}$

\section{Historisches zu Obergurgl}

Obergurgl (Abb. 4), als Dorf der Ortschaft Gurgl der Gemeinde Sölden im Bezirk Imst, liegt auf einer Seehöhe von $1927 \mathrm{~m}$. Gurgl findet sich 1250 erstmals urkundlich im Namen eines Dienstmannes der Herrn von Montalban aus dem Vinschgau erwähnt: „Heberhardus von Gurgele ". ${ }^{25}$ Es ist Sitz der Pfarre zum Hl. Johannes Nepomuk. Die Pfarrkirche wurde 1726 aus einer älteren Kapelle erbaut und 1737 geweiht. Seit 1736 wirkte ein eigener Seelsorger im Ort. 1769 wurde in Gurgl eine Kuratie eingerichtet und 1891 zur Pfarre erhoben. Das Dorf zählte 2001 rund 420 EinwohnerInnen (1970: 120; 1910: 39 Personen). Um 1760 lebten in Gurgl ca. 200 BewohnerInnen. Die Zahl der EinwohnerInnen verringerte sich bis in die Mitte des 19. Jahrhunderts auf rund 150 Personen und nahm auch in der zweiten Hälfte dieses Jahrhunderts ab. Die Menschen lebten vor allem von der Landwirtschaft, insbesondere von der Viehzucht, die vorwiegend auf Subsistenzbasis betrieben wurde. Die Ausübung der Landwirtschaft war von der Lage des Dorfes (über 1900 m) sowie der Witterung (sieben Monate Vegetationsruhe) geprägt. Zur Sicherung der Existenzgrundlage wurden auch außerlandwirtschaftliche Tätigkeiten ausgeübt, insbesondere das Weben. Laut eines Berichtes im Tiroler Boten von 1821 waren im Ötztal fast alle Bauern im Winter als Leinenweber oder Lodenwirker tätig. Daneben wurde Flachs angebaut und über das Timmelsjoch ins Passeier zum Verspinnen verkauft. ${ }^{26}$ Eine Besonderheit im Gurgler Tal ist, dass die der Gemeinde gehörenden Almgebiete schon seit langem als Weidegebiete für Schafe an Bauern aus Schnals und Passeier verpachtet sind. Noch heute werden jährlich tausende Tiere über das

24 Entsprechende Hinweise finden sich im von Adolf Trientl verfassten Tagebuch der Kuratie und Gemeinde Gurgl. Vgl. Hofinger W. (1991) Tagebuch der Kurazie und Gemeinde in Gurgl. Angefangen im Jahre 1858 von Adolf Trientl d.Z. Provisor. Abschrift einer Kopie der durch Pfarrer Franz Danler (1920-1953) ergänzten Handschrift, Innsbruck: hier 4 (Torflager in Obergurgl), 44 (Kalkbrennen), 45 (Marmor in Rotmoos sowie Torf).

25 S. http://www.geschichte-tirol.com/orte/nordtirol/bezrik-imst/695-sn.html [geprüft 7.11.2009]. Vgl. auch Kranzmayer E. (1963) Die Ortsnamen des Ötztales als siedlungsgeschichtliche Quelle. In: Klebelsberg R. (eds.) Ötztaler Buch. Schlern-Schriften 229, Innsbruck, 93-110, hier 107.

26 Bote für Tirol und Vorarlberg, Nr. 88 (1821) sowie Wopfner H. (1951) Zur Geschichte des bäuerlichen Hausgewerbes in Tirol. In: Tiroler Wirtschaft in Vergangenheit und Gegenwart. Gerhardinger, H., Huter, F. (eds.) Bd. 1: Beiträge zur Wirtschafts- und Sozialgeschichte Tirols. Schlern-Schriften 77, Innsbruck, 203-232, hier 211-212. 


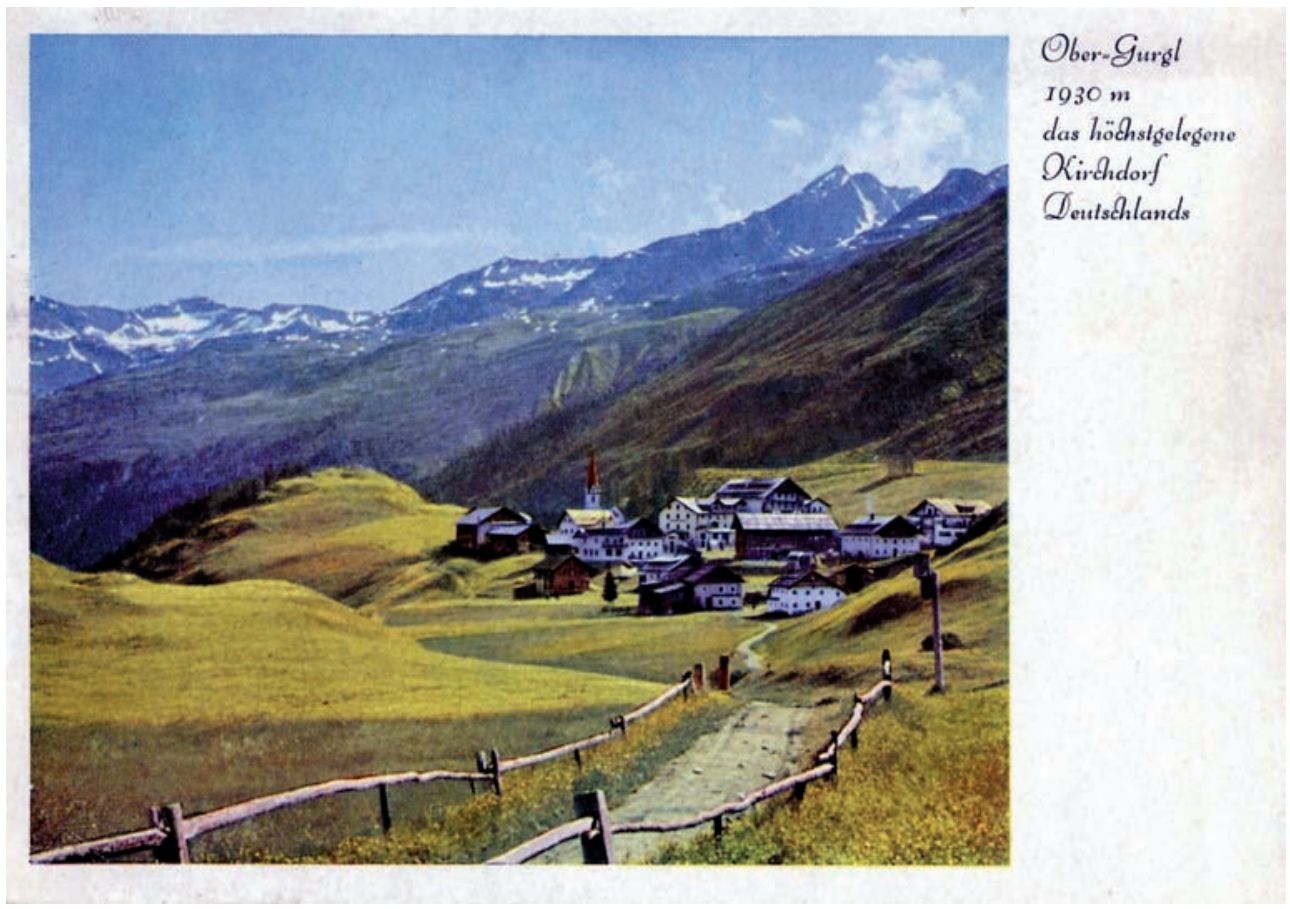

Abb. 4:

Ober-Gurgl. 1930 m. Das höchstgelegene Kirchdorf Deutschlands. Farbige Bildpostkarte. Postkartensammlung der Bibliothek des Tiroler Landesmuseums Ferdinandeum, Stichwort „Obergurgl“.

Gurgler Eisjoch und das Langtaler Joch aufgetrieben. ${ }^{27}$

Vor der allgemeinen Grundentlastung 1848, übten das Amt Petersberg, das Stift Frauenchiemsee sowie das Amt Imst, früher Starkenberg, die Grundherrschaft im hinteren Ötztal aus. Nur ein Viertel des Grundbesitzes war vor 1848 im freien Eigen der Bauern gestanden. ${ }^{28}$ So wird im Urbar von Petersberg von 1406 in Gurgl ein Hof „auf Engern“ erwähnt. Die Steuerbereitung (= Steuerbeschreibung) von 1627 nennt im Söldener Kirchspiel für Gurgl folgende Höfe: „Inderisthof genennt Innergurgl“ mit 36 Kuhfuhren (K.) und 3 Häusern (H.), Grundherrschaft (Gh.) Amt Passeyr; „Hof Pirchlpach“ mit 36 K. und 2 H., „frei und aigen“; „Hof

27 Vgl. Stolz, O. (1963) Zur Geschichte des Ötztales. In: Ötztaler Buch. R. (eds.) Schlern-Schriften 229, Innsbruck, 183-247, hier 219 sowie Zipperle A., de Rachewiltz, S., Togni, R. (1994) Transumanza. Weideplätze wechseln, Bozen; Haid H. (2008) Wege der Schafe. Die Jahrtausendalte Hirtenkultur zwischen Südtirol und dem Ötztal. Schriftenreihe Ötztal-Archiv 22, Innsbruck-Wien und Bozen.

28 Vgl. Stolz, O. (1963) Zur Geschichte des Ötztales. In: Ötztaler Buch. R. (eds.)Schlern-Schriften 229, Innsbruck, 183-247, hier 211. 
Pirchit" 32 K., 3 H., Gh. Amt Imst; „Kinigsrain“ 12 K., 1 H., Gh. Petersberg; "Gütl Poschach" 12 K., 1 H., „eigen“; "Oberlechen“ 24 K., 2 H., „eigen“; "Mitterlechen" 12 K., 1 H., „eigen“; „Haidenlechen“ 24 K., 1 H., Gh. Petersberg; ,Jungenlechen " 24 K., 3 H., ,eigen“; „Röschenlechen“ 24 K., 2 H., „eigen“. 29

\section{Verkehr und Tourismus im inneren Ötztal}

Obwohl ein Weg über das Timmelsjoch schon seit dem Mittelalter bekannt ist, dürfte dieser beschwerlich und wenig ausgebaut gewesen sein. In der TirolKarte von Peter Anich findet sich 1770 ein Saumweg bis Gurgl und Vent eingezeichnet. Laut Baedeckers Reisehandbuch von 1855 war der Weg ins Ötztal nur bis Längenfeld befahrbar. Dies änderte sich vorerst nur bedingt, als 1884 die Arlbergbahn und damit der Bahnhof Ötztal er- öffnet worden waren. Die neu errichtete Fahrstrecke reichte nur bis Ötz. Die Postbotenfahrt vom Bahnhof Ötztal bis Längenfeld dauerte 4,5 bis 6 Stunden und von dort bis Sölden weitere 3 Stunden. 1895 hatte der Tiroler Landtag beschlossen, eine neue Straße durch das Ötztal ins Passeier zu errichten. Bis 1904 war der Abschnitt bis Sölden errichtet worden; 1911 wurde die Straße bis Zwieselstein neu gebaut. Um 1930 wurde die Straße im Ötztal für Kraftwagen gehärtet und 1936 der Streckenabschnitt von Zwieselstein nach Gurgl für den Automobilverkehr freigegeben. Zehn Jahre nach dem Zweiten Weltkrieg, 1955, wurde auf Nordtiroler Seite mit dem Ausbau der Straße über das Timmelsjoch begonnen, nachdem auf Südtiroler Seite bereits in den 1930er Jahren eine befahrbare Militärstraße errichtet worden war. Die Strecke ist seit 1969 während der Sommermonate gegen Maut befahrbar. ${ }^{30}$

29 Vgl. Stolz, O. (1963) Zur Geschichte des Ötztales. In: Ötztaler Buch. R. (eds.) Schlern-Schriften 229, Innsbruck, 183-247, hier 246. Die Bezeichnung „Kuhfuhre“ findet sich nur im Ötztal zur Beschreibung des Feldbestandes, die zur Haltung je einer Kuh ausreichte. Zur Siedlungsentwicklung vgl. auch Timmermann O., Hambloch, H. (1958) Die Talschaft Gurgl. Eine kulturgeographische Studie. In: Zur Kulturgeschichte der Ötztaler Alpen. Westfälische Geographische Studien 13, Münster, 21-75 sowie Meleghy, T., Preglau, M., Walther, U. (1982) Die Entwicklung Obergurgls vom Berg-Bauerndorf zum Tourismuszentrum. Sozialhistorische Analyse und evolutionstheoretische Rekonstruktion. Forschungsbericht 18 des Instituts für Soziologie der Universität Innsbruck, Innsbruck und Walther, U. (1982) Sozial-historischer Wandel in Obergurgl. Entwicklung der Besitzverhältnisse und familiären Beziehungen in Hinblick auf den sozialen Wandel - seit Mitte des 18. Jahrhunderts. Forschungsbericht 16 des Instituts für Soziologie der Universität Innsbruck, Innsbruck.

Allg. vgl. Scharr K. (2004) Übergänge - Siedlungen - Wirtschaft. Eine kurze Geschichte der Kulturlandschaft des Ötztaler Gebirgsraumes. In: Ritschel B. (eds.) Ötztaler Alpen, München, 46-55.

30 Vgl. Stolz, O. (1963) Zur Geschichte des Ötztales. In: Ötztaler Buch. R. (eds.) Schlern-Schriften 229, Innsbruck, 183-247, hier 227-228 sowie Zwanowetz G. (1986) Das Straßenwesen Tirols seit der Eröffnung der Eisenbahn Innsbruck - Kufstein (1858). Dargestellt unter Berücksichtigung der regionalen Bahnbaugeschichte. Tiroler Wirtschaftsstudien 11, Innsbruck, hier 101-102. 
Dieser Ausbau des Verkehrswegenetzes ging Hand in Hand mit einem Wandel der Wirtschaftsstruktur. Die traditionellen Produktionszweige Landwirtschaft und außerlandwirtschaftliche Tätigkeiten wie Weben und Lodenerzeugung waren durch den im 19. Jahrhundert einsetzenden Wandel des Konsumverhaltens in den Absatzgebieten unter Druck geraten und reichten nicht mehr aus, die Existenz der Bevölkerung nachhaltig zu sichern. Folge davon war einerseits eine Abwanderung der heimischen Bevölkerung. Zwischen 1750 und 1850 wanderte rund ein Viertel der männlichen sowie rund $40 \%$ der weiblichen Bevölkerung ab. ${ }^{31}$ Der im 19. Jahrhundert einsetzende Tourismus in Form des Alpinismus stoppte aber diese Entwicklung. Die Etablierung desselben beruhte einerseits auf dem Anschluss an einen wachsenden Markt an TouristInnen sowie andererseits auf der Etablierung touristischer Einrichtungen im Tal selbst. Die Etablierung eines neuen städtischen Bürgertums: Hand in Hand mit dem Anwachsen der Großstädte in Mitteleuropa, ließ ein reisefreudiges und zahlungskräftiges Publikum entstehen, das die Eisenbahn als modernes Massenverkehrsmittel des 19. Jahrhunderts zu nutzen wusste. Mit dem Bau der Arlbergbahn waren für dieses Publikum aus Berlin, Wien oder Frankfurt das Ötztal und seine Bergwelt erreichbar ६eworden. ${ }^{32}$ Für die Etablierung des Tourismus im Ötztal verantwortlich waren zwei engagierte Priester: Pfarrer Adolf Trientl, der von 1857 bis 1864 in Gurgl wirkte sowie Franz Senn, von 1860 bis 1872 Seelsorger der Kuratie Vent. ${ }^{33}$ Beide waren nicht nur Pioniere des ersten alpinen Wegebaues, indem sie für die Wiederbelegung der Saumpfade sorgten und den frühen AlpinistInnen bereitwillig Auskunft gaben, sondern stellten

31 Vgl. Preglau, M., Meleghy, T., Frantz, K., Tafertshofer, A. (1985) Fremdenverquer. Kosten und Nutzen des Tourismus am Beispiel Obergurgl. Schriftenreihe der Michael-Gaismair-Gesellschaft 4, Innsbruck, hier 57 sowie ausführlich Meleghy, T., Preglau, M., Walther, U. (1982) Die Entwicklung Obergurgls vom Berg-Bauerndorf zum Tourismuszentrum. Sozialhistorische Analyse und evolutionstheoretische Rekonstruktion. Forschungsbericht 18 des Instituts für Soziologie der Universität Innsbruck, Innsbruck.

Vgl. auch Scharr K. (2001) Leben an der Grenze der Dauersiedlung. Grund und Boden im „Ötztaler Gebirgsraum" (Ötztal-Schnals-Passeier) vom 13. bis zur Mitte des 19. Jahrhunderts. Schlern-Schriften 314, Innsbruck.

32 Vgl. dazu stellvertretend für zahlreiche Publikationen Kramer, D. (1983) Der sanfte Tourismus. Umwelt- und sozialverträglicher Tourismus in den Alpen, Wien sowie Luger K., Rest F. (eds.) (2002) Der Alpentourismus. Entwicklungspotentiale im Spannungsfeld von Kultur, Ökonomie und Ökologie, Innsbuck, Wien München, Bozen. Für das Ötztal im Allgemeinen vgl. Jäger H. (1989) Über den frühen Tourismus. Ausstellung in der Galerie zum Alten Oetztal, Oetz; zu Obergurgl im Besonderen vgl. Preglau, M., Meleghy, T., Frantz, K., Tafertshofer, A. (1985) Fremdenverquer. Kosten und Nutzen des Tourismus am Beispiel Obergurgl. Schriftenreihe der Michael-Gaismair-Gesellschaft 4, Innsbruck.

33 Kammhuber A. (2004) Der Kurat von Vent. Ein Porträt des Pfarrers Franz Senn (1831-1884). In: Ritschel B. (eds.) Ötztaler Alpen, München, 56-63. 
auch ihr Pfarrwidum als Unterkunft zur Verfügung. Da beide Männer von der heimischen Bevölkerung sehr geschätzt wurden, vermochten sie den BewohnerInnen des Ötztals die Angst vor diesen (wirtschaftlichen und sozialen) Neuerungen $\mathrm{zu}$ nehmen. ${ }^{34}$ Dadurch fanden Männer wie Kinder in den Sommermonaten im Tal Beschäftigung als Bergführer, Proviant- und Gepäckträger. Die ersten alpinistischen Stützpunkte im Gebirge wurden ebenfalls durch Einheimische errichtet; etwa 1871/72 das Hochjochhospitz sowie die Samoarhütte 1877/78 durch Josef Grüner aus Sölden, das Ramolhaus 1881/83 durch Martin Scheiber aus Gurgl. ${ }^{35}$ Diesen folgten zwischen 1882 und 1896 weitere hochalpine Schutzhütten (Hildesheimer-, Karlsruher-, Fidelitas, Vernagt- sowie Breslauerhütte), die durch ein eigenes Wegenetz verbunden waren. Grundstock dafür war die Gründung Alpiner Vereine. Franz Senn gehörte 1869 zu den Gründungsmitgliedern des Deutschen Alpenvereins (DAV), nachdem ihn der 1862 gegründete und mehr wissen- schaftlich ausgerichtete Österreichische Alpenverein (ÖAV) bei einem Wegebauprojekt im Stich gelassen hatte. ${ }^{36}$

Die Anfänge des Tourismus in Obergurgl waren zunächst noch überschaubar. Einen ersten Überblick liefert Adolf Trientl in seinem "Tagebuch der Kurazie und Gemeinde in Gurgl“, wo er für das Jahr 1863 vermerkte ${ }^{37}$ :

„Der Fremdenzufluß im Sommer hat sich seit 10 Jahren sehr gesteigert. Während in den Jahren vor 1830 bis 1850 und 1860 die Anzahl der Reisenden jährlich oft nicht die Zahl 50 erreichte, ist dieselbe bis 1863 wohl schon auf 100 gestiegen."

Diese ersten „Touristen“ waren aber weniger Alpinisten, denn Naturforscher und Landschaftsmaler, die nicht zuletzt den Gurgler Eissee aufsuchten, der damals im Langtal aufgestaut war.

Um 1875 verzeichnete Obergurgl im Sommer bereits an die 400 TouristInnen, die vorwiegend über das Ramoljoch gingen. Bis 1904 steigerte sich die Zahl der Übernachtungen in Obergurgl auf über 2.000, blieb damit aber immer noch weit

34 Allem Fremden gegenüber reservierter eingestellt war etwa der Priester Sebastian Rieger, bekannt als Reimmichl. Vgl. dazu Hackl, W. (2004) Eingeborene im Paradies. Die literarische Wahrnehmung des alpinen Tourismus im 19. und 20. Jahrhundert, Tübingen, hier 116-134; zu Rieger vgl. Sauser E. (1995) Biographisch-Bibliographisches Kirchenlexikon. Band VIII, Herzberg: 313-314.

35 Scheiber E. (1989) 1889-1989. 100 Jahre Edelweiss. Die Geschichte des Hotels »Edelweiss \& Gurgl « in Obergurgl, Ötztal, Tirol, Obergurgl, hier 8.

36 Zur Gründungsgeschichte der Alpenvereine vgl. Gidl, A. u.a. (2007) Alpenverein. Die Städter entdecken die Alpen. Der Deutsche und Österreichische Alpenverein von der Gründung bis zum Ende des Ersten Weltkrieges, Wien.

37 Hofinger W. (1991) Tagebuch der Kurazie und Gemeinde in Gurgl. Angefangen im Jahre 1858 von Adolf Trientl d.Z. Provisor. Abschrift einer Kopie der durch Pfarrer Franz Danler (1920-1953) ergänzten Handschrift, Innsbruck. 

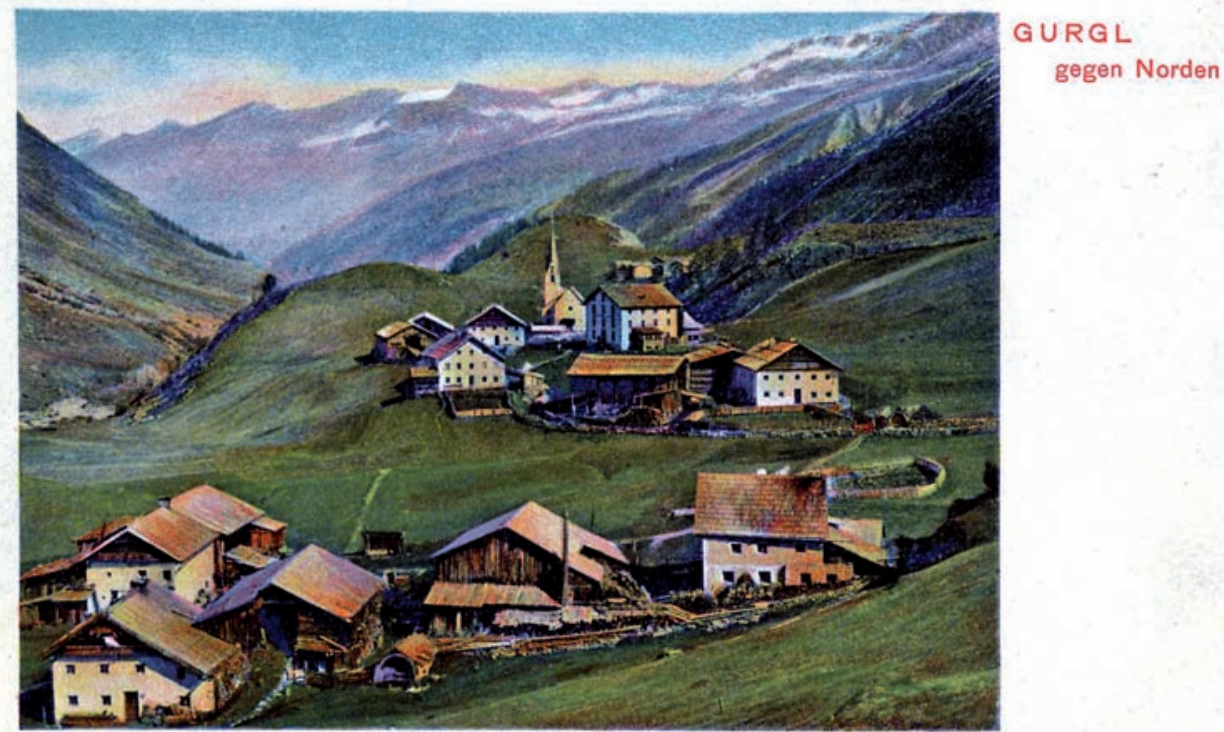

Scheiber, Gasthof Edelwelss, Gurgl.

Abb. 5:

Gurgl gegen Norden. Scheiber, Gasthof Edelweiss, Gurgl. Farbige Bildpostkarte. Postkarten Sammlung der Bibliothek des Tiroler Landesmuseums Ferdinandeum, Sichwort „Obergurgl“.

hinter denen von Vent (4.758) und Sölden (4.540) zurück. ${ }^{38}$

Ende der 1880er Jahre erfolgte die Eröffnung zweier Gasthäuser in Obergurgl und neben dem Kuraten im Widum vermietete das Gasthaus Edelweiß (Abb. 5) um 1900 drei Betten. ${ }^{39}$ Dieser Beherbergungsbetrieb war aus einer ehemaligen Bauernwirtschaft hervorgegangen und von Martin Scheiber aufgebaut und 1904 erweitert worden..$^{40}$

\section{Wintertourismus}

Um die vorletzte Jahrhundertwende (1900) kamen die ersten Schiläufer ins Tal. Diese waren noch mit nur einem

38 Scheiber E. (1989) 1889-1989. 100 Jahre Edelweiss. Die Geschichte des Hotels »Edelweiss \& Gurgl« in Obergurgl, Ötztal, Tirol, Obergurgl, hier 10 u. 12.

39 Vgl. Meleghy, T., Preglau, M., Walther, U. (1982) Die Entwicklung Obergurgls vom Berg-Bauerndorf zum Tourismuszentrum. Sozialhistorische Analyse und evolutionstheoretische Rekonstruktion. Forschungsbericht 18 des Instituts für Soziologie der Universität Innsbruck, Innsbruck, hier 93.

40 Scheiber E. (1989) 1889-1989. 100 Jahre Edelweiss. Die Geschichte des Hotels »Edelweiss \& Gurgl« in Obergurgl, Ötztal, Tirol, Obergurgl. 
Stock und Brettern mit einer respektablen Länge $(2,30 \mathrm{~m})$ ausgestattet. Im Winter 1903/04 wurden Gurgler Bergführer vom Alpenverein zu einem Schikurs einberufen. Dem folgten Versuche, Schier im Tal selbst herzustellen (etwa durch den Gurgler Tischler Josef Klotz, vulgo „StasnSeppl“). Für den Winter 1909/10 ist eine Schitour zum Rotmoosjoch durch Jakob und Josef Gstrein mit Angelus Scheiber verbürgt. Am 10. Januar 1911 kam es, angeregt durch das Vorbild anderer Orte wie St. Anton, Kitzbühel und Innsbruck zur Gründung des „Ski-Club Gurgl“, als dessen erster Obmann Jakob Gstrein, vulgo „Krumpns Joggl“ fungierte. ${ }^{41}$ Damit begann sich in Obergurgl ein Zweisaisonentourismus zu etablieren. Sportliche Wettkämpfe, etwa der 1922 erstmals ausgetragene 30-km-Lauf, der auch durch das Rotmoostal führte, und später den Namen „Gurgler Gletscherrennen“ erhielt, trugen in der Zwischenkriegszeit zur Bekanntheit Obergurgls als Wintersportzentrum bei. Diese wurde durch auswärtige Wettkampfsiege des SC-Gurgl noch gesteigert. Eine unerwartete Publicity für den Ort brachte die (Not-)Landung des Schwei- zer Wissenschaftlers Auguste Piccard am 27. August 1931 am Gurgler Ferner. Ihm zu Ehren wurde am 10. Januar 1932 das erste internationale Piccardrennen vom Festkogel ausgetragen. Im Dezember 1933 eröffnete der SC Gurgl die Skiclubhütte Schönwies am Ausgang des Rotmoostales, die als „neue[r] Stützpunkt für den Fremdenverkehr" fungierte und vom Wettläufer Hugo Gstrein gepachtet wurde. ${ }^{42}$ In den folgenden Jahren wurde der Fremdenverkehr in Tirol durch die so genannte „1000-Mark-Sperre“ stark beeinträchtigt. ${ }^{43}$ Der Initiative des damaligen Obmanns des SC-Gurgl war es zu verdanken, dass in Obergurgl fast 80 Prozent des bisherigen Gästestandes gehalten werden konnten. ${ }^{44}$ Die Kriegswirren ließen auch in Obergurgl ab 1939 den Fremdenverkehr nahezu zum Erliegen kommen. Wenige Monate nach Kriegsende erfolgte die Wiedergründung der touristischen und alpinsportlichen Vereine und Institutionen (etwa am 8. Januar 1946 mit der ersten Clubversammlung des SC-Gurgl im Hotel Edelweiss). Am 14. März 1948 wurde der erste Schilift in Obergurgl und damit des gesamten Ötztales als Bügellift

41 Scheiber, P. (Hg.) (1971) 60 Jahre Ski-Club Gurgl, Obergurgl.

42 Skihütten-Einweihung und anderes aus Ober-Gurgl. In: Der Oberländer, Donnerstag 14. Dezember 1933, Nr. 50: 5.

43 Vgl. Nussbaumer, J. (1988) Die Tausend-Mark-Sperre vom Mai 1933 und der Tiroler Fremdenverkehr. In: Albrich, T., Eisterer, K., Steininger, R. (eds.) Tirol und der Anschluß. Voraussetzungen, Entwicklungen, Rahmenbedingungen 1918-1938. Innsbrucker Forschungen zur Zeitgeschichte 3, Innsbruck, 307-330.

44 Scheiber, P. (eds.) (1971) 60 Jahre Ski-Club Gurgl, Obergurgl. 
mit einer Länge von $300 \mathrm{~m}$ in Betrieb genommen. ${ }^{45}$ Dieser Wiederaufbau der touristischen Infrastruktur erreichte vier Jahre später, 1954, mit der Errichtung des damals höchsten Schiliftes in Österreich, vom Gaisberg $(2.050 \mathrm{~m})$ zur Hohen Mut $(2.669 \mathrm{~m})$ ihren ersten Höhepunkt. Dieser „Gletscherlift“ wies eine schräge Länge von $1.350 \mathrm{~m}$ und eine Beförderungskapazität von 220 Personen per Stunde auf. ${ }^{46}$ Durch den Tourismus wurde die Einwohnerzahl in Obergurgl stabilisiert und sogar gesteigert. Über 70 Prozent der Haushalte sind heute im Tourismus engagiert, auch die Nebenerwerbsbauern sind im Fremdenverkehr tätig. ${ }^{47}$ Ab den 1960er Jahren etablierte sich das Hoteldorf Hochgurgl, das vorwiegend im Winter frequentiert wird. Derzeit verfügt Obergurgl-Hochgurgl über 4.200 Gästebetten und beherbergt jährlich über 100.000 Gäste. Der Großteil der BesucherInnen kommt aus Deutschland, Großbritannien, Österreich und den Benelux-Staaten. ${ }^{48}$
Der boomende Massentourismus bewirkte, dass sich Obergurgl in der zweiten Hälfte des 20. Jahrhunderts von einem Bergbauerndorf zu einem (Winter-)Tourismuszentrum wandelte.

\section{Verzeichnis der AutorInnen}

\author{
Wolfgang Meixner \\ Universität Innsbruck \\ Institut für Geschichtswissenschaften und \\ Europäische Ethnologie \\ Innrain 52, 6020 Innsbruck, Österreich \\ Wolfgang.Meixner@uibk.ac.at
}

\author{
Gerhard Siegl \\ Universität Innsbruck \\ Institut für Geschichtswissenschaften und \\ Europäische Ethnologie \\ Innrain 52, 6020 Innsbruck, Österreich \\ Gerhard.Siegl@uibk.ac.at
}

45 Vgl. Auch Obergurgl bekommt einen Skilift. In: Tiroler Tageszeitung, Mittwoch, 3. März 1948, Nr. 52: 3 sowie Obergurgl eröffnet seinen Skilift. In: Tiroler Tageszeitung, Mittwoch, 17. März 1948, Nr. 64: 3 .

46 Vgl. Österreichs höchster Skilift in Obergurgl. In: Tiroler Nachrichten, Freitag, 8. Januar 1954, Nr. 5: 5 sowie Kollaudierung des höchsten Skiliftes Europas. In: Tiroler Nachrichten, Freitag, 29. Mai 1954, Nr. 122: 4.

47 Vgl. Preglau, M., Meleghy, T., Frantz, K., Tafertshofer, A. (1985) Fremdenverquer. Kosten und Nutzen des Tourismus am Beispiel Obergurgl. Schriftenreihe der Michael-Gaismair-Gesellschaft 4, Innsbruck, hier 71-117.

48 Vgl. http://www.obergurgl.com/main/DE/GG/WI/orte/geschichte/index.html [geprüft 20.12.2009]. 


\title{
Kapitel 2 | Geologie und Geomorphologie von Obergurgl und Umgebung
}

\author{
Karl Krainer
}

\section{Zusammenfassung}

In der Umgebung von Obergurgl sind Gesteine des Ötztal-Stubai-Komplexes und des Schneeberger Komplexes aufgeschlossen. Beide Einheiten gehören zum ostalpinen Deckensystem. Der Ötztal-Stubai-Komplex setzt sich in der Umgebung von Obergurgl hauptsächlich aus Paragneisen und Glimmerschiefern zusammen. In den Gesteinen des Ötztal-Stubai-Komplexes konnten bislang drei Metamorphoseereignisse (kaledonisch, variszisch und alpidisch) und mehrere Deformationsphasen nachgewiesen werden. Der Schneeberg Komplex besteht aus grobkörnigen Glimmerschiefern mit Zentimetergroßen Granaten und Hornblenden, Amphibolit und Marmor. Die Gesteine zeigen nur eine alpidische Metamorphose.

Die morphologische Gestaltung der Hochgebirgslandschaft erfolgte vor allem durch die großen, eiszeitlichen Gletscher. Spuren der glazialen Tätigkeit wie Trogtäler, Hängetäler, Kare, Karseen, Rundhöcker, Gletscherschliffe und Moränen sind häufig zu finden. Daneben sind auch periglaziale Erscheinungsformen wie Solifluktionsloben oder Bültenböden sowie Permafrost-Erscheinungen, insbesondere Blockgletscher, anzutreffen.

\section{Abstract}

In the area of Obergurgl basement rocks of the Ötztal-Stubai Complex and Schneeberg Complex are exposed. Both units are part of the Austroalpine Nappe System. The ÖtztalStubai Complex is mainly composed of paragneiss and mica schists. Within rocks of the Ötztal-Stubai Complex three metamorphic events and several phases of deformation have been recorded, which are ascribed to the $\mathrm{Ca}$ ledonian, Variscan and Alpine events. The Schneeberg Complex consists of coarse mica schists with centimeter-large phenocrysts of garnet and hornblende, of amphibolite and marble. The rocks are overprinted by Alpine metamorphism.

The morphological shaping of the high-mountain landscape around Obergurgl by the huge glaciers took place mainly during the Ice Age. Traces of the glacial activity such as U-shaped valleys, hanging valleys, cirques, cirque lakes, rock drumlins, glacial striations and moraines are common. Besides, periglacial phenomena such as solifluction lobes or earth hummocks as well as permafrost features, particularly rock glaciers, occur. 


\section{Erforschungsgeschichte}

Die erste geologische Aufnahme der Ötztaler Alpen haben Stotter und Trinker in den Jahren 1840 - 1842 durchgeführt, ihre „Geognostische Karte von Tirol“ im Maßstab 1:72.000 erschien 1849. Im Zeitraum 1859 bis 1890 hat Pichler geologische Untersuchungen in den Ötztaler Alpen getätigt. Die erste systematische geologische Kartierung für die Geologische Reichsanstalt in Wien erfolgte durch Teller $(1877,1878)$, seine Ergebnisse liegen jedoch nur in Form einer handkolorierten geologischen Karte vor. Schließlich hat Hammer im Auftrag der Geologischen Bundesanstalt einen Großteil der Ötztaler Alpen neu kartiert, die Ergebnisse seiner Aufnahmen sind auf den geologischen Karten Blatt Nauders, Blatt Ötztal und Blatt Sölden (alle im Maßstab 1:75.000) festgehalten. Weitere Beiträge zur Geologie der Ötztaler Alpen lieferten Schmidegg (1932, 1933, 1936, 1964) und Sander (1920, 1921, 1929). Eine erste zusammenfassende Darstellung der Geologie der Ötztaler Alpen ist in Klebelsberg (1935) enthalten. Nach dem 2. Weltkrieg wurde die geologischpetrologische Erforschung der Gesteine der Ötztaler Alpen intensiviert, vor allem durch das Institut für Mineralogie und Petrographie der Universität Innsbruck. Eine ausführliche Darstellung der Geologie und Petrographie der Ötztaler Alpen stammt von Purtscheller (1969, 1978), eine Zusammenfassung ist auch in Tollmann (1977) enthalten.

In den letzten 30 Jahren wurde der Kenntnisstand zur Geologie, Mineralogie und Petrologie der Ötztaler Alpen durch zahlreiche Detailarbeiten und vor allem auch durch den Einsatz neuer Untersuchungsmethoden bedeutend erweitert, sodass heute die Ötztaler Alpen zu den am besten untersuchten Gebirgsgruppen in den Ostalpen zählen, die aus metamorphen Gesteinen („Altkristallin“) bestehen. Während die Festgesteine der Ötztaler Alpen sehr gut untersucht sind, liegen über die geomorphologischen Prozesse und Erscheinungsformen bislang nur wenige Studien vor.

\section{Überblick über die Geologie der Ötztaler Alpen}

Die Ötztaler und Stubaier Alpen gehören zur geologischen Einheit des „Ötztal-Stubai-Komplexes“, die südlichen Anteile zur geologischen Einheit des „Schneeberger Zuges“ oder „Schneeberg Komplexes“.

Der Ötztal-Stubai-Komplex stellt innerhalb der Ostalpen eine eigene tektonische Deckeneinheit dar, die von Tollmann (1977) dem „mittelostalpinen Deckenstockwerk" zugeordnet wurde. Heute wird der Ötztal-Stubai-Komplex auch als Teil des oberostalpinen Deckensystems aufgefasst (Schmid et al. 2004). 


\section{Ötztal-Stubai-Komplex}

Der Ötztal-Stubai-Komplex setzt sich aus folgenden lithologischen Einheiten zusammen:

a) „Altkristallin“ (metamorphes Grundgebirge)

b) Metamorph überprägte mesozoische Sedimente (Brenner Mesozoikum)

c) Ganggesteine

a) „Altkristallin“

Die Hauptmasse der Ötztaler und Stubaier Alpen besteht aus „Altkristallingesteinen". Hauptgesteine sind Paragneise (Abb. 1) und Glimmerschiefer. In diese eingeschaltet sind Orthogneise, Amphibolite und selten Eklogite.
In den Gesteinen konnten drei Metamorphoseereignisse nachgewiesen werden (siehe z.B. Hoinkes und Thöni 1993, Miller und Thöni 1995, Chowanetz et al. 1997, Hoinkes et al. 1997, Thöni 1986, 1999, Konzett et al. 2003, Tropper und Recheis 2003, Thöny et al. 2008):

1. Eine kaledonische Metamorphose konnte in Migmatiten der BiotitPlagioklasgneise in den zentralen Ötztaler Alpen nachgewiesen werden. Diese Metamorphose erreichte Temperaturen von $660-685^{\circ} \mathrm{C}$ und Drucke von $\geq 4$ kbar (obere Amphibolit- bis untere Granulitfazies) und wurde mit 430 - 490 Millionen Jahren datiert.

2. Eine druckbetonte variszische Metamorphose führte im zentralen Teil der Ötztaler Alpen

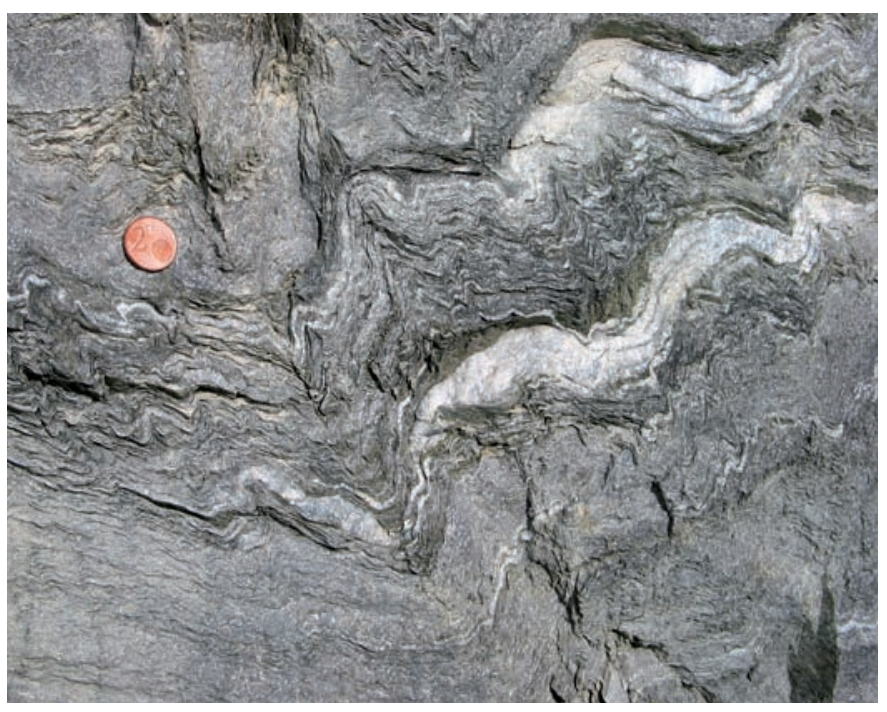

Abb. 1:

Paragneis mit dünnen Quarzlagen und Quarzlinsen, im mm- bis cmBereich verfaltet (Ötztal Kristallin). (Foto: K. Krainer) zur Eklogitbildung bei Temperaturen von $710-748^{\circ} \mathrm{C}$ und extrem hohen Drucken von 26,7 - 27,9 kbar. Diese Metamorphose ereignete sich vor 359-373 Millionen Jahren. Eine variszische Metamorphose in Amphibolitfazies konnte vielerorts mit $330-350$ Millionen Jahren datiert werden. Im Nordwesten der Ötztaler Alpen wurden Temperaturen von $570-640^{\circ} \mathrm{C}$ bei $5,8-$ $7,5 \mathrm{kbar}$ erreicht, in der 
Sillimanit-Zone $610-670^{\circ} \mathrm{C}$ bei $4-8$ kbar, und in der Disthen-Zone 570 $610^{\circ} \mathrm{C}$ bei ebenfalls $4-8$ kbar.

3. Die alpidische Metamorphose wurde mit 73 - 100 Millionen Jahren datiert (Kreide) und zeigt einen zunehmenden Metamorphosegrad von Nordwest (untere Grünschieferfazies) nach Südost wo die Amphibolit- und sogar Eklogitfazies erreicht wurde (550 $600^{\circ} \mathrm{C},>11 \mathrm{~kb}$ ).

Während im Norden Schieferung und Faltenachsen in Ost-West-Richtung streichen, sind im südlichen Teil der Ötztaler Alpen große, offene Falten im KilometerBereich mit steil stehenden Faltenachsen anzutreffen („Schlingentektonik“).

In den Gesteinen des Ötztal-Stubai-Komplexes konnten vier Deformationsphasen (D1 - D4) nachgewiesen werden (van Gool et al. 1987):

Die älteste Phase D1 ist nur selten reliktisch erhalten. Die nächstjüngere Phase ist dagegen in Form einer intensiven Foliation und Isoklinalfaltung deutlich ausgeprägt. Der D3-Phase werden offene Chevron Falten zugeordnet, das Alter dieser Phase ist unklar. Die jüngste Deformationsphase D4 wird durch lokale Scherzonen und offene Falten repräsentiert und dem alpidischen Deformationsereignis zugeordnet (Thöni 1986, 1988).

\section{b) Brenner Mesozoikum}

Im Bereich der Kalkkögel, der Serlesgruppe und im Tribulaun-Gebiet wird das Altkristallin von metamorph überprägten mesozoischen Sedimentgesteinen überlagert. Die bis zu 1200 m mächtige Schichtfolge reicht von quarzitischen Gesteinen der untersten Trias (Krois und Stingl 1990, Stingl und Krois 1990) über mächtige Kalk- und Dolomitmarmore der Trias bis zu den rötlichen, fossilführenden Kalkmarmoren des Jura (Kübler und Müller 1962, Geyssant 1973, Tollmann 1977, Brandner et al. 2003, Prager 2003). Die Sedimentabfolge wurde während der alpidischen Gebirgsbildung metamorph überprägt, wobei im nördlichen Bereich $450^{\circ} \mathrm{C}$, im Süden und Südwesten bis zu $530^{\circ} \mathrm{C}$ und Drucke von 3,5 - 4 kbar erreicht wurden (Purtscheller et al. 1987).

\section{c) Ganggesteine}

Im Altkristallin treten bis zu etwa $10 \mathrm{~m}$ mächtige basaltische bis andesitische postvariszische Gänge auf, die jedoch die mesozoischen Metasedimente nicht durchschlagen (Purtscheller und Rammlmair 1982).

\section{Schneeberg Komplex}

Der südlich angrenzende Schneeberg Komplex zeigt eine zum Ötztal-StubaiKomplex deutlich abweichende lithologische Ausbildung. Hauptgesteine sind 
Metapelite und Metakarbonate, also metamorph überprägte tonige und kalkige Sedimente. Diese Sedimente stammen aus dem Altpaläozoikum bis Präkambrium und haben ursprünglich das Altkristallin des Ötztal-Stubai-Komplexes überlagert. Im Vergleich zum Ötztal-Stubai-Komplex konnte in den Gesteinen des Schneeberger Zuges nur eine alpidische (kretazische) Metamorphose nachgewiesen werden, und zwar im Übergangsbereich Grünschiefer - Amphibolitfazies (Hoinkes und Thöni 1993). Heute bilden die Gesteine des Schneeberg Komplexes mehrere Ost-West-streichende Muldenstrukturen mit der "Schneeberger Hauptmulde“ als dominierender Struktur. Im Süden wird der Schneeberg Komplex von der Laaser Serie, die durch mächtige Marmorzüge charakterisiert ist, begrenzt.

Südlich von Obergurgl, im südlichen Teil des Gaisbergtales und Rotmoostales, sind Gesteine der „nördlichen Randserie“ des Schneeberg Komplexes aufgeschlossen (Purtscheller 1978): grobkörnige Granatglimmerschiefer, grobkörnige Hornblendeschiefer, Amphibolite, Marmore und Quarzite.

\section{Geologie von Obergurgl und Umgebung}

Die Geologie in der Umgebung von Obergurgl ist geprägt von Gesteinen des südlichen Ötztal-Stubai-Komplexes und von der nördlichen Randzone des Schneeberg Komplexes.

Die Grenze zwischen Ötztal-Stubai Komplex und Schneeberg Komplex verläuft vom Königskogel in südwestlicher Richtung, an der Westseite des westlichen Verwallferners vorbei, in das Gaisbergtal, zieht südlich des Hohe Mutsattels weiter in das Rotmoostal, zwischen Nördlichen und Mittleren Seelenkogel in das Langtal, quert den südlichen Schwärzekamm und Mitterkamm und zieht zwischen Karles Spitz und Falschungg Spitz hinunter in das Pfossental (Südtirol).

Hauptgesteine des Ötztal-Stubai-Komplexes sind Biotit-Plagioklasgneis (Paragneis) und mineralreiche Glimmerschiefer. Vereinzelt sind geringmächtige Quarzite eingeschaltet. Lokal werden die Gesteine von Diabasgängen durchschlagen. Amphibolite und Orthogneise fehlen in der Umgebung von Obergurgl weitgehend (Purtscheller 1978).

Biotit-Plagioklasgneise bestehen aus Quarz, Plagioklas, Biotit und etwas Muskovit, stellenweise auch Granat und Staurolith. Akzessorisch sind Apatit, Zirkon, Titanit und Turmalin enthalten. Charakteristisch ist die bräunliche Verwitterungsfarbe.

Die Biotit-Plagioklasgneise zeigen Übergänge oder befinden sich in Wechsellagerung ( $\mathrm{cm}$ - bis $\mathrm{dm}$-Bereich) mit mineralreichen Glimmerschiefern und selten Quarziten. 
Die mineralreichen Glimmerschiefer setzen sich zusammen aus Quarz, Plagioklas, Muskovit, Biotit, Chlorit, Granat, Staurolith, Andalusit, Disthen, Sillimanit in wechselnden Anteilen sowie akzessorisch Zirkon, Turmalin und Apatit. Staurolith ist stellenweise randlich in Chloritoid umgewandelt.

Quarzite sind selten rein, sie enthalten neben Quarz meist auch Muskovit und Plagioklas.

Die nördlichen und nordwestlichen Hänge des Gurgler Tales werden aus BiotitMuskovit-Plagioklasgneis mit mächtigen Einschaltungen von Granatglimmerschiefer und grauen, mineralreichen Glimmerschiefern aufgebaut (Baumann et al. 1967). Vereinzelt sind geringmächtige Amphibolite eingeschaltet wie beispielsweise im Bereich des Hinteren Spiegelkogels oder unmittelbar westlich der Firmisanschneid. Orthogneis (Augen-Flasergranitgneis, Muskovit-Granitgneis) ist selten, ein schmaler Orthogneiszug ist beispielsweise am Kamm zwischen Ramolferner und Spiegelferner, zwischen Ramoljoch und Mittleren Ramolkogel (Baumann et al. 1967) aufgeschlossen.

Der südliche Bereich des Ötztal-Stubai-Komplexes ist charakterisiert durch die „Schlingentektonik" in Form mehrerer großdimensionaler Falten im Kilometerbereich mit steil stehenden Faltenachsen (Stubaier,

Abb. 2:
Venter, Marzell-, Schnals- und Mittelberg-Schlinge).

Die Gesteine des Gurgler Tales markieren die südlichen Ausläufer der Venter Schlinge. Falten streichen im Gurgler Tal von Nord-Nord-Ost nach Süd-Süd-West und tauchen überwiegend flach nach Norden ab. Die Schieferung streicht ungefähr von Nord-Ost nach Süd-West mit wechselnd starkem Einfallen (Baumann et al. 1967). Die Gesteine des Schneeberg Komplexes sind im südlichen Abschnitt des Gaisbergtales und Rotmoostales sehr schön in Form einer Wechsellagerung von grobkörnigen Granatglimmerschiefern, Hornblendeschiefern, Amphiboliten und Marmoren aufgeschlossen. Selten sind auch Quarzite eingeschaltet.

Die für den Schneeberg Komplex typischen grobkörnigen Granatglimmerschie-

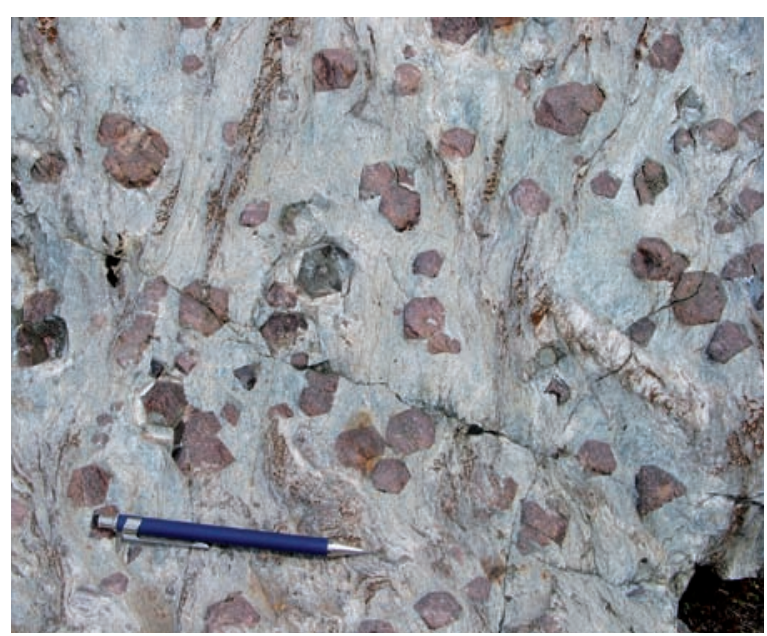

Granatglimmerschiefer mit $\mathrm{cm}$-großen, meist idiomorphen Granaten (Schneeberg-Komplex, Rotmoostal).

(Foto: K. Krainer) 
fer bestehen aus Granat, Biotit sowie untergeordnet Muskovit, Paragonit, Plagioklas, Chlorit und Erzmineralen (Abb. 2). In granatreichen Typen erreichen einzelne Granate eine Größe von über $10 \mathrm{~cm}$, in glimmerreichen Gesteinstypen sind die Granate kleiner. Die Granate sind häufig

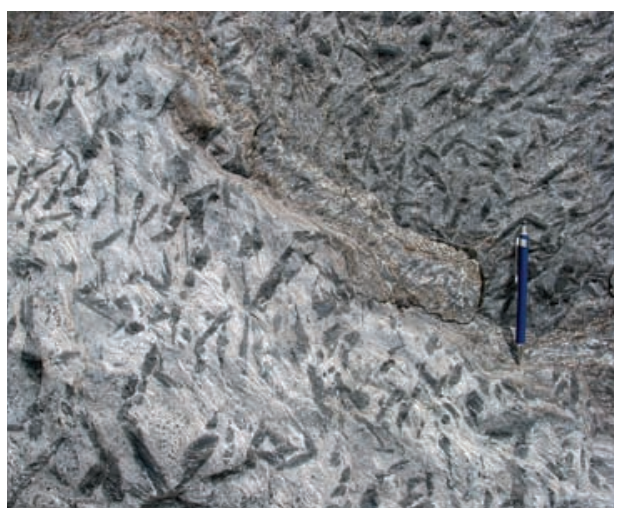

Abb. 3:

Hornblendeschiefer mit $\mathrm{cm}$-großen, dunkelgrünen Hornblenden (Schneeberg-Komplex, Rotmoostal). (Foto: K. Krainer)

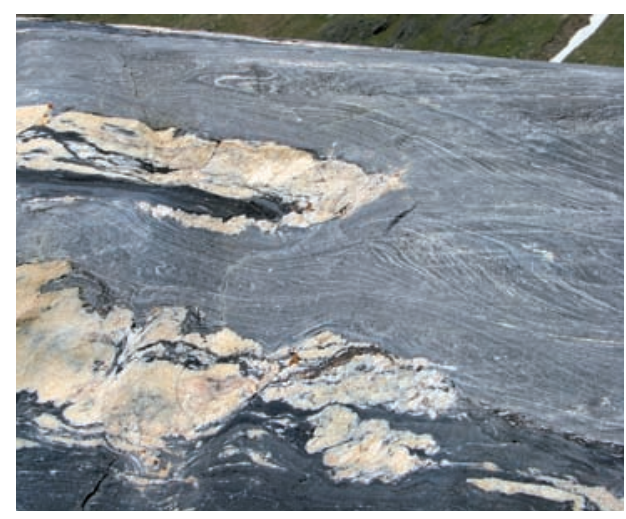

Abb. 5:

Grauer Kalkmarmor, im cm- bis dm-Bereich verfaltet (Schneeberg-Komplex, Gaisbergtal).

(Foto: K. Krainer) auch schön idiomorph ausgebildet und lassen sich oft gut aus dem Nebengestein herauspräparieren. Sie sind daher bei Mineraliensammlern sehr begehrt. Teilweise zeigen die Granate deutliche, rotierte Interngefüge aus Quarz und Glimmern. Hauptvorkommen der großen Granate ist

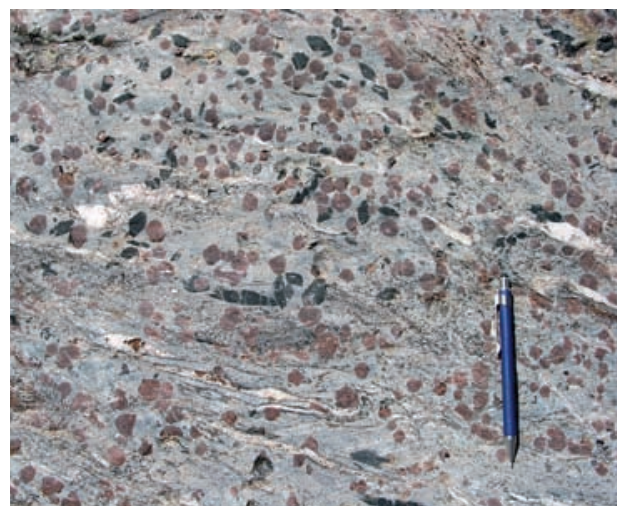

Abb. 4:

Granat-Hornblendeschiefer mit cm-großen Granaten und Hornblenden (Schneeberg-Komplex, Rotmoostal). (Foto: K. Krainer)

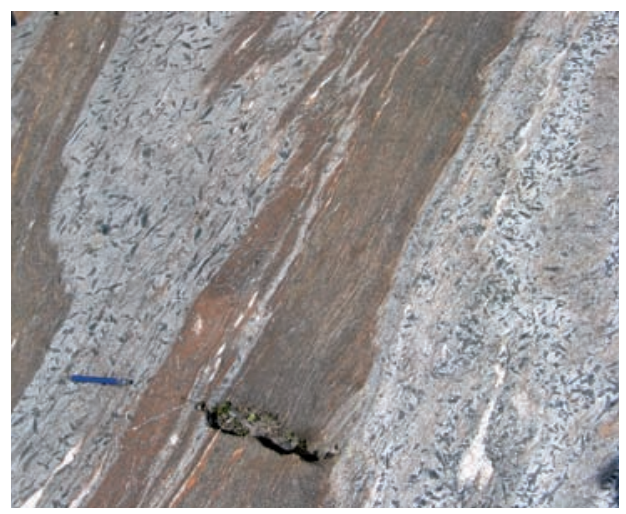

Abb. 6:

Rötlichbraune Kalkmarmorlagen zwischengeschaltet in Granat- und Hornblendeschiefer (Schneeberg Komplex, Rotmoostal). (Foto: K. Krainer) 
der Bereich Granatenkogel - Granatenwand auf der Ostseite des Gaisbergtales. Ein weiteres sehr charakteristisches Gestein ist der grobkörnige Hornblendeschiefer mit Übergängen in Amphibolit (Abb. 3). Neben Hornblende sind Plagioklas, Biotit, Muskovit, Karbonatminerale und Paragonit enthalten. In einzelnen Lagen sind auch bis zu mehrere Zentimeter große Granate enthalten (Granat-Hornblendeschiefer; Abb. 4). Auch ParagonitHornblendeschiefer mit Zentimeter-großen Hornblenden kommen vor. Einzelne Hornblenden können eine Länge von über $10 \mathrm{~cm}$ erreichen.

Kalkmarmore treten als bis zu mehrere Meter mächtige Einschaltungen auf. Die

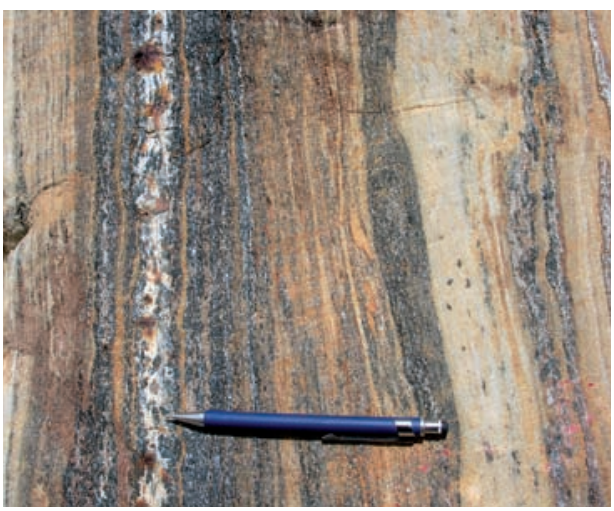

Abb. 7:

Wechsellagerung von Granatglimmerschiefer, Hornblendeschiefer, Amphibolit und Marmor im Rotmoostal (Schneeberg Komplex).

(Foto: K. Krainer)
Farbe reicht von grau (Gaisbergtal; Abb. 5) über gelblich bis rötlichbraun (Rotmoostal; Abb. 6). Neben Kalzit sind teilweise auch Muskovit und Quarz enthalten.

Vereinzelt kommen auch geringmächtige Quarzite vor, die neben Quarz auch einen geringen Anteil an Muskovit und Biotit enthalten.

Granatglimmerschiefer, Granathornblendeschiefer, Hornblendeschiefer, Amphibolite und Marmore treten in enger Wechsellagerung (Dezimeter- bis MeterBereich) auf (Abb. 7) und zeigen auch allmähliche Übergänge. Die Gesteine sind oft auch im Dezimeter- bis Meter-Bereich verfaltet (Abb. 8).

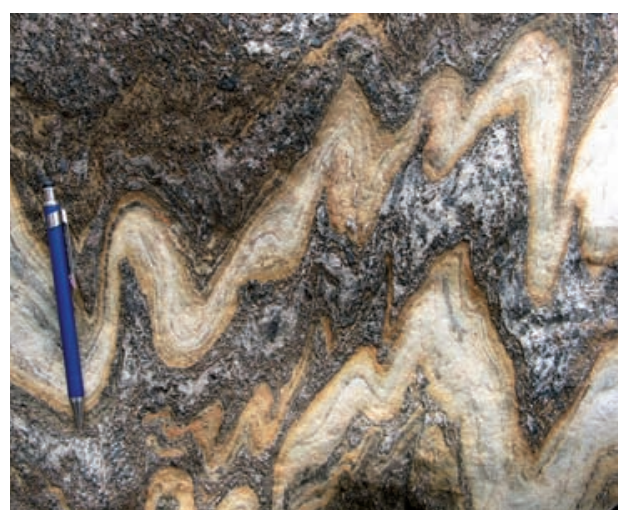

Abb. 8:

Dünne, stark verfaltete Marmorlagen im GranatHornblendeschiefer (Schneeberg Komplex, Rotmoostal).

(Foto: K. Krainer) 


\section{Die Eiszeit und Gestaltung der Landschaft durch Gletscher}

Während der Eiszeit, die ca. die letzten 2 Millionen Jahre umfasst, gab es mehrere große Vereisungsphasen. Während dieser Vereisungsphasen waren die Alpen jeweils in einen riesigen Eispanzer gehüllt, die Täler waren von einem gewaltigen Eisstromnetz ausgefüllt.

Der Höhepunkt der letzten Vereisungsphase war vor ca. 20.000 Jahren. Der Inngletscher reichte damals bis in das Alpenvorland. Das Ötztal war vollkommen von Gletschern ausgefüllt, lediglich die höchsten Gipfel und Grate ragten aus dem Eis heraus. Der Ötztalgletscher

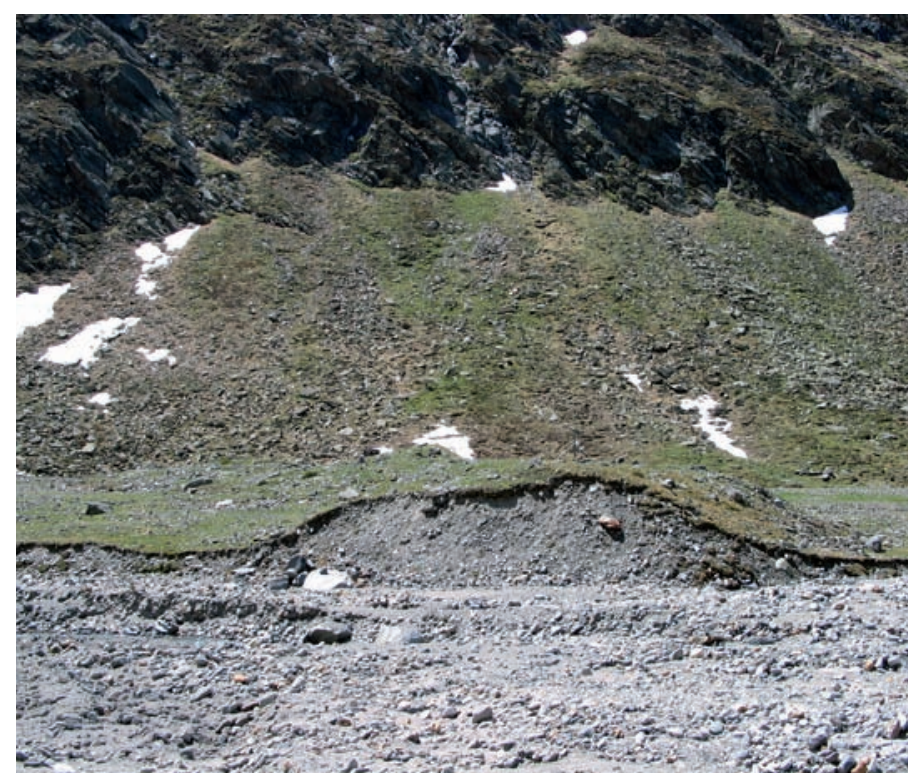

Abb. 9:

Dieser vom Gletscherbach anerodierte Endmoränenwall markiert den letzten Gletscherhochstand um 1854 im Rotmoostal. (Foto: K. Krainer) war ein bedeutender Seitengletscher des großen Inngletschers, dessen Eisoberfläche damals bei Ötz bei ca. $2.500 \mathrm{~m} \mathrm{lag}$ (van Husen 1987).

Nach dem Abschmelzen der großen Gletscher der letzten Vereisungsphase gab es noch eine Reihe von kleineren Gletschervorstößen, die durch entsprechende Moränen auch im Ötztal dokumentiert sind. Im Steinach-Stadium (vor ca. 14.000 Jahren) erreichte der Ötztalgletscher nochmals das Inntal. Ein nächstjüngerer Vorstoß (Gschnitz, vor ca. 13.000 Jahren) endete ebenfalls im Mündungsbereich des Ötztales in das Inntal. Im Egesen Stadium (vor ca. 10.500 Jahren) reichte der Ötztalgletscher bis in den Bereich von Kaisers nördlich von Sölden (Hantke, 1983). Der letzte starke Gletschervorstoß während der Kleinen Eiszeit mit seinem Höhepunkt um 1850 ist durch zahlreiche Moränenwälle gut dokumentiert. Vor allem im Rotmoostal und Gaisbergtal, aber auch an vielen anderen Stellen, sind die Seitenund Endmoränen von 1850 noch sehr gut erhalten (Abb. 9). Auch um 1920 gab es noch eine kurze Vorstoßphase, die ebenfalls durch Moränen dokumentiert ist. 
Nach dem Abschmelzen der riesigen Eismassen wurden die steilen Talflanken oft instabil, was zu entsprechenden Massenbewegungen wie Hangrutschungen und Bergstürzen führte.

Heute schneiden sich die Bäche aufgrund des mitgeführten Geschiebes verstärkt in den Untergrund ein („Tiefenerosion“).

Stellenweise haben sich die Bäche bereits schluchtartig in den Felsuntergrund eingeschnitten.

\section{Die geologische Tätigkeit der Gletscher}

Die hochalpine Gebirgswelt der Ötztaler Alpen wird gekrönt von zahlreichen Gletschern, die dieser Hochgebirgslandschaft einen besonderen Reiz verleihen. Die Ötztaler Alpen sind die am stärksten vergletscherte Gebirgsgruppe in Österreich. Immerhin bedecken die 213 Gletscher eine Fläche von rund $170 \mathrm{~km}^{2}$ bzw. 32\% der Gesamtfläche (Stand 1969: Hasslacher und Lanegger 1988). Seither hat sich die vergletscherte Fläche um ca. 17\% verringert.

Gletscher sind dynamische „geologische Körper", die auf klimatische Veränderungen mit Vorstoß oder Rückzug reagieren und durch die Bewegungen des Gletschereises exogene Prozesse der Erosion, des Transportes und der Sedimentation ausüben. Dadurch sind Gletscher sehr wesentlich an der morphologischen Gestaltung des Hochgebirges beteiligt. Das Relief der Ötztaler Alpen wurde vor allem während der quartären Vereisungsphasen stark von den Gletschern überprägt und geformt. Bewegt sich ein Gletscher talwärts, so übt er dabei verschiedene exogene Prozesse aus: Erosion, Transport und Sedimentation. Je größer ein Gletscher und je mächtiger das Gletschereis ist, desto stärker sind die exogenen Prozesse, vor allem die Glazialerosion. Diese Prozesse waren besonders während der quartären Vereisungsphasen von großer Bedeutung, als fast die gesamten Alpen von Gletschereis bedeckt, die Täler von einem gewaltigen Eisstromnetz ausgefüllt waren und die Gletscher teilweise weit in das Alpenvorland hinausreichten.

Die Glazialerosion beruht auf der schürfenden, kratzenden, schleifenden und scheuernden Wirkung des sich talwärts bewegenden Gletschereises, wobei das Eis selbst keine große Erosionskraft ausübt. Die Erosion geht auf die an der Sohle des Gletschers mitgeschleppten Gesteinsbrocken unterschiedlicher Größe zurück. Durch die schürfende Tätigkeit dieser durch den Druck des überlagernden Gletschereises gegen den Felsuntergrund gedrückten Gesteinsbrocken werden Unebenheiten im Gesteinsuntergrund ausgeglichen, Kerbtäler (V- Täler) werden zu Trogtäler (U- Täler) umgeformt und es entstehen dabei charakteristische Erosionsmerkmale wie Rundhöcker und Gletscherschliffe mit Kratzspuren („Gletscherschrammen") und Sichelausbrüchen. Gletscherschrammen zeigen die ursprüngliche Fließrichtung des Eises an. 
Durch Wiedergefrieren der Schmelzwässer an der Unterseite der Gletscher im Druckschatten von Hindernissen können aus dem Felsuntergrund auch Gesteinsbrocken herausgerissen werden.

Trogtäler sind gekennzeichnet durch einen breiteren, relativ flachen Trogboden, übersteilte Trogwände, eine Trogschulter und eine durch verstärkte Frostverwitterung am ehemaligen Gletscherrand herausgeformte Schliffkehle. Das Ötztal und seine Seitentäler sind klassische, von den Gletschern geformte Trogtäler. Eines der schönsten Beispiele für ein Trogtal ist das Rotmoostal bei Obergurgl (Abb. 10). An vielen Stellen, insbesondere im inneren Ötztal, sind auch zahlreiche Rundhöcker und Gletscherschliffe zu beobachten.

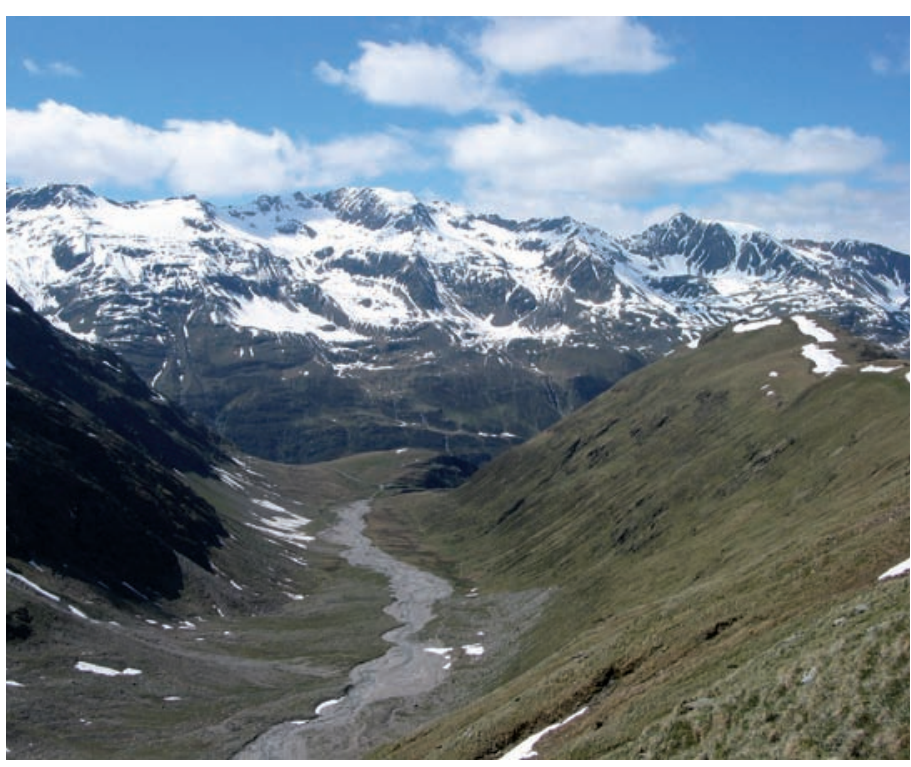

Abbildung 10:

Das Rotmoostal ist ein klassisches glazial geformtes Trogtal.

(Foto: K. Krainer)
Auch die Karbildung ist eine Folge der Eiserosion. In geschützten Mulden oberhalb der Schneegrenze entstehen durch Schneeanwehung zunächst ein Firnfeld und schließlich ein kleiner Gletscher. An der Grenze Gletscher-Gestein kommt es infolge größerer Temperaturunterschiede (Gestein absorbiert die Sonnenenergie und erwärmt sich, firnbedeckter Gletscher reflektiert einen Großteil der Sonnenenergie) und wiederholter Auftau- und Ciefrierprozesse zu verstärkter Frostverwitterung. Das dabei entstehende Lockermaterial wird durch den sich talwärts bewegenden Gletscher, auch durch Schmelzwässer abtransportiert und an der Stirn des Kargletschers als Moränenwall angehäuft. So entsteht im Laufe der

Zeit ein Kar mit steilen Wänden und einem relativ flachen Karboden. Viel Kare sind durch die Glazialerosion übertieft und werden durch eine Karschwelle in Form eines Felsriegels, der manchmal noch von einem Moränenwall gekrönt wird, talwärts begrenzt. In diesen Karmulden haben sich nach dem Eisrückzug vielfach Karseen gebildet. In der Umgebung von Obergurgl finden sich 
Karseen im Hinteren Wurmeskar, im Zirmeggenkar, im Hallwart am Aufstieg zur Gurgler Scharte oder im Seekarl am Fuße des Nörderkogels).

Im Langtal sind unmittelbar südlich der Langtalereck-Hütte noch die Reste von Seeablagerungen des ehemaligen Gurgler Eissees in Form von Terrassen aufgeschlossen. Der Gurgler Eissee wurde vom Gurgler Ferner aufgestaut, erreichte eine Länge von ca. $800 \mathrm{~m}$, eine Breite von ca. 250-300 $\mathrm{m}$ und eine Tiefe von bis zu 100 m. Die Seeablagerungen zeigen drei Sedimentabfolgen, die durch Erosionsflächen unterbrochen sind und vermutlich im Zeitraum 1717 - 1719, 1770 - 1774 und 1848 - 1850 abgelagert wurden. Eine tiefer liegende Terrasse entstand während

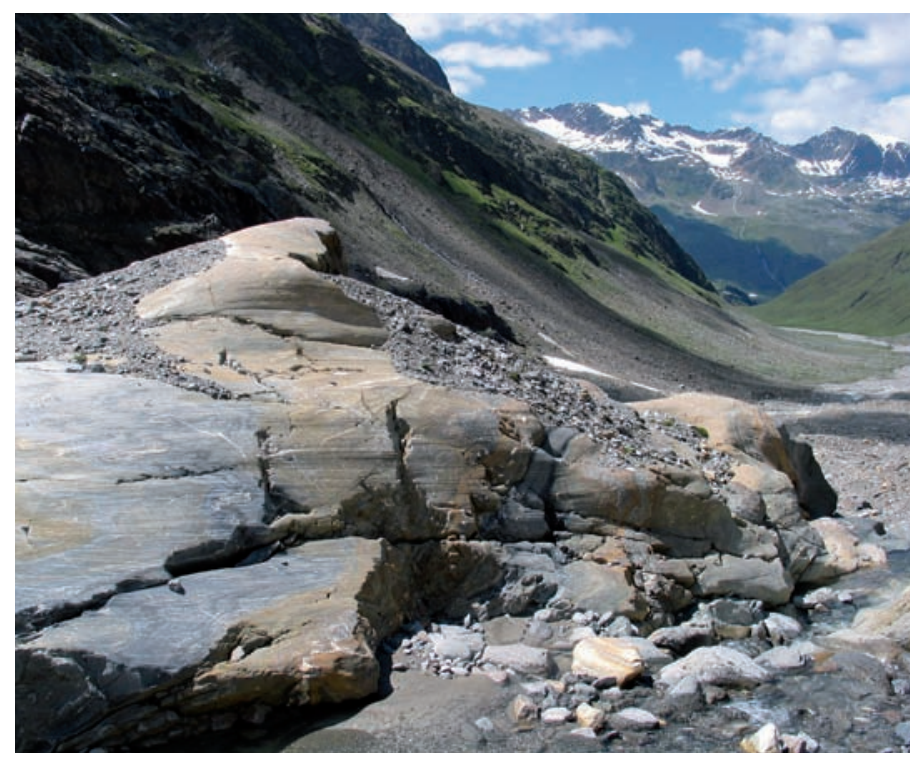

Abb. 11:

Vom Gletscher geformter Rundhöcker mit schönen Gletscherschliffen im Vorfeld des Rotmoosferners im hinteren Talbereich. (Foto: K. Kainer) der Schmelzperiode von 1915 (Krainer und Spieler, 1999).

Die Bildung von Hängetälern geht ebenfalls auf die Galzialerosion zurück. Hängetäler sind Seitentäler, die in Form einer Steilstufe in das Haupttal münden. Diese Steilstufe wird von den Bächen nicht selten in Form eines Wasserfalles überwunden. In den Haupttälern, die während der quartären Vereisungsphasen von mächtigen Gletschern ausgefüllt waren, war die Glazialerosion wesentlich stärker als in den nur von kleinen Nebengletschern erfüllten Seitentälern. Daher haben sich die Haupttäler stärker erosiv eingeschnitten als die Seitentäler und bereits bestehende Steilstufen wurden verstärkt oder überhaupt neu geschaffen. Gaisbergtal und Rotmoostal sind zwei klassische Hängetäler. Spuren der Gletschererosion sind praktisch überall anzutreffen. Rundhöcker und Gletscherschliffe (Abb. 11) sind in härteren Gesteinen am besten erhalten. Gletscher transportieren den Verwitterungsschuttunterschiedlichster Korngröße (von Tonpartikeln bis zu großen Felsblöcken) vom Nährgebiet zur Gletscherstirn. Der Großteil des Materials wird dabei an der Glet- 
scherbasis mitgeschleppt, aber auch an der Seite (Seitenmoränen) und an der Gletscheroberfläche (Oberflächenmoränen). Ein Teil wird auch als im Eis eingefrorenes Material transportiert. Das Material, welches ein Gletscher transportiert, stammt zum Großteil von der Frostverwitterung, gelangt teilweise durch Steinschlag und mit Lawinen auf den Gletscher oder wird auch teils vom Gletschereis aus dem Felsuntergrund herausgerissen.

Vor allem an der Unterseite und im basalen Teil eines temperierten Gletschers werden durch die Eisbewegung die einzelnen Gesteinsbrocken gegeneinander gestoßen und dabei bearbeitet - nämlich zerkleinert, poliert und gekritzt. Dabei entstehen die für Grundmoränen charakteristischen gekritzten Geschiebe, die auf ihrer Oberfläche nach verschiedenen Richtungen verlaufende Kratzspuren aufweisen.

Das vom Gletschereis transportierte Material wird vor allem an der Gletscherstirn in Form von Stirn- oder Endmoränen abgelagert, aber auch an deren Rändern (Seitenmoränen) und im Zehrgebiet an der Gletscherbasis (Grundmoränen). Moränen sind meist ungeschichtet, sehr schlecht sortiert und die Gerölle sind überwiegend eckig. Charakteristisch für Grundmoränen sind gekritzte Geschiebe und ein hoher Feinanteil.

Das Moränenmaterial wird teilweise durch die Schmelzwässer umgelagert und bei entsprechendem Relief im Gletschervorfeld, auf einer „Sanderfläche“ (aus dem isländ. „Sandr" = Schotter- und Sandfläche, die im Vorfeld eines Gletschers durch Schmelzwässer sedimentiert werden), abgelagert.

\section{Periglaziale Erscheinungsformen}

Jene Bereiche, die unmittelbar außerhalb der Gletscher liegen und durch ein kaltes Klima mit einer durchschnittlichen Jahrestemperatur von unter $+3^{\circ} \mathrm{C}$ geprägt sind, werden als Periglazial bezeichnet (French 1996). In diesen Bereichen spielen Frost-Prozesse eine große Rolle, charakteristisch sind die Entwicklung von Permafrost, Frostverwitterung, verschiedene Prozesse der Frostaktivität (Frostaufbrüche, Bodenkriechen, Strukturböden etc.) und Massenbewegungen in den wassergesättigten Auftauzonen (Solifluktion, Hangrutschungen). Typische morphologische Erscheinungsformen periglazialer Bereiche sind Frostbodenstrukuren wie Steinringe, Steinnetze, Streifenböden, Pflasterböden, Schuttloben und Rasenloben.

Wenn Wasser gefriert, kommt es zu einer Volumszunahme von neun Prozent. Dazu kommt, dass einmal gebildetes Bodeneis Wasser aus seiner Umgebung anzieht und das Bodeneis unter entsprechenden Temperaturbedingungen wächst. Dies führt an der Oberfläche zur Frosthebung (Frostaufbrüche). 
Als Folge der Tau- und Gefrierprozesse, vor allem durch die Frosthebung, werden größere Steine mit der Zeit an die Oberfläche transportiert und gleiten dann von der gewölbten Oberfläche in die randlichen Furchen, wo sie sich anreichern und Strukturböden wie Steinringe, Steinnetze oder Streifenböden bilden.

Eine besondere Form der Frostaktivität sind die Bültenböden (Thufur). Damit werden rundliche bis ovale Buckel mit einem Durchmesser bis zu $1 \mathrm{~m}$ und einer Höhe bis zu $50 \mathrm{~cm}$ bezeichnet. Sie entstehen in feinkörnigen, stark durchfeuchteten, ebenen bis wenig geneigten Böden mit einer geschlossenen Vegetationsdecke aus Gräsern, Moosen, Flechten und Zwergsträuchern. Diese Thufurhügel entstehen als Folge der Frostdynamik, Permafrost ist jedoch nicht Voraussetzung. Die Entstehung der Bültenböden wird fälschlicherweise auch durch Weidegang (Viehtritt) erklärt. Bültenböden sind oberhalb von $2.200 \mathrm{~m}$ Seehöhe vielerorts anzutreffen, beispielsweise in der Umgebung des Schönwieskopfes.

Solifluktionsloben entstehen durch die langsame, hangabwärts gerichtete Bewegung von wassergesättigten Böden als Folge der Frostdynamik. Die Bewegung erfolgt einerseits als Folge des Frostkriechens (Frosthub), andererseits als langsames Fließen des wassergesättigten, aufgetauten Bodens im Sommer. Die Fließgeschwindigkeit bewegt sich je nach Neigung, Wassergehalt und Sedimenttyp zwischen wenigen $\mathrm{cm} / \mathrm{Jahr}$ bis zu ca.
$30 \mathrm{~cm} /$ Monat. Solifluktionsloben findet man unter anderem im Verwalltal.

\section{Alpiner Permafrost}

Unter Permafrost (Dauerfrostboden) versteht man einen Boden (Lockersediment), der zumindest über zwei Jahre hindurch, auch im Sommer, gefroren bleibt (Definition siehe z.B. Davis 2001). Im Sommer taut nur die oberste Schicht auf, darunter bleibt der Boden ständig gefroren. Diese Auftauschicht wird als aktive Lage bezeichnet und erreicht in den Alpen eine Mächtigkeit von meist mehreren Metern. Ein wichtiger Bestandteil des Permafrostes ist das Bodeneis in Form von linsigen Körpern aus klarem, reinen Eis. Bodeneis entsteht in feinkörnigen Lockersedimenten und kann bis zu 80 Volumsprozent des Bodens einnehmen.

Permafrost ist auch in den Alpen, und zwar je nach Exposition ab einer Seehöhe von 2.500 bis $2.700 \mathrm{~m}$ vorhanden. Das verstärkte Abschmelzen von Permafrosteis in den letzten Jahren als Folge der globalen Klimaerwärmung, hat auch in den Ötztaler Alpen zur Destabilisierung des Untergrundes geführt. Auch die erhöhte Steinschlagaktivität ist teilweise auf das verstärkte Abschmelzen von Permafrost zurückzuführen.

Über den Alpinen Permafrost ist nach wie vor wenig bekannt, es gibt keine Daten über Mächtigkeiten, Verbreitung, Art des Bodeneises und Frostaktivitäten. Mögli- 
cherweise handelt es sich bei den bekannten Frostbodenstrukturen teilweise nur um Relikte früherer, kälterer Zeiten.

In den Alpen tritt Permafrost in unterschiedlicher Form in Erscheinung. Die weitaus häufigste Form sind die zahlreichen Blockgletscher, die zu den auffälligsten und häufigsten morphologischen Erscheinungsformen des Hochgebirges zählen. Weiters ist Permafrost auch in den Lockergesteinen, insbesondere im Hangschutt außerhalb der Blockgletscher anzutreffen. Außerdem tritt Permafrost auch im Festgestein in Form des Spaltenfrostes auf.

Alle Formen des alpinen Permafrostes enthalten Eis, wobei der weitaus größte Anteil des Permafrost-Eises vermutlich in den zahlreichen Blockgletschern enthalten ist. Da im alpinen Permafrost beträchtliche Eismengen gespeichert sind, könnte sich das verstärkte Abschmelzen des Permafrost-Eises auch auf das Abflussgeschehen im Hochgebirge auswirken.

\section{Was sind Blockgletscher?}

Blockgletscher sind lappen- bis zungenförmige Körper aus gefrorenem Lockermaterial (Hangschutt, Moräne) und Eislinsen oder Eiskörpern, die sich deutlich von ihrer Umgebung abheben und sich langsam hangabwärts bewegen. Gletscher sind Erscheinungen des alpinen Permafrostes, können aber auch aus zurück- schmelzenden, schuttbedeckten Kargletschern entstehen (Barsch 1996, Haeberli 1985, Haeberli et al. 2006).

Man unterscheidet a) aktive Blockgletscher, die Eis enthalten und sich langsam hangabwärts bewegen, b) inaktive Blockgletscher, die auch noch Eis enthalten, sich aber nicht mehr bewegen, und c) fossile Blockgletscher, die kein Eis mehr enthalten.

Blockgletscher sind meist einige $100 \mathrm{~m}$ lang und 100 - $200 \mathrm{~m}$ breit. Einzelne Blockgletscher in den Ötztaler und Stubaier Alpen erreichen eine Länge von bis zu $1,6 \mathrm{~km}$.

\section{Blockgletscher im Äußeren Hochebenkar}

In den österreichischen Alpen hat erstmals Pillewizer (1938) am Hochebenkar-Blockgletscher Bewegungsmessungen durchgeführt. Seither, also seit mehr als 60 Jahren, werden am HochebenkarBlockgletscher jährlich die Bewegungsraten des Gletschers gemessen (Pillewizer 1957; Vietoris 1958, 1972; Haeberli and Patzelt 1982; Kaufmann 1996; Schneider and Schneider 2001; Kaufmann and Ladstätter 2002, 2003; Ladstätter and Kaufmann 2005).

Für die Periode 1938 - 1953 hat Pillewizer (1957) im oberen Bereich (Profil B) eine maximale Fließgeschwindigkeit von $75 \mathrm{~cm} \mathrm{a}^{-1}$ beobachtet, und $85 \mathrm{~cm} \mathrm{a}^{-1}$ für die Periode 1953 - 1955. Im Profil 2 wurden jährliche Geschwindigkeiten von 
1,61 m für die Periode 1951 - 1952, 1,84 m für die Periode $1952-1953$ and 1,53 $\mathrm{m}$ für die Periode 1953 - 1955 gemessen (Pillewizer 1957, Vietoris 1958).

Nach Kaufmann (1996) stieß die Stirn des Hochebenkar-Blockgletschers in 50 Jahren um 148 m vor, was eine jährliche Bewegungsrate von $3 \mathrm{~m} \mathrm{a}^{-1}$ für diese Periode ergibt.

Im untersten Profil 1 wurden die höchsten Fließbewegungen von $3,57 \mathrm{~m} \mathrm{a}^{-1}$ (1953 1955) gemessen, die schließlich auf $5 \mathrm{~m}$ $\mathrm{a}^{-1}$ anstiegen (Vietoris 1972).

Haeberli und Patzelt (1982) haben Messungen von der Basis der winterlichen Schneedecke, Wassertemperaturen an Quellen und refraktionsseismische Untersuchungen durchgeführt.

Der Blockgletscher liegt im Äußeren Hochebenkar, einem nach Nordwest ausgerichteten Kar, ca. 4,3 km Süd-Süd-Ost von Obergurgl (Abb. 12, 13). Der Hochebenkar-Blockgletscher ist ein aktiver, zungenförmiger, großer Blockgletscher. Er erstreckt sich von $2.840 \mathrm{~m}$ (Wurzelzone) bis auf $2.360 \mathrm{~m}$ Meereshöhe (Stirn), ist $1.550 \mathrm{~m}$ lang, ca. $160 \mathrm{~m}$ (im Bereich der Stirn), bis $335 \mathrm{~m}$ (im mittleren Bereich) und bis zu $470 \mathrm{~m}$ (im oberen Bereich) breit.
Der Blockgletscher bedeckt eine Fläche von $0,4 \mathrm{~km}^{2}$, die Fläche des Einzugsgebietes beträgt $1 \mathrm{~km}^{2}$. Die Schuttlage besteht aus einer grobblockigen Lage an der Oberfläche mit unterschiedlichen Korngrößen. Die Oberfläche des Blockgletschers weist eine ausgeprägte Morphologie aus transversalen und longitudinalen Rücken und Vertiefungen auf. Im westlichen Teil der Wurzelzone ist eine Depression ausgebildet.

Die Stirn des Blockgletschers ist steil und völlig frei von Vegetation. Die Flanken sind ebenfalls steil, teilweise aktiv und vegetationsfrei, teilweise inaktiv und mit etwas Vegetation bewachsen. Auch an der Oberfläche des Blockgletschers ist lokal, vor allem auf feinkörnigen Flächen im Bereich der Wurzelzone, eine leichte Vegetationsbedeckung vorhanden.

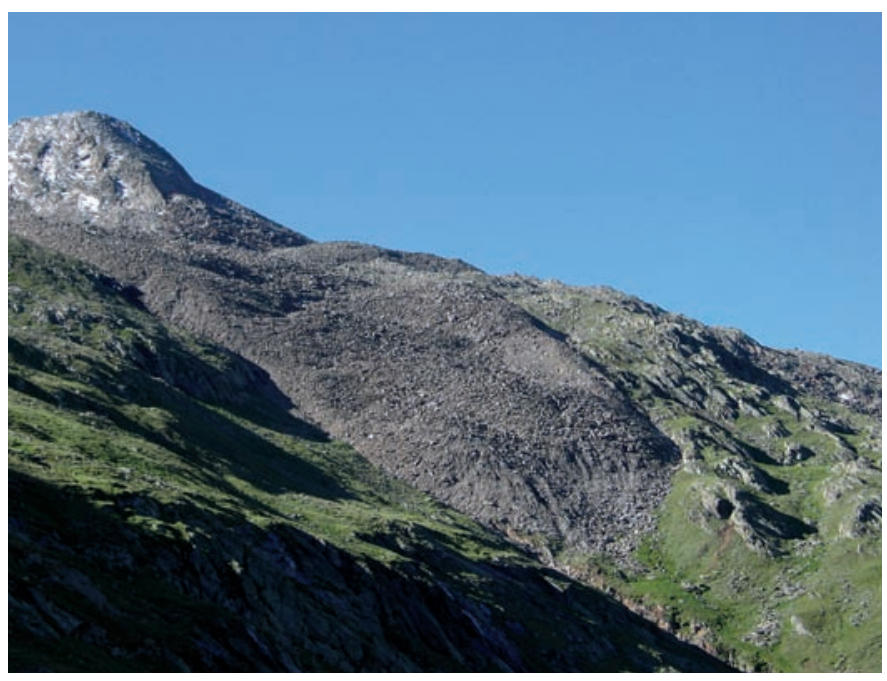

Abb. 12:

Blick von der Gurgler Alm auf die Zunge des aktiven Blockgletschers im Äußeren Hochebenkar. (Foto: K. Krainer) 


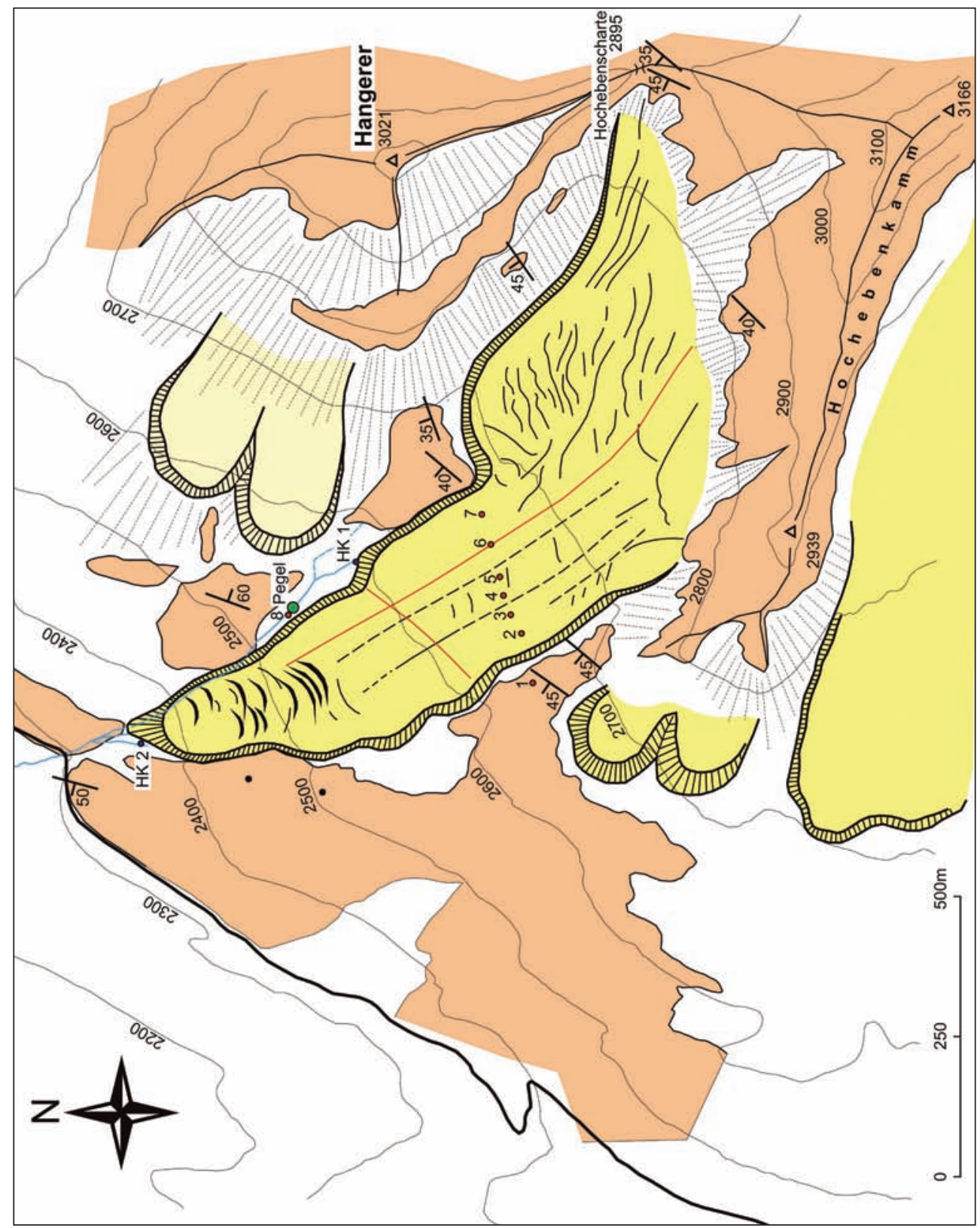

Abb. 13:

Geologisch-morphologische Karte des aktiven Blockgletschers im Äußeren Hochebenkar. HK 1 und HK 2: Sedimentproben, Punkte $1-8$ markieren die Stellen, an denen die Temperaturen an der Basis der winterlichen Schneedecke (BTS) gemessen wurden. Rote Linien: Georadar-Profile. (Foto: K. Krainer) 
Im Osten wird der Blockgletscher vom Massiv des Hangerer $(3.021 \mathrm{~m})$ und im Süden, getrennt durch die Hochebenscharte $(2.895 \mathrm{~m})$, vom Hochebenkamm mit der höchsten Erhebung auf 3.149 m begrenzt.

Der Blockgletscher wird ausschließlich vom Hochebenkamm mit Verwitterungsschutt versorgt.

Die Festgesteine im Einzugsgebiet des Blockgletschers bestehen aus Paragneis und Glimmerschiefer des Ötztal-StubaiKristallins.

Lokal sind klein- und großdimensionale Falten erkennbar. Am Hochebenkamm werden die Gesteine von zahlreichen steilen Störungen durchzogen. Entlang dieser Störungen sind die Gesteine stark aufgelockert und durch Frostverwitterung extrem zerlegt. Daher bilden diese Störungen rinnenförmige Einschnitte, entlang der vor allem mit Beginn der Schneeschmelze sehr viel Verwitterungsschutt anfällt und sich auf den steilen Lawinenkegeln am Fuße der steilen Rinnen eine dünne Schuttlage ansammeln kann.

\section{Literatur}

Barsch, D. (1996) Rockglaciers. Indicators for the Present and Former Geoecology in High Mountain Environments. SpringerVerlag, Berlin, 331 p.

Baumann, M., Helbig, P. \& Schmidt, K. (1967) Die steilachsige Faltung im Bereich des Gurgler und Venter Tales (Ötztaler Alpen). Jahrbuch der Geologischen Bundesanstalt Wien 110: 1-72.

Brandner, R., Resch, W. \& Reiter, F. (2003) Das Brennermesozoikum. Sedimentäre Faziesentwicklungen in metamorphen Gesteinen und tektonische Konsequenzen. Geologische Bundesanstalt Wien, Arbeitstagung 2003, Blatt 148 Brenner: 95-98.

Chowanetz, E. (1994) The age of the Ötztal migmatites - still a matter of debate. Mitteilungen der Österreichischen Mineralogischen Gesellschaft 139: 284-286.

Davis, N. (2001) Permafrost. A Guide to Frozen Ground in Transition. University of Alaska Press, Fairbanks, Alaska, 351 p.

Frank, W., Hoinkes, G., Purtscheller, F. \& Thöni, M. (1987) The Austroalpine Unit West of the Hohe Tauern: The ÖtztalStubai Complex as an Example for the Eoalpine Metamorphic Evolution. In: Geodynamics of the Eastern Alps, Flügel, H.W. \& Faupl. P. (Eds.), Deuticke, Vienna, 179-225.

French, H.M. (1996) The Periglacial Environment (2 $2^{\text {nd }}$ Ed.). Longman, Essex, 341 p. 
Geyssant, J. (1973) Stratigraphische und tektonische Studien in den Kalkkögelgruppe bei Innsbruck in Tirol. Verhandlungen der Geologischen Bundesanstalt Wien, 1973: 377-396.

Haeberli, W. (1985) Creep of mountain permafrost: Internal structures and flow of alpine rock glaciers. Mitteilungen der Versuchsanstalt für Wasserbau, Hydrologie und Glaziologie ETH Zürich, 77: 1-142.

Haeberli, W., Hallet, B., Arenson, L., Elconin, R., Humlum, O., Kääb, A., Kaufmann, V., Ladanyi, B., Matsuoka, N., Springman, S. \& VonderMühl, D. (2006) Permafrost Creep and Rock Glacier Dynamics. Permafrost and Periglacial Processes, 17, 189-214.

Hammer, W. (1923) Geologische Spezialkarte der Republik Österreich, Blatt Nauders (5242) 1:75:000, mit Erläuterungen (62 Seiten). Geologische Bundesanstalt Wien.

Hammer, W. (1925) Cordieritführende metamorphe Granite aus den Ötztaler Alpen. Tschermaks mineralogisch-petrographische Mitteilungen 38, Wien: 67-87.

Hammer, W. (1926) Eklogit und Peridotit in den mittleren Ötztaler Alpen. Jahrbuch der Geologischen Bundesanstalt Wien, 76: 97-123.

Hammer, W. (1931) Zur Umgrenzung der Ötztaler Alpen als Schubdecke. Verhandlungen der Geologischen Bundesanstalt 1931: 175-188, Wien.

Hammer, W. \& Ohnesorge, Th. (1929) Geologische Spezialkarte der Republik Ös- terreich, Blatt Ötzthal (5146) 1:75.000, mit Erläuterungen (58 Seiten). Geologische Bundesanstalt Wien.

Hantke, R. (1983) Eiszeitalter, Band 3: Die jüngste Erdgeschichte der Schweiz und ihrer Nachbargebiete (Westliche Ostalpen mit ihrem bayerischen Vorland bis zum Inn-Durchbruch und Südalpen zwischen Dolomiten und Mont Blanc). Ott Verlag Thun, 730 S.

Hasslacher, P. \& Lanegger, C. (1988) Österreichs Gletscherbachinventar. Fachbeiträge des Österr. Alpenvereins, Serie Alpine Raumordnung, Nr. 1: 1-33, Innsbruck.

Hoinkes, G. \& Thöni, M. (1993) Evolution of the Ötztal-Stubai. Scarl-Campo and Ulten Basement Units. In: Pre-Mesozoic Geology in the Alps, Raumer, von J.F. \& Neubauer, F. (Eds.), Springer, Berlin, 485-494.

Hoinkes, G., Thöni, M., Bernhard, F., Kaindl, R., Lichem, C., Schweigl, J., Tropper, P. \& Cosca, M. (1997) Metagranitoids and associated metasediments as indicators for the pre-Alpine magmatic and metamorphic evolution of the Western Austroalpine Ötztal Basement (Kaunertal, Tirol). Schweizer Mineralogisch-Petrographische Mitteilungen 77: 299-314.

Husen, D. van (1987) Die Ostalpen in den Eiszeiten. Geologische Bundesanstalt Wien (mit einer Karte 1:500.000), 24 S. Kaufmann, V. (1996) Geomorphometric monitoring of active rock glaciers in the Austrian Alps. - $4^{\text {th }}$ International Symposium on High Mountain Remote 
Sensing Cartography. Karlstad - Kiruna - Tromso, August 19-29, 1996: 97-113.

Kaufmann, V. \& Ladstätter, R. (2002) Spatiotemporal analysis of the dynamic behaviour of the Hochebenkar rock glaciers (Oetztal Alps, Austria) by means of digital photogrammetric methods. Grazer Schriften der Geographie und Raumforschung 37: 119-140.

Kaufmann, V. \& Ladstätter, R. (2003) Quantitative analysis of rock glacier creep by means of digital photogrammetry using multi-temporal aerial photographs: two case studies in the Austrian Alps. In: Proceedings of the $8^{\text {th }}$ International Conference on Permafrost, Phillips, M., Springman, S.M. and Arenson, L.U. (eds), 21-25 July 2003, Zürich, Switzerland, Vol. 1: 525-530.

Klebelsberg, R.v. (1935) Geologie von Tirol. Borntraeger, Berlin, 872 S.

Konzett, J., Hoinkes, G. \& Tropper, P. (2003) 5th Workshop of Alpine Geological Studies, Field Trip Guide E4: Alpine metamorphism in the Schneeberg Complex and neighbouring units (immediate vicinity of Obergurgl). Geologisch-Paläontologische Mitteilungen Innsbruck 26: 21-45.

Krois, P. \& Stingl, V. (1990) Die stratigraphische Neueinstufung der basalen klastischen Gesteine im Brennermesozoikum (Stubaier Alpen/Tirol). Zentralblatt für Geologie und Paläontologie, Teil I, 1989, H. 9/10: 1455-1466, Stuttgart.

Kübler, H. \& Müller, W.E. (1962) Die Geologie des Brenner Mesozoikums zwischen
Stubai- und Pflerschtal (Tirol). Jahrbuch der Geologischen Bundesanstalt Wien 105: 173-242.

Miller, C. \& Thöni, M. (1995) Origin of eclogites from the Austroalpine Ötztal basement (Tirol, Austria): geochemistry and $\mathrm{Sm}-\mathrm{Nd}$ vs. Rb-Sr isotope systematic. Chemical Geology 122: 199-225.

Prager, C. (2003) Das Brenner-Mesozoikum nördlich des Pflerschtals. Geologische Bundesanstalt Wien, Arbeitstagung 2003, Blatt 148 Brenner: 99-110.

Purtscheller, F. (1978) Ötztaler und Stubaier Alpen. Sammlung Geologischer Führer, Band 53 (2. Auflage). Gebr. Borntraeger, Berlin - Stuttgart, 128 S.

Krainer, K. \& Spieler, A. (1999) The sedimentary record of ice-dammed lakes in the Ötztal Alps. Zeitschrift für Gletscherkunde und Glazialgeologie 35: 65-86.

Ladstätter, R. \& Kaufmann, V. (2005) Studying the movement of the Outer Hochebenkar rock glacier: Aerial vs. groundbased photogrammetric methods. 2 European Conference on Permafrost, Potsdam, Germany, Terra Nostra 2005(2): 97 (abstract).

Pillewizer, W. (1938) Photogrammetrische Gletscheruntersuchungen im Sommer 1938. Zeitschr. Ges. Erdkde Berlin 9/1: 367-372.

Pillewizer, W. (1957) Untersuchungen an Blockströmen der Ötztaler Alpen. Geomorphologische Abhandlungen des Geographischen Institutes der FU Berlin (Otto-Maull-Festschrift) 5:37-50. 
Purtscheller, F. \& Rammlmair, D. (1982) Alpine metamorphism of diabase dikes in the Ötztal-Stubai metamorphic complex. Tschermaks Mineralogisch-Petrographische Mitteilungen 29: 205-221.

Sander, B. (1920) Tektonik des Schneeberger Gesteinszuges zwischen Sterzing und Meran. Jahrbuch der Geologischen Bundesanstalt Wien 70: 325-334.

Sander, B. (1921) Zur Geologie der Zentralalpen. Jahrbuch der Geologischen Staatsanstalt Wien, 71: 173-224.

Sander, B. (1929) Erläuterungen zur Geologischen Karte Meran - Brixen 1:100.000. Schlernschriften 16: 1-111.

Schmidt, S.M., Fügenschuh, B., Kissling, E. \& Schuster, R. (2004): Tectonic map and overtall architecture of the Alpine orogen. Eclogae geologicae Helvetiae 97: 93-117.

Schmidegg, O. (1932) Geologische Spezialkarte der Republik Österreich 1:75.000, Blatt Sölden und St. Leonhard. Geologische Bundesanstalt Wien.

Schmidegg, O. (1933) Neue Ergebnisse in den südlichen Ötztaler Alpen. Verhandlungen der Geologischen Bundesanstalt , Wien 1933: 83-95.

Schmidegg, O. (1936) Steilachsige Tektonik und Schlingenbau an der Südseite der Tiroler Zentralalpen. Jahrbuch der Geologischen Bundesanstalt, Wien.

Schmidegg, O. (1964) Die Ötztaler Schubmasse und ihre Umgebung. Verhandlungen der Geologischen Bundesanstalt , Wien 1964: 27-47.
Schneider, R. \& Schneider, H. (2001) Zur 60-jährigen Messreihe der kurzfristigen Geschwindigkeitsschwankungen am Blockgletscher im Äusseren Hochebenkar, Ötztaler Alpen, Tirol. Zeitschrift für Gletscherkunde und Glazialgeologie, 37:1-33.

Stingl, V. \& Krois, P. (1990) Sedimentological investigations of metamorphic clastics: the basal clastic rocks of the Brenner Mesozoic (Stubai Alps, Austria/Italy). Terra Nova, 2: 271-279.

Teller, F. (1877) Aufnahmen im oberen Oetzund Passeierthale. Verhandlungen der Geologischen Reichsanstalt, Wien 1877: 231-235.

Teller, F. (1878) Geologische Mittheilungen aus der Oetzthaler Gruppe. Verhandlungen der k.k. Geologischen Reichsanstalt, Wien 1878: 64-66.

Thöni, M. (1986) The Rb-Sr thin slab isochron method - an unreliable geochronologic method for dating geologic events in polymetamorphic terrains? Mem.Sci.Geol. 38: 283-352.

Thöni, M. (1988) Rb-Sr isotopic resetting in mylonites and pseudotachylites: implications fort he detachment and thrusting of the Austroalpine basement nappes in the Eastern Alps. Jahrbuch der Geologischen Bundesanstalt, Wien 131: 169-201.

Thöni, M. (1999) A review of geochronological data from the Eastern Alps. Schweizer Mineralogisch-Petrographische Mitteilungen 79: 209-230.

Thöny, W.E., Tropper, P., Schennach, F., Krenn, E., Finger, F., Kaindl, R., Bern- 
hard, F. \& Hoinkes, G. (2008) The metamorphic evolution of migmatites from the Ötztal Complex (Tyrol, Austria) and constraints on the timing of the pre- $\mathrm{Va}$ riscan high-T event in the Eastern Alps. Swiss Journal of Geosciences 101, Supplement 1: 111-126.

Tollmann, A. (1977) Geologie von Österreich. Band I - Die Zentralalpen. Franz Deuticke, Wien.

Tropper, P. \& Recheis, A. (2003) Garnet zoning as a window into the metamorphic evolution of a crystalline complex: the northern and central Austroalpine Ötztal-Complex as a polymorphic example. Mitteilungen der Österreichischen Geologischen Gesellschaft 94: 27-53.
Vietoris, L. (1958) Der Blockgletscher des äußeren Hochebenkares. Gurgler Berichte 1: 41-45.

Vietoris, L. (1972) Über die Blockgletscher des Äußeren Hochebenkars. Zeitschrift für Gletscherkunde und Glazialgeologie, 8: 169-188.

\section{Autor}

\section{Karl Krainer}

Universität Innsbruck

Institut für Geologie und Paläontologie Innrain 52, 6020 Innsbruck, Österreich Karl.Krainer@uibk.ac.at 


\title{
Kapitel 3 | Klima und Gletscher in Obergurgl
}

\author{
Andrea Fischer
}

\section{Zusammenfassung}

Rund um die Alpine Forschungsstelle Obergurgl befindet sich eines der am stärksten vergletscherten Gebiete der Alpen. Seit über hundert Jahren wird hier Gletscherforschung betrieben. Die Beobachtungen der heutigen und früheren Gletschergrenzen in der Landschaft machen Klimaänderungen sichtbar und helfen dabei den Zusammenhang zwischen Gletscher und Klima zu erforschen.

Die Grundlagen für diese Forschung bilden eine Reihe von glaziologischen und klimatologischen Langzeitbeobachtungen wie etwa die Massenbilanzreihen vom Hintereisferner, Kesselwandferner und Vernagtferner und die Klimastationen Vent und Obergurgl. Seit dem Hochstand der kleinen Eiszeit um etwa 1850 sind die Gletscher, unterbrochen von kurzen Vorstoßphasen, kleiner geworden. Sie haben dabei fast die Hälfte der Fläche verloren.

Das Wetter und somit auch das Klima im Hochgebirge sind durch starke lokale Unterschiede geprägt. Die großräumige Luftströmung wird durch die starke Topographie modifiziert, lokale Windsysteme bilden sich aus. Seit Beginn der Messungen in Obergurgl 1953 erhöhte sich das Jahresmittel der Lufttemperatur bis heute um $1,2^{\circ} \mathrm{C}$.

\begin{abstract}
The Alpine Research Centre Obergurgl is located in the centre of one of the most glacierized areas in the Alps. These glaciers are subject to scientific research for more than 100 years. The observed former and recent glacier changes visualize the corresponding changes of climate and allow the investigation of the relationship between glacier and climate.

The data base for these investigations is provided by a number of glaciological and climatological long term monitoring programmes, amongst them the mass balance monitoring of the Hintereisferner, Kesselwandferner and Vernagtferner as well as the climate stations in Vent and Obergurgl.

The glaciers around Obergurgl reached their maximum area about 1850, at the end of the Little Ice Age. After that, the glacier area reduced by nearly $50 \%$.

Weather and climate in high alpine regions show strong regional differences. The flow of the air masses is modified by the topography, local wind systems form. Since the beginning of the climate measurements in Obergurgl in 1953, the annual mean of the air temperature increased by $1.2^{\circ} \mathrm{C}$.
\end{abstract}




\section{Einleitung}

Die Landschaft um Obergurgl ist von den Spuren eiszeitlicher Gletscher überprägt. Die Ferner des inneren Ötztals sind eindrucksvolle Indikatoren von vergangenen und gegenwärtigen Klimaschwankungen. Weit über dem Talboden an den Berghängen sieht man die Spuren glazialer Erosion (wie Schliffe und Schliffkanten) und glazialer Ablagerung (wie z.B. Moränen). In den Seitentälern weisen gut ausgeprägte Moränen auf den derzeitigen Rückgang der Gletscher seit dem letzten Hochstand um 1850 hin.

Gletscher ändern ihre Form, wenn nicht die gleiche Menge an Eis abschmilzt wie Schnee über den Sommer liegen bleibt. Die Klimaelemente Temperatur und Niederschlag steuern diese Volumens- bzw. Flächenänderungen wesentlich. Die Erforschung des Zusammenhangs zwischen Gletscher und Klima ermöglicht es, aus dem Verhalten der Gletscher Rückschlüsse auf das Klima und dessen Änderungen zu ziehen. Mit Hilfe glaziologischer Beobachtungen werden die Veränderungen der Gletscher dokumentiert und durch numerische Simulationen berechnet. Dies sind nicht nur wichtige Kenntnisse für den Alpenraum. Auch weltweit sind sie von Relevanz, da Gebirgsgletscher einen hohen Anteil am derzeitigen Anstieg des Meeresspiegels tragen.

An all diesen Themen wird in den heutigen Forschungsprojekten im Bereich des inneren Ötztals gearbeitet. Die Gletscherforschung rund um Obergurgl hat aber auch aus einem anderen Grund eine lange Tradition: In Zeiten höherer Gletscherstände, 1770 beispielsweise, wurden durch das vorrückende Eis immer wieder große Seen aufgestaut, die bei ihrem Ausbruch im gesamten Ötztal katastrophale Überschwemmungen verursachten (Nicolussi 1990). Die Naturgefahr trieb den Menschen verstärkt dazu an, sich mit seiner Umwelt auseinanderzusetzen und förderte damit die glaziologische Forschung. Heute zählen die Gletscher rund um Obergurgl zu den am besten untersuchten weltweit. Seit Jahrzehnten werden vom Hydrografischen Dienst und der Kommission für geophysikalische Forschungen der Österreichischen Akademie der Wissenschaften LangzeitmonitoringProgramme durchgeführt. In Obergurgl befinden sich eine Klimastation, eine Abflussmessstelle und das Messnetz zur Erfassung des Gebietsniederschlages im Einzugsgebiet der Gurgler Ache des Hydrologischen Dienstes (Abteilung Wasserwirtschaft, Amt der Tiroler Landesregierung; HZB 2002). All diese meteorologischen und hydrologischen Daten bilden die Grundlage zur Erforschung der Beziehung zwischen Gletscher und Klima. Im Rahmen des UNESCO-Programms ,Man and Biosphere' (MAB) wurden in Obergurgl eine Vielzahl von meteorologischen, glaziologischen und vegetationskundlichen Untersuchungen in verschiedenen Höhenlagen durchgeführt (Patzelt 
1987, Rott 1979). Eine von R. Rudolph zusammengestellte Bibliographie der älteren Arbeiten findet man unter http://iahs. info/hsj/082/082017.pdf.

Das Einzugsgebiet Obergurgl mit seinen $73 \mathrm{~km}^{2}$ ist zu $32 \%$ vergletschert. Die Abflussmessstelle, also der tiefste Punkt des Einzugsgebietes, liegt auf $1.876 \mathrm{~m}$ Höhe, die höchsten Gipfel ragen fast bis 3.500 m hinauf. Das Klima von Obergurgl ist durch die inneralpine Höhenlage geprägt, mit niedrigeren Temperaturen und geringeren Niederschlägen im Vergleich zum österreichischen Mittel. Das Jahresmittel der Temperatur beträgt $2,8^{\circ} \mathrm{C}$, die Jahressumme des Niederschlags $851 \mathrm{~mm}$ (für die Periode 1961-1990). Die Anzahl der mittleren jährlichen Sonnenscheinstunden beträgt 1321; an nur 28 Tagen im Jahr gibt es Nebel. An 124 Tagen im Jahr fällt mehr als $1 \mathrm{~mm}$ Niederschlag, an 198 Tagen im Jahr liegt eine Schneedecke von mehr als $1 \mathrm{~cm}$ (http://www.zamg.ac.at/ klima/klimadaten/?ts=1257524581). Die maximale Schneedecke beträgt $200 \mathrm{~cm}$. Im Mittel gibt es an 14 Tagen Gewitter, aber nur alle zwei Jahre wird Hagel oder Graupel beobachtet (http://www.zamg. ac.at/fix/klima/oe71-00(klima2000/ klimadaten_oesterreich_1971_frame1. htm).
Klima

Die Erdatmosphäre ist ein chaotisches, dynamisches System, das heißt bei einer Berechnung eines zukünftigen Zustandes können kleine Unterschiede in den Ausgangsdaten große Unterschiede in den Ergebnissen zur Folge haben. Aus diesem Grund ist es physikalisch nicht möglich, das zukünftige Wetter oder Klima in ähnlich genauer Weise zu berechnen wie die Zeit, die ein Apfel braucht, um von einem Baum zu fallen. Klimaschwankungen haben die verschiedensten Ursachen, z.B. die geometrische Konstellation von Erde und Sonne, die nicht nur die Unterschiede in den Tages- und Jahreszeiten verursacht, sondern auch längerfristige Schwankungen der Einstrahlung. Änderungen in der Zusammensetzung und Strömungen der Meere sowie Änderungen der Albedo der Erdoberfläche oder der chemischen Zusammensetzung der Atmosphäre verursachen eine längerfristige Modifikation der durchschnittlichen Witterung, also Klimaänderungen. Um kurzfristige Schwankungen der Klimaelemente von längerfristigen Schwankungen zu unterscheiden, mittelt man über einen längeren Zeitraum, üblicherweise über eine Periode von mindestens 30 Jahren (http://www.wmo.int/ pages/themes/climate/index_en.php). Unter Klima versteht man also einen durchschnittlichen Zustand der Atmosphäre und die Schwankungen um diesen 

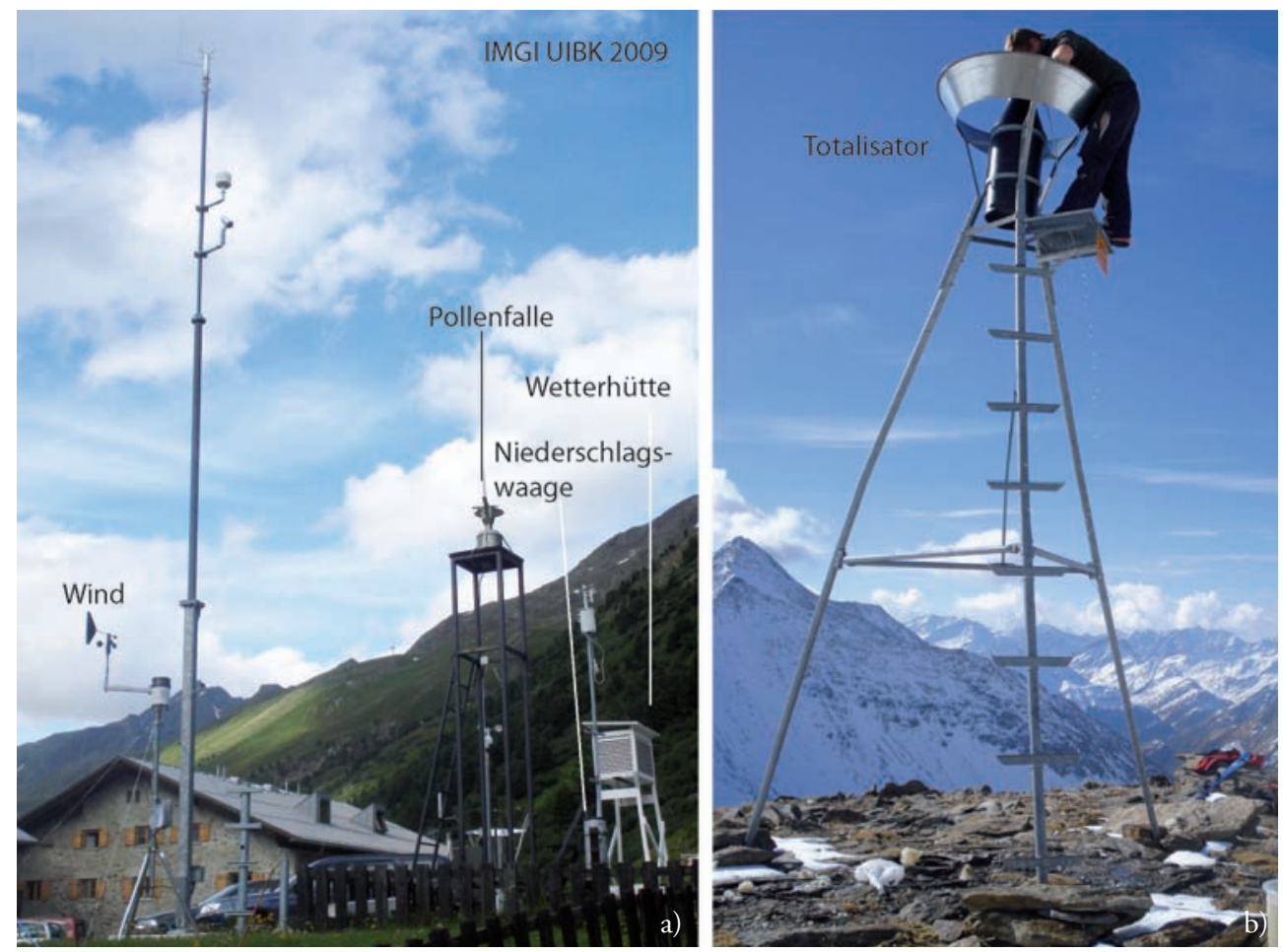

Abb. 1:

a) Klimastation in Obergurgl, b) Totalisator im Gelände (Foto: A. Fischer)

Mittelpunkt (Liljequist und Cehak 1984; Stull 2000). In der Klimatologie wertet man Messdaten der Klimaelemente statistisch aus (Schönwiese 2008). Den aktuellen Zustand der Atmosphäre erfasst man durch die Größen Lufttemperatur, Luftfeuchtigkeit, Taupunkt, Luftdruck, Windrichtung, Windgeschwindigkeit, Menge und Art des Niederschlags und Bewölkung. Heutzutage geschieht dies meist nicht mehr durch direkte Beobachtungen, sondern durch automatische Stationen und Satellitenfernerkundung.
Diese Parameter bestimmen das Wetter, ihr zeitliches Mittel das Klima. Abb. 1 zeigt die automatische Station und die Wetterhütte für die Klimabeobachtung in Obergurgl sowie einen Totalisator, wie er zum Messen des Niederschlags verwendet wird.

Wie in Abb. 2 ersichtlich, werden großräumige Luftströmungen auch im regionalen Maßstab durch das Gebirge modifiziert: Die Luftmassen werden gezwungen aufzusteigen, die Temperatur sinkt, die relative Feuchte steigt bis zur Konden- 


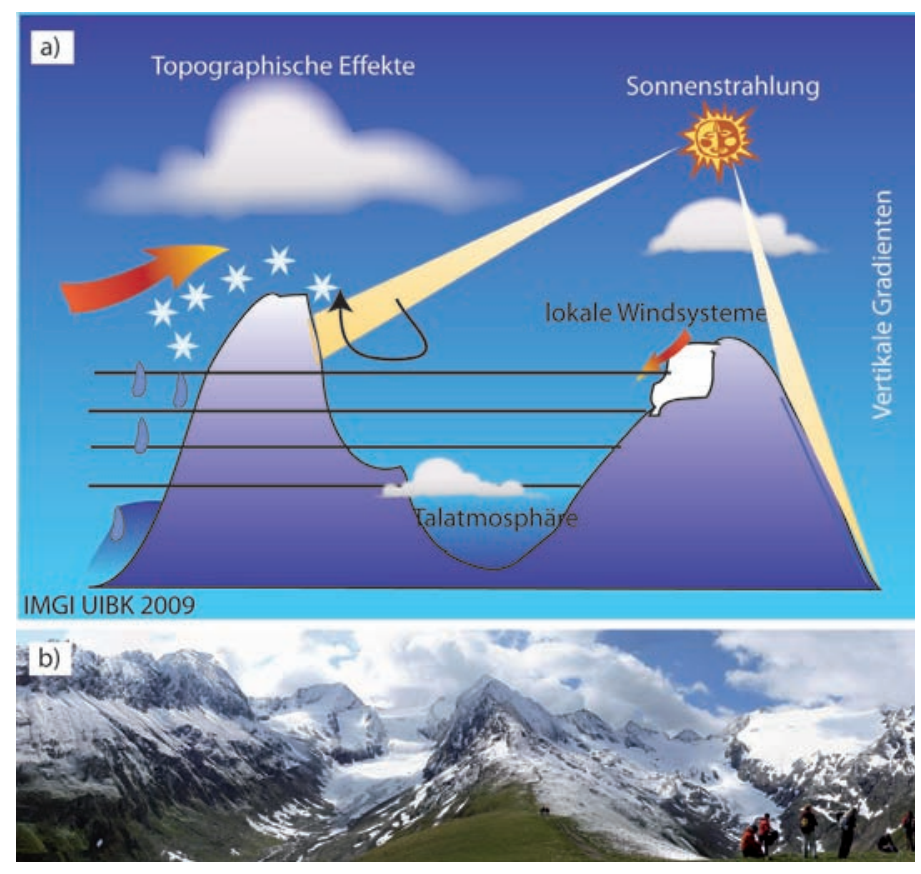

Abb. 2:

a) Die Gebirgstopographie führt zu großen lokalen Unterschieden in den Klimaelementen

b) Das Foto, welches am 07. Juli 2009 von der Hohen Mut aus aufgenommen wurde, zeigt die unterschiedliche Schneedecke nach einem Neuschneefall. (Foto: A. Fischer)

sation, es kommt zu Stauniederschlägen (Whiteman 2000). Auch das bekannte Phänomen des Südföhns tritt entlang des Alpenhauptkammes auf. In Obergurgl kommt es dabei zur Bildung einer Föhnmauer, die dort den Namen ,Timmelwurm' trägt, weil die Wolkenmauer über das Timmelsjoch nach Norden ,kriecht'. Auch die Sonnenstrahlung wird durch die Gebirgszüge modifiziert, ihre erwärmende Wirkung ist hier unterschiedlich zu ihrer Wirkung in der Ebene (Abb. 2).
Es kommt zur Bildung von thermischen Lokalwinden in allen Skalenbereichen: vom Gletscherwind über Hangauf- und Hangabwind bis zum Taleinund Talauswind. Es sei vermerkt, dass der Gletscherwind wegen seiner hohen Turbulenz nicht zur Konservierung des Gletschers beiträgt.

Die Gebirge sind ein Hilfsmittel bei der Untersuchung der Vertikalprofile der einzelnen meteorologischen $\mathrm{Pa}$ rameter. In der Ebene erfolgt deren Messung durch Wetterballone (Radiosondenaufstiege), im Gebirge jedoch wird entlang eines Höhenprofils an den Berghängen gemessen. In der Troposphäre nimmt die Temperatur mit der Höhe um ca. $0,65^{\circ} \mathrm{C}$ pro $100 \mathrm{~m}$ ab. Kleinräumig können jedoch aufgrund der Geländeformen deutliche Unterschiede auftreten, die Messung dieser Unterschiede ist Aufgabe der Mikrometeorologie. Das Kleinklima ist besonders wichtig in Zusammenhang mit vegetationskundlichen Untersuchungen. 
Die oben erwähnte Temperaturabnahme von ca. $0,65^{\circ} \mathrm{C}$ pro $100 \mathrm{~m}$ stellt einen Jahresmittelwert dar und wird im Gebirge in den Becken und Tälern oft ,umgekehrt'. Es kommt zur Ausbildung von Kaltluftseen, sogenannten Inversionen, deren Schichtung (die kalte und daher schwere Luft liegt unter warmen und leichten Luftschichten) sehr stabil ist und daher lange andauern können.

\section{Tagesgang}

Der Tagesgang der Klimaelemente wird durch die Sonnenstrahlung und gegebenenfalls durch einen Luftmassenwechsel bestimmt. In der Nacht sinkt die Temperatur, da Energie vom Boden und boden- nahen Schichten langwellig abgestrahlt wird. Am Tag steigt die Temperatur durch die kurzwellige Sonnenstrahlung. Wolken oder Wind verändern diese Energieflüsse. Das Minimum der Lufttemperatur wird vor Sonnenaufgang erreicht, das Maximum nach dem Höchststand der Sonne, also am Nachmittag. Da kalte Luft weniger Wasserdampf aufnehmen kann als warme Luft, ist der Tagesgang der relativen Feuchte genau entgegengesetzt, also Höchstwerte bei Nacht und tiefere Werte bei Tag.

Abb. 3 zeigt ein typisches Beispiel für einen Tagesgang in drei verschiedenen Höhenstufen. Die Talstation, Obergurgl Wiese $(1900 \mathrm{~m})$, zeigt das höchste Temperaturmaximum, die Bergstation Hohe Mut das niedrigste. In der Nacht des

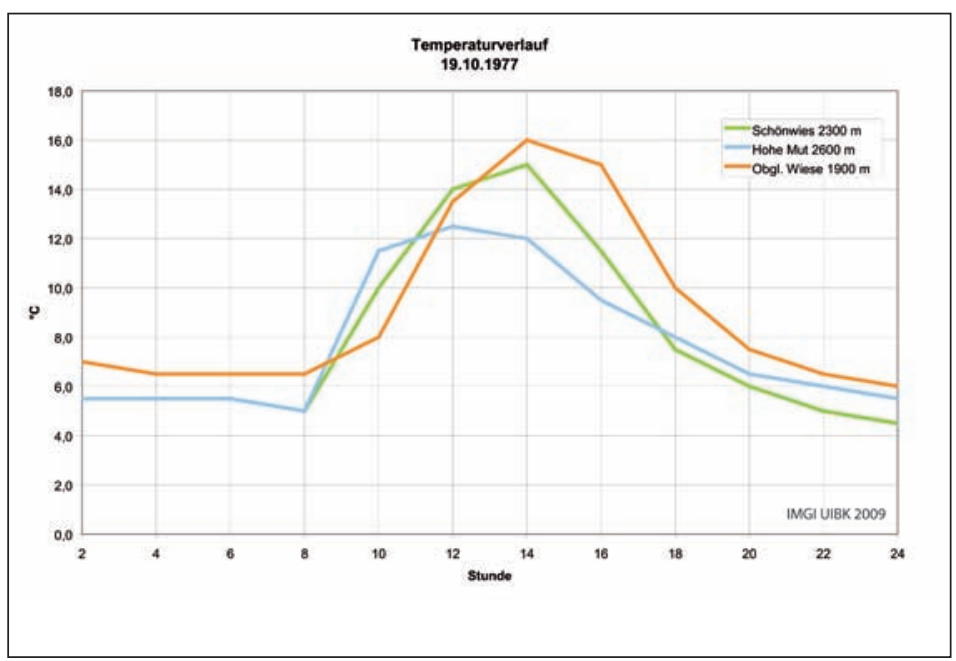

Abb. 3:

Tagesgang der Luftemperatur an den Stationen Obergurgl-Wiese (1900 m), Schönwies $(2300 \mathrm{~m})$ und Hohe Mut $(2600 \mathrm{~m})$ gemessen am 19.10.1977 im Rahmen des MAB-Programms.
19.10.1977 bildete sich eine Temperaturinversion, wie sie an vielen Tagen in den Tallagen der Gebirgevorkommt. Dabei sind die Temperaturen an der Station Hohe Mut höher als an der $300 \mathrm{~m}$ tiefer gelegenen Station Schönwies. 


\section{Jahresgang}

In Obergurgl tritt das Minimum der Temperatur im Mittel im Jänner auf, das Maximum im Juli (Abb. 4). Das Maximum des Niederschlags liegt im Sommer.

Die Schneedeckenverhältnisse in den verschiedenen Monaten sind in Abb. 5 dargestellt. Dabei fällt auf, dass in Obergurgl in allen Sommermonaten mit einer Schneedecke zu rechnen ist und die Wahrscheinlichkeit für eine Schneedecke immer Anfang Juni noch höher ist als im September. In der Hauptsaison von Anfang Dezember bis Ende März bie- tet Obergurgl absolute Schneegarantie (Abb. 5). Mitte Oktober steigt die Wahrscheinlichkeit einer geschlossenen Schneedecke sehr stark an. Im Mai schmilzt der Schnee, die Wahrscheinlichkeit sinkt auf Werte unter $15 \% \mathrm{ab}$.

\section{Klimareihe}

Die große Bedeutung der Klimastation Obergurgl liegt in der Länge der Datenreihe; hier wird seit 1953 an ein und derselben Stelle unverändert gemessen.

Abbildung 6 zeigt die zeitliche Entwick-

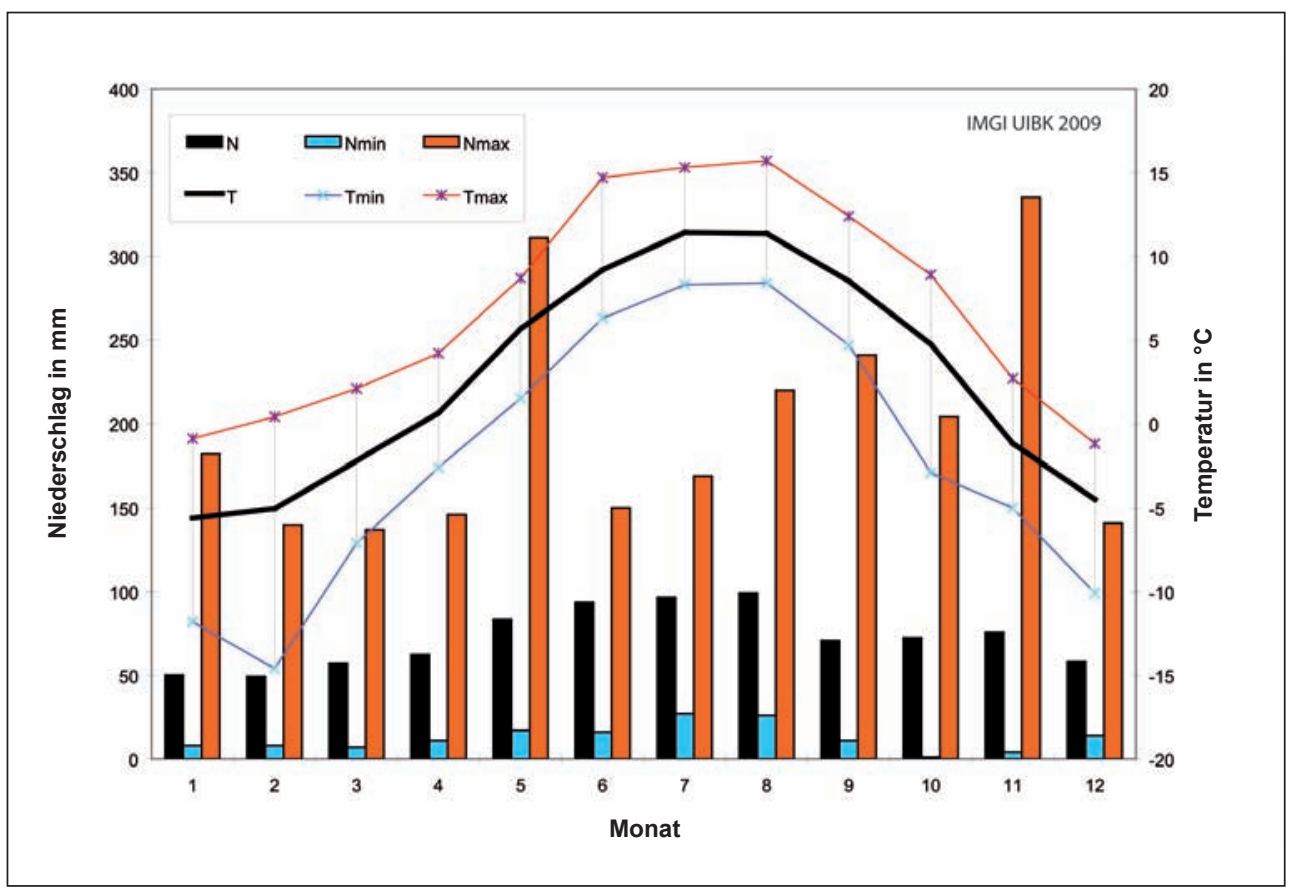

Abb. 4:

Tagesgang der Luftemperatur an den Stationen Obergurgl Wiese (1900 m), Schönwies (2300 m) und Hohe Mut (2600 m) gemessen am 19.10.1977 im Rahmen des MAB Programms. 


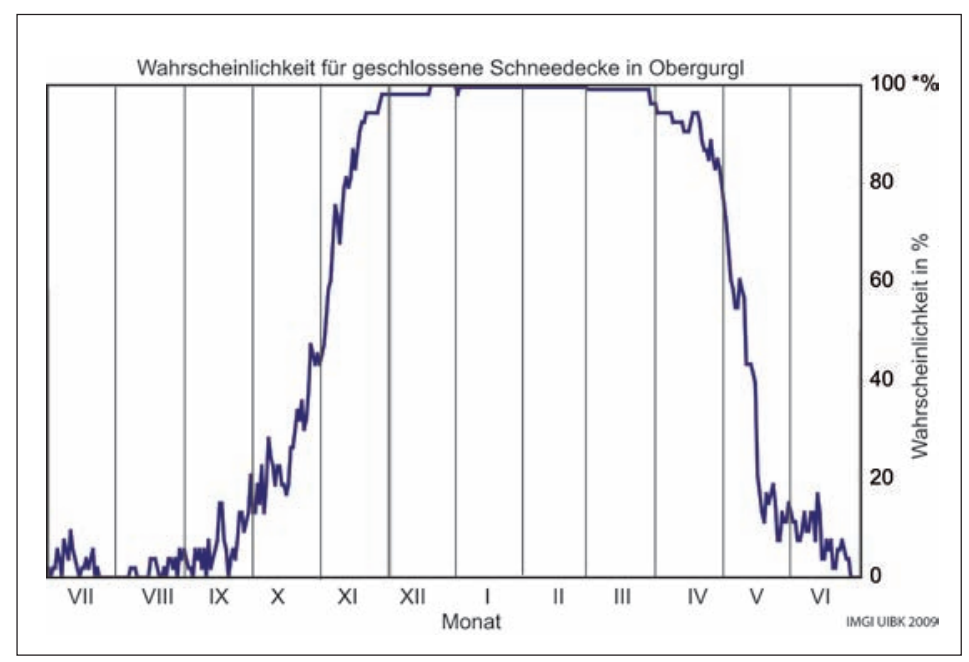

Abb. 5:

Die Wahrscheinlichkeit für eine geschlossene Schneedecke in Obergurgl an verschiedenen Tagen des Jahres.

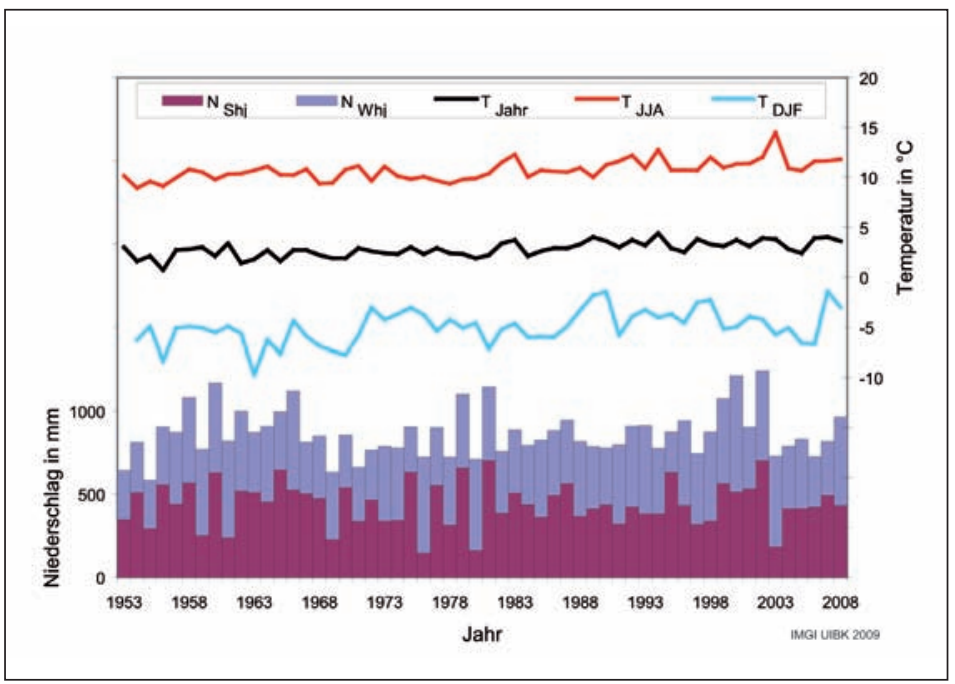

Abb. 6:

Zeitreihe des Jahresmittels der Lufttemperatur $\mathrm{T}_{\text {Jahr }}$, des Mittels der Lufttemperatur für die Sommermonate Juni Juli und August $\mathrm{T}_{\mathrm{JJA}}$ und der Wintermonate Dezember, Jänner und Februar $\mathrm{T}_{\mathrm{DJF}}$. Die Jahressummen des Niederschlags sind als Summen der Niederschläge im Winterhalbjahr $\mathrm{N}_{\text {Whj }}$ (X-III) und im Sommerhalbjahr $\mathrm{N}_{\text {Shj }}$ (IV-IX) 3 . 
lung der Niederschlagssummen und der Mittelwerte der Lufttemperatur zwischen 1953 und 2008. Die Variation des Niederschlages ist sehr groß. Es gibt Monate mit über $300 \mathrm{~mm}$, dem fünffachen des mittleren Monatswertes, aber auch Monate ohne jeglichen Niederschlag.

Die Zeitreihen der Temperatur zeigen sowohl im Gesamtjahr als auch im Sommer und Winter den auch in anderen Regionen in und um die Alpen beobachteten Anstieg (Tab. 1).

Die beobachtete Erwärmung in Obergurgl liegt im Vergleich zu anderen mitteleuropäischen Stationen (http://www. zamg.ac.at/histalp/) im unteren Bereich.

Entgegen den in den Medien oft kolportierten Werten über die extremen Temperaturzunahmen im Gebirge haben die
Untersuchungen im HISTALP Programm (Auer et al. 2007) gezeigt, dass sich die Zunahme der Jahresmitteltemperatur an den Bergstationen (1500-3500m) nicht von der Zunahme der Temperaturen an den Flachlandstationen unterscheidet. Dieses HISTALP Projekt umfasst mit 242 untersuchten Stationen das Kernland Mitteleuropas und das Gebiet von Paris bis Budapest bzw. von Karlsruhe bis Florenz.

Weder die Schneeverhältnisse noch die Niederschlagssummen zeigen im Beobachtungszeitraum (1953-2006) einen einheitlichen Trend. Wie stark die einzelnen Winter von einem mittleren $\mathrm{Zu}$ stand (Abb. 5) abweichen, wird aus Abb. 7 ersichtlich. Neben extrem schneereichen gibt es selbst in dieser Höhenlage auch immer wieder extrem schneearme Winter.

\begin{tabular}{|l|c|c|c|}
\hline & $\mathrm{T}_{\mathrm{Jahr}}$ in ${ }^{\circ} \mathrm{C}$ & $\mathrm{T}_{\mathrm{JJA}}$ in ${ }^{\circ} \mathrm{C}$ & $\mathrm{T}_{\mathrm{DJF}}$ in ${ }^{\circ} \mathrm{C}$ \\
\hline Mittelwert des Gesamtzeitraums 1953-2008 & 2,8 & 10,7 & $-5,0$ \\
\hline Mittelwert der Dekade I: 1953-1962 & 2,3 & 10,0 & $-5,6$ \\
\hline Mittelwert der Dekade II: 1999-2008 & 3,4 & 11,7 & $-4,7$ \\
\hline $\begin{array}{l}\text { Differenz der Mittelwerte der } \\
\text { Dekaden I und II }\end{array}$ & 1,2 & 1,7 & 1,0 \\
\hline
\end{tabular}

Tab. 1:

Vergleich der Mittelwerte der Lufttemperaturen zwischen der ältesten und der jüngsten Dekade zum Gesamtzeitraum der Beobachtungen in Obergurgl. Abkürzungen siehe Abb. 6. 


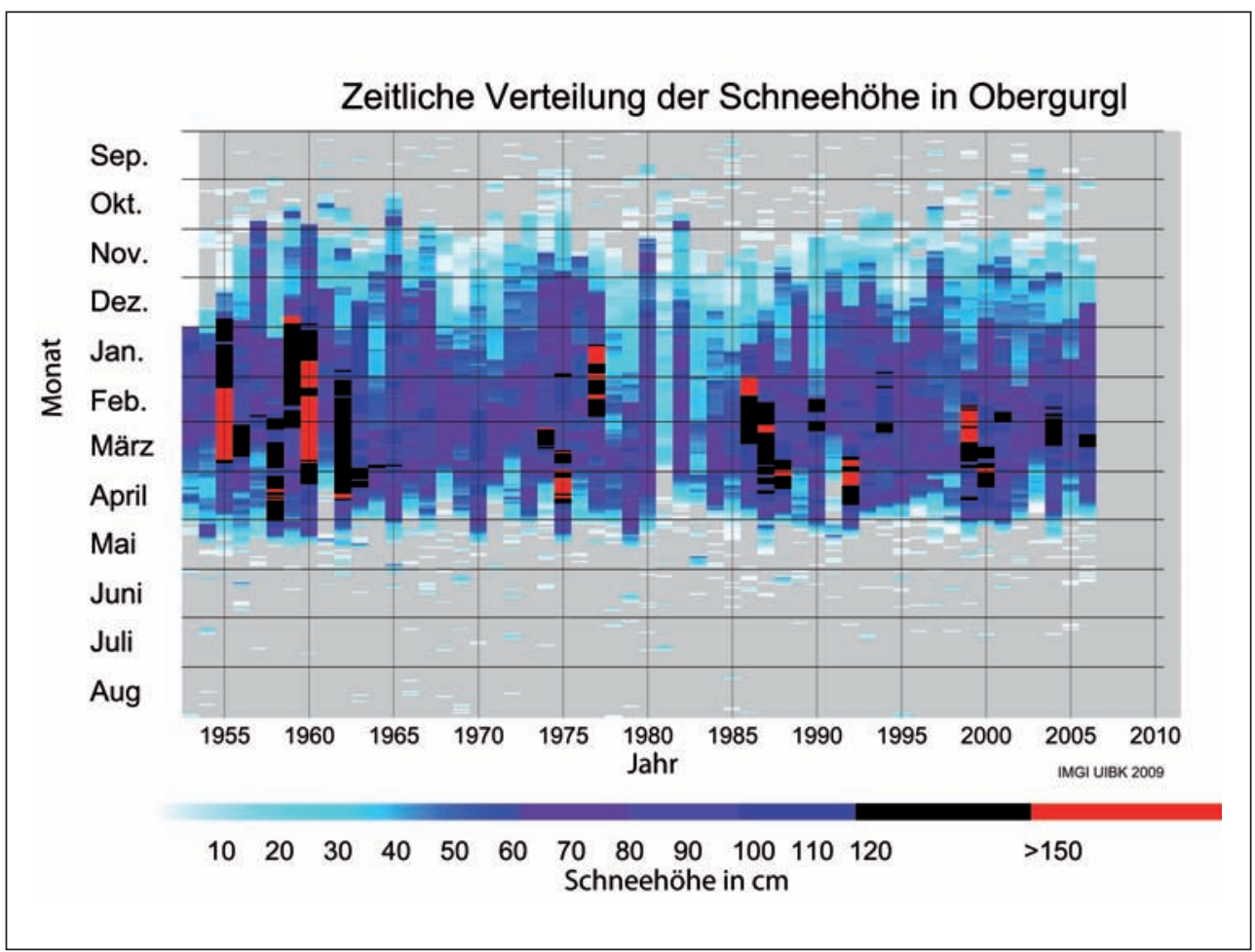

Abb. 7:

Wahrscheinlichkeit für eine geschlossene Schneedecke in Obergurgl.

\section{Gletscher}

Gletscher bestehen aus Eis-, Firn- und Schneemassen, die durch den Einfluss der Schwerkraft abwärts fließen. Die Größe und Form eines Gletschers ergibt sich aus der Geländeform, dem aktuellen Klima und der Klimageschichte. Ändert sich das Klima, bewirkt dies auch eine Änderung der Form und Größe des Gletschers (Paterson 1994, Winkler 2009).
Im Einzugsgebiet des Pegels Obergurgl gab es im Gletscherinventar 199727 Gletscher mit Flächen zwischen 9,584 $\mathrm{km}^{2}$ und 0,004 $\mathrm{km}^{2}$ (Abb. 8). Der größte Gletscher war 1997 der Gurgler Ferner, gefolgt vom Langtaler Ferner $(2,894$ $\left.\mathrm{km}^{2}\right)$, dem Rotmoosferner $\left(2,878 \mathrm{~km}^{2}\right)$ und dem Gaisbergferner $\left(1,191 \mathrm{~km}^{2}\right)$. Die übrigen Gletscher des Einzugsgebietes sind deutlich kleiner (Lambrecht und Kuhn 2007). Zwischen 1969 und 1997 verringerte sich die gesamte Gletscherfläche des Einzugsgebietes um $17 \%$ (siehe 


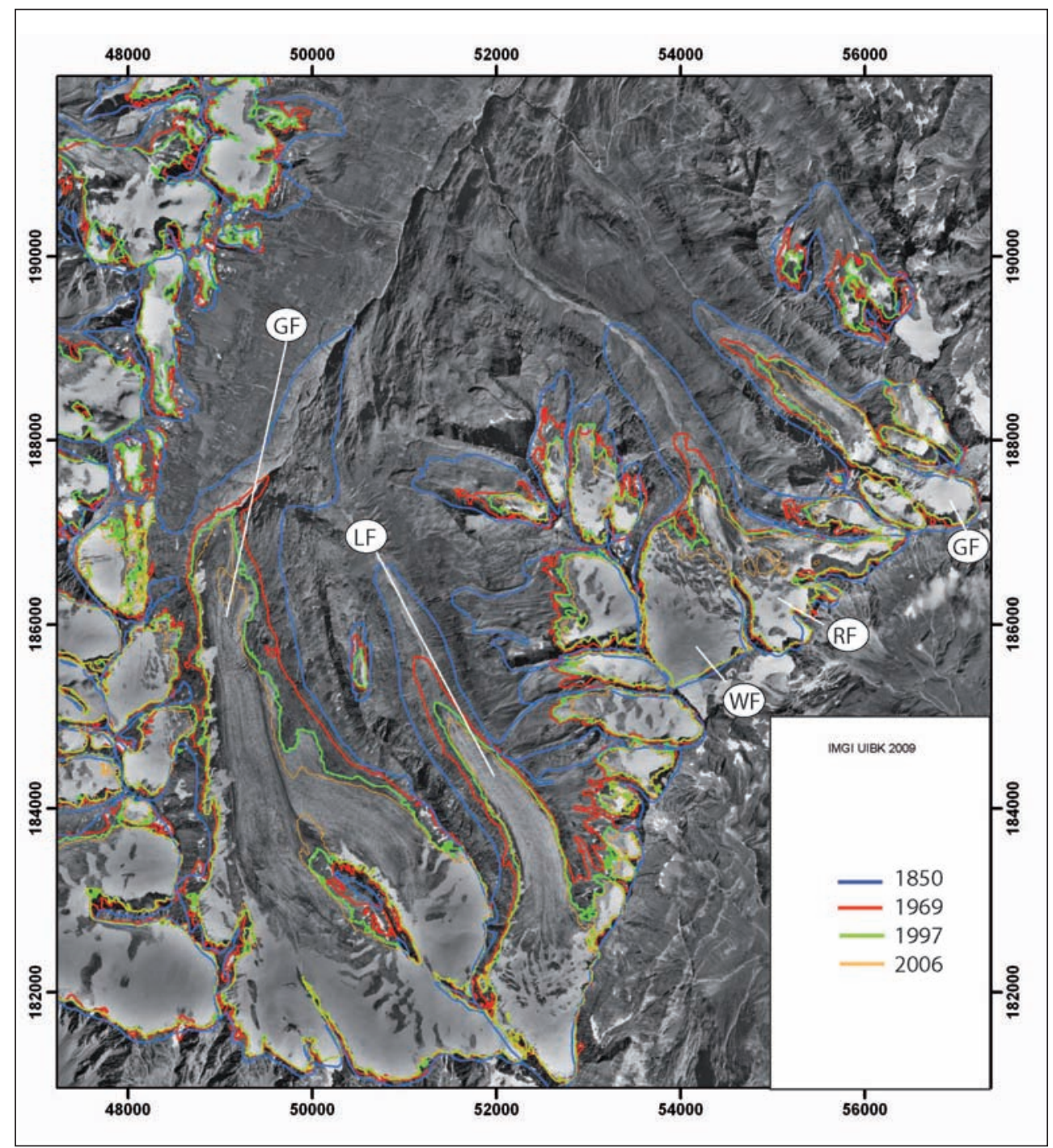

Abb. 8:

Die Gletscher im Einzugsgebiet des Pegels Obergurgl. GF ... Gurgler Ferner, LF... Langtaler Ferner, WF... Wasserfallferner, RF...Rotmoosferner, GF...Gaisbergferner (Orthofoto aus dem Gletscherinventar 1997 zu Ende der Ablationssaison). 
Beilage). Am Ende der kleinen Eiszeit um 1850 hatten die Gletscher im Vergleich zu 1997 noch die 1,7-fache Fläche.

\section{Grundlagen}

Das Eis der Gletscher entsteht durch Umwandlung aus Schnee, welcher über den Sommer nicht schmilzt und nach einigen Jahrzehnten die Dichte von Eis erreicht. Diese Umwandlung findet im sogenannten Nährgebiet oder auch Akkumulationsgebiet (Abb. 9) statt. Dies sind die höher gelegenen Bereiche eines Gletschers, in denen der Schnee über den Sommer liegenbleibt, also Masse akkumuliert wird. Im Nährgebiet ist die Schmelzperiode kurz, auch im Sommer fällt in diesen Höhen immer wieder Schnee. In Abb. 10 ist ein typischer Jahresverlauf dargestellt: Im Winter liegt über die ganze Gletscherfläche Schnee, der über den Sommer in tieferen Bereichen schmilzt, in den hochgelegenen aber liegenbleibt. In den tiefer gelegenen, also auch wärmeren Bereichen der Gletscher ist die Schmelzperiode wesentlich länger als im Firngebiet. An den Gletscherzungen der großen Talgletscher, die am weitesten ins Tal hinunterreichen, dauert die Schmelze von April/Mai bis Ende Oktober. Hier schmilzt zuerst der Winterschnee $\mathrm{ab}$ und danach das Gletschereis.

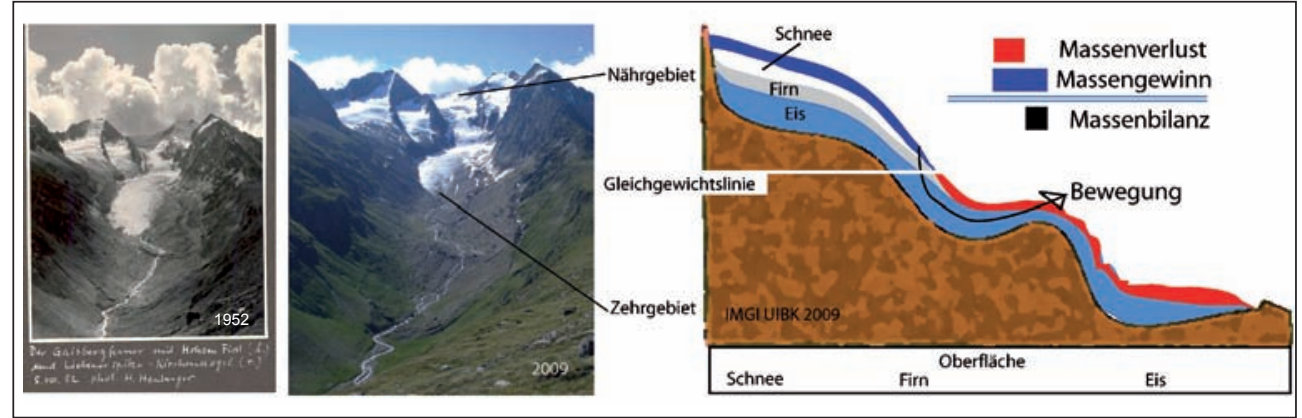

Abb. 9:

Entwicklung des Gaisbergferners zwischen 1952 und 2009 mit schematischer Skizze eines Gletschers. (Foto: A. Fischer)

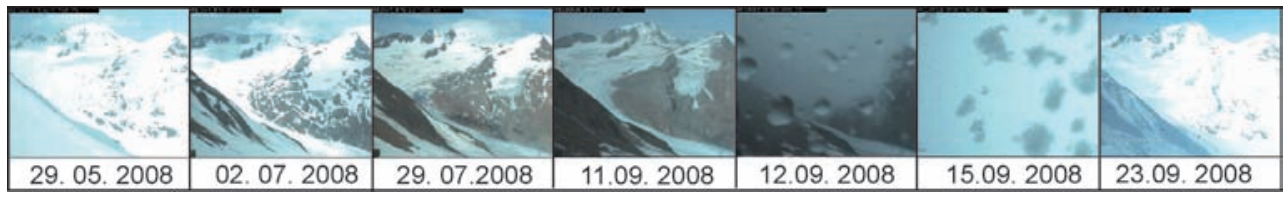

Abbildung 10:

Verlauf des Rückzugs der saisonalen Schneedecke im Firngebiet des Hintereisferners in der Ablationsperiode 2008. (Foto: A. Fischer) 
Eine wichtige Größe für die Energieumsätze ist der Begriff der Albedo. Definiert wird er als reflektierte Sonnenstrahlung dividiert durch die einfallende Sonnenstrahlung. Gletschereis hat eine sehr niedrige Albedo ( 0,2 bei stark verschmutztem bis 0,5 bei sehr sauberem Eis) im Vergleich zu Schnee $(0,9)$. Das heißt, dass schneefreie Gletscher viel mehr Energie aufnehmen als schneebedeckte. Sommerschneefälle sind demnach ein sehr effektiver Schutz des Gletschers von Abschmelzung. In einer Höhenlage von 2600 m können in der Schmelzperiode im Juni und Juli etwa $10 \mathrm{~cm}$ Eis pro Tag schmelzen. Im September ist die Schmelzrate durch die niedrigeren Temperaturen und die kürzere Tageslänge nur mehr etwa halb so groß. An den Zungen der großen Talgletscher können so im Laufe eines Sommers ca. neun Meter Eis pro Jahr schmelzen. Das heißt aber nicht, dass dort die Oberfläche am Ende der Ablationssaison um 9 Meter niedriger ist, da von oben Eis nachfließt. Fließt genau gleich viel Eis von oben nach wie an der Zunge schmilzt, ändert der Gletscher seine Fläche und seine Form nicht, es gibt keine Änderung der Zungenposition. Man spricht dann von einem ,Gletscher im Gleichgewicht', bei dem die Summe aus Massengewinn pro Akkumulation $\mathrm{B}_{\mathrm{c}}$ und Massenverlust (Ablation) $\mathrm{B}$ null ist. Die Nettomassenbilanz B wird in $\mathrm{m}^{3}$ oder kg Wasseräquivalent angegeben.

$\mathrm{B}=\mathrm{B}_{\mathrm{c}}+\mathrm{B}_{\mathrm{a}}$
Ist die Massenbilanz eines Haushaltsjahres positiv, erfähırt der Gletscher einen Nettomassengewinn, der zu einem Gletschervorstoß führen kann. Ist die Massenbilanz über mehre:e Jahre negativ, schmilzt an der Zunge rnehr Eis als ersetzt wird. Der Gletscher wird kürzer, seine Fläche wird kleiner.

Um verschiedene Gletscher miteinander vergleichen :zu können, dividiert man den Massenumsatz B durch die Gletscherfläche $S$ und erhält so eine spezifische Massenbilanz b, die in $\mathrm{mm}$ Wasseräquivalent (w.e.) angegeben wird.

$\mathrm{b}=\mathrm{B} / \mathrm{S}$

Wertet man die spezifische Massenbilanz für jede Höhenzone aus, gibt es einen oder mehrere Schnittpunkte mit der Linie $b=0$. Den am tiefsten gelegenen dieser Schnittpunkte bezeichnet man als Höhe der Gleichgewichtslinie (Equilibrium Line Altitude, ELA). Das ist die Höhe, in der die spezifische Bilanz $b=0$ ist. Langjährige Messungen im inneren Ötztal haben gezeigt, dass etwa 2/3 der Gletscherfläche oberhalb und $1 / 3$ unterhalb dieser Höhe liegt, wenn ein Gletscher im Gleichgewicht ist. Die horizontalen Fließgeschwindigkeiten sind im Bereich dieser Gleichgewichtslinie am höchsten. Oberhalb der ELA ist der Vektor der Fließgeschwindigkeit gletschereinwärts gerichtet (Submergenz), unterhalb gletscherauswärts (Emergenz). Die ELA ist eine theoretisch ermittelte Kurve, die 
ähnlich der temporären Schneegrenze am Ende des Massenhaushaltsjahres (Abb. 8), sein kann, aber nicht muss. Die horizontalen Fließgeschwindigkeiten haben auf manchen Gletschern rund um Obergurgl um 1980 noch mehr als 100 m pro Jahr betragen. Heute betragen die Fließgeschwindigkeiten nur mehr etwa ein Zehntel davon (Span et al. 1997).

Wenn Eis mehr als etwa $10 \mathrm{~cm}$ dick mit Schutt bedeckt ist, schmilzt es langsamer als sauberes Eis. Größere Felsblöcke bilden sogenannte Gletschertische: Unter dem Stein schmilzt das Eis weniger als daneben, der Block wächst aus seiner Umgebung heraus. Dies ist am Gaisbergferner häufig zu beobachten.

\section{Messmethoden und Ergebnisse}

Es gibt verschiedene Meßmethoden, um Größe und Volumen der Gletscher zu erfassen und Änderungen zu quantifizieren. Die ältesten Evidenzen für vergangene Gletscherstände sind Moränen. Schriftliche Aufzeichnungen, Bilder und Karten über die Größe von Gletschern gibt es erst seit wenigen hundert Jahren. Die Dokumentation des Vernagtferners im Venter Tal ist ein Beispiel für diese Art der Beobachtung (Nicolussi 1990). Die ersten wissenschaftlichen Berichte wurden Mitte des 19. Jahrhunderts herausgegeben (z.B. Sonklar 1857, 1860, 1877; Schlagintweit 1850). Seit 1891 werden die Längenänderungen der Glet- scher systematisch vom Österreichischen Alpenverein erfasst. Um 1870 wurden die Gletscherflächen erstmals systematisch im Zuge der Landesaufnahme kartiert. Von der folgenden raschen Entwicklung von Technik und Naturwissenschaften sowie des Alpintourismus profitierte auch die Erforschung der Gletscher, die Anzahl der Veröffentlichungen stieg (z.B. Hess 1904; Srbik 1936, 1939). Die Massenbilanzen wurden erst nach dem 2. Weltkrieg gemessen. Die Messungen an Hintereisferner und Kesselwandferner im Venter Tal nahe Obergurgl werden seit 1952/53 durchgeführt und gehören damit zu den längsten Reihen weltweit (Kuhn et al. 1999; Fischer und Markl 2009).

Das Gletschervolumen kann heute mit Radioecholot, Seismik oder Geoelektrik bestimmt werden. Die am weitesten verbreitete Methode ist das Radioecholot, welches in Frequenzen zwischen vier und etwa $120 \mathrm{MHz}$ meist bodengebunden auf den Alpengletschern eingesetzt wird. Die Eisdicke der Gletscher rund um Obergurgl beträgt bis zu $180 \mathrm{~m}$ am Gurgler Ferner und um $50 \mathrm{~m}$ am Rotmoos- und am Gaisbergferner (Fischer et al. 2007). In höheren Frequenzen (ab etwa 200 $\mathrm{MHz}$ ) wird mit dem Radioecholot auch die Dicke von Winterschneeschichten bestimmt. Die Erkenntnisse aus den weltweiten Gletschermessungen sind in Lemke et al. (2007) zusammengefasst. Die Detailmessungen werden vom World Glacier Monitoring Service (www.wgms. ch) publiziert. Flächeninventare werden 
von der GLIMS Initiative (www.glims. org) und im World Glacier Inventory (WGI) gesammelt.

\section{Gletscherinventare}

Gletscherinventare werden aus Orthofotos oder Fernerkundungsdaten erstellt und erfassen die Flächen und Umrisse, manchmal auch die Digitalen Höhenmodelle ganzer Gebirgsgruppen. Gibt es verschiedene Gletscherinventare, die in einem größeren Zeitabstand aufgenommen wurden, kann man daraus die Flächenund Volumsänderungen in diesem Zeitraum bestimmen (Gross 1987; Lang und Patzelt 1971). Für die österreichischen Gletscher gibt es die Inventare von 1969 (Patzelt 1980) und 1998 (Lambrecht und Kuhn 2007). Für den Bereich Obergurgl ist das Inventar 2006 fertig gestellt (Abermann et al. 2009), für die anderen Gebirgsgruppen Österreichs in Arbeit.

\section{Messungen des Massenhaushalts}

Es gibt im Wesentlichen drei Methoden, um die Massenbilanz eines Gletschers zu bestimmen (Paterson 1994):

- nach der direkten oder glaziologischen Methode (Hoinkes 1970; Kaser 2003),

- der hydrologischen Methode oder

- der geodätischen Methode.

Bei der direkten glaziologischen Methode werden Akkumulation und Ablation an verschiedenen Stellen des Gletschers mit Schneeschächten und Ablationspegeln bestimmt (Abb. 11). Der Massenauftrag an einer Stelle ergibt sich durch den Wasserwert der Schneedecke über dem Horizont des letzten Jahres. Dieser wird bestimmt, indem mit einer zylindrischen Dichtekanone mit bekanntem Volumen Schnee abgestochen und gewogen wird, um den Wassergehalt des Schnees zu be-

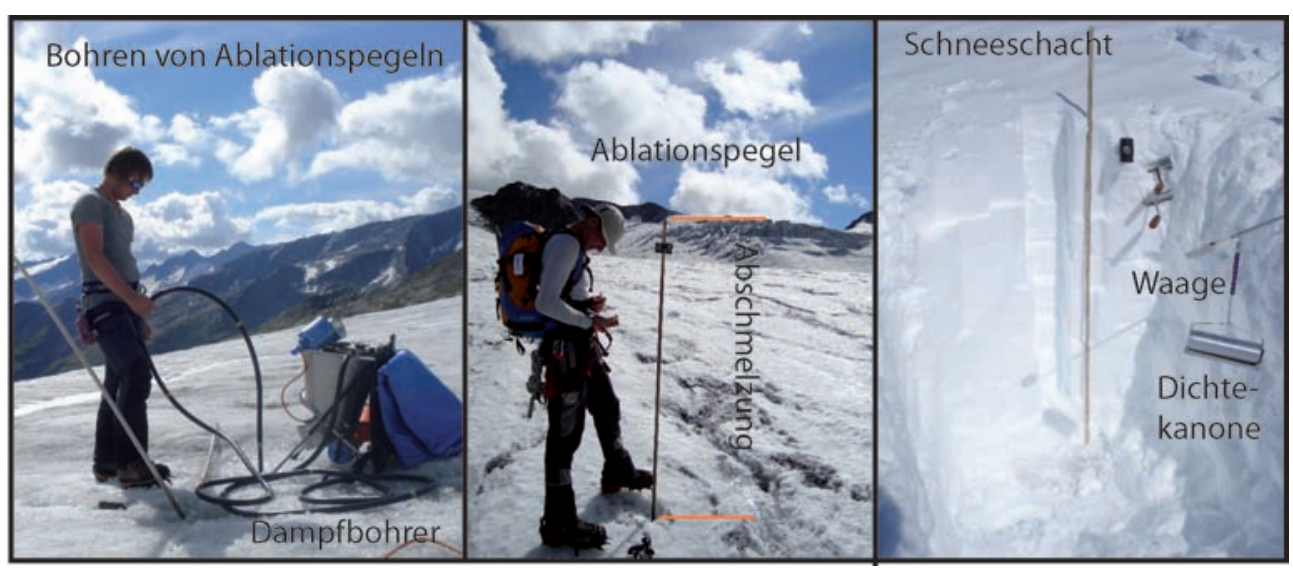

Abb. 11:

Bestimmen des Massenhaushalts nach der direkten glaziologischen Methode. (Foto: A. Fischer) 
stimmen. Diese Schächte werden jedes Jahr an der gleichen Stelle gegraben und mit Sondierungen ergänzt, falls dafür ein geeigneter, d.h. eindeutiger Horizont vorhanden ist. Die direkte glaziologische Methode ist die genaueste, aber auch die aufwendigste. Sie wird in Österreich nur an etwa zehn Gletschern durchgeführt, drei davon befinden sich im Venter Tal (Vernagtferner, Hintereisferner und Kesselwandferner). Die Massenbilanzen benachbarter Gletscher können, obwohl sie einem ähnlichen Klima ausgesetzt sind, bei unterschiedlicher Topographie deutlich voneinander abweichen (Kuhn et al.
1985). Die Massenbilanzreihe des Hintereisferners zeigt, dass der Gletscher in einigen Jahren zwischen 1965 und 1980 positiv bilanziert hat (Abb. 12). In diesen Jahren waren, wie der Vergleich mit Daten der Klimastation Vent zeigt, die Temperaturen im Mittel etwas niedriger als heute. Diese gletschergünstige Phase hat an vielen Gletschern Österreichs zu leichten Vorstößen geführt. Seit etwa 1985 ist die Massenbilanz des Hintereisferners negativ, seit dem Rekordjahr der Gletscherschmelze im Jahr 2003 ist die Gleichgewichtslinie meist über Gipfelniveau.

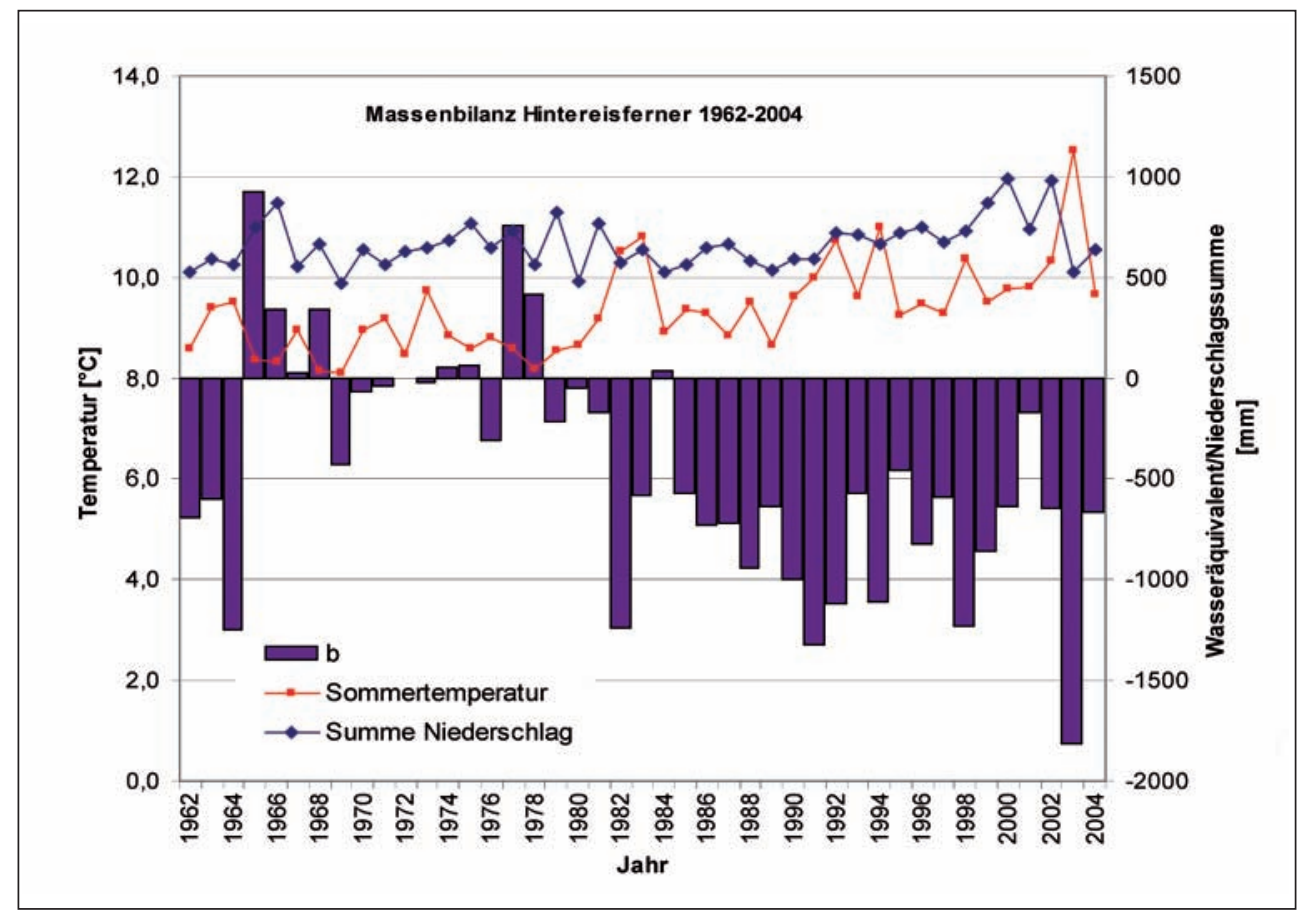

Abb. 12:

Spezifische Massenbilanz b am Hintereisferner im Vergleich zu der in Vent gemessenen mittleren Sommertemperatur und den Jahressummen des Niederschlages. 
Die hydrologische Methode der Bestimmung des Massenhaushalts bedient sich der gemessenen Abflüsse eines vergletscherten Einzugsgebietes. Der Abfluss bestimmt sich aus dem Gebietsniederschlag, der Gletschermassenbilanz und der Verdunstung. Aus dieser Beziehung kann man für das gesamte Einzugsgebiet des Pegels die Gletschermassenbilanzen berechnen, nicht aber für einen einzelnen Punkt in diesem Einzugsgebiet.

Die Volumsänderungen über große vergletscherte Flächen kann man aus der Differenz zweier Höhenmodelle berechnen. Nach der geodätischen Methode werden mit Hilfe von Annahmen über die Dichte der Oberflächenschicht des Gletschers die
Massenänderungen berechnet. Da sich der Höhenunterschied eines Punktes der Gletscheroberfläche aus der Massenbilanz und der Vertikalbewegung ergibt, sind auch mit dieser Methode nur Aussagen für den Gesamtgletscher möglich, nicht aber für einzelne Höhenstufen.

\section{Längenänderungen}

Die Erfassung der Längenänderungen stellt das umfangreichste und am längsten zurückreichende Archiv direkt gemessener glaziologischer Daten in Österreich dar (Patzelt 1970, 1977, 2005, 2006). Dabei wird jährlich der Abstand zwischen einem Fixpunkt und dem Rand des Gletschers mit einem Maßband an verschie-

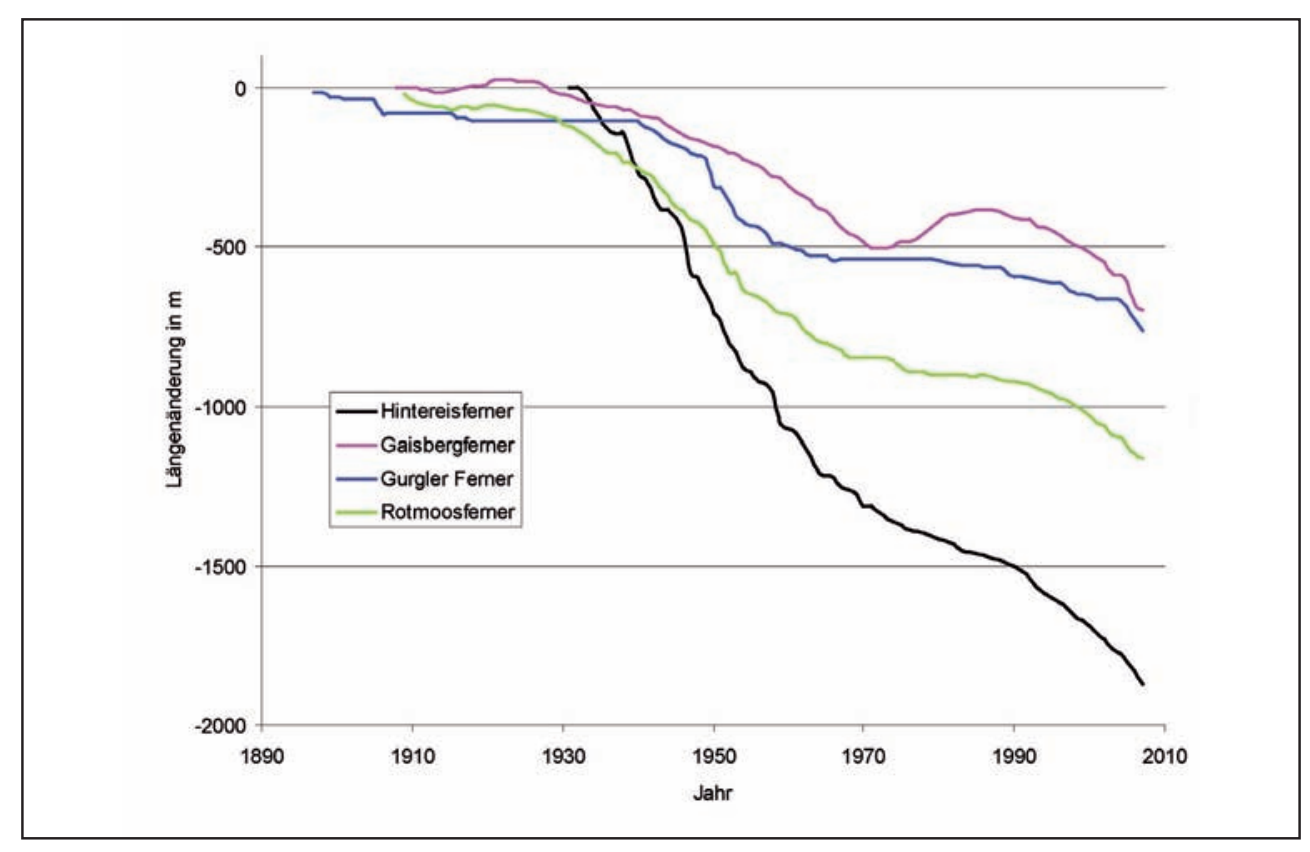

Abb. 13:

Änderungen der Länge von Gletschern um Obergurgl seit Beginn der Messungen 1891. 
denen Stellen bestimmt und die Werte gemittelt. Die Position der Zunge wird von der Massenbilanz, der Fließgeschwindigkeit und der Eisdicke eines Gletschers bestimmt. Die Reaktion des Gletschers auf eine Klimaänderung wirkt sich also unter Umständen gedämpft und/oder verzögert in der Längenmessung aus. Beim Gletscherrückgang kann auch ein Teil der Zunge abreißen oder zusammenbrechen. Hier kann die Längenänderung in einem Jahr sehr stark, in anderen wieder moderat sein. Dieses Verhalten steht nicht in unmittelbarem Zusammenhang mit dem Klima, sondern erklärt sich aus den glaziologischen Mechanismen. Abb. 13 zeigt die Längenänderungen von vier Gletschern des inneren Ötztals. Alle zeigen eine Abnahme der Länge seit Beginn der Messungen. Sie ist aber unterschiedlich stark. Die höher gelegenen, kleinen Gletscher Gaisbergferner und Gurgler Ferner zeigen die geringste Längenänderung. Obwohl Rotmoos- und Gaisbergferner unmittelbar benachbart und etwa gleich groß sind, ist der Gaisbergferner in den 1980er Jahren deutlich vorgestoßen, nicht aber der Rotmoosferner. Der Rückgang des Hintereisferners ist aufgrund der unterschiedlichen Topographie deutlich stärker als der des Gurgler Ferners. Der Vergleich zeigt, dass für die Interpretation von Längenänderungen im Hinblick auf Klimaänderungen immer eine größere Stichprobe herangezogen werden muss.

\section{Literatur}

Auer, I., Böhm, R., Jurkovic, A., Lipa, W., Orlik, A., Potzmann, R., Schöner, W., Ungersböck, M., Matulla, C., Briffa, K., Jones, PD., Efthymiadis, D., Brunetti, M., Nanni, T., Maugeri, M., Mercalli, L., Mestre, O., Moisselin, J.-M., Begert, M., Müller-Westermeier, G., Kveton, V., Bochnicek, O., Stastny, P., Lapin, M., Szalai, S., Szentimrey, T., Cegnar, T., Dolinar, M., Gajic-Capka, M., Zaninovic, K., Majstorovic, Z. \& Nieplova, E. (2007) HISTALP - Historical instrumental climatological surface time series of the greater Alpine region 1760-2003. International Journal of Climatology 27: $17-46$.

Abermann, J., Lambrecht, A., Fischer, A. \& Kuhn, M. (2009) Quantifying changes and trends in glacier area and volume in the Austrian Ötztal Alps (1969 - 1997 2006), The Cryosphere Discussion, accepted.

Fischer, A., Span, N., Kuhn, M., Massimo, M. \& Butschek, M. (2007) Radarmessungen der Eisdicke Österreichischer Gletscher. Band II: Messungen 1999 bis 2006., Österreichische Beiträge zu Meteorologie und Geophysik, 39, 142 S.

Fischer, A. \& Markl, G. (2009) Mass balance measurements on Hintereisferner, Kesselwandferner and Jamtalferner 2003 to 2006: database and results, Zeitschrift für Gletscherkunde und Glazialgeologie, 42/1: 47-83. 
Gross, G. (1987) Der Flächenverlust der Gletscher in Österreich 1850-1920-1969. Zeitschrift für Gletscherkunde und Glazialgeologie, 23(2): 131 -141.

Hess, H. (1904) Die Gletscher, Braunschweig, Friedrich Vieweg und Sohn, $426 \mathrm{~S}$.

Hoinkes, H. (1970) Methoden und Möglichkeiten von Massenhaushaltsstudien auf Gletschern. Zeitschrift für Gletscherkunde und Glazialgeologie, 6: 37 - 90.

HZB (2002) Hydrographisches Jahrbuch von Österreich, Hydrographisches Zentralbüro / Bundesministerium für Land- und Forstwirtschaft, Umwelt und Wasserwirtschaft, Abteilung VII/3 - Wasserhaushalt, Wien : Hydrograph. Zentralbüro. - CDROM.

Kaser, G., Fountain, A. \& Jansson, P. (2003) A manual for monitoring the mass balance of mountain glaciers. UNESCO: Paris.

Kuhn, M., Markl, G., Kaser, G., Nickus, U., Obleitner, F. \& Schneider, H. (1985) Fluctuations of climate and mass balance: Different responses of two adjacent glaciers, Zeitschrift für Gletscherkunde und Glazialgeologie, 21: 409-416.

Kuhn, M., Dreiseitl, E., Hofinger, S., Markl, G., Span, N. \& Kaser, G. (1999) Measurements and Models of the Mass Balance of Hintereisferner. Geografiska Annaler: A, 81(4): 659-670.

Lambrecht, A. \& Kuhn, M. (2007) Glacier changes in the Austrian Alps during the last three decades, derived from the new Austrian glacier inventory, Annals of Glaciology, 46: 177-184.
Lang, H. \& Patzelt, G. (1971) Die Volumenänderungen des Hintereisferners (Ötztaler Alpen) im Vergleich zur Massenänderung im Zeitraum 1953-64. Zeitschrift für Gletscherkunde und Glazialgeologie, VII (1-2): 229-238.

Lemke, P., Ren, J., Alley, R.B., Allison, I., Carrasco, J., Flato, G., Fujii, Y., Kaser, G., Mote, P., Thomas, R.H. \& Zhang, T., (2007) Observations: Changes in Snow, Ice and Frozen Ground. In: Climate Change 2007: The Physical Science Basis. Contribution of Working Group I to the Fourth Assessment Report of the Intergovernmental Panel on Climate Change [Solomon, S., D. Qin, M. Manning, Z. Chen, M. Marquis, K.B. Averyt, M. Tignor and H.L. Miller (eds.)]. Cambridge University Press, Cambridge, United Kingdom and New York, NY, USA.

Liljequist, G. H. \& Cehak, K. K. (1984) Allgemeine Meterorologie, 3. Auflage, Braunschweig Vieweg.

Nicolussi, K. (1990) Bilddokumente zur Geschichte des Vernagtferners im 17. Jahrhundert. Zeitschrift für Gletscherkunde und Glazialgeologie 26 (2): 97-119.

Paterson, W.S.B. (1994) The Physics of Glaciers, 3rd edition, Pergamon Press, Elsevier.

Patzelt, G. (1980) The Austrian Glacier inventory: Status and first results. IAHS Publ. 126: 181-183.

Patzelt, G. (1970) Die Längenmessungen an den Gletschern der österreichischen Ostalpen 1890-1969, Zeitschrift für Glet- 
scherkunde und Glazialgeologie, 6/1-2: 151-159.

Patzelt, G. (1977) Statistik der Längenmessungen an den österreichischen Gletschern 1960 bis 1975., Zeitschrift für Gletscherkunde und Glazialgeologie, 12/1: 91-94.

Patzelt, G. (1987) (Hrsg.): MaB-Projekt Obergurgl. - Veröff. Österr. MaB Progr. Universitätsverlag Wagner. Innsbruck: $350 \mathrm{~S}$.

Patzelt, G. (2005) Gletscherbericht 2003/ 2004. Sammelbericht über die Gletschermessungen des Österreichischen Alpenvereins im Jahre 2004. Mitteilungen des Oesterreichischen Alpenvereins. Jg. 60 (130), Heft 2/05: 24-31.

Patzelt, G. (2006) Gletscherbericht 2004/ 2005. Sammelbericht über die Gletschermessungen des Österreichischen Alpenvereins im Jahre 2005. Bergauf 2/2006: 6-11.

Rott, H. (1979) Vergleichende Untersuchungen der Energiebilanz im Hochgebirge, Archiv für Meteorologie, Geophysik und Bioklimatologie, V. 28, N. 2-3: 211-232.

Schlagintweit, K. \& Schlagintweit, A. (1850) Untersuchungen über die physikalische Geographie der Alpen in ihren Beziehungen zu den Phänomenen der Gletscher, zur Geologie, Meteorologie und Pflanzengeographie, Leipzig, $600 \mathrm{~S}$.

Schönwiese, C.D. (2008) Klimatologie. Ulmer, Stuttgart,. 3. Aufl., 472 S.

Sonklar, K. v. (1857) Das Ötztaler Eisgebiet. M. G. Ges. Wien: 1-15.

Sonklar, K. v. (1860) Die Ötztaler Gebirgsgruppe, mit besonderer Rücksicht auf
Orographie und Gletscherkunde. Gotha, 292 S.

Sonklar, K. v. (1877) Studie über den Gurgler Gletscher in der Ötztaler Gebirgsgruppe Z. DÖA, V. 8: 1-14.

Span N., Kuhn, M. \& Schneider, H. (1997) 100 years of ice dynamics of Hintereisferner, Central Alps, Austria, 1894-1994, Annals of Glaciology 24: 297-302.

Srbik, R. v. (1936) Ein Vierteljahrhundert Ötztaler Gletschermessungen Zeitschrift für Gletscherkunde 24, 188-191.

Srbik, R. v. (1939) Die Gletscher der Gurgler Tales. Festsch. d. Zweiges Karlsruhe d. DÖAV., $18 \mathrm{~S}$.

Stull, R. B. (2000) Meteorology for scientists and engineers. 2nd Edition. Brooks/ Cole.

Whiteman, C.D. (2000) Mountain Meteorology; Fundamentals and Applications. Oxford University Press, New York, S. 355.

Winkler, S. (2009) Gletscher und ihre Landschaften, Primus Verlag, 183 S.

\section{Verzeichnis der Autorin}

Andrea Fischer

Universität Innsbruck

Institut für Meteorologie und Geophysik Innrain 52, 6020 Innsbruck, Österreich Andrea.Fischer@uibk.ac.at 


\section{Kapitel 4 I Klima- und Vegetationsgeschichte}

\section{Das Rotmoostal im Wandel (1895-2009)}

Eva-Maria Koch

Von 1895 bis heute hat sich der Rotmoosferner und damit das Rotmoostal, wie die Bilderserie (Abb. 1-4) zeigt, stark verändert. Die Endmoräne von 1858 markiert den letzten Gletscherhochstand. Seither zieht sich der Gletscher, bis auf Ausnahmen zwischen 1916 und 1922 sowie in den 1980er Jahren, zurück und verliert massiv an Volumen und Oberfläche. Die Längenänderung des Rotmoosferners beläuft sich auf etwa zwei Kilometer, der Eisdickenverlust im Zungenbereich betrug zwischen 1850 (Gross 1987) und 2006 (Abermann et al. 2009) ca. 150 m.

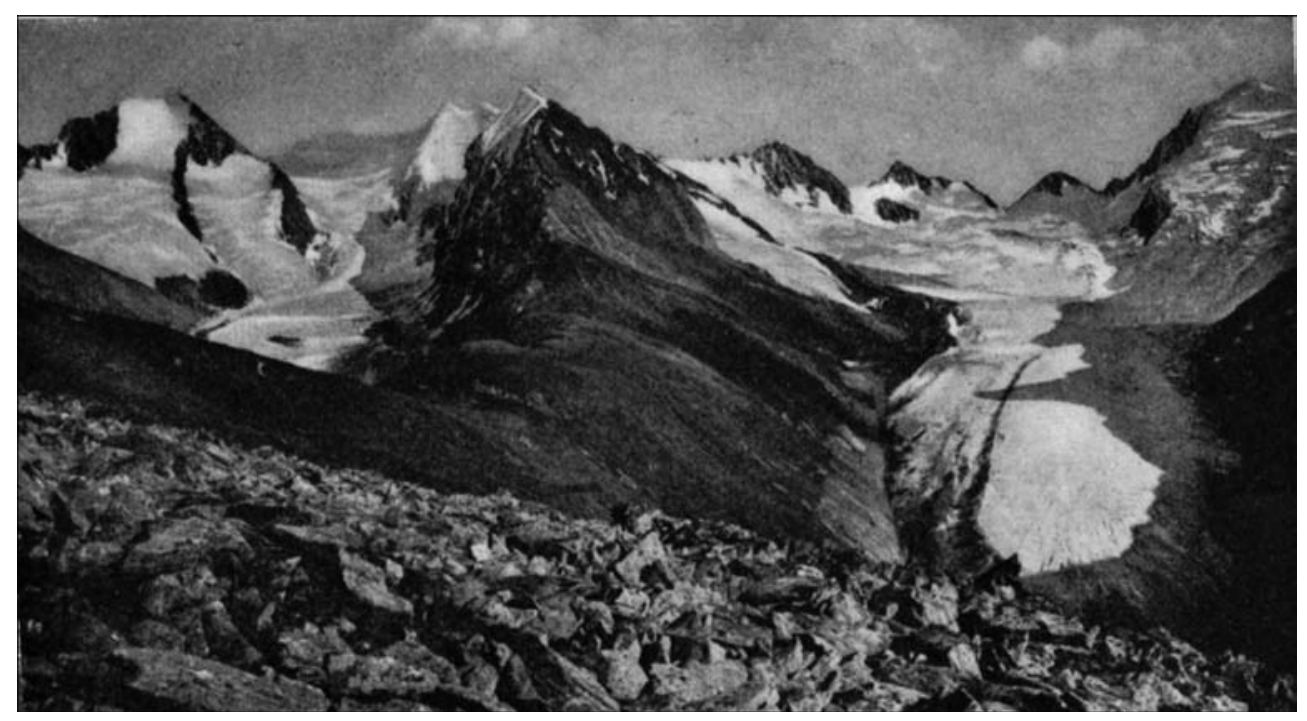

Abb. 1:

Der Rotmoosferner im Jahr 1895 (Foto aus der Zeitschrift des D-Ö-Alpenvereines, 1895) 


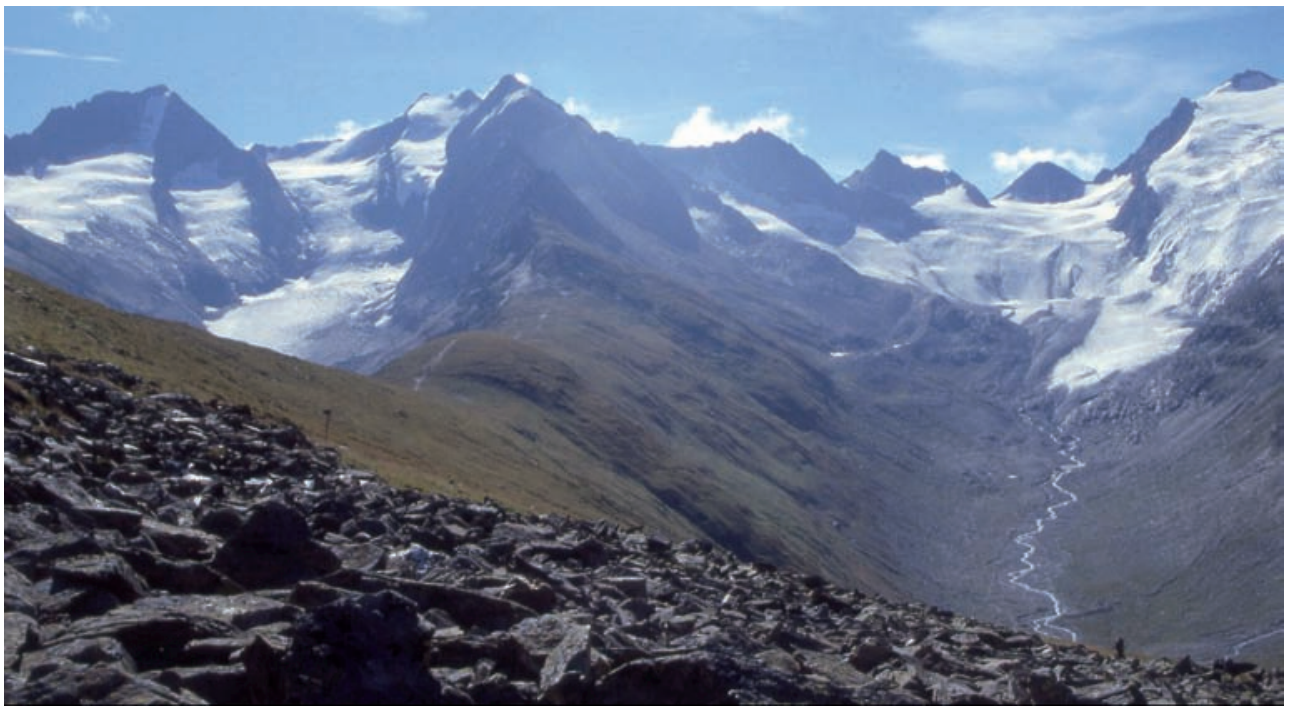

Abb. 2:

Der Rotmoosferner im Jahr 1999 (Foto: R. Kaufmann)

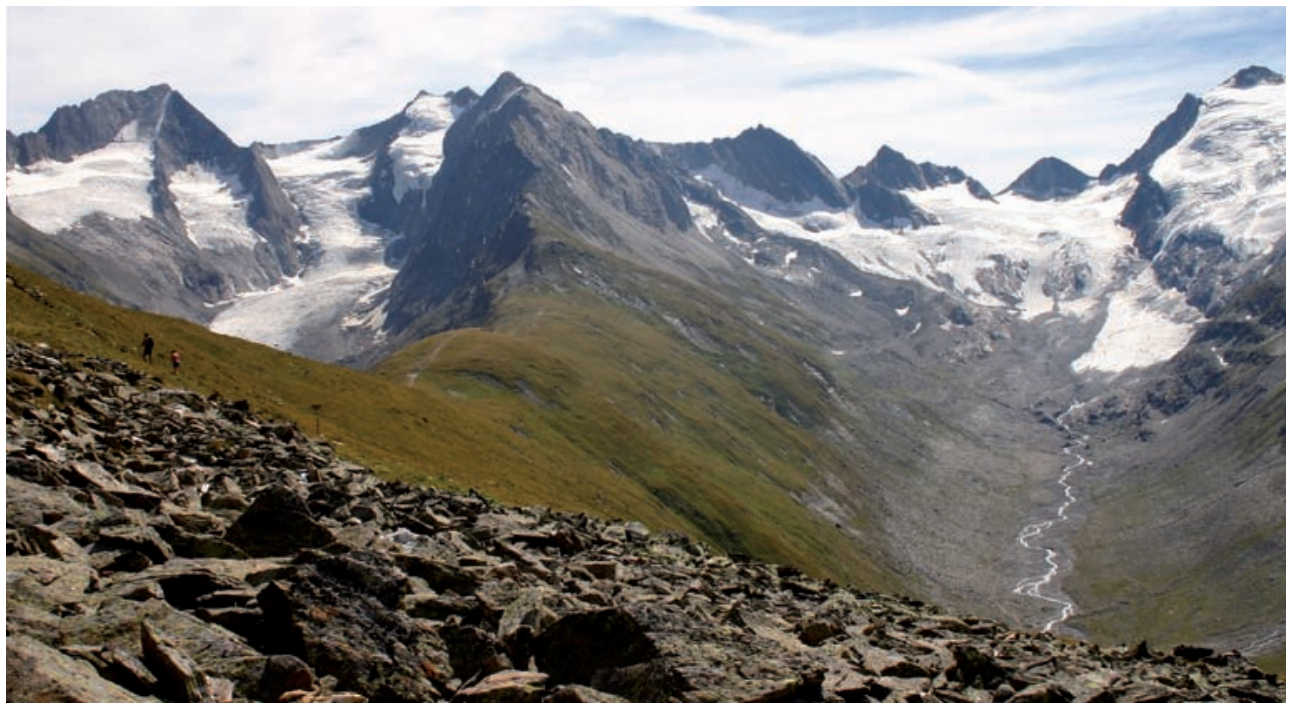

Abb. 3:

Der Rotmoosferner im Jahr 2004 (Foto: R. Kaufmann) 


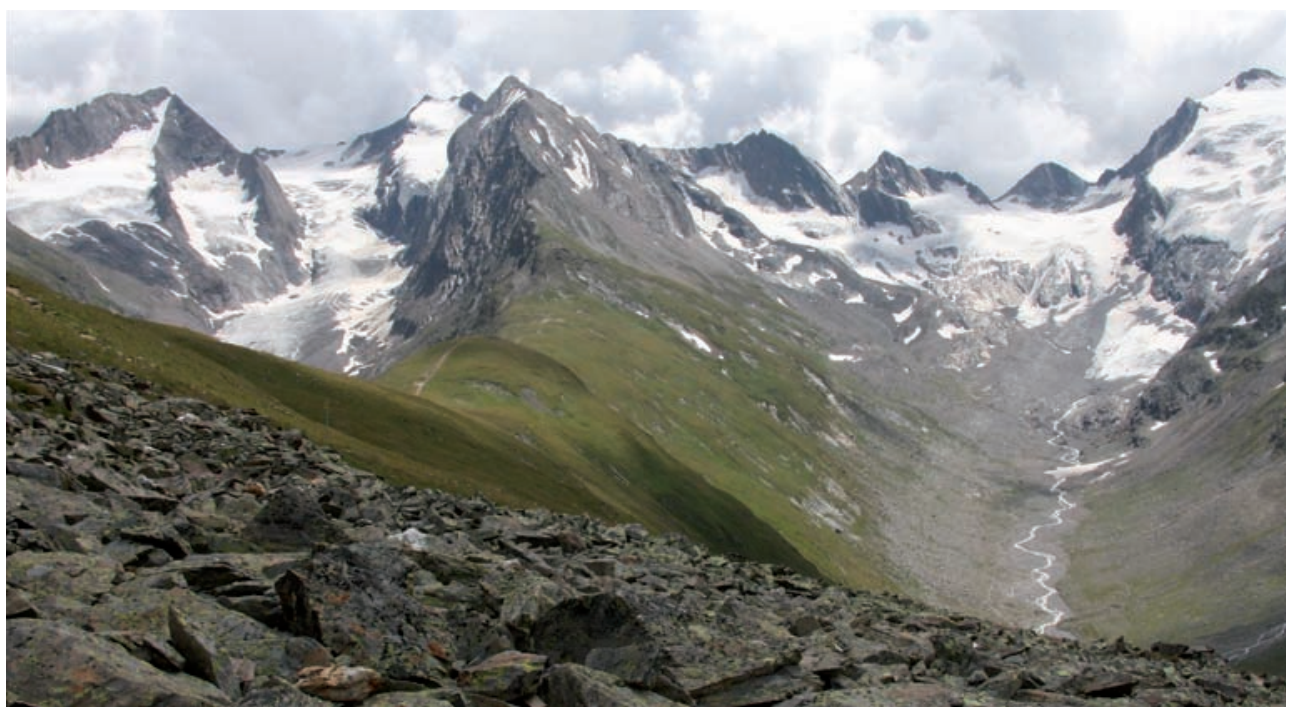

Abb. 4:

Der Rotmoosferner im Jahr 2009 (Foto: R. Kaufmann)

\section{Literatur}

Abermann, J., Lambrecht, A., Fischer, A. \& Kuhn, M. (2009) Quantifying changes and trends in glacier area and volume in the Austrian Ötztal Alps (1969-19972006), The Cryosphere, 3, 205- 215, http://www.the-cryosphere-discuss. net/3/205/2009/.

Gross, G. (1987) Der Flächenverlust der Gletscher in Österreich 1850-1920-1969. Zeitschrift für Gletscherkunde und Glazialgeologie 23 (2), 131-141.

\section{Verzeichnis der Autorin}

Eva-Maria Koch,

Universität Innsbruck

Alpine Forschungsstelle Obergurgl

Gaisbergweg 3, 6456 Obergurgl, Österreich

Eva-Maria.Koch@uibk.ac.at 


\section{Vegetationsgeschichte im Bereich des Rotmoostales}

Sigmar Bortenschlager

\section{Zusammenfassung}

Die Vegetationsgeschichte im Bereich des Rotmoostales in Abhängigkeit von Einwanderungsmöglichkeiten, Klima, Höhenlage und menschlichem Einfluss wird anhand von drei untersuchten Mooren dargestellt. Besonderes Augenmerk wird auf die Waldgrenzschwankungen als Folge von Temperaturänderungen und den Beginn der Weidewirtschaft gelegt.

\section{Summary}

The vegetation history of the Rotmoos valley, depending on the possibilities of immigration, climate, altitude and human influence is presented. Three mires are investigated. Special attention is turned to the fluctuation of the timberline as indicator for changing temperature in the past and the beginning of grazing.

\section{Historisches}

Schon vor mehr als 150 Jahren haben die Moore im Raum Obergurgl die Aufmerksamkeit auf sich gezogen. Der Kurat Trientl (Bothe für Tirol und Vorarlberg 1858) hat die Nutzung des Torfes der Moore im Raum Obergurgl für Heizzwecke und zur Bodenverbesserung empfohlen und selbst die Kirche damit geheizt. A. Kerner von Marilaun (1863) hat in seinem Werk „Pflanzenleben der Donauländer" auf die Einmaligkeit des Rotmooses hingewiesen. Graf Rudolf von Sarnthein (1936) hat 17 Torfproben, die H. Hanke aus dem natürlichen Aufschluss des Rotmooses entnommen hat, pollenanalytisch untersucht. Hanke (1935) selbst untersuchte die Quartärgeologie im inneren Ötztal. Die pollenanalytischen Ergebnisse, die Sarnthein veröffentlichte, zeigen eine Dominanz von Pinus-Pollen, die selten von einer Picea-Dominanz abgelöst wird. Dieses Bild stimmt gut mit allen späteren Untersuchungen überein. Sensationell aber war die Bestimmung von einem Holz aus dem Rotmoos, das E. Hoffmann lapidar Acersp. nannte.

Diese Bestimmung war der Ausgangspunkt von zahlreichen spekulativen Folgerungen, die wiederum Anlass für Neuuntersuchungen waren.

Wenn Acer in $2260 \mathrm{~m}$ Meereshöhe vorkam, heute aber im Ötztal die obere Grenze dieser Art bei etwa 1800 m liegt, 
müsste in einer ehemaligen Wärmezeit die Waldgrenze bei etwa 2700 bis 2800 $\mathrm{m}$ gelegen sein. Auch das Vorkommen von Torfmoosen als Beweis der biogenen Verlandung nur unterhalb der Waldgrenze wurde mit diesen Befunden verknüpft (Gams 1942, 1958, 1962). In die gleiche Richtung deuteten auch die Ergebnisse eines Pollenprofils von Sitte und Lürzer (Gams 1963), das im Moor bei der Schönwies Hütte eine fast durchgehende Picea-Dominanz zeigte.

Die Fortschritte und neuen Möglichkeiten in der Pollenanalyse (Absolutzählungen und Influxdiagramme), die Möglichkeit der Absolutdatierung mit Hilfe von C-14 und die Verknüpfung dieser Daten mit Ergebnissen von glaziologischen und quartärmorphologischen Untersuchungen haben in den letzten 30 Jahren zu neuen und stichhaltigen Resultaten geführt.

\section{Methoden}

Um die Vegetationsgeschichte abzuklären, ist die Pollenanalyse die Methode der Wahl. Die ausgefeilte Nichtbaumpollendiagnostik erlaubt es, den klimatischen oder den menschlichen Einfluss auf die Vegetation genauer zu fassen. Im Bereich Obergurgl spielen hier vor allem die Weidezeiger eine große Rolle. Folgende Arten, Gattungen oder Familien werden hier zu einer Summenkurve zusammengefasst:
Chenopodiaceae, Filipendula, Gentianaceae, Ligusticum, Lotus, Papilionaceae (= Fabaceae), Plantago, Ranunculaceae, Rhinanthus, Rosaceae, Rumex, Umbelliferae (= Apiaceae) und Urtica. Als Kulturzeiger sind die Cerealia inkl. Secale, Castanea und Vitis in einer Kurve zusammengefasst. Sie sind hier nur als Fernflug aus tieferen, südlichen Lagen einzustufen.

Auch die quantitative Erfassung des Pollenniederschlags insgesamt, in Verbindung mit dem Verhältnis Baumpollen zu Nichtbaumpollen, macht es möglich, die Schwankungen der Waldgrenze in der Vergangenheit sehr genau festzulegen (Oeggl 1998). Ein Anteil von etwa 25 \% Nichtbaumpollen spricht für Waldfreiheit, wenn die lokalen Pollen, hier die torfbildenden Cyperaceae, aus der $100 \%$ Summe ausgeschlossen sind.

Großrestanalysen und Holzbestimmungen sind ein weiteres Mittel, um Informationen über Vegetation und Klima zu erhalten. Ein großer Vorteil für die Verknüpfung vom Klima mit der Vegetation und Waldgrenze besteht darin, dass in Obergurgl die Waldgrenze durch Pinus cembra gebildet wird. Während eine Absenkung der Waldgrenze durch ungünstiges Klima für alle immergrünen Nadelbäume über den Mechanismus des Frosttrocknis verläuft (Baig et al. 1974), ist der Anstieg über die Samenverbreitung am raschesten bei Pinus cembra gegeben (Mattes 1982). Durch den Tannenhäher werden die Samen weit über die Waldgrenze hinauf vertragen und Pinus cembra keimt und 
wächst dort, sobald es die klimatischen Verhältnisse erlauben. Eine Verzögerung von nur etwa 20 Jahren bis zur Blühreife muss man einkalkulieren. Bei Picea hingegen ist die Samenverbreitung über den Standort hinaus viel schwieriger, nur 1\% der Samen fliegt über die Wipfelregion hinaus (Kuoch 1965).

Klimaänderungen können auch über die ehemalige Größe der Gletscher anhand subfossiler Moränen kartographisch erfasst werden. Über das Teilungsverhältnis dieser Fläche 2:1 - Nährgebiet: Zehrgebiet - kann die Gleichgewichtslinie und damit die ehemalige Schneegrenze abgeschätzt werden. Etwa 900 m darunter liegt die Waldgrenze.

Aber auch Sauerstoffisotopenanalysen in Sedimenten liefern wichtige Beiträge. Alle diese Methoden in Kombination mit C-14 Daten erlauben es für bestimmte Gebiete Vegetations- und Klimarekonstruktionen zu erstellen, die auch über große Räume hinweg Gültigkeit haben (Magny et al. 2006).

\section{Untersuchungslokalitäten}

Im Raum Obergurgl und im benachbarten Venter Tal gibt es zahlreiche Moore, die heute noch wachsen. Ebenso gibt es Moorbildungen, die durch Moränen verschüttet worden sind. Die Untersuchungen dieser Moorbildungen im Ötz- tal reichen bis in die erste Hälfte des letzten Jahrhunderts zurück (Sarnthein 1936, Gams 1948) und wurden dann gegen Ende des letzten Jahrhunderts auch im Zusammenhang mit dem Fund des Eismannes intensiviert (Bortenschlager 1970, 1984, 1993, 2000; Rybnicek et al. 1977, Vorren et al. 1993). Sie sind auch heute noch nicht abgeschlossen (Kutschera et al., im Druck).

Für die Vegetationsentwicklung im hier angesprochenen Tal sind vor allem das Rotmoos und das Moor bei der Schönwieshütte von Belang. Mit der Höhenlage um $2250 \mathrm{~m}$ liegen sie in etwa im Bereich der Waldgrenze und bilden damit die Schwankungen dieser im Holozän sehr gut ab. Für die Dokumentation des menschlichen Einflusses, hier die Weidewirtschaft, ist auch noch das Moor bei der Gurgler Alm von Bedeutung. Für schlüssige Interpretationen muss man alle anderen untersuchten Lokalitäten ebenfalls mit einbeziehen.

\section{Rotmoos}

Das über $1 \mathrm{~km}$ lange und heute bis zu 120 $\mathrm{m}$ breite Moor liegt am rechten Ufer der Rotmoosache am Ausgang des Rotmoostales und nimmt die mehr oder weniger ebene Fläche am Fuß der Hohen Mut ein. Die Rotmoosache erodiert permanent den Steilabbruch des Moores (Abb. 1). Auf einem Aquarell von Thomas Ender aus der Mitte des 19. Jahrhunderts ist deutlich zu 


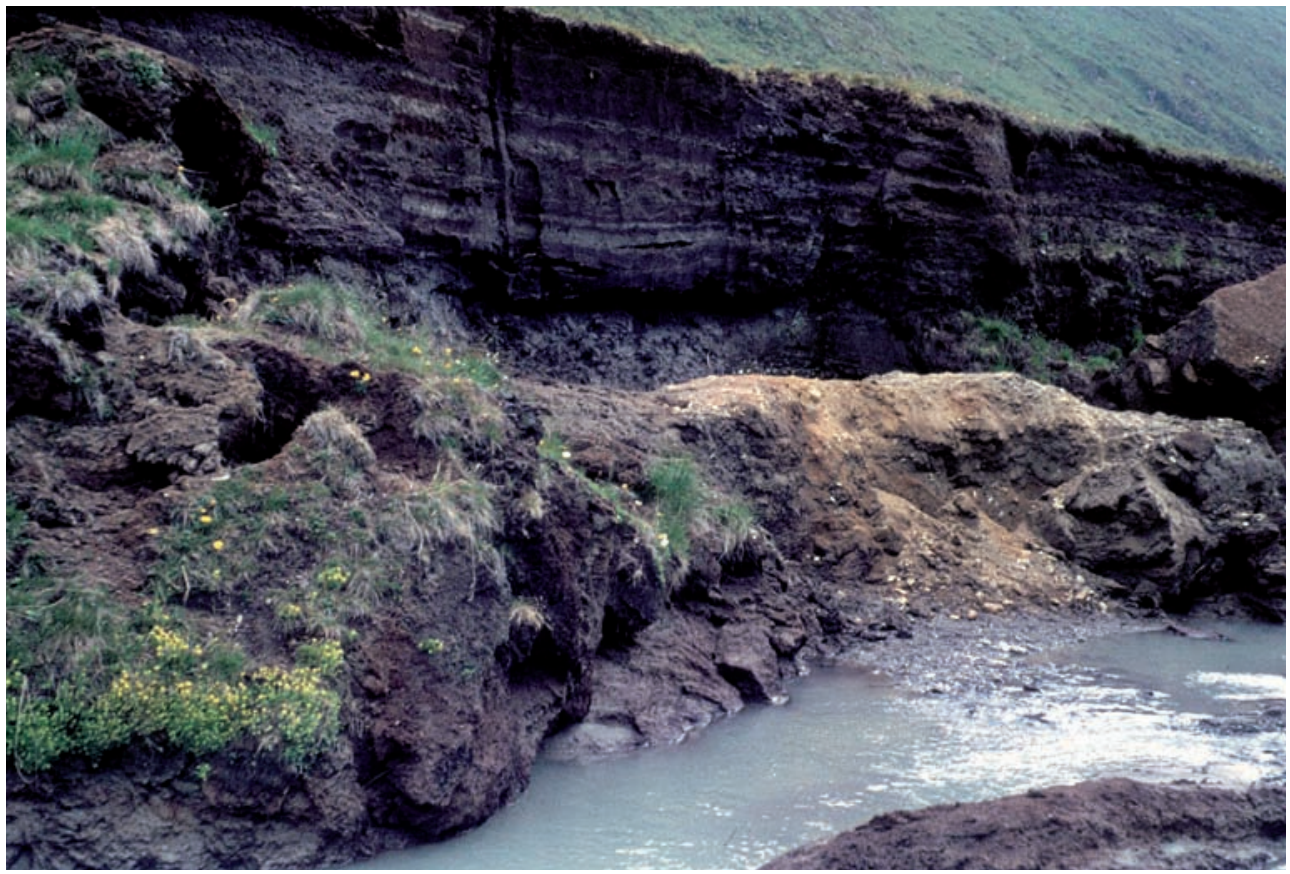

Abb. 1:

Rotmoos - Stichwand, aus der das Profil entnommen wurde. (Foto: S. Bortenschlager)

sehen, dass die Rotmoosache ursprünglich am Hangfuß des Hangerers auf der linken Talseite floss und dass das gesamte Tal vom Moorkörper ausgefüllt war. Nach Gams (1962) zeigt dieses „Zeitweise überschüttete Gletschertalmoor" mit seinen Ton-, Schluff- und Sandeinlagerungen deutlich die früheren Gletschervorstöße. In einem engmaschigen Netz wurde die Stratigraphie des Moores von Rybnicek et al. (1977) aufgenommen und er konnte zeigen, dass die Schlufflagen ihren Ursprung einerseits im Gletscherbach haben, andererseits aber auch von den Talflanken ihren Ausgang nehmen.
Diese Sand- und Schluffeinlagerung sind kantig und zeigen keinerlei fluviatile Einwirkung.

Ebenfalls von Rybnicek et al. (1977) stammt eine detailierte Vegetationskartierung, in der das Carici echinataeTrichophoretum caespitosum typicum und Drepanoclado-exanulati-Caricetum fuscae typicum als charakteristische Pflanzengesellschaften ausgewiesen werden. Besonders erwähnenswert sind aber von ihm gefundene Sphagnum fuscum-Bulten. Weite Flächen werden heute von NardusBeständen eingenommen, eine typische Folge der Beweidung. 


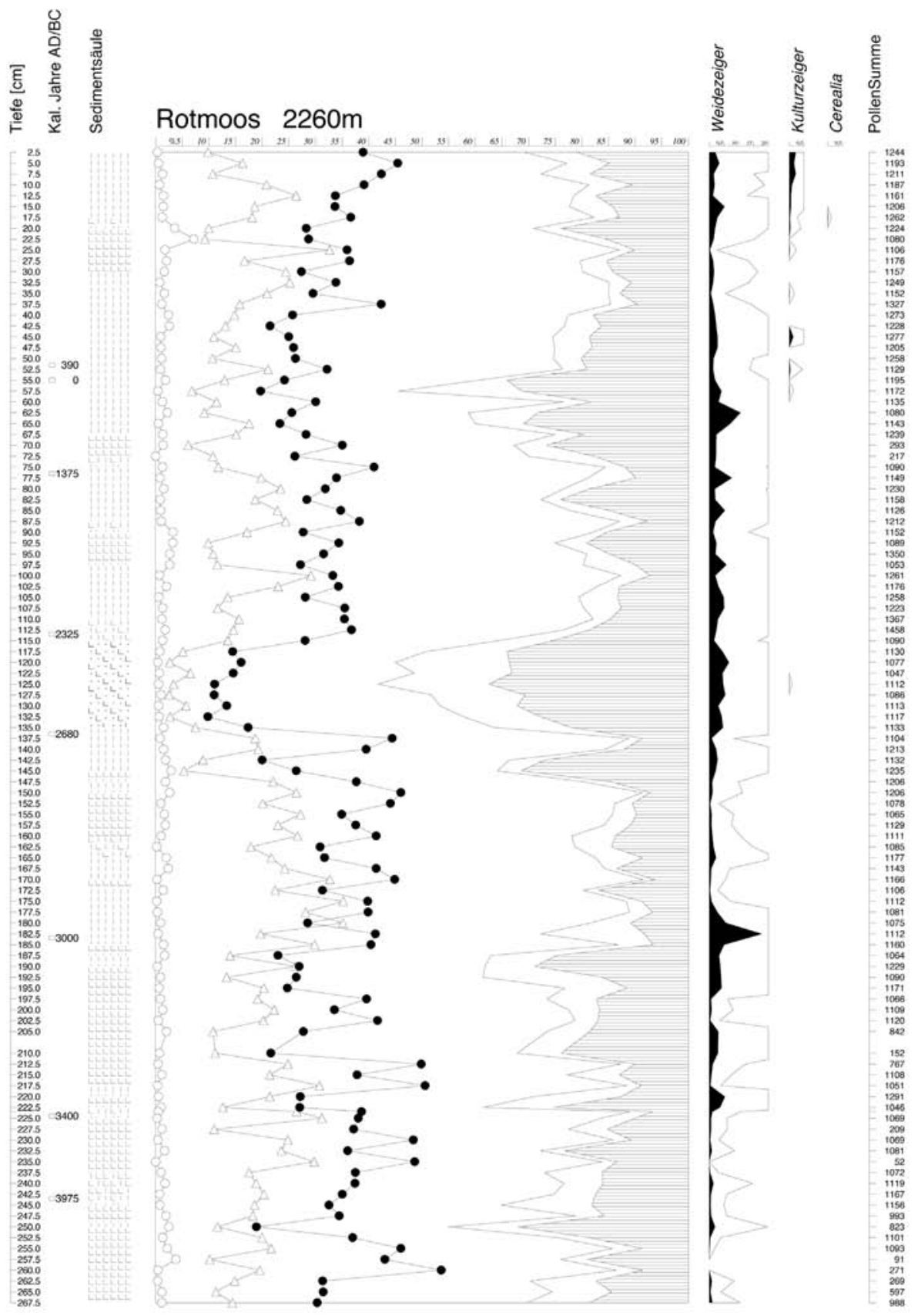

Abb. 2:

Vereinfachtes Pollenprofil Rotmoos (Legende in der Beilage, ebenso das Gesamtprofil) 


\section{Profilbesprechung}

Das Profil beginnt mit einer Wechsellagerung von tonig-schluffigen und organogenen Sedimenten (Abb. 2). Parallel dazu schwankt die Baumpollen/NichtBaumpollen (BP/NBP)-Kurve um den Wert von $25 \%$ NBP, Werte bis $40 \%$ können erreicht werden. Diese hohen NBP-Werte sprechen für Waldfreiheit am Standort. Diese von 265 bis $185 \mathrm{~cm}$ Tiefe dauernde Phase wurde von Patzelt (1973) als Rotmoosschwankung I und II in die Literatur eingeführt. Die Wiederbewaldung durch Zirben am Standort wird durch Weiden eingeleitet, die in 192,5 $\mathrm{cm}$ einen markanten Gipfel haben. Auch die Fichten zeigen deutlich höhere Werte. Die außerordentlich hohen Werte der $C y$ pereaceae weisen Carex als Torf bildende Standortspflanzen aus.

In diesen organischen Lagen zwischen 180 bis $140 \mathrm{~cm}$ Tiefe treten auch zahlreiche Holzreste auf, die ebenfalls ein Beweis für Wald am Standort sind. Aus dieser Lage dürften auch die von E. Hoffmann, (in Sarnthein 1936) bestimmten „Ahorn“-Reste stammen. Mehrere Duzend Nachbestimmungen haben keinen einzigen Ahornfund erbracht. Es konnten nur Pinus-, Alnus- und Populus-Reste gefunden werden. Unter gewissen Umständen ist eine Verwechslungsmöglichkeit von Acer und Populus gegeben. Das dürfte E. Hoffmann passiert sein. Alle mit dem Vorkommen von Acer in dieser Höhe zusammenhängenden Schlussfolgerungen wie eine Waldgrenze bei $2800 \mathrm{~m}$ und biogene Verlandung nur unterhalb der Waldgrenze, sind somit hinfällig.

Diese günstige Phase wird jäh durch eine schluffig sandige Lage von $135-115 \mathrm{~cm}$ unterbrochen. In dieser Sandlage befinden sich auch Steine bis mehrere dm Größe, die kantig sind und keine fluviatile Einwirkung zeigen. Die NBP erreichen in dieser Schicht die Höchstwerte im Profil, während die Cyperaceae die geringsten Werte aufweisen. Auch Alnus - hier Alnus viridis - erreicht hier die höchsten Werte. Aus den Sondierungen von Rybnicek et al. (1977) kann man erkennen, dass diese Lage sowohl talaus als auch talein und in Richtung Mutrücken auskeilt. Hier wird ein Lawinenereignis vom Hangerer herunter dokumentiert. Durch die C-14 Daten wird das gesamte Ereignis bis zur normalen Wiederbewaldung auf 355 Jahre eingeengt.

Die steigenden NBP-Werte ab $85 \mathrm{~cm}$ Tiefe und dann besonders in 72,5 bis 60 $\mathrm{cm}$ Tiefe zeigen wieder ungünstige Bedingungen mit Waldgrenzabsenkungen an. Waldfreiheit ist hier für diese Höhenlage dokumentiert.

Die Ausdehnung des römischen Reiches und die damit verbundene intensive Landwirtschaft zeigen sich im Fernflug der Kulturzeiger. Die in den obersten Schichten wieder zunehmenden NBP, die wiederum Waldfreiheit anzeigen, müssen sowohl auf das Klima als auch auf die Rodungen zurückgeführt werden. 
Die durchgehend hohen Werte der Weidezeiger belegen, dass das Rotmoostal seit etwa 4.000 v. Chr. als Schafweide genutzt wurde.

\section{Schönwies}

Das Moor bei der Schönwieshütte (Abb.

3) ist der Rest eines Hangmoores, das

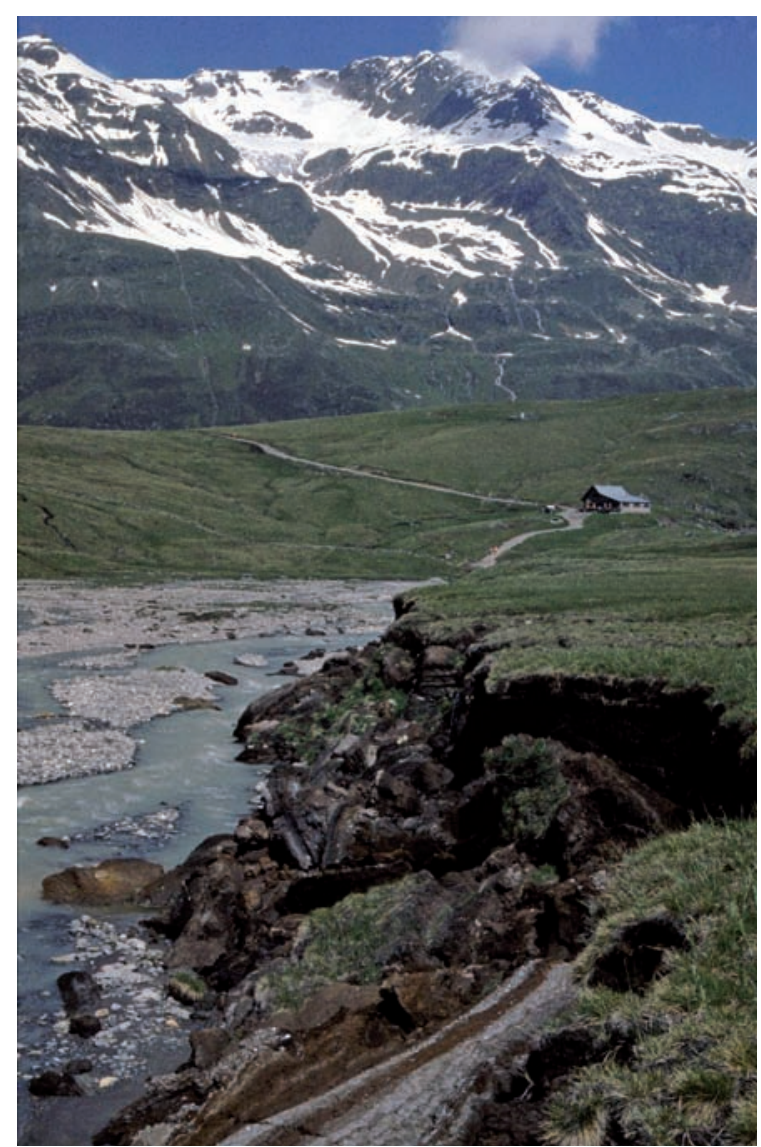

Abb. 3:

Blick über das Rotmoos zum Moor bei der Schönwieshütte (Foto: S. Bortenschlager) durch Sickerwässer aus der Umgebung gespeist wird. Es liegt außerhalb des Einflussbereiches der Rotmoosache und zeigt deshalb auch keine deutlichen Sand- und Schluffeinlagerungen. Das Torflager wurde zum Großteil abgebaut. Die Torfnutzung erfolgte vor allem in der ersten Hälfte des letzten Jahrhunderts für die Beheizung der Schönwieshütte. Diese Torfstichtätigkeit ist noch deutlich an dem unruhigen Relief der Oberfläche zu erkennen. Die nicht abgebauten Torfpakete erreichen heute noch etwa 2 m Mächtigkeit und sind mit Nardus-Rasen bestanden. An der Stelle der größten Torfmächtigkeit wurde das Profil (Abb. 4) entnommen. Bei einer Nachgrabung etwa $80 \mathrm{~cm}$ südlich vom ersten Profil konnte G. Patzelt an einer vertieften Stelle ein älteres Schichtpaket von $28 \mathrm{~cm}$ Mächtigkeit bergen, das als Profil Schönwies II das erste Profil ergänzt.

\section{Profilbesprechung}

Durch das C-14 Datum von ca. 8.000 v. Chr. ist der Beginn des Torfwachstums dieses Profils festgelegt (Abb. 5). Die BP dominieren und ein Zirbenwald am Standort ist durch Holzfunde und den Fund von Teilen eines Zirbenzapfens mit Samen belegt. Diese günstige Phase wird in $187 \mathrm{~cm}$ Tiefe durch ein feines 


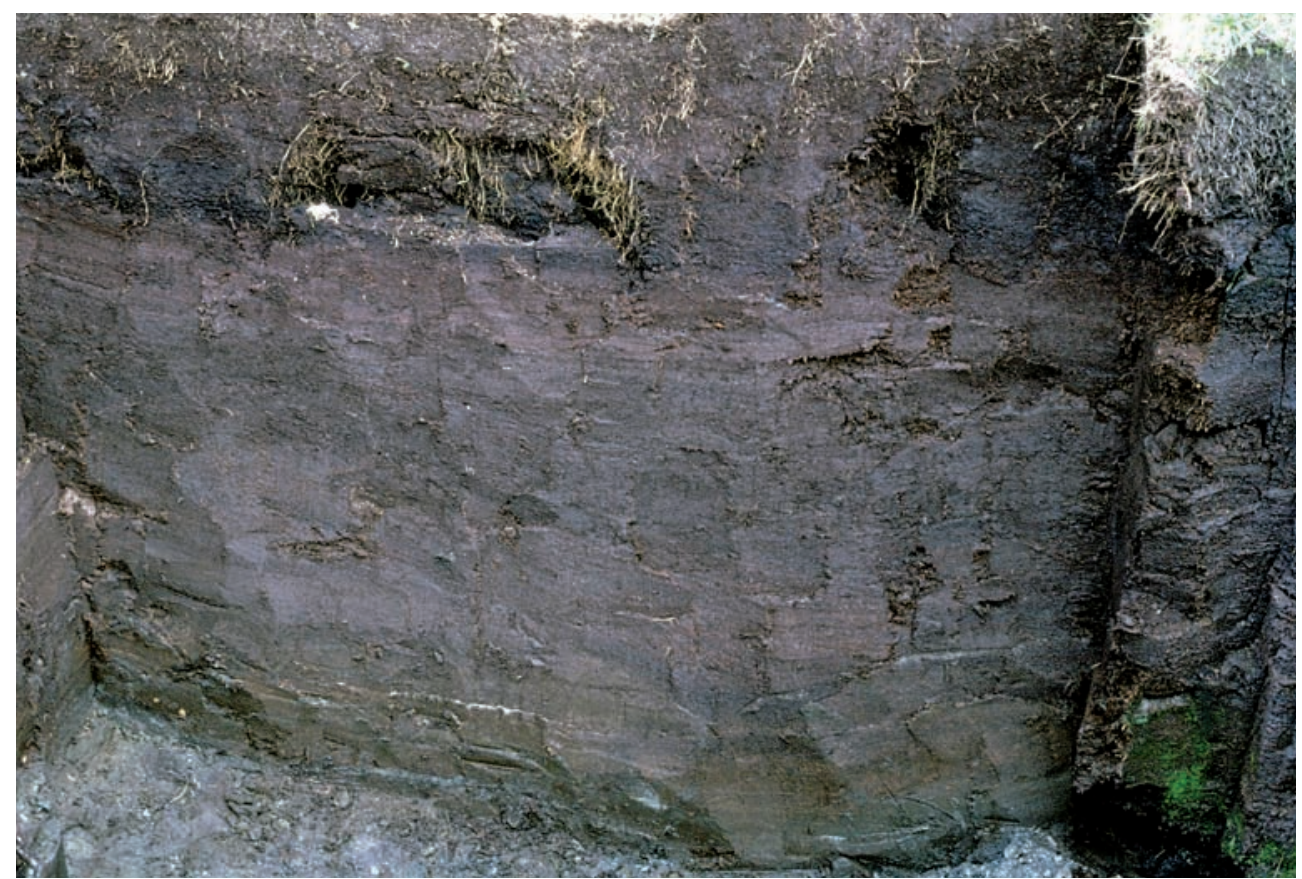

Abb. 4:

Moor bei der Schönwieshütte-Stichwand, aus der das Profil entnommen wurde. (Foto: S. Bortenschlager)

Tonband, eine Einwehung aus dem Gletschervorfeld, beendet. Die NBP nehmen auf fast $40 \% \mathrm{zu}$ und es beginnt eine mehrgliedrige Phase von Waldfreiheit. Eine deutliche Zweiteilung tritt mit dem BP-Maximum in der Tiefe von 160-155 $\mathrm{cm}$ auf. Die Waldgrenze dürfte zu dieser Zeit nahe an das Moor gekommen sein. Ein feines Tonband in $153 \mathrm{~cm}$ Tiefe beendet diese Gunstphase und die Waldgrenze sinkt wieder deutlich ab. Diese ungünstige Phase dauert etwa bis 7.000 v. Chr., in ihr dominieren Arten der alpinen Rasen und Rohbodenzeiger wie Gramineae (= Poaceae), Rosaceae, Cichoriaceae, Umbelliferae (= Apiaceae), Artemisia, Thalictrum,
Selaginella selaginoides und Botrychium. Ab 127,7 cm bildet Picea eine geschlossene Kurve, die geringen Werte sind Fernflug aus tieferen Lagen. Ab $135 \mathrm{~cm}$ wird die 5\%-Marke überschritten, was für einzelne Picea-Exemplare in der Nähe oder direkt am Standort spricht. Picea gewinnt dann weiter an Areal und ist in $90 \mathrm{~cm}$ Tiefe mit dem Höchstwert von $25 \%$ wenig unterhalb der Lokalität Bestand bildend, was durch Großreste im Zirbenwaldmoor (Rybnicek et al. 1977) belegt ist.

Von 115- $90 \mathrm{~cm}$ tritt die BP-reichste Phase im Profil auf. Hier macht sich auch regelmäßig der Fernflug von $A b i e s$ und $F a$ gus bemerkbar, die in tieferen Lagen seit 
Kapitel 4 I Klima- und Vegetationsgeschichte
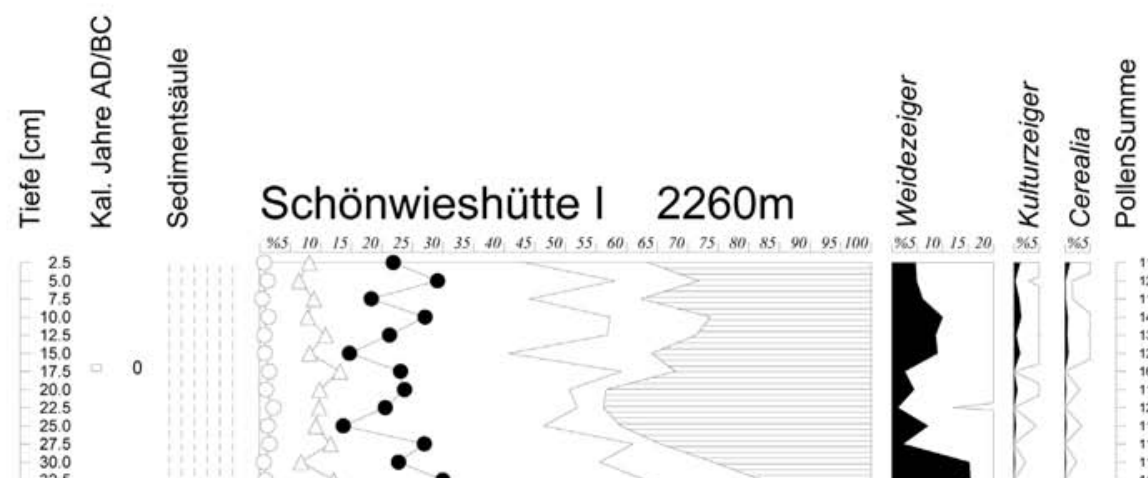

2000
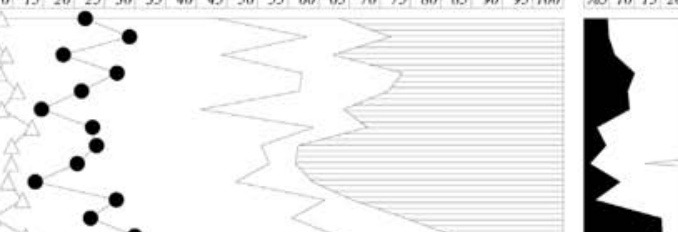

[ $\begin{array}{r}1157 \\ -1274\end{array}$

$35.0 \quad 2000$

37.5
40.0

42.5

45.0

50.0

55.0
57.5
60.0

60.0

65.0
-67.5
70.0

70.0
-72.5
-75.0

77.5

4620

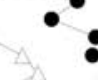

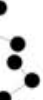
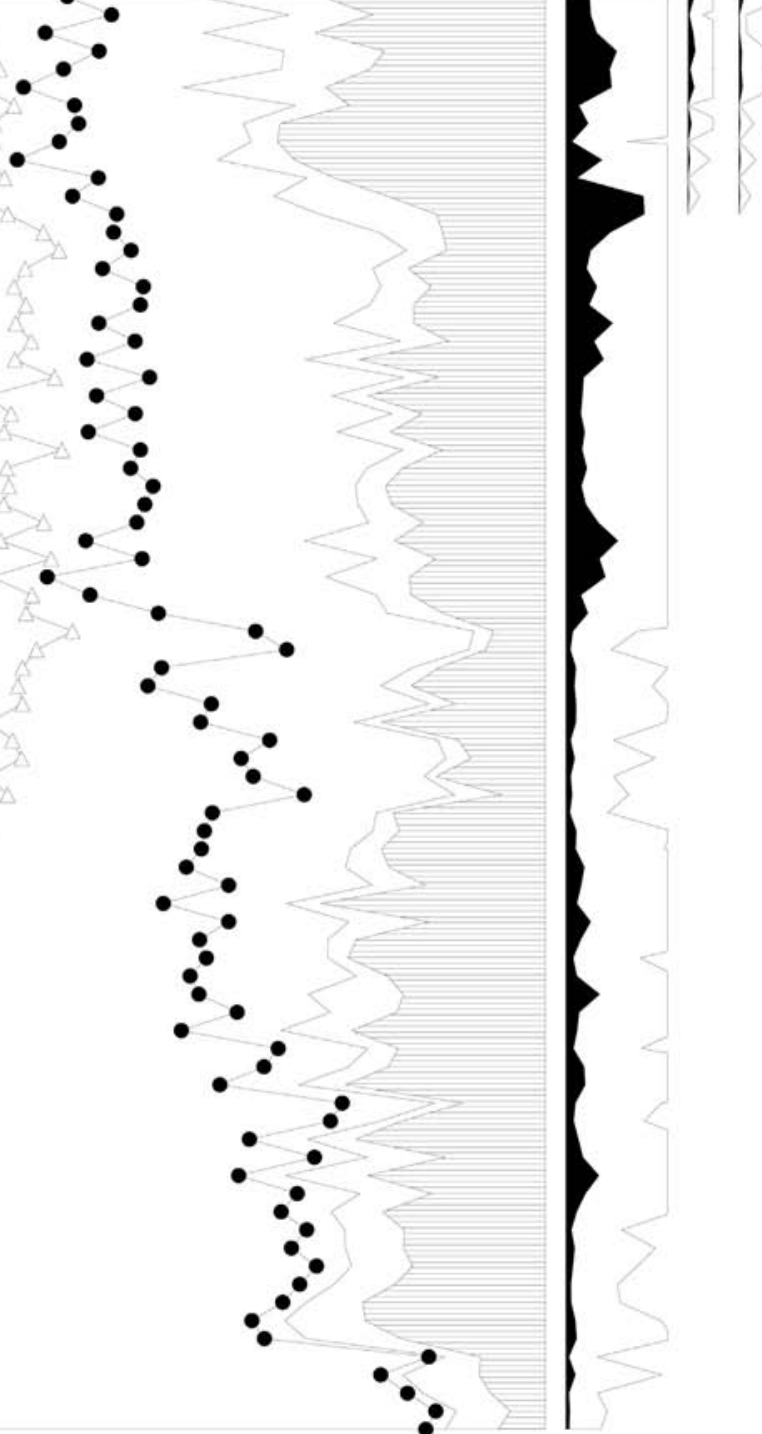

$\begin{array}{r}1182 \\ -1488 \\ -1359 \\ \hline\end{array}$

1205
1651
1171

1171
1245

1182
1138

1138
1104
1116

1021
1069

1239
1138
1261

1261
-1188
-1205
1105

1185
1181
1021

1021
$-\quad 1100$
1171

$\begin{array}{r}1171 \\ -1277 \\ -1112 \\ \hline\end{array}$

1112
1071
1068

$\begin{array}{r}1068 \\ 1332 \\ 1145 \\ \hline\end{array}$

1108
1023
1073

1073
1032
1094

$\begin{array}{r}1032 \\ -\quad 1084 \\ -\quad 1033 \\ -\quad 1054 \\ \hline\end{array}$

$\begin{array}{r}1054 \\ -1200 \\ -1171 \\ \hline\end{array}$

$\begin{array}{r}1171 \\ -\quad 1200 \\ -1161 \\ \hline\end{array}$

1035
-1104
-1079

104
1079
1081
1216

6850

127.5
130.0

135.0

137.5
140.0

142.5

147.5
1500

152.5

155.0
157.5

160.0

162.5
-165.0
167.5

170.0
172.5

172.5
175.0

177.5
180.0

182.5

85.0
$\square 950$

190.0

1925

200.0

8075

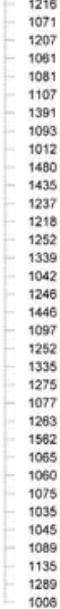

Abb. 5:

Vereinfachtes Pollenprofil - Moor bei der Schönwieshütte (Legende in der Beilage, ebenso das Gesamtprofil) 
etwa 5.500 v. Chr. auftraten. Interessant ist hier die Zuwachsrate des Cyperaceentorfs. Betrug sie im unteren NBP-reichen Abschnitt noch um die $6 \mathrm{~cm}$ pro $100 \mathrm{Jah}-$ re, nahm sie im BP-reichen Abschnitt auf unter $2 \mathrm{~cm}$ pro 100 Jahre ab. Im kontinental getönten Ötztal scheinen also kühle, feuchte Bedingungen das Torfwachstum eher zu fördern als trockene warme.

Ab $85 \mathrm{~cm}$ Tiefe nehmen die NBP-Werte wieder deutlich zu, Spitzenwerte von $40 \%$ werden erreicht. Die Pinus cembra-Werte nehmen deutlich ab aber auch die PiceaWerte sinken etwas. Alnus als Krummholz im Zentralalpenbereich nimmt hingegen deutlich zu. Die Waldgrenze ist in diesem Zeitraum bis unterhalb des Moores abgesunken. Diese kühlere Phase kann der von Patzelt (1973) festgelegten Rotmoosschwankung zugeordnet werden.

Gering zeitversetzt, etwa um 4.000 v. Chr. steigen die Werte der Weidezeiger stärker an, sinken dann zwar wieder etwas ab und zeigen ab $55 \mathrm{~cm}$ Tiefe - etwa ab 3.000 v. Chr. wieder deutlich höhere Werte, die bis zu den obersten Proben andauern.

$\mathrm{Ab} 35 \mathrm{~cm}$ Tiefe treten die Kulturzeiger, vor allem Getreide, auf. Es handelt sich hier um Fernflug aus tieferen Lagen. Sie belegen aber auch eine dichtere Besiedlung und eine intensivere Nutzung der Landschaft. Die Weidewirtschaft wurde nochmals intensiviert und durch Brandrodung zur Weidegewinnung wurde die Waldgrenze deutlich abgesenkt. Ab dieser Zeit überlagern sich natürliche und an- thropogene Ursachen für die Waldgrenzabsenkung.

Im Profil Schönwies II (siehe Beilage) wird durch 12 Proben ein Zeitabschnitt dokumentiert, der deutlich älter ist als die Basisprobe des Profils Schönwies I und in seiner Gesamtheit eine Waldgrenze knapp unterhalb des Standortes mit Vorposten direkt beim Moor belegt. In der Mitte des Profils konnten Holzreste gefunden werden. Die Datierungen ergaben für das Holz (9.050 v. Chr.) und den umgebenden Torf (8.500 v. Chr.) keinen signifikanten Altersunterschied. Der Mittelwert dieser Proben ergab mit $95 \%$ Wahrscheinlichkeit ein Alter von 9.300 - 8.300 v. Chr. Es ist dies ein Mindestalter für das Eisfreiwerden des Gebietes, das somit in den ersten Jahrhunderten des Präboreals erfolgt sein muss.

Das Sediment ist Cyperaceentorf, dem an der Basis und im mittleren Abschnitt Schluff bzw. Ton beigemengt ist. Reichlich treten in diesem Profilstück Diatomeen auf. Ein direkter Anschluss an das Profil Schönwies I ist nicht gegeben.

\section{Gurgler Alm}

Das kleine Moor liegt etwas unterhalb der Hütte der Gurgler Alm (Abb. 6) innerhalb des potentiellen Waldgebietes. Heute ist die gesamte Umgebung waldfrei und die Moorvegetation ist durch den Weidebetrieb degradiert. Die gesamte Torfsäule 


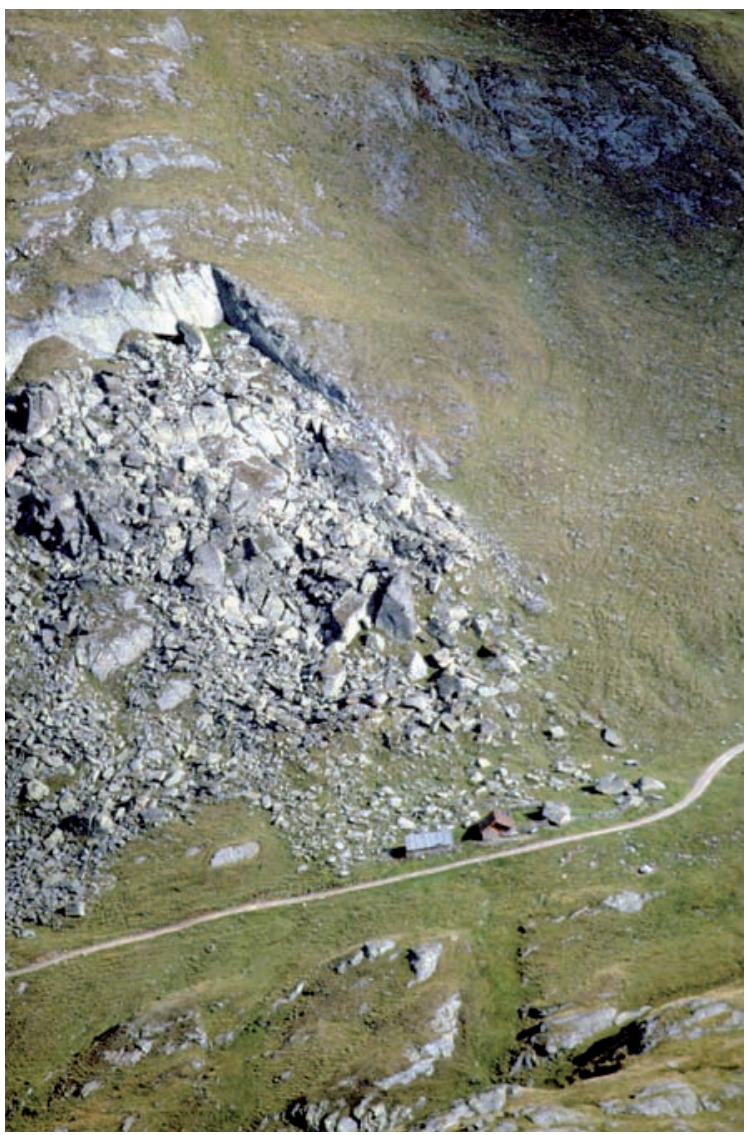

Abb. 6:

Blick zur Gurgler Alm - links unterhalb der Hütte liegt die Profilentnahmestelle (Foto: G. Patzelt)

besteht aus Cyperaceentorf. Glühverlustuntersuchungen, deren Ergebnis normal mit der Humifizierung des Torfes parallel verlaufen, zeigen aber an vier Stellen Abweichungen und teils geringfügige mineralische Einwehungen. Und zwar zwischen $4.300-3.800$ v. Chr. und 5.500 -4.900 v. Chr. war infolge des höheren, minerogenen Eintrags der Glühverlust geringer. Für die Perioden 6.400 - 5.900 v. Chr. und $7.600-7.000$ v. Chr. war infolge eines feuchteren Sommerklimas die Humifizierung deutlich niedriger und damit der Zuwachs des Sediments höher, ähnlich wie beim Moor bei der Schönwieshütte.

Diese Phasen können nach Vorren et al. (1993) sehr gut mit Gletscherhochständen korreliert werden und entsprechen dem frühen Sub-Atlantikum, dem Rotmoos I- und dem Frosnitz-Stadial. Besonders interessant ist bei diesem Profil die Erfassung der Holzkohlepartikel, welche direkte Schlüsse auf die menschlichen Aktivitäten zulassen.

\section{Profilbesprechung}

Das Profil beginnt in $140 \mathrm{~cm}$ Tiefe mit einer NBP-reichen Phase, die im Präboreal liegt und für den Standort Waldfreiheit anzeigt (Abb. 7). Diese kühle Phase kann der Venediger Schwankung (Patzelt 1973) zugeordnet werden. In $132 \mathrm{~cm}$ Tiefe etwa um 7.700 v. Chr. beginnt die Wiederbewaldung des Gebietes der Gurgler Alm, die geschlossene Picea-Kurve um $5 \%$ belegt ihr Vorkommen in diesen Höhenlagen. Die Pinus cembra-Dominanz im Bereich der Gurgler Alm erstreckt sich über das gesamte Profil. Am Standort war Pinus cembra aber nur bis $1.300 \mathrm{v}$. Chr. vorhanden. Dann nehmen die NBP so 
S. Bortenschlager

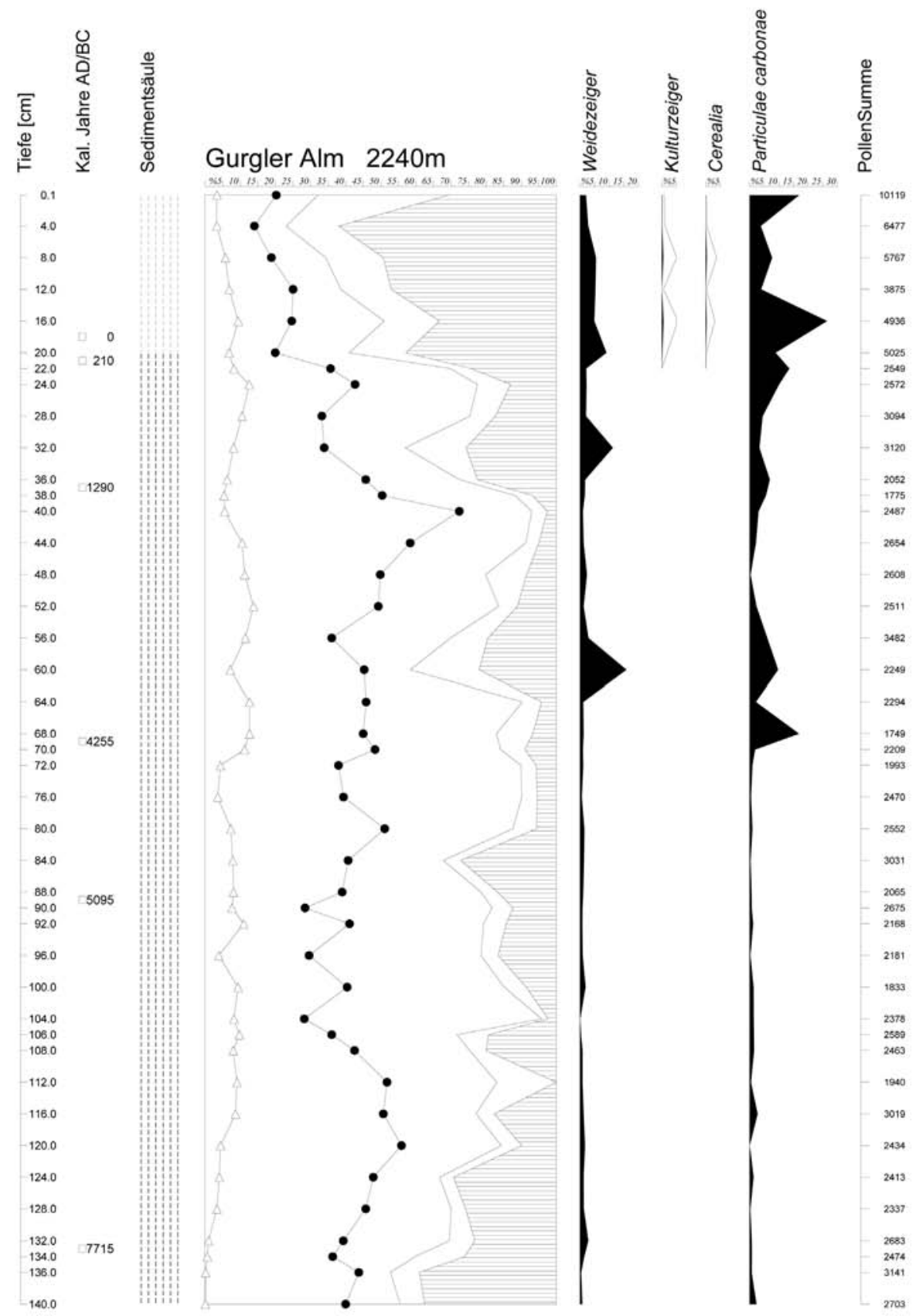

Abb. 7:

Vereinfachtes Pollenprofil - Moor bei der Gurgler Alm (Legende in der Beilage, ebenso das Gesamtprofil) 
stark zu, dass für das Gebiet Waldfreiheit angenommen werden muss. Eine Änderung der Pollenspektren zeichnet sich in etwa $75 \mathrm{~cm}$ Tiefe ab: Pinus cembra nimmt ab, Picea zu, parallel dazu treten die Holzkohlereste sehr stark in Erscheinung. Hier begann der Mensch mit der Brandrodung für die Weidegewinnung. Dies wird auch durch den gering zeitverzögerten Anstieg der Weidezeiger belegt. Mit dem Datum 4.255 v. Chr. sind diese Ereignisse zeitlich fixiert. Nach Vorren et al. (1993) erleidet diese intensive Weidewirtschaft eine Unterbrechung zwischen $2.000-1.500$ v. Chr. $(52-38 \mathrm{~cm})$ und $600-200 \mathrm{v}$. Chr. $(28-22 \mathrm{~cm})$. In beiden Abschnitten steigt die Kurve von Pinus cembra an. Die NBP, vor allem die Weidezeiger, nehmen stark ab. Dazwischen liegt eine Phase mit deutlich erhöhten Werten der Apokraten, was eventuell auf eine permanente Sommerbesiedelung, sogar auf eine Überwinterung, schließen lässt. $\mathrm{Ab} 20 \mathrm{~cm}$ Tiefe nehmen die NBP sprunghaft zu, die Weidewirtschaft und die Brandrodungen werden intensiviert. Der eher gleichmäßige Verlauf der Pollenkurven von Picea, Larix, Salix und Alnus (Waldbildner in etwas tieferen Lagen) zeigt, dass Aktivitäten zur Weidegewinnung nur direkt an der Waldgrenze gesetzt wurden. Die teils abrupten Schwankungen der Pollenkurve von Betula werden als Sukzessionsstadien von Betula nach Lawinenereignissen in nächster Nähe des Standortes interpretiert.

Die intensive Nutzung der Landschaft in tieferen Lagen, seit der Römerzeit, wird durch den Fernflugpollen von Cerealia, Juglans und Castanea belegt.

\section{Schlussfolgerungen}

Die pollenanalytisch - vegetationsgeschichtlichen Untersuchungen im Gebiet des Rotmoostales zeigen, dass nach dem Ende der Jüngeren Dryas, zu Beginn des Holozäns, die Waldgrenze schon in dieser Höhe anzutreffen ist. Das lässt die Schlussfolgerung zu, dass bereits im Alleröd im inneren Ötztal Bäume wachsen konnten und dass der Gletschervorstoß in der Jüngeren Dryas, der über Sölden hinaus reicht, in bewaldetes Gebiet vordrang.

Weiters belegen die Befunde, dass im gesamten Holozän die Waldgrenze im Bereich der untersuchten Moore lag, mit einem Schwankungsbereich von 200 bis 250 Höhenmetern. Für größere klimabedingte Waldgrenzschwankungen konnten keine Anzeichen gefunden werden.

Die Höhenlage der Waldgrenze wird durch die Temperatur der Vegetationsperiode festgelegt, die in den Hochlagen auf ca. Mai bis September beschränkt ist. Sie wird in erster Linie durch den Wärmemangel bestimmt, der ein Ausreifen der Neutriebe verhindert. Sie wird deshalb auch als Wärmemangelgrenze bezeichnet. Schwankungen der Waldgrenze sind daher auf Klimaschwankungen zurückzu- 
führen, solange eine weidewirtschaftliche Nutzung im Waldgrenzbereich ausgeschlossen werden kann.

Eindeutige Belege für die Weidewirtschaft in diesem Raum finden sich ab 4.000 v. Chr. Ab diesem Zeitpunkt treten sowohl die Weidezeiger in stark erhöhtem Ausmaß auf, aber auch die Holzkohlenreste sind Zeugen für Brandrodungen zur Gewinnung von Weideflächen. Ab 1.000 v. Chr. nehmen Zeiger für eine Almnutzung und Sommersiedlung deutlich zu. Kurz vor der Zeitenwende treten die anthropochoren Pflanzen so deutlich in Erscheinung, dass sie ein Zeichen für eine Dauersiedlung sein könnten.

\section{Literatur}

Baig, M. N., Tranquillini, W. \& Havranek, W.M. (1974) Cuticuläre Transpiration von Picea abies und Pinus cembra Zweigen aus verschiedener Seehöhe und ihre Bedeutung für die winterliche Austrocknung der Bäume an der alpinen Waldgrenze. Centralbl.ges.Forstwesen 91: 195-211.

Bortenschlager, S. (1984) Beiträge zur Vegetationsgeschichte Tirols I. Inneres Ötztal und Unteres Inntal. Ber.nat.-med.Ver. Innsbruck 71: 19-56.

Bortenschlager, S. (1993) Das höchstgelegene Moor der Ostalpen „Moor am Rofen- berg" 2760 m. Diss. Botanicae 1196: 329-334.

Bortenschlager, S. (2000) The Iceman's environment. In: The Icememan and his $\mathrm{Na}-$ tural Environment. Springer, 11-24.

Gams, H. (1948) Die Fortschritte der alpinen Moorforschung von 1932 bis 1946. ÖBZ XCIV: 235-264.

Gams, H. (1962) Das Gurgler Rotmoos und seine Stellung innerhalb der Gebirgsmoos. Veröff. Geobot. Inst. E.T.H. Stift. Rübel, Festschr. Franz Firbas. Zürich 37: 74-82.

Gams, H. (1963) Waldgrenzverschiebungen und Palynologie. Grana 4: 292-301.

Kerner, A. (1863) Pflanzenleben der Donauländer. Innsbruck.

Hanke, H. (1935) Quartärgeologische Untersuchungen im Inneren Ötztal. Jb. Geol.B.A., 85 (1/2): 191-223.

Kuoch, R. (1965) Der Samenfall 1962/63 an der oberen Fichtenwaldgrenze im Sertigtal. Mitt.schweiz.Anst.forstl.Versuchswesen, 41: 63-85.

Kutschera, W., Patzelt, G., Wild, E-M., Jettmar, B., Kofler, W., Lippert, A., Oeggl, K., Pak, E., Priller, A., Steier, P., Wahlmüller-Oeggl, N. \& Zanesco, A. (2010) Early human presence at high altitudes in Europe: Radiocarbondating at the Iceman site and other locations in the Ötztal Alps (im Druck).

Magny, M., Leuzinger, U., Bortenschlager, S. \& Haas, J-N. (2006) Tripartite climate reversal in Central Europe 5600 - 5300 years ago. Quarternary Research 65: 3-19. 
Mattes, H. (1982) Die Lebensgemeinschaft von Tannenhäher und Arve. Ber. Eidgenossische Anstalt für das forstliche Versuchswesen 241: 1-74.

Oeggl, K. (1998) Plant macrofossil record and recent vegetation along an altitudinal transect in a tree-line ecotone. Institut für Hochgebirgsforschung der Universität Innsbruck, Jahresbericht 1997: 71-83.

Rybnicek, K. \& Rybnickova, E. (1977) Mooruntersuchungen im Oberen Gurgltal, Ötztalere Alpen. Folia Geobot.Phytotax.12: 245-291.

Sarnthein, R. (1936) Moor- und Seeablagerungen aus den Tiroler Alpen in ihrer waldgeschichtlichen Bedeutung I. Teil:Brennergegend und Eisacktal. Beih. bot.Centralbl., LV: 544-631.

Vorren, K.-D., Morkved, B. \& Bortenschlager, S. (1993) Human impact on the Holocene forest line in the Central Alps. Vegetation History and Archaeobotany 2: 145-156.

\section{Verzeichnis des Autors}

Sigmar Bortenschlager

Universität Innsbruck

Institut für Botanik

Sternwartestr. 15, 6020 Innsbruck, Österreich

Sigmar.Bortenschlager@uibk.ac.at 


\title{
Kapitel 5 I Die Böden eines alpinen Gletschertales
}

\author{
Erich Schwienbacher, Eva-Maria Koch
}

\section{Zusammenfassung}

Die Bodenentwicklung ist eines der deutlichsten Merkmale der Primärsukzession. In erster Linie ist sie eine Funktion der Zeit, wobei zahlreiche Faktoren und Prozesse die Richtung und Geschwindigkeit der Genese bestimmen: das Ausgangsmaterial, welches Gefüge, Mineralbestand und Körnung des Bodens beeinflusst, das Klima, wobei hier vor allem Temperatur und Niederschlag zu den wichtigsten Parametern der Bodengenese zählen, und die Verwitterung, vor allem jene durch physikalische Prozesse. Auch Vegetation, Bodenfauna und Bodenmikroorganismen zählen zu den Boden prägenden Faktoren. Heterogene Verhältnisse im Bezug auf Substrat, Relief, Wassereinfluss, Mikroklima, Oberflächenstruktur sowie Erosionserscheinungen führen zu einem Verwischen des Zeitgradienten. Ausgangspunkt der Sukzession im Gletschervorfeld des Rotmoostales sind Rohböden, die sich zu Pararendzinen weiterentwickeln. Im Einflussbereich von Bächen entstehen Schwemmböden, außerhalb des Gletschervorfeldes finden sich Braunerde- und Podsolböden. Die Bodenreaktion im Gletschervorfeld ist aufgrund unterschiedlicher Ausgangsgesteine heterogen, jedoch lässt sich mit zunehmendem Alter eine Versauerung beobachten. Bezüglich der Bo- denelemente ist vor allem die Zunahme der organischen Substanz als deutlichstes Merkmal der Bodenentwicklung zu erkennen.

\section{Abstract}

For primary succession, soil development is one of the most significant characteristics. Predominantly it is a function of time, whereas the direction and speed of soil genesis is affected by numerous different factors and processes: parent rock material, which causes structure, mineralogical composition and grain size of soil, climate, especially temperature and precipitation, and weathering, mainly because of physical processes. Also vegetation, soil fauna and microorganisms are soil formative factors. Heterogeneous circumstances in substrate, relief, water influence, microclimate, surface structure and erosion obscure the time gradient partly. The succession in the glacier foreland of the Rotmoosvalley starts with virgin soils (Regosol), which develop further into ,Pararendzina' (Rendzic Leptosol). In the near of streams alluvial soils (Fluvisol) are formed, whereas outside the glacier foreland ,Braunerde' (Cambisol) and ,Podsol' (Podzol) dominate. Different rock material within the foreland causes a high variation of soil reaction, though generally soil is getting more acid with increa- 
sing age. Concerning soil elements the increase of organic matter is most relevant.

Forschungsgeschichte

Die „Dicke der Erdkrume in den Alpen“ beschäftigte bereits die Pioniere der Alpenerforschung wie die Brüder Schlagintweit, die in ihrem umfassenden Werk über die Alpen auch von ihren Forschungsaufenthalten im Hinteren Ötztal berichten (Schlagintweit und Schlagintweit 1850). Sie liefern bereits detaillierte Angaben zu Verwitterungsprozessen und dem Humusgehalt der Böden. Die ersten umfangreichen Untersuchungen der Böden im Raum Obergurgl wurden Mitte des 20. Jahrhunderts in der subalpinen Stufe von Poschach $(1.850 \mathrm{~m}$ bis $2.300 \mathrm{~m})$ durchgeführt. Neuwinger und Czell (1959) beschrieben dabei 18 unterschiedliche Bodenformen sowie mehrere Entstehungsreihen in Wechselbeziehung mit dem Relief und der vorhandenen Vegetation. Im Rahmen des UNESCOProgramms „Man and Biosphere“ (MaB) folgte dann eine detaillierte Kartierung der alpinen Böden im Bereich der Hohen Mut (Neuwinger 1987), welche von Starnberger (2006) durch weitere Bodenuntersuchungen im Gebiet des Biosphärenreservats „Gurgler Kamm“ ergänzt wurde.
Die Böden der alpinen Stufe standen im Alpenraum jedoch schon länger im Interesse der Forschung (z.B. Braun-Blanquet und Jenny 1926). Vor allem die Bodenentwicklung im Laufe der Primärsukzession der Gletschervorfelder war eine zentrale Fragestellung zahlreicher Studien in den Alpen (Friedel 1934, Friedel 1938a, 1938b, Lüdi 1945), aber auch in anderen vergletscherten Gebieten der Erde (Crocker und Major 1955, Crocker und Dickson 1957). Der Tradition dieser Pionierarbeiten folgend, untersuchte auch Jochimsen (1962) erstmals die Bodenverhältnisse in den Gletschervorfeldern des Rotmoos- und des Gaisbergferners, die sie in Relation zu den Vegetationsverhältnissen beschrieb. Obwohl in Folge auch die Böden im Gaisbergtal noch öfters untersucht wurden (Duelli 1987, Wiedemann 1991), stand in den letzen 20 Jahren vor allem das Rotmoostal im Mittelpunkt der wissenschaftlichen Forschung.

Erschbamer et al. (1999) untersuchten erstmals gezielt die Bodenentwicklung entlang der Chronosequenz im Gletschervorfeld des Rotmoosferners im Vergleich zur Vegetationsentwicklung, während Kaufmann et al. (2002) die Bodenentwicklung mit der Sukzession der Bodenfauna verglich. Schwienbacher (2004) lieferte eine umfangreiche Darstellung der potentiellen Bodenreaktion vom Gletschervorfeld des Rotmoosferners und bestätigte damit die Unterschiede in den Bodenverhältnissen und dem Sukzessionsverlauf zwischen den beiden 
Talseiten, welche bereits früher schon von anderen Autoren angeführt wurden (Jochimsen 1962, 1970, Rudolph 1991, Raffl 1999, Mallaun 2001, Kaufmann 2001). Neben den Änderungen der bodenphysikalischen und -chemischen Eigenschaften entlang der Chronosequenz war auch die mikrobielle Bodenaktivität ein zentrales Thema wissenschaftlicher Studien. Nachdem bereits Insam und Haselwandter (1989) erstmals die Bodenatmung von Böden unterschiedlichen Alters im Rotmoostal analysierten, folgten rund 15 Jahre später weitere Studien zur Aktivität und Diversität der mikrobiellen Gemeinschaften (Tscherko et al. 2003, 2004, 2005, Nicol et al. 2005, 2006, Kandeler et al. 2006, Deiglmayr et al. 2006). Es wurden aber nicht nur die bakteriellen Mikroorganismen untersucht, auch die Pilzgemeinschaften der Böden wurden analysiert. Zahlreiche Studien lieferten einen detaillierten Einblick in die Diversität und die Bedeutung der Mykorrhizapilze in den Böden des Rotmoostales (vgl. Kap. 9).

Das Rotmoostal, und hier vor allem das Gletschervorfeld des Rotmoosferners, zählen wohl auch hinsichtlich der Bodenverhältnisse zu den am besten untersuchten Primärsukzessionen weltweit. Dieses fundierte Wissen bildet auch die Basis für zahlreiche neue Fragestellungen zur Bodengenese und zur Rolle des Bodens, welche auch in Zukunft für die wissenschaftliche Erforschung dieses Ökosystems spannende Herausforderungen dar- stellen. Ein Reihe aktueller internationaler Studien zu verschiedenen Aspekten des Ökosystems Boden in der Primärsukzession von Gletschervorfeldern belegen die Aktualität dieses Forschungsbereichs (z.B. Egli et al. 2006a, 2006b, Haugland und Haugland 2008, Dolezal et al. 2008, He und Tang 2008, Strauss et al. 2009, Mahaney et al. 2009, Lazzaro et al. 2009).

\section{Die Bodenentwicklung entlang der Chronosequenz}

In der Sukzessionsforschung wird häufig mit der Chronosequenz als Skala für die Entwicklung gearbeitet, d.h. man untersucht an Stelle einer zeitlichen Entwicklung eines Stadiums einer bestimmten Lokalität, eine räumliche Abfolge von Stadien unterschiedlichen Alters. In der Literatur wird diese Methode auch mit den Begriffen „space for time-substitution“ oder "location for time-substitution“ bezeichnet (Matthews 1992). Dieser Ansatz hat nur unter bestimmten Bedingungen Gültigkeit, und daher finden sich in der Literatur auch eine Reihe von kritischen Anmerkungen zu diesem Forschungsansatz (siehe Review in Johnson und Miyanishiate 2008). Trotzdem hat sich diese Herangehensweise vor allem aus praktischen Gründen bewährt und wurde in der Erforschung von Primärsukzessionen weltweit erfolgreich angewandt: 
z.B. in Sanddünen (Lichter 1998), auf Vulkanen (Aplet et al. 1998) und in Gletschervorfeldern (Matthews 1992). Auch bei der Untersuchung der Bodengenese in Gletschervorfeldern wurde dieser Ansatz bereits in der klassischen Arbeit von Crocker und Major (1955) benutzt, in Folge vielfach aufgegriffen (siehe Review in Stevens und Walker 1970) und findet bis heute weltweit Anwendung z.B. in aktuellen Studien in China ( $\mathrm{He}$ und Tang 2008), in Japan (Dolezal et al. 2008), in Venezuela (Mahaney et al. 2009) und auch in der Antarktis (Strauss et al. 2009). Diese Vorgehensweise ist vor allem dann aussagekräftig, wenn eine räumlich möglichst klar getrennte Abfolge von Moränen bekannten Alters vorliegt, wie dies im Rotmoostal der Fall ist (vgl. Kap. 7). Man sollte sich jedoch bewusst sein, dass die Bodenentwicklung zwar in erster Linie eine Funktion der Zeit ist (Mückenhausen 1993), jedoch zahlreiche weitere Faktoren die Bodenentwicklung prägen und verschiedenste Prozesse auch im Modellgebiet Rotmoostal zum „Verwischen“ des Zeitgradienten führen können (Mallaun 2001).
Prägende Faktoren und Prozesse der Bodengenese

\section{Ausgangsmaterial}

Das Ausgangsmaterial beeinflusst Gefüge, Mineralbestand und Körnung des Bodens und somit Richtung und Geschwindigkeit der Entwicklung (Scheffer und Schachtschabel 1998). Der Gletscher transportiert durch die Fließbewegung unterschiedliches Schuttmaterial. Dieses wird an der Gletscherstirn, am Rand und im Zehrgebiet vorwiegend unsortiert ab- und eventuell durch Schmelzwasser wieder umgelagert (vgl. Kap. 2). Dieses Material ist meist skelettreich, jedoch kann die Korngrößenverteilung bereits am Beginn der Bodengenese beträchtlich variieren. So unterscheiden sich die Anteile des Feinbodens verschiedener Pionierstandorte im Rotmoostal signifikant voneinander (Abb. 1.B). Auf Grund der heterogenen geologischen Verhältnisse, wie sie im hinteren Rotmoostal, aber auch im Gaisbergtal vorherrschen, ist dieses Material aus unterschiedlichen Gesteinen zusammengesetzt (vgl. Kap. 2). Es überwiegen sauer verwitternde Paragneise und mineralreiche Glimmerschiefer, jedoch ist das Material der Moränen im Rotmoostal durch den Einfluss der Gesteine des Schneeberg Komplexes im südlichen Talbereich karbonatreich. 


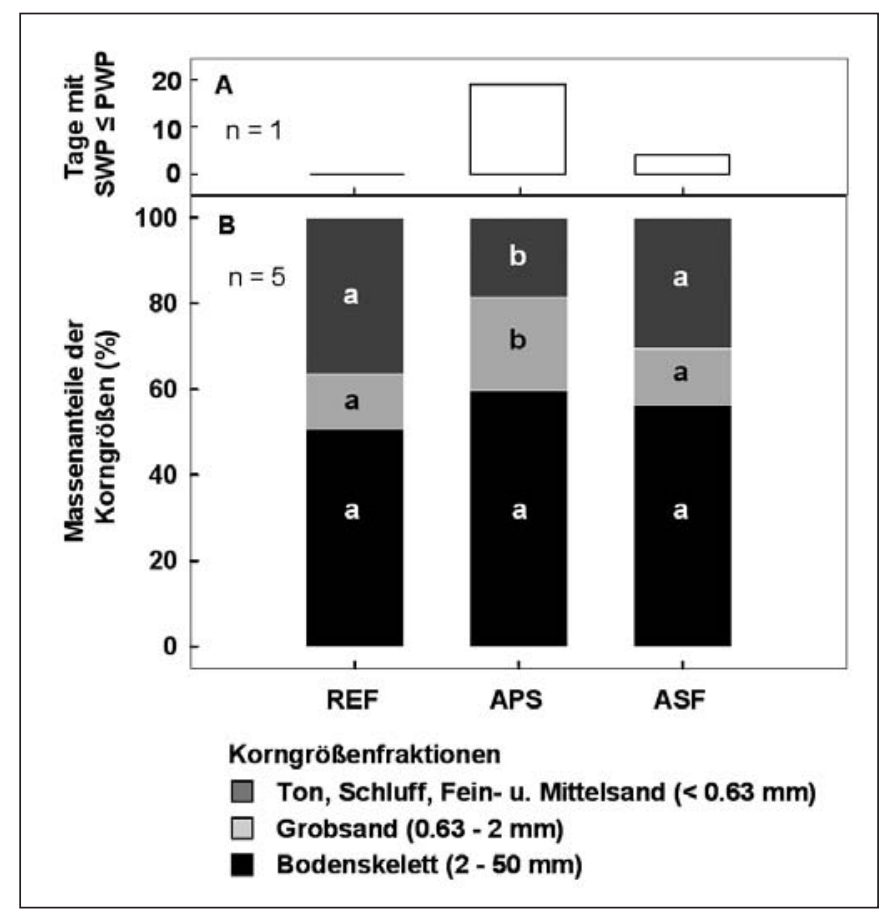

Abb. 1:

(A) Anzahl der Tage, an denen das Bodenwasserpotential (SWP) den permanenten Welkepunkt (PWP) von $-1,5 \mathrm{MPa}$ in einer Bodentiefe von $3 \mathrm{~cm}$ während der Vegetationsperiode 2008 an unterschiedlichen Pionierstandorten erreichte. (B) Korngrößenanteile des Feinbodens und Anteil des Bodenskeletts von Rohböden der Pionierstandorte (Probentiefe $10 \mathrm{~cm}$ ). REF - Rezent eisfreie Fläche (2003er Moräne); APS - Alter Pionierstandort (1971er Moräne); ASF - Alluviale Schwemmfläche des Bachbetts (zuletzt vor ca. 15 Jahren überschottert). Unterschiedliche Buchstaben kennzeichnen signifikante Unterschiede innerhalb einer Korngrößenfraktion.

\section{Klima und Relief}

Temperatur und Niederschlag zählen zu den wichtigsten Parametern der Bodengenese. Eine Charakterisierung dieser beiden klimatischen Faktoren für den Raum Obergurgl liefert Kapitel 3. Im Gebirgsraum werden diese beiden Fakto- ren durch das Relief zum Teil erheblich modifiziert. Neuwinger (1987) bezeichnete das Relief sogar als den maßgeblich prägenden Faktor bei der Ausbildung der Böden im Raum Obergurgl. Die Wirkung des Reliefs besteht vor allem darin, dass es alle weiteren Boden bildenden Faktoren durch die Höhenlage, die Exposition und die Geländeform modifiziert (Scheffer und Schachtschabel 1998). Dies gilt sowohl für die Schwerkraft, als auch für die Wasserführung und die klimatischen Einflüsse. So ist im Rotmoostal, neben der eigentlichen Wirkung der Exposition, die Besonnungsdauer auf den Nord- bis Nordost exponierten Hängen der orographisch linken Talseite (Abb. 2, Abb. 3) gegenüber den durchwegs Süd- bis Südwest gerichteten Seitenhängen der rechten Talseite entlang des Hohen Mut Rückens (Abb. 4, Abb. 5) deutlich reduziert. Dies ist eine Folge der Horizontüberhöhung durch die Gipfel des südlichen Talschlusses (Kaufmann 2001, Raffl et al. 2006). Die Gipfel am Zentralkamm befinden 


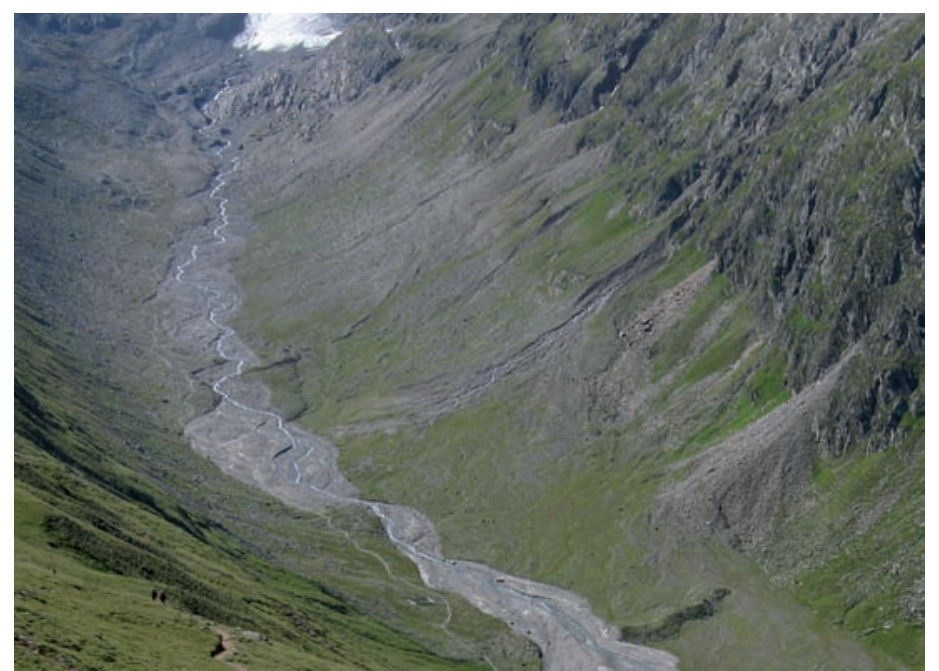

Abb. 2:

Innerer Talbereich des Rotmoostales - orographisch linke Seite des Rotmoos-Gletschervorfeldes mit zahlreichen Schuttkegeln am Hangfuß und mit episodisch überrieselten, von Rinnen durchzogenen Schwemmfächern im Talboden. Im unteren, rechten Bildbereich der Moränenwall der markanten Endmoräne aus dem Jahr 1858. (Foto: E. Schwienbacher)

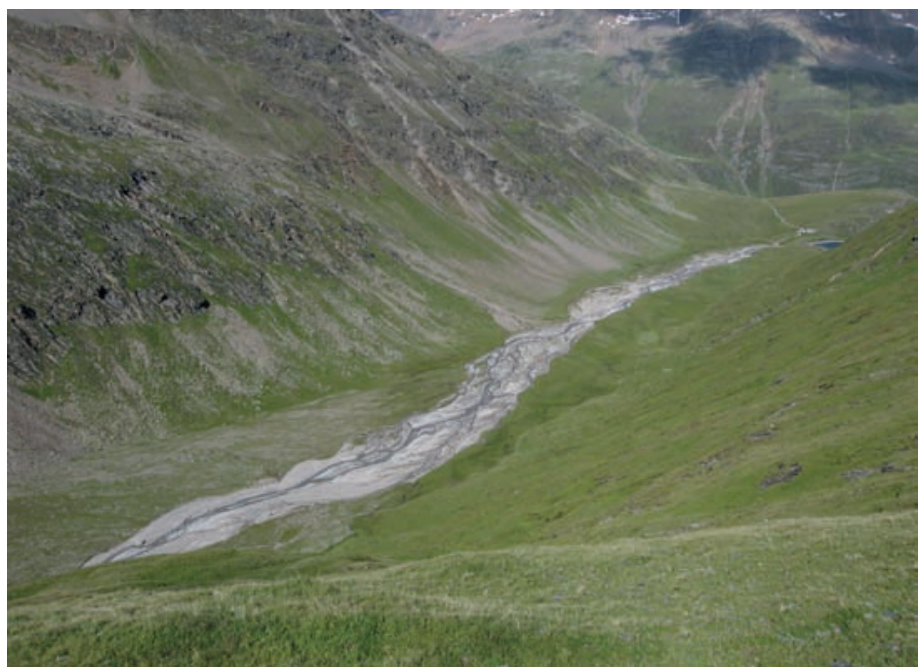

Abb. 3:

Äußerer Talbereich des Rotmoostales mit dem nordostexponierten Unterhang des Hangerers auf der orographisch linken Seite (linke obere Bildhälfte) und den ausgeprägten Bachalluvionen der Rotmoosache, die auf der rechten Talseite bis zum Rotmoosmoor reichen (Bildmitte). Am Talausgang unterhalb der Senke das Schönwiesmoor, das nach Norden in den Schönwieskopf übergeht (obere rechte Bildhälfte).

(Foto: E. Schwienbacher) 


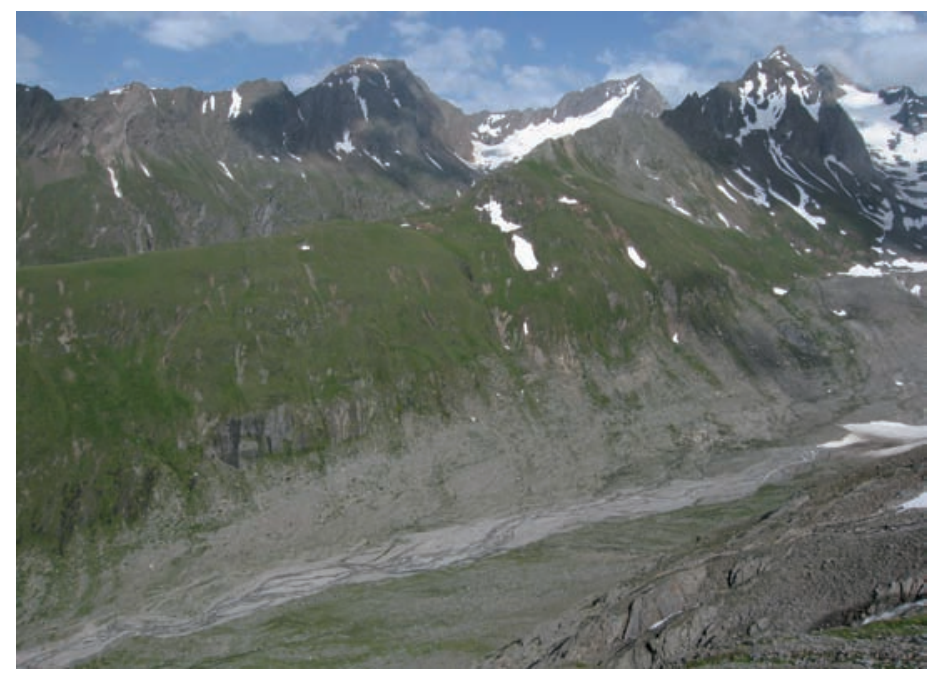

Abb. 4:

Innerer Talbereich des Romtoostales mit dem Hohe Mut Rücken auf der orographisch rechten Seite (Bildzentrum), der nach Südosten in den Kamm des Kirchenkogels übergeht. Am Unterhang hebt sich das Gletschervorfeld des Rotmoosferners anhand des Gerölls deutlich von den darüberliegenden, vegetationsbedeckten Seitenhängen ab. (Foto: E. Schwienbacher)

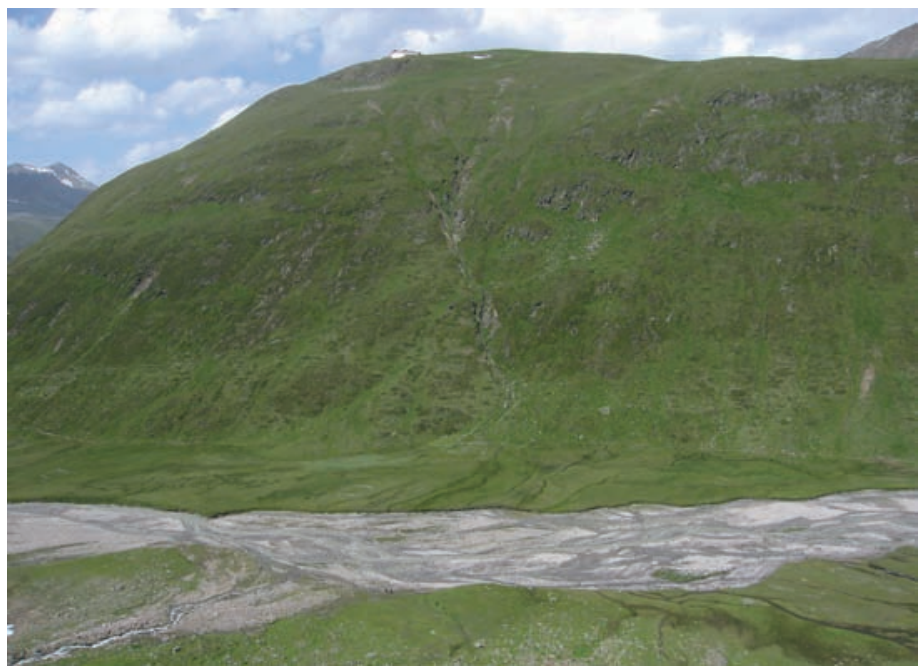

Abb. 5:

Äußerer, orographisch rechter Talbereich des Rotmoostales mit den von der Hohen Mut herabführenden, wärmebegünstigten, süd- bis südwestexponierten Hängen, wo sich auf Braunerdekolluvien gras- und krautreiche Zwergstrauchgesellschaften ausgebildet haben (Neuwinger 1987). Im Talboden finden sich kleinere Schwemmfächer, die in das große Rotmoosmoor übergehen, welches von der Rotmoosache mit ihren ausgeprägten Bachalluvionen nach Süden begrenzt wird.

(Foto: E. Schwienbacher) 
sich außerdem häufig im Einflussbereich einer Föhnmauer (vgl. Kap. 3), die zur Beschattung des Talschlusses führt, während der Großteil des Tales noch vom Sonnenschein profitiert. Gleichzeitig scheint die Bewindung auf den zum Rotmoostal abfallenden Hängen der Hohen Mut gering zu sein, da sie im Lee der vorherrschenden Höhenströmung aus Nordwest liegen (Neuwinger 1987). Niederschlagsmengen, Sonnenscheindauer und Bewindung wirken sich auf die Schneemächtigkeit, den Ausaperungszeitpunkt, die Energiebilanz und in Folge auch auf die Bodenentwicklung aus.

\section{Verwitterung}

Im Hochgebirge nimmt die physikalische Verwitterung bedingt durch häufigere Temperaturextreme zu, während biologisch-chemische Verwitterungsprozesse vor allem auf Grund der niedrigen Temperaturen und der langen Schneedeckung langsamer verlaufen (Veit 2002). Dies gilt im verstärkten Ausmaß für vegetationsfreie Pionierstandorte. Diese Standorte sind häufiger Gefrier-Tau-Zyklen ausgesetzt, da die isolierende Vegetationsschicht fehlt und sich die Rohböden bei starker Sonneneinstrahlung rasch erhitzen und in

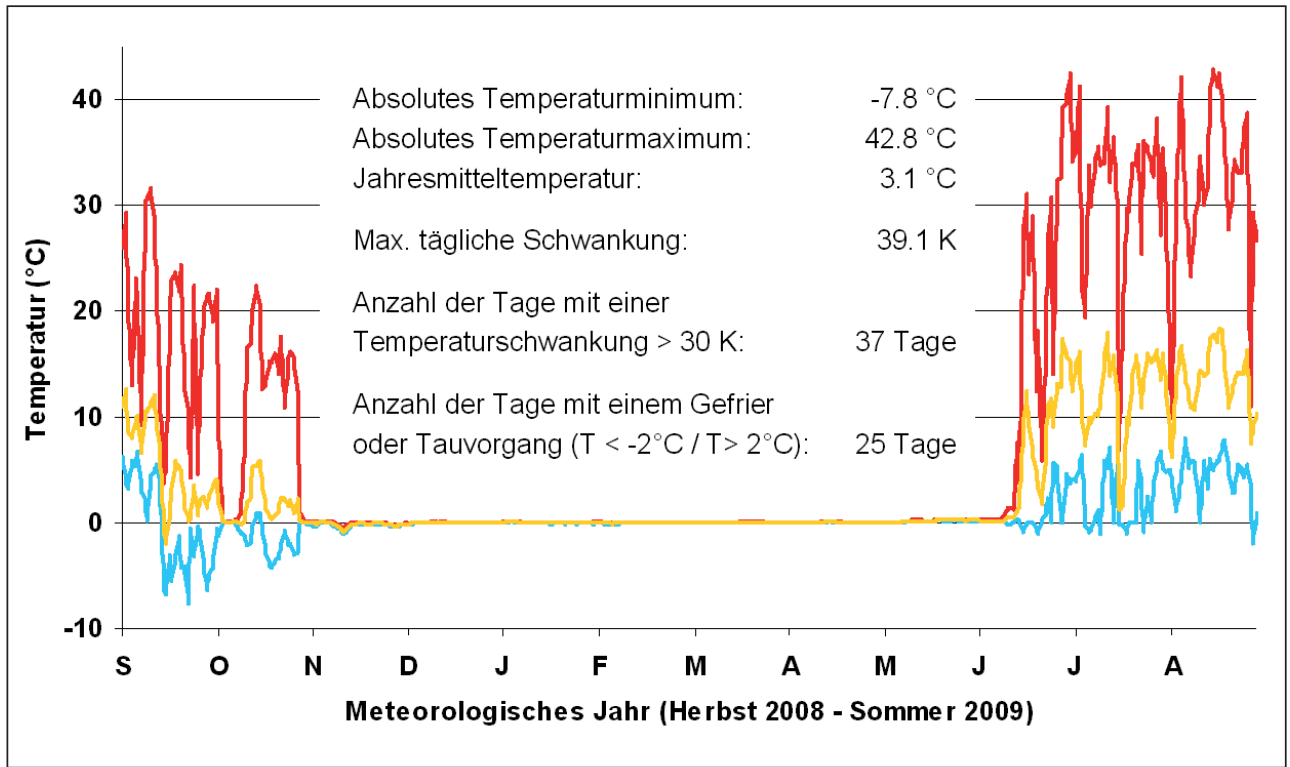

Abb. 6:

Jahresgang der Bodenoberflächentemperatur eines Pionierstandortes im Gletschervorfeld des Rotmoosferners (1971er Moräne). Dargestellt sind Tagesminimum (blau), -mittelwert (orange) und -maximum (rot). (Quelle: AG Stressphysiologie und Klimaresistenz u. AG Geobotanik, Institut für Botanik, Univ. Innsbruck, unpubl. Daten) 
der Nacht schnell auskühlen. Frostsprengungen treten vor allem im Herbst, teilweise auch im Frühjahr auf, wenn noch keine mächtige Schneedecke ausgebildet ist bzw. bereits wieder fehlt (Abb. 6). Weiters zählen auch Temperatursprengungen zu den dominierenden Verwitterungsprozessen, da Temperaturschwankungen von 30 - $40 \mathrm{~K}$ innerhalb eines Sommertages, vor allem auf offenen Rohböden, regelmäßig vorkommen (Abb. 6).

Der Grad der Verwitterung bestimmt die Verteilung der Korngrößen und beeinflusst somit wesentlich die physikalisch-chemischen Eigenschaften des Bodens. Kleinräumig heterogene Ausgangssituationen (Substrat, Relief, Wassereinfluss, Mikroklima, Oberflächenstruktur) sind charakteristisch für die Verhältnisse im Gletschervorfeld. Gemeinsam mit weiteren Boden bildenden Faktoren, vor allem der Vegetation, der Bodenfauna und der Bodenmikroorganismen, bestimmen sie die Verwitterungsgeschwindigkeit und die Dauer bis zur Ausbildung eines initialen Humushorizontes. Mit zunehmender Mineralisation und Humusanreicherung werden die physikalisch-chemischen Eigenschaften vom entstehenden Bodentyp und dem Bodengefüge geprägt (Mückenhausen 1993).

Abb. 7:

\section{Erosion}

Die Entwicklung des Bodens läuft im Hochgebirge nicht ungestört ab. So ist der Faktor Zeit zwar wesentlich, jedoch wird diese gerichtete Entwicklung häufig unterbrochen oder in ein früheres Stadium zurückversetzt. Im Gletschervorfeld sind Störungen geradezu charakteristisch. Kontinuierliche Erosionserscheinungen, bedingt durch Wind und Was-

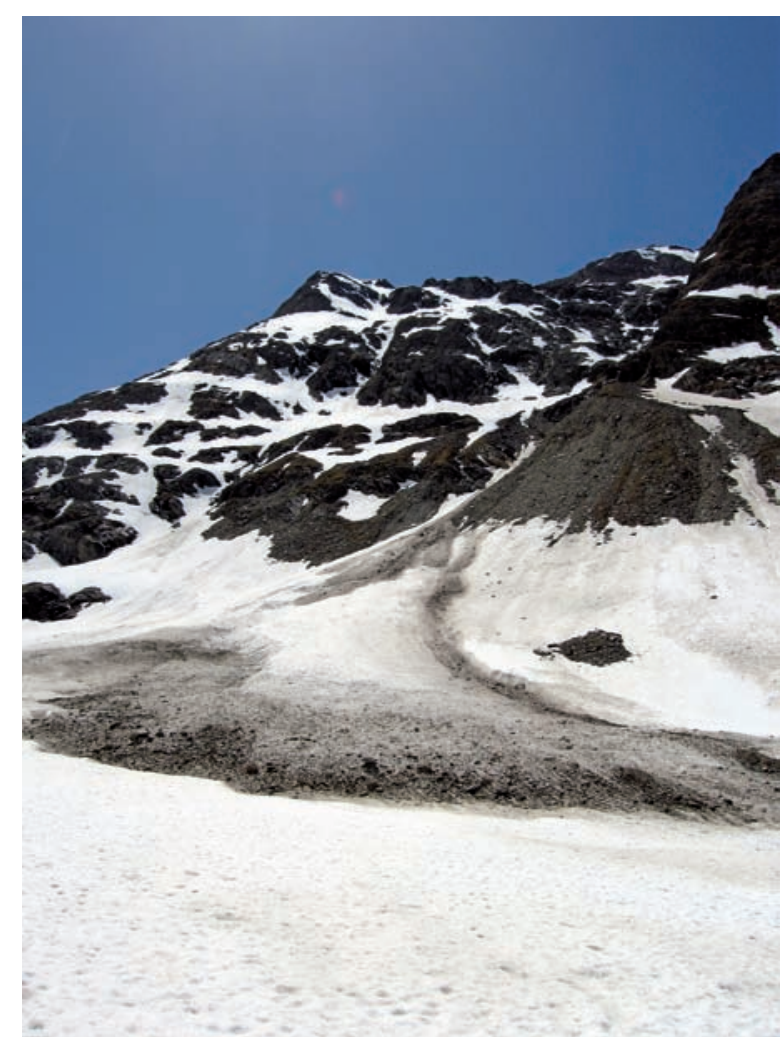

Lawinenkegel im inneren Bereich des Rotmoostales. Mit dem Schnee werden auch größere Mengen an Boden- und Pflanzenmaterial von den Seitenhängen in das Gletschervorfeld transportiert. (Foto: E. Schwienbacher) 


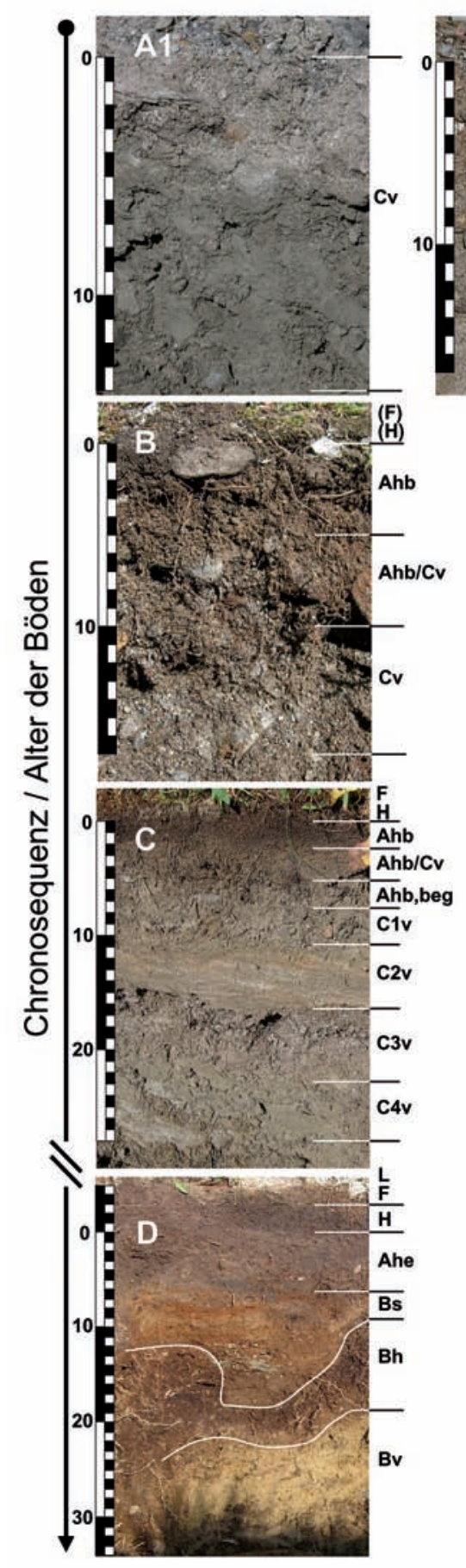

Abb. 8:

Bodentypen im Rotmoostal.

Profile unterschiedlicher Pionierstandorte (A1 - A3) und von Böden unterschiedlichen Alters $(B-D)$. Die Standorte befinden sich zwischen $2.500 \mathrm{~m}$ (A1) und $2.300 \mathrm{~m}$ ü. A. (D). Bodennomenklatur nach Nestroy et al. (2000). Interpretation der Profile mit Hilfe von Hr. DI M. Wallner u. Hr. Mag. Th. Kiebacher. (Fotos: E. Schwienbacher)

\section{Carbonathaltige Grobmaterial-Rohböden}

ohne oder mit sehr lückiger Vegetation

A1: Rezent eisfreie Fläche (Moräne 2003)

Sehr flachgründig

A2: „Alter“ Pionierstandort (Moräne 1971)

Sehr flachgründig bis flachgründig

A3: Alluviale Schwemmfläche im Rotmoostal (vor ca. 15 Jahren überschottert)

Sehr flachgründig bis flachgründig

\section{Proto-Pararendzinen}

B: Moos- und Polsterpflanzenreiche

Pioniervegetation (Moräne 1923)

Überwiegend flachgründig

C: Von Nacktried dominierter Initialrasen

(Moräne 1858)

Flachgründig

\section{Eisen-Humus-Podsol}

D: Subalpiner Bürstlingsrasen

(Schönwieskopf, ca. 10.000 Jahre eisfrei)

Mittel- bis tiefgründig 
ser, aber auch größere Einzelereignisse, wie Hangrutschungen, Lawinenabgänge oder Vermurungen, führen zu Abtragungen, Um- und Überlagerungen von Bodenschichten (Abb. 7). Sie können dazu führen, dass Standorte, die bereits viele Jahrzehnte eisfrei sind, nach wie vor keinen oder nur einen rudimentären $\mathrm{Hu}-$ mushorizont aufweisen (Abb. 8.A2-A3). Diese Störungen spiegeln sich auch in der Horizontabfolge von bereits weiterentwickelten Böden wider (Abb. 8.C-D).

Felsstürze, Lawinen, Muren und episodische Überflutungen dürften, neben

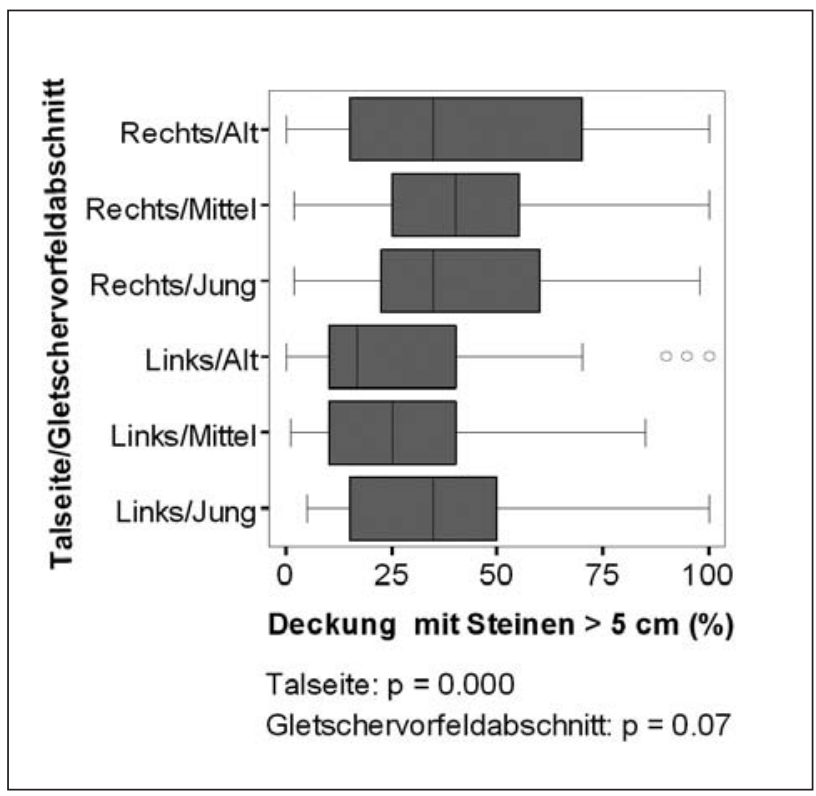

Abb. 9:

Vergleich des Grobskelettanteils der Bodenoberfläche zwischen den beiden Talseiten (orographisch links, orographisch rechts) und Gletschervorfeldabschnitten unterschiedlichen Alters. Erhoben wurden 439 Flächen á 1 m²$^{2}$. Jung: 1981er-1956er Moränen; Mittel: 1921er - 1956er Moränen; Alt: 1858er - 1921er Moränen (Quelle: verändert nach Schwienbacher 2004). den geomorphologischen Gegebenheiten, auch hauptrerantwortlich für die Unterschiede im Sukzessionsverlauf der beiden Talseiten im Rotmoostal sein (Abb. 2, Abb. 4), da auf der orographisch linken Talseite die ÏJberformung der natürlichen Entwicklunģ wesentlich stärker ausgeprägt ist (Rıdolph 1991, Schwienbacher 2004). Obwohl auf der linken Talseite der Hangfuß von vielen Schuttkegeln überzogen ist (Abb. 2), führt der kontinuierliche Eintrag von Feinmaterial auf der meist breiteren Talsohle zum Rückgang des Grobskeletts an der Bodenoberfläche im Gletschervorfeld (Abb. 9) und die Vegetationsdeckung nimmt entlang der Chronosequenz kontinuierlich zu (Schwienbacher 2004). Dort findet man auch deutlich ausgebildete Schwemmfächer (Abb. 2), die durch zahlreiche Rinnen und Rücken zergliedert sind und die Oberflächenform der Talsohle prägen (Rudolph 1991). Auf der rechten Talseite sind diese Verebnungen vor allem in den älteren Gletschervorfeldabschnitten wesentlich kleinflächiger. Das Schutt- und Blockmaterial der Grund- sowie Seitenmoränen befindet sich großteils noch an der Bodenoberfläche (Abb. 2, Abb. 9). Mit Wasser, Schnee und 
Schutt gelangen auch Pflanzenmaterial und verschiedenste Bodenorganismen in das Gletschervorfeld, welche die Sukzession ganz wesentlich antreiben.

\section{Kolluviale Bodenbildungen}

Wird der Oberboden von Schmelzwasser durchweicht kann es bei ausreichendem Gefälle zu wiederholten Rutschungen auf den hangparallelen Gesteinsschichten kommen (Neuwinger 1987). Am Hangfuß oder in konkaven Geländeformen kommt es in Folge zur Ablagerung des humosen Bodenmaterials. Böden, die durch solche natürlichen Verlagerungsprozesse entstehen, werden Kolluvien genannt. Sie sind durch eine gestörte Horizontabfolge im Bodenprofil gekennzeichnet. Diese Phänomene sind im Rotmoostal vor allem an den Seitenhängen der Hohen Mut (Abb. 5) zu beobachten (Neuwinger 1987).

\section{Bodentypen im Rotmoostal}

\section{Rohboden}

Das Ausgangsstadium der Bodenentwicklung in der Primärsukzession eines Gletschervorfeldes, also nach Freigabe des chemisch unveränderten Substrates durch Abschmelzen des Eiskörpers, bilden Roh- böden, welche aus abgelagertem Moränenmaterial bestehen (Abb. 8.A1). Im Rotmoostal sind diese Rohböden häufig sehr flachgründig (Abb. 8.A1-A2), stellenweise tritt sogar noch der anstehende Fels zutage. Durch die Dynamik des Gletschers und des abfließenden Schmelzwassers können sich lokal auch tiefgründigere Schuttansammlungen bilden. Die Alluvionen des Gletscherbaches, die noch episodisch umgelagert werden, zeigen ebenfalls die Merkmale eines Rohbodens (Abb. 8.A3) und auch in der subnivalen und nivalen Stufe, wo sich auf Grund der kurzen Vegetationsperiode nur eine spärliche Pflanzendecke ausbildet, geht die Bodenentwicklung meist nicht über die Rohböden hinaus (Abb. 10). Trotz der unterschiedlichen Gründigkeit des teils beträchtlichen Anteils an Feinboden und des variierenden Karbonatgehalts sind im Rotmoostal alle Pionierstandorte im Gletschervorfeld und die rezenten Alluvionen der Rotmoosache den karbonathaltigen Grobmaterial-Röhboden (sensu Nestroy et al. 2000) zuzuordnen.

Bereits ein spärlicher Bewuchs mit Pionierpflanzen führt zu einem Initialstadium der Bodenentwicklung über lockerem Ausgangsmaterial. So berichteten Erschbamer et al. (1999) von Humusansammlungen unter Saxifraga aizoides Polstern auf ca. 30 Jahre eisfreien Flächen. Die Anhäufung von organischem Material erfolgt jedoch nicht lückenlos. Das Bodenprofil ist auf einen rudimentär 


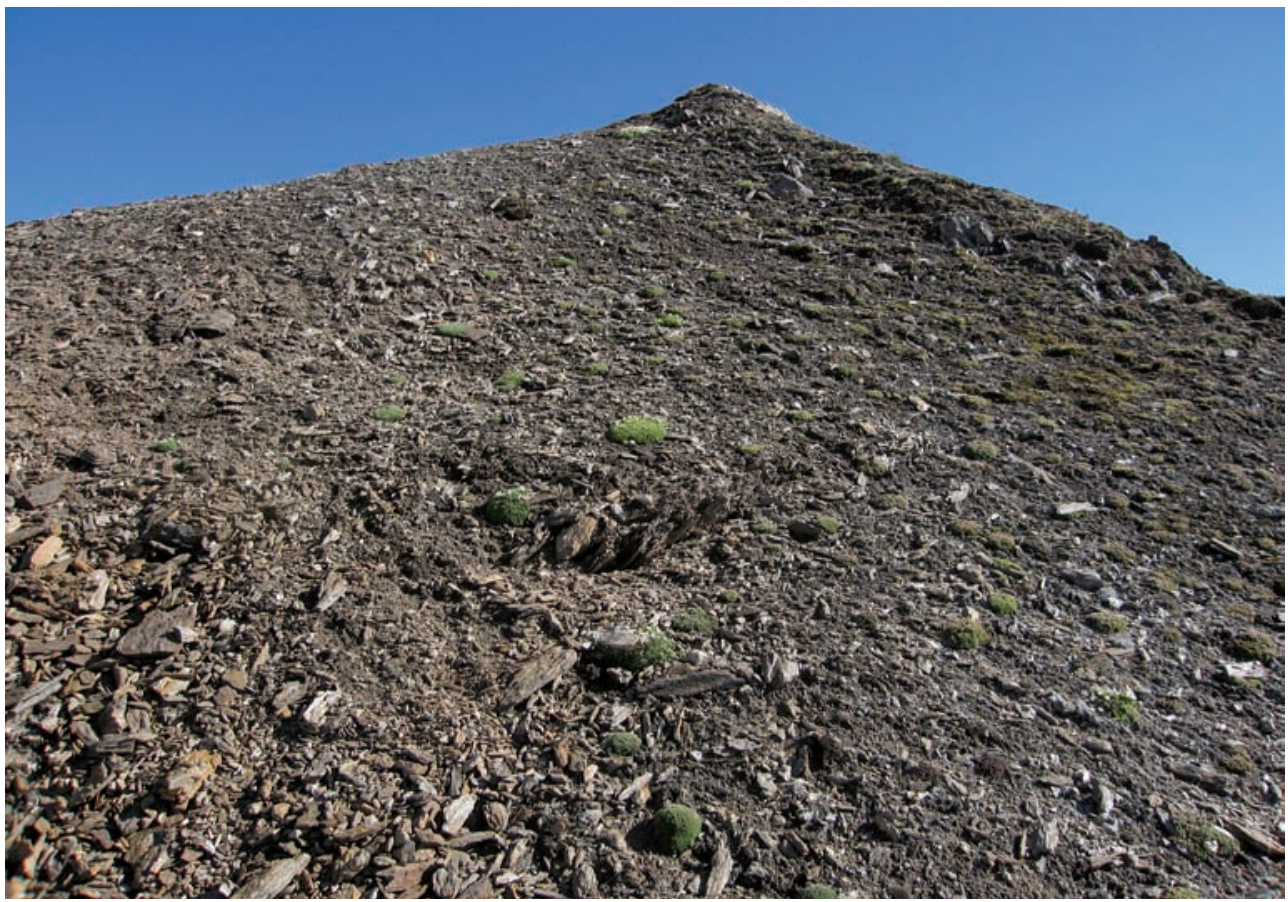

Abb. 10:

Grobmaterial-Rohboden mit spärlichem Polsterpflanzen-Bewuchs im subnivalen Bereich des inneren Rotmoostales. Der Standort befindet sich auf 3.150 m Meereshöhe im obersten Bereich der sogenannten „Liebener Rippe“, einem Felsrücken der westlich der Liebener Spitze in das Rotmoostal hinabführt.

(Foto: E. Schwienbacher)

entwickelten Humushorizont (Ai) beschränkt und ein Mineralbodenhorizont fehlt (Abb. 8.A2).

\section{Pararendzina}

Nimmt die Vegetationsdeckung deutlich zu, so kommt es zur Ausbildung eines durchgehenden A-Horizonts. Die Akkumulation von organischem Material in einem Auflagehorizont ist weiterhin kaum feststellbar, nur unter bestimmten Pflanzen wird ein Auflagehumus gebildet. Erschbamer et al. (1999) stellten auf der 1923er Seitenmoräne eine flachgründige Pararendzina mit einem mehrere Zentimeter mächtigen A-Horizont fest (Abb. 8.B). Sowohl der deutliche Karbonatgehalt im gesamten Gletschervorfeld, als auch das Vorkommen von zahlreichen kalkholden Pflanzen (vgl. Kap. 6) begründen die $\mathrm{Zu-}$ ordnung dieser Böden zur Entwicklungsreihe der Kalk-Silikat-Mischgesteine. 
Manche Rohböden bzw. A-C-Böden des Rotmoos- als auch des Gaisbergtales wurden bei fehlendem Kalkeinfluss auch als Silikatsyroseme bzw. Ranker eingestuft (Neuwinger 1987, Starnberger 2006). Die Böden auf den ältesten Moränen der orographisch rechten Seite, die bereits einen geschlossenen Initialrasen aufweisen, sind zwar etwas tiefgründiger, aber weiterhin den A-C-Böden zuzuordnen (Erschbamer et al. 1999). Hier sind auch Störungen in der Horizontabfolge festzustellen, die vermutlich auf fluviatile Ablagerungen einzelner Horizonte bzw. Materialeintrag durch Hangrutschungen zurückzuführen sind (Abb. 8.C).

\section{Schwemmboden}

Für die flachen Bereiche in der Talsohle, vor allem auf der orographisch linken Seite, die im Einflussbereich der Seitenbäche oder der längs verlaufenden Gerinne stehen (Abb. 2), sowie für die nur selten und mäßig gefluteten Bereiche entlang der Rotmoosache, sind großteils glacio-fluviatil gebildete, flach- bis mittelgründige Böden anzunehmen. Diese Bereiche werden im Hochsommer während des tageszeitlichen Anstiegs der Gletscherabflüsse regelmäßig von Schmelzwasser überrieselt. Dabei wird mittransportiertes Feinsediment abgelagert, so dass der Sandgehalt im Oberboden hoch sein dürfte. Da sich auf solchen Schwemmböden auf Grund des lockeren Pflanzenbewuchses wenig organisches Material anreichert, ist der Humushorizont typischerweise nur rudimentär entwickelt und ein eigentlicher A-Horizont fehlt. Häufig können begrabene Horizonte differenziert werden (Nestroy et al. 2000). Solche episodisch überfluteten Böden sind zu den Schwemmböden zu stellen, bei denen die Korngrößen kaum sortiert vorliegen (Nestroy et al. 2000). Eine Beschreibung eines solchen Bodentyps aus dem Rotmoostal lieferten Erschbamer et al. (1999), die einen alpinen Schwemmmboden auf der 1923er Grundmoräne beschrieben.

\section{Braunerde und Podsol}

Außerhalb des Gletschervorfeldes, das mit der End- und den Seitenmoränen von 1858 klar umgrenzt ist (vgl. Kap. 7), findet man im Rotmoostal vor allem am Seitenhang der Hohen Mut (Abb. 5) flach- bis mittelgründige A-B-C-Böden. Diese Bereiche sind zwar seit nahezu 10.000 Jahren eisfrei, aber die eigentliche Bodengenese scheint wesentlich jünger zu sein (Patzelt und Bortenschlager 1979). Auf diesen wärmebegünstigten Hanglagen kam es vermutlich auch zu einer Beeinflussung der Bodengenese durch die menschliche Bewirtschaftung (Neuwinger 1987). Beweidung dürfte die bereits unter natürlichen Umständen gegebenen abwärtsgerichteten Materialverlagerungen nochmals begünstigt haben. Dadurch entstanden die Braunerde-Kolluvien, die 
man vor allem unter kräuterreichen Weiderasen und grasreichen Zwergstrauchgesellschaften findet (Neuwinger 1987). Auf der linken Talseite, an den Nordosthängen des Hangerermassivs (Abb. 3), wurde von Starnberger (2006) ebenfalls eine flachgründige Braunerde vorgefunden, während auf Verebnungen der Hohen Mut unter Krummseggenrasen auch tiefgründige Braunerden vorhanden sind. Die Mächtigkeit dieser Böden könnte auf den Eintrag von äolisch transportiertem Feinmaterial aus vegetationsfreien Bereichen zurückgehen (Neuwinger 1987, Starnberger 2006). Die Braunerdeböden weisen im Oberhangbereich der Hohen Mut oft Pseudovergleyungen auf und gehen unter Schneebodenvegetation in Frostgleye (sensu Neuwinger 1987) über. Böden aus der Podsolserie mit deutlich ausgebildeten Profilen finden sich im Rotmoostal als pseudovergleyte Podsolkolluvien am Hangfuß der Hohen Mut (Neuwinger 1987, Abb. 5). Auch am Schönwieskopf (Abb. 3) wurde unter einem Bürstlingsrasen ein Eisen-HumusPodsol vorgefunden, der allerdings Anzeichen von Störungen im B-Horizont aufweist (Abb. 8.D). Neuwinger (1987) geht davon aus, dass die Bildung der Böden der Podsolserie zu Zeiten stattfand, als diese Bereiche noch bewaldet waren. Diese Interpretation steht im Einklang mit den Pollenfunden im Schönwiesmoor (vgl. Kap. 4).

\section{Hydromorphe Böden}

Als besondere Bodentypen der gletschergeformten Täler im Bereich von Obergurgl, wenn auch nicht in unmittelbarem Zusammenhang mit der Gletscherdynamik stehend, kommen hydromorphe Böden, vor allem An- und Niedermoore, vor. Neben den zahlreichen kleinflächigen Mooren, sind es vor allem das große Namens gebende ,Moos' am Eingang des Rotmoostales und der Moorbereich am Hangfuß des Hangerers und des Schönwieskopfs (Abb. 3), die überregionale Bedeutung erlangt haben (vgl. Kap. 4). Im Einflussbereich von stehendem bzw. langsam fließendem Grund- und Hangwasser hat sich hier, durch Anreicherung organischer Substanz unter vorwiegend anaeroben Bedingungen, ein z.T. mehrere Meter hoher Torfhorizont gebildet (vgl. Kap. 4).

\section{Bodentextur}

Die Bodentextur, oder die Körnung des Bodens, hängt vom Ausgangsgestein und dem Verwitterungsgrad ab. Zahlreiche Eigenschaften des Bodens, vor allem sein Wasser- und Lufthaushalt, werden von der Zusammensetzung der Korngrößenfraktionen bestimmt (Scheffer und Schachtschabel 1998). Der Anteil an Feinmaterial bestimmt die Wasserhaltekapazität und 


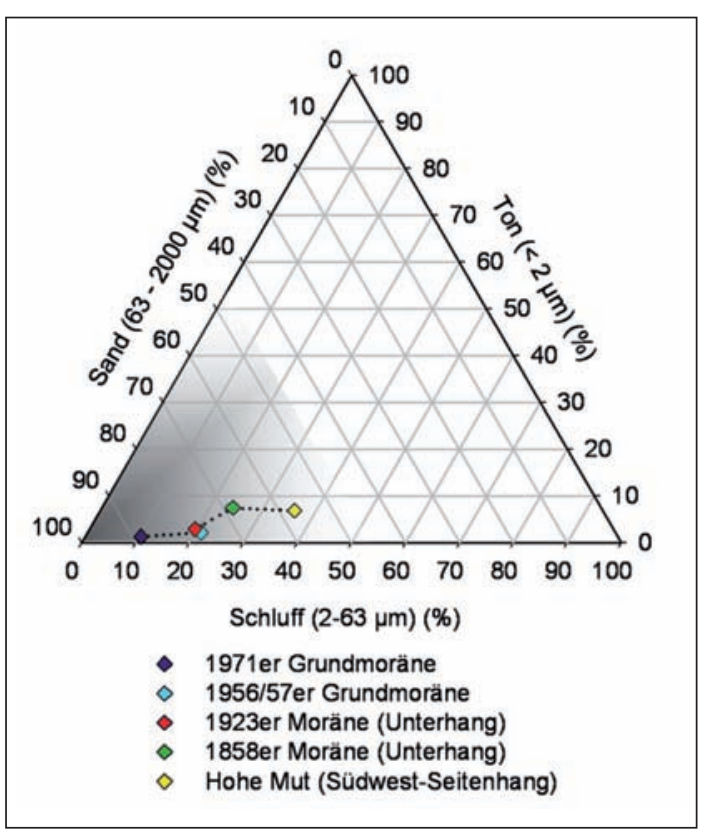

Abb. 11:

Korngrößenanteile im Feinboden auf verschiedenen Moränen entlang der Chronosequenz und einer Referenzfläche außerhalb des Gletschervorfeldes zur Charakterisierung der Bodenart. Das grau hinterlegte Eck kennzeichnet den Bereich der Sandböden (Quelle: verändert nach Erschbamer et al. 1999).

das für Organismen verfügbare Wasser. Bei den Rohböden im Rotmoostal handelt es sich um reine Sandböden und erst durch die Mineralisation organischer Bestandteile nimmt der Anteil an Schluff und Ton zu, so dass z.B. an den Seitenhängen der Hohen Mut ein Sand-SchluffBoden festgestellt wurde (Abb. 11), der eine deutlich höhere Wasserhaltekapazität aufweist. Die Bodenfeuchte beeinflusst direkt die biologische Aktivität des Stand- ortes und somit die Bodenentwicklung. Trocknet der Oberboden zu schnell und zu häufig aus, erschwert dies die Ansiedelung von Pflanzen. Dieses Phänomen konnte selbst auf seit 35 Jahren eisfreien Flächen noch beobachtet werden, wo die Keimlinge verschiedener Pionierpflanzen extrem hohe Mortalitätsraten aufwiesen (Niederfriniger Schlag und Erschbamer 2000, E. Schwienbacher, unpubl. Daten). Auf diesen nahezu vegetationsfreien Flächen überwiegte im Feinboden der Grobsand und wies einen geringeren Anteil der kleineren Korngrößen auf (Abb. 1.B, Abb. 8.A2). Im Sommer 2008 wurde an diesem Standort an 19 Tagen eine extreme Austrocknung des Oberbodens festgestellt (Abb. 1.A). Auf Rohböden mit ausreichender Bodenfeuchte siedeln sich hingegen die ersten pflanzlichen und tierischen Organismen bereits in den ersten Jahren nach Abschmelzen des Eises an (vgl. Kap. 6 und 7). Auf einem solchen Pionierstandort wurde ein höherer Anteil der kleinsten Korngrößenfraktionen $(<0,63 \mathrm{~mm})$ festgestellt und der Oberboden trocknete während der gesamten Vegetationsperiode niemals komplett aus (Abb. 1.B, Abb. 8.A1). 


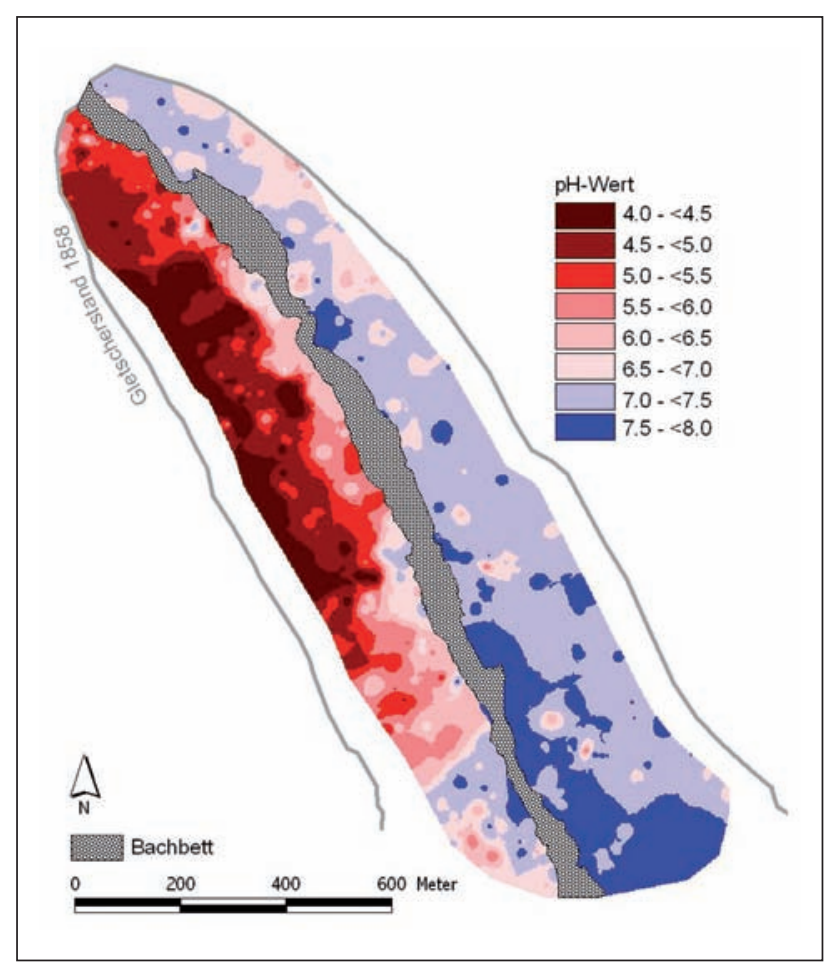

Abb. 12:

Bodenreaktion des obersten Horizonts im Gletschervorfeld des Rotmoosferners. Interpolierte Werte aus pH Messungen (0,01-m $\mathrm{CaCl}_{2}$-Suspension) von 570 Bodenproben.

(Quelle: Schwienbacher 2004)

\section{Bodenreaktion}

Die Bodenreaktion, also der Säure- und Basengehalt des Bodens, ist eine wesentliche Eigenschaft und beeinflusst entscheidend die Verwitterung, das Bodengefüge und die Verfügbarkeit von Nährstoffen (Mückenhausen 1993). Zu Beginn der Bodengenese wird die Bodenreaktion primär durch das Ausgangsgestein bestimmt. Ein Großteil des Rotmoostales fällt in die
Zone der Paragneise und mineralreichen Glimmerschiefer (vgl. Kap. 2). Auf diesen Gesteinen bildet sich im Normalfall ein saurer Humusboden aus (Reisigl 1987). Der südliche Talbereich befindet sich jedoch im Einflussbereich des Schneeberg Komplexes, wodurch die Gesteine karbonatreich sind. Dies kommt je nach Talseite und -abschnitt unterschiedlich zum Tragen. Erhebungen der potentiellen Bodenreaktion im Gletschervorfeld (Abb. 12) lieferten durchwegs geringere $\mathrm{pH}$ Werte auf der linken Talseite als auf vergleichbaren Standorten auf der rechten Talseite (Mallaun 2001, Schwienbacher 2004). Die jüngsten Moränen weisen $\mathrm{pH}$-Werte über 7,0 auf. Auf der orographisch linken Talseite nehmen diese Werte bereits auf 30 Jahre eisfreien Flächen deutlich ab und mit zunehmendem Alter der Moränen tritt eine Versauerung der Böden ein. So weisen vor allem hangnahe Bereiche $\mathrm{pH}$-Werte von 4,0 bis 4,5 auf (Abb. 12). Auf der rechten Talseite tritt diese Entwicklung wesentlich später auf und nur tiefgründigere Böden der ältesten Seitenmoränen weisen im Oberboden deutlich saure Verhältnisse auf. Als Folge dieser meist neutralen bis leicht basischen 
Böden im Gletschervorfeld, bildete sich eine Vegetation mit zahlreichen basiphilen Elementen aus (Jochimsen 1962, Rudolph 1991, Erschbamer et al. 1999, Mallaun 2001, Schwienbacher 2004, Raffl et al. 2006). Auf den Seitenhängen der Hohen Mut außerhalb des Gletschervorfeldes, auf denen Neuwinger (1987) flachgründige Braunerdekolluvien identifizierte, lag der $\mathrm{pH}$ bei 4,3 (Erschbamer et al. 1999), während Starnberger (2006) auf der gegenüberliegenden Talseite am Fuß des Hangerers in einer Braunerde eine $\mathrm{pH}$-Zahl von 4,9 ermittelte und $\mathrm{R}$. Kaufmann (Univ. Innsbruck, unpubl. Daten) am Schönwieskopf-Werte von 4,0 in einem Podsol feststellte.

Die Abnahme des pH-Wertes entlang der Chronosequenz ist charakteristisch für die Bodengenese (Matthews 1992) und bestätigt sich auch im Rotmoostal. Die pH-Werte spiegeln dabei einerseits den Grad der Bodenentwicklung wider (Erschbamer et al. 1999), andererseits wird die Bodenreaktion auch sehr stark von den vorhandenen Pflanzenarten (Crocker und Major 1955) und den mit ihnen assoziierten mikrobiellen Gemeinschaften beeinflusst. Der pH-Wert im Bereich der Rhizosphäre unterscheidet sich in späteren Sukzessionsstadien deutlich vom angrenzenden Bodenmaterial (Deiglmayr et al. 2006). Die Ausgangssituation und die Störungseinflüsse können die Änderung der Bodenreaktion ebenfalls beeinflussen. So sind die Gletschervorfeldbereiche auf der orographisch linken Talseite weitge- hend von Muren- und Schwemmkegeln der von den Gletschern nördlich des Vorderen Seelenkogels herabführenden Bächen überformt (Abb. 2). Diese Gletscher überlagern geologische Bereiche, die kaum Einlagerungen des Schneebergzugs aufweisen (Schmidegg 1932), und daher kein basisch verwitterndes Gestein eintragen. Bei diesen Seitenbächen wurde ein $\mathrm{pH}$ von 6,4 festgestellt, während die Seitenbäche der orographisch rechten Seite einen $\mathrm{pH}$ von rund 8,0 aufwiesen (Burger 1999, Wallinger 1999). Dort, wo diese Ablagerungen der Seitenbäche wiederum von der Rotmoosache beeinflusst werden, finden sich weniger saure Bereiche (Abb. 12).

\section{Bodenelemente}

\section{Organische Substanz}

Die Limitierung der organischen Substanz im Boden zu Beginn der Primärsukzession und die Zunahme im Laufe der Zeit ist das deutlichste Merkmal der Bodenentwicklung. Wenngleich auf den jüngsten Stadien bereits Mikroorganismen und Bodenfauna zur Akkumlation von organischer Substanz beitragen (Schmidt et al. 2008), so sind es in Folge vor allem pflanzliches Streumaterial und Wurzelteile. Der Anstieg des Humusgehalts im Boden zeigt sich im Allgemeinen auch in den 
Studien, die im Rotmoostal durchgeführt wurden (Erschbamer et al. 1999, Kaufmann et al. 2002, Tscherko et al. 2005, Deiglmayr et al. 2006). Die Anreicherung der organischen Substanz im Oberboden erfolgt im Vergleich zu anderen Lokalitä- ten jedoch relativ langsam (vgl. Matthews 1992). Die Böden entwickelten sich im Laufe einiger Jahrzehnte von humusfrei zu gering humos (organische Substanz $5 \%$ ), wobei auf der rechten Talseite des Gletschervorfeldes der Anteil an organi-

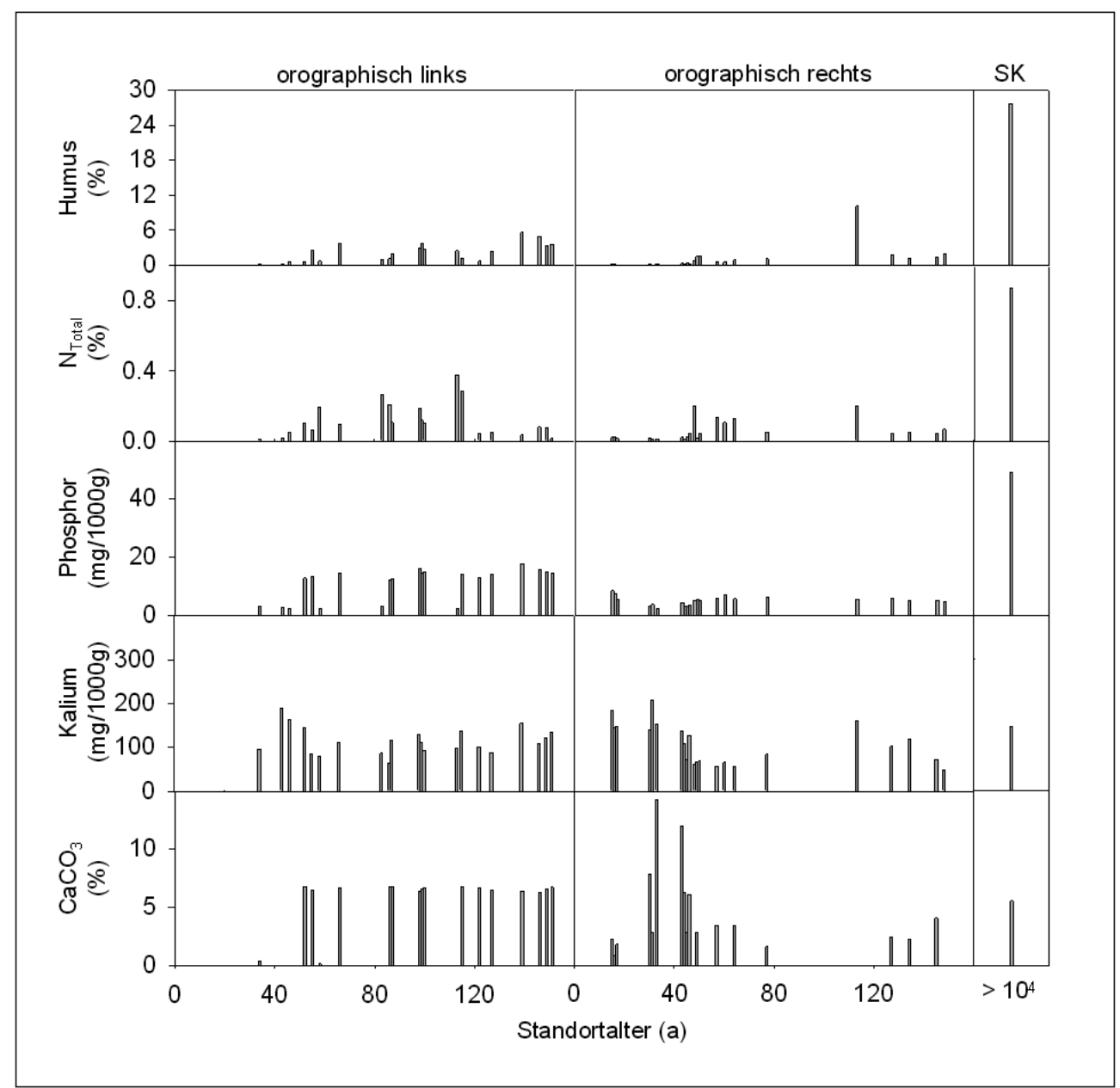

Abb. 13:

Ausgewählte Bodenelemente im Oberboden unterschiedlich alter Sukzessionsstadien der orographisch linken und rechten Talseite des Gletschervorfeldes im Rotmoostal im Vergleich mit einem Referenzstandort am Schönwieskopf (SK), auf welchem ein subalpiner Bürstlingsrasen ausgebildet ist (Quelle: R. Kaufmann, Univ. Innsbruck, unpubl. Daten). 
scher Substanz geringer bleibt (Abb. 13). Die Anreicherung hängt nicht nur vom Zeitfaktor ab, auch die Beschaffenheit der Streu spielt eine zentrale Rolle. Diese wird wiederum von der vorhandenen Vegetation bestimmt und steht in enger Wechselwirkung mit weiteren Boden bildenden Faktoren. Sind die mikroklimatischen Bedingungen ungünstig für den Streuabbau, kommt es zur verstärkten Bildung von organischen Auflagen. Ein schneller Abbau der Streuschicht kann Ursache für einen geringmächtigen Auflagehorizont sein. Im Gletschervorfeld findet man kleinräumig starke Abweichungen der Boden bildenden Faktoren und somit auch der Bodengenese. Die Böden weisen z.T. einen Anteil an organischer Substanz von bis zu $10 \%$ auf (Abb. 12, vgl. auch Erschbamer et al. 1999). Die Heterogenität der Standorte dürfte auch einer der Hauptgründe für die teils stark variierenden Werte zwischen unterschiedlichen Studien sein (Erschbamer et al. 1999, Kaufmann et al. 2002, Tscherko et al. 2005, Deiglmayr et al. 2006). Aber auch die Beeinflussung der Bodengenese durch Düngung, die auf Grund der Beweidung durch Schafe und Pferde gegeben ist, sollte bei der Interpretation der Daten nicht vernachlässigt werden. Außerhalb des Gletschervorfeldes wurde eine deutliche Zunahme der organischen Substanz im Boden festgestellt, so dass der Gehalt an organischer Substanz im Oberboden der Braunerdekolluvien und Podsole bis über $25 \%$ steigt (Abb. 12, vgl. auch Erschbamer et al. 1999,
Kaufmann et al. 2002, Tscherko et al. 2005, Deiglmayr et al. 2006).

\section{Die Boden-Makronährelemente Stickstoff, Phosphor und Kalium}

Rezent eisfreie Terrains sind primär nährstofflimitiert, d.h. die für lebende Organismen notwendigen Bodenelemente sind nicht in ausreichendem Maß verfügbar. Vielfach sind die Nährstoffe zwar im Ausgangsgestein vorhanden, aber erst durch die Verwitterung werden sie für die Organismen verfügbar. Andere Nährstoffe, vor allem Stickstoff, werden erst durch die Bindung aus der Atmosphäre angereichert. Als deutliches Merkmal der Bodengenese akkumulieren sich einige Bodenelemente im Oberboden als Folge der Etablierung von Mikroorganismen, Invertebraten- und Pflanzengemeinschaften. Die Nährstoffanreicherung in jungen Stadien ist eine der Schlüsselmechanismen für das Fortschreiten der Sukzession (Hodkinson et al. 2002).

Entsprechend den Erwartungen war auf den Pionierstadien im Rotmoostal kaum Stickstoff im Boden festzustellen. Die Entwicklung der Stickstoff-Verhältnisse zeigte keine generelle Zunahme mit dem Alter der Sukzessionsstadien (Abb. 13). Die höchsten Werte wurden im mittleren Gletschervorfeldabschnitt (ca. 50 - 120 Jahre eisfrei) gemessen, während der Stickstoffgehalt auf älteren Moränen wieder deutlich abnimmt (Abb. 13). Die 
von Crocker und Major (1955) berichtete Entwicklung des Gesamtstickstoffes im Boden des Gletschervorfeldes der Glacier Bay Region zeigt eine weitgehende Übereinstimmung dieses Verlaufs. Die Ursache dafür könnte an der Änderung des Vegetationstyps und einem damit verbundenen Rückgang der Stickstofffixierungsrate liegen. Auf älteren Stadien anderer Ökosysteme wurde auch eine zunehmende Verlagerung des Stickstoffs in tiefere Bodenschichten beobachtet. Der Gesamtstickstoffgehalt zeigt auch nicht die ganze Variabilität des Stickstoff-Kreislaufs. So fanden Deiglmayr et al. (2006), dass im Rotmoostal zwar die Ammonium-Konzentration dem Trend des ansteigenden Humusgehaltes folgt, jedoch der Nitrat-Gehalt auf allen Sukzessionstadien sehr niedrig blieb. Auch Kaufmann et al. (2002) berichteten, dass der NitratGehalt nicht mit dem Alter der Stadien korreliert, jedoch von der Sonnenscheindauer beeinflusst wird.

Im Gletschervorfeld des Rotmoosferners fielen auf den jüngsten Stadien die relativ hohen Werte beim Phosphor- und noch mehr beim Kalium-Gehalt (siehe auch Tscherko et al. 2005) auf. Diese Werte dürften die Verhältnisse in den Ausgangsgesteinen widerspiegeln. Die Entwicklung des Phosphorgehalts im Boden unterschiedlicher Gletschervorfelder zeigte keine einheitlichen Trends (Matthews 1992), jedoch scheint in sehr langen Entwicklungsreihen der Gesamtphosphorgehalt durch Auswaschungsverluste zurückzugehen. Im Rotmoostal nahm hingegen der Gehalt an Phosphor entlang der Chronosequenz leicht zu, allerdings war dieser Zusammenhang nur auf der orographisch linken Seite signifikant (Abb. 13), wo in vielen Bereichen ein ständiger Eintrag von Feinsedimenten aus höher gelegenen Gletscherabflüssen zu beobachten ist. Im Kalium-Gehalt spiegelte sich dieser „Düngungseffekt“ nicht wider. Auch sonst zeigten die Messwerte für Kalium keinen Zusammenhang mit der Chronosequenz (Abb. 13).

Die fehlenden Trends bei der Entwicklung der Bodenelemente im Rotmoostal deuten wiederum darauf hin, dass die Bodengenese in dieser Primärsukzession nicht ganz ungestört abläuft. Die Boden bildenden Faktoren im Gletschervorfeld variieren kleinräumig und schaffen sehr heterogene Bodenverhältnisse (Erschbamer et al. 1999, Kaufmann et al. 2002, Schwienbacher 2004).

Außerhalb des Gletschervorfeldes stieg der Gehalt an Nährstoffen, vor allem Stickstoff und Phosphor, jedoch sprunghaft an (Tscherko et al. 2005). Im Oberboden des Bürstlingsrasen am Schönwieskopf wurden nochmals deutlich höhere Anteile aller Nährstoffe nachgewiesen (Abb. 13). Diese sind vergleichbar mit den Verhältnissen, die Neuwinger (1987) vom Auflagehorizont eines Eisenpodsols im etwas tiefer gelegenen Alpenrosen-Zirbenwald berichtete. Während im Gletschervorfeld lediglich ein Anstieg des PhosphorGehalts mit zunehmendem Humusgehalt 
entlang der Chronosequenz festgestellt wurde und sonst keine Zusammenhänge zwischen den Elementen auf den unterschiedlichen Standorten zu beobachten waren, nahm an den Standorten außerhalb des Gletschervorfeldes sowohl der Stickstoff-, als auch der Phosphorgehalt, mit der Menge an organischer Substanz deutlich zu. Neuwinger und Czell (1959) wiesen bei ihren Untersuchungen in Obergurgl nach, dass die Auflagehorizonte der alpinen Podsole und Braunerden den eigentlichen Speicher für pflanzenverfügbare Nährstoffe darstellen, und man bereits im Mineralboden nur mehr geringe Anteile der Elemente vorfindet. Im Auflagehorizont findet sich auch der höchste Durchwurzelungsgrad des Bodens mit Feinwurzeln. Nachdem im Gletschervorfeld die Humusauflage anfänglich nur kleinflächig und auch in älteren Stadien nur geringmächtig ausgebildet ist, dürften hier unter anderem Faktoren wie Ausgangssubstrat, Eintrag von Nährstoffen durch Materialverlagerungen, unterschiedliche Nährstoffbindung durch Organismen, aber auch Düngeeffekte durch die Beweidung eine übergeordnete Rolle für die Zusammensetzung der Bodenelemente spielen und so den Gradienten der Chronosequenz verwischen.

\section{Karbonat}

Der Anteil an Karbonatgesteinen beeinflusst die chemischen und physikalischen
Eigenschaften des Bodens, wie beispielsweise die Gefügebildung (Krümelstruktur) und damit den Wasser-, Luft- und Wärmehaushalt (Sitte et al. 2002). Tscherko et al. (2005) berichteten von einem kontinuierlichen Rückgang des Karbonatgehalts im Laufe der Sukzession im Gletschervorfeld des Rotmoosferners, aber die Untersuchungen von R. Kaufmann (Univ. Innsbruck, unpubl. Daten) bestätigten dieses Bild nicht (Abb. 13). Auf der linken Talseite wurde ein gleichbleibender Anteil an Karbonat auf nahezu allen Probenstellen festgestellt, während auf der rechten Talseite der Karbonatgehalt allgemein etwas geringer ist, mit Ausnahme des ca. 30 - 45 Jahre eisfreien Abschnitts, an dem der höchste Karbonatgehalt von $14 \%$ festgestellt wurde, aber die Werte kleinräumig stark variieren. Auch am Schönwieskopf änderte sich der Karbonatgehalt im Vergleich zu den Durchschnittswerten im Gletschervorfeld nicht wesentlich (Abb. 13). Karbonat kann die Versauerung von schwach bis mäßig sauren Böden etwas puffern und ist für die Basenverfügbarkeit besonders wichtig (Mückenhausen 1993). Im Rotmoostal zeigte sich jedoch kein Zusammenhang zwischen dem Karbonatgehalt und dem Boden-pH. Während im Großteil des Gletschervorfeldes nur eine mäßige Versauerung der Böden durch Anreicherung von organischer Substanz zu beobachten war, dürfte diese auf der linken Talseite das Pufferungsvermögen der Böden übersteigen. 


\section{Literatur}

Aplet, G.H., Flint, H.R. \& Vitousek, P.M. (1998) Ecosystem development on Hawaiian lava flows: biomass and species composition. J. Veg. Sci 9: 17-26.

Braun-Blanquet, J. \& Jenny, H. (1926) Vegetationsentwicklung und Bodenbildung in der alpinen Stufe der Zentralalpen (Klimaxgebiet des Caricion curvulae). Denkschr. Schweiz. Naturf. Ges. 63: 183-349.

Burger, R. (1999) Die Chiromidenemergenz zweier Hochgebirgsbäche im Raum Obergurgl (Rotmoosache, Königsbach, Tirol). Diplomarbeit, Universität Innsbruck.

Crocker, R.L. \& Major, J. (1955) Soil development in relation to vegetation and surface age at Glacier Bay, Alaska. J. Ecol. 43: 427-448.

Crocker, R.L. \& Dickson, B.A. (1957) Soil development on the recessional moraines of the Herbert and Mendenhall Glaciers, South-Eastern Alaska. J. Ecol. 45: 169-185.

Deiglmayr, K., Philippot, L., Tscherko, D. \& Kandeler, E. (2006) Microbial succession of nitrate-reducing bacteria in the rhizosphere of Poa alpina across a glacier foreland in the Central Alps. Environ. Microbiol. 8: 1600-1612.

Dolezal, J., Homma, K., Takahashi, K., Vyatkina, M.P., Yakubov, V., Vetrova, V.P. \& Hara, T. (2008) Primary succession following deglaciation at Koryto Glacier Valley, Kamchatka. AAAR 40: 309-322.

Duelli, M.T. (1987) Die Vegetation des Gaißbergtales, Obergurgl, Ötztal. In: MaB - Projekt Obergurgl, Patzelt G. (ed) Veröff. d. österr. MaB-Programms 10, Innsbruck, 205-231.

Egli, M., Wernli, M., Kneisel C. \& Haeberli, W. (2006a) Melting glaciers and soil development in the proglacial area Morteratsch (Swiss Alps): I. Soil Type Chronosequence. AAAR 38: 499-509.

Egli, M., Wernli, M., Kneisel, C., Biegger, S. \& Haeberli, W. (2006b) Melting glaciers and soil development in the proglacial area Morteratsch (Swiss Alps): II. Modeling the present and future soil state. AAAR 38: 510-521.

Erschbamer, B., Bitterlich, W. \& Raffl, C. (1999) Die Vegetation als Indikator für die Bodenbildung im Gletschervorfeld des Rotmoosferners (Obergurgl, Ötztal, Nordtirol). Ber. nat.-med. Verein Innsbruck 86: 107-122.

Friedel, H. (1934) Boden- und Vegetationsentwicklung am Pasterzen Ufer. Carinthia II 43/44: 29-41.

Friedel, H. (1938a) Boden- und VegetationsEntwicklung im Vorfelde des Rhonegletschers. Ber. Geobot. Inst. Rübel 65-76.

Friedel, H. (1938b) Die Pflanzenbesiedlung im Vorfeld des Hintereisferners. Zeitschrift für Gletscherkunde 26: 215-239.

Haugland, J.E. \& Haugland, B.S.O. (2008) Cryogenic disturbance and pedogenic lag effects as determined by the profile 
developmental index: The styggedalsbreen glacier chronosequence, Norway. Geomorphology 96: 212-220.

He, L. \& Tang Y. (2008) Soil development along primary succession sequences on moraines of Hailuogou Glacier, Gongga Mountain, Sichuan, China. Catena 72: 259-269.

Hodkinson, I.D., Webb, N.R. \& Coulson, S.J. (2002) Primary community assembly on land - the missing stages: why are the heterotrophic organisms always there first? J. Ecol. 90: 569-577.

Insam, H. \& Haselwandter, K. (1989) Metabolic quotient of the soil microflora in relation to plant succession. Oecologia 79: 174-178.

Jochimsen, M. (1962) Die Vegetationsentwicklung in den Vorfeldern des Rotmoos- und Gaisbergferners im Ötztal. Dissertation, Universität Innsbruck.

Jochimsen, M. (1970) Die Vegetationsentwicklung auf Moränenboden in Abhängigkeit von einigen Umweltfaktoren. Alpin-Biologische Studien. Veröff. Univ. Innsbruck 46: 5-22.

Johnson, E.A. \& Miyanishiate, K. (2008) Testing the assumptions of chronosequences in succession. Ecology Letters 11: 419431.

Kandeler, E., Deiglmayr, K., Tscherko, D., Bru D. \& Philippot, L. (2006) Abundance of nar $G$, nirS, nirK, and nos $Z$ genes of denitrifying bacteria during primary successions of a glacier foreland. Appl. Environ. Microbiol. 72: 5957-5962.
Kaufmann, R. (2001) Invertebrate succession on an alpine glacier foreland. Ecology 82: 2261-2278.

Kaufmann, R., Fuchs, M. \& Gosterxeier, N. (2002) The soil fauna of an alpine glacier Foreland: colonization and succession. AAAR 34: 242-250.

Lazzaro, A., Abegg, C. \& Zeyer, J. (2009) Bacterial community structure of glacier forefields on siliceous and calcareous bedrock. Eur. J. Soil Sci. 60: 860-870.

Lichter, J. (1998) Primary succession and forest development on coastal Lake Michigan sand dunes. Ecol. Monogr. 68: 487-510.

Lüdi, W. (1945) Besiedlung und Vegetationsentwicklung auf den jungen Seitenmoränen des Grossen Aletschgletschers, mit einem Vergleich der Besiedlung im Vorfeld des Rhonegletschers und des Oberen Grindelwaldgletschers. Ber. Geobot. Inst. Rübel 35-112.

Mahaney, W.C., Kalm, V., Kapran, B., Milner, M.W. \& Hancock, R.G.V. (2009) A soil chronosequence in Late Glacial and Neoglacial moraines, Humboldt Glacier, northwestern Venezuelan Andes. Geomorphology 109: 236-245.

Mallaun, M. (2001) Verlauf der Primärsukzession in einem zentralalpinen Gletschervorfeld (Ötztaler Alpen, Tirol). Diplomarbeit, Universität Innsbruck.

Matthews, J. (1992) The ecology of recentlydeglaciated terrain: a geoecological approach to glacier forelands and primary succession. Cambridge University Press, Cambridge. 
Mückenhausen (1993) Die Bodenkunde und ihre geologischen, geomorphologischen, mineralogischen und petrologischen Grundlagen. 4. Auflage. DLG-Verlag, Frankfurt am Main.

Nestroy, O., Danneberg, O.H., Englisch, M., Geßl, A., Hager, H., Herzberger, E., Kilian, W., Nelhiebel, P., Pecina, E., Pehamberger, A., Schneider, W. \& Wagner, J. (2000) Systematische Gliederung der Böden Österreichs (Österreichische Bodensystematik 2000). Mitt. d. Österr. Bodenkundl. Ges. 60: 1-99.

Neuwinger, I. (1987) Bodenökologische Untersuchungen im Gebiet Obergurgler Zirbenwald - Hohe Mut. In: MaB - Projekt Obergurgl, Patzelt G. (ed) Veröff. d. österr. MaB-Programms 10, Innsbruck, 173-190.

Neuwinger, I. \& Czell, A. (1959) Standortsuntersuchungen in subalpinen Aufforstungsgebieten. I. Teil: Böden in den Tiroler Zentralalpen. Forstwiss. Centralblatt 78: 327-372.

Nicol, G.W., Tscherko, D., Embley T.M. \& Prosser, J.I. (2005) Primary succession of soil Crenarchaeota across a receding glacier foreland. Environ. Microbiol. 7: 337-347.

Nicol, G.W., Tscherko, D., Chang, L., Hammesfahr, U. \& Prosser, J.I. (2006) Crenarchaeal community assembly and microdiversity in developing soils at two sites associated with deglaciation. Environ. Microbiol. 8, 1382-1393.

Niederfriniger Schlag, R. \& Erschbamer, B. (2000) Germination and establishment of seedlings on a glacier foreland in the Central Alps, Austria. AAAR 32: 270277.

Patzelt, G. \& Bortenschlager, S. (1979) Spätund nacheiszeitliche Gletscher- und Vegetationsentwicklung im Inneren Ötztal. In: Patzelt G. (ed) Gletscherkundliche Forschungen in den Ostalpen und im Großen Pamir. Universität Innsbruck, Innsbruck, 78-89.

Raffl, C. (1999) Vegetationsgradienten und Sukzessionsmuster in einem zentralalpinen Gletschervorfeld (Ötztaler Alpen, Tirol). Diplomarbeit, Universität Innsbruck.

Reisigl, H. (1987) Die Untersuchung der alpinen Grasheide im Rahmen der Klimaxvegetation des Gurglertales (Ötztaler Alpen). In: MaB - Projekt Obergurgl, Patzelt G. (ed) Veröff. d. österr. MaBProgramms 10, Innsbruck, 191-203.

Rudolph, D. (1991) Vergleichende Studien zur Vegetationsentwicklung im Vorfeld des Rotmoosferners/Ötztaler Alpen. Diplomarbeit, Universität Gießen.

Scheffer, F. \& Schachtschabel, P. (1998) Lehrbuch der Bodenkunde. 14. Auflage. Ferdinand Enke Verlag, Stuttgart.

Schlagintweit, H. \& Schlagintweit, A. (1850) Untersuchungen über die physicalische Geographie der Alpen in ihren Beziehungen zu den Phänomenen der Gletscher, zur Geologie, Meteorologie und Pflanzengeographie. Verlag J. A. Barth, Leipzig.

Schmidegg, O. (1932) Geologische Spezialkarte der Republik Österreich 1:75.000, 
Blatt Sölden und St. Leonhard. Geologische Bundesanstalt Wien.

Schmidt, S.K., Reed, S.C., Nemergut, D.R., Grandy, A.S., Cleveland, C.C., Weintraub, M.N., Hill, A.W., Costello, E.K., Meyer, A.F., Neff, J.C. \& Martin, A.M. (2008) The earliest stages of ecosystem succession in high-elevation (5000 metres above sea level), recently deglaciated soils. Proc. R. Soc. B 275: 2793-2802.

Schwienbacher, E. (2004) Populationsbiologische Studien an frühen Sukzessionsarten im Gletschervorfeld des Rotmoosferners (Ötztal, Tirol). Verbreitung und Standortsansprüche von Artemisia genipi und A. mutellina, Populationsstruktur von $A$. genipi. Diplomarbeit, Universität Innsbruck.

Sitte, P., Weiler, E., Kadereit, J., Bresinsky, A. \& Körner, C. (2002) Strasburger - Lehrbuch der Botanik. 35. Auflage. Spektrum Akademischer Verlag, Heidelberg, Berlin.

Starnberger, R. (2006) Der Biosphärenpark Gurgler Kamm - Vegetation, Böden und Standortsfaktoren. Diplomarbeit, Universität Innsbruck.

Stevens, P.R. \& Walker, T.W. (1970) The chronosequence concept and soil formation. Q. Rev. Biol. 45: 333-350.

Strauss, S.L., Ruhland, C.T. \& Day, T.A. (2009) Trends in soil characteristics along a recently deglaciated foreland on Anvers Island, Antarctic Peninsula. Polar Biol. 32: 1779-1788.
Tscherko, D., Rustemeier, T.R.A., Wanek, W. \& Kandeler, E. (2003) Functional diversity of the soil microflora in primary succession across two glacier forelands in the Central Alps. Eur. J. Soil Sci. 54: 685-696.

Tscherko, D., Hammesfahr, U., Marx, M.C. \& Kandeler, E. (2004) Shifts in rhizosphere microbial communities and enzyme activity of Poa alpina across an alpine chronosequence. Soil Biol. Biochem. 36: 1685-1698.

Tscherko, D., Hammesfahr, U., Zeltner, G., Kandeler, E. \& Böcker, R. (2005) Plant succession and rhizosphere microbial communities in a recently deglaciated alpine terrain. Basic Appl. Ecol. 6: $367-$ 383.

Veit, H. (2002) Die Alpen - Geoökologie und Landschaftsentwicklung. Verlag Eugen Ulmer, Stuttgart.

Wallinger, M. (1999) Die Emergenz von Ephemeropteren, Plekopteren und Trichopteren in zwei Hochgebirgsbächen (Rotmoosache, Königsbach) im Raum Obergurgl, Tirol. Diplomarbeit, Universität Innsbruck.

Wiedemann, T. (1991) Die Entwicklung von Boden und Vegetation im Vorfeld des Gaißbergferners, Ötztaler Alpen. Diplomarbeit, Universität Gießen. 


\section{Verzeichnis der AutorInnen}

Erich Schwienbacher

Universität Innsbruck

Institut für Botanik

Sternwartestr. 15, 6020 Innsbruck, Österreich

Erich.Schwienbacher@uibk.ac.at

Eva-Maria Koch

Universität Innsbruck

Alpine Forschungsstelle Obergurgl

Gaisbergweg 3, 6456 Obergurgl, Österreich

Eva-Maria.Koch@uibk.ac.at 


\title{
Kapitel 6 I Pflanzliche Sukzession im Gletschervorfeld
}

\section{Vegetation und Besiedelungsstrategien}

\author{
Fabian Nagl, Brigitta Erschbamer
}

\section{Zusammenfassung}

Die Primärsukzession auf alpinem Neuland wurde im Gletschervorfeld des Rotmoosferners vegetationskundlich und populationsbiologisch untersucht. Einhergehend mit der zunehmenden Stabilisierung des Substrates und der voranschreitenden Bodenbildung kann im Gletschervorfeld eine Abfolge von verschiedenen Stadien der Vegetationsentwicklung beobachtet werden. Ausgehend von einem gletschernahen Pionierstadium nehmen mit zunehmender Entfernung vom Gletscherrand Diversität und Vegetationsbedeckung zu und es entwickeln sich rasenartige, geschlossene Bestände. Die Besiedelungsprozesse werden von abiotischen Faktoren - wie Meereshöhe, Mikrotopographie, Korngröße des Substrats, Feuchtigkeit - und biotischen Faktoren - wie Diasporenverfügbarkeit, Keimungsfähigkeit, Wachstumspotential, Interaktionen - beeinflusst.

\section{Abstract}

Primary succession on alpine virgin soil was studied in the glacier foreland of the Rotmoos- ferner under the aspect of plant sociology and population biology. With increasing stabilization of the substrate and progression of soil development, a sequence of different stages of vegetation development can be observed. With increasing distance from the glacier, diversity and vegetation cover accumulate and pioneer stages close to the glacier evolve into grassland with closed structure. Colonization processes are affected by abiotic factors - such as sea level, microtopography, grain size of substrate and humidity - and biotic factors such as seed availability, germination ability, growth potential and interactions.

\section{Die Erforschung der pflanzlichen \\ Besiedelung}

Der Klimawandel bedingt seit 150 Jahren einen mehr oder weniger kontinuierlichen Rückzug vieler Gletscher (IPCC 2007). Laufend wird dabei am Gletscherrand eine vegetationslose Zone zur Besie- 
delung freigesetzt (Walker und del Moral 2003). Durch eine räumliche Abfolge unterschiedlich lang eisfreier Moränen mit verschiedenen Entwicklungsphasen der Vegetation bieten Gletschervorfelder die Möglichkeit, die Primärsukzession von Beginn an zu untersuchen (Matthews 1992, vgl. auch Kap. 7).

Erste vegetationskundliche Beobachtungen in Gletscherrandzonen und Gletschervorfeldern des Ötztals gehen zurück auf Heufler \& Stotter (1840). In der Folge beschrieben Kerner von Marilaun (1863), Klebelsberg (1913) und Gams (1939) die pflanzliche Besiedelung. Friedel (1938) veröffentlichte erste genaue Untersuchungen zur Vegetationsentwicklung im Vorfeld des Hintereisferners. Jochimsen (1962, 1963, 1970) untersuchte die Sukzession der Gletschervorfelder des Rotmoos- und des Gaisbergferners und stellte den Verlauf der Primärsukzession kartographisch dar. Rudolph bzw. Wiedemann wiederholten 1991 die Kartierung und beschrieben die Veränderungen der Vegetation dieser beiden Gletschervorfelder.

Das Rotmoostal bietet aufgrund der geringen Höhenerstreckung und des breiten Talquerschnitts gute Voraussetzungen für das Studium der Primärsukzession auf alpinem Neuland. Die Gletscherzunge des Rotmoosferners hat sich seit 1858 nahezu kontinuierlich um über $2 \mathrm{~km}$ zurückgezogen. Zeitlich eindeutig datierte Stadien des Gletscherrückzugs sind in einer Reihe von Moränen dokumentiert (Kap. 7, Abb. 2).
Seit 1995 ist das Rotmoostal Objekt umfangreicher botanischer Studien. Sukzessionsmuster und Vegetationsgradienten sollten im Vergleich zu den Flächen außerhalb des Gletschervorfeldes ergründet werden (Erschbamer et al. 1999, Raffl 1999, Mallaun 2001, Raffl und Erschbamer 2004, Raffl et al. 2006a, Nagl, unpubl.). Populationsbiologische Untersuchungen beschäftigten sich vor allem mit den Prozessen und Faktoren der Sukzession (Erschbamer et al. 2008, Schwienbacher und Erschbamer 2008a,b, Erschbamer 2009), so z.B. mit dem Diasporenregen und der Diasporenbank (Kneringer 1998, Erschbamer et al. 2001, Finch 2008, Marcante et al. 2009a), der Lebensdauer und Keimfähigkeit von Samen (Schwienbacher und Erschbamer 2002, Schwienbacher et al. 2010), dem Keimlingsaufkommen und Überleben der Keimlinge (Niederfriniger Schlag und Erschbamer 2000, Niederfriniger Schlag 2001). Weitere Forschungsaspekte bildeten die Populationsentwicklung sowie die Alters- und Populationsstruktur ausgewählter Arten (Kuen 2001, Kuen und Erschbamer 2002, Schwienbacher 2004, Marcante et al. 2009b). Mit Hilfe von molekulargenetischen Studien wurde die Diversität und Differenzierung der Populationen im Rotmoos-, Gaisberg- und Langtal analysiert (Raffl et al. 2006b, RafflWallinger 2006, Raffl et al. 2008). Einen weiteren Schwerpunkt der Forschung im Rotmoostal stellte die Untersuchung des Wachstums von Gletschervorfeldarten 
unter veränderten Mikroklimabedingungen dar (Erschbamer 2001, 2007).

Von den jüngsten zu den ältesten Moränen

\section{Rezent eisfreie Flächen}

\section{0-3 Jahre eisfrei - orographisch rechte Talseite}

Die rezent eisfreien Moränen in der unmittelbaren Gletscherrandzone sind frei von pflanzlichem Bewuchs.

\section{Pionierstadien}

\section{3-40 Jahre eisfrei - orographisch rechte Talseite}

Die Primärsukzession beginnt mit einem artenarmen Pionierstadium (Tab. A1, Anhang). Erste Individuen treten bereits drei

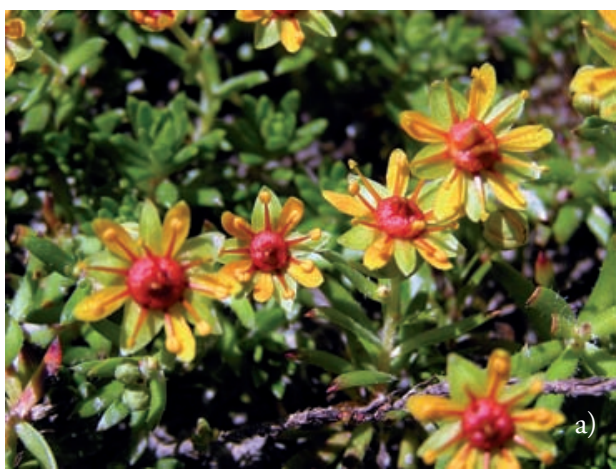

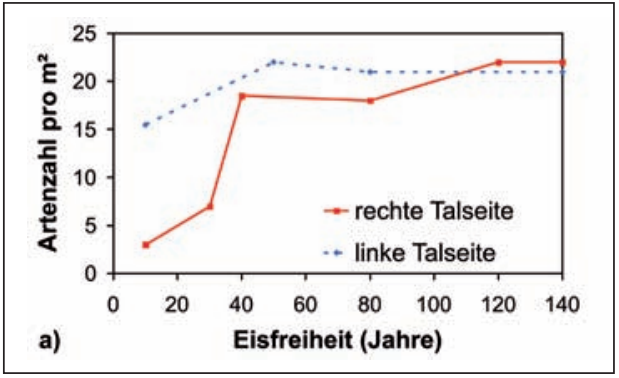

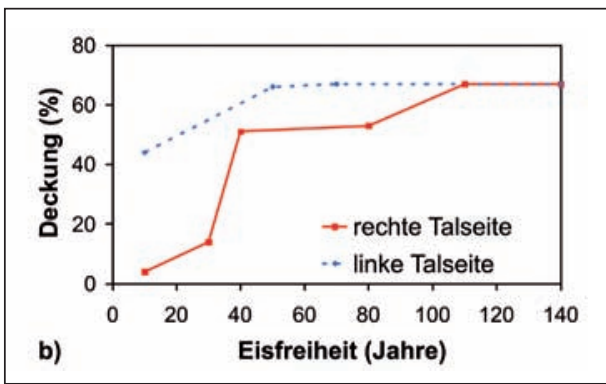

Abb. 1:

Entwicklung von a) Artenzahl und b) Deckung der Vegetation auf der orographisch rechten und linken Talseite des Gletschervorfeldes im Rotmoostal in $1 \mathrm{~m}^{2}$-Flächen

Jahre nach dem Gletscherrückzug auf. Mit 3-4 Arten pro $\mathrm{m}^{2}$ bleiben sowohl Artenzahl als auch Deckung in diesem Stadium sehr niedrig (Abb. 1). Erstbesiedler sind

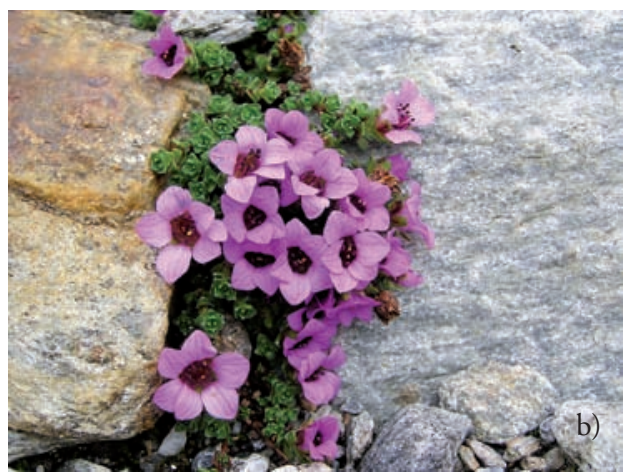

Abb. 2:

Pioniere auf gletschernahen Flächen: a) Saxifraga aizoides und b) Saxifraga oppositifolia (Fotos: F. Nagl) 
vor allem Saxifraga aizoides (Abb. 2a) an gut durchfeuchteten, feinschuttreichen Standorten und Saxifraga oppositifolia (Abb. 2b) auf trockenem, feinsandigen Substrat.

Mit zunehmender Entfernung vom Gletscherrand nehmen Artenvielfalt und De- ckung zu (Abb. 1). Im artenreichen Pionierstadium (Tab. A1, Anhang; Abb. 3) an 25 bis 40 Jahre eisfreien Standorten zeigt sich eine Entwicklung von offener Pioniervegetation (ca. $10 \%$ Deckung) hin zu einer zunehmend geschlossenen Siedlungsweise (ca. 50 \% Deckung). Es treten

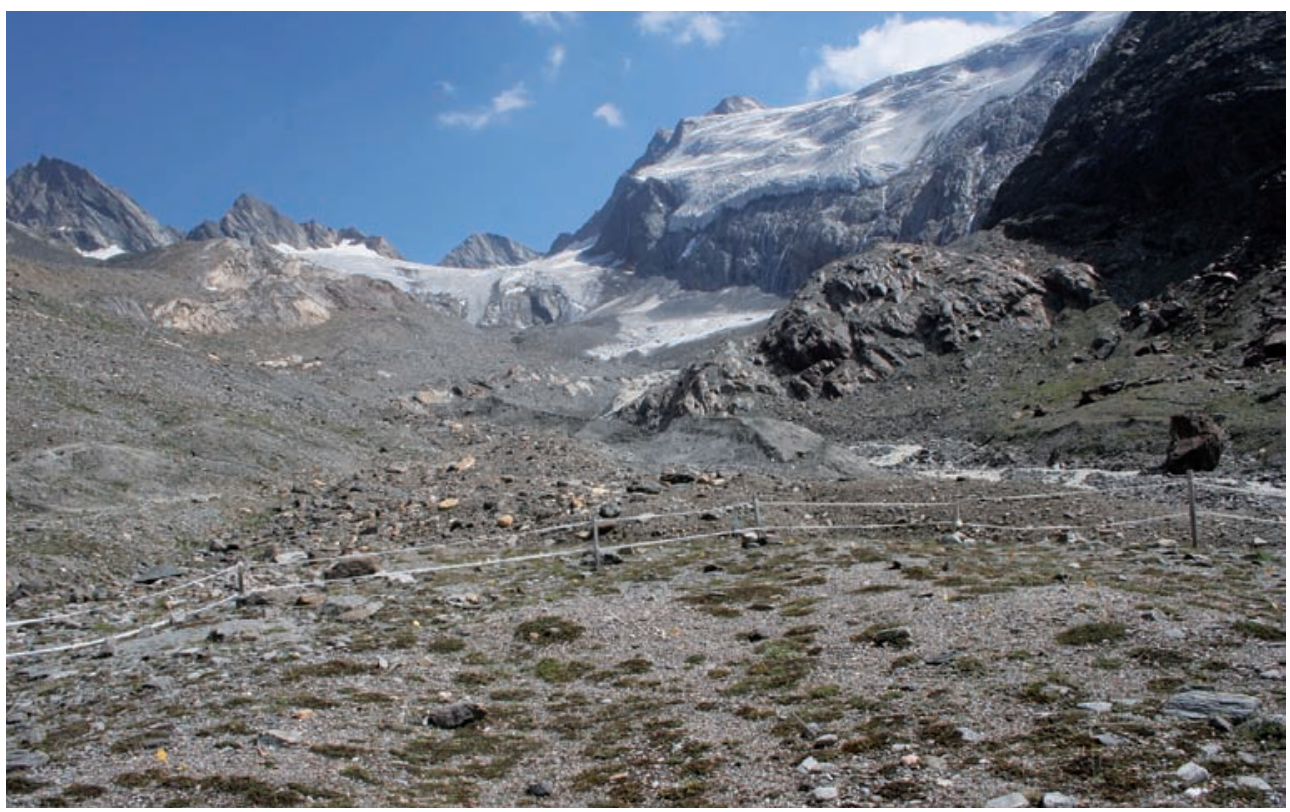

Abb. 3:

Versuchsfläche im artenreichen Pionierstadium (Foto: B. Erschbamer)
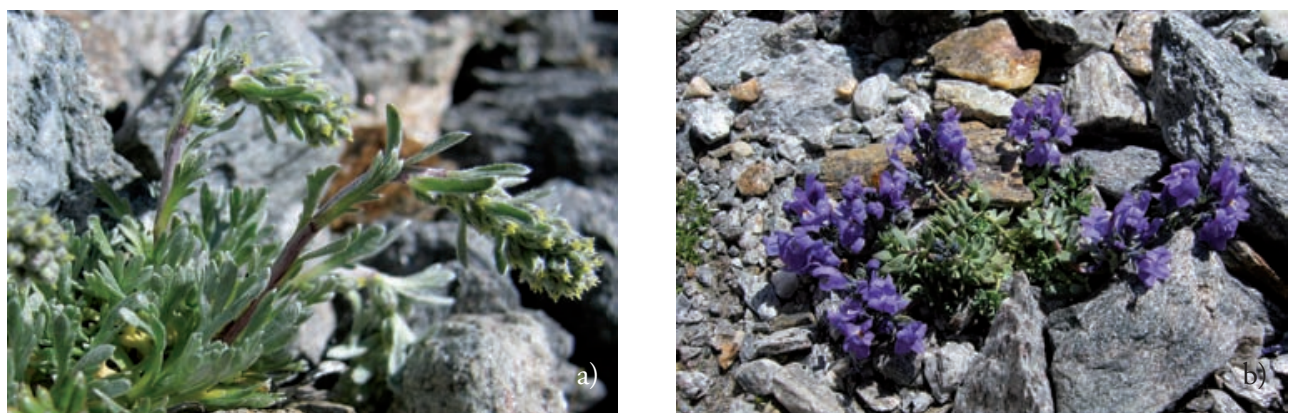

Abb. 4:

a) Artemisia genipi-b) Linaria alpina (Foto: E. Schwienbacher) 
weitere Pioniere der Schuttgesellschaften mit hoher Konstanz hinzu, wie Artemisia genipi (Abb. 4a), Linaria alpina (Abb. 4b) und die ubiquitär verbreitete Poa alpina. Daneben bereichern Folgearten wie Stereocaulon alpinum, Racomitrium canescens, Saxifraga bryoides und Arabis alpina mit etwas geringerer Stetigkeit die Artenkombination.

\section{Frühes Sukzessionsstadium}

40-70 Jahre eisfrei - orographisch rechte Talseite

15-40 Jahre eisfrei - orographisch linke Talseite

Auf der orographisch linken Talseite tritt kein ausgeprägtes Pionierstadium auf. Felsiger Untergrund verhindert hier teilweise im gletschernahen Bereich das Aufkommen von Pflanzen. Auf 15 bis 40 Jahre eisfreien Flächen findet sich ein, in seiner Entwicklung bereits weiter fortgeschrittenes, frühes Sukzessionsstadium (Tab. A1, Anhang). Die rasche Vegetationsentwicklung kann zum einen auf die steilen angrenzenden, seit langem eisfreien Hänge zurückgeführt werden, von denen Lawinen, Erdrutsche und Steinschläge Pflanzenmaterial sowie Bodenbruchstücke mit Samen eintragen und damit die Pflanzenansiedelung fördern. Die relative Schattlage bedingt au- ßerdem eine bessere Wasserversorgung der Moränenflächen dieser Talseite. Zum anderen sind hier die kleinräumig-standörtlichen Bedingungen für die Entwicklung von Pflanzen vorteilhafter: größere Steine und Felsblöcke erzeugen Schutzstellen, welche unter den rauen Bedingungen der gletschernahen Standorte günstige Voraussetzungen für die Keimlingsetablierung bieten (Niederfriniger Schlag und Erschbamer 2000).

Auf der orographisch rechten Talseite steigen Artenzahl und Deckungsgrad langsamer an (Abb. 1). Einhergehend mit der zunehmenden Stabilisierung des Substrats und der voranschreitenden Bodenbildung entwickelt sich das frühe Sukzessionsstadium dort auf 40 bis 70 Jahre altem Substrat. Die Artenzahl erreicht hier ihr erstes Maximum.

Charakteristisch für dieses Entwicklungsstadium ist das gemeinsame Vorkommen früher und später Sukzessionsarten. Die Pioniere Saxifraga oppositifolia und Saxifraga aizoides sind noch maßgeblich am Bestandesaufbau beteiligt. Mit hoher Konstanz sind auch Linaria alpina, Cerastium uniflorum (Abb. 5a), Arabis caerulea (Abb. 5b) und Minuartia gerardii vertreten. Daneben gewinnen Racomitrium canescens und Stereocaulon alpinum an Bedeutung, ebenso wie Trifolium pallescens (Abb. 5c) und Silene acaulis s. lat. (Abb. 5d). 

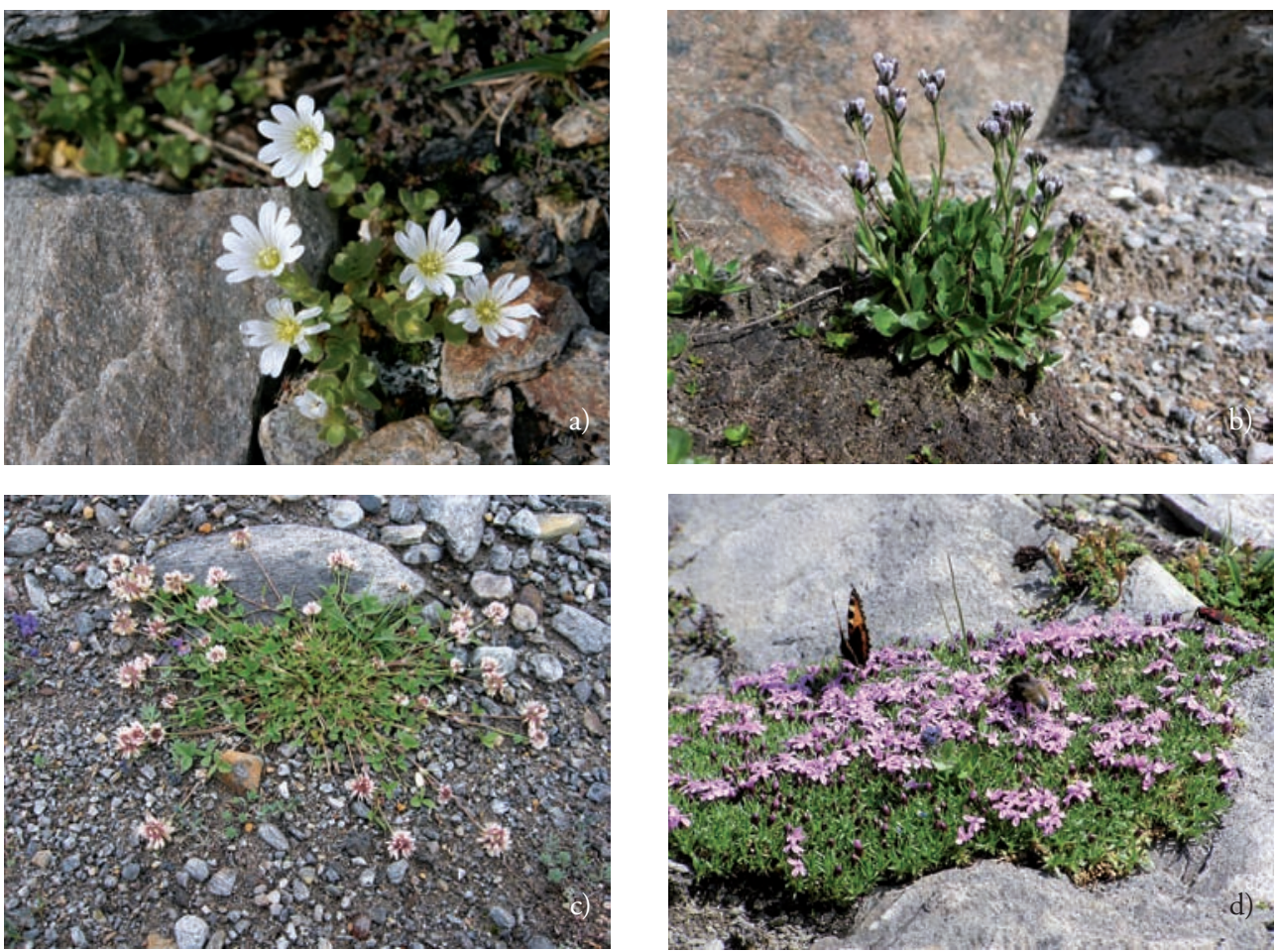

Abb. 5:

a) Cerastium uniflorum - b) Arabis caerulea - c) Trifolium pallescens - d) Silene acaulis s. lat. (Fotos: B. Erschbamer, E. Schwienbacher, F. Nagl)

\section{4. Übergangsstadium}

40-60 Jahre eisfrei - orographisch linke Talseite

Kennzeichnend ist ein stark strukturiertes Relief, das eine kleinräumige Variation der Standortsbedingungen bewirkt, welche sich in einem mosaikförmigen Vegetationsmuster widerspiegelt. Schmelzwassereinfluss und eine lange Schneebedeckung in Muldenlagen fördern das Auftreten von Schneebodenarten (Tab. A1, Anhang), wie Salix herbacea (Abb. 6a), Luzula al- pinopilosa und Gnaphalium supinum. Typisch sind darüber hinaus Oxyria digyna (Abb. 6b) und Leucanthemopsis alpina. An Kuppen und Erhebungen finden sich hingegen trockenheitsertragende Arten wie Saxifraga bryoides (Abb. 6c), Agrostis rupestris und Luzula spicata, vergesellschaftet mit den Kryptogamen Stereocaulon alpinum und Racomitrium canescens, welche zuweilen in ihrer Artmächtigkeit die Phanerogamen übertreffen. Weiter verbreitete Arten wie v.a. Poa alpina (Abb. 6d) und Trifolium pallescens vermitteln zwischen 

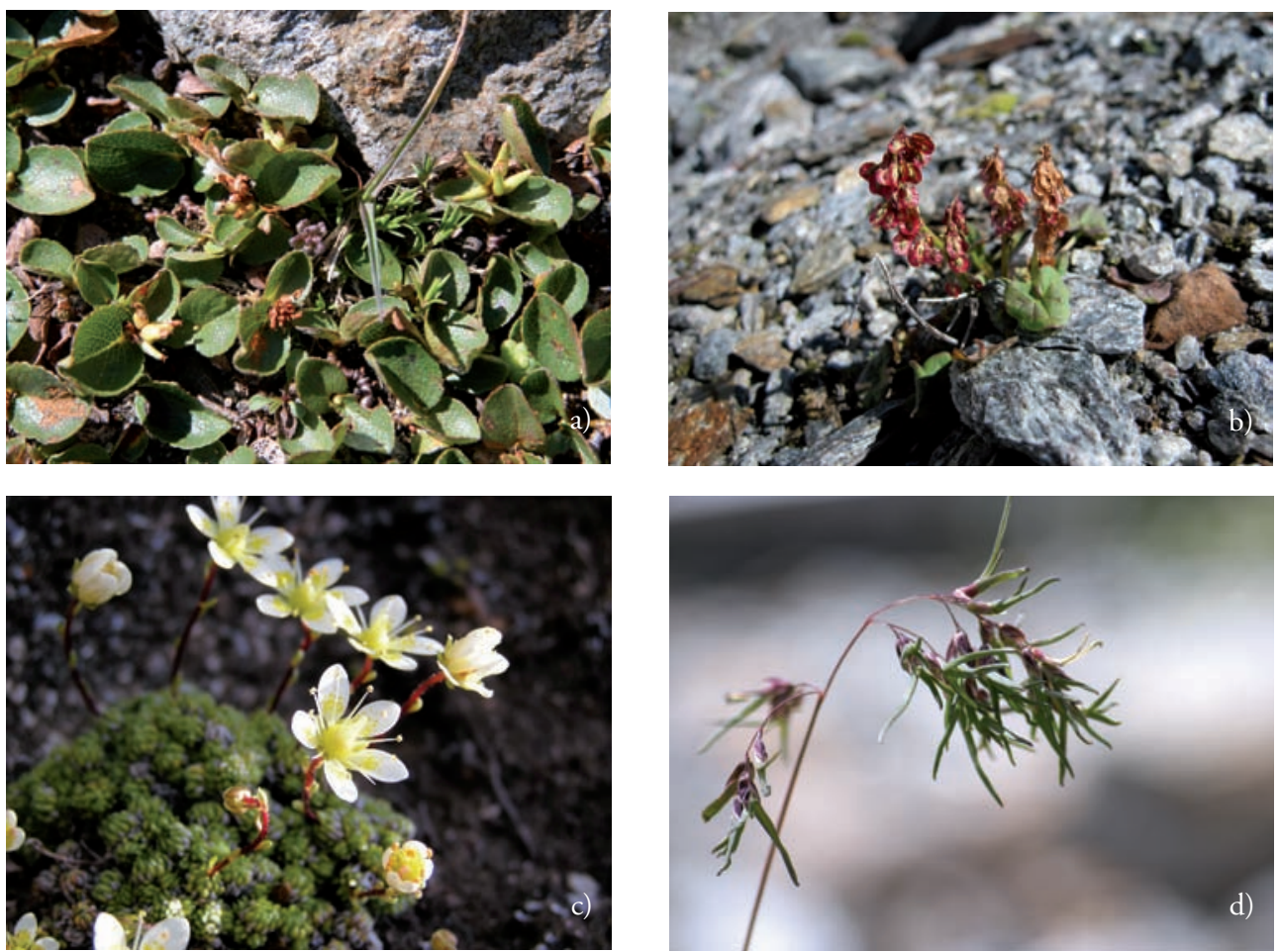

Abb. 6:

a) Salix herbacea - b) Oxyria digyna - c) Saxifraga bryoides - d) Poa alpina (vivipare Form)

(Fotos: B. Erschbamer, E. Schwienbacher, F. Nagl)

den zwei Extremen. Die Pioniere Saxifraga oppositifolia und Saxifraga aizoides sind zwar noch relativ häufig anzutreffen, hinsichtlich ihrer Artmächtigkeit spielen sie jedoch nur mehr eine untergeordnete Rolle für den Bestandesaufbau.

Durch die kleinräumige floristische Differenzierung bedingt erreicht die Artenzahl hier mit 22 Arten pro $\mathrm{m}^{2}$ ein Maximum auf dieser Talseite (Abb. 1). Die Deckung nimmt innerhalb des Übergangsstadiums deutlich von 44 auf $66 \%$ zu.

\section{Initialrasen}

70-100 Jahre eisfrei - orographisch rechte Talseite

60-140 Jahre eisfrei - orographisch linke Talseite

Mit dem zunehmenden Alter der Standorte schreitet die Bodenbildung voran. Damit verbunden sind eine verbesserte Wasser- und Nährstoffverfügbarkeit, die es anspruchsvolleren Arten ermöglicht sich auszubreiten, während die konkurrenzschwachen Pionierarten verdrängt 

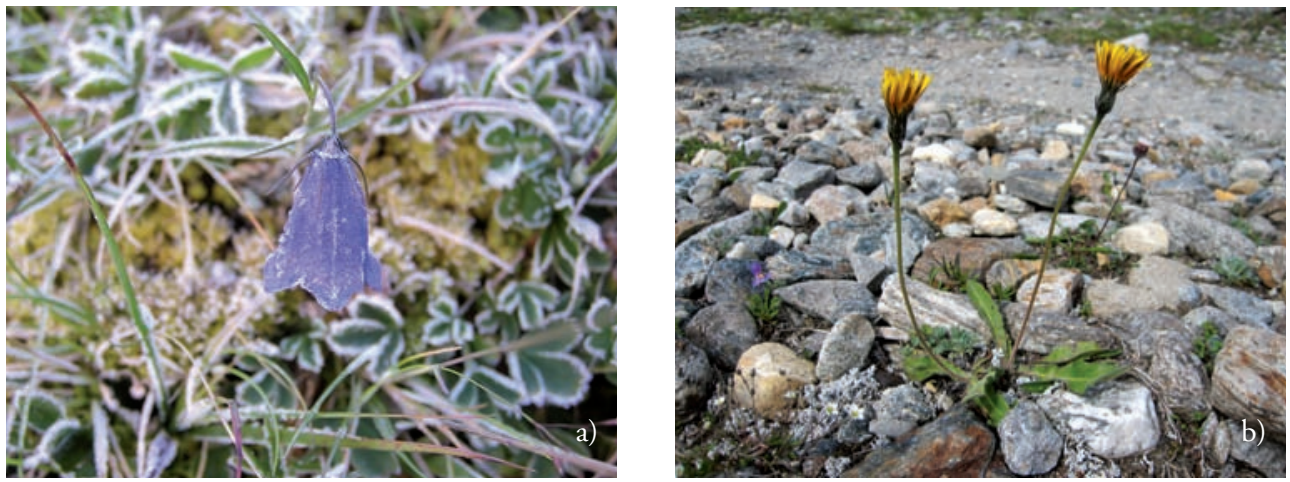

Abb. 7 :

a) Campanula scheuchzeri-b) Leontodon hispidus (Fotos: F. Nagl, E. Schwienbacher)

werden (Tab. A1, Anhang). An beiden Talseiten ist eine Entwicklung hin zu zunehmend rasenartigen Beständen zu beobachten. Häufig sind in diesem Entwicklungsstadium neben Trifolium pallescens und Poa alpina, die auch in jüngeren Stadien konstant auftreten, Campanula scheuchzeri (Abb. 7a) und Leontodon hispidus (Abb. 7b).

Auf der orographisch linken Talseite treten Agrostis rupestris, Trifolium badium, Leucanthemopsis alpina und Salix herbacea konstant auf. Die Initialrasen nehmen hier 60 bis 140 Jahre alte Moränenflächen ein. Die Abgrenzung gegenüber dem Übergangsstadium ist physiognomisch deutlich durch das rasenartige Erscheinungsbild. Hinsichtlich der herrschenden Arten fällt das verstärkte Auftreten von Achillea moschata, Campanula scheuchzeri und Leontodon hispidus auf. Kaum Unterschiede sind hinsichtlich des Deckungsgrades gegeben, die Artenzahl nimmt hingegen ab (Abb. 1).
Orographisch rechts sind Initialrasen vor allem auf 70 bis 100 Jahre eisfreien Flächen ausgebildet. Der Übergang zwischen dem frühen Sukzessionsstadium und den Initialrasen ist fließend. An den älteren Standorten verzahnt sich der Vegetationstyp mit dem Kobresia myosuroides-Rasen und beschränkt sich immer mehr auf trockene Erhebungen, wie z.B. auf den Moränenscheitel der Endmoräne von 1858. Charakteristische Arten sind Achillea moschata, Erigeron uniflorus, Minuartia gerardii und Saxifraga paniculata.

\section{Initialrasen mit Kobresia myosuroides}

85-140 Jahre eisfrei - orographisch rechte Talseite

Auf der orographisch rechten Talseite werden die ältesten, 85 bis 140 Jahre eisfreien Standorte des Gletschervorfeldes von Initialrasen mit Kobresia myosu- 
roides (Abb. 8) eingenommen (Tab. A1, Anhang). Neben der namengebenden Art sind Poa alpina, Leontodon hispidus, Campanula scheuchzeri, Persicaria vivipara, Trifolium pallescens und Silene acaulis s. lat. stete Elemente in diesen Beständen. Bedeutend für den Bestandesaufbau sind außerdem Agrostis alpina, Anthyllis vulneraria ssp. alpicola (Abb. 9), Myosotis alpestris und Achillea moschata. In Muldenlagen bilden sich nahezu geschlossene, grasreiche Bestände aus, während exponierte Kuppen nur schütter bewachsen sind und durch das Auftreten von trockenheitsertragenden Arten wie Saxifraga paniculata, Saxifraga bryoides, Stereocaulon alpinum, Achillea moschata, Racomitrium canescens und Sempervivum montanum charakterisiert werden. Der Deckungsgrad erreicht nach 110 Jahren Eisfreiheit ein Maximum von durchschnittlich 67\%. Die Artenzahl steigt im Endstadium der Sukzessionsreihe der orographisch rechten Talseite auf 22 Arten pro $\mathrm{m}^{2}$ an (Abb. 1).

\section{Sonderstandorte}

\section{Gletscherbachalluvionen}

Die Vegetation auf den Alluvionen des Gletscherbaches ähnelt jener der rezent eisfreien Pionierstandorte. Die Rotmoosache weist eine typische Gletscherbachdynamik auf, mit stark wechselnder Wasserführung, Umlagerungen und Änderungen im Bachlauf. Die natürliche Dynamik im

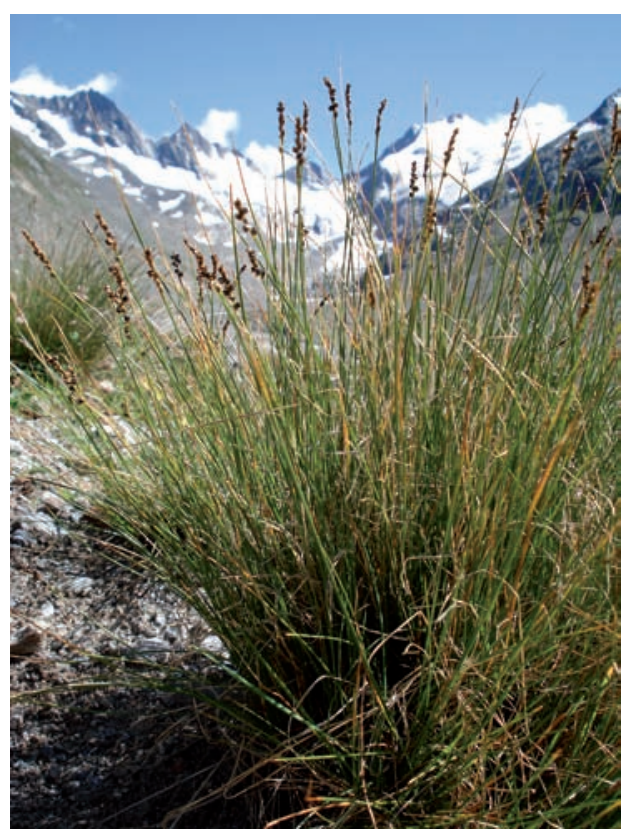

Abb. 8:

Kobresia myosuroides (Foto: B. Erschbamer)

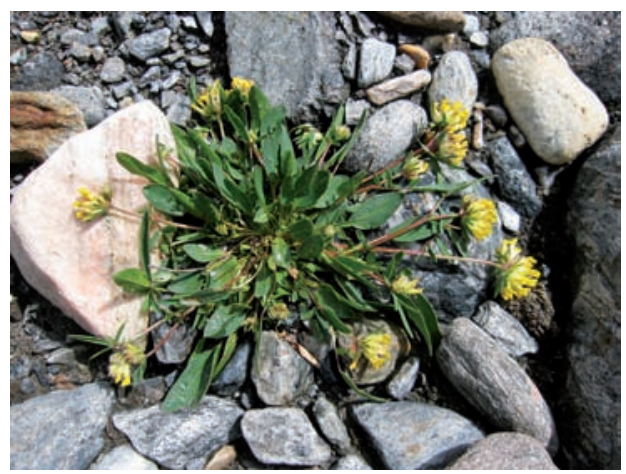

Abb. 9:

Anthyllis vulneraria ssp. alpicola

(Foto: E. Schwienbacher)

Einflussbereich des Baches verhindert hier die Entwicklung hin zu einer Schlussgesellschaft. 


\section{Feuchtflächen}

Zahlreiche Hangwasseraustritte bestimmen die Seitenmoräne 1923 auf der orographisch rechten Talseite. Die dort kleinflächig auftretenden Rieselfluren werden durch das dominante Auftreten von Carex frigidagekennzeichnet (Tab. A1, Anhang). Daneben ist die Gesellschaft durch eine hohe Deckung von Moosen charakterisiert. Eine enge floristische Verbindung $\mathrm{zu}$ den Quellfluren des Cratoneurion zeigen Saxifraga aizoides, Saxifraga stellaris, Pinguicula leptoceras und Epilobium alsinifolium an. Die begleitende Artengarnitur enthält neben typischen Arten der Feuchtlebensräume auch Elemente angrenzender Rasengesellschaften wie z.B. Agrostis alpina, Campanula scheuchzeri, Festuca pumila, Leontodon hispidus, Trifolium badium und Silene acaulis s. lat.

Gegen den Talschluss hin durchziehen etliche Bäche den orographisch rechten Seitenhang. Entlang dieser Gerinne finden sich v.a. in gletschernahen Berei-

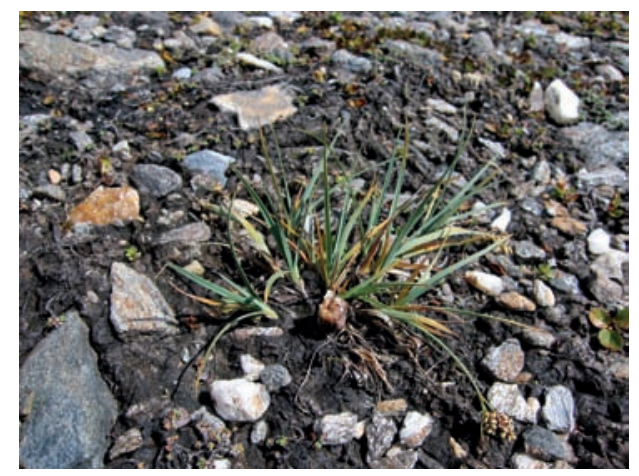

Abb. 10:

Carex bicolor

(Foto: E. Schwienbacher) chen vernässte Standorte zwischen Blockschutt, welche durch eine hohe Deckung von Saxifraga aizoides auffallen (Tab. A2, Anhang). Darüber hinaus sind nur wenige Phanerogamen, z.B. Epilobium alsinifolium, Epilobium anagallidifolium und Deschampsia cespitosa anzutreffen und diverse Lebermoose kennzeichnen mit hoher Dominanz die Bestände.

Im Bereich der Moräne 1923 wird am Talboden der Uferbereich dieser Bäche von feinsandigen, kiesigen Schwemmbereichen geprägt. An diesen lückenhaft bewachsenen Flächen ist die seltene Carex bicolor (Abb. 10) anzutreffen, eine der namengebenden Arten der alpinen Schwemmufergesellschaften des Caricion bicoloris-atrofuscae. Zum typischen Arteninventar gehören Juncus triglumis, Carex bipartita und Epilobium anagallidifolium sowie weiter verbreitete Arten wie Saxifraga aizoides, Deschampsia cespitosa, Cirsium spinosissimum, Phleum commutatum und Poa alpina (Tab. A2, Anhang).

Vegetation außerhalb des Gletschervorfeldes

1. Seitenhänge oberhalb des rezent eisfreien Bereichs: Liebener Rippe

Orographisch rechts gelegen im Talschluss des Rotmoostales bildet die Liebener Rippe (Abb. 11) einen markanten Felsrücken, 


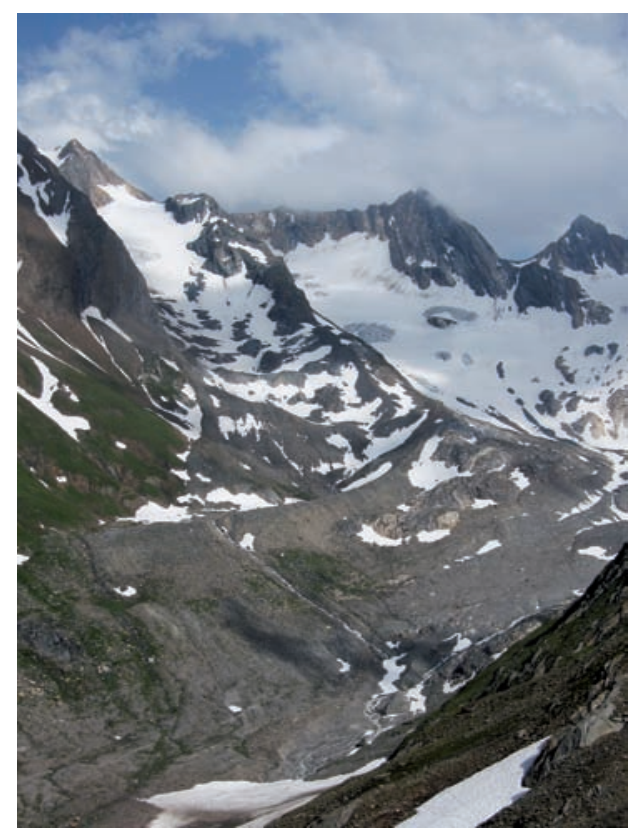

Abb. 11:

Liebener Rippe (Foto: E. Schwienbacher)

der in mehreren Stufen ansteigt. In einem Höhenbereich von ca. 2780 bis 2940 m verzahnen sich in Abhängigkeit von edaphischen Voraussetzungen und Relief vegetationsarme Schuttflächen, Rohböden mit Pioniervegetation und kleinflächige, geschlossene Rasengesellschaften z.T. sehr kleinräumig und ergeben insgesamt ein mosaikartiges Bild der Vegetation. Zunehmend lückigere Schuttfluren kennzeichnen die höher gelegenen, durch Blockwerk und Schutt bestimmten Bereiche. Bedeutend für die Zusammensetzung der Vegetation ist die wechselnde Gesteinszusammensetzung. Das Nebeneinander von Kalk- und Silikatarten gibt einen Hinweis auf die heterogene geologische Situation (siehe Kap. 2).

\section{Alpenmannschild-Flur \\ (Androsacetum alpinae Br.-Bl. 1918)}

Die Alpenmannschild-Flur (Tab. A3, Anhang) stockt auf schwach sauren bis sauren Böden. Den Grundstock der untersuchten Bestände bilden überwiegend Arten der alpin-nivalen Silikatschuttgesellschaften aus der Ordnung der Androsacetalia alpinae. Bedeutend für den Bestandesaufbau sind meist Saxifraga bryoides, Minuartia sedoides (Abb. 12a) und Silene acaulis s. lat. Mit hoher Stetigkeit treten Poa laxa, Ranunculus glacialis (Abb. 12b), Gentiana bavarica, Cerastium uniflorum, Saxifraga exarata (Abb. 12c) und auch Androsace alpina (Abb. 12d) auf. Die edaphische Variabilität an den untersuchten Standorten manifestiert sich zum einen im Hinzutreten von Kalkschieferschuttarten wie Trisetum spicatum und Draba hoppeana. Zum anderen zeigen feuchteliebende Arten an geschützten, feinerdereicheren Standorten einen Übergang zum Hygrocaricetum curvulae an.

\section{Sesleria ovata-Gesellschaft}

Diese Gesellschaft ist kleinräumig über deutlich frischem und feinerdereichem Boden ausgebildet. Durch die neutrale Bodenreaktion bedingt, fallen hier zahlreiche Arten der Silikatschuttgesellschaften aus und es entwickelt sich eine artenarme Gesellschaft, in der Sesleria ovata zur Do- 

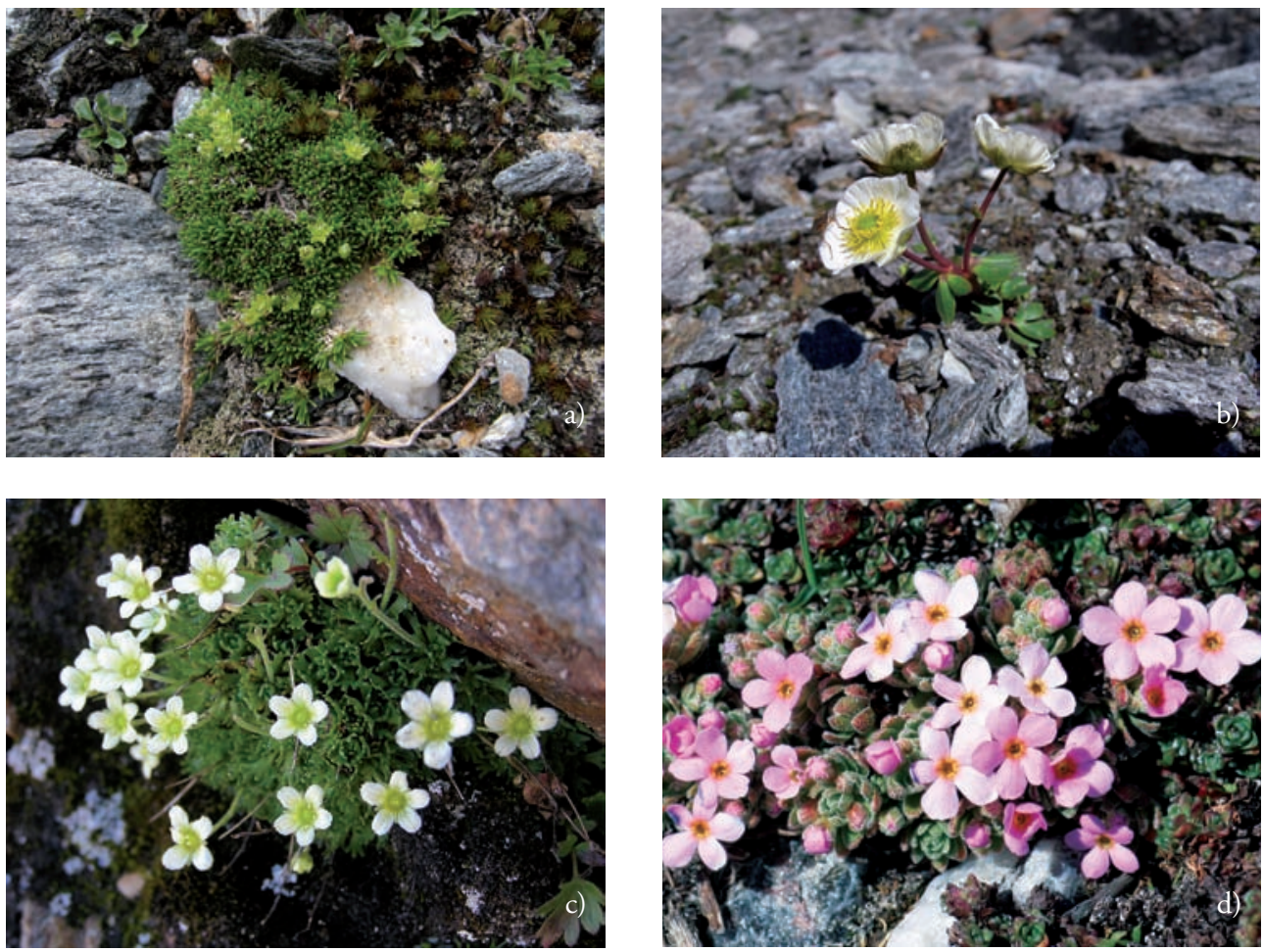

Abb. 12:

a) Minuartia sedoides - b) Ranunculus glacialis - c) Saxifraga exarata - d) Androsace alpina (Foto: E. Schwienbacher, F. Nagl, E. Erschbamer)

minanz kommt (Tab. A3, Anhang). Saxifraga oppositifolia und Minuartia sedoides sind bedeutend für den Bestandesaufbau. Daneben finden sich überwiegend Vertreter der Kalkschiefer-Schuttfluren (Drabetalia hoppeanae).

\section{Nacktriedrasen}

(Elynetum myosuroides Rübel 1911)

Nacktriedrasen (Tab. A3, Anhang) kommen an durchwegs stark geneigten Flanken und exponierten, dem Gletscherwind ausgesetzten Standorten vor, die bereits einen gewissen Feinerdegehalt aufweisen. Auf neutralen Böden dominieren Kobresia myosuroides oder Festuca pumila die dicht geschlossenen, überwiegend von Gräsern aufgebauten Bestände. Ebenso ist Carex rupestris in der Regel deckend vertreten. Persicaria vivipara, Minuartia gerardii, Silene acaulis s. lat., Agrostis alpina, Astragalus australis, Lloydia serotina und Oxytropis lapponica sind weitere typische Arten der Assoziation. An Standorten geringerer Bodenreife tritt Kobresia myosuroides zurück und Salix serpyllifolia oder Festuca pumila 
unterstreichen den Pioniercharakter dieser Bestände. Auf Böden fortgeschrittener Entwicklung, welche durch Humusakkumulation und beginnende oberflächliche Versauerung gekennzeichnet sind, prägen neben der dominierenden Kobresia myosuroides vor allem Säurezeiger den Bestand: Avenula versicolor, Agrostis rupestris, Veronica bellidioides, Carex curvula, Festuca intercedens, Juncus trifidus, Phyteuma hemisphaericum und Leucanthemopsis alpina.

\section{Sauerbodenrasen}

Sauerbodenrasen (Tab. A3, Anhang) treten kleinflächig auf, verzahnt mit Schuttfluren, deren Arten als Begleiter hinzutreten. Die Bestände werden von Carex curvula oder von Oreochloa disticha und

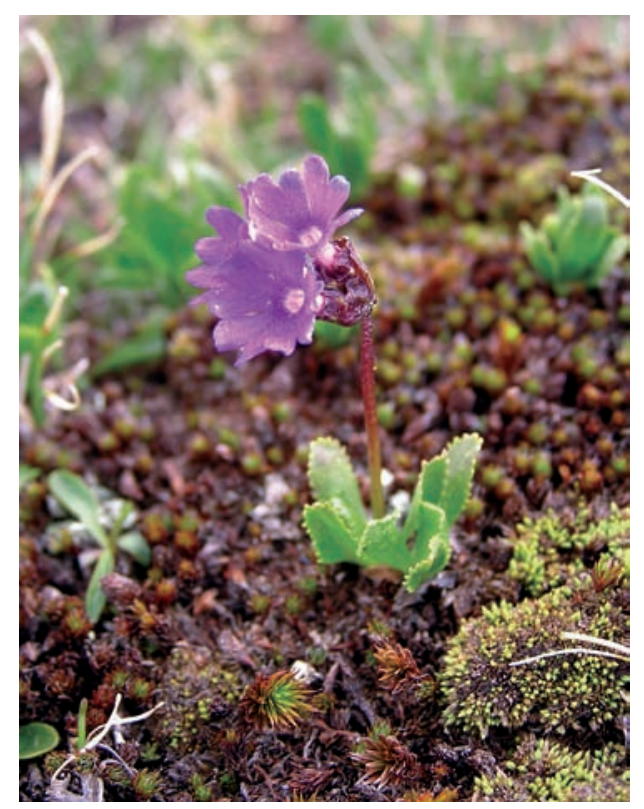

Abb. 13:

Primula glutinosa (Foto: F. Nagl)
Festuca intercedens dominiert. Auch Kobresia myosuroides kann bestandesprägend auftreten. Unter den Kräutern tragen vor allem Silene acaulis s. lat. und Trifolium pallescens zum Bestandesaufbau bei.

\section{Chionophile Krummseggenrasen} (Hygrocaricetum curvulae Braun 1913)

Diese Gesellschaft tritt in windgeschützten Muldenlagen auf, die sich durch eine lange Schneebedeckung, feuchte Bodenverhältnisse sowie Feinerdereichtum in Relation zu den umliegenden Schutthabitaten auszeichnen. Die Charakterart der Assoziation, Primula glutinosa (Abb. 13), prägt durch ihr dominantes Auftreten den Bestand. Kennzeichnend ist daneben Salix herbacea, die mit hoher Artmächtigkeit wesentlich die Struktur der Bestände mitbestimmt. Carex curvula und Leucanthemopsis alpina sind weitere typische konstante Begleiter. Charakteristisch für die schneefeuchten Standorte ist das Zurücktreten der Flechten (Tab. A3, Anhang).

\section{Seitenhänge außerhalb der Glet- scherstände 1923 und 1858}

Die Flächen außerhalb der Seitenmoräne von 1858 sind seit über 10.000 Jahren eisfrei (Bortenschlager 1984). Aufgrund der fortgeschrittenen Bodenentwicklung zeigt sich ein deutlicher Unterschied zur Vegetation des Gletschervorfeldes. 


\section{Silikat-Horstseggenhalden}

(Caricetum sempervirentis Rübel 1911)

Im Bereich steiler Hangpartien des sonnenexponierten, orographisch rechten Seitenhanges ist ein Caricetum sempervirentis (Tab. A1, Anhang) ausgebildet. Für die Gesellschaft typische Arten sind Carex sempervirens, Avenula versicolor, Anthoxanthum alpinum und Nardus stricta unter den Gräsern, sowie die Kräuter Campanula barbata, Potentilla aurea und Geum montanum. An windexponierten Stellen ist ein hoher Anteil von Strauchflechten, vor allem von Cladonia arbuscula und Cetraria islandica auffallend. Charakteristisch ist das Auftreten zahlreicher Zwergsträucher wie Juniperus communis ssp. nana, Arctostaphylos uva-ursi, Calluna vulgaris, Vaccinium vitis-idaea, V. myrtillus und Rhododendron ferrugineum. Sie erreichen v.a. im Bereich oberhalb der Moräne von 1858 zuweilen bedeutende Deckungswerte, gehen aber mit zunehmender Nähe zum Gletscher zurück.
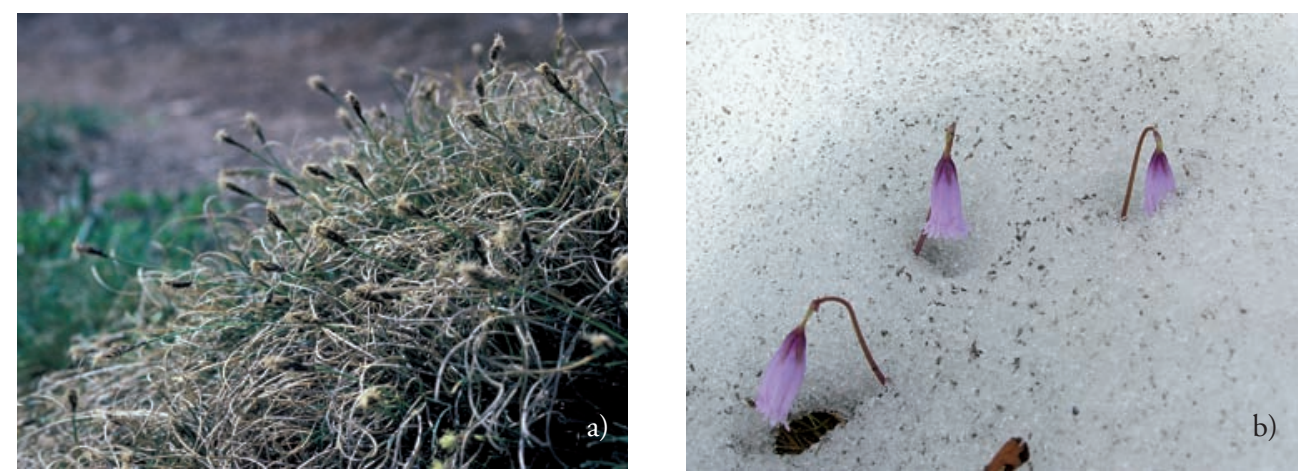

Typischer Krummseggenrasen

(Caricetum curvulae Rübel 1911)

Krummseggenrasen (Tab. A1, Anhang) finden sich großflächig am Rücken der Hohen Mut. Im Rotmoostal ist die Gesellschaft in wenig bewegten Seitenhangbereichen außerhalb des Gletschervorfeldes ausgebildet: Im Bereich der Moräne 1858 tritt sie am orographisch linken Hang recht ausgedehnt, sowie kleinflächig im Unter- und Oberhangbereich orographisch rechts auf. Im Bereich der Moräne 1923 kann man die Gesellschaft kleinflächig im oberen Hangbereich am orographisch rechten Seitenhang antreffen.

Bei geringer Hangneigung tritt Carex curvula (Abb. 14a) rasenbildend in Erscheinung, die assoziierte Begleitartengarnitur ist kaum relevant, so z.B.: Anthoxanthum alpinum, Festuca halleri, Avenula versicolor, Potentilla aurea, Geum montanum und Phyteuma hemisphaericum. Stellenweise werden Standorte längerer Schneebedeckung von Schneebodenelementen wie

Abb. 14:

a) Carex curvula - b) Soldanella pusilla (Foto: B. Erschbamer, F. Nagl) 
Salix herbacea, Arenaria biflora, Sibbaldia procumbens und Soldanella pusilla (Abb. 14b) gekennzeichnet. An exponierten Windecken beteiligen sich Strauchflechten verstärkt am Bestandesaufbau.

Bei zunehmender Neigung im Bereich der Seitenhänge kennzeichnet ein stufiger Aufbau die Bestände. Neben den inselartig wachsenden Horsten von Carex curvula gewinnen andere Arten wie Agrostis rupestris, Avenula versicolor, Juncus trifidus, Luzula lutea, Minuartia sedoides, Silene acaulis s. lat., Potentilla aurea, Euphrasia minima, Veronica bellidioides, Pedicularis kerneri und Campanula barbata an Bedeutung.

\section{Vegetation der Talebene}

\section{Nardus stricta-Gesellschaft}

Bürstlingsrasen bilden die vorherrschende Gesellschaft der Weideflächen in der subalpinen und unteren alpinen Stufe (Grabherr 1993). Am Taleingang im Bereich des Schönwieskopfes stellen sie eine großflächig verbreitete Vegetationseinheit dar. Infolge der Weidenutzung hat sich hier Nardus stricta stark ausgebreitet und dominiert mit hoher Deckung die in der Regel kurzrasigen Bestände (Tab. A4, Anhang). Potentilla aurea und Scorzoneroides helvetica treten stärker in Erscheinung. Daneben spielen auch Mutellina adonidifolia und Geum montanum eine Rolle für den Bestandesaufbau. $\mathrm{Zu}$ den häufigen Begleitern zählen darüber hinaus Antho- xanthum alpinum, Euphrasia minima, Homogyne alpina, Phyteuma hemisphaericum, Soldanella pusilla, Carex curvula, Festuca rubra agg. und Luzula sudetica.

\section{Besiedelungsprozesse}

Die Besiedelungsprozesse im Gletschervorfeld werden von abiotischen und biotischen Faktoren bestimmt (Matthews 1992). Höhenlage, Mikrotopographie, Korngröße des Substrats und Feuchtigkeit sind entscheidende abiotische Parameter. Unter den biotischen Faktoren sind Diasporenverfügbarkeit (Diasporeneintrag, Diasporenbank, Diasporenproduktion), Keimungsfähigkeit, Wachstumspotential und die Interaktionen zwischen den Pflanzen bedeutsam.

\section{Diasporengröße, Diasporenregen, Diasporenbank}

Pionierarten wie beispielsweise Saxifraga aizoides oder Saxifraga oppositifolia haben viele, kleine Samen (109 bzw. 65 Samen pro Kapsel, Kneringer 1998) mit einem Gewicht von 0,05 bzw. 0,09 mg (Marcante 2008). Durchschnittlich werden mehrere Tausend Samen pro Pflanze produziert, die durch den Wind verbreitet werden (Stöcklin und Bäumler 1996, Kneringer 1998, Finch 2008). Ein Vergrabungsex- 


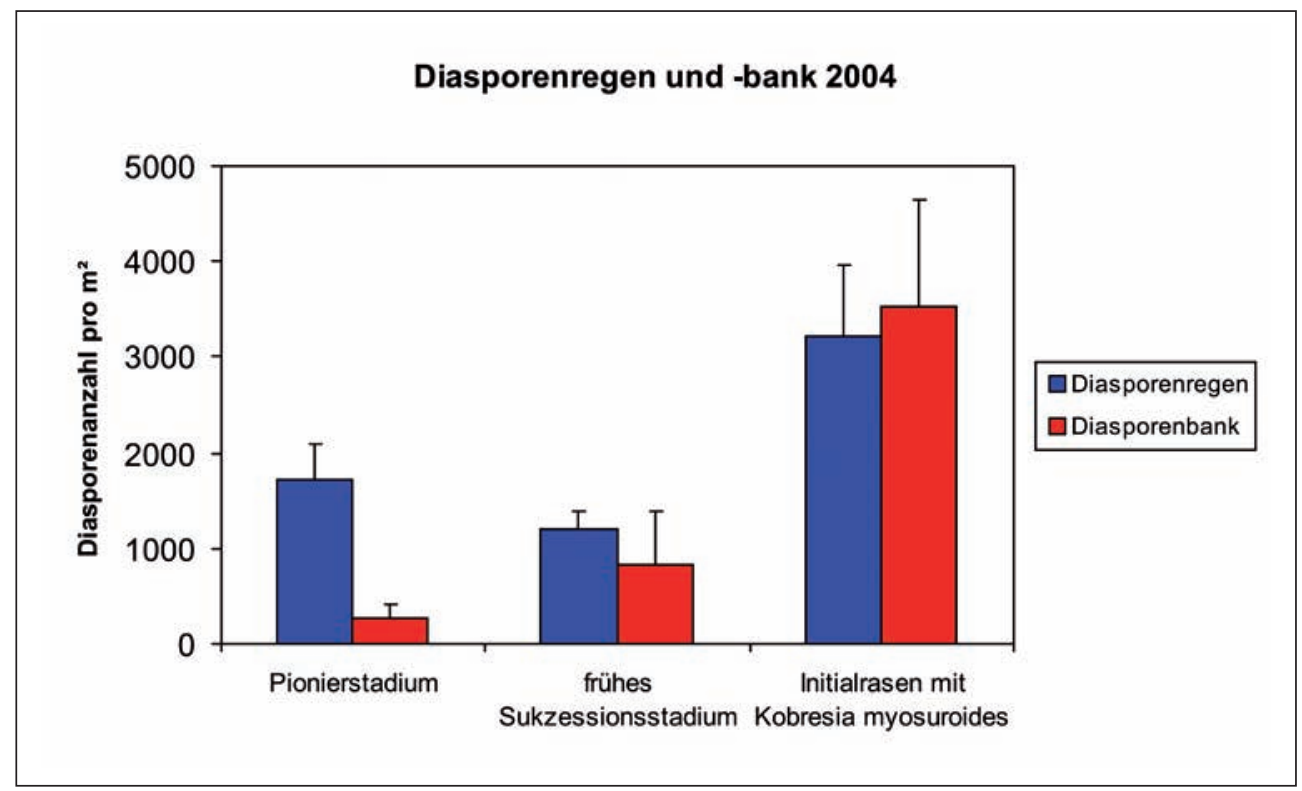

Abb. 15:

Diasporenregen (Finch 2008) und Diasporenbank (Marcante et al. 2009a) 2004 im Gletschervorfeld des Rotmoosferners. Angegeben sind die mittlere Diasporenanzahl pro $\mathrm{m}^{2}$ und die Standardabweichung.

periment zeigte, dass Saxifraga-Samen über eine lange Lebensfähigkeit verfügen (mindestens 5 Jahre, Schwienbacher et al. 2010). Sie sind es auch, die den Großteil des Diasporenregens und der Diasporenbank im Bereich des Pionierstadiums bestimmen (Abb. 15, Finch 2008, Marcante et al. 2009a). Der Eintrag von Saxifraga aizoides auf rezent eisfreie Moränen des Rotmoosferners erfolgt hauptsächlich über Samen und Pflanzenbruchstücke vom orographisch rechten Seitenhang des Gletschertales (48\%, Raffl et al. 2006b). Der rezente Genfluss im Bereich des Gletschervorfeldes selbst beträgt $24 \%$ (Raffl et al. 2006b). Aber auch Ferneintrag aus dem angrenzenden Gaisbergtal (4\%,
Raffl et al. 2006b) wurde mit Hilfe von molekulargenetischen Analysen nachgewiesen.

Folgearten haben in der Regel bereits größere Diasporen (Trifolium pallescens: 0,57 $\mathrm{mg}$, Silene acaulis s. lat. 0,24 mg, Marcante 2008) und produzieren entsprechend weniger (463 bzw. 683 Samen pro Pflanze, Kneringer 1998). Aber auch sie werden hauptsächlich durch den Wind ausgebreitet und finden sich vor allem im Diasporenregen (Abb. 15, Finch 2008) und in der Diasporenbank (Abb. 15, Marcante et al. 2009a) des frühen Sukzessionsstadiums und des Initialrasenstadiums auf 40-70 bzw. 70-100 Jahre eisfreien Moränen. Im Initialrasen mit Kobresia myosuroides ist 
die Varianz des Diasporengewichts am höchsten (Saxifraga paniculata: 0,05 mg; Anthyllis vulneraria ssp. alpicola: $3,75 \mathrm{mg}$, Marcante 2008). Pflanzen mit schweren Diasporen bilden vergleichsweise viel weniger pro Pflanze aus (Anthyllis vulneraria ssp. alpicola 33, Kneringer 1998).

Viele Gletschervorfeldarten sind sog. "Wintersteher", d.h. sie streuen ihre Diasporen nicht zur Gänze im Herbst aus, sondern entlassen sie teilweise erst nach der Schneeschmelze im Frühsommer. Untersuchungen von Finch (2008) haben gezeigt, dass beispielsweise Saxifraga aizoides, Saxifraga oppositifolia, Linaria alpina, Silene acaulis s. lat. im Diasporenregen der Monate Juni und Juli zu finden waren. Es handelte sich dabei um Samen aus dem Vorjahr, da die Arten zu diesem Zeitpunkt erst blühten oder Blütenknospen aufwiesen.

Die Diasporenbank wird entlang des Gletschervorfeldes kontinuierlich aufgebaut (Abb. 15). Die Pionierarten bleiben zwar bis in das Stadium der Initialrasen mit Kobresia myosuroides im Boden vorhanden (Marcante et al. 2009a), dominant sind jedoch die im jeweiligen Stadium oberirdisch vorherrschenden Arten (Tab. A1, Anhang).

\section{Keimlingsaufkommen}

Abhängig von den mikroklimatischen Bedingungen nach der Schneeschmelze und während der jeweiligen Vegetationsperiode variiert die Anzahl der Keimlinge. Im Pionierstadium wurden beispielsweise 6-934 Keimlinge pro $\mathrm{m}^{2}$ festgestellt, im frühen Sukzessionsstadium 13-1373 Keimlinge pro $\mathrm{m}^{2}$ (Niederfriniger Schlag \& Erschbamer 2000). Allerdings ist das Pionierstadium ganz klar samenlimitiert: eine Ansaat erhöhte die Keimlingsanzahl, sofern genügend Feuchtigkeit vorhanden war (Erschbamer et al. 2008, Schwienbacher, unpubl.). Späte Sukzessionsarten können durchaus in jungen Flächen keimen, wenn sie angesät werden (Niederfriniger Schlag \& Erschbamer 2000) und sie etablieren sich dort auch (Erschbamer et al. 2008). Obwohl für Gletschervorfeldarten ein gutes Fernausbreitungspotential festgestellt wurde (Tackenberg und Stöcklin 2008), scheinen vor allem die späten Sukzessionsarten kaum die jungen Moränen zu erreichen.

Die bereits vorhandene Vegetation fördert eine dauerhafte Ansiedelung (Erschbamer et al. 2008). Entscheidend für den Keimungs- und Etablierungserfolg ist die Korngröße des Substrates: grobkörniges Material mit wenig Schluff und Ton ist nicht ideal für das Keimlingsaufkommen (Schwienbacher, unpubl.), da es kaum Feuchtigkeit halten kann. 


\section{Wachstumspotential}

Das Wachstumspotential ist bei Saxifraga aizoides sehr gering. Nach 100 Tagen Wachstum in der Klimakammer erreichte die Art eine Gesamtbiomasse von 8,11 mg. Für Poa alpina resultierte bei diesem Experiment eine Gesamtbiomasse von 445,22 mg, Anthyllis vulneraria ssp. alpicola wies 160,52 mg auf (Niederfriniger Schlag 2001). Diese Ergebnisse stimmen sehr gut mit den Elementen der Populationsentwicklung überein (Marcante et al. 2009b): bei Saxifraga aizoides spielt das Wachstum eine geringe Rolle für den Erhalt der Population, während das Überleben von großen Individuen als entscheidender Parameter identifiziert wurde. Auch die Fekundität hatte nicht einen überragenden Einfluss, sondern reichte gerade aus, um einen Anstieg der Populationsgröße zu garantieren. Im Gegensatz dazu übte das Wachstum bei Poa alpina und Anthyllis vulneraria ssp. alpicola einen wesentlich stärkeren Einfluss auf die Populationsentwicklung aus (Marcante et al. 2009b).

\section{Konkurrenz}

Ein besonders spannender Aspekt im Sukzessionsgeschehen ist die Abfolge und Ersetzung von Arten. Studien in Dauerflächen sind geeignet, die Geschwindigkeit dieser Prozesse zu untersuchen (Erschbamer et al. 2008). Im Pionierstadium nahmen Saxifraga oppositifolia und Saxifraga

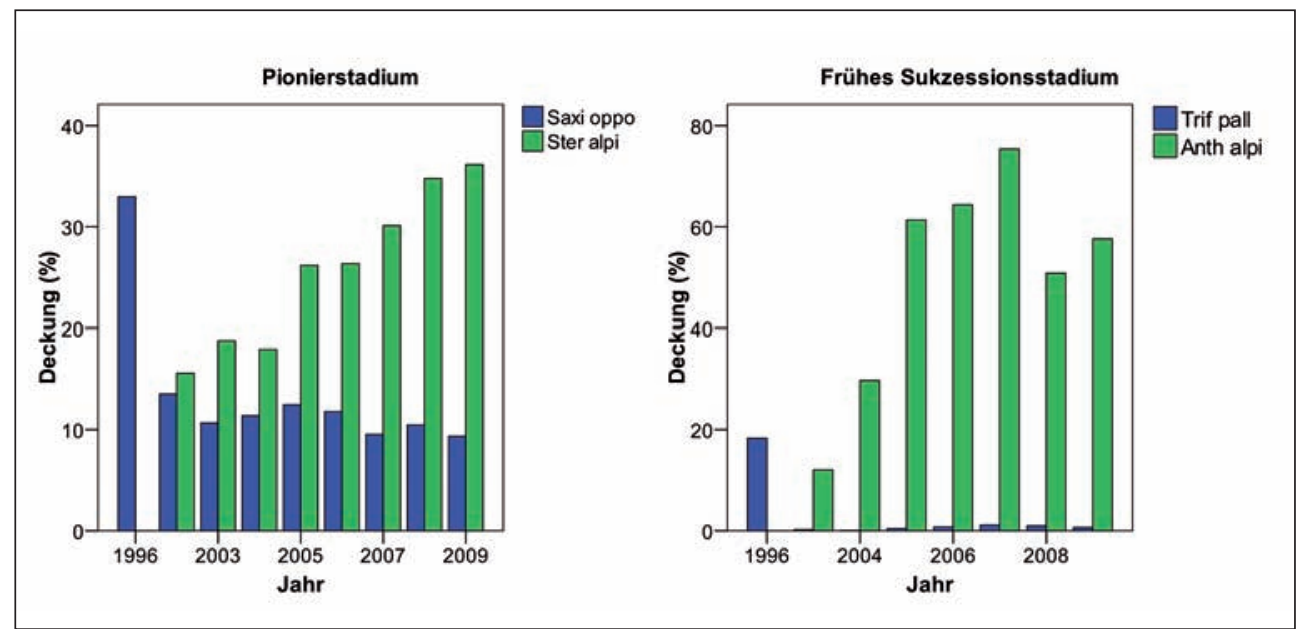

Abb. 16:

links - Deckung von Saxifraga oppositifolia und Stereocaulon alpinum von 1996 bis 2009 in 25x25 cm Dauerflächen im Pionierstadium (Flächen ohne Behandlung); rechts - Deckung von Trifolium pallescens und Anthyllis vulneraria ssp. alpicola im frühen Sukzessionsstadium (Flächen mit Ansaat in den Jahren 1996/1997). 
aizoides im Verlauf von 13 Jahren signifikant ab (Abb. 16). Diese Pionierpflanzen scheinen aber nicht durch Folgearten in Bedrängnis geraten zu sein, sondern sie starben wohl aus Altersgründen ab. Für Saxifraga oppositifolia wurde beispielsweise mit Hilfe der Herbchronologie (Dietz und Schweingruber 2001) ein maximales Alter von 17 Jahren festgestellt (Erschbamer und Retter 2004). Die abgestorbenen Saxifraga-Bereiche wurden bislang kaum wiederbesiedelt, obwohl in den Dauerflächen gerade die Flechte Stereocaulon alpinum signifikant an Deckung zunahm (Abb. 16).

Auch im frühen Sukzessionsstadium wurde ein altersbedingtes Absterben beobachtet, und zwar von Trifolium pallescens (Erschbamer et al. 2008). Aus der Herbchronologie-Studie wissen wir, dass Trifolium pallescens im frühen Sukzessionsstadium ein durchschnittliches Alter von 6 Jahren erreichen kann (Kuen 2001). Das Maximalalter dieser Art beläuft sich auf 11 (Kuen 2001) bzw. 10 Jahre (Schweingruber et al. 2007). In angesäten Flächen des frühen Sukzessionsstadiums zeigen sich allerdings sehr wohl Ersetzungsvorgänge: hier dehnte sich Anthyllis vulneraria ssp. alpicola sehr stark aus, sodass Trifolium pallescens zwar als Keimling noch vorhanden war, aber sich nicht mehr zu adulten Pflanzen weiterentwickeln konnte (Abb. 16).

Detaillierte Studien zu den Interaktionsvorgängen zwischen Gletschervorfeldpflanzen auf unterschiedlich alten Morä- nenflächen wären unbedingt notwendig. In der Literatur gibt es zwar verschiedenste Modelle, die eine allgemeine Erklärung der Primärsukzession anbieten, so z.B. das „facilitation-tolerance-inhibition- model“ von Connell \& Slatyer (1977), das „resource ratio- model“ von Tilman (1985, 1988), das "invasion model” (van Hulst 1992), das "Competition-StresstoleratorRuderal-model“ (Grime 2001, Caccianiga et al. 2006), um nur einige zu nennen. Eine einschlägige empirische Studie über Interaktionen im Gelände fehlt jedoch.

\section{Literatur}

Bortenschlager, S. (1984) Beiträge zur Vegetationsgeschichte Tirols I. Inneres Ötztal und unteres Inntal. Berichte des Naturwissenschaftlich-Medizinischen Vereins in Innsbruck 71: 19-56.

Caccianiga, M., Luzzaro, A., Pierce, S., Ceriani, R.M. \& Cerabolini, B. (2006) The functional basis of a primary succession resolved by CSR classification. Oikos 112: 10-20.

Connell, J.H. \& Slatyer, R.O. (1977) Mechanisms of succession in natural communities and their role in community stability and organization. The American Naturalist 111: 1119-1144.

Dietz, H. \& Schweingruber, F. (2001) Development of growth rings in roots of dicotyledonous perennial herbs: experimental 
analysis of ecological factors. Bulletin of the Geobotanical Institute ETH Zürich 67: 97-105.

Erschbamer, B. \& Retter, V. (2004) How long can glacier foreland species live? Flora 199: 500-504.

Erschbamer, B. (2001) Responses of some Austrian glacier foreland plants to experimentally changed microclimatic conditions. In: Fingerprints of Climate Change, Walther, G-R, Burga, CA, Edwards, PJ (eds) Kluwer Academic/Plenum Publishers, New York, 263-279.

Erschbamer, B. (2007) Winners and losers of climate change in a central alpine glacier foreland. Arctic, Antarctic, and Alpine Research 39: 237-244.

Erschbamer, B. (2009) Faktoren und Prozesse der Besiedelung im alpinen Neuland. Berichte der Reinhold-Tüxen-Gesellschaft 21: 253-265.

Erschbamer, B., Bitterlich, W. \& Raffl, C. (1999) Die Vegetation als Indikator für die Bodenbildung im Gletschervorfeld des Rotmoosferners (Obergurgl, Ötztal, Nordtirol). Berichte des Naturwissenschaftlich-Medizinischen Vereins in Innsbruck 86: 107-122.

Erschbamer, B., Kneringer, E. \& Niederfriniger Schlag, R. (2001) Seed rain, soil seed bank, seedling recruitment, and survival of seedlings on a glacier foreland in the Central Alps. Flora 196: 304-312.

Erschbamer, B., Niederfriniger Schlag, R. \& Winkler, E. (2008) Colonization processes on a central Alpine glacier foreland.
Journal of Vegetation Science 19/6: 855862.

Finch, K. (2008) Diasporenregen im Gletschervorfeld des Rotmoosferners, Obergurgl, Ötztal. Diplomarbeit Universität Innsbruck.

Fischer, M.A., Oswald, K. \& Adler, W. (2008) Exkursionsflora für Österreich, Liechtenstein und Südtirol. 3. Aufl. Land Oberösterreich, Biologiezentrum der Oberösterreichischen Landesmuseen, Linz.

Friedel, H. (1938) Die Pflanzenbesiedelung im Vorfeld des Hintereisferners. Zeitschrift für Gletscherkunde 26: 215-239.

Gams, H. (1939) Die Pflanzendecke der Vendter Täler. Festschrift zum 40jährigen Bestehen des DAV, Zweig Mark Brandenburg. Bruckmann Verlag, München, 56-63.

Grabherr, G. (1993) Caricetea curvulae. In: Die Pflanzengesellschaften Österreichs Teil II, Grabherr G, Mucina L (eds) Gustav Fischer Verlag, Jena, 343-372.

Grime, J.P. (2001) Plant strategies, vegetation processes, and ecosystem properties. John Wiley \& Sons, Chichester, New York, Toronto.

Heufler, L.v. \& Stotter, M. (1840) Geognostisch-botanische Bemerkungen auf einer Reise durch Oetzthal und Schnals. Neue Zeitschrift des Ferdinandeums für Tirol und Vorarlberg 6.

IPCC (2007) Climate Change 2007 - The Physical Science Basis. Contribution of Working Group I to the Fourth Assessment Report of the Intergovernmental 
Panel on Climate Change. Cambridge University Press, Cambridge, United Kingdom and New York, NY, USA.

Jochimsen, M. (1962) Die Vegetationsentwicklung in den Vorfeldern des Rotmoos- und Gaisbergferners im Ötztal. Dissertation Universität Innsbruck.

Jochimsen, M. (1963) Vegetationsentwicklung in hochalpinem Neuland. Beobachtungen der Dauerflächen im hochalpinen Neuland. Berichte des Naturwissenschaftlich-Medizinischen Vereins in Innsbruck 53: 109-123.

Jochimsen, M. (1970) Die Vegetationsentwicklung auf Moränenböden in Abhängigkeit von einigen Umweltfaktoren. Veröffentlichungen der Universität Innsbruck 46: 5-22.

Kerner von Marilaun, A. (1863) Das Pflanzenleben der Donauländer. Verlag der Wagner'schen Universitäts-Buchhandlung, Innsbruck.

Klebelsberg, R. (1913) Das Vordringen der Hochgebirgsvegetation in den Tiroler Alpen. Österreichische Botanische Zeitschrift 63: 177-186, 241-254.

Kneringer, E. (1998) Diasporenregen und Diasporenbank im Gletschervorfeld des Rotmoosferners (Ötztaler Alpen, Tirol). Diplomarbeit Universität Innsbruck.

Kuen, V. \& Erschbamer, B. (2002) Comparative study between morphology and age of Trifolium pallescens in a glacier foreland of the Central Alps. Flora 197: 379-384.

Kuen, V. (2001) Alters- und Populationsstruktur von Trifolium pallescens im
Gletschervorfeld des Rotmoosferners (Ötztal, Tirol). Diplomarbeit Universität Innsbruck.

Mallaun, M. (2001) Verlauf der Primärsukzession in einem zentralalpinen Gletschervorfeld (Ötztaler Alpen, Tirol). Diplomarbeit Universität Innsbruck.

Marcante, S. (2008) Life history traits and population dynamics of glacier foreland species. Dissertation Universität Innsbruck.

Marcante, S., Schwienbacher, E. \& Erschbamer, B. (2009a) Genesis of a soil seed bank on a primary succession in the Central Alps (Ötztal, Austria). Flora 204: 434-444.

Marcante, S., Winkler, E. \& Erschbamer, B. (2009b) Population dynamics along a primary succession gradient: do alpine species fit into demographic succession theory? Annals of Botany 103: 11291143.

Matthews, J.A. (1992) The Ecology of Recently-Deglaciated Terrain. A geoecological approach to glacier forelands and primary succession. Cambridge University Press, Cambridge.

Niederfriniger Schlag, R. \& Erschbamer, B. (2000) Germination and establishment of seedlings on a glacier foreland in the Central Alps, Austria. Arctic, Antarctic, and Alpine Research 32: 270-277.

Niederfriniger Schlag, R. (2001) Primärsukzession im Gletschervorfeld. Keimung, Etablierung, Wachstum und Interaktionen im Gletschervorfeld des Rotmoos- 
ferners (Ötztal, Tirol). Dissertation Universität Innsbruck.

Raffl, C. \& Erschbamer, B. (2004) Comparative vegetation analyses of two transects crossing a characteristic glacier valley in the Central Alps. Phytocoenologia 34/2: 225-240.

Raffl, C. (1999) Vegetationsgradienten und Sukzessionsmuster in einem zentralalpinen Gletschervorfeld (Ötztaler Alpen, Tirol). Diplomarbeit Universität Innsbruck.

Raffl, C., Holderegger, R., Parson, W. \& Erschbamer, B. (2008) Patterns in genetic diversity of Trifolium pallescens populations do not reflect chronosequence on alpine glacier forelands. Heredity 100: 526-532.

Raffl, C., Mallaun, M., Mayer, R. \& Erschbamer, B. (2006a) Vegetation succession pattern and diversity changes in a glacier valley, Central Alps, Austria. Arctic, Antarctic, and Alpine Research 38/3: 421 428.

Raffl, C., Schönswetter, P. \& Erschbamer, B. (2006b) 'Sax-sess' - genetics of primary succession in a pioneer species on two parallel glacier forelands. Molecular Ecology 15: 2433-2440.

Raffl-Wallinger, C. (2006) Comparative analyses of the primary succession on Central Alpine glacier forelands on inter- and intraspecific levels. Dissertation Universität Innsbruck.

Rudolph, D. (1991) Vergleichende Studien zur Vegetationsentwicklung im Vorfeld des Rotmoosferners/Ötztaler Alpen. Diplomarbeit Universität Gießen.

Schweingruber, F., Münch, A., \& Schwarz, R. (2007) Dendrochronologie von Kräutern und Sträuchern im Vorfeld des Morteratschgletschers. Bauhinia 20: 5-17.

Schwienbacher, E. \& Erschbamer, B. (2002) Longevity of seeds in a glacier foreland of the Central Alps - A burial experiment. Bulletin of the Geobotanical Institute ETH Zürich 68: 63-71.

Schwienbacher, E. \& Erschbamer, B. (2008a) Sensitivity of glacier foreland species to drought conditions during germination. Berichte des Naturwissenschaftlich-Medizinischen Vereins in Innsbruck, Supplementum 18: 29.

Schwienbacher, E. \& Erschbamer, B. (2008b) Effects of temperature and drought stress on germination and establishment of glacier foreland species. Sauteria 16: 388-389.

Schwienbacher, E. (2004) Populationsbiologische Studien an frühen Sukzessionsarten im Gletschervorfeld des Rotmoosferners (Ötztal, Tirol). Verbreitung und Standortsansprüche von Artemisia genipi und A. mutellina, Populationsstruktur von $A$. genipi. Diplomarbeit Universität Innsbruck.

Schwienbacher, E., Marcante, S. \& Erschbamer, B. (2010) Alpine species seed longevity in the soil in relation to seed size and shape - a 5-year burial experiment in the Central Alps. Flora 205: in press. 
Stöcklin, J. \& Bäumler, E. (1996) Seed rain, seedling establishment and clonal growth strategies on a glacier foreland. Journal of Vegetation Science 7: 45-56.

Tackenberg, O. \& Stöcklin, J. (2008) Wind dispersal of alpine plant species: a comparison with lowland species. Journal of Vegetation Science 19: 109-118.

Tilman, D. (1985) The resource-ratio hypothesis of plant succession. The American Naturalist 125: 827-852.

Tilman, D. (1988) Plant strategies and the dynamics and structure of plant communities. Princeton University Press, Princeton, New Jersey.

van Hulst, R. (1992) From population dynamics to community dynamics: modelling succession as a species replacement process. In: Succession, Glenn-Lewin DC (ed) Chapman \& Hall, London, 188-214.

Walker, L.R. \& Del Moral, R. (2003) Primary Succession and Ecosystem Rehabilitation. Cambridge University Press, Cambridge.
Wiedemann, T. (1991) Die Entwicklung von Boden und Vegetation im Vorfeld des Gaißbergferners/Ötztaler Alpen. Diplomarbeit Universität Gießen.

\section{Verzeichnis der AutorInnen}

Fabian Nagl

Universität Innsbruck

Institut für Botanik

Sternwartestr. 15, 6020 Innsbruck, Österreich

Fabian.Nagl@uibk.ac.at

Brigitta Erschbamer

Universität Innsbruck

Institut für Botanik

Sternwartestr. 15, 6020 Innsbruck, Österreich

Brigitta.Erschbamer@uibk.ac.at 


\title{
Zur Kryptogamenflora im Rotmoostal
}

\author{
Georg Gärtner
}

\section{Zusammenfassung}

Das Gurgler Rotmoostal mit seinem am Talausgang gelegenen, mächtigen Moorkomplex gehört zu den eindrucksvollsten Naturräumen in den Ötztaler Alpen im Raum Obergurgl (Nordtirol, Österreich). Nach kurzer historischer Darstellung der naturwissenschaftlichen Erforschung, die eng mit der Gletscherforschung verknüpft ist, werden charakteristische Vertreter der Moose, Flechten und Algen des eigentlichen Moorkomplexes sowie des Gletschervorfeldes mit Hinweisen zu ihrer Systematik und Ökologie angeführt. Ergänzende Artenlisten aus der Literatur sowie nach Herbarbelegen sind im Anhang zusammengestellt.

\section{Abstract}

Data on cryptogams (mosses, lichens, algae) are presented from the Rotmoos valley (Obergurgl, Tyrol, Austria), one of the most intensively studied areas in the Central Alps. Classical floristic studies from middle of $19^{\text {th }}$ and $20^{\text {th }}$ century as well as recent investigations provide an overview of characteristic cryptogams in the mire complex of Rotmoos and the glacial retreat area. Notes are also included on taxonomy and ecology of dominant species. Some accompanying lists of recorded mosses, lichens and algae from literature and herbaria provide additional informations on the biodiversity of the area.

\section{Einleitung}

Das Gurgler Rotmoostal mit seinem am Talausgang gelegenen, mächtigen Moorkomplex gehört zu den eindrucksvollsten Naturräumen in den Ötztaler Alpen. Seine naturwissenschaftliche Erforschung ist, wie im gesamten inneren Ötztal, eng mit der Gletscherforschung verknüpft. Über die Floren- und Vegetationsgeschichte im Raum Obergurgl und im Rotmoos liegen bereits zahlreiche Veröffentlichungen vor (siehe Übersichten in Gams 1970, Erschbamer 2000, Gärtner 2000, vgl. Kap. 4, Bortenschlager). Die ersten Hinweise zum Rotmoos lieferte Kerner (1863), wobei er auf Berichte des Gurgler Pfarrers, Wanderlehrers und „Mistapostels" Kurat Adolf Trientl (bei Kerner loc. cit. p. 269 als Alois Triendl!) zurückgriff. Trientl, ab 1856 als Pfarrer in Gurgl tätig, regte die Bevölkerung zum Torfabbau für die Gewinnung von Heizmaterial im Rot- 
moos (im Bereich der Schönwieshütte) an (Kerner 1863, Jäger 1992). Während sich die moorkundlich-pollenanalytischen Forschungen beginnend mit Sarnthein (1936) bis heute auf den talauswärts gelegenen eigentlichen Moorkomplex des Rotmooses beschränken, bilden zur Zeit vegetationskundliche und populationsbiologische Untersuchungen im eigentlichen Gletschervorfeld des inneren Talbereiches botanische Forschungsschwerpunkte (dazu Erschbamer et al. 1999, Erschbamer 2000).

\section{Zur Forschung an Kryptogamen}

Historische Daten über Vorkommen niederer Pflanzen im Rotmoostal liegen erstmals aus den Jahren 1895/96 von Schmidle vor. Mehrere Exkursionen ins Ötztal führten ihn nicht nur zu den Flachslöchern von Längenfeld, sondern bis hinauf ins Rotmoos zum Studium der Algenflora in den Torfgewässern. An die hundert Arten, vorwiegend Desmidiaceen (Zieralgen), beschrieb Schmidle aus dem Rotmoos, allerdings fehlen detaillierte Standortsangaben (Schmidle 1895/96, Lenzenweger et al. 1997). Eine Artenliste der Aufsammlungen Schmidles findet sich im Anhang (Tab. A1). Die Erforschung der Flechtenflora des Ötztales beginnt mit Arnold (1876, 1878), spätere Daten vor allem aus der nivalen Zone der zentralen Ötztaler Alpen lieferten Poelt (1953), Pitschmann und Reisigl
(1955) und Tobolewski (1976). Eine aktuelle detaillierte Flechtenliste im Raum Obergurgl veröffentlichten Hofmann et al. (1988), speziell für das Rotmoostal sei auf Kap. 6, Türk und Erschbamer, verwiesen. Zur Moosflora des Rotmoostales liegen diverse Belege in den Herbarien des Botanischen Institutes der Universität Innsbruck (IB) und der AFO Obergurgl sowie in Privatherbarien diverser Teilnehmer von Exkursionen oder Botanischen Hochschulkursen. Eine gezielte Begehung des Tales sollte weitere Funddaten liefern (Tab. A2-3 im Anhang). Aus den wenigen Veröffentlichungen zur Moosflora des Obergurgler Gebietes sei hier der Beitrag von Pitschmann und Reisigl (1954) angeführt.

\section{Das Gurgler Rotmoos}

Vom südöstlichen Ende des Rotmoostals nach Nordwesten (talauswärts) blickend (Abb. 1) lassen sich deutlich zwei Landschaftsräume unterscheiden: Erstens von etwa Talmitte bis zur Kuppe des Schönwieskopfes der ca. $2 \mathrm{~km}$ lange eigentliche Rotmoos-Moorkomplex. Zweitens vom Ende der 1920er Moräne taleinwärts gegen den Gletscher der Grund-und Endmoränenkomplex bis zur Gletscherzunge. Landschaftsprägend für das gesamte Rotmoostal sind die mächtigen Sandund Schotterlagen der Rotmoosache. 


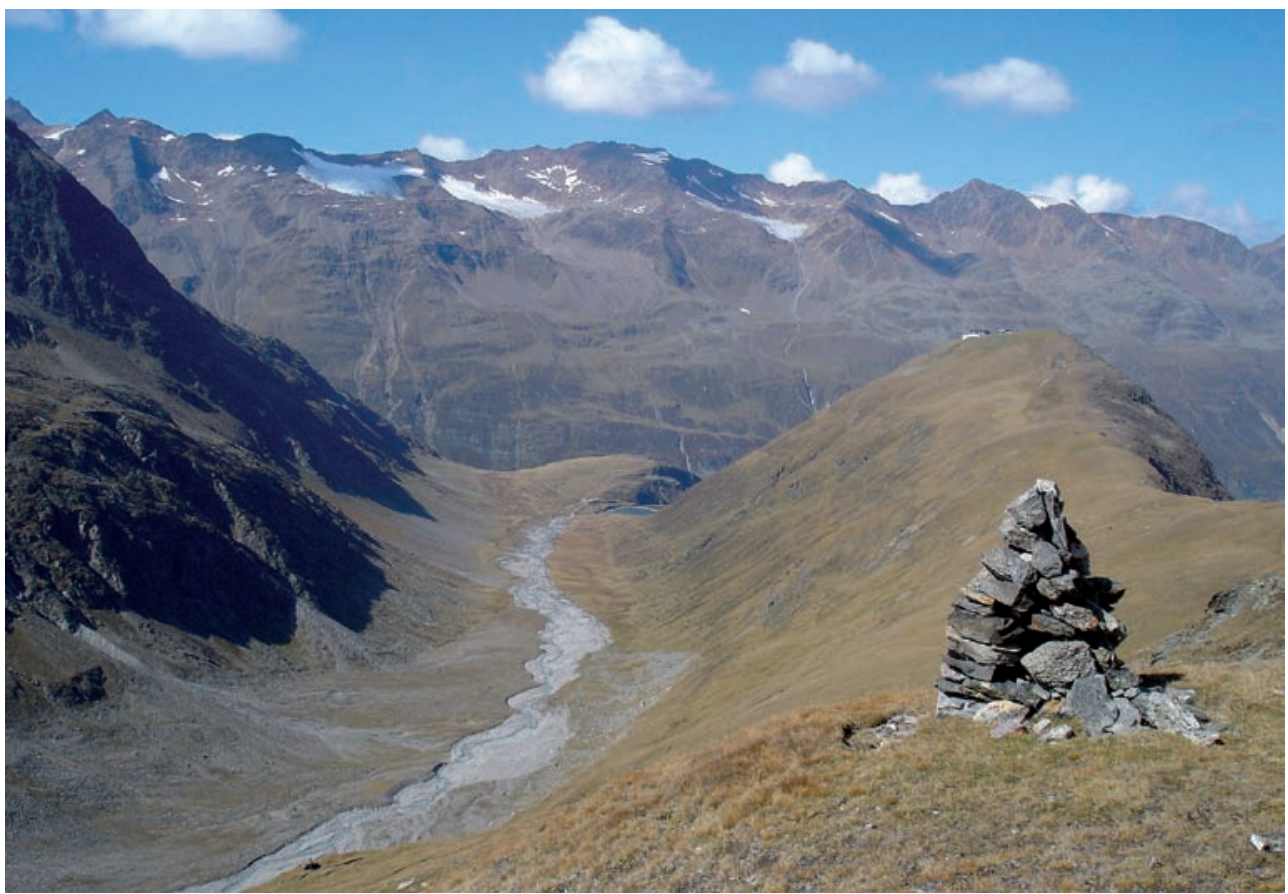

Abb. 1:

Das Rotmoostal talauswärts in nordwestlicher Richtung, rechts im Bild der Rücken der Hohen Mut, linke Hangseite „unter den Wasserfällen“ gegen Hangerer; typische Herbstfärbung des eigentlichen Moores im Hintergrund gegen Schönwieshütte; Aufnahmedatum: 23.9.2009 (Foto: G. Gärtner)

Ihre periodischen Überschwemmungen überschütten den Talgrund, aber auch das Moor, wobei der Torfkörper auf einer Länge von ca. 1,5 km immer wieder angeschnitten und erodiert wird. Nach Gams (1962) handelt es sich beim Rotmoos um ein beispielhaft ausgeprägtes Gletschertalmoor vom Kuchlmoos-Typ (benannt nach dem Kuchlmoos im Zillertal). Aus pollenanalytischen Untersuchungen von Bortenschlager (1970) geht hervor, dass die Torflager des Gurgler Rotmooses zur Gänze nachwärmezeitliche Bildungen sind. An den bachseitigen Aufschlüssen des Torfkörpers mit deutlich erkennbaren Wechsellagerungen von Torf und Ton lassen sich postglaziale Gletscherschwankungen nachweisen (Bortenschlager 1970, vgl. Kap. 4, Bortenschlager).

\section{Das eigentliche Rotmoos}

Der Name ist nach Gams (1962) nicht auf rotgefärbte Moosorganismen, sondern auf die rostfarbenen Eisenocker in den Moortümpeln und kleinen Seitenrinnsalen zurückzuführen. Solche Klein- 
gewässer beherbergen spezielle Bakterien (Eisenoxidierende Bakterien wie Leptothrix, Gallionella und andere), welche ölähnliche Oberflächenfilme verursachen können. Die außerordentlich charakteristische Herbst- und Frühjahrsfärbung der Vegetation (Abb. 1, 23. 9. 2009) in braunroten Farbtönen könnte nach Meinung des Verfassers durchaus auch namensgebend gewesen sein. In der schneefreien Zeit dominiert im Moor vor allem im Frühjahr und Herbst die Farbe rotbraun, verursacht einerseits durch Seggen, Wollgras und Haarbinse (Carex nigra, Eriophorum scheuchzeri und in großen Beständen Trichophorum caespitosum), andererseits durch „Braunmoose“. Dabei handelt es sich um eine Reihe von Laubmoos-Arten von dunkel-, rot - goldbrauner Farbe, die vor allem im Spätherbst am intensivsten wird. Im Moorkomplex nachgewiesene Arten (Belege im Herbar IB, leg. Rybnickova und Rybnicek 1970) sind unter anderen Pseudocalliergon trifarium, Warnstorfia sarmentosa (beide Sippen früher innerhalb der Sammelgattung Calliergon, Grims 1999, Köckinger et al. 2008), Warnstorfia trichophylla, Warnstorfia exannulata und Scorpidium revolvens (früher unter Drepanocladus). Von den Torfmoosen findet sich zwischen den Braunmoosen und Carex-Stängeln nicht selten Sphagnum platyphyllum. Bemerkenswert und auffallend durch die dunkelrote, fast schwarzrote Färbung sind quadratmetergroße Bestände des Lebermooses Scapania undulata (vor allem an den ins Moor strömenden Quellfluren von der orographisch rechten Talflanke) vergesellschaftet mit Philonotis sericea und Dicranella palustris (= Dichodontium p.). An den von der Rotmoos-Ache angeschnittenen Torfwänden kommen Dicranella cerviculata zusammen mit Pohlia proligera (leg. W. Maurer, Beleg im Herbar AFO) vor. Flechten treten im eigentlichen Moorkomplex weniger in Erscheinung, auf älterem angewittertem Torf wächst Icmadophila ericetorum. In den Trichophorum- und Carex-Beständen findet man Elemente der Zwergstrauchheiden, die mit Rasenfragmenten der Seitenhänge abrutschen oder an wasserzügigen Hängen ins Moor verschwemmt werden. Darunter sind verschiedene Rentierflechten (Cladonia arbuscula, $C$. rangiferina), sowie mehrere Strauchflechten wie Cetraria islandica, $C$. ericetorum, diverse Becherflechten (Cladonia fimbriata, C. pyxidata) und andere. Eine erste Zusammenstellung der gefundenen und belegten Moosarten ist im Anhang zu finden, sie ist aber bei weitem nicht vollständig.

\section{Moose des Gletschervorfeldes}

In den Pionierstadien der höheren Vegetation an trockenen oder feuchteren Abschnitten des Vorfeldes im Rotmoostal dominieren auch einige Moosarten. An trockenen, sandig-kiesigen Flächen 
wächst in großen Polstern Racomitrium canescens subsp. canescens (Abb. 2), eine anpassungsfähige, weitverbreitete Art, die durch ihre weißgrauen Glashaare an den Blattspitzen relativ leicht anzusprechen ist. Dieses Laubmoos ist im gesamten Gletschervorfeld auf unterschiedlichsten, doch meist trockeneren Substraten anzutreffen. Sehr häufig ist diese Pionierart mit einem weiteren xerophytischen Moos, Polytrichum piliferum, und der weißlichen Strauchflechte Stereocaulon alpinum vergesellschaftet. An feuchteren, wasserzügigen Stellen auf nassem Schwemmsand treten ebenfalls bestandsbildend die Laub- moose Pohlia filum (syn. P. gracilis) und Bryum schleicheri auf. Auf lange schneebedeckten ebenen Flächen im gesamten Gletschervorfeld kann sich eine Schneetälchenflora entwickeln, mit dominanten Moosen wie der grauschwarze, durch Wachsüberzug auffällige Schimmel-Lebermoos Anthelia juratzkana (Abb. 3) in Gesellschaft mit Polytrichum sexangulare (= $P$. norvegicum) (weitere Moosarten siehe Anhang).

Im gletschernahen Bereich des Rotmoostales sind einige weitere Moose aufgrund ihres Höhenvorkommens bemerkenswert: das Lebermoos Preissia quadrata (mit

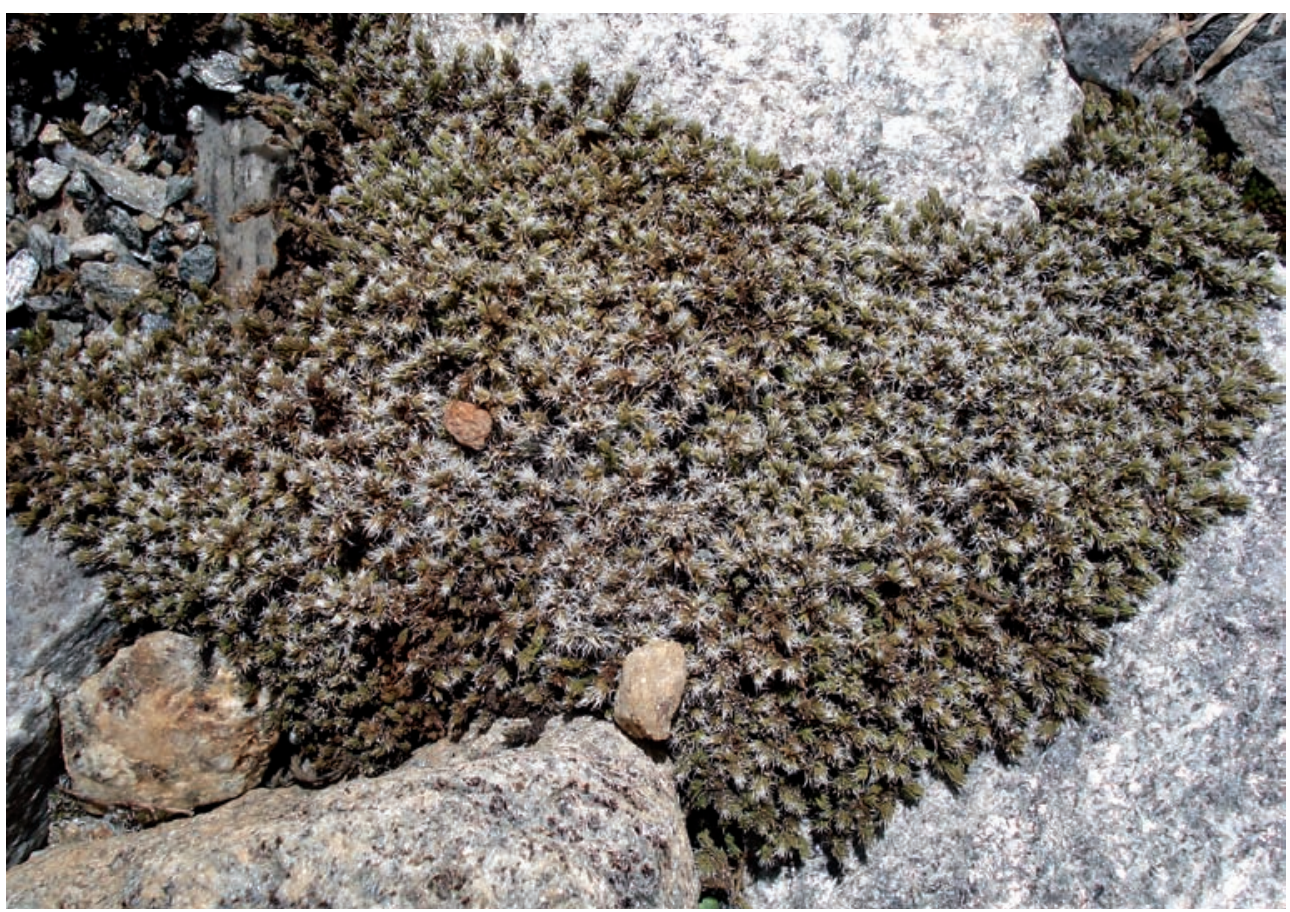

Abb. 2:

Pioniermoos des Gletschervorfeldes auf trockenen Sand-und Kiesböden: Racomitrium canescens subsp. canescens (Foto: G. Gärtner) 


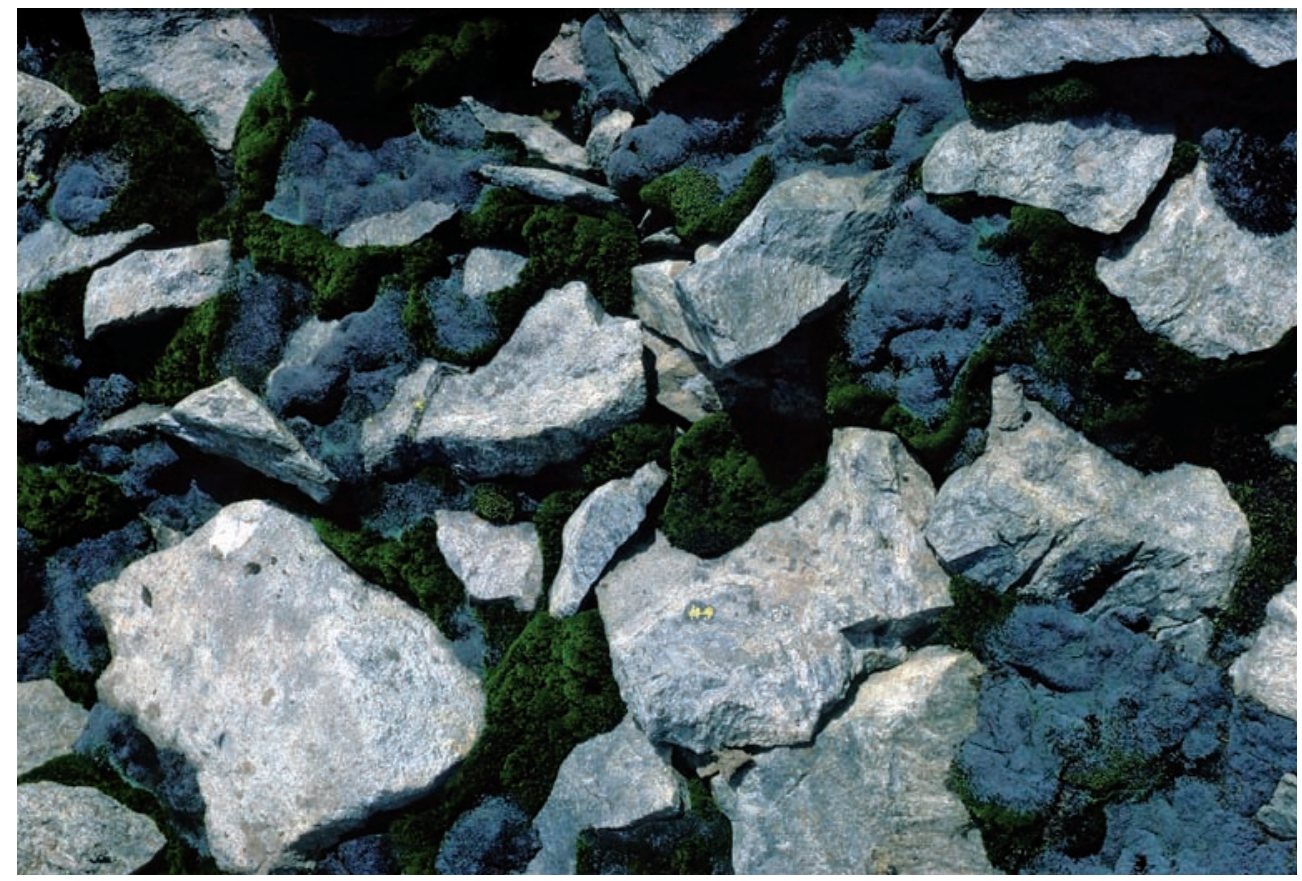

Abb. 3:

Auf vernässten Schneeböden im Gletschervorfeld: das Schimmel-Lebermoos Anthelia juratzkana mit grauem Wachsüberzug (Foto: G. Gärtner)

3.080 m Seehöhe auf einer Felsrippe im Rotmoosferner wohl höchster Fundort in den Alpen) sowie die Laubmoose Syntrichia ruralis und Mnium thomsonii (= $M$. orthorhynchum) jeweils auf $3180 \mathrm{~m}$ an der gleichen Lokalität (Pitschmann und Reisigl 1954).

Über die Flechten im Gletschervorfeld sei auf die Zusammenstellung im Kap. 6, Türk und Erschbamer, verwiesen. Während Rudolph (1991) noch 16 Flechtenund 18 Moosarten für das Rotmoos-Gletschervorfeld angibt, umfasst die Liste der Flechten bei Türk und Erschbamer bereits 75 Arten. Zwei auffällige Sippen, das häufig auf den älteren, bereits verfestigten Moränenstadien vorkommende Stereocaulon alpinum sowie die als Totengebein oder Wurmflechte leicht anzusprechende terrestrische Thamnolia vermicularis var. vermicularis, zeigen Abb. 4 und 5. Im Rahmen eines flechtenfloristischen Kurses an der Alpinen Forschungsstelle Obergurgl 1987 wurde eine erste floristische Übersicht über die Flechtendiversität des Gebietes um Obergurgl publiziert (Hofmann et al. 1988). Aus der Artenliste sind im Anhang hier noch einmal die für das Rotmoostal belegten Funde zusammengestellt (Tab. A4, Anhang). 


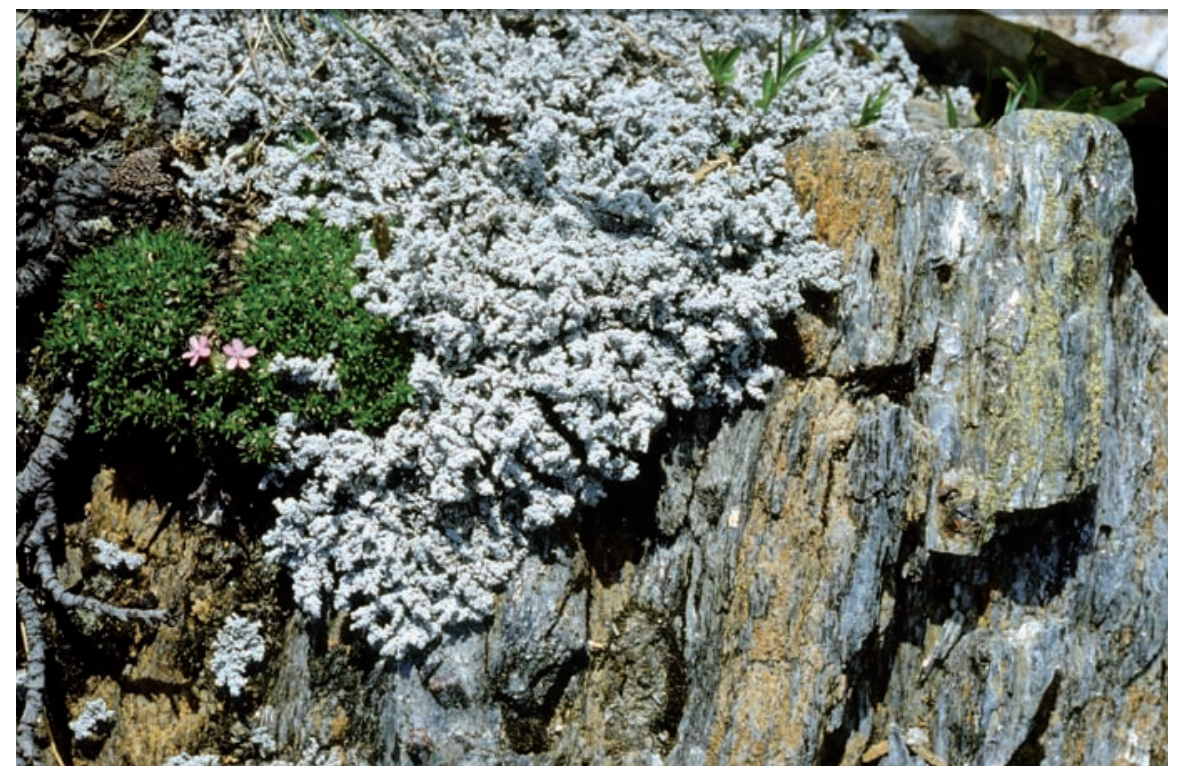

Abb. 4:

Ein Flechten-Pionier im Gletschervorfeld ist Stereocaulon alpinum, Foto: G. Gärtner

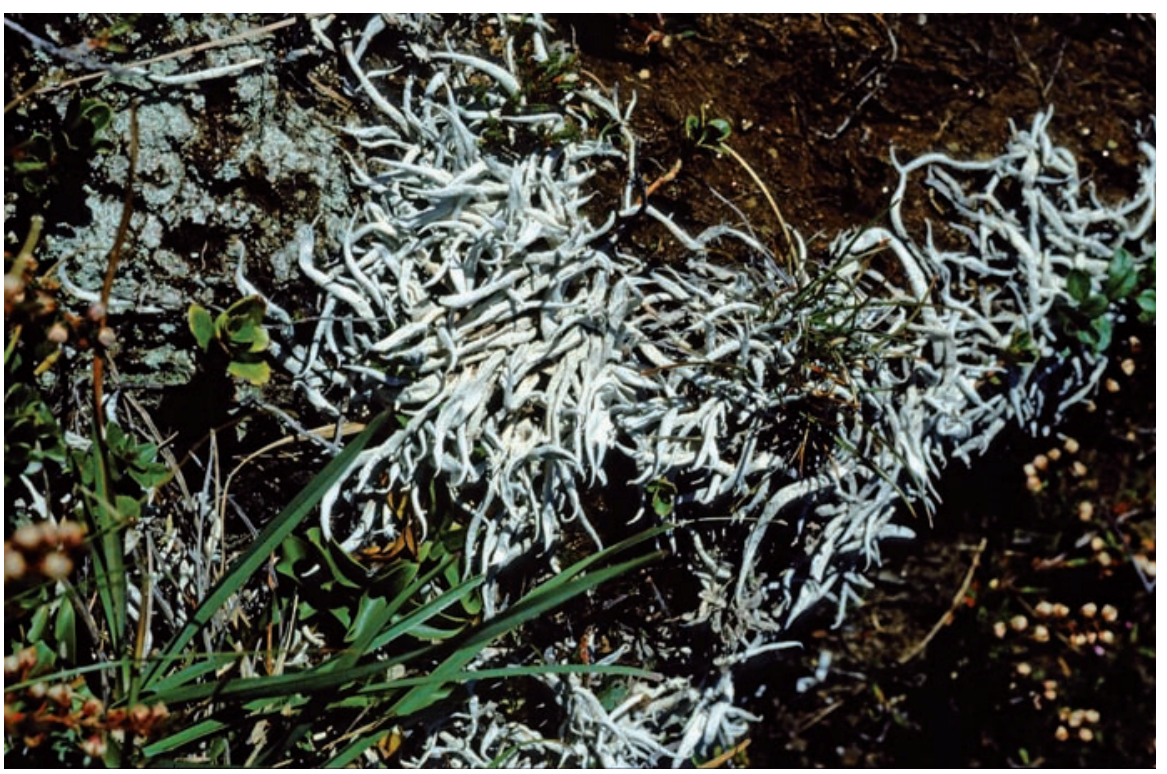

Abb. 5:

Auf Moränenböden an windexponierten Stellen auch im Gletschervorfeld nicht selten ist die

Wurmflechte Thamnolia vermicularis, Foto: G. Gärtner 
Algen im Rotmoos

Erste Fundnachweise von Algen aus dem Rotmoos (ohne genaue Lokalitätsangabe aber wohl beschränkt auf das eigentliche Rotmoos und die Torfstiche bei der Schönwieshütte) gehen auf Schmidle (1895, 1896) zurück, eine Liste seiner Funde ist als Anhang beigefügt (Tab. A1, Anhang). Ettl (1968) erwähnt das auffällige Auftreten vieler grüner Fadenalgen bei den zum Teil bereits verwachsenen Torfstichen oberhalb der Schönwieshütte sowie in den sauren Gewässern der dortigen Umgebung. Unter anderem wurden folgende Arten bestimmt: Synura sphagnicola, Chromulina flavicans, Dinobryon cylindricum, Mallomonas caudata, Trachelomonas hispida, Tribonema vulgare, Ophiocytium capitatum, Monomastix ophiostigma, Chlamydomonas angustissima, Chlamydomonas kvildensis, Chlamydomonas vulgaris, Chlamydomonas similis, Sphaerellocystis globosa, Gloeococcus schroeteri, Eremosphaera viridis, Dictyosphaerium pulchellum, Botryococcus braunii, Microthamnion strictissimum, sowie verschiedene Desmidiaceen, sterile Conjugaten und Microspora lauterbornii (Ettl, loc. cit. p. 184).

Aus dem übrigen Rotmoos werden von Ettl (1968) aus sumpfigen Wasserstellen, Quellen und Bächen neben sterilen Conjugaten noch Bulbochaete sp., Microspora pachyderma, Desmidiaceen, Tetraspopra lacustris, Gloeococcus schroeteri,
Botryococcus braunii, Botryosphaera sudetica, Chromulina flavicans, Chrysococcus cordiformis, Peridinium sp u.a. angeführt (Ettl 1968 loc. cit. p. 184). Im Rahmen eines Algenkurses des Verfassers mit B. Lokhorst aus Utrecht im Sommer 1999 konnten zahlreiche Funde neuerlich bestätigt werden. Eine aktuelle Bearbeitung der benthischen Algen der Fließgewässer im Rotmoostal liegt von Gesierich und Rott (2004) vor. Neben dominiernden Kieselalgenarten, Cyanophyceen und Zygnemaphyceen sind auch einige Wassermoose (Palustriella commutata, Scapania uliginosa u.a.) nachgewiesen worden. Über Lebensraumtypen und Algendiversität siehe Kap. 8, Rott.

\section{Literatur}

Arnold, F. (1868-1897) Lichenologische Ausflüge in Tirol, 1 - 30. Verhandl. zool.bot. Ges. Wien 1868-1897. Gesammelte Lichenolog. Schr. v. F. Arnold, 3. repr. 1970, Cramer, Lehre.

Bortenschlager, S. (1970) Waldgrenz- und Klimaschwankungen im pollenanalytischen Bild des Gurgler Rotmooses. Mitt. Ostalpin-din. Ges. f. Vegetkde. 11: 1926.

Erschbamer, B. (2000) Die alpine Stufe in den Zentralalpen. In: Die subalpine und alpine Vegetation in Tirol, Erschbamer B., Grabner S. (eds) Exkursionsführer 
50. Jahrestagung d. Floristisch-Soziolog. Arbeitsgemeinschaft, 114-146.

Erschbamer, B., Bitterlich, B. \& Raffl, C. (1999) Die Vegetation als Indikator für die Bodenbildung im Gletschervorfeld des Rotmoosferners (Obergurgl, Ötztal, Nordtirol). Ber. Nat.-Med. Ver. Innsbruck 86: 107-122.

Ettl, H. (1968) Ein Beitrag zur Kenntnis der Algenflora Tirols. Ber. Nat.-Med. Ver. Innsbruck 56: 177-354.

Gärtner, G. (2000) Eine Einführung in die Exkursionsgebiete. In: Die subalpine und Alpine Vegetation in Tirol, Erschbamer B., Grabner S. (eds) Exkursionsführer 50. Jahres-Tagung d. Floristisch-Soziolo. Arbeitsgemeinschaft, 58-67.

Gams, H. (1962) Das Gurgler Rotmoos und seine Stellung innerhalb der Gebirgsmoore. Veröff. Geobot.Inst. Rübel, Zürich, 37: 74-82.

Gams, H. (1970) Die Erforschung der Floren- und Vegetationsgeschichte der Ötztaler Alpen. Mitt. Ostalpin-din. Ges. f. Vegetkde. 11: 55-62.

Gesierich, D. \& Rott, E. (2004): Benthic Algae and Mosses from Aquatic Habitats in the Catchment of a Glacial Stream (Rotmoos, Ötztal, Austria). Ber. Nat.-Med. Ver. Innsbruck 91: 7-42.

Grims, F. (1999) Die Laubmoose Österreichs, Biosystematics and Ecology 15, Catalogus Florae Austriae II, Bryophyten (Moose) 1, Musci (Laubmoose), Österr. Akad. Wiss., Wien, 418 S.
Grolle, R., Long, D.G. (2000) An annotated check-list of the Hepaticae and Anthocerotae of Europe and Macaronesia. J. Bryol. 22: 103-140.

Hofmann, P., Türk, R. \& Gärtner, G. (1988) Beitrag zur Flechtenflora Tirols: Obergurgl (Ötztaler Alpen, Nordtirol). Ber. Nat.-Med. Ver. Innsbruck 75: 7-19.

Jäger, H. (1992) Adolf Trientl, Priester, Wanderlehrer, „Mistapostel“. Galerie z. alten Oetztal, 6433 Oetz, 132 S.

Jochimsen, M. (1970) Die Vegetationsentwicklung auf Moränenböden in Abhängigkeit von einigen Umweltfaktoren. Veröff. Universität Innsbruck 46: 1-22.

Kerner, A. (1863) Das Pflanzenleben der Donauländer. Wagner, Innsbruck, $348 \mathrm{~S}$.

Köckinger, H., Suanjak, M., Schriebl, A. \& Schröck, C. (2008) Die Moose Kärntens. Sonderreihe Natur Kärnten 4, Naturwiss. Ver. für Kärnten, Klagenfurt, 319 S.

Lenzenweger, R., Gärtner, G. \& Pfattner, S. (1997) Zur bemerkenswerten Wiederentdeckung von Staurastrum gurgeliense Schmidle und Staurastrum sparseaculeatum Schmidle in Obergurgl (Ötztal, Tirol). Ber. Nat.-Med. Ver. Innsbruck 84: 75-80.

Pitschmann, H. \& Reisigl, H. (1954) Zur nivalen Moosflora der Ötztaler Alpen (Tirol). Rev. Bryolog. Lichenolog. 23: 123-131.

Pitschmann, H. \& Reisigl, H. (1955) Beiträge zur nivalen Flechtenflora der Oetztaler 
und Ortleralpen. Rev. Bryol. Lichenol. 24: 138-143.

Poelt, J. (1953) Mitteleuropäische Flechten I. Mitt. Bot. Staatssamml. München 6: 230-238.

Poelt, J. (1953) Mitteleuropäische Flechten II. Mitt. Bo. Staatssamml. München 8: 323-332.

Rudolph, D. (1991) Vergleichende Studien zur Vegetationsentwicklung im Vorfeld des Rotmoosferners/Ötztaler Alpen. Diplomarb. Justus-Liebig-Univ. Gießen, $108 \mathrm{~S}$.

Sarnthein, R. v. (1936) Moor- und Seeablagerungen aus den Tiroler Alpen in ihrer waldgeschichtlichen Bedeutung. I. Beih. Bot. Cbl., 55: 544-631.

Schmidle, W. (1895) Beiträge zur alpinen Algenflora. Österr. B. Z. 45: 249-253, 305-311, 346-350, 387-391, 454-459.
Schmidle, W. (1896) Beiträge zur alpinen Algenflora. Österr. B. Z. 46: 20-25, 5965, 91-94.

Tobolewski, Z. (1976) Flechten aus den Ötztaler-Alpen (Österreich) - Porosty z Alp Ötztalskich (Austria). Fragmenta Floristica et Geobotanica 22: 559-574.

Verzeichnis des Autors

\section{Georg Gärtner}

Universität Innsbruck

Institut für Botanik

Sternwartestr. 15, 6020 Innsbruck, Österreich

Georg.Gaertner@uibk.ac.at 


\title{
Die Flechten im Gletschervorfeld des Rotmoosferners
}

\author{
Roman Türk, Brigitta Erschbamer
}

\section{Zusammenfassung}

Im Gletschervorfeld des Rotmoosferners wurden 75 terricole, saxicole und Detritus-bewohnende Flechten festgestellt. Auf den etwa zehn Jahre eisfreien Flächen wachsen hauptsächlich höhere Pflanzen und einige wenige Moose. Mit zunehmendem Alter der eisfreien Flächen finden sich zunächst sporadisch terricole Flechten-Arten ein, erst in älteren Moränen ( $\mathrm{ab}$ ca. 35-40 Jahren Eisfreiheit) steigt die Biodiversität der terricolen, saxicolen und Detritus-bewohnenden Flechten an. An den ältesten Moränenwällen ist die Abundanz und Diversität der Flechten am höchsten.

\section{Abstract}

In the forefield of the Rotmoos glacier 75 terricolous, saxicolous and debricolous lichens occur. On 10 years icefree areas only higher plants and some bryophytes occur. With advancing age of the icefree areas terricolous lichens appear sporadically. In the older margines (icefree since 35-40 years) the biodiversity of the terricolous, saxicolous and debricolous lichens increases. The abundance and diversity of lichens is the highest on the oldest moraines.

\section{Einleitung}

In der Literatur werden Flechten oftmals als „Pionierpflanzen - Pionierorganismen“ bezeichnet, zumal sie aufgrund ihrer Konsistenz imstande sind, Rohböden, freiliegende Gesteinsoberflächen, Borke, Holz, absterbende Moose und Detritus in relativ kurzer Zeit zu besiedeln (Brodo 1973, Seaward 2008). Flechten benötigen für ihre Entwicklung weitgehend unbewegte, stabile Habitate. Frische, von rückziehenden Gletschern freigelegte Flächen zeichnen sich - je nach Hangneigung oder Exposition - durch mehr oder weniger stark bewegten Untergrund aus. An solchen Flächen finden sich vorerst höhere Pflanzen ein, deren Früchte bzw. Samen vornehmlich durch Wind (Stöcklin und Bäumler 1996, Erschbamer et al. 2001, Tackenberg und Stöcklin 2008), aber auch durch Wasser (Ryvarden 1971) und vermutlich auch durch Vögel verbreitet werden.

Für die lichenologische Erforschung der Gletschervorfelder in den Tiroler Alpen haben Beschel (1950) sowie Heuberger und Beschel (1958) grundlegende Beiträ- 
ge geleistet. Dies nicht nur hinsichtlich der Lichenometrie zur Datierung von Moränen, sondern auch zur floristischen Erfassung der saxicolen und terricolen Arten. Hofmann et al. (1988) geben einen ersten Überblick über die reichhaltige Flechtenflora des inneren Ötztals, auch aus dem Rotmoostal sind einige Funde angeführt.

Ziel der vorliegenden Arbeit war es, die Flechtendiversität im Gletschervorfeld des Rotmoosferners zu erfassen.

Die Begehung des Gletschervorfeldes des Rotmoosferners erfolgte am 20.08.2009. Besonderes Augenmerk wurde den bodenliegenden Steinen in den Schuttflächen und den Rohböden geschenkt, um nach Möglichkeit auch die Primordialstadien von Flechten zu entdecken. Da gerade in den jüngeren Flächen die Flechten sehr sporadisch auftreten und zumeist Einzelfunde gemacht werden, wurde auf Vegetationsaufnahmen verzichtet.

Als Bestimmungsliteratur dienten Poelt (1969), Poelt und Vězda (1977 und 1981), Wirth (1995) und Clauzade und Roux (1984) sowie weiterführende Spezialliteratur. Die Nomenklatur richtet sich nach Hafellner und Türk 2001.
Flechten in rezent eisfreien Moränen und Pioniergesellschaften

Im Bereich der Gletscherstände $1997-$ 1999, wurden lediglich höhere Pflanzen aufgefunden, und zwar Arabis caerulea, Arenaria ciliata, Artemisia genipi, Artemisia mutellina, Cerastium uniflorum, Cirsium spinosissimum, Festuca halleri, Gnaphalium supinum, Linaria alpina, Poa alpina, Poa laxa, Saxifraga aizoides, Saxifraga oppositifolia, Trisetum spicatum und Veronica alpina. Es traten weder terricole, saxicole noch Detritus-bewohnende Flechten auf abgestorbenen Saxifraga oppositifolia-Polstern auf. Die Bodenbildung hat in diesen Flächen noch kaum statt gefunden, sodass der Großteil des Untergrundes noch zu stark bewegt ist, um Flechten aufkommen zu lassen.

Erst im Bereich der 1981er Moräne treten einige wenige Flechtenarten äußerst sporadisch auf (Tab. A1, Anhang). Auf kleinen Steinen dominiert Polyblastia cupularis, die auf 11 Proben aufgefunden wurde. Dieses zahlreiche Auftreten von Polyblastia cupularis ist überraschend, denn diese Flechte wurde bisher noch in keiner Arbeit über Flechten in Gletschervorfeldern angeführt. Vereinzelt finden sich auf den Rohböden und Mooskissen Peltigera-Arten mit Cyanobacterien als Photobionten ein, und zwar Peltigera rufescens (Abb. 1) und Peltigera didactyla, die durchaus den Charakter einer Pionierflechte zeigt, zumal sie neben der sexuellen Vermehrung 


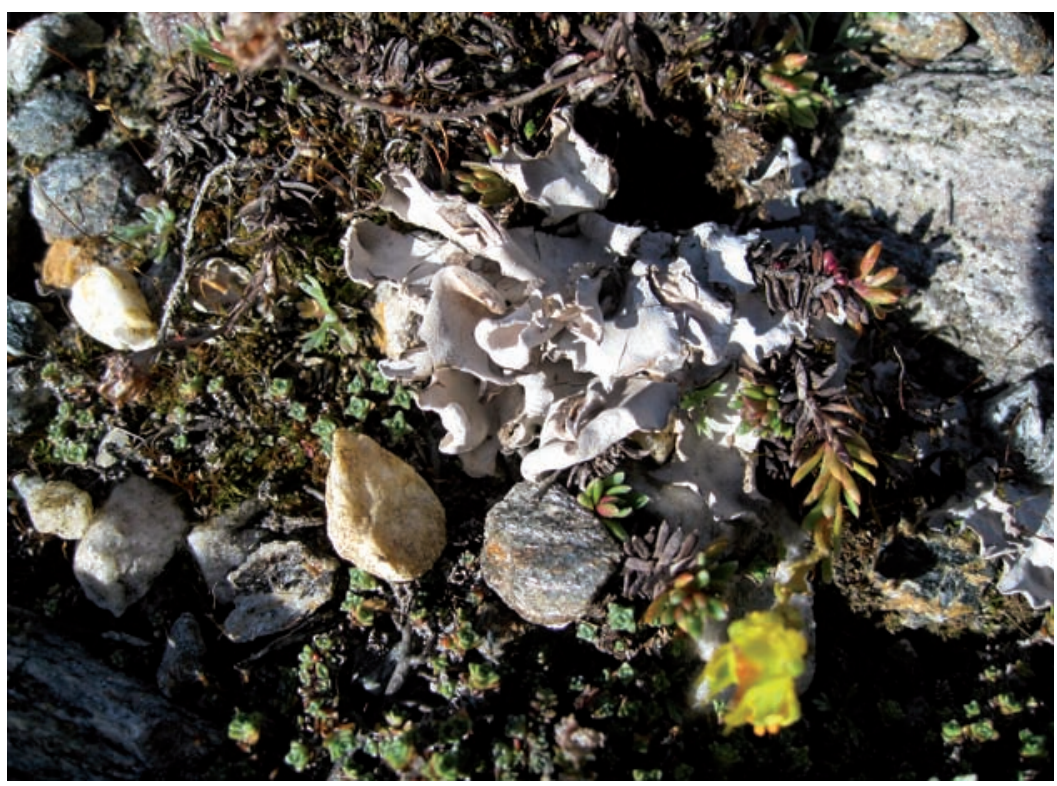

Abb. 1:

Peltigera rufescens - juveniles Exemplar - im Bereich der 1981er-Möräne (Foto: R. Türk)

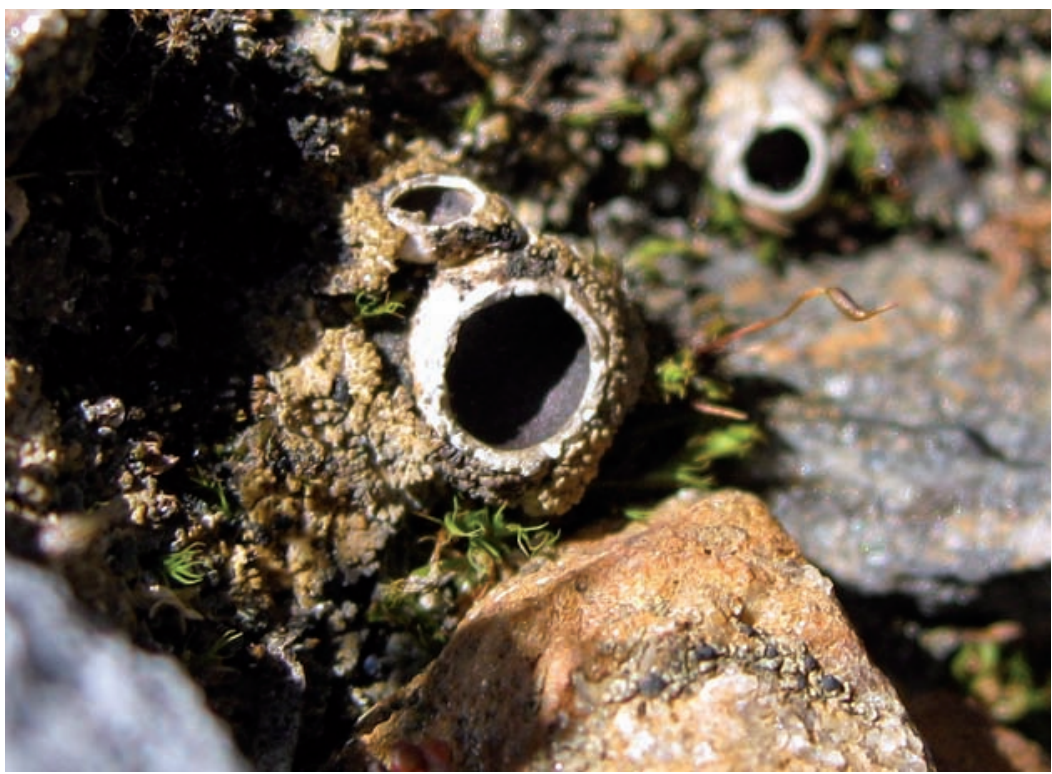

Abb. 2:

Solorina spongiosa ist eine Flechte mit Grünalgen und Cyanobacterien als Symbionten. So ist es ihr möglich, Luftstickstoff zu fixieren. (Foto: R. Türk) 
auch eine sehr effektive vegetative Vermehrung in Form von Soredien aufweist. Auf einem abgestorbenen Mooskissen tritt Myxobilimbia microcarpa mit einigen wenigen Apothezien auf. Solorina spongiosa (Abb. 2) konnte ebenfalls hier gefunden werden.

Flechten in ca. 40 - 80 Jahre eisfreien Moränen

In der Versuchsfläche der 1971er-Moräne nimmt die Biodiversität der Flechten zu. Auf den bodenliegenden Steinen wachsen als bemerkenswerte Arten - in sehr gerin- gem Deckungsgrad - Acarospora veronensis und Bellemerea alpina. Lecanora polytropa (Abb. 3) kommt als Pionierflechte auf kleinen, bodenliegenden Steinchen vor, stellenweise gemeinsam mit Porpidia crustulata (Abb. 3). Unter den Boden bewohnenden Arten dominieren Peltigera rufescens (Abb. 4) und Stereocaulon alpinum (Abb. 5). Die Strauchflechten aus den Gattungen Cladonia und Cetraria treten nur vereinzelt und in sehr juvenilen Stadien auf. Auf Pflanzenresten wächst Caloplaca stillicidiorum und Candelariella vitellina, die sonst silikatische Gesteine als Substrat bevorzugt. Auf Rohhumus sind einige kleinflächige Thalli von Rinodina mniaraea var. mniaraea entwickelt.

Erstaunlich gering ist die Artenzahl auf

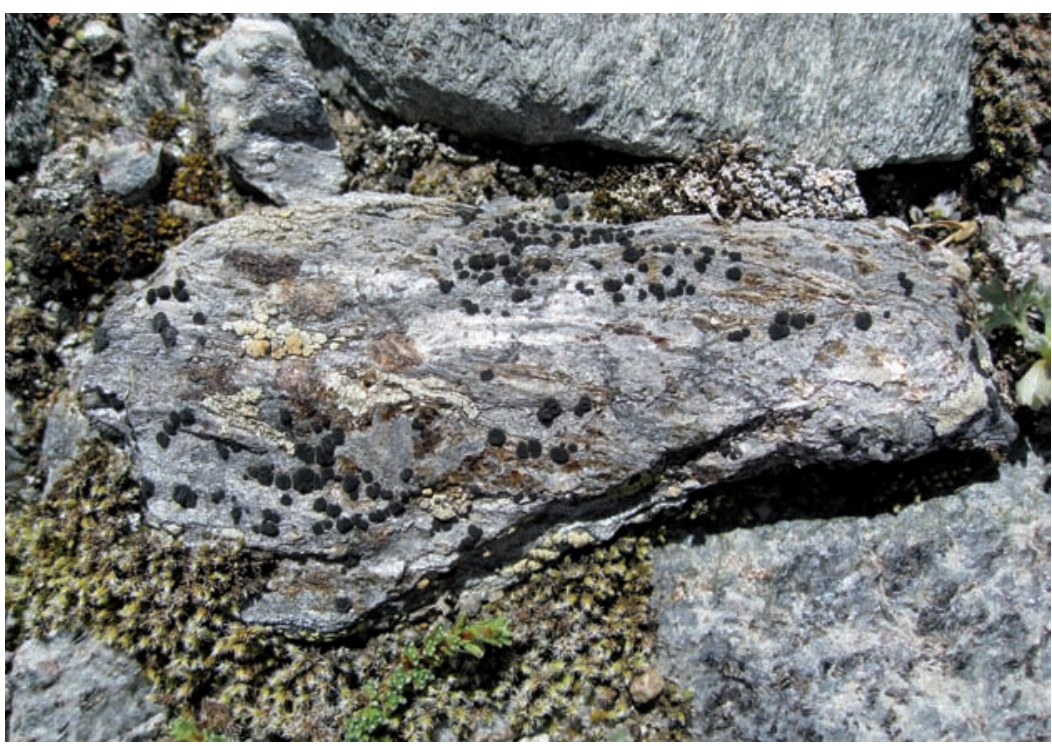

Abb. 3:

Porpidia crustulata (schwarze Apothezien) und Lecanora polytropa (gelb-grüne Apothezien) sind Pioniere auf bodenliegenden Steinen. (Foto: R. Türk) 


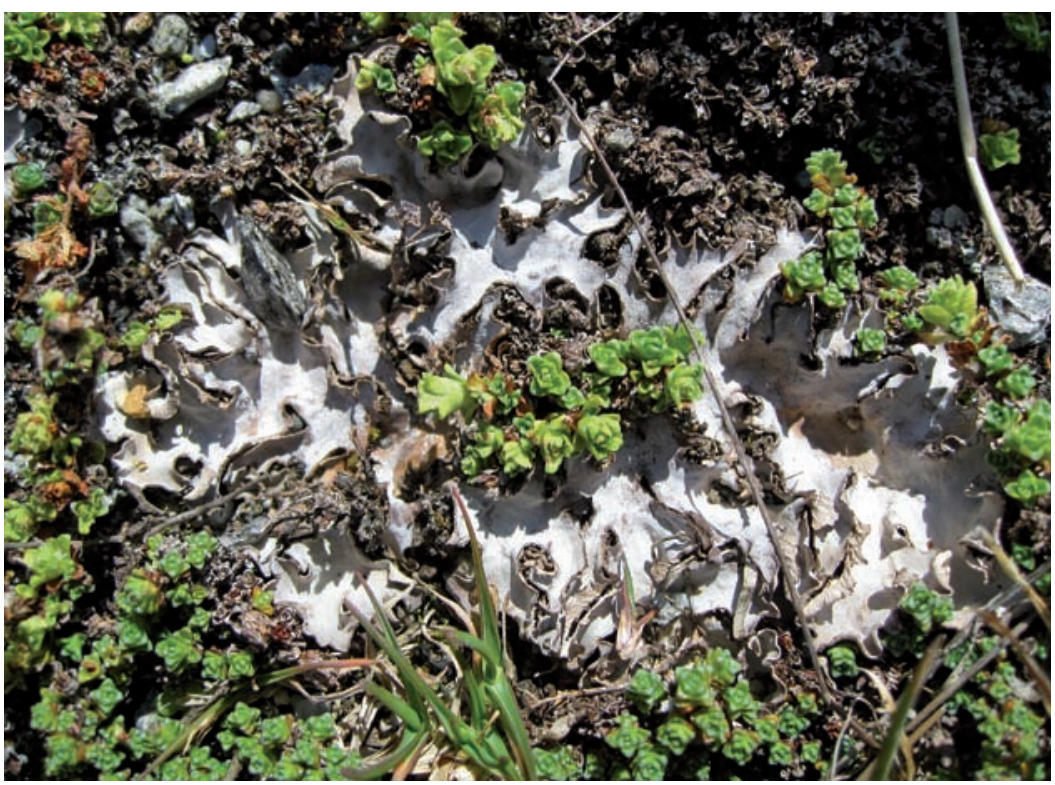

Abb. 4:

Peltigera rufescens im Bereich der 1971er-Moräne (Foto: R. Türk)

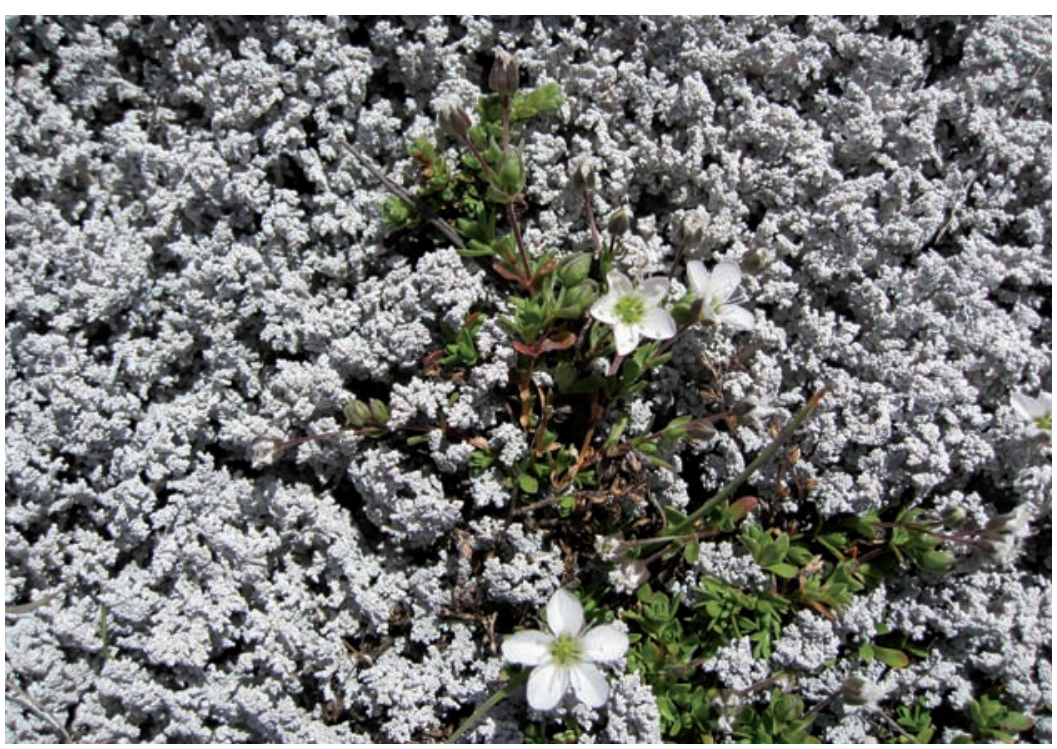

Abb. 5:

Stereocaulon alpinum im Bereich der 1971er-Moräne, wo sie eine hohe Abundanz aufweist. (Foto: R. Türk) 


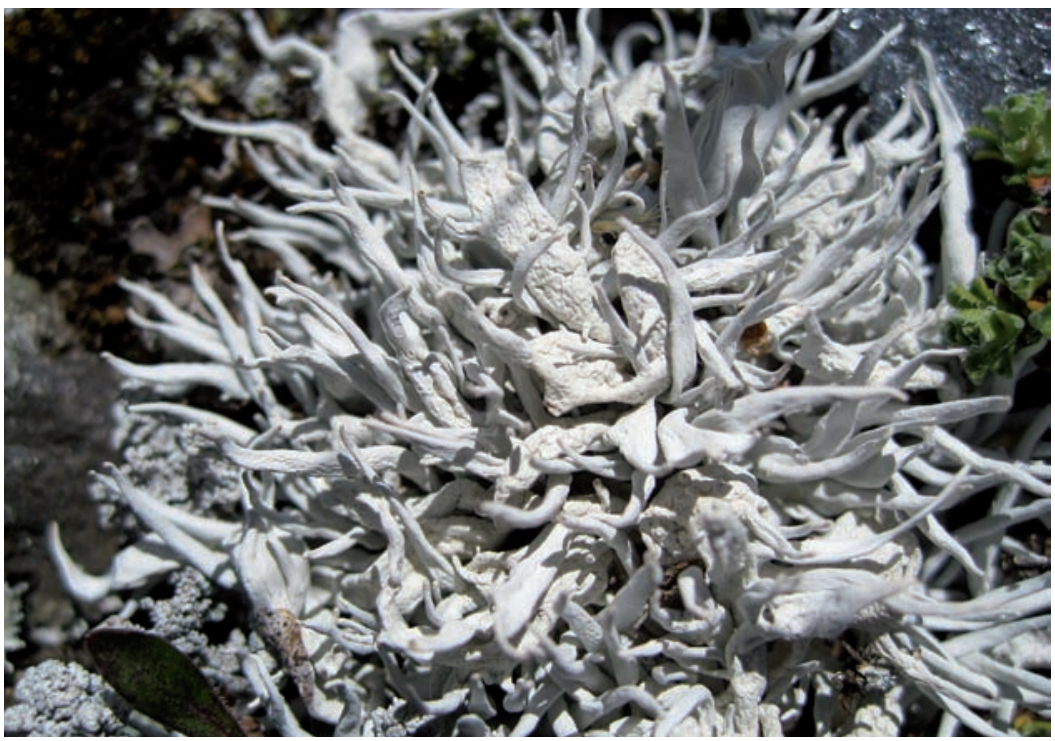

Abb. 6:

Thamnolia vermicularis ssp. vermicularis an windgefegten Stellen im Bereich der 1923er-Moräne. (Foto: R. Türk)

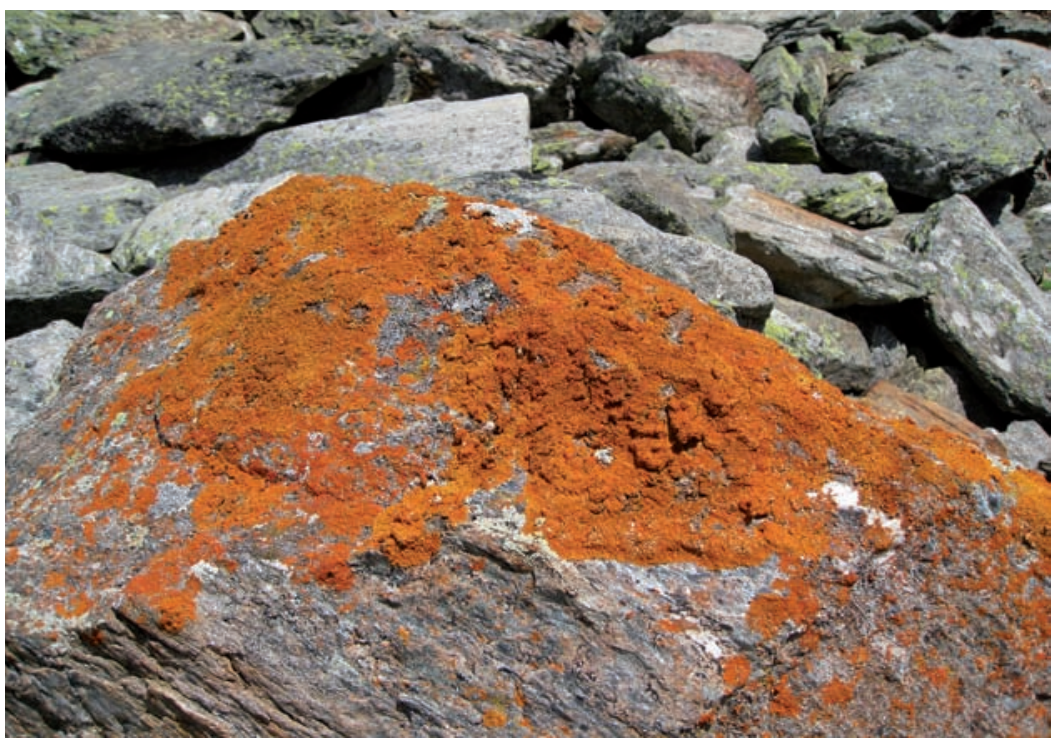

Abb. 7:

Xanthoria elegans wächst auf einem durch Vogeldung eutrophierten Felsblock.

(Foto: R. Türk) 
der 1956/57er - Moräne. Hier dominieren die gesteinsbewohnenden Arten wie Acarospora veronensis, Bellemerea alpina, Bellemerea cinereorufescens, Bellemerea subsorediza, die auf den hohen Fe-Gehalt der Glimmerschiefer hinweisen, sowie Lecanora polytropa (als Pionierflechte auf Steinchen), Rhizocarpon geographicum und Rhizocarpon polycarpum. Diese Fläche scheint in der Vergangenheit teilweise durch Ausuferungen des Gletscherbaches beeinträchtigt worden zu sein. Daher stimmt die Entwicklung der Flächen vermutlich nicht ganz mit der Zeit der Eisfreiwerdung überein.

Flechten in älteren Moränenstadien (80-150 Jahre eisfrei)

Die höhere Stabilität der 1923er-Moräne spiegelt sich in der Abundanz und im Entwicklungszustand der terricolen Strauchflechten wider. Stereocaulon alpinum erreicht hier die höchste Abundanz aller Strauchflechten, beigemengt sind Cetraria islandica, Cladonia cervicornis ssp. cervicornis, vereinzelt Flavocetraria nivalis und Thamnolia vermicularis ssp. vermicularis (Abb. 6). Cladonia symphycarpa, die den Gehalt von karbonatischen Gesteinselementen im Untergrund anzeigt, bildet stellenweise dichte Bestände. Als terricole Blattflechte ist Peltigera rufescens vorhanden, terricole bzw. Detritus-bewohnende
Krustenflechten sind Arthrorhaphis alpina, Bacidia bagliettoana, Caloplaca holocarpa, und Mycobilimbia berengeriana. Als bemerkenswerte Kruste auf Gestein ist Acarospora peliscypha zu nennen. Die übrigen Arten sind der Tab. 1 (Anhang) zu entnehmen.

In den beweideten Flächen ist die Vitalität der vorkommenden Flechten stellenweise eingeschränkt, was sich in der verminderten Thallusgröße und in Veränderungen der Thallusfarbe äußert.

Auf einem exponierten Felsblock (Vogelsitzfelsen) der 1923er-Moräne wachsen insgesamt 23 Arten (siehe Tab. 1). Bemerkenswert ist hier das Aufkommen von Hypogymnia physodes und Pseudevernia furfuracea, die als Epiphyten auf Umbilicaria cylindrica wachsen. Augenfällig ist hier vor allem Xanthoria elegans (Abb. 7).

\section{8-Moränenfläche (Grund- und Seitenmoräne)}

Naturgemäß steigt die Biodiversität und die Abundanz der Flechten in den ältesten Moränenflächen stark an. Auf einer kleinen Fläche von etwa 40 x 30 Metern kommen 13 terricole bzw. Detritus-bewohnende Arten vor, an saxicolen Arten sind 30 vertreten (siehe Tab. A1, Anhang). Der Deckungsgrad der saxicolen Flechten ist hier schon sehr hoch, zumeist sind die meisten Blöcke schon zu 80 bis fast 
$100 \%$ mit Krusten-, Blatt- und Nabelflechten bewachsen. Als bemerkenswerte Arten kommen hier Bellemerea cinereorufescens und Lecidea atrobrunnea vor.

Die Entwicklung der Flechten benötigt in den Gletschervorfeldern offensichtlich eine weitaus längere Zeit als die Bildung einer Vegetationsdecke, die von höheren Pflanzen aufgebaut wird. Dies steht im Zusammenhang mit der Durchfeuchtung und der Bewegung des Substrates, denn die meisten Flechten benötigen für ihre Entwicklung weitgehend unbewegten Untergrund. Erst bei entsprechendem Stabilitätsgrad der eisfrei gewordenen Flächen finden sich auch die Flechten ein. Während über Wachstum und Wachstumsgeschwindigkeit von ausgesuchten Flechten (vor allem Rhizocarpon- und Aspicilia-Arten) in Gletschervorfeldern der Alpen schon ausreichende Informationen vorhanden sind, benötigt die Aufklärung über die Biodiversität der Flechten in diesen speziellen Habitaten in der Zukunft sicherlich noch einiges an Arbeit. Unter dem Aspekt des rasanten Rückzugs der Gletscher in den letzten Jahrzehnten im Zuge des Klimawandels wird dies eine reizvolle Aufgabe für die kommenden Generationen von lichenologisch interessierten Personen sein.

\section{Literatur}

Beschel, R. (1950) Flechten als Altersmaßstab rezenter Moränen. - Ztschr. f. Gletscherk., N.F. 1: 152-161.

Brodo, I.M. (1973) Substrate ecology. In: The Lichens, ed. V. Ahmadjian \& Hale, M. E., 401-444. New York: Academic Press.

Clauzade, G. \& Roux, C. (1984) Likenoj de Okcidenta Europo, 893 S., Société Botanique du Centre Quest, Royan.

Erschbamer, B., Kneringer, E. \& Niederfriniger Schlag, R. (2001) Seed rain, soil seed bank, seedling recruitment, and survival of seedlings on a glacier foreland in the Central Alps. Flora 196: 304-312.

Hafellner, J. \& Türk, R. (2001) Die lichenisierten Pilze Österreichs - eine Checkliste der bisher nachgewiesenen Arten mit Verbreitungsangaben. - Stapfia 76: $1-167$.

Heuberger, H. \& Beschel, R (1958) Beiträge zur Datierung alter Gletscherstände im Hochstubai (Tirol). Schlern-Schriften 190 (Festschrift H. Kinzl): 73-100.

Hofmann, P., Türk, R. \& Gärtner, G. (1988) Beitrag zur Flechtenflora Tirols: Obergurgl (Ötztaler Alpen, Nordtirol). Ber. nat.-med. Verein Innsbruck 75: 7-19.

Poelt, J. (1969) Bestimmungsschlüssel europäischer Flechten. 757 pp. Lehre.

Poelt, J. \& Vězda, A. (1977) Bestimmungsschlüssel europäischer Flechten. Ergänzungsheft I. 258 S., J. Cramer, Vaduz. 
Poelt, J. \& Vězda, A. (1981) Bestimmungsschlüssel europäischer Flechten. Ergänzungsheft II. 390 S., J. Cramer, Vaduz.

Ryvarden, L. (1971) Studies in seed dispersal I. Trapping of diaspores in the alpine zone at Finse, Norway. Norw. J. Bot. 18: 215-226.

Seaward, M.R.D. (2008) Environmental role of lichens. In: Lichen Biology, ed. Nash III, T. H., 274-298. Cambridge University Press.

Stöcklin, J. \& Bäumler, E. (1996) Seed rain, seedling establishment and clonal growth strategies on a glacier foreland. J. Veg. Sci. 7: 45-56.

Tackenberg, O. \& Stöcklin, J. (2008) Wind dispersal of alpine plant species: A comparison with lowland species. J. Veg. Sci. 19: 109-118.

Wirth, V. (1995) Flechtenflora. Bestimmung und ökologische Kennzeichnung der Flechten Südwestdeutschlands und angrenzender Gebiete. 661 S. UTB Eugen Ulmer, Stuttgart.

\section{Verzeichnis der AutorInnen}

Roman Türk

Universität Salzburg

FB Organismische Biologie, AG Ökologie und Diversität der Pflanzen

Hellbrunnerstr. 34, 5020 Salzburg, Österreich

Roman.Tuerk@sbg.ac.at

Brigitta Erschbamer

Universität Innsbruck

Institut für Botanik

Sternwartestr. 15, 6020 Innsbruck, Österreich

Brigitta.Erschbamer@uibk.ac.at 


\title{
Kapitel 7 I Die tierische Besiedlung von Gletschermoränen
}

\author{
Eva-Maria Koch, Rüdiger Kaufmann
}

\section{Zusammenfassung}

Um zu erfahren, wie ein Ökosystem aus dem Nichts entstehen kann und wie lange es dafür benötigt, wird das Gletschervorfeld des Rotmoostales seit Jahren untersucht. Nachdem die pflanzliche Sukzession in Kap. 6 bereits dargestellt wurde, wird in diesem Kapitel auf die tierische Besiedelung eingegangen. Entlang der Chronosequenz zeigt sich, dass sich in den ersten 50 Jahren die Pioniergesellschaften rasch entwickeln und sich die auftretenden Arten ändern. Danach erfolgen nur mehr wenige Veränderungen, die Artengemeinschaften ähneln bereits denen angrenzender Gebiete. Die ersten Kolonisatoren sind fast ausschließlich räuberische Arten. Pflanzenfresser und Streuzersetzer folgen erst später nach. In 30 Jahre alten Böden siedeln sich Springschwänze, Milben, Borstenwürmer, Käfer- sowie Schmetterlingsraupen an. Es folgen Mücken und Tausendfüßer, die restlichen Gruppen treten erst nach 90 Jahren Bodenentwicklung auf. Auch bei der Bodenfauna steigt die Artenzahl in den ersten 50 Jahren rasch an und stabilisiert sich danach auf dem für alpine Rasen typischen Niveau. Die wichtigsten äußeren Effekte, welche auf die tierische Besiedelung einwirken, sind die Bodenbildung und die Vegetationsentwicklung entlang der Chronosequenz. Kleinräumig wirken sich zusätzlich das Temperatur- und Feuchtemilieu aus. Modellierungen zeigen, dass die Pioniergesellschaften im Gletschervorfeld sehr stark auf Klimaänderungen reagieren.

\section{Abstract}

To find out, how an ecosystem can develop on barren ground and how long this process takes, the glacier foreland of the Rotmoos valley has been investigated over years. Plant succession is described in chapter 6 , this chapter focuses on the settlement of invertebrate animals in the glacier foreland. Along the chronosequence of 140 years it is shown that rapid development of pioneer communities with fast species turn-over for 50 years is followed by little change in older stages when animal communities already resemble those of adjacent areas. The first colonizers are almost exclusively predators. Herbivores and decomposers appear later. On 30 years old moraines Collembola, Acari, Enchytraeidae and larvae of Lepidoptera as well as Coleoptera are present. Nematocera and Myriapoda follow later on. Other groups appear after 
90 years of soil formation as an organic layer develops. Species numbers rapidly increase over the first 50 years, then they stabilize at a level typical for alpine grasslands. The major factors affecting faunal succession are soil formation and vegetation development along the chronosequence, temperature and moisture exert additional small-scale influences. Furthermore, model calculations show that the pioneer communities in the glacier foreland react strongly to climate change.

\section{Die Erforschung der tierischen} Besiedlung

Seit 150 Jahren gehen in den Alpen die Gletscher zurück und geben rohe Moränenböden für die Besiedlung durch Pflanzen und Tiere frei. Hier entstehen neue Ökosysteme mit Wechselwirkungen zwischen den Organismen und ihren Nahrungsnetzen. Entlang dieser Gletschervorfelder lassen sich alle Altersstadien der Entwicklung beobachten. Sie stellen gewissermaßen natürliche Experimente dar und zeigen die Lebenskraft, aber auch die Empfindlichkeiten der alpinen Ökosysteme unter sich verändernden Umweltbedingungen.

Zoologische Besiedelungsprozesse im Gletschervorfeld wurden erstmals von Janetschek (1949) und in den letzten Jahren in den Arbeiten von Gereben (1995) und Kaufmann (2001, 2002) analysiert.
Jüngere Untersuchungen zu diesem Thema gibt es auch aus den Südalpen (Gobbi et al. 2006), aus der Arktis (Hodkinson et al. 2001), sowie eine sehr umfangreiche Studie über norwegische Gletschervorfelder (Vater 2006). Rüdiger Kaufmann von der Universität Innsbruck und seine MitarbeiterInnen führen seit 1995 Langzeitstudien über die Kolonisation und die Sukzession der auftretenden Tierarten im Gletschervorfeld des Rotmoosferners in Obergurgl durch (Abb. 1). Die ÖkologInnen (Juen 1998, Spitaler 1998, Kapl 1999, Schallhart 2005, Koch 2006, König 2006, Baldes 2009) untersuchen die tierischen Gesellschaften, den Aufbau der Nahrungsnetze, die Konkurrenz zwischen Arten, den Fraßdruck Pflanzen fressender Tiere sowie den Einfluss von Umweltfaktoren und Klimaänderungen auf die Entwicklung der Artengemeinschaften und der Bodenbildung. Ein aktuelles Forschungsprojekt, welches 2008 gestartet wurde, beleuchtet die Nahrungsnetze von wirbellosen Tieren in Gletscherrückzugsflächen (Raso et al. 2008).

Auch andere Primärstandorte, die für einen Vergleich mit dem Gletschervorfeld interessant sind, wurden auf ihre tierische Besiedelung hin untersucht: Im Jahr 1948 beschäftigte sich Dammermann erstmals mit der Faunengemeinschaft auf der aktiven Vulkaninsel Krakatau. Auf den kanarischen Inseln standen 1992 für Ashmole und seine KollegInnen (Ashmole und Ashmole 1987, Ashmole et al. 1992) die Vulkankegel auf La Palma im Mittelpunkt 


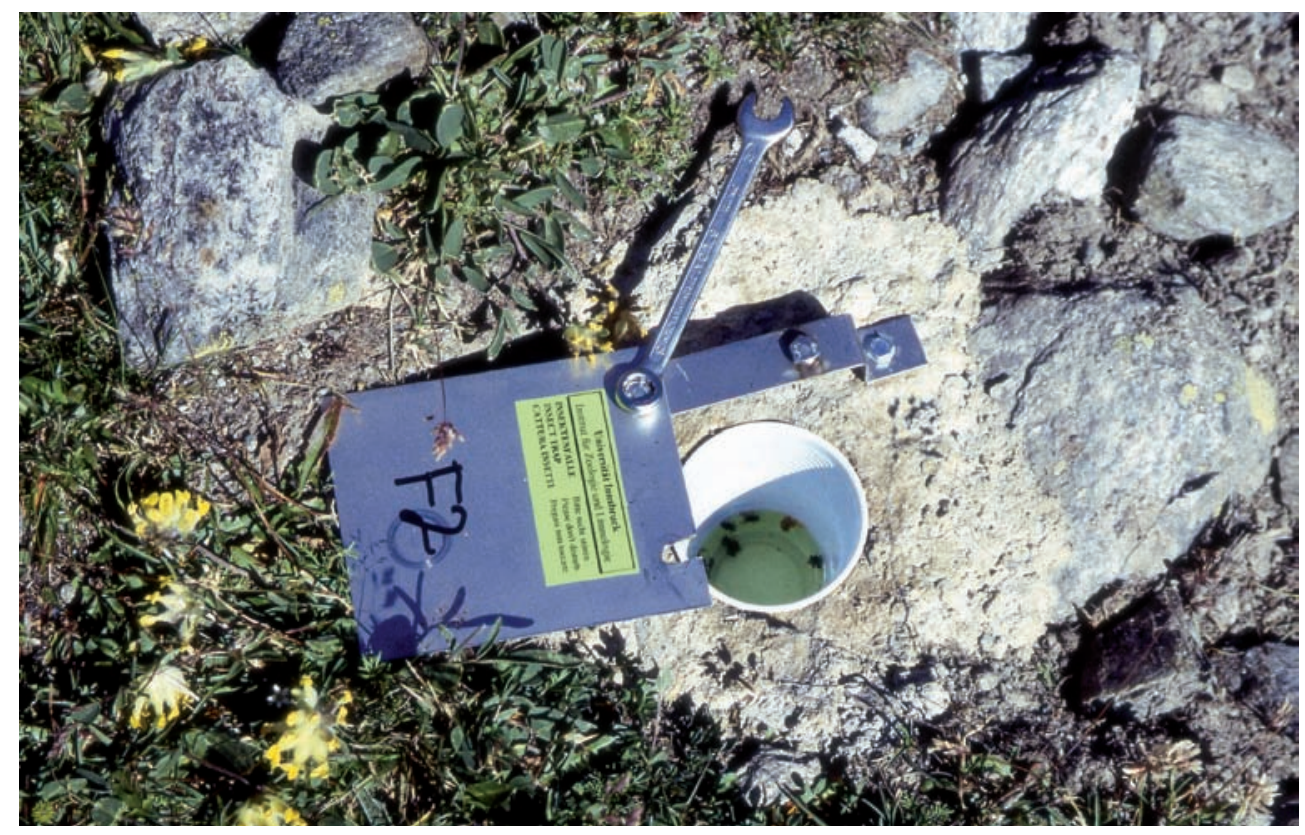

Abb. 1:

In den Boden betonierte Barberfallen - ein Beispiel für die arbeitsintensive, ökologische Beprobung des Rotmoostales (Foto: R. Kaufmann)

der faunistischen Erforschung. Auch am Mount St. Helens im US-Bundesstaat Washington wurden zahlreiche ökologische Untersuchungen durchgeführt: Edwards und Sugg erforschten 1993 und 1998 die Arthropodengemeinschaft. Die Arbeitsgruppe rund um die Forscher $\mathrm{Fa}$ gan und Bishop (Fagan und Bishop 2000, Bishop 2002, Fagan et al. 2004) hingegen beleuchteten die Kolonisierung der Vulkanflächen durch Lupinus lepidus ssp. lobbii im Zusammenhang mit dem Auftreten herbivorer Insekten. Von Dormann et al. wurden im Jahr 2000 Salzmarschen in den Niederlanden im Bezug auf interspezifischen Wettbewerb und Fraßdruck während des Sukzessionsablaufs untersucht.

Die Chronosequenz und die

Sukzession der Arten

Um etwa 1858 erreichten die alpinen Gletscher ihre größte Ausdehnung seit der letzten Eiszeit vor ca. 10.000 Jahren. Das Areal außerhalb der End- und Seitenmoränen des Rotmoosferners ist seither eisfrei. Hinter der Endmoräne hat der schmelzende Gletscher über die letz- 


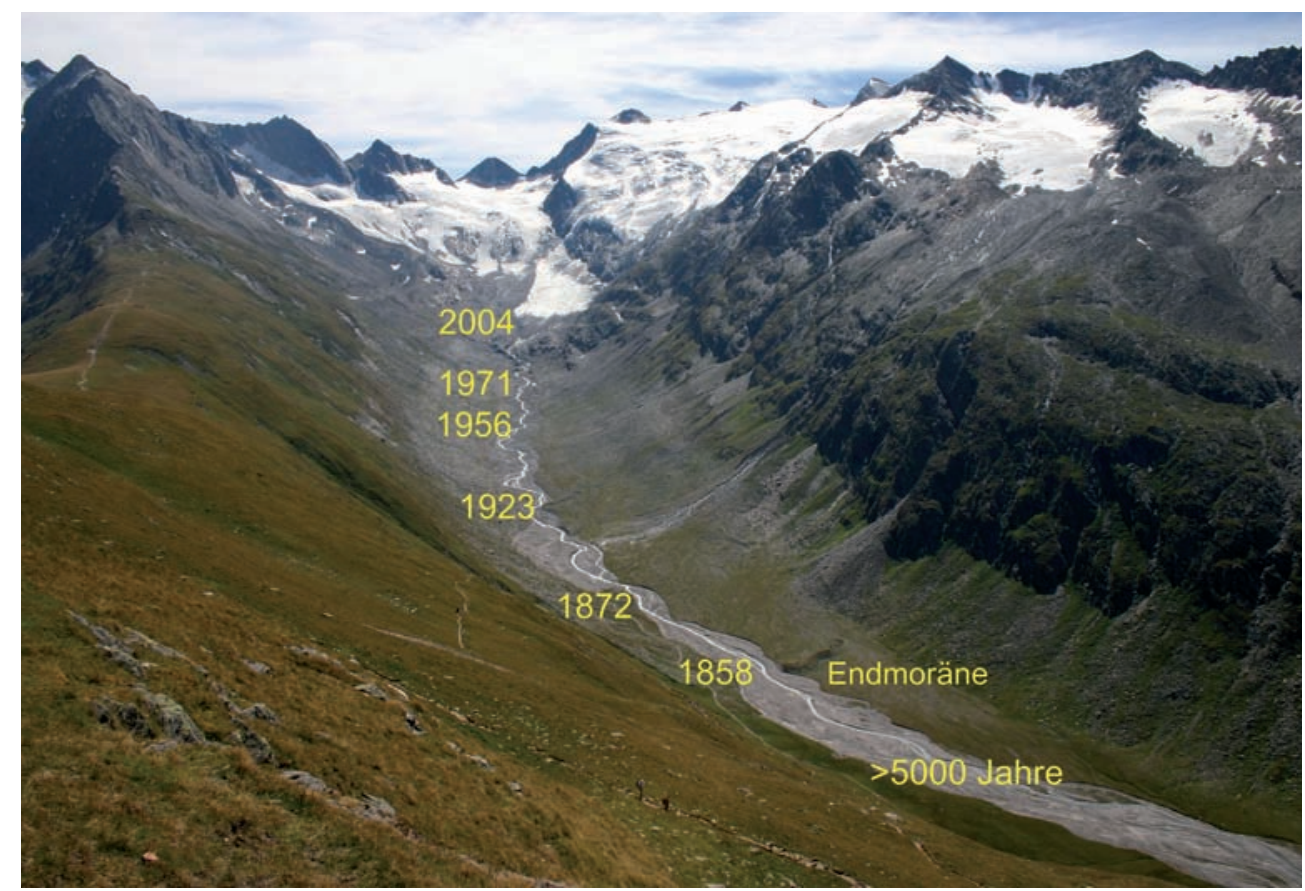

Abb. 2:

Die Chronosequenz des Rotmoostales (Ötztal, Tirol) von der Endmoräne, die auf 1858 datiert wird, bis zum derzeitigen Gletscherrand (Foto: R. Kaufmann)

ten 150 Jahre eine sogenannte Chronosequenz (Abb. 2) geschaffen, eine räumlich geordnete Abfolge aller Stadien der Bodenbildung und der sich entwickelnden Artengemeinschaften von Pflanzen und Tieren.

\section{Verteilung der epigäischen Arthro- podenfauna im Gletschervorfeld (Kaufmann 2001)}

Die einzelnen, an der Bodenoberfläche lebenden (epigäischen) Gliedertierarten besiedeln das Areal in einer charakteristischen Abfolge. Den Beginn der Besiedelung machen die so genannten Pionierarten, die bereits in den ersten Jahren unmittelbar am Gletscherrand auftreten. Im Fall des Gletschervorfeldes sind das beispielsweise der Gletscher-Weberknecht Mitopus glacialis oder auch der Laufkäfer Nebria jockischii.

Mit dem Entstehen artenreicherer Gemeinschaften werden viele dieser frühen Kolonisatoren durch nachfolgende Arten ersetzt (Kaufmann 2001). Diesen Vorgang nennt man Sukzession. Eine Aus- 

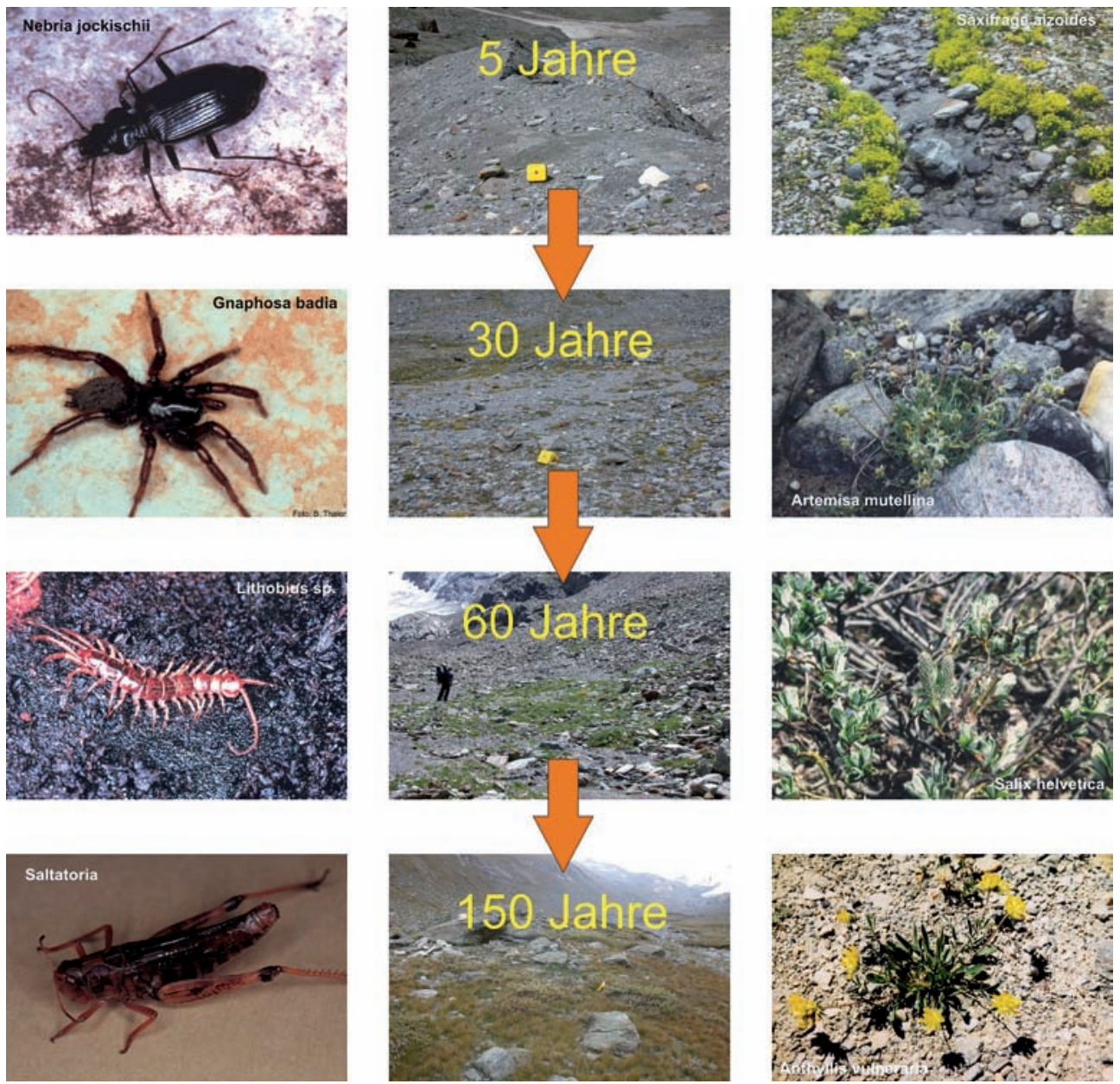

Abb. 3:

Veränderung der Landschaft mit dem Alter seit der Ausaperung zusammen mit charakteristischen Tier- und Pflanzenarten dieser Entwicklungsstufe (Fotos: R. Kaufmann)

wahl typischer Tier- und Pflanzenarten für bestimmte Altersstadien im Gletschervorfeld zeigt Abb. 3.

Im Altersverlauf des Gletschervorfeldes im Rotmoostal ist bei Laufkäfern eine klare Abfolge der Arten zu erkennen (Abb. 4). Von der Gattung Nebria treten in den jüngsten Moränenbereichen insgesamt vier verschiedene Arten auf. Die große Heterogenität der Landschaft ermöglicht die Koexistenz dieser nahverwandten Arten, die normalerweise in unterschiedlichen Höhenstufen vorkommen. Im Gletschervorfeld besetzt jede der Nebria-Arten eine 


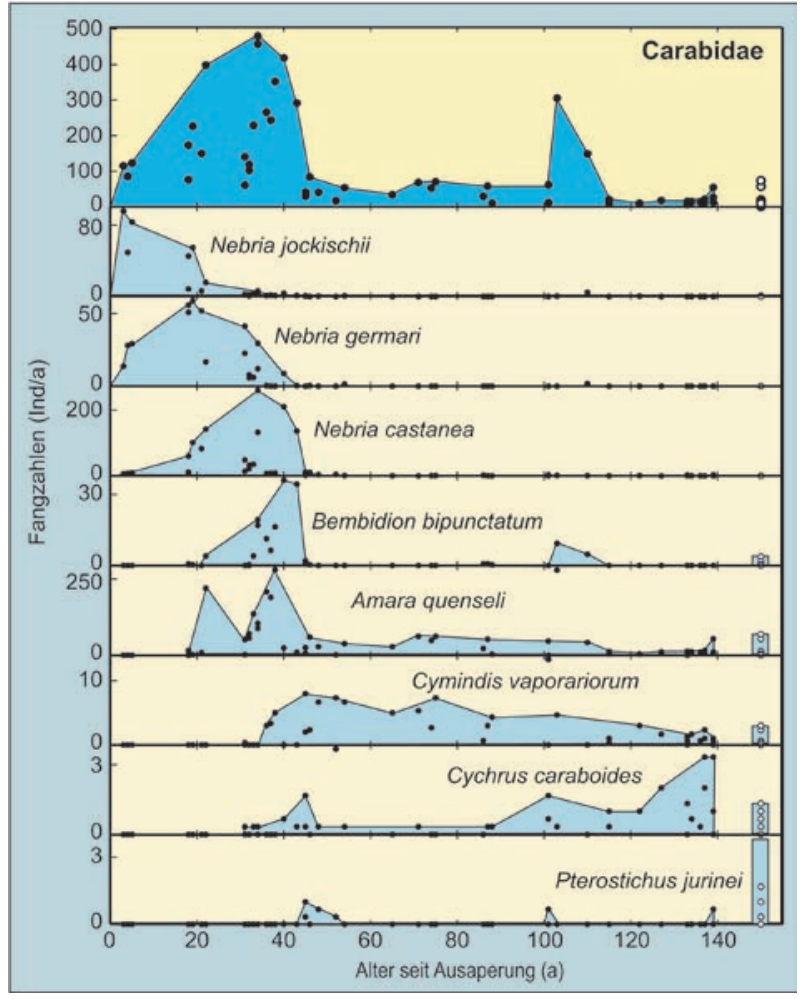

Abb. 4:

Sukzession im Gletschervorfeld - die Abfolge von Arten am Beispiel verschiedener Laufkäferarten

andere ökologische Nische (Kaufmann und Juen 2001).

Spinnen sind im gesamten Vorfeld anzutreffen. Die ersten Arten, welche auf den jungen Flächen eintreffen, sind Vertreter der Baldachinspinnen (Linyphiidae) und der Wolfsspinnen (Lycosidae). Ihnen folgen etwas später die Glattbauchspinnen (Gnaphosidae). Ab einem Alter von 30 Jahren besiedeln auch Hundertfüßer und Pflanzen fressende Käferarten die Moränen. Mit Beginn der Bodenbildung (ab ca.
80 Jahren entsteht ein organischer Bodenhorizont) nimmt die Anwesenheit der Zersetzer zu, verschiedene Vertreter der Tausendfüßer (Diplopoden) treten vermehrt auf. Eine Ausnahme stellt nur die Art Trimerophorella rhaetica dar: dieser spezialisierte, in den Alpen endemische Tausendfüßer siedelt bereits auch auf ganz jungen Standorten im Gletschervorfeld.

Obwohl Ameisen in fast allen Regionen der Welt vorkommen - selbst in der Wüste und im Polarkreis - schafft es nur eine einzige Art, Formica lemani, in das Gletschervorfeld vorzudringen. Sie besiedelt sonnige Plätze in den ältesten Bereichen des Vorfeldes. Auch typische Graslandbewohner wie Grashüpfer leben nur nahe der Endmoräne an fast 150 Jahre alten Standorten mit geschlossener Vegetation.

\section{Verteilung der Bodenfauna im Gletschervorfeld (Kaufmann et al. 2002)}

Nicht nur an der Bodenoberfläche des Gletschervorfeldes findet eine Sukzession statt, dieser Prozess ist ebenso unter der Erde zu beobachten. Eine Studie 


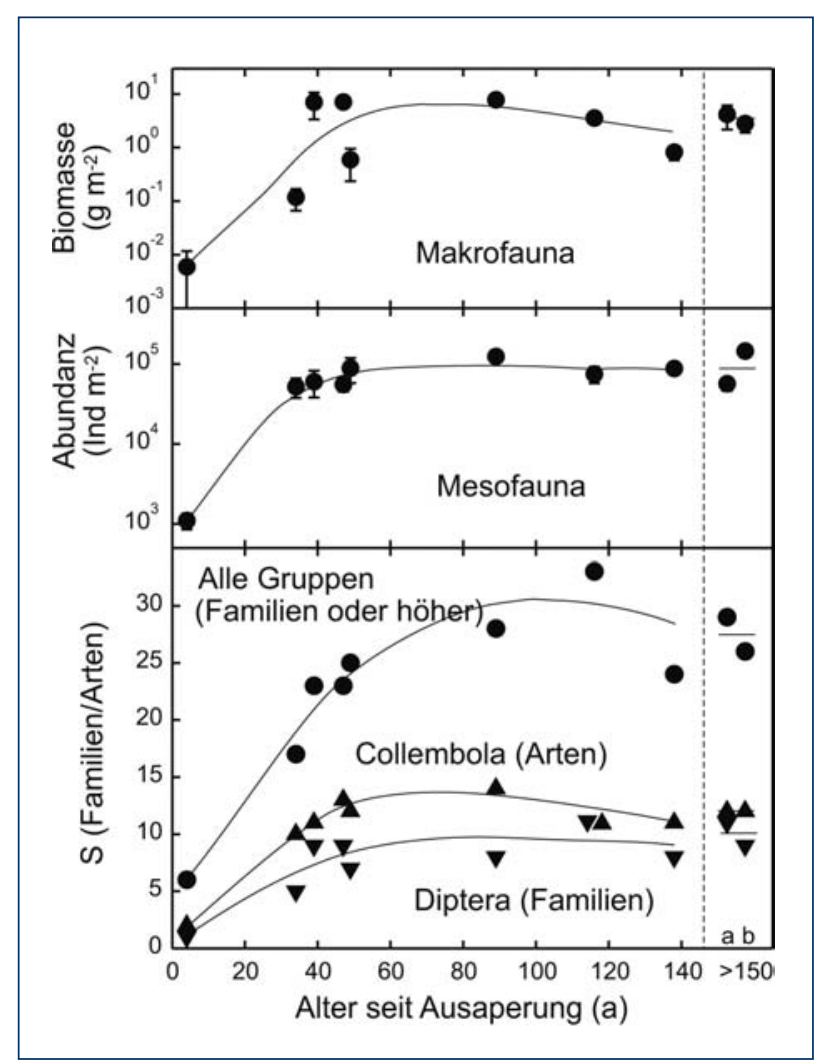

Abb. 5:

Verteilung und Abfolge der Meso- und Makrofauna im Boden höchsten Individuendichten der Mesofauna (=Bodentiere mit einer Größe zwischen 0,3 und 1 Millimeter) erreichen die Milben, die Biomasse der Makrofauna (= Bodentiere größer als 1 Millimeter) wird von Mückenlarven dominiert.

Die Biomasse der Makrofauna sowie die Abundanz der Mesofauna steigen in den ersten 50 Jahren rapide an (Abb. 5). Zu den älteren Standorten hin ändern sich die Werte jedoch kaum mehr. Betrachtet man den Verlauf einer einzelnen Vegetationsperiode, steigt die Biomasse der Bodenfauna über den kurzen Sommer hin an. Die Artenzusammensetzung bleibt jedoch über diesen Zeitraum weitgehend konstant.

Da erst ab einem Standortal- von Kaufmann et al. aus dem Jahr 2002 zeigt, dass erste Gruppen der Bodenfauna (Abb. 5), wie die Springschwänze (Collembola), Milben (Acari), Borstenwürmer (Enchytraeidae) sowie Schmetterlingsraupen (Lepidoptera), bereits in 30 Jahre alten Böden auftreten. Nach etwa 40 bis 50 Jahren Bodenbildung folgen Mückenlarven (Nematocera) und Tausendfüßer (Myriapoda). Alle weiteren BodentierGruppen erreichen erst nach 90 Jahren eine nennenswerte Abundanz. Die ter von etwa 80 Jahren eine echte Bodenbildung mit einem dünnen A-Horizont auftritt (Erschbamer et al. 1999), ist das Vordringen von Gruppen wie Regenwürmern (Lumbriciden) und Schnecken (Gastropoden) stark begrenzt. Die jüngsten Areale sind Pionieren mit hoher Mobilität und Verbreitungsfähigkeit vorbehalten. Diese Bereiche werden von räuberischen Käferlarven dominiert.

Das Standortalter ist der wichtigste Einflussfaktor auf die Zusammensetzung der 
Bodenfauna. Zusätzlich dazu sind jedoch auch lokale Variationen der mikroklimatischen Bedingungen oder der Bodeneigenschaften für den Verlauf der Besiedelung von Bedeutung.

\section{Verteilung der Flugfauna im Gletschervorfeld (Kapl 1999)}

Über 90 Prozent der Flugfauna im Gletschervorfeld sind Vertreter der Zweiflügler (Diptera). Die restlichen zehn Prozent entfallen auf Käfer (Coleoptera), Gleichflügler (Hymenoptera), Webspinnen (Araneae) und Schnabelkerfen (Hemiptera). Innerhalb der Mücken (Nematocera) sind die dominanten Familien die Zuckmücken (Chironomidae), Gritzen (Ceratopogonidae), Schnaken (Tipulidae) und Trauermücken (Sciaridae). Bei den Fliegen (Brachycera) treten vor allem Echte Fliegen (Muscidae), Blumenfliegen (Anthomyiidae), Buckelfliegen (Phoride), Taufliegen (Drosophilidae) und Schwebfliegen (Syrphidae) auf. Gletscherferne Standorte (Abb. 6) werden am häufigsten von Muscidae besucht, in der Nähe des Gletschers kommen dann auch Chironomidae in ähnlicher Dichte vor.

Untersuchungen von Kapl aus dem Jahr 1999 zeigen zudem, dass zum Gletscher hin sowohl die Anzahl der vertretenen Familien als auch die Biodiversität der Flugfauna abnimmt. Auch die Flugaktivität wird geringer. Eine besondere Anpassung weisen die beiden Familien Chironomi- dae und Muscidae auf: In Gletschernähe ist ihre Flugaktivität vom Morgen beziehungsweise Vormittag in die Mittagszeit und in den Nachmittag verschoben. Untersuchungen mit Hilfe von Schlüpftrichtern zeigen, dass zahlreiche Fluginsekten (Tipulidae, Muscidae, Anthomyiidae und Syrphidae) häufiger von außen in den Bereich des Gletschervorfeldes einfliegen, als vor Ort schlüpfen. Die höchste Schlüpfproduktion findet an den ältesten Standorten im Gletschervorfeld statt. Die gemessenen Werte entsprechen Befunden aus alpinen Grasheiden. Im jungen Gletschervorfeld ist die Schlüpfrate hingegen vergleichsweise gering.

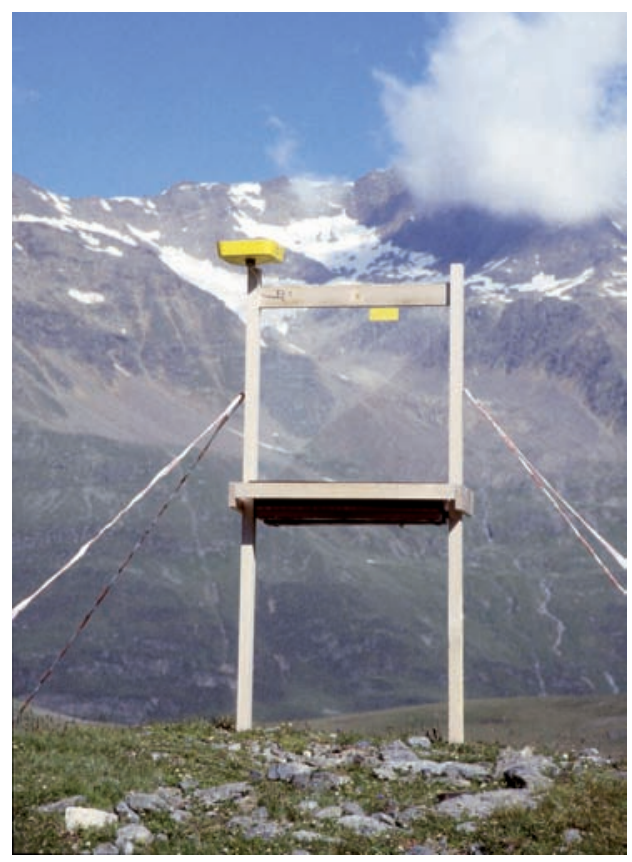

Abb. 6:

Fensterfalle zum Fang der Flugfauna an einem gletscherfernen Standort (Foto: R. Kaufmann) 


\section{Verteilung Pflanzen fressender Arthropoden im Gletschervorfeld (Koch 2006)}

Die häufigsten Pflanzen fressenden (herbivoren) Gruppen im Gletschervorfeld (Abb. 7) sind Thripse (Thysanoptera), Kugelspringer (Symphypleona), Gleichflügler (Homoptera) und Schmetterlingsraupen (Lepidoptera). Einzelne Weiden werden besonders stark von Raupen des Alpenwollafters (Eriogaster arbusculae) und Blattkäfer-Larven (Chrysomelidae, Abb. 9) befallen.

Die Herbivorendichte nimmt anfangs mit dem Sukzessionsalter und damit auch mit der Vegetationsdeckung zu. In den Bereichen mittleren Sukzessionsalters treten die höchsten Herbivorendichten auf. Der
Grund dafür könnte der höhere Nährstoffgehalt der Pflanzen sein, da in den nicht so dichten Beständen weniger Konkurrenz zwischen den Pflanzen herrscht. Thysanoptera (Abb. 8) sind erst ab einem Standortalter von mindestens 25 Jahren anzutreffen, die jüngsten Bereiche werden noch nicht besiedelt. Zikaden treten ab einem Standortalter von etwa 50 Jahren auf, da sie zur Etablierung auf eine Vegetationsdichte von etwa 30 Prozent angewiesen sind.

Nahezu alle herbivoren Gruppen, ausgenommen die Larven von Dipteren und Lepidopteren, erreichen im Juli ihre höchste Abundanz und nehmen zum Herbst hin schnell ab. Auch die beiden Talseiten unterscheiden sich in ihren Herbivorendichten deutlich.

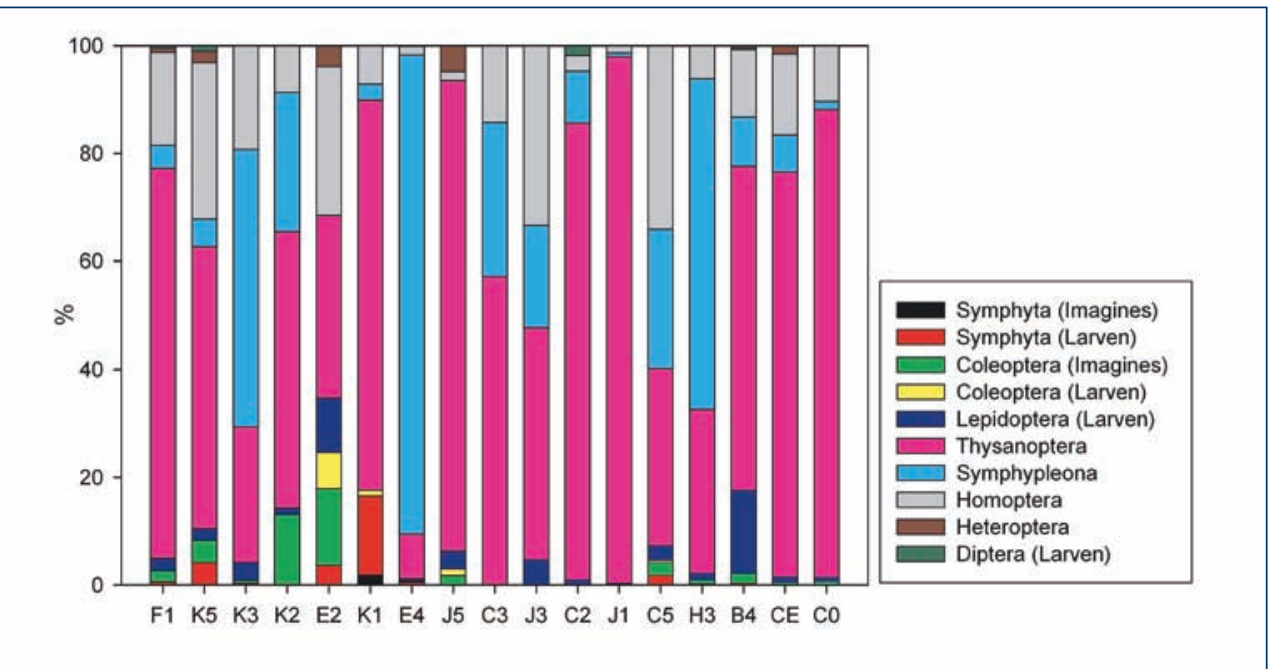

Abb. 7:

Dominanzspektrum (\%, ermittelt aus der Summe von drei Saugbeprobungen) der herbivoren Gruppen an den einzelnen Standorten (nach Sukzessionsalter gereiht, F1... 146 Jahre, C0...31 Jahre) 


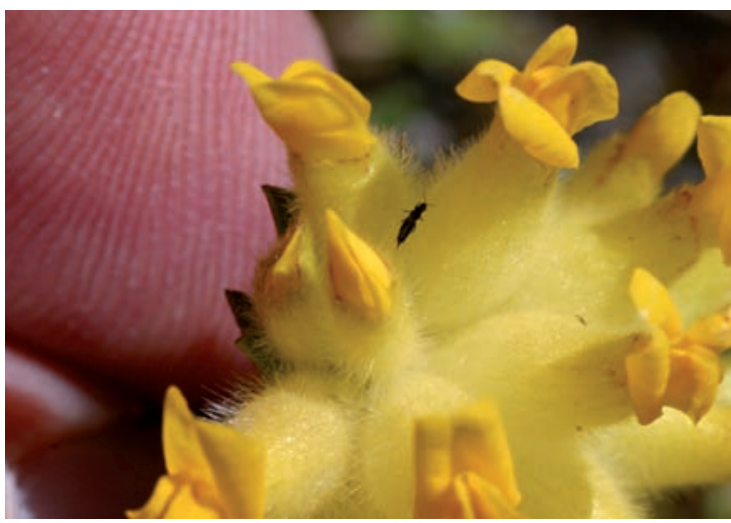

Abb. 8:

Thrips auf Anthyllis vulneraria ssp. alpicola (Foto: R. Kaufmann)

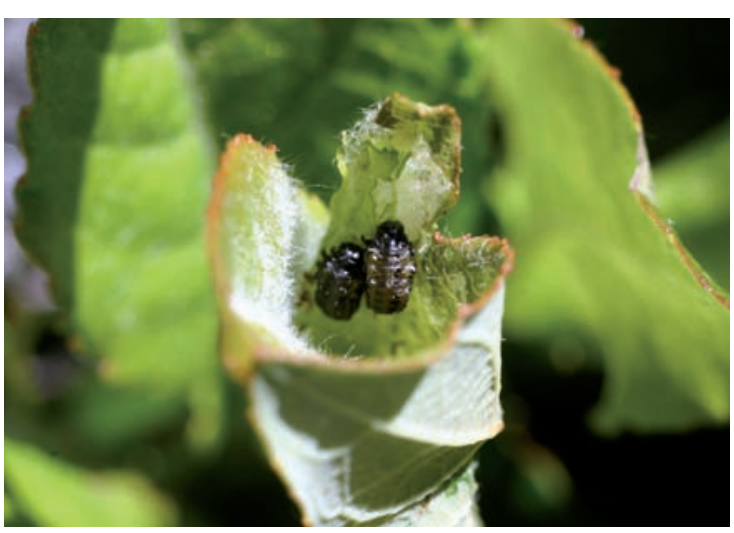

Abb. 9:

Blattkäferlarven auf einer Weide (Foto: R. Kaufmann)

Um zu erkennen, ob nun herbivore Arthropoden einen bremsenden Effekt auf die Sukzession oder die Etablierung einzelner Arten im Gletschervorfeld haben, untersuchte Koch 2005 im Rotmoostal die Ab- undanz und das Artenspektrum von Herbivoren an verschiedenen Pflanzen. Die drei häufigen Gletschervorfeldarten Fetthennen-Steinbrech (Saxifraga aizoides), Moränenklee (Trifolium pallescens) und AlpenWundklee (Anthyllis vulneraria ssp. alpicola) weisen ein ähnliches Herbivorenspektrum auf. Die Individuendichten der Pflanzenfresser sind jedoch auf Trifolium pallescens beträchtlich höher als auf den anderen beiden Arten. Dies deutet auf einen unterschiedlich hohen Fraßdruck hin. Insektenausschlussversuche innerhalb einer Vegetationsperiode haben jedoch in Bezug auf den Wachstums- und Reproduktionserfolg der drei Arten keine oder keine deutlich signifikanten Unterschiede ergeben. Möglicherweise muss eine derartige Versuchsreihe über mehrere Vegetationsperioden hinweg durchgeführt werden, um Auswirkungen ausreichend erfassen $\mathrm{zu}$ können.

Auch der intensive Fraßdruck der Raupen des Alpenwollafters und der Blattkäfer-Larven an Weiden könnte einen bremsenden Einfluss auf die Sukzession im Gletschervorfeld haben. Die Pflanzenfresser befallen die Sträucher in hoher Dichte und reduzieren deren Wachstum stark. 


\section{Entwicklung der Biodiversität}

Die Zahl der verschiedenen tierischen Besiedler steigt innerhalb der ersten 50 Jahre rasch an. Danach gibt es nur noch geringe Zunahmen. Die Artenzahien, die nach 150 Jahren erreicht werden, entsprechen jenen in den reifen Standorten außerhalb des Gletschervorfeldes (Abb. 10). Die Zusammensetzung der Artengremeinschaft hat nach dieser Zeit hingegen noch kein Endstadium erreicht. Während bei den
Pflanzen in den ersten Jahren der Besiedelung nur wenige Pionierarten auftreten, etabliert sich sehr rasch eine diverse Tierwelt in den jüngsten Gletschervorfeldbereichen. Un.mittelbar am Gletscherrand sind - bedingt durch die hohe Mobilität der Tiere - deutlich mehr Tier- als Pflanzenarten präsent.

\section{Bestimmende Faktoren für die Fauna}

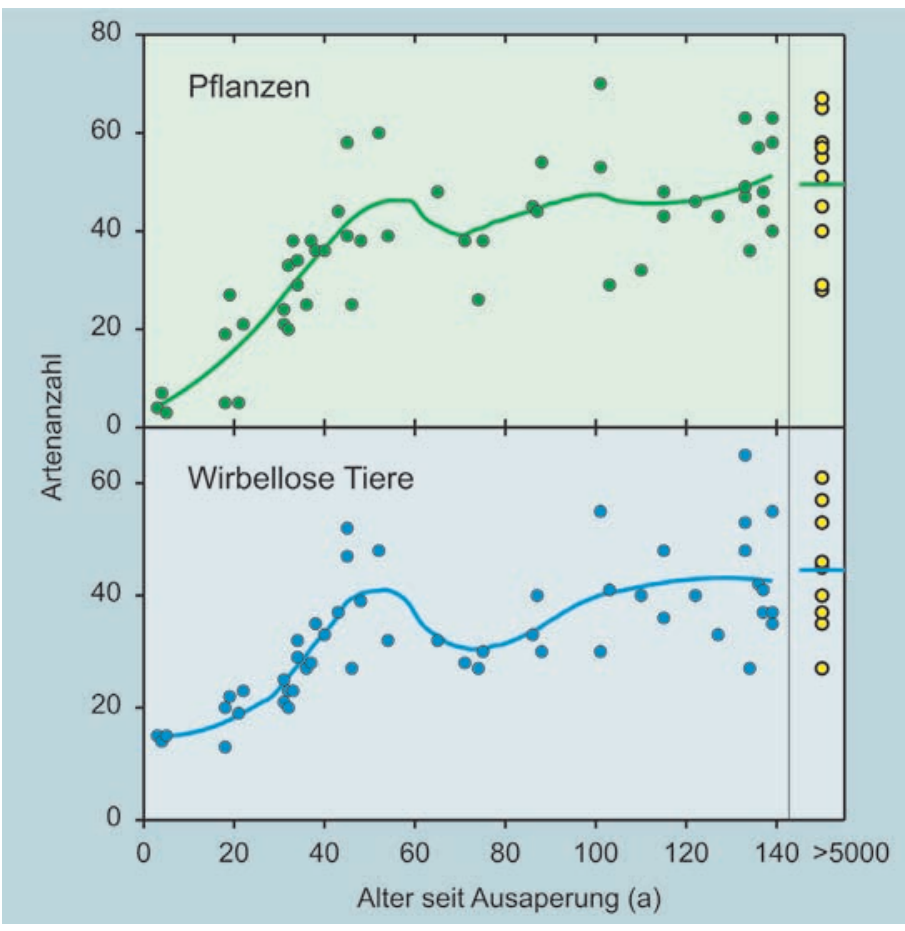

Abb. 10:

Artenzahlen von wirbellosen Tieren und Pflanzen entlang der Chronosequenz des Gletschervorfeldes. Als Vergleich dienen die Artenzahlen der reifen Standorte (älter als 5000 Jahre) außerhalb des Gletschervorfeldes.
Jene Faktoren, welche die Fauna im Gletschervorfeld am stärksten beeinflussen, sind die im Altersverlauf zunehmende Bodenbildung und Vegetationsentwicklung (Tab. 1).

Im Gletschervorfeld verändern sich aber nicht nur entlang der Chronosequenz die Bedingungen für die tierische Lebewelt. Auch lokal treten unterschiedliche Standortfaktoren auf, zum Beispiel durch die unterschiedlich intensive Besonnung. Die Ausrichtung des Tales von Südost nach Nordwest 


\begin{tabular}{|c|c|}
\hline Faktor & $\begin{array}{l}\text { Erklärter Anteil der } \\
\text { Artenvariabilität (\%) }\end{array}$ \\
\hline $\begin{array}{l}\text { Moränenalter (inklusive zunehmender Vegetationsbedeckung } \\
\text { und Bodenentwicklung) }\end{array}$ & -15 \\
\hline \multicolumn{2}{|c|}{ + klimatische Faktoren, die den Verlauf der Sukzession beeinflussen } \\
\hline Sonneneinstrahlung und Temperatur & -5 bis 8 \\
\hline Schneebedeckung und Feuchtigkeit & -4 \\
\hline
\end{tabular}

\section{Tab. 1:}

Einfluss von Umweltfaktoren auf die Fauna im Gletschervorfeld

und die umgebenden Bergzüge teilen das rechte Talseite, Abb. 11), auf welcher der Tal in eine Schattseite (orographisch linke Sukzessionsprozess begünstigt abläuft. Talseite) und eine Sonnseite (orographisch Auch das unterschiedliche Feuchtemi-

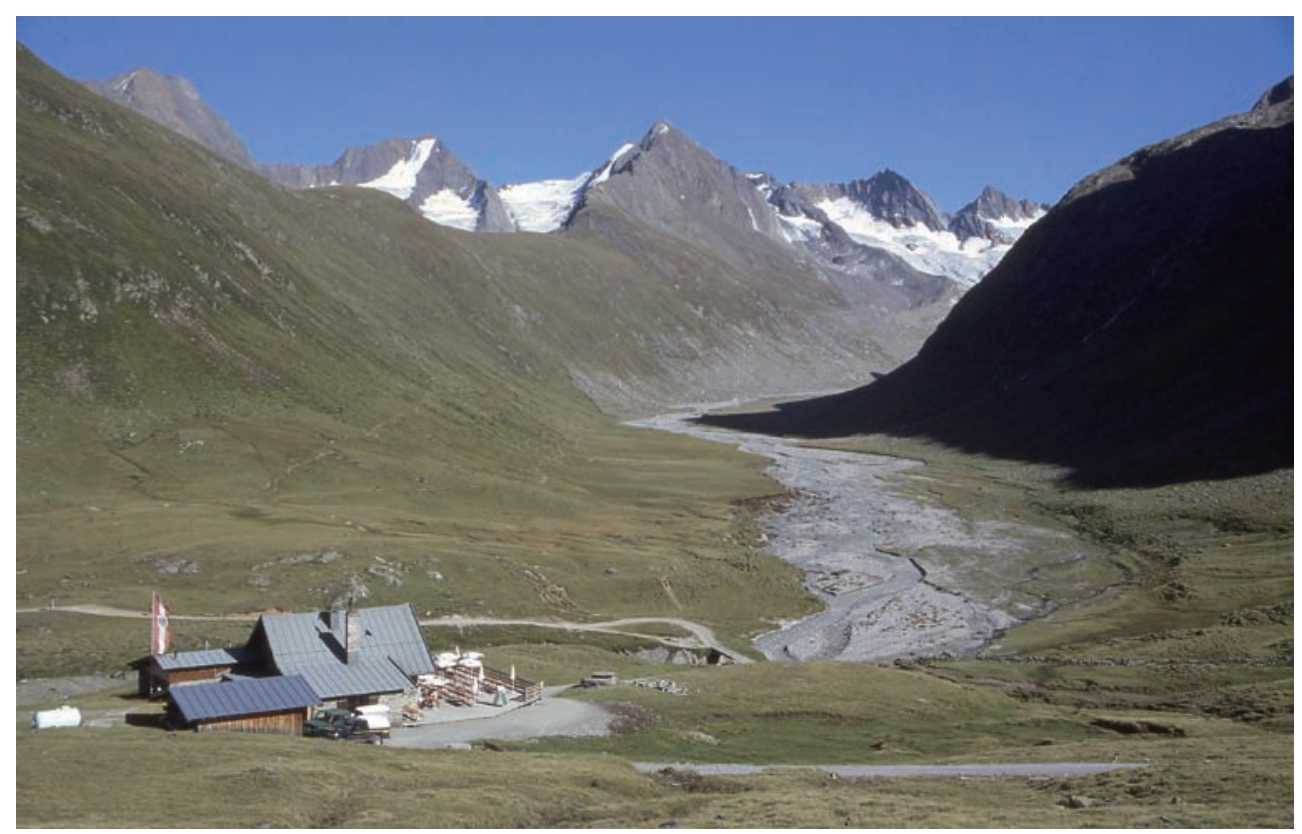

Abb. 11:

Unterschiedliche Besonnung im Rotmoostal (Foto: R. Kaufmann) 


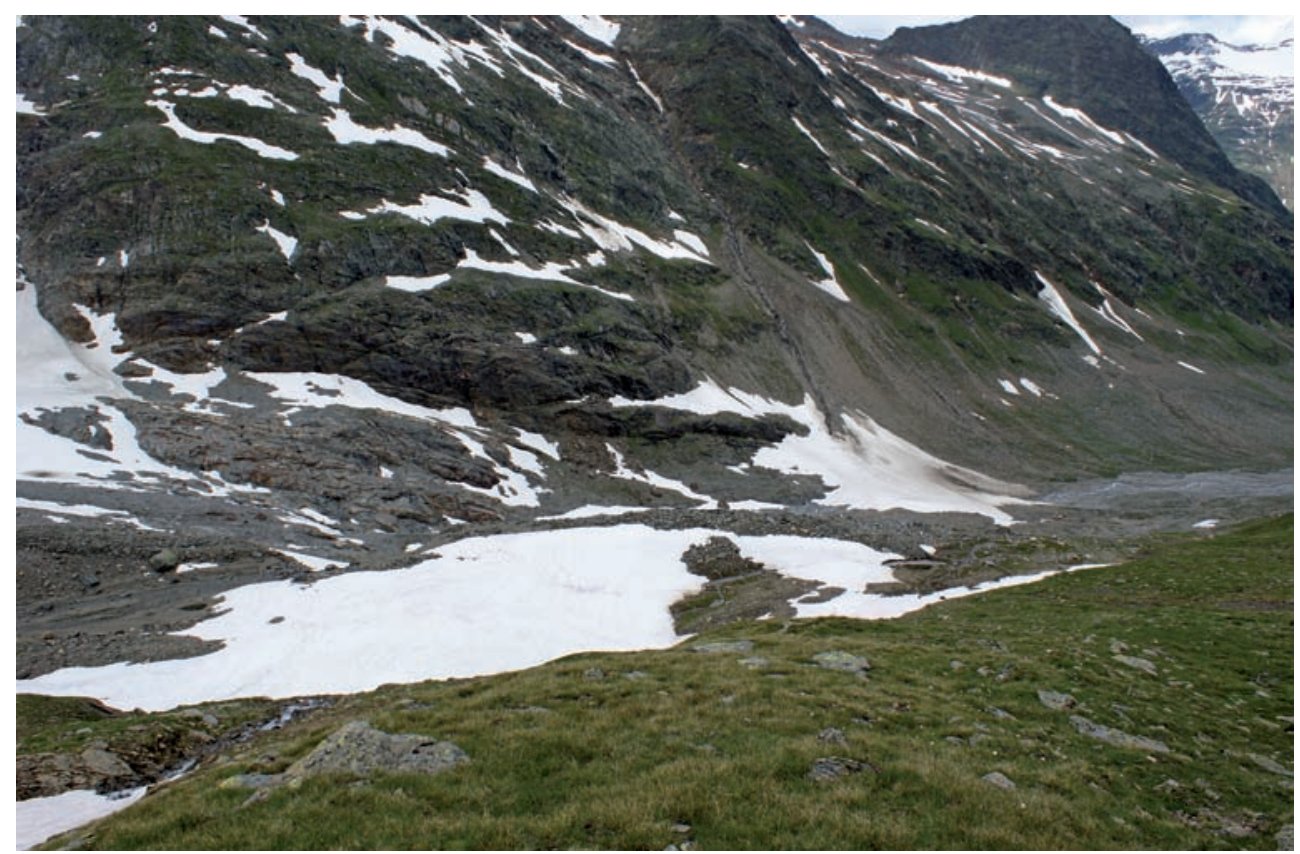

Abb. 12:

In manchen Jahren bleiben die Lawinenkegel den ganzen Sommer über liegen und sorgen dadurch für unterschiedliche Bedingungen im Bezug auf das Feuchtemilieu und die Schneedeckendauer.

(Foto: E.-M. Koch)

lieu und die Dauer der Schneebedeckung (Abb. 12) variieren im Vorfeld und beeinflussen lokal die Besiedelung und die Artenzusammensetzung der Standorte.

Lokale Störungen wie Überflutung und Erosion verlangsamen vermutlicherweise den Sukzessionsprozess. Sie spielen aber im Rotmoostal, abgesehen von den häufig überschwemmten Flächen entlang der Rotmoosache und einigen, von Lawinen beeinflussten Seitenhängen, kaum eine Rolle. Dies kann jedoch nicht auf jedes Gletschervorfeld umgelegt werden.
Die abiotischen Umweltparameter, der Vegetationsaufbau und die Pflanzengesellschaft greifen als erklärende Faktoren ineinander. Pioniergesellschaften zeigen ebenso wie auch die älteren Gemeinschaften einen Bezug zu den äußeren Faktoren auf. Daraus lässt sich folgern, dass sowohl die erste Kolonisierung als auch die Faunensukzession in alpinen Gletschervorfeldern großteils vorhersagbaren und deterministischen Gesetzmäßigkeiten folgen und stochastische Effekte von geringer Wichtigkeit sind. 
Ernährungstypen der Tiere

Unerwarteterweise handelt es sich bei den ersten Kolonisatoren fast ausschließlich um räuberische Tiere (Abb. 13), obwohl es in diesem Stadium auf den ersten Blick

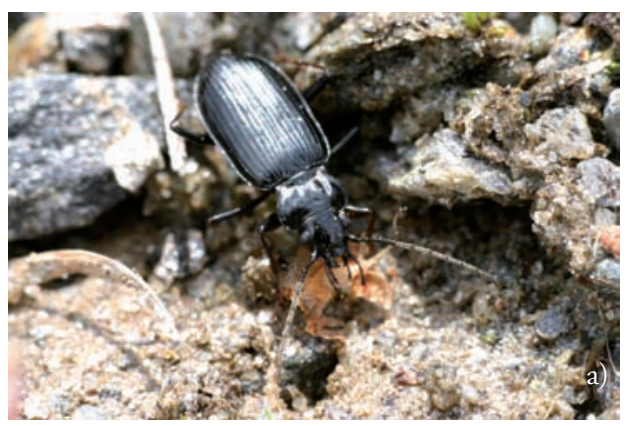

kein erkennbares Nahrungsnetz zu ihrer Versorgung gibt. Eine Vermutung ist, dass die Räuber von Insekten leben, die vom Wind aus anderen Gebieten eingetragen werden. Demnach wäre der Nährstoffeintrag aus angrenzenden Gebieten eine wesentliche Voraussetzung für die rasche

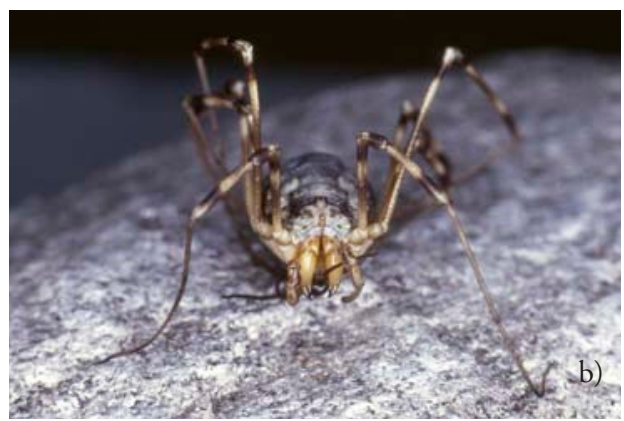

Abb. 13:

Räuberische Kolonisatoren auf den jüngsten Moränenböden: Ein Laufkäfer (Nebria jockischii, a) und der Gletscher-Weberknecht (Mitopus glacialis, b) - (Fotos: R. Kaufmann)

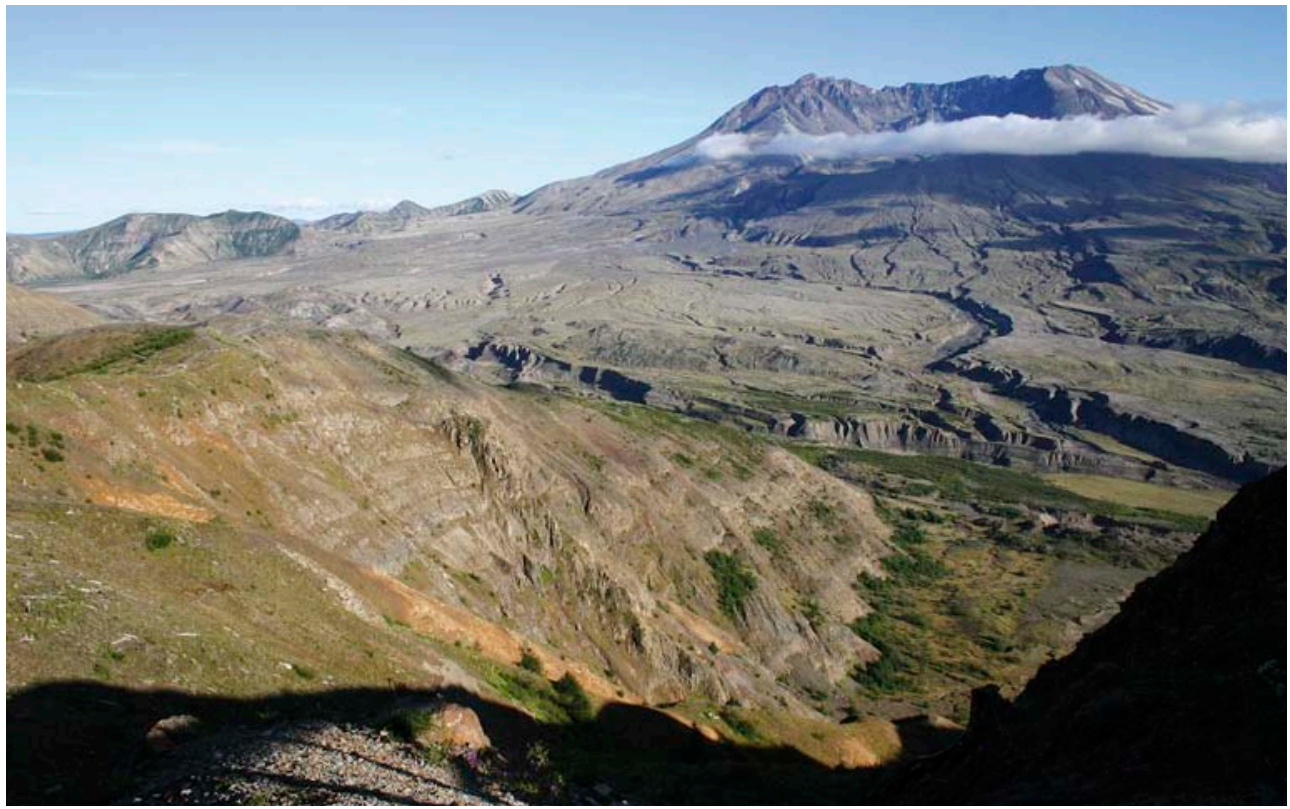

Abb. 14: Der Vulkankegel des Mount St. Helens, Washington USA (Foto: R. Kaufmann) 


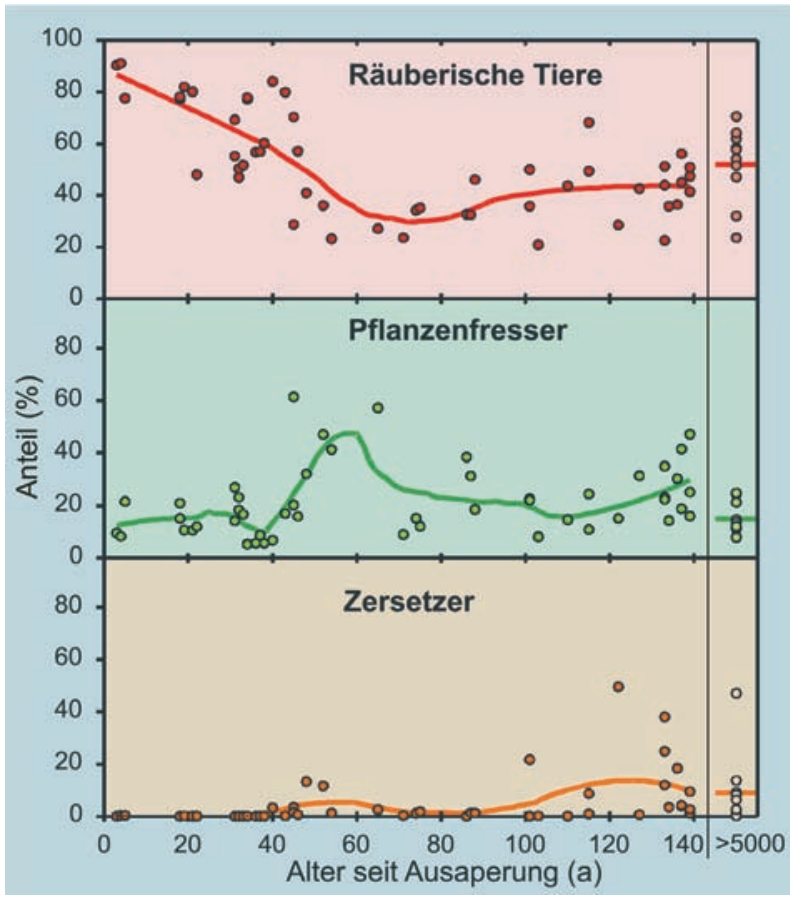

Abb. 15:

Auftreten der Ernährungstypen der wirbellosen Tiere entlang des Gletschervorfeldes: Räuberische Tiere (bzw. Aasfresser), Pflanzenfresser und Zersetzer.
Besiedlung der Moränenflächen (Swan 1963, Kaufmann 2001). Auch auf den Primärsukzessionsflächen der Vulkane Mount St. Helens (Abb. 14) und Krakatau haben Forscher (Dammermann 1948, Ashmole and Ashmole 1987, Edwards und Sugg 1993, Sugg and Edwars 1998) dieses Räuber-Phänomen beobachtet.

Untersuchungen zum Beutespektrum räuberischer Käfer mit Hilfe von Isotopensignaturen stärken zudem die Annahme, dass sich die Käfer auch von epigäisch lebenden Collembola ernähren (Schallhart 2005), die ebenso wie die räuberischen Arten in den jüngsten Moränenflächen siedeln. Weiters zeigten
Isotopensignaturen $\left(\delta^{13} \mathrm{C}\right.$ und $\left.\delta^{15} \mathrm{~N}\right)$, dass die Nahrungskette der Pionierstandorte eine Trophieebene weniger aufweist als die älterer Standorte, und dass einzelne Arten ihre Ernährungsweise entlang der Chronosequenz dem Nahrungsangebot entsprechend ändern können (König 2006).

Pflanzenfressende Insekten erscheinen erst nach etwa 50 bis 60 Jahren in größerer Dichte, sobald sich die Vegetationsdecke zu entwickeln beginnt. Zersetzer, die organisches Material abbauen, treten erst in späteren Stadien mit beginnender Bodenbildung auf (Abb. 15). 


\section{Empfindlichkeit auf}

Klimaschwankungen

Auch klimatische Änderungen beeinflussen die tierische Lebewelt eines Gletschervorfeldes stark. Das ergab sich aus einem Vergleich von Klimadaten, der über einige Jahre hinweg beobachteten Veränderungen der Artengemeinschaften und dem Verteilungsmuster entlang der Chronosequenz (Abb. 16). Die Veränderung der Temperatur ist dabei nicht der einzige Faktor, der die Kolonisation und Sukzession eines Gletschervorfeldes beeinflusst. Vor allem auch die Feuchtigkeit ist ein wichtiger Motor für diese beiden Prozesse (Matthews und Witthaker 1987, Kaufmann 2001).

Die jüngsten Stadien entwickeln sich derzeit rascher und die 30 bis 50 Jahre alten Standorte langsamer als man aus dem Muster entlang der Chronosequenz des Tales erwarten würde (Kaufmann 2002). Die Ursache dafür waren vermutlich $\mathrm{Kli}$ maschwankungen mit einer Phase unge-

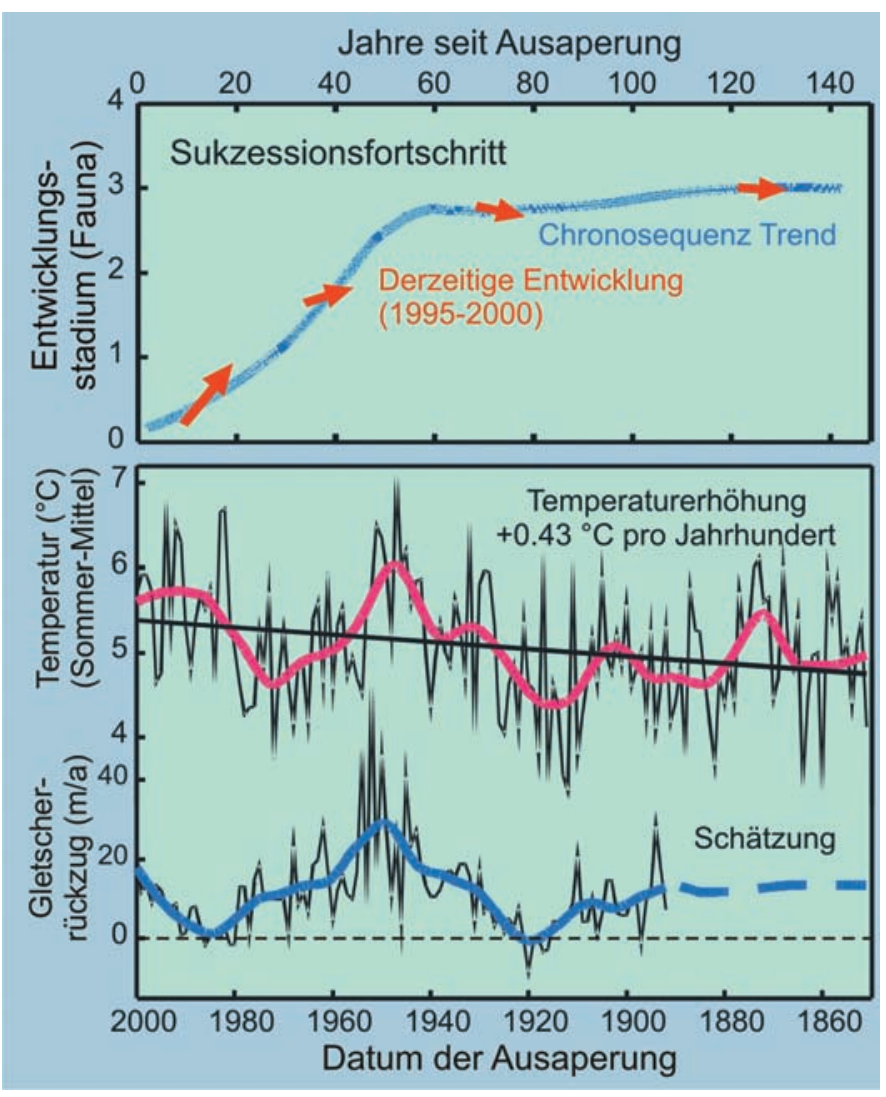

Abb. 16:

Analyse des Klimawandeleffektes auf die Kolonisation der Tierarten. Unterschiede zwischen dem Trend der Chronosequenz und der direkten Beobachtung der derzeitigen Entwicklungsgeschwindigkeit lassen sich aus Temperaturschwankungen der letzten Jahrzehnte erklären. 
wöhnlich warmer Sommer in den 1950er Jahren, gefolgt von einer sehr kühlen Periode 1960 bis 1980 und einer neuerlichen, bis heute dauernden warmen Periode $a b$ etwa 1980. Es scheint, dass die Erstkolonisation nahe dem Gletscherrand in warmen Phasen mit hohen Rückschmelzgeschwindigkeiten der Gletscher deutlich beschleunigt wird.

\section{Literatur}

Ashmole, N.P. \& Ashmole, M.J. (1987) Arthropod communities supported by biological fallout on recent lava flows in the Canary Islands. Entomologia Scandinavica, Supplement 32: 67-88.

Ashmole, N.P., Oromi, P., Ashmole, M.J. \& Martin, J.L (1992) Primary faunal succession in volcanic terrain: lava and cave studies on the Canary Islands. Biological Journal of the Linnean Society of London 46: 207-234.

Baldes, M. (2009) Abundanz, räumliche Verteilung und Nahrungsquellen räuberischer Arthropoden in einem Gletschervorfeld. Diplomarbeit Universität Innsbruck, $83 \mathrm{~S}$.

Bardgett, R.D., Bowman, W.D., Kaufmann, R. \& Schmidt, S.K. (2005) A temporal approach to linking aboveground and belowground ecology. Trends in Ecology and Evolution 20: 634-641.
Dammermann, K. (1948) The fauna of Krakatau, 1883-1933. Verhandlingen Koninklijke Nederlnadsche Akademie Wetenschapen Afdeling Natuurkunde (tweede dectie) 44: 1-594.

Edwards, J.S. \& Sugg, P.M. (1993) Arthropod fallout as a resource in the recolonization of Mount St. Helens. Ecology 74: 954958.

Erschbamer, B., Bitterlich, W. \& Raff, C. (1999) Die Vegetation als Indikator für die Bodenbildung im Gletschervorfeld des Rotmoosferners (Obergurgl, Ötztal, Nordtirol). Ber. nat.-med. Verein Innsbruck, 86: 107-122.

Gereben, B. (1995) Co-occurence and Microhabitat Distribution of six Nebria species (Coleoptera: Carabidae) in an Alpine Glacier retreat zone in the Alps, Austria. Arctic and Alpine Research 27: 371-379.

Gobbi, M., De Bernardi, F., Pelfini, M., Rossaro, B. \& Brandmayr, P. (2006) Epigean arthropod succession along a 154year glacier foreland chronosequence in the Forni Valley (Central Italian Alps). Arctic Antarctic and Alpine Research 38: 357-362.

Hodkinson, I.D., Coulson, S.J., Harrison, J. \& Webb, N.R. (2001) What a wonderful web they weave: spiders, nutrient capture and early ecosystem development in the high Arctic - some conterintuitive ideas on community assembly. Oikos 95: 349-352. 
Janetschek, H. (1948/49) Tierische Successionen auf hochalpinem Neuland. Ber. nat.- med. Verein Innsbruck, $48 \& 49$.

Juen, A. (1998) Artenzusammensetzung und Verteilung von Käfern im Gletschervorfeld des Rotmoostales (Ötztaler Alpen, Tirol). Diplomarbeit Universität Innsbruck, $157 \mathrm{~S}$.

Kapl, T. (1999) Verteilung und Phänologie von Fluginsekten im Gletschervorfeld des Rotmoosferners. Diplomarbeit, Universität Innsbruck, 109 S.

Kaufmann, R. \& Juen, A. (2001) Habitat use and niche segregation of the genus Nebria (Coleoptera: Carabidae) in the Austrian Alps. Mitteilungen der Schweizerischen Entomologischen Gesellschaft 74: 237-254.

Kaufmann, R. (2001) Invertebrate succession on an Alpine glacier foreland. Ecology 82: 2261-2278.

Kaufmann, R. (2002) Glacier foreland colonisation: distinguishing between shortterm and long-term effects of climate change. Oecologia 130: 470-475.

Kaufmann, R., Fuchs, M. \& Gosterxeier, N. (2002) The soil fauna of an Alpine glacier foreland: Colonization and succession. Arctic Antarctic and Alpine Research 34: 242-250.

Kaufmann, R. \& Raffl, C. (2002) Diversity in primary succession: The chronosequence of a glacier foreland. In: Global Mountain Biodiversity: A Global Assessment, Körner C, Spehn E (eds) Parthenon Publishing, London. pp. 177-190.
Koch, E.-M. (2006) Fraßdruck herbivorer Arthropoden in der Primärsukzession eines Gletschervorfeldes, Rotmoostal (Ötztaler Alpen, Tirol). Diplomarbeit, Universität Innsbruck, 77 S.

König, T. (2006) Nahrungsbeziehungen und primäre Ressourcen epigäischer Wirbelloser eines Gletschervorfeldes (Rotmoosferner, Tirol) - eine Studie basierend auf den stabilen Isotopen $15 \mathrm{~N}$ und 13C. Diplomarbeit, Technische Universität Darmstadt, $71 \mathrm{~S}$.

Matthews, J.A. \& Whittaker, R.J. (1987) Vegetation succession on the Storbreen glacier foreland, Jotunheimen, Norway: a review. Arctic and Alpine research 19: 385-395.

Meyer, E. \& Thaler, K. (1995) Animal diversity at high altitudes in the Austrian Central Alps. In: Arctic and Alpine Biodiversity, Körner C, Chapin FS (eds), Springer, Berlin, Heidelberg, 95-106.

Raso, L., Sint, D., Kaufmann, R. \& Traugott, M. (2008) Assessing trophic interactions in pioneer communities: macro-invertebrate food webs in recently deglaciated alpine areas. Ber. nat.-med. Verein Innsbruck, Supplementum 18: 42.

Schallhart, N. (2005) Das Beutespektrum der räuberdominierten Kolonisatorengemeinschaften im Gletschervorfeld des Rotmoosferners (Ötztaler Alpen, Tirol), Diplomarbeit, Universität Innsbruck, $104 \mathrm{~S}$.

Spitaler, T. (1998) Einfluss der Herbivorie auf die Sukzession in einem Gletscher- 
vorfeld. Diplomarbeit, Universität Innsbruck, $104 \mathrm{~S}$.

Sugg, P.M. \& Edwards, J.S. (1998) Pioneer aeolian community development on pyroclastic flows after the eruption of Mount St. Helens, Washington, U.S.A. Arctic and Alpine Research 30: 400-407.

Swan, L.W. (1963) Aeolian zone. Science 140: 77-78.

Vater, A.E. (2006) Invertebrate and arachnid succession on selected glacier forelands in southern Norway. Dissertation, University of Wales, Swansea, 372 S.

\section{Verzeichnis der AutorInnen}

Rüdiger Kaufmann

Universität Innsbruck

Institut für Ökologie

Technikerstr. 25, 6020 Innsbruck, Österreich

Ruediger.Kaufmann@uibk.ac.at

Eva-Maria Koch,

Universität Innsbruck

Alpine Forschungsstelle Obergurgl

Gaisbergweg 3, 6456 Obergurgl, Österreich

Eva-Maria.Koch@uibk.ac.at 


\section{Kapitel 8 | Aquatische Lebensräume}

\section{Hochalpine Flusslandschaft Rotmoos}

Leopold Füreder

\section{Zusammenfassung}

Die Ökosysteme der Hochgebirge gelten als Extremökosysteme, beurteilt man sie nach der Ausprägung und Wirkung der klimatischen, meteorologischen und physikalischen Faktoren. Die Lebewelt solcher Regionen findet man durch unterschiedlichste Strategien und Strukturen an diese spezielle Situation angepasst. Oft werden die Land- und Gewässersysteme wegen ihrer Artenarmut als nur bedingt wertvoll bezeichnet, so dass deren Nutzung gerechtfertigt oder weniger dramatisch erscheint. Wegen der bereits in manchen Ländern weit fortgeschrittenen Einbeziehung der aquatischen und terrestrischen Lebensräume in gewinnorientierte Wirtschaftsinteressen, sei hier der Gletscherbach im Rotmoostal als eines dieser Extremökosysteme genauer betrachtet, und einige faszinierende abiotische und biotische Besonderheiten dargestellt. Die Lebewelt - obwohl artenarm im Vergleich zu tiefer liegenden und weniger dynamischen Fließgewässern - ist reich an Spezialisten mit zahlreichen, unterschiedlichsten Anpassungen an die vorherrschenden extremen Umweltbedingungen. Die vorliegenden Ergebnisse der strukturellen und funktionellen Organisation der Gewässerfauna aus einer Reihe von unterschiedlichen Gewässerlebensräumen des Rotmoostales können für die Vorhersagen und Analyse der Auswirkungen von Umweltveränderungen und des Klimawandels verwendet werden.

\footnotetext{
Abstract

Alpine river systems are fed by glacial icemelt, snowmelt and groundwater. They share common features (e.g., steep gradients, high flow velocities and dynamics) but each source and local conditions produce a characteristic discharge regime and a distinctive suite of physical and chemical characteristics. The distribution of snow, ice and groundwater springs varies spatially from stream-reach to catchment scale, resulting in stream segments with characteristics, reflecting the different runoff sources. The freshwater ecosystems although species poorer compared with freshwaters at lower elevations - are rich in specialists which are strongly adapted to the extreme environmental parameters. In various investi-
} 
gations in the Rotmoos Valley we have been focusing on the variety of natural freshwater ecosystems and, based on hydromorphological conditions at catchment and reach scale, we defined specific habitat types and their invertebrate assemblages. In analysing their temporal and spatial patterns we defined a conceptual model to be used for the scenarios of environmental and climate change effects on the abiotic factors and, consequently, on the structure and function of aquatic biocenoses in alpine streams.

\section{Einleitung}

Flusslandschaften im Hochgebirge sind Landschaften der besonderen Art. Neben dem Neuland an der Gletscherfront, die besonders von der Macht des Eises und des Wassers geprägt sind, tragen aber auch die daran anschließenden hochdynamischen, erosiven oft verzweigten Umlagerungsstrecken zur Faszination alpiner Landschaften bei. Fließgewässer, insbesondere Gletscherflüsse, sind da besonders auffällige und wesentliche Bestandteile alpiner Landschaften, denen als verbindende Lebensadern zwischen einerseits hochalpinen Eis- und Schneemassen sowie alpinen Graslandschaften und andererseits den natürlichen, meist aber menschlich-geprägten Lebensräumen in tieferen Lagen große Bedeutung zukommt. Der Gletscherbach ist nur eine von vielen Besonderheiten des Hochgebirges und der Gebirgslandschaften, welche die Einmaligkeit und daher auch die touristische Attraktion dieses Raumes ausmachen. Die zunehmende Rarität ungenutzter und in ihrer Gesamtheit ökologisch intakter Gletscherbäche soll zum Nachdenken über den Verbrauch alpiner Beispiellandschaften anregen. Ihr ökologischer und ökonomischer Wert als eine der letzten Ressourcen unverschmutzten Wassers für die Zukunft wurde vielfach erkannt. Das öffentliche Interesse ist auch durch die breitere Kenntnis von Umweltproblemen verursacht durch menschliche Aktivitäten auf lokaler, regionaler (z.B. Wasserkraftnutzung, Gewässerverbauung, Tourismus, Kunstschneeerzeugung) und globaler Ebene (z.B. Klimawandel, saurer Regen) gestiegen. Mehrfach wurde gezeigt, dass diese Beeinträchtigungen und Veränderungen besonders in den sensiblen Landschaften in hohen Lagen und geografischen Breiten wirken. Die Flusslandschaften des Hochgebirges sind Extremökosysteme, die besonders empfindlich auf organische Verschmutzung, Tourismus, sauren Regen und Klimaveränderungen reagieren. Sie beherbergen aber auch eine Vielfalt an pflanzlichen und tierischen Organismen, die mit einer Reihe von Anpassungen ausgestattet die großteils extremen Umweltbedingungen überleben und stabile Populationen aufbauen können. 
Die Rotmoosache - ein typischer Gletscherbach

Fließgewässer stellen keine einheitlichen Lebensräume von ihrer Quelle bis zur Mündung dar. Die maßgeblichen Umweltfaktoren und die Zusammensetzung der vorkommenden Lebensgemeinschaften ändern sich deutlich im Längsverlauf. Klima (sowohl regionales Klima als auch lokale Witterungsverhältnisse), Häufigkeit, Menge und Saisonalität des Niederschlags, Geologie, Pflanzendecke des Einzugsgebiets und Ufervegetation beeinflussen die Hydrologie und Temperaturverhältnisse im Gewässer und bestimmen mit der Substratzusammensetzung, Bachmorphologie und Wasserchemie die wesentlichen Systemeigenschaften von Fließgewässern. In alpinen Gebieten jedoch kann der Ursprung des Gewässers und der größeren Zuflüsse die Fließgewässercharakteristik entscheidend prägen. So werden entsprechend der Herkunft des Wassers (Grundwasser, Regen, Schnee, Gletscher) und des Gletschereinflusses vier grundsätzliche Typen alpiner Fließgewässer unterschieden (Abb. 1; detailliert dargestellt in FÜREDER 1999): Gletscherbach (KRYAL), Quellbach (KRENAL), regen- bzw. schneebeeinflusster Bach (RHITHRAL) und Bachabschnitte, wo der Gletschereinfluss noch immer entscheidend die Lebensbedingungen prägt (GLACIO-RHITHRAL). Alpine Fließgewässerlandschaften können auch ein

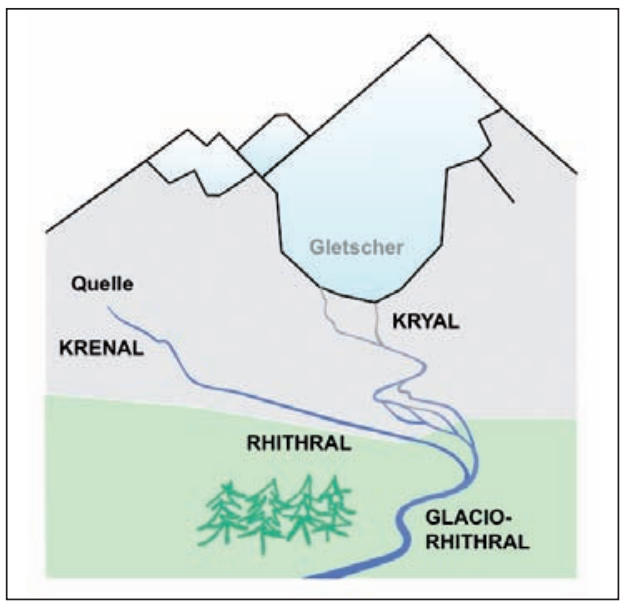

Abb. 1:

Die typischen Fließgewässerabschnitte der kalten Regionen, wie sie aufgrund der wesentlichen Umweltfaktoren und der darin vorkommenden Organismengemeinschaften eingeteilt werden. Entscheidend dabei ist die Herkunft des Wassers.

komplexes Netzwerk von gletscher- und grundwasserbeeinflussten Bachläufen bilden, das sich in seiner Zusammensetzung besonders in Bezug auf den Einfluss der einzelnen Komponenten sowohl im Längsverlauf als auch im Jahresverlauf stark ändern kann.

Diese alpinen Flusstypen sind analog zur Verbreitung der alpinen Vegetationszone weltweit zu finden, wo Vergletscherung, eine relativ lange Dauer der Schneebedeckung und andere meist damit zusammenhängende extreme Umweltfaktoren ihre physikalischen und chemischen Eigenschaften prägen (Füreder 1999, Brittain und Milner 2001). Kurzum - es handelt sich um Fließgewässerökosysteme der kalten Regionen. 
Abflussdynamik, Temperatur, Chemismus und Trübstoffführung gelten als jene Umweltfaktoren, die einen Gletscherbach und einen gletscherbeeinflussten Fluss prägen und am deutlichsten von übrigen Gebirgsbächen der alpinen und subalpinen Region abgrenzen lassen. Das charakteristische Abflussverhalten, mit maximaler Wasserführung im Sommer und Abflussspitzen am Nachmittag und in den Abendstunden sowie Niederwasser über die lange Winterperiode gehören zu den Besonderheiten des Gletscherbaches (Abb. 2). Übers Jahr herrschen meist niedrige Temperaturen vor, die mit zunehmendem Abstand zum Gletscher deutlich saisonal schwanken können. Ein oft in Quellbächen ausgeprägter Temperaturanstieg im Sommer ist im Gletscherbach durch das Abschmelzen des Gletschers eingeschränkt oder verhindert.

Bei einem Vergleich physikalisch-chemischer Parameter, gemessen in der Rotmoosache (Abb. 3) und dem unvergletscherten Königsbach, werden die gewässertypische Dynamik und die diesbezügliche Extremsituation eines Gletscherbaches besonders deutlich (Abb. 4). Die Wassertemperatur ist über die Wintermonate sehr niedrig und zeigt keine Tagesunterschiede. Im Sommer erreicht sie in beiden Bächen ihre höchsten Werte, die über den Tag deutlich schwanken. In Zeiten stärkster Gletscherablation sind die Temperaturen der Rotmoosache deutlich niedriger als im Königsbach. Jahreszeitliche und tageszeitliche Muster des Abflussgesche-

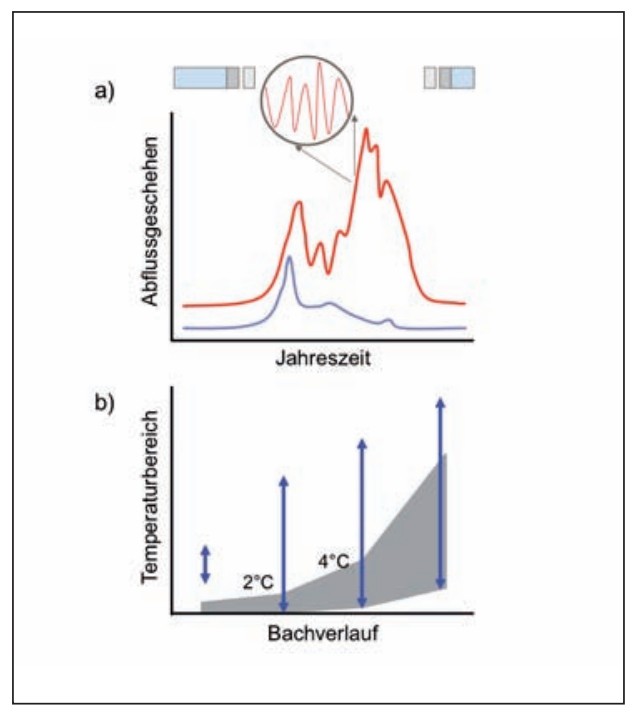

Abb. 2:

a) Abflussgeschehen in einem Gletscherbach (rot) und einem Quellbach (blau). Die erste deutliche Erhöhung des Abflusses ist in beiden Bächen zur Zeit der Schneeschmelze festzustellen. Im Gletscherbach erfolgt im Verlauf des Sommers eine deutliche Steigerung der Schüttung, bedingt durch das Schmelzen des Gletschers. Im erhöhten Sommerabfluss ist eine charakteristische Tagesdynamik festzustellen (Kreis). Der Balken über dem Diagramm zeigt die Dauer der Schneebedeckung, die Schneeschmelze im Frühjahr, die in beiden Gewässertypen zur Abflusserhöhung führt, und die erneute Schneebedeckung im Herbst an.

b) Typischer Längsverlauf der Schwankungen der Wassertemperaturen in einem Gletscherbach (grau) und einem Quellbach (blaue Pfeile) mit zunehmendem Abstand vom Ursprung (Gletschertor, Quellaustritt). Die sommerlichen Höchstwerte in den oberen Abschnitten eines Gletscherbaches liegen zwischen 0 und $4{ }^{\circ} \mathrm{C}$. Mit zunehmendem Abstand wird der Bach zwar wärmer, wegen des Einflusses des Schmelzwassers im Sommer erwärmt er sich aber weniger als ein Quellbach in vergleichbarer Lage und Größe. 


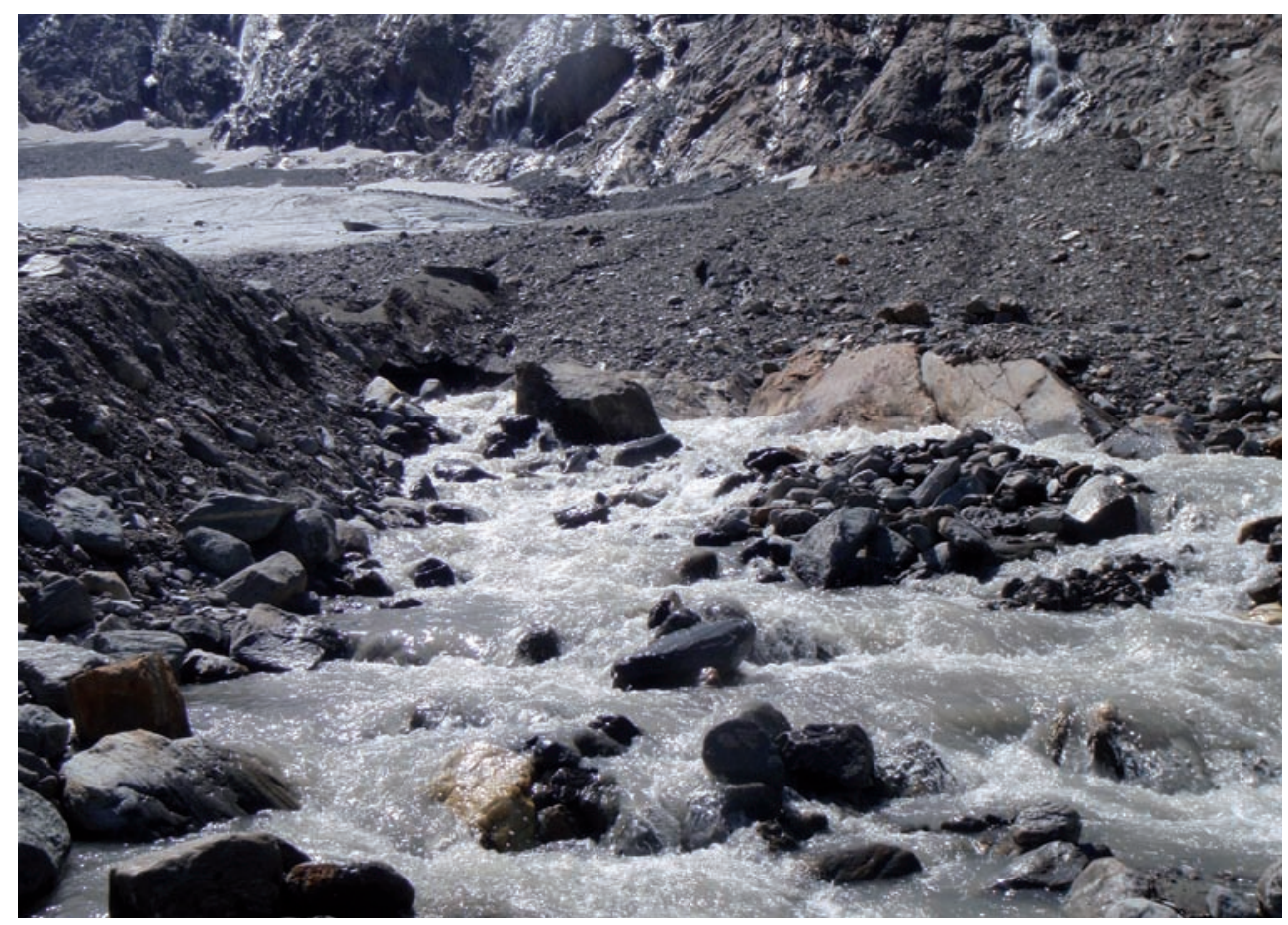

Abb. 3:

Die Rotmoosache - ein typischer Gletscherbach (Foto: L. Füreder)

hens und der Trübstoffkonzentration unterscheiden sich ebenfalls deutlich. Der sommerliche Abfluss ist im Gletscherbach deutlich erhöht und zeigt ausgeprägte Tagesschwankungen, während im Quellbach fast keine Dynamik festzustellen ist. Ähnliche Muster ergeben sich für den Trübstoffgehalt. An einigen Parametern wird besonders der Anteil des Grundwassers und des Gletscherschmelzwassers im abfließenden Wasser deutlich. Im Winter, wo im Gletscherbach der Grundwasser- anteil am höchsten ist, erreicht auch die von der Geologie des Einzugsgebietes abhängige Leitfähigkeit die höchsten Werte. Im Sommer bewirkt der erhöhte Anteil des Gletscherschmelzwassers eine deutliche Abnahme der Leitfähigkeit. Im Königsbach, wo im Einzugsgebiet keine kalkhältigen Gesteine vorkommen, ist sie übers ganze Jahr gering. 


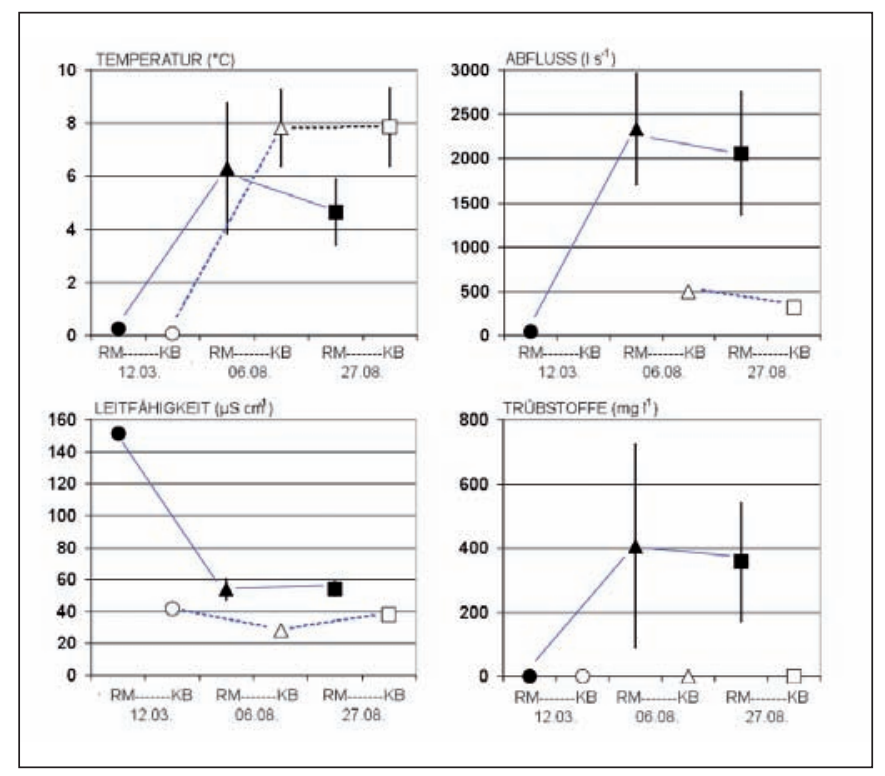

Abb. 4:

Veränderungen von Temperatur, Abfluss, Leitfähigkeit und Trübstoffgehalt im Gletscherbach Rotmoosache (RM, dunkle Symbole) im Vergleich zum Quellbach Königsbach (KB, helle Symbole). Gemessen wurden diese Parameter in zweistündigen Abständen (6:00 bis 20:00 Uhr) während der Schneebedeckung (12. 03.) und im Sommer zu Beginn der Gletscherschmelze (06. 08.) sowie zum Maximum der Gletscherschmelze (27. 08.). Die Symbole sind die Mittelwerte aus den über den Tag verteilten Einzelmessungen, die vertikalen Balken zeigen die jeweilige Standardabweichung und damit die Tagesdynamik an den Untersuchungsterminen.

\section{Die Fauna der Gletscherbäche}

Gletscherbäche erfahren durch die Wirkung des schmelzenden Eises genau in den Zeiten, in denen in gletscherunbeeinflussten Bächen stabilere Bedingungen herrschen, eine zusätzliche Dimension der abiotischen Bedingungen. Die Schmelzwässer und deren große Schwan- kungen sind die stärkste und für den Lebensraum bedeutendste Komponente; sie prägen die ökologischen Verhältnisse im Gletscherbach. Bei maximaler Gletscherablation (Schmelzwasserbildung), die normalerweise in den Nachmittagsstunden eines warmen Sommertages eintritt, erhöhen sich Strömungsgeschwindigkeit, Abfluss, Trübstoffgehalt und Substratumlagerung des Baches dramatisch. Die Folge sind deutliche Störungen für das Leben im Gletscherbach.

Für die Tiere der Gletscherbäche und gletscherbeeinflussten Flüsse sind dabei zwei Faktorenkomplexe von besonderer Bedeutung: zum einen sind es die instabilen und extremen physikalischen Verhältnisse, zum anderen die geringe Nährstoffkonzentration und Nahrungsverfügbarkeit, die als Folge der geringen Temperaturen vor allem aber der Störungshäufigkeit zu sehen sind. Dennoch finden sich Mikroorganismen, Kieselalgen und zu bestimmten Jahreszeiten andere Algen (wie z.B. die zottigen Kolonien der Goldalge Hydrurus foetidus), die den wirbellosen Organismen zumindest 
periodisch Nahrung und/oder nährstoffreiches Substrat bieten (Rott et al. 2006, vgl. Kap. 8, Rott).

Wie in anderen Gebirgsbächen zählen auch in Gletscherbächen die wasserlebenden Larven der Insektenordnungen Eintagsfliegen (Ephemeroptera), Steinfliegen (Plecoptera), Köcherfliegen (Trichoptera) und innerhalb der Zweiflügler (Diptera) besonders die Vertreter der Zuckmücken (Chironomidae) zu den wirbellosen Wasserbewohnern. Weltweit, von den arktischen Regionen über die Alpen, Pyrenäen, Kaukasus bis sogar in die tropischen Hochgebirge wurden charakteristische Gesetzmäßigkeiten und Eigenheiten der Lebewelt, wie eine generelle Artenarmut mit einer geringen Besiedlungsdichte so- wie eine ganz typische Faunenabfolge, in Gletscherbächen festgestellt (Milner und Petts 1994, Ward 1994, Füreder 1999, Brittain und Milner 2001). Je näher man zum Gletscher kommt, desto geringer werden Artenzahl und Individuendichte der Artengemeinschaft, wenige tausend Meter entfernt dominieren die Zuckmücken, fast ausschließlich mit der Gattung Diamesa. Unmittelbar am Gletschertor bei einem Temperaturbereich von 0 bis $1{ }^{\circ} \mathrm{C}$ übers Jahr kommt meist nur mehr eine Art vor, nämlich die Gletscherbachzuckmücke Diamesa steinboecki. Je nach Grundwasser- bzw. Quelleinfluss können sich einige andere Arten dazu gesellen. Mit zunehmender Entfernung vom Gletschertor steigt durch Zuflüsse, Quellaustritte und Hangwässer der Anteil gletscherunbeeinflussten Wassers. Entsprechend ist auch die Fauna artenreicher und in größeren Besiedlungsdichten vorhanden (Abb. 5, Abb. 6).

Um den extremen Bedingungen standzuhalten, sind diese Organismen mit einer Reihe von besonderen morphologischen Strukturen und Anpassungen in ihrer Lebensweise ausgestattet. Die hochspezialisierten Larven der Gletscherbachzuckmücken haben „überflüssige“ 

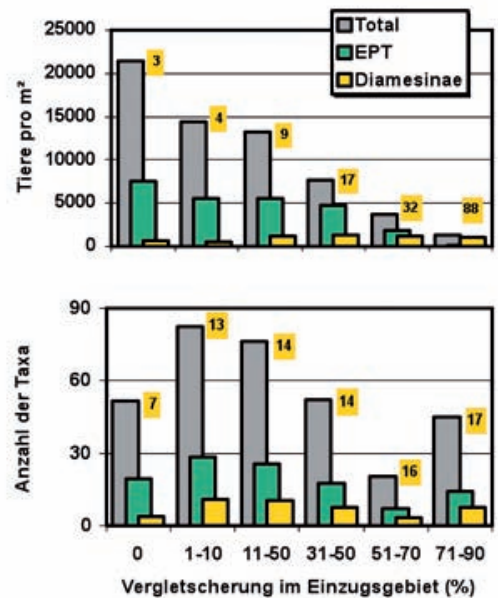

Abb. 6:

Besiedlungsdichte und Taxazahl in einem Gletscherbach sind in besonderem Maße vom Vergletscherungsgrad des Einzugsgebietes abhängig. Eine faunistische Auswertung zahlreicher Untersuchungen in Gletscherbächen der österreichischen Zentralalpen (60 Gewässerabschnitte zwischen 1000 und $2500 \mathrm{~m}$ ü.M.) lässt ein deutliches Bild der Wirkung der Vergletscherung erkennen. In wenig vergletscherten Bereichen kommen durchschnittlich mehr als 20.000 Tiere pro $\mathrm{m}^{2}$ Gewässersohle vor. Eine Dichte, die dann mit zunehmender Vergletscherung rasch abnimmt. Bei größerem Gletschereinfluss wird die Gesellschaft immer deutlicher von Insekten, bei starker Vergletscherung nur mehr von Arten der Diamesinae (eine Unterfamilie der Zuckmücken) dominiert. Die Anzahl der vorkommenden Arten nimmt ebenso stark ab, die Diamesinae können aber ihre Artenzahl beibehalten. Es handelt sich dabei aber um andere Arten als in Gewässern mit geringerer Vergletscherung. "Graue“ Säulen zeigen alle wirbellosen Tiere, „grün“ sind Eintagsfliegen, Steinfliegen und Köcherfliegen zusammengefasst, und „gelb“ sind die Zuckmücken Diamesinae. Das obere Diagramm zeigt die Individuendichten und das untere die Anzahl der verschiedenen taxonomischen Einheiten (Taxa, Arten).
Körperanhänge reduziert, kräftige Stummelbeine mit großen Krallen (Abb. 7a) gewährleisten selbst bei extremen Strömungsverhältnissen ein gutes Festhalten der Larven auf den Steinen. Analog dieser Einrichtungen haben Eintagsfliegen der Gattung Rhithrogena ihre seitlichen Abdominalkiemen zu einer ventralen Haftplatte angeordnet (Abb. 7b). Zudem ermöglicht ihr abgeflachter Körperbau ein relativ gutes Beharrungsvermögen in der Strömungsgrenzschicht auf den Steinen. Andere Eintagsfliegen-Arten wiederum (z.B. Gattung Baetis) sind aus strömungsdynamischen Gründen seitlich zusammengedrückt und stromlinienförmig gebaut (Abb. 7c). Neben kräftigen Extremitäten und Haftvorrichtungen gewährleisten oft eine schlanke, wurmförmige Gestalt oder die winzige Körpergröße die Existenz bestimmter Arten in den strömungsoptimalen Gesteinszwischenräumen und im Schotterlückenraum.

Arten, die im Gletscherbach vorkommen, haben auch ihren Entwicklungszyklus den hydrologischen Verhältnissen angepasst. Ihre Bestandsmaxima bilden die Gletscherbacharten in der winterlichen Niederwasserperiode aus, das Minimum ist zur Zeit der hochsommerlichen Schmelzwasserabflüsse festzustellen. Bereits im Frühjahr und Frühsommer schlüpfen viele als geschlechtsreife Fluginsekten; dennoch ist bei zahlreichen Arten die Emergenz über die Sommermonate festzustellen (Füreder et al. 2005). Eine Reihe weiterer Besonderheiten können 


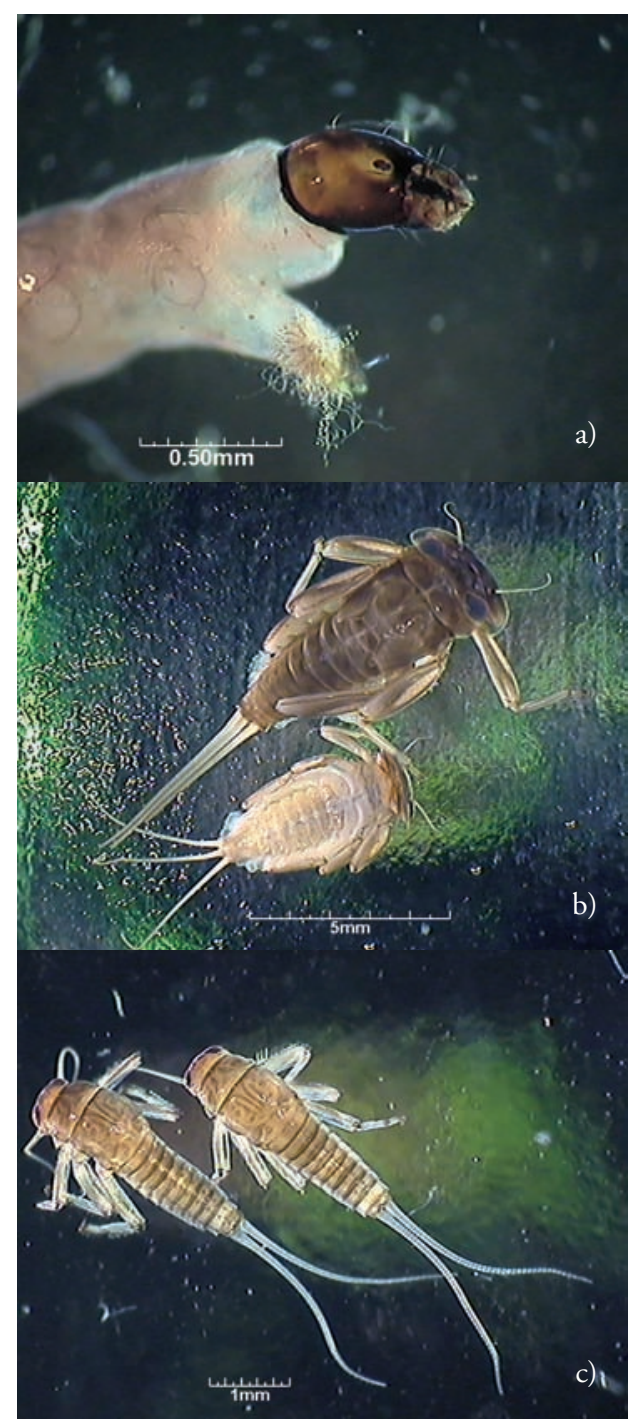

auch hinsichtlich der tiefen Temperaturen und der geringen Nährstoffverfügbarkeit realisiert sein, wie zum Beispiel die Verlängerung der Generationszyklen (von einem bis mehrere Jahre), kleinere Körpergröße, weniger und/oder kleinere Nachkommen (Füreder 1999).
Abb. 7:

Das Tierleben in einem Gletscherbach. Die vorkommenden Arten sind in Lebensweise, Stoffwechselleistung und Körpergestalt an die extremen Umweltfaktoren angepasst.

a) Die Larven der Gattung Diamesa sind die typischen Bewohner der Gletscherbäche.

b) Eintagsfliegen der Gattung Rhithrogena sind durch die Abflachung des Körpers und der Anordnung der seitlichen Hinterleibskiemen zu einer Haftscheibe gekennzeichnet.

c) Andere Arten, wie zum Beispiel die Eintagsfliege Baetis alpinus, sind seitlich schmäler und stromlinienförmig in ihrer Gestalt.

Die morphologischen Anpassungen, strukturellen Einrichtungen und Besonderheiten in Lebensweise und Stoffumsatz ermöglichen den Arten eine dauerhafte Besiedlung und die Ausbildung stabiler Populationen in Gletscherbächen bis in die extremsten Bereiche. Diese Aus- 
stattungen wurden über Jahrmillionenen entwickelt. Zahlreichen anderen wasserlebenden Wirbellosen ist dies aber nicht gelungen, ihr Vorkommen ist dann auf Bachregionen beschränkt, wo die Umweltfaktoren weniger extrem ausgebildet sind. Wenn die limitierenden Faktoren an Intensität abnehmen, werden die Arten der Extremgemeinschaft allmählich von anderen Arten abgelöst und es gesellen sich weitere dazu.

So gelten als Schlüsselfaktoren für die Entwicklungsmöglichkeit der Lebensgemeinschaft an einer bestimmten Stelle im Längsverlauf eines Gletscherbaches vor allem der Zeitraum seit der letzten Vergletscherung, die Wassertemperatur, die Stabilität und die Nährstoffverfügbarkeit (Abb. 8). Gerade diese für Struktur und Funktion der Gletscherbachzönosen maßgeblichen Faktoren erlangen besonders in der Diskussion globaler Klimaänderungen und deren Auswirkungen auf natürliche Ökosysteme an Bedeutung.

\section{Räumliche Muster der Gewässerfauna im Rotmoostal}

Die Flusslandschaft des Rotmoostales ist als Gletschervorfeld mit einer abschließenden Endmoräne, einer davon ausgehenden Schotterfläche und dem Gletscherbach in der Ausprägung eines verzweigten Flusses mit glazialen und fluvioglazialen
Sedimenten reich gegliedert. Der Rotmoosferner im Talschluss reicht von $3400 \mathrm{~m}$ Meereshöhe bis etwa $2500 \mathrm{~m}$ und bedeckt derzeit eine Fläche von beinahe $3 \mathrm{~km}^{2}$. Zusammen mit anderen kleineren Gletschern, von denen kleinere Nebenbäche orographisch links in die Rotmoosache münden, beträgt die Vergletscherung des Einzugsgebietes etwa $4 \%$. Wie fast alle Alpengletscher zeigt der Rotmoosferner einen Massen- und Flächenverlust seit der letzten Hochstandsperiode um die Mitte des 19. Jhts. und hinterlässt in seinem Rückzugsgebiet Moränenund Schotterflächen, die allmählich von Pioniervegetation besiedelt werden. Im äußeren, flachen Bereich des Rotmoostales kam es durch Ablagerung und Auflandung zur Entstehung des Rotmooses, das aus mehreren Lagen aufgebaut ist, wo deutliche Wechsel zwischen schluffigsandigen Sedimenten und Torfschichten festzustellen sind. Dieses Mosaik an unterschiedlichen Landschaftselementen hat auch die Ausbildung zahlreicher Vegetationseinheiten und Lebensräume zur Folge. Auch die Gewässer sind vielfältig gestaltet: das Spektrum reicht vom dominierenden Gletscherbach über Quellbäche, kleineren Rinnsälen, Quellen und diffusen Grundwasseraustritten bis zu Überflutungstümpeln in flachen Bereichen. Die strukturelle und funktionelle Organisation dieser Lebensräume ist wegen der vorherrschenden extremen Bedingungen des Hochgebirges meist artenarm im Vergleich zu tiefer liegenden Ökosystemen, zeichnet sich aber 
durch das Vorkommen von vielen Spezialisten aus.

In einer Biodiversitätsstudie wurden an vier Untersuchungsstellen im Rotmoostal (Tab. 1, Psenner et al. 2003), die entlang eines Gradienten vom Gletscherbach (Umweltbedingungen extrem) über einen Quellbach (moderat) bis zu einem quellgespeisten Bach mit Überflutungstümpel (gemäßigt) liegen, faunistische Aufnahmen vorgenommen. In 60 Einzelproben wurden fast 20000 Individuen an Chironomiden gesammelt (Anhang). Insgesamt wurden 43 Chironomidentaxa identifiziert, die eine mittlere Besiedlungsdichte von 7065 Individuen pro $\mathrm{m}^{2}$ und eine relative Häufigkeit von $58,1 \%$ in allen aquatischen Gruppen und $81 \%$ in den aquatischen Insekten innehatten.

Trotz saisonaler und habitatspezifischer Schwankunģen, hatten die Larven und Puppen der Chironomiden die höchsten relativen Besiiedlungsdichten in den meisten Lebensriumen. Das galt vor allem in der gletsche:gespeisten Rotmoosache, wo alle Kleinstlebensräume von Chironomiden dominiert wurden. In den Quellbächen waren sie in den meisten Kleinstlebensräumen auch über $50 \%$. Nur im Quellrinnsal mit dem Überflutungs-

\begin{tabular}{|c|c|}
\hline & Rotmoosache \\
\hline Koordinaten & $46^{\circ} 49^{\prime} \mathrm{N}, 11^{\circ} 03^{\prime} \mathrm{E}$ \\
\hline Höchster Gipfel im Einzugsgebiet [m ü.NN.] & 3472 \\
\hline Größe des Einzugsgebietes (EZ) am Talausgang $\left[\mathrm{km}^{2}\right]$ & 10,4 \\
\hline Vergletscherung $\left[\mathrm{km}^{2}\right]$ & 4,1 \\
\hline Status der Gletscher & Rückzug \\
\hline Baumgrenze [m ü.NN.] & -2000 \\
\hline Höhenbereich der untersuchten Strecke [m ü.NN.] & $2250-2450$ \\
\hline Durchschnittliches Gefälle [\%] & 7.2 \\
\hline Vergletscherung des EZ [\%] an niedrigster Stelle & 40 \\
\hline Anzahl der Stellen / Proben / Individuen Chironomiden & $4 / 60 / 18649$ \\
\hline Chironomiden: Taxazahl / Mittlere Abundanz [Ind m²] & $43 / 7065$ \\
\hline Anteil Chironomiden in aquatischen Invertebraten [\%] & 58.1 \\
\hline Anteil Chironomiden in aquatischen Insekten [\%] & 81.0 \\
\hline
\end{tabular}

Tab. 1:

Kenngrößen des Einzugsgebietes Rotmoosache und Übersicht über die im Zuge des Biodiversitätsprojektes erfolgten Aufsammlungen 
tümpel blieben ihre relativen Anteile unter $50 \%$.

Etwa die Hälfte der 43 Chironomidenta$\mathrm{xa}$, die in allen Lebensräumen gefunden wurden, kam in den Schottersubstraten der Rotmoosache vor (23 Taxa). Häufige Taxa waren Larven der Unterfamilie Diamesinae, nämlich mehrere Arten der Diamesa latitarsis-Gruppe und D. cinerella/zernyi-Gruppe. Die andere für Hochgebirgsbäche typische, aber weniger dominante Chironomiden-Unterfamilie ist Orthocladiinae, die durch die Gattungen Corynoneura, Eukiefferiella, Orthocladius, Parametriocnemus, Parorthocladius, Thienemanniella und Tvetenia vertreten ist. Nur jeweils eine Gattung wurde in der Unterfamilie bzw. Tribus Prodiamesinae und Tanytarsini gefunden.

Die Faunengesellschaft der Quellbäche gleicht in mancher Hinsicht jener des Gletscherbaches, sie ist jedoch dominiert von Larven der Unterfamilie Orthocladiinae. Ein bis drei Taxa in der Gattung Diamesa und ein Taxon im Tribus Tanytarsini standen der höheren Taxazahl der Orthocladiinae gegenüber.

Als typischer aquatisch-terrestrischer Übergangsbereich wurde das Quellrinnsal mit dem Überflutungstümpel von einer völlig anderen Fauna besiedelt. Der augenscheinliche Unterschied zur Rotmoosache (in Substrat, Temperatur, Strömung) wurde durch das Vorkommen von Taxa bestätigt, die für gemäßigte Lebensbedingungen als typisch gelten. Neben einigen häufigen Orthocladiinae fanden sich
Vertreter der Triben Tanytarsini und Pentaneurini: Micropsectra attrofasciata-Gr., Neozavrelia sp., Paratanytarsus sp., Tanytarsus lugens-Gr., Krenopelopia binotata. Die meisten dieser Taxa kommen in Wassermoosen und Quelllebensräumen vor, andere wiederum gelten als hygropetrische Taxa (z.B. Micropsectra hygropetricus-Gr.). Die Nicht-Chironomidenfauna der Rotmoosache besteht aus wenigen Vertretern mehrerer Ordnungen, wobei die Ephemeroptera Baetis alpinus und Rhithrogena loyolea mit geringen Anteilen in den schottrigen Kleinstlebensräumen dominieren. Im Sandlebensraum (Psammal) fallen besonders die Kleinkrebse Harpacticoida auf.

Im Quellbereich dominiert der Alpenstrudelwurm Crenobia alpina die NichtChironomiden-Zönose. Im rascher fließenden Bereich dominieren wieder die Harpacticoida, in langsam fließenden Abschnitten gesellen sich zu diesen Würmer (Nematoda, Oligochaeta), Moostierchen und Ostracoda.

Im aquatisch-terrestrischen Übergangsbereich (Quellrinnsal und Überflutungstümpel) wird die Zönose besonders von Nicht-Insekten gestellt, das sind Würmer (Nematoda und Oligochaeta) und Kleinkrebse (Harpacticoida und Ostracoda). Im Quellbereich dominiert wieder Crenobia alpina. In den Kleinstlebensräumen, Algen und Detritus, überwiegen Harpacticoida, Ostracoda und Oribatida. Auch Wassermilben (Hydrachnellae) erreichen einen höheren Anteil. 
Die Gletscherbachfauna: Gletscherschwund und Gewässernutzung

Besonders in den Gebirgslandschaften sind die zeitlichen und räumlichen Heterogenitäten von Klima, Hydrologie und Geomorphologie zu sehen. Während der letzten Eiszeit haben Gletscher etwa $32 \%$ der gesamten Landfläche bedeckt, woraus sich die enorme Bedeutung der Gletscherflüsse über Jahrhunderte hinweg ableiten lässt. Da heute weniger als $10 \%$ der Landfläche mit Gletschern bedeckt sind, wurden viele Gletscherflüsse von Flüssen abgelöst, die heute von Schneeschmelze vor allem aber von Niederschlägen in ihrem Abflussverhalten übers Jahr beeinflusst sind. Daraus ist zu schließen, dass der Anteil der gletschergeprägten Fließgewässer über die letzten Jahrtausende stark abgenommen hat.

Dieser Tatbestand und auch jüngere Beobachtungen verdeutlichen, dass der Klimawandel ständige Realität ist. Seit dem letzten Hochstand der Vergletscherung um 1850 konnte ein kontinuierlicher Rückgang der Gletscher in vielen Teilen der Erde beobachtet werden. Auch Beispiele aus den europäischen Alpen verdeutlichen, dass das letzte Jahrhundert von einem signifikanten Rückzug der Talgletscher charakterisiert ist.

Moderne Klimamodelle prognostizieren eine Reihe von Veränderungen, die deutliche Auswirkungen auf den Wasserkreislauf und damit auf Fließgewässer haben werden. So sind durch die zeitliche Verschiebung der Niederschlagshäufigkeit und -mengen, vermehrte Starkniederschläge, weniger Niederschläge in Form von Schnee, der Anstieg der Schneegrenze, das Abschmelzen eines Großteils der Gletscher und durch die Veränderung des Abflussregimes ein deutlicher Einfluss auf die Fließgewässerökosysteme zu erwarten.

Die Auswirkungen des Klimawandels auf die alpinen Fließgewässerökosysteme sind zwar vielerorts als äußerst komplex diskutiert worden, dennoch lassen sich von eigenen Untersuchungen in den Ostalpen einige grundsätzliche Tendenzen voraussagen, die in alpinen Fließgewässern zu erwarten sind - zumindest was das ökosystemare Niveau betrifft.

Durch den prognostizierten Klimawandel und den fortschreitenden Rückgang der Vergletscherung kommt es zu einer Veränderung der Schlüsselprozesse in Gletscherbächen (Abb. 8). Betrachtet man Gebirgsbäche entlang einer Umweltextreme-Diversität-Kurve, so kommen Gletscherbäche am unteren Ende des absteigenden Astes zu liegen. Neben dem Rückgang der Vergletscherung des Einzugsgebietes sowie der Abnahme der Dauer der Schneebedeckung werden sich besonders Temperaturhaushalt, Menge und chemische Zusammensetzung des Wassers auf den Gewässertyp auswirken. Die durch extreme Umweltfaktoren charakterisierten Gletscherbäche werden allmählich in KRENAL- und/oder 


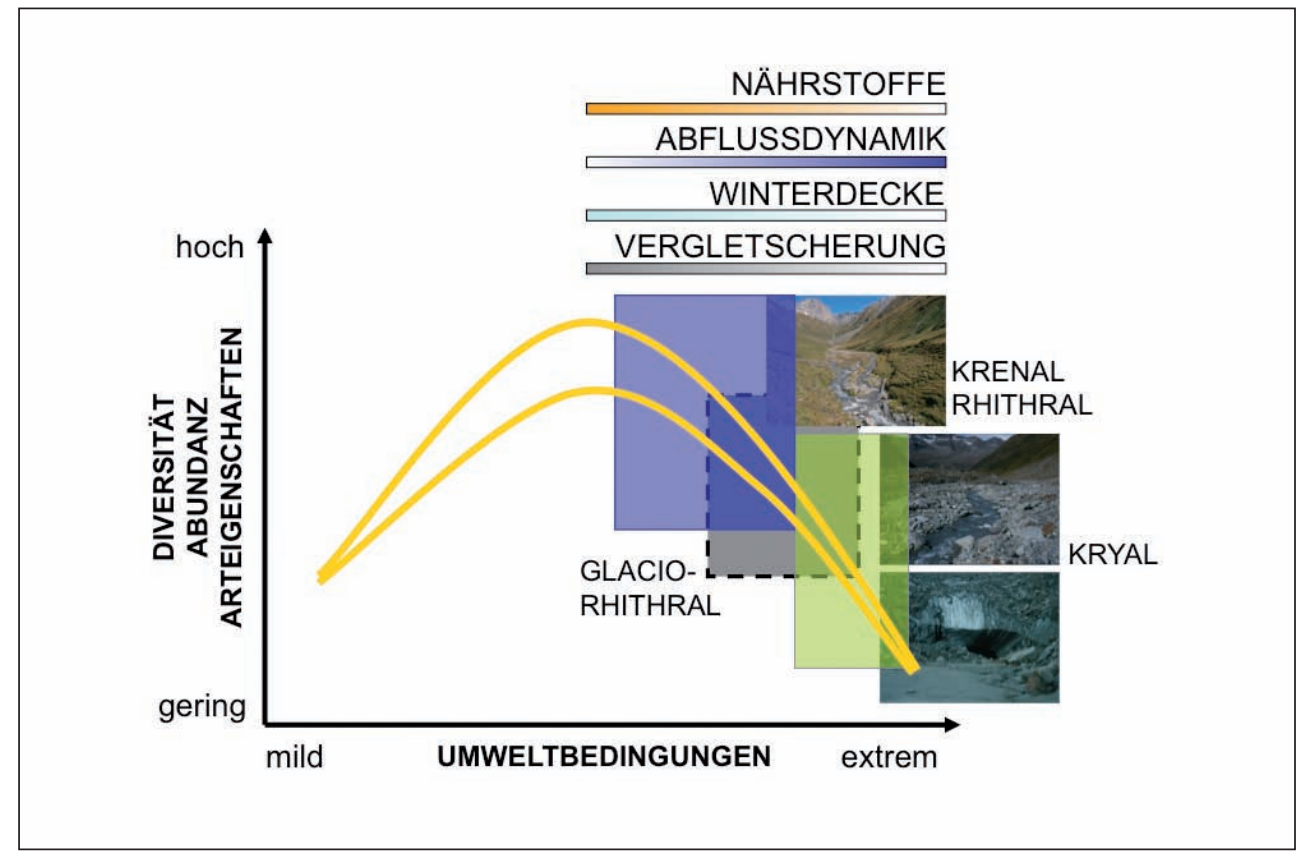

Abb. 8:

Szenario der Auswirkung des Klimawandels auf Umweltfaktoren und damit Struktur und Funktion der Lebensgemeinschaften (hier als Diversität ausgedrückt) von Gletscherbächen. Die alpinen Bäche liegen entlang einer Diversität-Extremfaktoren-Kurve in der rechten Hälfte. Gletscherbäche (KRYAL) kommen wegen der extremen Ausprägung der Umweltfaktoren (Abflussdynamik, Temperatur, Nährstoffverfügbarkeit) und der wenigen, aber best angepassten Arten am äußeren Ende der Kurve zu liegen. In Quellbächen (KRENAL) und in durch Schneeschmelze und Regen geprägten Bächen (RHITHRAL) ist wegen der moderaten Umweltbedingungen die Existenz vieler Organismen möglich, wodurch dort die höchste Diversität zu erwarten ist. Bei äußerst gemäßigten Umweltfaktoren werden die Gewässer sehr produktiv, es kommt zu höheren Temperaturen, einer erhöhten Produktion von Bakterien und niederen Pflanzen und damit zu einem Überangebot an Nährstoffen. Es wird das Vorkommen bestimmter Arten gefördert, die dann zahlenmäßig dominieren und für andere Arten eine große Konkurrenz darstellen. Folglich sinkt die Diversität in diesen Gewässern. Die Auswirkungen des Klimawandels würden die Gegebenheiten in den Gletscherbächen folgendermaßen ändern: Durch den Gletscherschwund geht die Vergletscherung des Einzugsgebietes stark zurück, folglich sinkt auch die Tages- und Jahresdynamik im Abflussgeschehen. Die Dauer der Schneebedeckung nimmt wegen des Temperaturanstiegs ab. All diese Faktoren begünstigen die Produktion im Einzugsgebiet sowie im Gewässer selbst, sodass die Nährstoffverfügbarkeit generell erhöht wird. Der „Gewässerzustand“ folgt dann der Kurve nach links. 
RHITHRAL-Gewässer übergehen. Bei Abnahme der Extremfaktoren positionieren sich die Gewässerabschnitte in günstigeren Lagen, d.h. sie bewegen sich zum Optimum der Kurve.

Mit der Abnahme oder dem völligen Rückgang der Vergletscherung in den Einzugsgebieten nimmt auch der extreme Charakter der Lebensräume $\mathrm{ab}$ und die Lebensbedingungen in alpinen Fließgewässern werden sich ähnlicher. Die durch wenige aber hochspezialisierte Arten gekennzeichnete Gletscherbachzönose wird durch eine abgelöst, welche durch mehrere (viele) Arten charakterisiert ist, die hinsichtlich Temperatur und Nahrungsanspruch weniger oder kaum spezialisiert sind. Spezielle Indikatorarten oder glaziale Arten werden sukzessive verschwinden. Abgesehen von den Veränderungen auf ökosystemaren Niveau gibt es möglicherweise noch eine Vielzahl von weiteren Auswirkungen des Klimawandels auf Fließgewässersysteme. Im Gegensatz zum Verlust der Gletscherbach-Arten, die an die extremen Umweltfaktoren optimal angepasst sind und von anderen Besiedlern verdrängt werden, ist ein verändertes Abflussgeschehen mit häufigen Hochwasserereignissen zuerst ein viel auffälligeres Zeugnis von Klimaveränderungen. Zusammen mit veränderter Niederschlagsaktivität destabilisieren sie möglicherweise alpine Vegetation und Waldgesellschaften. All diese Faktoren werden die Fließgewässer innerhalb aber auch außerhalb der Alpen in mannigfacher Weise direkt oder indirekt beeinträchtigen.

Neben dieser „natürlichen“ Veränderung durch Gletscherschwund, sind die Gletscherbäche aber auch einer weiteren Gefahr ausgesetzt. Eine große Zahl von Gletscherbächen wird genutzt. Unzählige Beispiele belegen die Veränderungen von Flora und Fauna, die eine Nutzung von Gletscherbächen bewirkt:

1) Veränderung des Bachcharakters:

Die schmelzwasserbeeinflusste Fließstrecke oberhalb einer Wasserfassung wird durch diese vom Unterlauf isoliert, so dass die Durchgängigkeit des Fließgewässers unterbrochen wird. Natürliche Verhaltensmuster der Wasserinsekten wie Drift und Aufwärtswanderungen (es handelt sich dabei um willkürliche und unwillkürliche Ortsveränderungen) sind dadurch erheblich gestört. Bereiche unterhalb der Wasserfassung werden durch den nun größeren Anteil von Hang-, Quell- und/oder Grundwasser in ein Fließgewässer anderen Charakters umgewandelt. Die limitierenden abiotischen Umweltfaktoren werden entschärft, das Gewässer wird wärmer, klarer und besitzt eine stabilere Sohle. Kurz - der Quellbachcharakter überwiegt.

2) Verschwinden von gletscherbachtypischen Spezialisten:

Da durch die veränderten hydrologischen und abiotischen Faktoren der 
Gletscherbachcharakter weitgehend verloren geht, verschwinden die gletscherbachtypischen Spezialisten. Die hochspezialisierten und seltenen Gletscherbachzuckmücken Diamesa steinböcki und andere Arten der Diamesinae sowie die nur in Gletscherbächen vorkommende Rhithrogena nivalis verschwinden und werden durch euryöke Arten (ertragen breites Spektrum an abiotischen Bedingungen) abgelöst oder verdrängt.

\section{3) Fauna:}

Generell gesehen entspricht die Fauna unterhalb einer Wasserfassung der eines Quellbaches, was dem Fließgewässertyp des Gletscherbaches nicht mehr entspricht. In mehreren $\mathrm{Ar}$ beiten wurde gezeigt, dass den von Schneeschmelze und Regenereignissen geprägten Fließgewässern selbst in großen Höhenlagen ein breites Artenspektrum an aquatischen Insekten eigen ist. Durch die Dämpfung der Extremfaktoren steigt die Höhenverbreitung vieler Arten aus tiefergelegenen Regionen deutlich an. Spezialisten, wie sie in Gletscherbächen vorkommen, sind kaum mehr vertreten. Durch die Verminderung der Strömungsgeschwindigkeit ist auch die Substratzusammensetzung eine andere, teilweise überwiegen feinkörnige bis sandige Strukturen, so dass auch dies eine Verschiebung der Großgruppen und Artendominanz bedingt. Typische
Feinsedimentbewohner, die ebenfalls für tiefer liegende Fließgewässerabschnitte charakteristisch sind, können dann überwiegen. Strömungsliebende, an turbulente Verhältnisse angepasste Gebirgsbacharten sind in der Minderzahl. Die reichhaltigen Zoobenthosgemeinschaften in Entnahmestrecken, insbesondere in Gletscherbächen entsprechen nicht den natürlichen Verhältnissen. Man könnte in diesem Zusammenhang von einer starken Vereinheitlichung der Bodenzönose mit vielen Arten und Individuen sprechen.

Durch die prognostierten Veränderungen des Klimas wird das Abflussverhalten der alpinen Bäche und insbesondere durch die zurückweichenden Gletscher das hydrologische Regime der Gletscherbäche signifikant verändert werden (McGregor et al. 1995). Sich verändernde Intensität und Dynamik von klimatischen Schlüsselfaktoren, die das Verhalten von Gletschern beeinflussen, werden maßgeblich die hydromorphologischen und thermischen Bedingungen in glazial geprägten Fließgewässern beeinflussen. Für das Rotmoostal haben wir die aquatische Fauna, ihre Artenzusammensetzung und Diversität in verschiedenen Fließgewässertypen charakterisiert (Tab. 2-4 im Anhang) und die Bedeutung der physikalisch-chemischen Gegebenheiten für die zeitlichen und räumlichen Muster analysiert. Das Makrozoobenthos wird weltweit zur 
ökologischen Bewertung von Gewässern und zur Berechnung der Gewässergüte als Ergebnis anthropogener Beeinträchtigungen, insbesondere organischer und toxischer Verunreinigung sowie Versauerung herangezogen (Rosenberg und Resh 1993, Jackson und Füreder 2006). Die vorliegenden Ergebnisse der strukturellen und funktionellen Organisation der Gewässerfauna aus einer Reihe von unterschiedlichen Gewässerlebensräumen des Rotmoostales können für die Vorhersagen und Analyse der Auswirkungen von Umweltveränderungen und des Klimawandels verwendet werden. Die Gewässer samt den vorkommenden Organismen sind einerseits Indikatoren für die hydrologischen, thermischen und biotischen Gegebenheiten in der Flusslandschaft und können andererseits auch als Zeiger für die Veränderungen im Gewässer und seinem Umland sowie auch im Einzugsgebiet verwendet werden.

\section{Literatur}

Burger, R. (1999) Die Chironomidenemergenz zweier Hochgebirgsbäche im Raum Obergurgl (Rotmoosache, Königsbach; Tirol). Diplomarbeit, Universität Innsbruck: $101 \mathrm{~S}$.

Brittain, J.E. \& Milner, A.E. (2001) Glacierfed rivers - unique lotic ecosystems. Special Issue, Freshwater Biology 46.
Füreder, L. (2007) Life at the edge: habitat conditions and bottom fauna of alpine running waters. Internat.Rev.Hydrobiol. 92: 491-513.

Füreder, L. (1999) High Alpine Streams: Cold Habitat for Insect Larvae. S. 181 - 196. In: Cold Adapted Organisms. Margesin, R. \& F. Schinner (eds). Ecology, Physiology, Enzymology and Molecular Biology. Springer Verlag, Berlin.

Füreder, L., Schütz, C., Wallinger, M. \& Burger, R. (2001) Physico-chemistry and aquatic insects of a glacier-fed and a spring-fed alpine stream. Freshwater Biology 46: 1573-1690.

Füreder, L., Vacha, C., Amprosi, K., Bühler, S., Hansen, C.M.E. \& Moritz, C. (2002) Reference conditions of alpine streams: Physical habitat and ecology. Water, Air \& Soil Pollution, Focus 2: 275-294.

Füreder, L., Welter, C. \& Jackson, J.K. (2003a) Dietary and stable isotope $\left(\delta^{13} \mathrm{C}\right.$, $\delta^{15} \mathrm{~N}$ ) analyses in alpine stream insects. Internat. Rev. Hydrobiol. 88: 314-331.

Füreder, L., Welter, C. \& Jackson, J.K. (2003b) Dietary and stable isotope $\left(\delta^{13} \mathrm{C}, \delta^{15} \mathrm{~N}\right)$ analyses in alpine Ephemeroptera and Plecoptera. Mayflies and Stoneflies, Proceedings of the International Symposium held in Perugia, August 2001: 39-46.

Füreder, L., Wallinger, M. \& Burger, R. (2005) Longitudinal and seasonal pattern of insect emergence in alpine streams. Aquatic Ecology 39: 67-78.

Jackson, J. K. \& Füreder, L. (2006) Long-term studies of freshwater macroinvertebrates: 
a review of the frequency, duration and ecological significance. Freshw. Biol. 51: 591-603.

McGregor, G., Petts, G.E., Gurnell, A.M. \& Milner, A.M. (1995) Sensitivity of alpine stream ecosystems to climate change and human impacts. Aquatic Conservation: Marine and Freshwater Ecosystems, 5, 233-247.

Milner, A. M. \& Petts, G.E. (1994) Glacial rivers: physical habitat and ecology. Freshw. Biol. 32: 295-307.

Psenner, R., Füreder, L., Rott, E., Schütz, C., Sonntag, B., Waldhuber, S. \& Wille, A. (2003) Biodiversity of an alpine catchment. An integrated approach to assess microbial, botanical and faunistic diversity of terrestrial and aquatic habitats in the Rotmoos Valley, Tyrol. Part II. Aquatic Biodiversity. Final Report Project Biodiversity of alpine landscapes. Österr. Akademie Wiss. Wien.

Rott, E., Cantonati, M., Füreder, L. \& Pfister, P. (2006) Benthic algae in high altitude streams of the Alps - a neglected component of aquatic biota. In: Ecology of high altitude aquatic systems in the Alps. Lami, A., Boggero A. (eds) Hydrobiol. 562: 195-216.

Schütz, C. (1999) The benthic fauna of high Alpine streams. Dissertation, Universität Innsbruck: $95 \mathrm{~S}$.
Schütz, C., Wallinger, M., Burger, R. \& Füreder, L. (2001) Effects of snow cover on the benthic fauna in high alpine streams. Freshw. Biol. 46: 1691-1704.

Wallinger, M. (1999) Die Emergenz von Ephemeropteren, Plekopteren und Trichopteren in zwei Hochgebirgsbächen (Königsbach, Rotmoosbach, Ötztal, Tirol). Die Chironomidenemergenz zweier Hochgebirgsbäche(Rotmoosache, Königsbach) im Raum Obergurgl, Tirol. Diplomarbeit, Universität Innsbruck: $100 \mathrm{~S}$.

Ward, J. V., (1994) The Ecology of Alpine streams. Freshwater Biology 32: 277-294.

\section{Verzeichnis des Autors}

Leopold Füreder

Universität Innsbruck

Institut für Ökologie

Technikerstr. 25, 6020 Innsbruck, Österreich

Leopold.Fuereder@uibk.ac.at 


\title{
Lebensraumtypen und Diversitätsgradienten lotischer Algen in einem Gletschereinzugsgebiet
}

\author{
Eugen Rott, Doris Gesierich, Nico Binder
}

\section{Zusammenfassung}

In alpinen Gletscherrückzugsgebieten findet man insbesondere Gletscherbäche (Kryal) und grundwassergespeiste Quellbäche (Krenal). Im Einzugsgebiet des Rotmoosferners (RM) wurden insgesamt 11 aquatische $\mathrm{Ha}$ bitate - ein Sickerquellkomplex mit humosen Moortümpeln, 4 klare Quellbäche und 6 sommertrübe Gletscherbäche - auf Algenzusammensetzung und -dominanz untersucht. Die Gletscherbäche wiesen im Vergleich zu Quellbächen einen geringeren Artenreichtum auf. Diatomeenzahlen scheinen einen deutlichen inversen Zusammenhang mit der Entfernung vom Hauptgletscher, also der Entstehungszeit der Gewässer, zu zeigen. Die Artenzahlen der epilithischen Cyanobakterien sind in den seitlich einmündenden Gletscherbächen stark reduziert. Der Hauptbach, die Rotmoosache, wies in frühzeitig schneefreien Abschnitten trotz mäßiger Nährstoffgehalte (niedere Gesamtphosphorgehalte, mittlere Stickstoffgehalte) alljährlich ein massives Wachstum der Goldalge Hydrurus foetidus in einem engen zeitlich-räumlichen Fenster im Frühjahr auf. Die dabei entstehenden gallertigen Algenmassen waren Habitat und Nahrungsgrundlage für hohe Zahlen spezifischer Bakterien, Ciliaten und benthischer Insektenlarven
(Zuckmücken). Ephemere Feuchtstandorte (z.B. feuchte Felsen) sowie die seit dem Jahr 2000 neu entstandenen Gletscherbäche sind vielversprechende Standorte zur Testung der Auswirkungen des klimatischen Wandels auf die Biodiversität innerhalb zukünftiger Untersuchungen.

\section{Abstract}

Lotic aquatic environments of glacial retreat areas are mainly characterized by glacier fed (kryal) streams and by ground water fed (krenal) spring streams. Within the glacial retreat area of the Rotmoos (RM) glacier we studied the algal richness and dominance within 11 different aquatic habitats including one seepage spring complex with small humic peat bogs, 4 clear spring streams and 6 small glacier streams of variable size characterized by high turbidity in summer. The glacier streams showed generally a lower species richness than the spring streams. The number of diatoms showed an inverse relationship to the distance from the central glacier, in other words seemed to be related to the age of the streams. The species numbers of epilithic cyanobacteria were highly reduced especially in the glacial tributaries. In the central glacier stream (Rot- 
moosache) we found the Golden alga Hydrurus foetidus to cause massive blooms within a distinct spatio-temporal window in spring in spite of low nutrient concentrations (low total phosphors, moderate total dissolved nitrogen values). The mucilage masses of this alga were evidently a suitable habitat, food and shelter for high numbers of specific bacteria, ciliates and benthic insect larvae (chironomids). Underexplored habitats for future studies of the effects of climatic change on biodiversity are mostly ephemeral wet places (wet rocks) and the glacier streams formed within the last few years.

\section{Einleitung}

In vergletscherten Einzugsgebieten der Alpen gibt es zwar oft eine Vielfalt von unterschiedlichen ephemeren (nicht dauerhaften) Feuchtstandorten an denen sich Algen entwickeln können, die höchste Diversität wird aber in permanenten lotischen Habitaten (Fließquellen, Bächen) bzw. in ausdauernden oder zumindest langzeitlich wasserführenden Tümpeln erreicht (Ettl 1968). In Gletschervorfeldern sind insbesondere die von Schmelzwasser gespeisten (kryalen) Gletscherbäche (Abb. 1a, b) und die aus Grundwasser gespeisten Quellbäche (Abb. 1c, d) von Bedeutung. Die Bedingungen zwischen diesen beiden Bachtypen unterscheiden sich wesentlich: Gletscherbäche sind im Hochsommer während der Abschmelzperiode der Gletscher von Gletschermilch (suspendierter Schluff) getrübt und weisen sehr hohe aber auch tageszeitlich stark schwankende Abflüsse (bis zu 15-fache Menge) auf, während Quellbäche meist klares Wasser mit wesentlich geringeren allenfalls durch Schneeschmelze und Regenereignisse variable Abflussmengen aufweisen (vgl. Kap. 8, Füreder). Der Algenaufwuchs wird durch die starken Abflussschwankungen im Gletscherbach und den mechanischen Abrieb durch die mitgeführte anorganische Fracht (von Ton bis Kies) insbesondere im Hochsommer stark verringert. Perioden für optimales Wachstum sind in diesem Bachtyp dann im Frühherbst vor Wintereinbruch bzw. im Frühjahr zu Beginn der Schneeschmelze nach Öffnung der Winterdecke, wobei zu dieser Zeit klares Wasser vorhanden ist (Abb. 1A). Die zeitlich-räumlichen Fenster scheinen für Gletscherbäche der Alpen ganz besonders charakteristisch zu sein (Rott et al. 2006, 2006a, Uehlinger et al. 2009). In der alpinen Zone weisen Quellbäche durch fehlenden Baum- und Strauchbestand oft fast keine Beschattung auf, d.h. dass diese je nach Sonnenexposition und Hangorientierung hoher bis sehr hoher Stahlungsintensität (sichtbares Licht, UVA, UVB) ausgesetzt sind, die zu einer deutlichen Erwärmung des Wassers führen kann. In Quellbächen entwickeln sich daher bevorzugt stark pigmentierte Formen (oxygene coccale und fädige Cyanobakterien mit dunklen Scheidenpigmenten, aber auch 

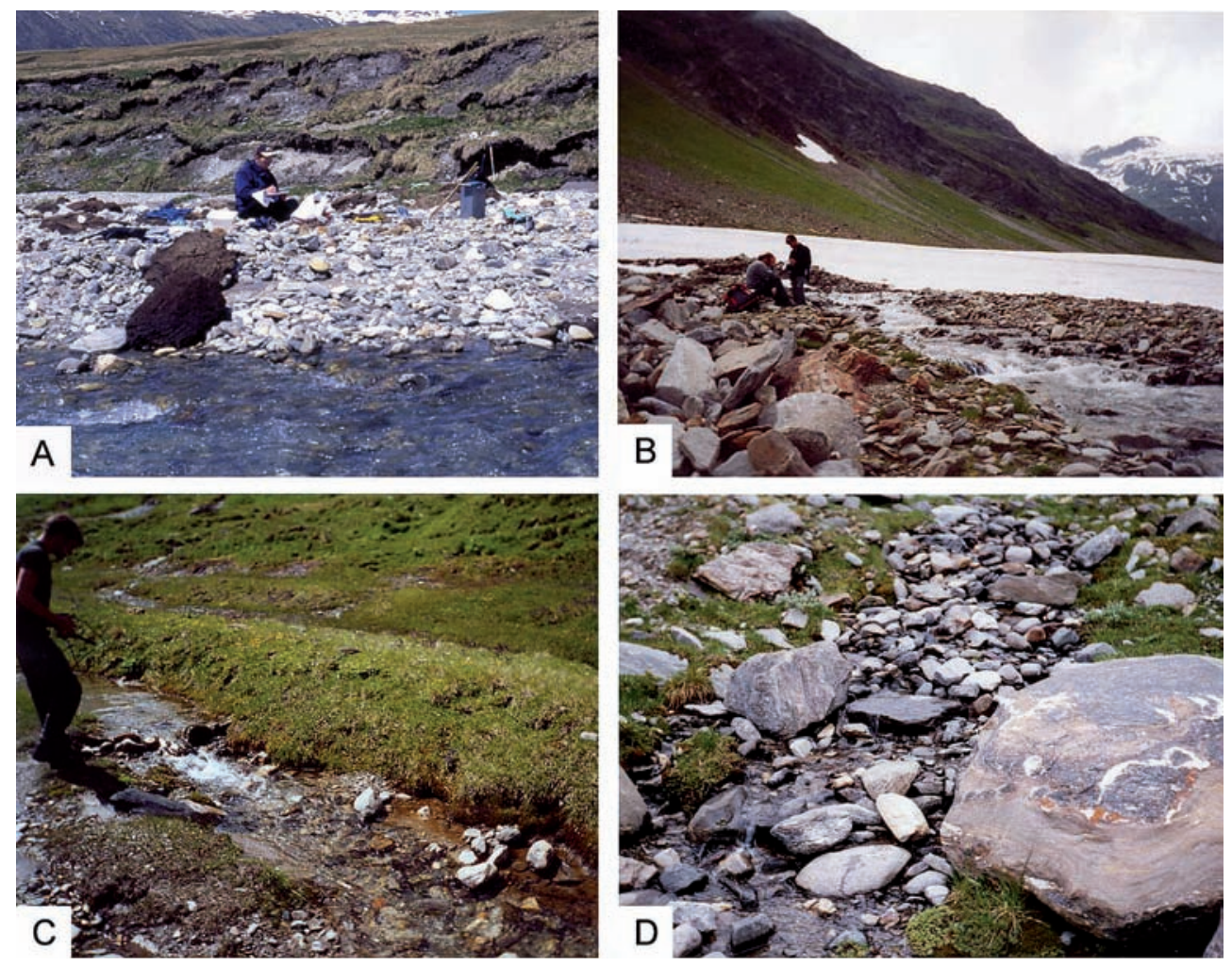

Abb. 1:

Gletscherbäche und Quellbäche zu unterschiedlichen Jahreszeiten:

1A) Rotmoosache im Juni 2003 bei kaltem Wetter mit klarem Wasser (Hypokryal / Glaciorhithral)

1B) Eiskögelebach im Juli (Kryal)

1C) Schönwiesbach

1D) Schneebergzugbach um Juli 2003 (Krenal)

(Fotos: E. Rott)

nicht sichtbaren UV-Schutzpigmenten wie Scytonemin - Garcia-Pichel und Castenholz 1991), die in Konkurrenz mit den Wasserflechten und Wassermoosen (vgl. Kap. 6, Gärnter) um den wasserbenetzten Lebensraum stehen.

Trotz nährstoffarmer Bedingungen und mäßiger Temperaturen kann es auch in Hochgebirgsbächen zu zeitlich begrenz- ten Massenentwicklungen von Algen kommen. Ob diese durch „Airborne pollution" in den letzten Jahren häufiger geworden sind - insbesondere durch Stickstoffanreicherung, aber teilweise auch durch Versauerung - ist für die Alpen mit Ausnahme der paläoökologischen Ansätze noch wenig untersucht. Bisherige Ergebnisse deuten an, dass der Gletschereinfluss 
den Artenreichtum verschiedener Algengruppen bzw. die Wuchsformtypen unterschiedlich stark beeinträchtigt. Besonders deutliche Unterschiede wurden zwischen oxygenen Cyanobakterien und Kieselalgen festgestellt (Rott et al. 2006). Diese Diversitätsgradienten von Mikroalgen im Spannungsfeld zwischen Gletscherbeeinflussung und Grundwasserverfügbarkeit in Quellbächen in Zusammenhang mit dem Klimawandel und der atmosphärischen Nährstoffbelastung sind bisher nur wenig erforscht.

\section{Forschungsgeschichte}

Trotz einzelner Aufnahmen der Algenflora, insbesondere von Moortümpelproben aus dem Rotmoostal bei der Schönwieshütte (Ettl 1968), war die Diversität der verschiedenen aquatischen Lebensräume im Gletschervorfeld des Rotmoosgletschers bis vor Kurzem noch weitgehend unbekannt (Gesierich und Rott 2004, Tab. A1 im Anhang). Neuere Untersuchungen erfolgten bisher in den Jahren 2001 bis 2003 innerhalb eines umfassenden Pilotprojekts „ALP-2000 Biodiversity of an Alpine Catchment: an integrated approach to assess microbial, botanical and faunistic diversity of terrestrial and aqua- tic habitats of the Rotmoos Valley, Tirol 2001-2003 (Psenner et al 2003). Wesentliche Zielsetzungen waren die Entwicklung geeigneter, reproduzierbarer Methoden und Protokolle (Sonntag 2002), um möglichst alle Arten zu erfassen, ohne dabei besonders hohe Ansprüche an die Erhebung quantitativer Maßzahlen und der Quantifizierung der Steuerungsmechanismen und deren Regulation zu haben. Bei dieser Vorgangsweise wurde besonderer Wert auf die taxonomische Expertise und Ausarbeitung von Ansätzen für die Vernetzung der Untersuchungen aquatischer und terrestrischer Lebensräume gelegt. Die erzielten Artenlisten wurden im Rahmen einer Dissertation veröffentlicht (Gesierich und Rott 2004), wobei auch die Algengemeinschaften, funktionale Artengruppen und deren Standortsfaktoren diskutiert wurden. Innerhalb der Methodenentwicklung war bei den aquatischen Expertisen eine möglichst hohe Vergleichbarkeit der Besammelungsstrategien, der Zeitpunkte und der Mikrohabitate angestrebt worden, die dann auch erste Vergleiche der Ergebnisse mit terrestrischen Aufnahmen ermöglichten. Diese wurden in einem Abschlussbericht (Psenner et al. 2003) und in einer kleinen mikrohabitatbezogenen Arbeit (Rott et al. 2006a) veröffentlicht. 
Stand der Forschungsarbeit und offene Fragen

Die Rückzugsgebiete von größeren Gletschern in den Alpen, die in den letzten 150 Jahren entstanden sind, weisen durch die Vielfalt der Habitate einen beachtlichen Artenreichtum an aquatischen Lebensräumen auf, in denen neben Wasserflechten und Moosen (siehe Kap. 6, Gärtner) insbesondere Algen (inkl. Cyanobakterien) eine wesentliche Rolle spielen. Besonders habitat- und artenreich sind breite mo- ränengefüllte Täler durch das vielfältige Ein- und Ausströmen von Grundwasserströmen und das Vorhandensein von Gletscherseen, wie Untersuchungen im Val Roseg, Schweiz (Bürgi et al. 2003) zeigen. Im oberen Rotmoostal spielen die Grundwasseraustritte im Talboden durch die Enge des Talgrundes eine wesentlich geringere Rolle als im Val Roseg, dafür sind aber einige Hangquellaustritte (Abb. $1 C, D)$ sowie eine größere Anzahl an kleinen seitlichen Gletscherbächen (z.B. Abb. 1B) mit unterschiedlichen Gletscheranteilen vorhanden (Gesierich und

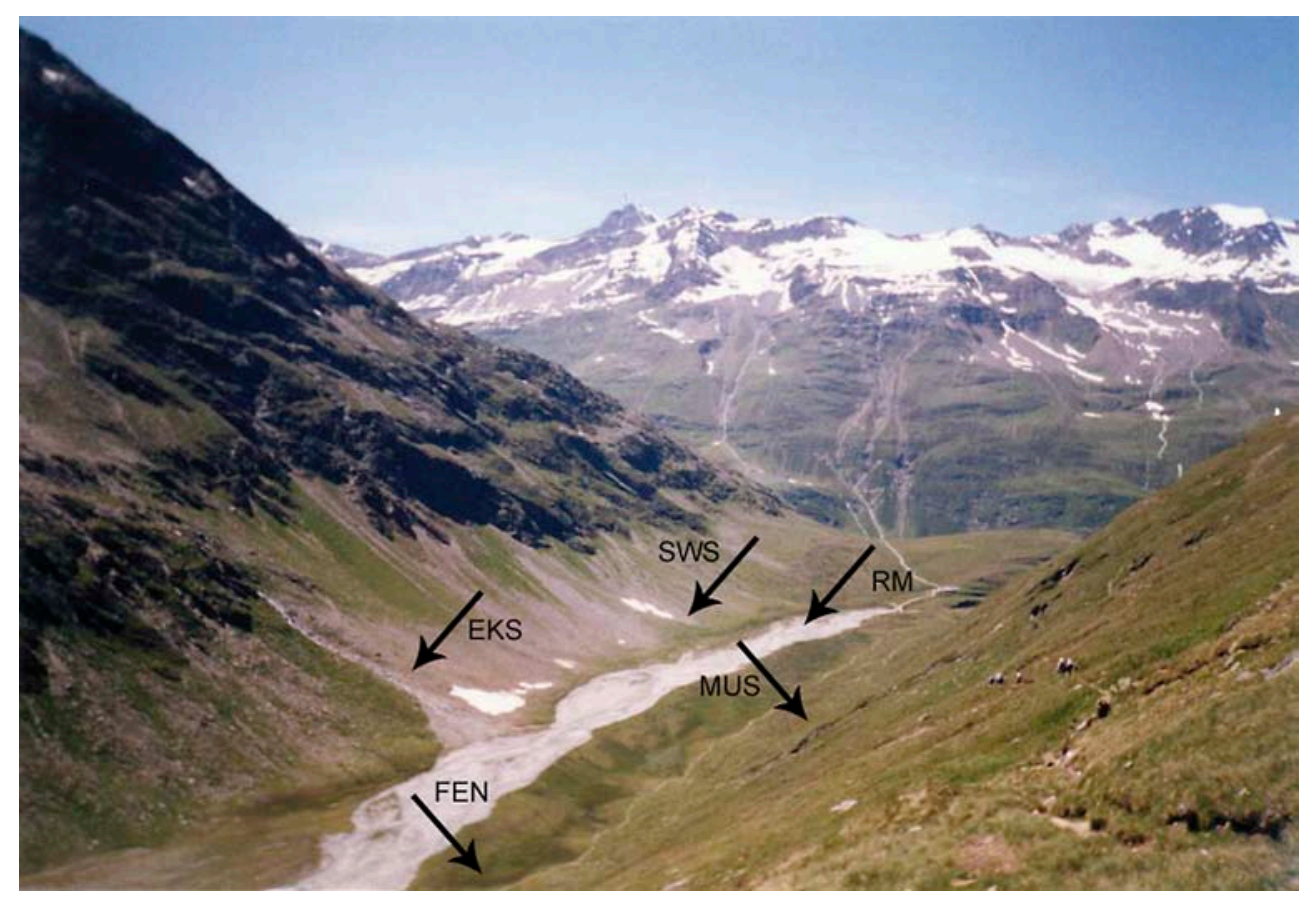

Abb. 2:

Unterer Abschnitt des Rotmoostales mit Furkationszone der Rotmoosache (Blickrichtung Schönwieshütte). Die Pfeile zeigen von links nach rechts die Probenstellen am Eiskögelebach (EKS, Kryal), Schönwiesbach (SWS, Krenal), Rotmoosache (RM, Hypokryal), Mutbach (MUS, Krenal) und Sickerquellkomplex am oberen Randes des Rotmooses (FEN), Juli 2003. (Foto: E. Rott) 
Rott 2004). Diese spezifische Situation erlaubte es Diversitätsgradienten auf kleinstem Raum zu ermitteln, die in ähnlicher Weise über einen weiteren Abschnitt des Längsverlaufs eines größeren Gletscherbaches verteilt sind (Isel in Osttirol, vgl. Rott et al. 2006). Die Verteilung der Artenzahlen an den einzelnen Sammelstellen im Rotmoostal (Abb. 2) lässt deutliche Unterschiede in der Verteilung der beiden häufigsten Algengruppen erkennen (Abb. 3A-C), wobei aber neben dem Gletschereinfluss aus dem Haupttal (Orientierung von rechts unten nach links oben in Abb. 3) auch seitliche Gletscher insbesondere von SW (links unten) und unterschiedliche Kalkgehalte (dargestellt durch die Leitfähigkeitswerte in Abb. 3D) die Verteilung beeinflussen. Die DiatomeenArtenzahlen zeigten einen negativen (statisch signifikanten $r=0,619, p=0,042$ ) Zusammenhang mit der Entfernung der Sammelstelle vom Hauptgletscher. Ähnliche Resultate hatten wir in einem ähnlich kleinen Gletschereinzugsgebiet der Coast Range in British Columbia, Kanada, ermittelt (unpubl. Daten). Cyanobakterien scheinen insbesondere in den Gletscherbächen stark reduziert zu sein, da deren Artenzahlen einen hochsignifkianten negativen Zusammenhang mit der Vergletscherung im Einzugsgebiet zeigen $(r=0,264, p=0,006)$. Cyanobakterien werden möglicherweise durch die bessere Kohlenstoffverfügbarkeit in den Quellbächen des Schneebergzuges mit höherer Leitfähigkeit gefördert (Abb. 3B, D).
Nach dem derzeitigen Kenntnisstand aus morphologisch-floristischen Algenuntersuchungen und ausstehenden molekularbiologisch-biogeographischen Studien ist keine eigene, scharf abgrenzbare Algenflora des Hochgebirges festzustellen. Es sieht vielmehr so aus, als wäre die Anpassung der Arten bzw. deren Resilienz gegen die extremen Bedingungen des Hochgebirges (UV, Temperatur, Nährstoffarmut, kurze Vegetationsperiode, Versauerungsschübe bei Schneeschmelze) wesentliche Voraussetzung für ihr Vorkommen. Das bedeutet eigentlich eine negative Selektion, welche bewirkt, dass Tieflandarten bzw. typische Algentaxa der Alpenflüsse (z.B. Ulothrix, Cladophora, Bangia) oder schattiger Quellbäche (Batrachospermum) im Hochgebirge fehlen. In den überwiegend nährstoffarmen, alpinen lotischen Habitaten sind oligotraphente Arten (Rote-Liste Arten der Diatomeen, seltene Cyanobakterien mit denen für diese Situation typischen funktionalen Gruppen wie $\mathrm{N}_{2}$-Fixierer, z.B. Tolypothrix oder typische Bergbachformen der Chrysophyceen wie Hydrurus foetidus) oft mit höheren Anteilen vertreten als in subalpinen Bereichen. Für lentische Gewässer (Tümpel) mag diese negative Selektion in geringerem Ausmaß zutreffen. Insbesondere die Tümpel im subalpinen Zirbenwald am Ochsenkopf nördlich von Obergurgl sind über nahezu 40 Jahre sehr artenreich geblieben (vgl. Ettl 1968 mit Rott 2007) und auch Stillgewässer-Fließgewässer-Netze der alpinen Regionen der Schweiz (Bernina) 

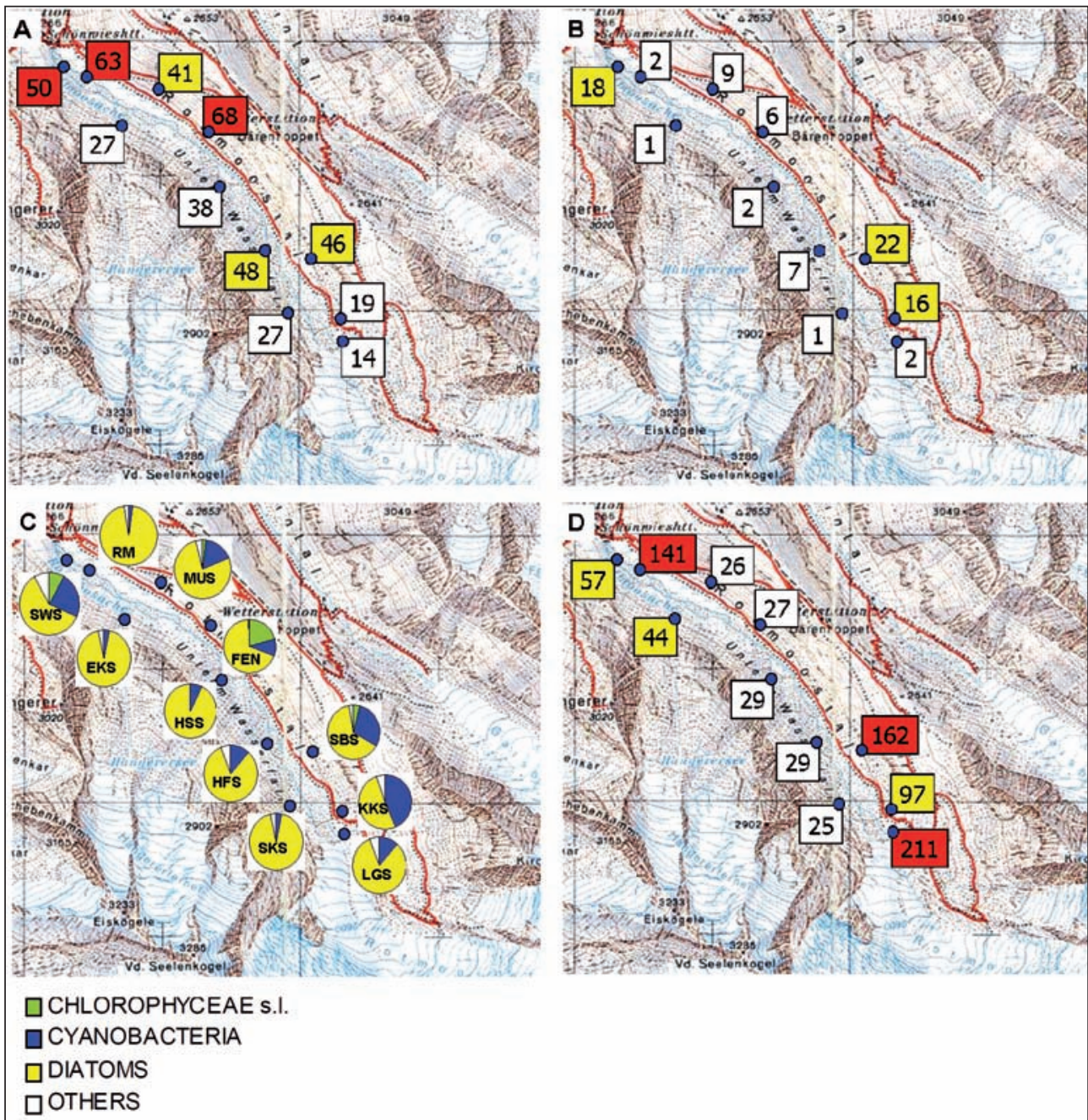

Abb. 3:

Topographische Karte (ÖAV) vom Rotmoostal mit folgenden Werten an den Sammelpunkten:

3A) Anzahl der Kieselalgen (gelb: > 40; rot $>50$ )

3B) Anzahl der Cyanobakterien (gelb > 20)

3C) Anteil der Algen-Grossgruppen an der Gesamtartenzahl

3D) Elektrische Leitfähigkeit in $\mu S$ (gelb > 50; rot > 100)

Abkürzungen siehe Abb. 2, zusätzlich: Hangendersee Bach (HSS, Kryal), Hangender Ferner Bach (HFS, Kryal), Schneebergbach (SBS, Krenal), Kirchkogelbach (KKS, Krenal), Seelenkogelbach (SKS, Kryal), Liebener Bach (LGS, Kryal) 

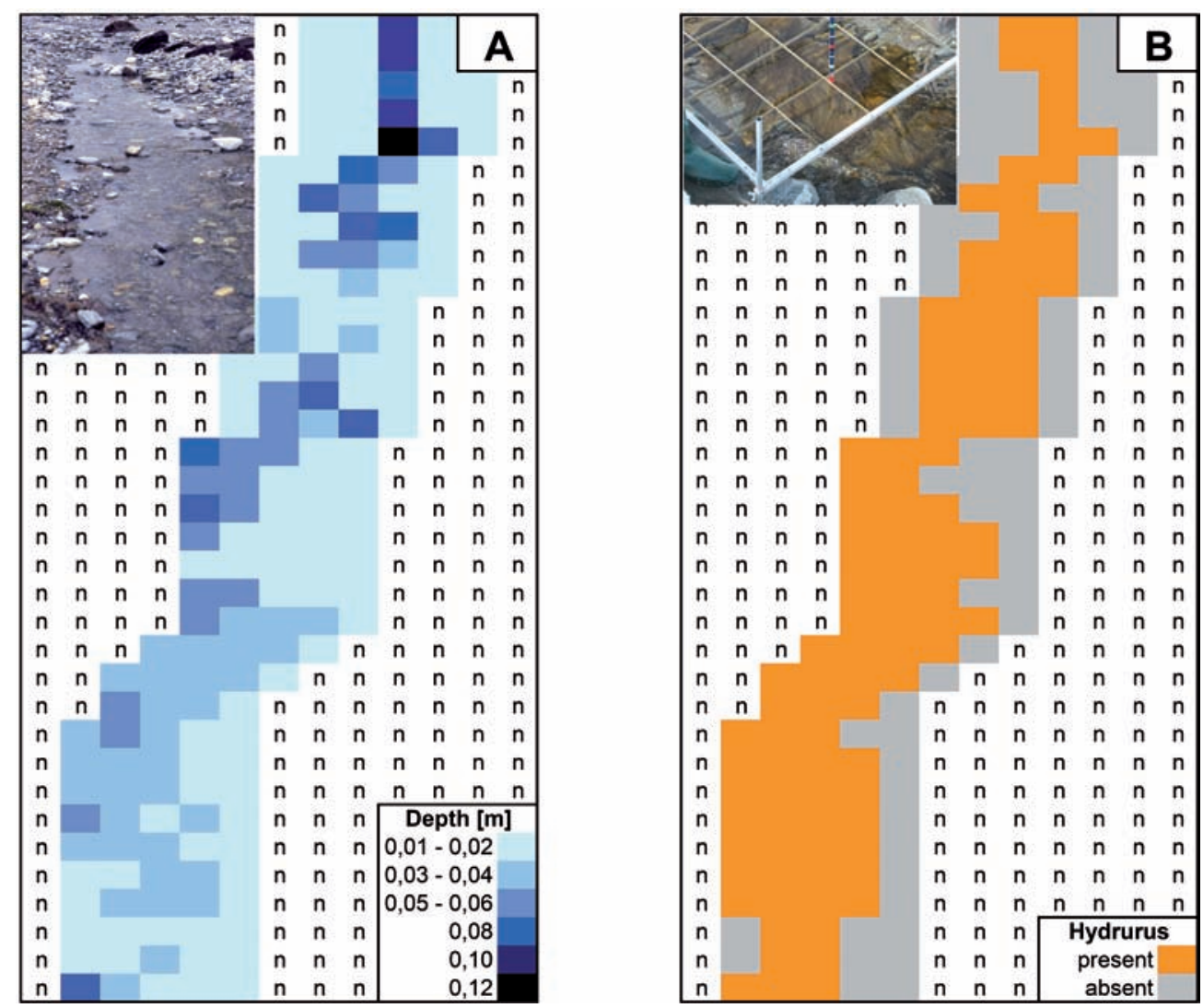

Abb. 4:

Verteilungmuster der Wassertiefe (A) und der makroskopisch sichtbaren Algenwatten von Hydrurus foetidus (B) in einem Seitenarm der Rotmoosache, 14. April 2002.

weisen heute noch einen erstaunlich hohen Artenreichtum auf (Robinson und Kawecka 2005). Die klare Abgrenzbarkeit von Nischen (wie z.B. Hydrurus foetidus im Gletscherbach) in hochalpinen Bächen (Abb. 4 A, B) lässt die Untersuchung von organismischen Interaktionen (von kompetitiver Konkurrenz bis zu Synergismen zwischen Bakterien, Algen, Ciliaten und Grazern) vielversprechend erscheinen. Welche Zusammenhänge zwischen der lotischen Algenflora, insbesondere in den neu entstandenen Bächen, mit der Algenflora des Kryokonit und des Schnees bestehen (vgl. Kap. 10, Sattler et al.), ist noch unerforscht.

Wir wissen heute noch zu wenig darüber, wie sich „Airborne Pollution“ (insbesondere die Zunahme der Stickstoffkomponenten in den Alpen) zu Zeiten des Klimawandels auf die Algendiversität und vor allem auf das Vorhandensein 
bestimmter funktionaler Algengruppen (z.B. $\mathrm{N}_{2}$-Fixierer) auswirken wird. Es ist möglich, dass vor allem $\mathrm{N}_{2}$-fixierende Taxa (fädige Cyanobakterien wie Tolypothrix und Scytonematopsis, vgl. Rott und Pernegger 1996) durch die Zunahme von fädigen Zygnemalen verdrängt werden und potentiell toxische Arten auch im alpinen Bereich weiter zunehmen (Mez et al. 1998). Ob diese Veränderungen - vor allem ein zu erwartender Rückgang oligotraphenter, seltener Arten (Rote-Listen Taxa) - dann generell einen höheren oder niederen Artenreichtum zur Folge haben werden, bleibt offen.

\section{Literatur}

Bürgi, H.R., Burgherr, P. \& Uehlinger, U. (2003) Aquatic flora. In: Ecology of a glacial floodplain, Ward J.V. \& Uehlinger U. (eds) Kluwer Academic Press, 139-151.

Ettl, H. (1968) Ein Beitrag zur Kenntis der Algenflora Tirols. Ber. nat.-med. Ver. Innsbruck 56: 177-354.

Garcia-Pichel, F. \& Castenholz, R. (1991) Characterization and biological implications of scytonemin, a cyanobacterial sheath pigment. J. Phycol. 27: 395-409.

Gesierich, D. \& Rott, E. (2004) Benthic algae and mosses from aquatic habitats in the catchment of a glacial stream (Rotmoos,
Ötztal, Austria). Ber. nat.-med. Ver. Innsbruck 91: 7-42.

Mez, K., Hanselmann, K. \& Preisig, H.R. (1998) Environmental conditions in high mountain lakes containing toxic benthic cyanobacteria. Hydrobiol. 368: $1-15$.

Psenner, R., Füreder, L., Rott, E., Schütz, C., Sonntag, B., Waldhuber, S. \& Wille, A. (2003) Biodiversity of an alpine catchment. An integrated approach to assess microbial, botanical and faunistic diversity of terrestrial and aquatic habitats in the Rotmoos Valley, Tyrol. Part II. Aquatic Biodiversity. Final Report. Project Biodiversity of alpine landscapes. Österr. Akademie Wiss. Wien.

Robinson, C.T. \& Kawecka, B. (2005) Benthic diatoms of an Alpine stream/lake network in Switzerland. Aquat. Scs 67: 492-506.

Rott, E. (2007) Algen (inkl. Blaualgen / Cyanobakterien) A) Aquatische Formen. In: Tag der Artenvielfalt 2007 in Tirol. - Erhebungen im Ötztal. Pagitz, K. (eds) Veröff. Landesmus. Ferdinand. Innsbruck 87: 114-119.

Rott, E. \& Pernegger, L. (1994) Epilithic cyanophytes from soft-water mountain lakes in the Central Alps (Austria) and in the Pirin mountains (Bulgaria) with special reference to taxonomy and vertical zonation. Arch. Hydrobiol., Algol. Stud. 75: 249-264.

Rott, E., Gesierich, D. \& Binder, N. (2002) Phytobenthos. In: Kleines Handbuch zur 
methodischen Erfassung der Biodiversität Alpiner Lebensräume. ALP-2000. Biodiversity of an alpine catchment. Sonntag B. (eds). 2-3.

Rott, E., Gesierich, D. \& Binder, N. (2003) Phytobenthos. In: Biodiversity of an alpine catchment. An integrated approach to assess microbial, botanical and faunistic diversity of terrestrial and aquatic habitats in the Rotmoos Valley, Tyrol. Part II. Aquatic Biodiversity. Psenner R et al (eds). 311-348 + Databank.

Rott, E., Cantonati, M., Füreder, L. \& Pfister, P. (2006) Benthic algae in high altitude streams of the Alps - a neglected component of aquatic biota. In: Ecology of high altitude aquatic systems in the Alps. Lami A., Boggero A. (eds.) Hydrobiol. 562: 195-216.

Rott, E., Füreder, L., Schütz, C., Sonntag, B. \& Wille, A. (2006a) A conceptual model for niche separation of biota within an extreme stream microhabitat. Verh. Internat. Verein. Limnol. 29: 2321-2323.

Sonntag, B. (2002) (eds) Kleines Handbuch zur methodischen Erfassung der Biodiversität Alpiner Lebensräume. ALP2000. Biodiversity of an alpine catchment. Projektbericht Österr. Akad. Wiss., Wien: Methodenhandbuch 1-10.

Uehlinger, U., Robinson, C.T., Hieber, M. \& Zah, R. (2009) The physico-chemical habitat template of periphyton in glacial streams of the Alps. Hydrobiol. DOI 10.1007/s10750-009-9963-x.

\section{Verzeichnis der AutorInnen}

Eugen Rott

Universität Innsbruck

Institut für Botanik,

Sternwartestr. 15, 6020 Innsbruck, Österreich

Eugen.Rott@uibk.ac.at

Doris Gesierich

Universität Innsbruck

Institut für Botanik,

Sternwartestr. 15, 6020 Innsbruck, Österreich

Doris.Gesierich@uibk.ac.at

Nico Binder

Schieferrollstr. 12, 6250 Kundl, Österreich 


\title{
Kapitel 9 | Pilze und mikrobielle Gemeinschaften im Gletschervorfeld
}

\author{
Ursula Peintner, Regina Kuhnert
}

\section{Zusammenfassung}

Im Gletschervorfeld des Rotmoosferners wurden Pilze alpiner Primärsukzessionsstandorte erstmals in umfangreicher Weise untersucht. Die mykologischen Arbeiten begannen bereits in den 1940er Jahren und umfassen Untersuchungen an Fruchtkörpern von Asco- und Basidiomyzeten, kulturtechnische Untersuchungen der Bodenpilze, bodenmikrobiologische Untersuchungen, Untersuchungen des Ektomykorrhizastatus alpiner Pflanzen und Analysen zu Bodenpilzgesellschaften basierend auf rDNA Klondatenbanken. In den letzten Jahren wurde besonderes Augenmerk auf die saisonale Dynamik von Pilzen der alpinen Zone und deren Aktivität im Winterhalbjahr gelegt. Die umfassenden Ergebnisse bestätigten in eindrucksvoller Weise, dass Pilze für die Etablierung und den Erhalt von Ökosystemen eine wichtige Rolle spielen. Daraus folgt zwingend, dass die Vertreter des artenreichen Organismenreiches Fungi bei ökologischen Fragestellungen nicht länger vernachlässigt werden dürfen.

\section{Abstract}

Fungi of alpine primary successional habitats have been extensively studied in a unique way at the glacier forefield of the Rotmoosferner. Mycological research started early in the 1940ies, since then including studies based on fruit body data of asco- and basidiomycetes, cultural techniques applied to soil borne fungi, soil microbiological approaches, investigations on the mycorrhizal status of alpine plants, and analysis of soil fungal communities based on rDNA clone libraries. The topics of saisonal dynamics and winter biology of fungi were especially approached during the last years. The comprehensive results show in an impressive way, that fungi are very important for ecosystem development, implying that representatives of the species-rich kingdom fungi can no longer be neglected in ecology and environmental science. 


\section{Einleitung}

Der fortlaufende Gletscherrückgang der vergangenen Jahrzehnte ermöglichte in besonders eindrucksvoller Weise räumliche und zeitliche Einblicke, um die Dynamik eines neues Ökosystems zu beobachten und zu untersuchen. Das Gletschervorfeld des Rotmoosferners (Ötztal, Tirol) ist aufgrund seiner geographischen Lage für Sukzessionsstudien bestens geeignet. Neben der Wiederbesiedelung durch Tiere und Pflanzen ist auch die Entwicklung von parasitischen, saproben und symbiontischen Pilzen von zentraler Bedeutung. Pilze wurden bisher bei Untersuchungen von Primärsukzessionsstandorten weitgehend vernachlässigt. Eine Studie am Lyman Gletscher (U.S.A.) zeigte, dass der Eintrag von Pilzsporen aus der Luft oder durch Vektoren wie Bodentiere zum Aufbau von Pilzgemeinschaften in einer primären Sukzessionsgesellschaft von Bedeutung ist (Jumpponen 2003). Saprobe Pilze sind besonders während der Wintermonate physiologisch aktiv, sie bauen u.a. pflanzliches organisches Material $\mathrm{ab}$, setzen hohe Mengen an $\mathrm{CO}_{2}$ frei, und sind somit für den globalen Kohlenstoffkreislauf von bisher weit unterschätzter Bedeutung (Monson et al. 2006).

Mykorrhiza-Assoziationen kommen in einem breiten Spektrum an Habitaten vor und sind auch an arktisch-alpinen Standorten weit verbreitet. Die alpine Zone beginnt über der Baumgrenze und ist durch eine wenig kompakte Vegetation und extreme abiotische Faktoren wie niedrige Temperaturen, intensive Sonnenstrahlung, Nährstoffmangel und eine kurze Vegetationsperiode charakterisiert. Die Anpassungsfähigkeit an diese Bedingungen ist für das Überleben aller Organismen ausschlaggebend. Über acht Prozent der Weltoberfläche sind mit arktischalpinen Habitaten bedeckt. Dadurch sind arktisch-alpine Pilze von großer ökologischer Bedeutung. Obwohl Pilze gerade in der alpinen Zone aufgrund ihrer nur kurzlebigen Fruchtkörper und ihrer im Boden verborgenen Myzelien kaum wahrgenommen werden, sind sie für das Funktionieren dieses sensiblen Ökosystems ein ausschlaggebender Faktor.

Der normalerweise an diesen Standorten vorherrschende Nährstoffmangel fördert im Allgemeinen die Entwicklung der Symbiose von höheren Pflanzen und Pilzen, die Ektomykorrhiza (ECM). Die Pilzpartner filtern mit ihrem ausgedehnten Myzelnetzwerk die nötigen Nährstoffe aus dem Boden und stellen den Pflanzen Spurenelemente und Wasser zur Verfügung. Für Pflanzen der alpinen Extremstandorte sind symbiontische Assoziationen mit Pilzen nicht nur vorteilhaft, sondern oft für das Etablieren und Überleben essentiell. Die ericoide Mykorrhiza ist schon lange für Ericaceen (Calluna vulgaris, Loiseleuria procumbens, Vaccinium myrtillus, V. uliginosum, $V$. vitis-idaea und Rhododendron ferrugineum) bekannt, viele von ihnen haben ihr Hauptverbrei- 
tungsareal oberhalb der Waldgrenze. Die Artenzusammensetzung und Intensität der arbuskulären Mykorrhiza (AM) von alpinen Gräsern und Zwergsträuchern variiert zwischen Pflanzenarten und nimmt mit zunehmender Höhenlage ab (Haselwandter 1979; Read und Haselwandter 1981).

1888 beschrieb Frank zum ersten Mal die Ektomykorrhizasymbiose der alpinen Zwergsträucher Salix reticulata und $S$. retusa. 1930 identifizierte Peyronel erstmals die Pilzpartner ektomykorrhizierter alpiner Pflanzenwurzeln als Vertreter der Gattungen Amanita, Cortinarius, Lactarius und anderen. ECM-Morphotypen alpiner Pflanzen wurden für Salix herbacea (Graf und Brunner 1996), Bistorta vivipara (= Persicaria vivipara), Kobresia bellardii ( $=K$. myosuroides), Massicotte et al. 1998, und Dryas octopetala (Harrington und Mitchell 2002) beschrieben, wobei nur wenige Mykobionten mit Hilfe der morphologischen Methoden identifiziert werden konnten. Die Morphologie von ECM-Morphotypen wird stark durch die Wirtspflanze selbst, und die vorherrschenden ökologischen Bedingungen wie Bodenbeschaffenheit, Feuchtigkeit, Entwicklungsstadium der Pflanze und der mykorrhizierten Wurzel beeinflusst. Zudem bringt die subjektive Beurteilung des Beobachters schwer reproduzierbare Ergebnisse mit sich. Weiters kann ein Morphotyp oft nur einer Pilzgattung zugeordnet werden oder auf mehrere Pilzarten zutreffen. Der Einsatz von moleku- laren Methoden, die heute routinemäßig eingesetzt werden, ermöglicht eine artgenaue Identifizierung der Pilzpartner, und trägt somit wesentlich zum Verständnis der Funktion und der ökologischen Rolle von Pilzen in der alpinen Zone bei.

\section{Forschungsgeschichte}

Den Grundstein für die Erfoschung von subalpinen und alpinen Pilzen in den Ostalpen legte Favre (1955) mit einer umfassenden Studie im Schweizerischen Nationalpark. Er dokumentierte in dieser Publikation über 200 Arten, davon eine große Anzahl an Neubeschreibungen, wobei ökologische und pflanzensoziologische Informationen berücksichtigt wurden. Erste Arbeiten über die Pilzökologie und -soziologie der subalpinen Stufe des Ötztales verfasste Friedrich (1942). Auch Moser (1959) berichtete schon früh über die Pilzsoziologie eines Zirben-Lärchenbestandes in der Kampfzone (1950 m - 2000 $\mathrm{m}$ ) in der Nachbarschaft des Rotmoostales und verknüpfte diese Studie mit ökologischen Beziehungen von Pilz-Baum-Symbiosen in der alpinen Zone. Alpine bzw. hochalpine Bodenpilze wurden erstmals von Gams (1959) im Bereich der Ötztaler und Zillertaler Alpen isoliert. Horak (1960) führte daraufhin eine Erhebung der Bodenpilze in verschiedenen Sukzessionsstadien (4 - 40 Jahre eisfrei) des Gletscher- 
vorfeldes im Rotmoostal durch. Die Untersuchung zeigte eine deutliche Häufung von speziellen Schimmelpilzarten (Trichoderma viride und Cladosporium ssp.) in den jüngsten Böden. Dagegen wiesen die älteren Sukzessionsstufen gleichförmigere und einheitlichere Pilzgesellschaften auf. Mit zunehmendem Bodenalter etablieren sich im Gletschervorfeld Pioniervereine von Moosen, ein- und mehrjährige Pflanzen und Zwergsträucher, welche die primären Bodenpilze verdrängen. Horak sammelte auch im gesamten eisfreien Raum des Gletschervorfeldes (bis zur Moräne von 1850) Pilzfruchtkörper von 34 Arten, ein Großteil davon waren potentielle Ektomykorrhizapartner.

Erste Untersuchungen zum regionalen Mykorrhizastatus von alpinen Pflanzen wurden von Read und Haselwandter (1981) durchgeführt, wobei das Vorkommen von verschiedenen Mykorrhizatypen (Ektomykorrhiza, vesikular-arbuskulare Mykorrhiza, ericoide Mykorrhiza und dunkel septierte Hyphen) im Besonderen erhoben wurde. Dabei konnten in der alpinen Grasheide bei Kobresia myosuroides und Persicaria vivipara Ektomykorrhizainfektionen des Coenococcum Typs nachgewiesen werden. Untersuchungen von
Pflanzenwurzeln an Moränenstandorten zeigten, dass der AM-Mykorrhizatyp eher unregelmäßig ausgeprägt war und „Dark septate Endophytes“ (DSE) dominierten (Haselwandter und Read 1980).

Das Rotmoostal bietet optimale Voraussetzungen für bodenmikrobiologische Sukzessionsstudien. Anhand des metabolischen Quotienten $\left(\mathrm{qCO}_{2}=\right.$ Verhältnis zwischen Basalatmung und mikrobieller Biomasse) wurde die energetische Effizienz von Bodenmikroorganismen erfasst. Der metabolische Quotient war in jungen Böden hoch und nahm mit zunehmender Stabilisierung des Ökosystems ab (Insam und Haselwandter 1989).

Weiterführende bodenmikrobiologische Untersuchungen von Tscherko (2004, 2005) zeigten, dass die Aktivität und Zusammensetzung der Bodenmikroorganismen innerhalb der ersten 43 Sukzessionsjahre von den extremen abiotischen Standortsbedingungen geprägt werden. Ab 75 Sukzessionsjahren konnte aufgrund verbesserter Boden- und Nährstoffbedingungen (Humusgehalt) ein pflanzenspezifischer Einfluss auf die mikrobielle Rhizosphärengemeinschaft nachgewiesen werden. 
Mykologische Forschung im Rotmoostal im Zeitraum $2004-2008$

Die Forschungsarbeiten wurden von der Arbeitsgruppe Ursula Peintner im Rahmen zahlreicher Projekte durchgeführt (Artenliste der Pilztaxa im Anhang).

\section{Pilzliche Diversität basierend auf Fruchtkörperdaten}

Verschiedene ökologische und soziologische Untersuchungen haben sich mit alpinen Makromyzeten (z.B. Bizio 1995, Graf 1994 und Senn-Irlet 1987) beschäftigt, aber es gibt kaum Daten über Pilze in Sukzessionsstadien eines Gletschervorfeldes (Jumpponen 2002). Pilzfruchtkörper liefern einerseits Information über Artenvielfalt und Häufigkeit, andererseits geben sie Hinweise auf die ökologische Bedeutung einzelner Arten. Ausschlaggebende Hinweise für die Funktion von Pilzen sind ihre Bindung an Wirtspllanzen und vor allem Substrate: Parasiten schwächen lebende Wirtspflanzen und führen oft zu deren Absterben, saprobe Pilze leben von totem organischen Material, symbiontische Pilze sind durch die Wechselwirkung zwischen lebenden Pflanzenwurzeln und Pilz gekennzeichnet. Die funktionelle $\mathrm{Zu}$ sammensetzung von Pilzgesellschaften ist von großer ökologischer Bedeutung für die Wiederbesiedelung von Pionierstandorten.
Um eine Vorstellung über die Artenvielfalt von fruchtkörperbildenden Pilzen im Bereich des Gletschervorfeldes zu bekommen, wurde in den Vegetationsperioden 2005 bis 2007 intensiv nach Pilzfruchtkörpern gesucht. Das Sammelgebiet erstreckte sich vom Eingang des Rotmoostales bei der Schönwieshütte $(2.268 \mathrm{~m})$, über die mykologisch am intensivsten untersuchten FWF-Projektflächen an der Moräne von 1858 (2.300 m) bis zur Moräne von 1971 (2.340 m). Erste ECM Pflanzen, vor allem Persicaria vivipara treten bereits nach 50 Jahren Bodenentwicklung (= Eisfreiheit) auf. Ausgedehnte Bestände von ECM Pflanzen wie Salix herbacea, S. retusa, Persicaria vivipara und Kobresia myosuroides werden nach ca. 150 Jahren dominierend. Diese Pflanzenarten wachsen "patchwork-artig“ mit Poa alpina, Alchemilla spp., Carex bicolor und anderen krautigen Pflanzen der alpinen Zone zusammen.

Pilzfruchtkörper konnten in allen Sukzessionsstadien, einschließlich der jüngsten schon von Pflanzen besiedelten Moräne, gefunden werden. Die Artenvielfalt und Diversität waren hoch: insgesamt wurden in drei Untersuchungsjahren Fruchtkörper von 222 Pilzarten gesammelt (Abb. 1-10). $46 \%$ davon waren potentielle Ektomykorrhizapartner, und $54 \%$ Saprobe. Die meisten der ECM Gattungen waren Basidiomyzeten (9), Ascomyzeten waren mit 2 Gattungen vertreten. Die artenreichsten symbiontischen Pilzgattungen waren Inocybe (39 spp.) und Cortinarius (27 spp.), 


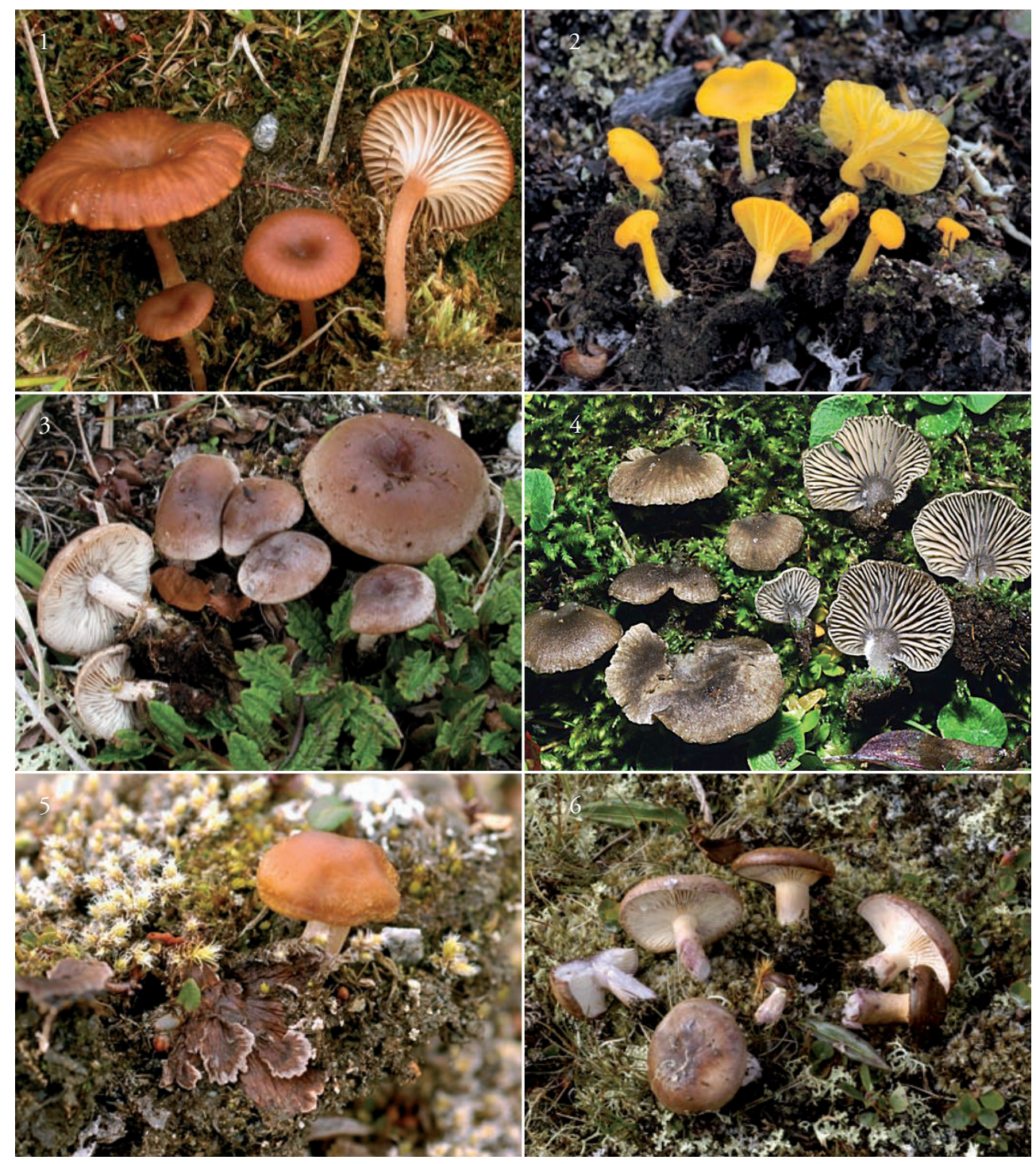

Abb. 1 - 6:

Beispiele einiger im Rotmoostal als Fruchtkörper festgestellten Pilztaxa:

1: Omphalina kuehneri (Foto: P. A. Moreau)

2: Lichenomphalia alpina, (Foto: U. Peinter)

3: Clitocybe festiva (Foto: P. A. Moreau)

4: Arrhenia latispora (Foto: E. Campo)

5: Thelephora caryophilea und Inocybe egenula (Foto: O. Mühlmann)

6: Lactarius robertianus (Foto: U. Peintner) 


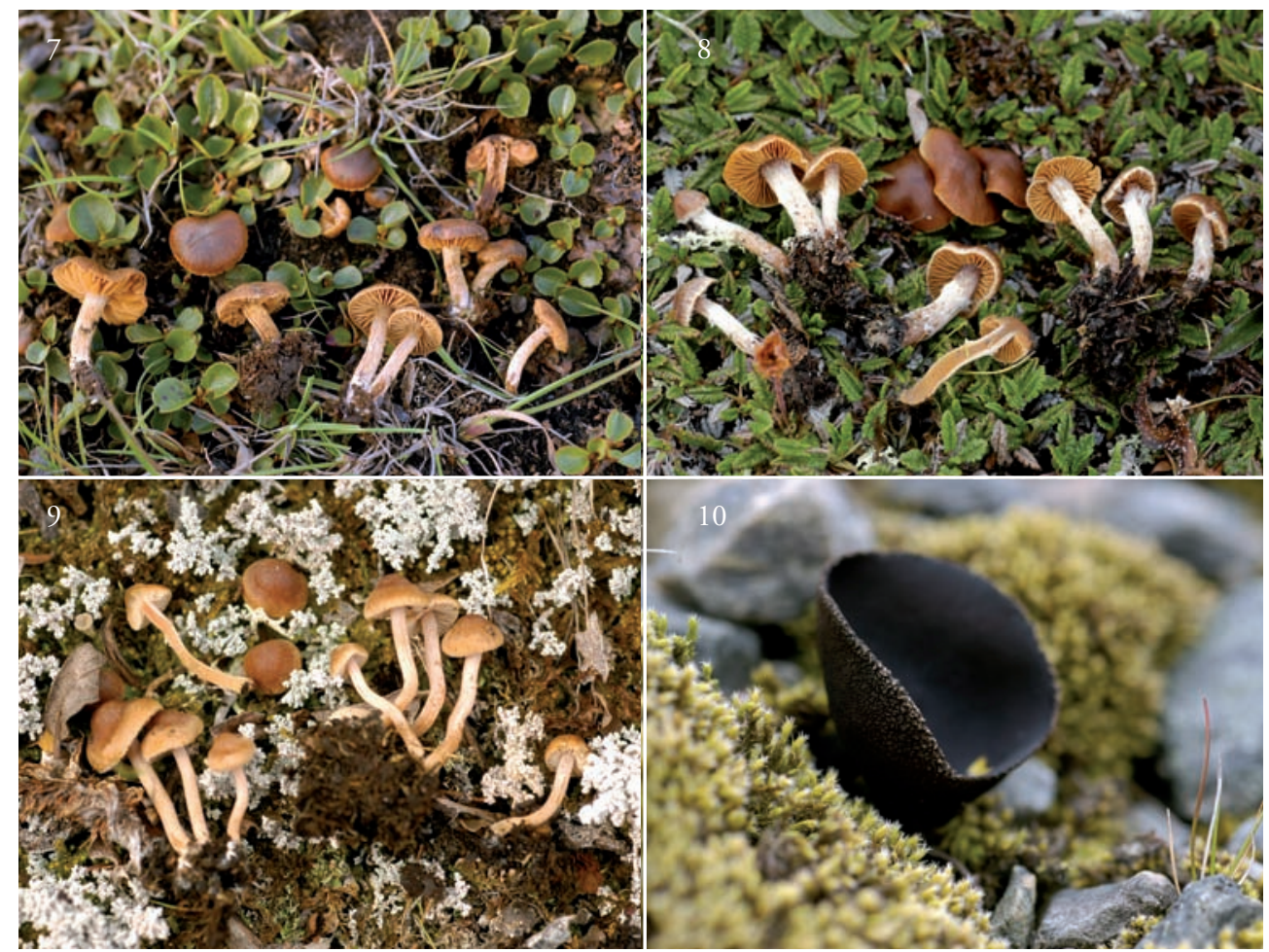

Abb. 7 - 10:

Beispiele einiger im Rotmoostal als Fruchtkörper festgestellten Pilztaxa:

7: Cortinarius chrysomallus (Foto: U. Peintner)

8: Cortinarius helvelloides (Foto: U. Peintner)

9: Inocybe egenula (Foto: U. Peintner)

10: Helvella corium (Foto: U. Peintner)

gefolgt von Hebeloma, Russula, Lactarius, Sebacina, Laccaria, Helvella, Tomentella und Thelephora (Abb. 11). Auffallend war der hohe Anteil an spezifisch alpinen Taxa (67). Das Wissen über alpine Pilze konnte mit der Dokumentation von 13 Neufunden für die alpine Zone erweitert werden. Besonders interessant war der erstmalige
Nachweis von Sebacina und Tomentella. Diese resupinaten Pilze bilden keine auffallenden Fruchtkörper und sind äußerst wichtige Symbiosepartner vieler verschiedener mykotropher Pflanzenarten. Normalerweise fruktifizieren sie an Totholz, und wurden aufgrund dessen in der alpinen Zone bisher nicht vermutet. 


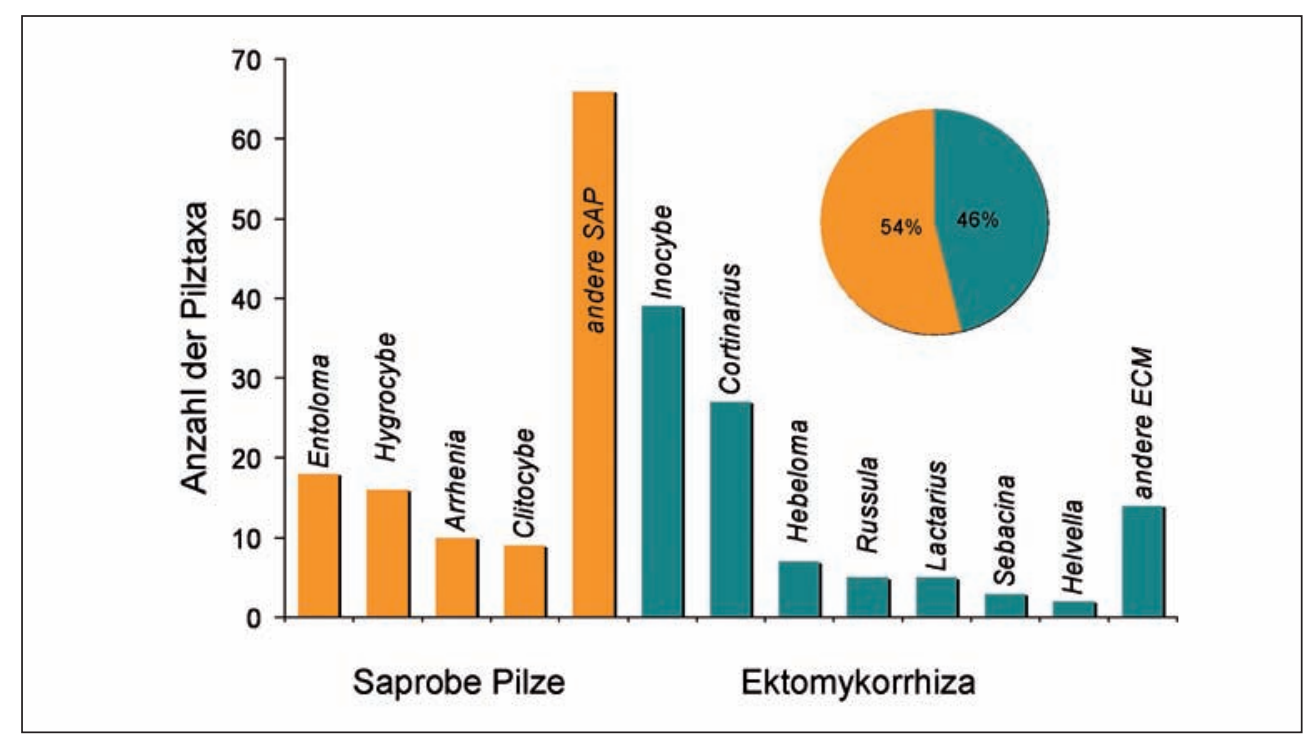

Abb. 11:

Verteilung der im Rotmoostal als Fruchtkörper festgestellten Pilztaxa auf Gattungen und ökologische Gruppen (potentielle Ektomykorrhizabildner ECM und Saprobe Pilze $(\mathrm{n}=222)$

Artenreichtum der Ektomykorrhizapartner von Persicaria vivipara, Kobresia myosuroides und Salix herbacea

Die Anzahl von an den Wurzeln dieser drei Pflanzenarten etablierten Ektomykorrhizapartnern war in den Projektflächen (Moräne von 1858) mit 37 Arten verhältnismäßig hoch: 18 Mykobionten wurden an den Wurzeln von Persicaria vivipara festgestellt (Mühlmann et al. 2008), 18 an Kobresia myosuroides (Mühlmann und Peintner 2008) und 19 an Salix herbacea (Mühlmann und Peintner 2008). Cenococcum geophilum sowie verschiedene Arten der Gattungen Sebacina und Tomentella waren an allen drei Wirtspflanzen die zahlenmäßig dominierenden Symbiosepartner (Abb. 12), gefolgt von Vertretern der Gattungen Cortinarius und Inocybe. Die Wirtspflanze beeinflusst durch selektives Mykorrhizierungsverhalten die Artenzusammensetzung ihrer Mykobionten nachhaltig. Neben den zahlenmäßig dominierenden Generalisten wurden für jede Pflanze auch wirtsspezifische Mykobionten festgestellt: Cortinarius inops war z.B. nur mit Salix assoziiert, eine Inocybe Art nur mit Kobresia, und zwei Tomentella Arten nur mit Persicaria.

Interessanterweise bilden die dominierenden Mykorrhizapartner entweder nur Sklerotien im Boden oder unscheinbare am Substrat aufliegende (= resupinate) 


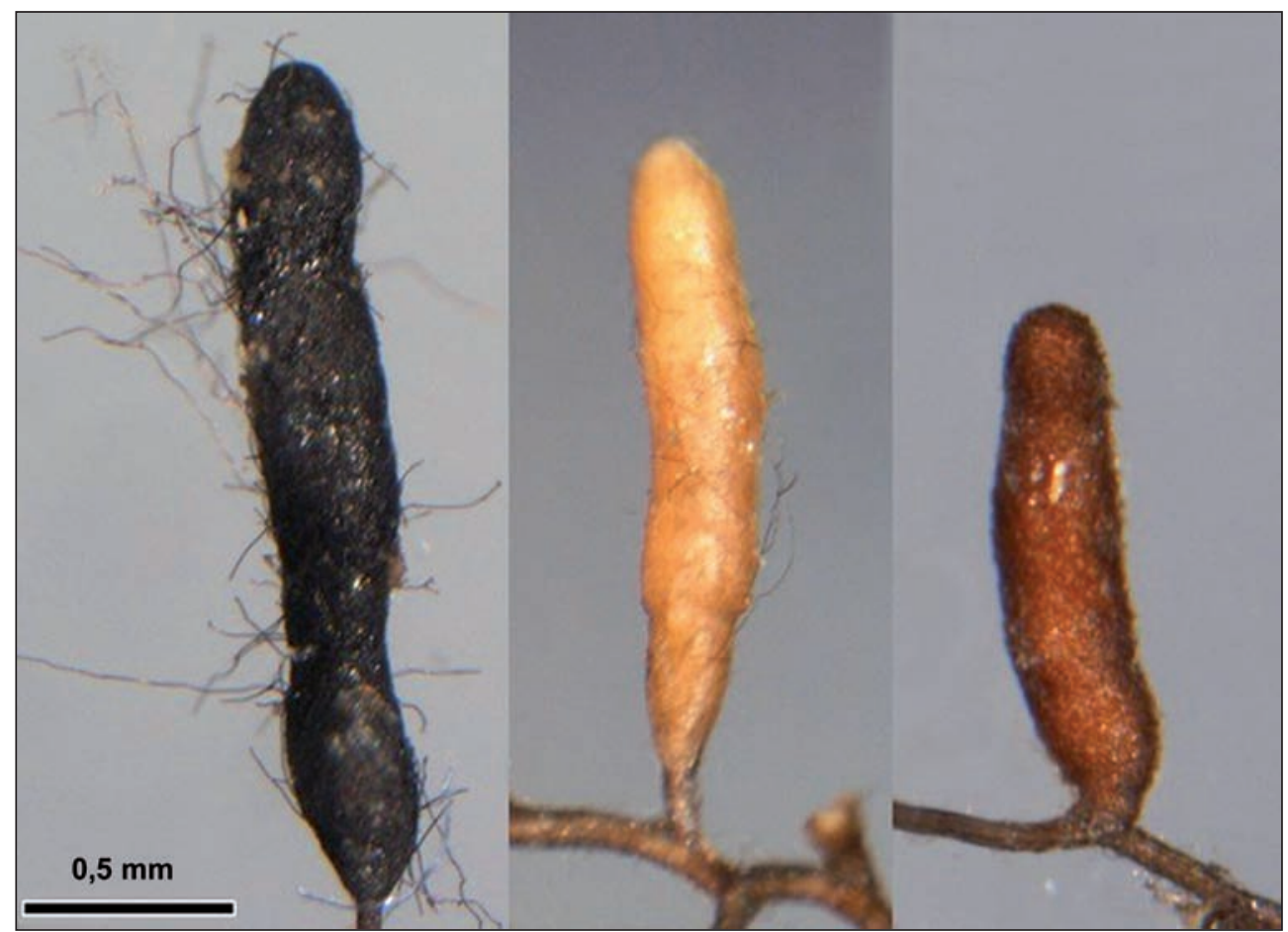

Abb. 12:

Ektomykorrhiza Morphotypen der drei häufigsten ECM Pilze: Cenococcum geophilum, Sebacina ssp. und Tomentella ssp. an Bistorta vivipara im Winter (Fotos: O. Mühlmann)

Fruchtkörper. 35 \% der mit Fruchtkörpern dokumentierten Arten konnten auch als Mykobionten festgestellt werden. Daraus folgt, dass aus Fruchtkörperdaten nur teilweise Rückschlüsse auf die Rolle einzelner Arten als Mykorrhizapartner gezogen werden können.

\section{Chronosequenz der Mykobionten von Persicaria vivipara}

Die Mykobionten von Persicaria vivipara wurden an drei Standorten im Rotmoos- tal untersucht, innerhalb der Moräne von 1971, 1858 und am Standort Schönwieshütte (Fleisch 2008). Persicaria vivipara wies bereits am jüngsten Standort eine relativ hohe Anzahl (17 Arten) von Mykobionten auf. Die Diversität der Mykobionten unterschied sich kaum von Standort zu Standort, wohl aber die Artenzusammensetzungen. So kam z.B. Cenococcum geophilum im Gletschervorfeld der Moräne von 1971 nicht vor, obwohl dieser Pilzpartner an beiden anderen Standorten dominant war. Andererseits kamen Inocybe Arten nur an den 40 - 150 Jahre eis- 
freien Standorten als Mykorrhizapartner vor. Diese Ergebnisse erlauben interessante Einblicke in die Verbreitung, Etablierung und in das Konkurrenzverhalten von symbiontischen Pilzen in Primärsukzessionsstandorten: C. geophilum verbreitet sich mittels unterirdisch gebildeter Sklerotien, welche wahrscheinlich erst spät durch Vektoren oder Bodenfragmente in Primärsukzessionsstandorte eingetragen werden. Inocybe Arten hingegen sind typische Pilze ruderaler Standorte, welche sich mittels luftverbreiteter Sporen etablieren, aber relativ konkurrenzschwach sind und in späteren Sukzessionsstandorten schnell von ECM Pilzen verdrängt werden.

\section{Monitoring von Arbuskulärer Mykorrhiza im Bereich der} Moräne von 1971

Viele Gräser und krautige Pflanzen der alpinen Grasheide (1900 m - 2500 m) bilden eine Endomykorrhizasymbiose mit Vertretern der Glomeromycota aus. Der Mykorrhizierungsgrad dieser AM nimmt mit zunehmender Meereshöhe ab (Read und Haselwandter 1981). Wir waren daran interessiert, wie schnell eine AM Mykorrhizierung an Primärsukzesionsstandorten erfolgen kann. Daher untersuchten wir an der Moräne von 1971 Artemisia genipi, Poa alpina, und Saxifraga oppositifolia auf Vorkommen und Intensität Arbuskulärer Mykorrhiza (AM)-Infektionen. 90 \% der Wurzeln von Poa alpina enthielten intrazelluläre pilzliche Vesikel und/oder Arbuskeln, die Hälfte der Wurzeln waren sogar sehr stark mykorrhiziert (Fleisch et al. 2008). Artemisia genipi und Saxifraga oppositifolia waren hingegen nicht mykorrhiziert.

\section{Bodenpilzgemeinschaften}

Bodenmikroorganismen (Bakterien und Pilze) spielen im Ökosystem eine Schlüsselrolle, da sie den Abbau organischer Substanzen und die Nährstoffverfügbarkeit für Pflanzen regulieren. Alpine Ökosysteme sind durch lange, kalte Winter, gefolgt von einer kurzen, kühlen Vegetationsperiode gekennzeichnet. Umso mehr ist die Wechselwirkung zwischen Pflanzen und Bodenmikroorganismen bedeutend, um limitierende Nährstoffe wie Kohlenstoff und Stickstoff verfügbar zu machen. Die Zusammensetzung von Bodenmikroorganismen unterliegt einer deutlichen saisonalen Verschiebung. Leicht verfügbare Kohlenhydrate stimulieren das Wachstum von Bakterien, die im Sommer ihr biologisches Maximum haben, komplexere Substrate fördern dagegen das Pilzwachstum, daher dominieren Pilze im Winter unter der Schneedecke. Pilzmyzelien sind kältetoleranter und können abgestorbenes Pflanzenmaterial auch unter der Schneedecke bei Temperaturen bis $\mathrm{zu}-5^{\circ} \mathrm{C}$ abbauen (Schadt 2003). Mit Beginn der Schneeschmelze sinkt der Gehalt an mikrobieller (v.a. pilzlicher) Biomasse, 
mikrobiell gebundener Stickstoff wird frei und somit für die Pflanzen verfügbar (Lipson et al. 1999). Andererseits benötigen die Bodenmikroorganismen die von den Pflanzen synthetisierten Kohlenstoffverbindungen.

Die mit Persicaria vivipara, Kobresia myosuroides und Salix herbacea assoziierten Bodenpilzgesellschaften (BPG) des Rotmoostales wiesen insgesamt eine sehr hohe Diversität auf, einschließlich vieler noch nicht identifizierter Pilzgruppen. Insgesamt konnten 428 OTUs (pilzliche Taxa mit 98 \% Sequenzhomologie in der rRNA ITS Region) festgestellt werden (Abb. 13): $54 \%$ Ascomycota, $27 \%$ Basidiomycota, $2 \%$ Chytridiomycota, 0,1\%
Glomeromycota, $6 \%$ Zygomycota und $8 \%$ ohne Zuordnung zu einer taxonomischen Gruppe. Standorte mit Persicaria waren mit 152 OTUs am artenreichsten, gefolgt von Kobresia (137 OTUs), nacktem Boden (133 OTUs) und Salix (131 OTUs) (Oberkofler und Peintner 2008). Im Sommer stand das Vorkommen von ECM Pilzen in engem Zusammenhang mit der Pflanzenbedeckung: ECM Pilze kamen in nackten Böden mit einer Ausnahme (Sebacina) nicht vor, hier waren anamorphe Pilze dominierend; Standorte mit Salix und Persicaria zeigten im Vergleich zu Kobresia einen höheren Anteil an ECM Pilzen.

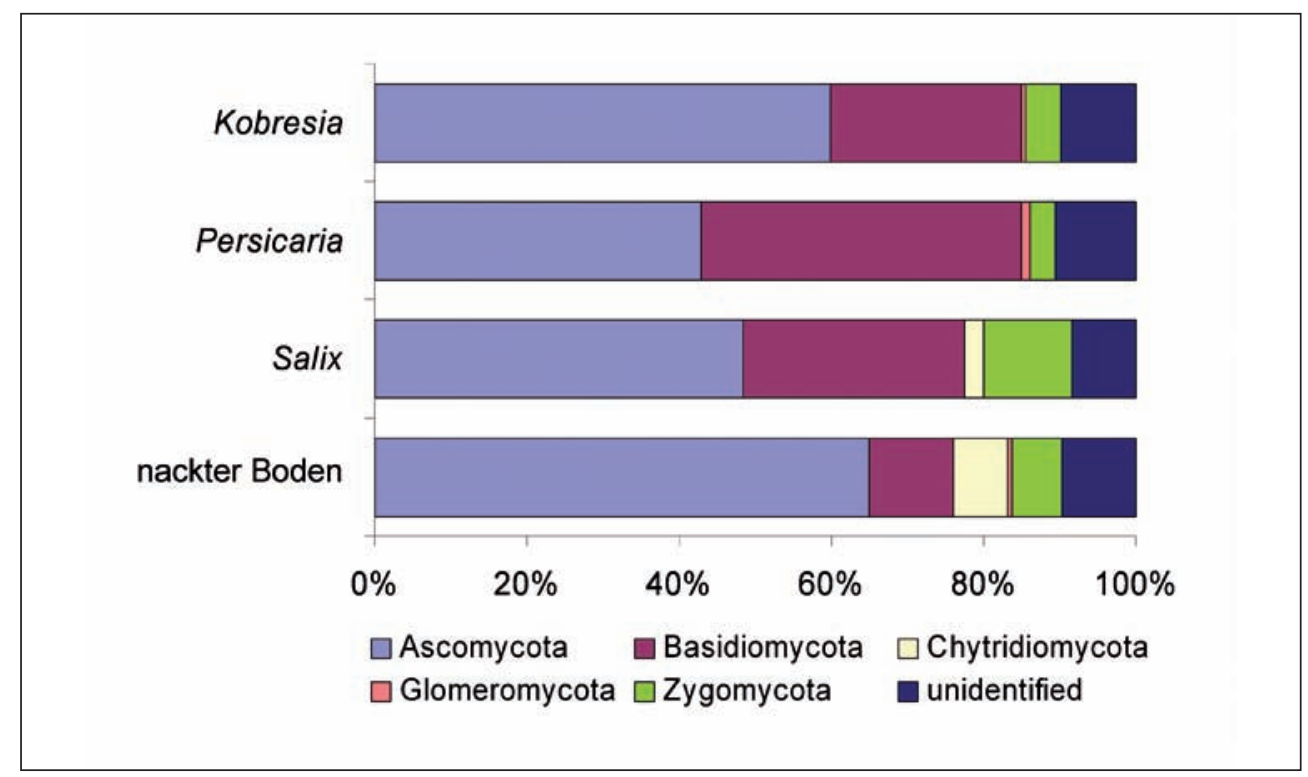

Abb. 13:

Zusammensetzung von Bodenpilzgesellschaften, welche während des Sommers mit Salix herbacea, Persicaria vivipara, Kobresia myosuroides und nacktem Boden assoziiert waren $(\mathrm{n}=428)$ basierend auf rDNA ITS Klon Datenbanken 
Glomeromycota sind wichtige AM-Partner, sie waren in den Böden der potentiell endomykorrhizabildenden Pflanzen Kobresia and Persicaria vertreten. Die aquatischen Chytridiomycota waren in Standorten mit Salix und in nackten Böden zu finden.

\section{Saisonale Dynamik von Pilzen im Boden}

Die Wintermonate wurden bei Untersuchungen von Bodenpilzgesellschaften (BPG) und ECM Pilzen bisher nicht berücksichtigt, da in dieser Periode bisher physiologische Inaktivität vermutet wurde. Untersuchungen zur saisonalen Dynamik von BPG und ECM Pilzen eines Primärsukzessionsstandortes wurden anhand dreier alpiner ECM Pflanzen (Persicaria vivipara, Kobresia myosuroides, Salix herbacea) sowie nackter Böden erstmals im Gletschervorfeld des Rotmoosferners systematisch durchgeführt.

Alle drei erwähnten ECM Pflanzen wiesen Sommer wie Winter einen überraschend hohen Mykorrhizierungsgrad (95-100 \%) auf. Die Anzahl abgestorbener Wurzelspitzen war im Frühjahr gering und erreichte dagegen im Winter im gefrorenen Boden ein Maximum (Mühlmann et al. 2008). Die Diversität der Mykorrhizapartner war im Frühling am höchsten und nahm zum Winter hin ab. Die dominierenden ECM Partner (Cenococcum geophilum, Sebacina incrustans und Tomentella spp.) waren noch im gefrorenen Boden vital. Auffallend war, dass schon kurz nach der Schneeschmelze gut entwickelte, mykorrhizierte Wurzelspitzen vorhanden waren, die eine hohe Diversität von Mykobionten aufwiesen. Das schnelle Wachstum im Frühjahr weist darauf hin, dass die physiologische Aktivität schon früh unter der Schneedecke beginnt. Dieser Wachstumsschub wird wahrscheinlich durch veränderte Feuchtigkeitsbedingungen, bedingt durch Schmelzwasser, ausgelöst. Im Gegensatz dazu änderte sich die Zusammensetzung der BPG von Sommer zu Winter deutlich. Die Artenvielfalt und Abundanzen von Ascomycota sind im Winter deutlich (> 10 \%) höher als im Sommer, dagegen nehmen Basidiomycota und Zygomycota vom Sommer zum Winter wesentlich ab. Diese winterliche Dominanz der Ascomycota scheint zumindest für arktisch-alpine Böden typisch zu sein, da sie auch in alpinen Böden der Rocky Mountains (U.S.A) festgestellt werden konnten (Jumpponen 2003, Schadt et al. 2003, Meyer 2004).

Pilzliche Myzelien überdauerten den Winter nicht nur (z.B. als Mykorrhizapartner an Wurzelspitzen), sie waren überdies auch physiologisch aktiv. Es ist bemerkenswert, dass die pilzliche Biomasse während der Wintermonate in den schneebedeckten Böden auf das 6-12fache der Sommerwerte anstieg. Anhand von im Winter im Boden eingegrabenen Einwuchssäckchen (Meshbags) konnte bewiesen werden, dass Pilze während der Wintermonate in 


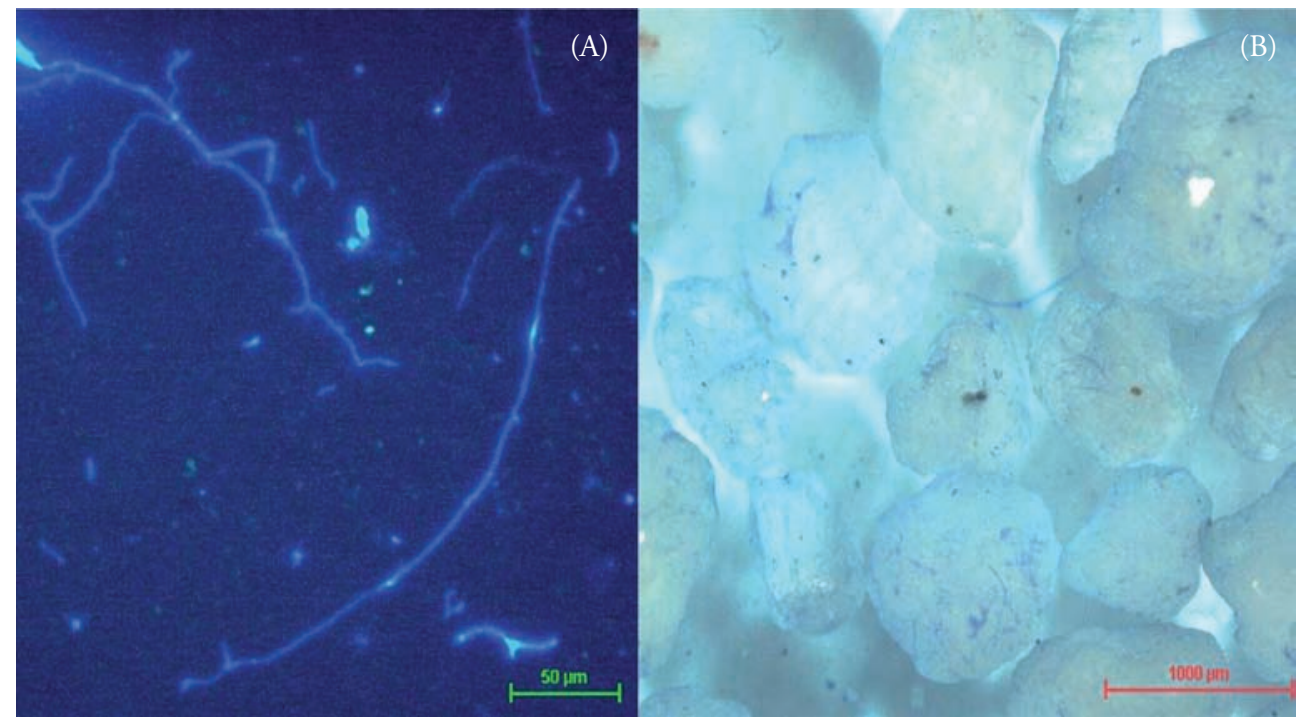

Abb. 14:

Pilzhyphen, welche im Winter in mit Quarzsand gefüllte sterile Einwuchssäckchen (Meshbags) eingewachsen sind. (A) Pilzhyphen wurden mittels Membran-Filter Technik (Hanssen et al. 1974) isoliert und mit Calcoflour white (M2R) gefärbt. (B) Direkte Färbung des sterilen Quarzsandes mit Phenolanilinblau (Foto: R. Kuhnert)

kalten schneebedeckten Böden wachsen können (Abb. 14). Dabei handelte es sich um verschiedenste saprobe Ascomyzeten, einschließlich vieler noch nicht beschriebener Pilze, welche bei Bodentemperaturen von $-0,6^{\circ} \mathrm{C}$ bis $-0,3^{\circ} \mathrm{C}$ einen hohen Anteil an Biomasse bildeten.
Der Nachweis von psychrotoleranten Basidiomyzeten-Hefen (Cryptococcus spp.) fiel in die Zeit der Schneeschmelze. Das Vorkommen von Hefen könnte durch die extreme Sättigung des Bodens mit Schmelzwasser begünstigt sein. 


\section{Literatur}

Bizio, E. (1995) Alcune Inocybe piu frequanti della zona alpina delle Dolomiti. Rivista di Micologia, Bolletino dell'Assoziazione Micologica Bresadola 38, 2, Supplement: 3-60.

Favre, J. (1955) Les champignons superieurs de la zone alpine du Parc National Suisse. Ergebnisse der wissenschaftlichen Untersuchungen des schweizerischen Nationalparks 5, 1-112.

Fleisch, M., Erschbamer, B. \& Peintner, U. (2008) Mycorrhizal status of pioneer plants growing on primary sucessional habitats of the Rotmoosferner glacier foreland. Berichte des naturwissenschaftlich-medizinischen Vereins Innsbruck. Supplementum 18.

Fleisch, M. (2008) Mykorrhizastatus von Pionierpflanzen und viviparen Pflanzen aus Primärsukzessionsstandorten des Rotmoosferner Gletschervorfeldes. Diplomarbeit, Universität Innsbruck.

Frank, A.B. (1888) Über die physiologische Bedeutung der Mykorrhiza. Berichte der Deutschen Botanischen Gesellschaft 6: 248-268.

Friedrich, K. (1942) Pilzökologische Untersuchungen in den Ötztaler Alpen. Berichte der Deutschen Botanischen Gesellschaft 60: 218-231.

Gams, W. (1959) Die Bodenpilze im zentralalpinen Rohhumus. Dissertation, Universität Innsbruck.
Graf, F. (1994) Ecology and sociology of macromycetes in snowbeds with Salix hebacea L. in the alpine Valley of Radönt (Grisons, Switzerland). Diss. Bot . 235. Berlin und Stuttgart, J. Cramer, $242 \mathrm{~S}$.

Graf, F. \& Brunner, I. (1996) Natural and synthesized ectomycorrhizas of the alpine dwarf willow Salix herbacea. Mycorrhiza 6: 227-235.

Harrington, T.J. \& Mitchell, D.T. (2002) Characterization of Dryas octopetala ectomycorrhizas from limestone karst vegetation, western Ireland. Canadian Journal of Botany 80: 970-982.

Haselwandter, K. (1979) Mycorrhizal status of ericaceous plants in alpine and subalpine areas. New Phytologist 83: 427-431.

Haselwandter, K. \& Read, D.J. (1980) Fungal Associations of Roots of Dominant and Sub-Dominant Plants in High-Alpine Vegetation Systems with Special Reference to Mycorrhiza. Oecologia 45: 5762.

Horak, E. (1960) Die Pilzvegetation im Gletschervorfeld (2290-2350 m) des Rotmoosferners in den Ötztaler Alpen. Nova Hedwigia II: 487-508.

Insam, H. \& Haselwandter, K. (1989) Metabolic quotient of the soil microflora in relation to plant succession. Oecologia 79, 174-178.

Jumpponen, A., Trappe, J.M. \& Cázares, E. (2002) Occurrence of ectomycorrhizal fungi on the forefront of retreating Lyman Glacier (Washington, USA) in relation to time since deglaciation. Mycorrhiza 12: 43-49. 
Jumpponen, A. (2003) Soil fungal community assembly in a primary successional glacier forefront ecosystem as inferred from rDNA sequence analyses. New Phytologist 158: 569-578.

Lipson, D.A., Schmidt, S.K. \& Monson, R.K. (1999) Links between microbial population dynamics and plant $\mathrm{N}$ availability in an alpine ecosystem. Ecology 80: 16231631.

Massicotte, H.B., Melville, L.H., Peterson, R.L. \& Luoma, D.L. (1998) Anatomical aspects of field ectomycorrhizas on Polygonum viviparum (Polygonaceae) and Kobresia bellardii (Cyperaceae). Mycorrhiza 7: 287-292.

Meyer, A. (2004) Phylogenetic characterization of alpine soil microbial diversity. Ph.D. Dissertation, University of Colorado, Boulder.

Monson, R.K., Lipson, D.L., Burns, S.P., Turnipseed, A.A., Delany, A.C., Williams, M.W. \& Schmidt, S.K. (2006) Winter forest soil respiration controlled by climate and microbial community composition. Nature 439: 711-714.

Moser, M. (1959) Pilz und Baum. Schweizerische Zeitschrift für Pilzkunde 37: 37-53.

Mühlmann, O. \& Peintner, U. (2008) Ectomycorrhiza of Kobresia myosuroides at a primary successional glacier forefront. Mycorrhiza 18: 355-362.
Mühlmann, O. \& Peintner, U. (2008) Mycobionts of Salix herbacea on a glacier forefront in the Austrian Alps. Mycorrhiza 18: 171-180.

Mühlmann, O., Bacher, M. \& Peintner, U. (2008) Polygonum viviparum mycobionts on an alpine primary successional glacier forefront. Mycorrhiza 18: 87-95.

Oberkofler, I. \& Peintner, U. (2008) Influence of plant cover on the development of soil fungal communities in 150 year old soils. Berichte des naturwissenschaftliche-medizinischen Vereins Innsbruck. Supplementum 18.

Peyronel, B. (1930) Simbiosi micorrizici tra piante alpine e Basidiomiceti. Nuovo Giornale Botanico Italiano 37: 655-663.

Read, D.J. \& Haselwandter, K. (1981) Oberservations on the mycorrhizal status of some alpine plant communities. New Phytologist 88: 341-352.

Schadt, C.W., Martin, A.P., Lipson, D.A. \& Schmidt, S.K. (2003) Seasonal dynamics of previously unknown fungal lineages in tundra soils. Science 301: 1359-1361.

Senn-Irlet, B. (1987) Ökologie, Soziologie und Taxonomie alpiner Makromyzeten (Agaricales, Basidiomycetes) der Schweizer Zentralalpen. Diss. Universität Bern: $310 \mathrm{~S}$.

Tscherko, D., Hammesfahr, U., Marx, M.-C. \& Kandeler, E. (2004) Shifts in rhizosphere microbial communities and enzyme activity of Poa alpina across an alpine chronosequence. Soil Biology and Biochemistry 36: 1685-1698. 
U. Peintner, R. Kuhnert

Tscherko, D., Hammesfahr, U., Zeltner, G., Kandeler, E. \& Bocker, R. (2005) Plant succession and rhizosphere microbial communities in a recently deglaciated alpine terrain. Basic and Applied Ecology 6: 367-383.

\section{Verzeichnis der AutorInnen}

Ursula Peintner

Universität Innsbruck

Institut für Mikrobiologie

Technikerstr. 25, 6020 Innsbruck, Österreich

Ursula.Peintner@uibk.ac.at

\section{Regina Kuhnert}

Universität Innsbruck

Institut für Mikrobiologie

Technikerstr. 25, 6020 Innsbruck, Österreich

Regina.Kuhnert@uibk.ac.at 


\title{
Kapitel 10 I Leben auf Schnee und Eis
}

\author{
Birgit Sattler, Daniel Remias, Cornelius Lütz, \\ Hieronymus Dastych, Roland Psenner
}

\section{Zusammenfassung}

Wir wissen heute, dass Gletscher nicht nur Eismassen, sondern Ökosysteme sind, welche in einen supraglazialen (auf dem Gletscher), englazialen (im Gletscher) sowie einen subglazialen (unter dem Gletscher) Lebensraum gegliedert werden können. Die Bedingungen für Organismen auf sowie in Schnee und Eis sind durch wiederholte Gefrier- und Tauzyklen, hohe UV-Strahlung und oft durch Nährstoffarmut gekennzeichnet. Die noch schneebedeckte Fläche des Gletschers beherbergt über eine kurze Zeitspanne im Frühsommer eine Vielfalt von Schneealgen, die sich durch Pigmente vor UV-Strahlung schützen und die im Volksmund als „Roter Schnee“ bekannt sind. Sobald der Schnee abschmilzt, finden sich auf der blanken Eisoberfläche Eisalgen, aber auch aktive mikrobielle Nahrungsnetze, welche sich in zylinderförmigen Schmelztrichtern auf dem Eis („Kryokonitlöcher“) etablieren und im Wesentlichen aus Viren, Bakterien, Pilzen, Algen und - je nach geographischer Position - auch aus Tieren bestehen. Besiedelt werden die Gletscheroberflächen über lokalen und regionalen Transport aus der Luft bzw. über Schmelzwasser. Die biologische Aktivität der Gletscherorganismen wurde bislang weit un- terschätzt, spielt jedoch im globalen Kohlenstoffkreislauf eine Rolle.

\section{Abstract}

Nowadays, glaciers are known as ecosystems which can be separated into a supraglacial, englacial and subglacial environment. Living conditions are harsh and characterized by repeated freeze- and thaw cycles, high UV-radiation and often low nutrient levels. During early summer, snow algae, containing UV protective pigments and known as "red snow", are flourishing on the surface of the snow cover. Once the snow pack is melting, ice algae can be found on the bare glacial surface. Beside the presence of psychrophilic phototrophs, active microbial communities are established in so called cryoconite holes (water filled cylindrical depressions which are formed by melting processes of dark matter). These food webs consist mainly of viruses, bacteria, algae, and fungi and - depending on the geographical position - also metazoa. The inocula are mostly airborne (local or regional) or transported by meltwater flows. Glacial communities play a hitherto neglected role in the global carbon cycle. 


\section{Bedingungen und Anforderungen für Lebensgemeinschaften in Schnee und Eis}

Der Autor Ludwig Lang hat im Jahre 1927 in seinem Werk „Gletschereis“ das damalige Auffassungsbild über Gletscher dokumentiert, indem er schreibt: „Am Menschen gemessen, ist der Gletscher ein Stück toter Natur, die nur langsam und allmählich ihre Züge verändert. “Tatsächlich sind viele Lebensräume, „am Menschen gemessen", unwirtlich und extrem. Eis und Schnee galten deshalb lange Zeit als unbelebte und lebensfeindliche Wüste. Doch dieses Bild hat sich grundlegend verändert - inzwischen ist weitgehend bekannt, dass ein Gletscher über eine Vielzahl von Lebensräumen verfügt, welche von Spezialisten besiedelt werden. Heute unterscheidet man zwischen einem supraglazialen Lebensraum, welcher die Oberflächengemeinschaften betrifft, einem englazialen, der die Organismen im Eis beherbergt, und einem subglazialen $\mathrm{Ha}$ bitat - damit sind die Lebensräume im Gletscherbett gemeint.

Die Lebensbedingungen für die hauptsächlich mikrobiell dominierte Lebewelt in Schnee und Eis sind jedoch hart und erfordern entsprechende Anpassungen. Sie sind charakterisiert durch tiefe Temperaturen mit zum Teil großen Tagesschwankungen. Wiederholte Gefrier- und Tauzyklen über einen Tagesrhythmus stellen an den Stoffwechsel einer Zelle große
Anforderungen. Der Organismus sollte durch eine geeignete Kombination von Enzymen und Schutzstoffen wie z.B. Zucker verhindern können, dass das Zellwasser bei Temperaturen unter $0^{\circ} \mathrm{C}$ gefriert und durch die Bildung von Eisnadeln die Zellmembran beschädigt. Diese speziellen Gefrierschutzproteine, welche reich sind an $\alpha$-Helices und polaren Gruppen, sind charakteristisch für Kälteanpassungen und ermöglichen auch ein Einfrieren über längere Perioden, ohne dass der Organismus beim Auftauen Schaden erleidet.

Zudem werden speziell die Oberflächengemeinschaften von Gletschern durch hohe UV-Strahlung belastet, was wiederum eine Anpassung wie Strahlungsschutz durch Pigmentierung oder eine effiziente DNA-Reparatur im Falle einer Schädigung des Erbmaterials erfordert. Glaziale Ökosysteme sind meist nährstoffarm, es kann aber beim Ausfrieren oder Umkristallisieren von Schnee und Eis zu lokalen Anreicherungen von Nährstoffen kommen. Außerdem sollten wir nicht vergessen, dass in vielen Teilen der Erde, z.B. in den Alpen, beträchtliche Mengen an Stickstoffverbindungen aus den Niederschlägen stammen. Organisches und anorganisches Material wird über Windverfrachtung, Schmelzwasserkanäle bzw. schmelzende Schneeauflagen transportiert. Letzteres verlangt die Verfügbarkeit von flüssigem Wasser, wovon jede Lebensform in erster Linie abhängt. Im englazialen Lebensraum findet im gefrorenen Zustand auch kaum 
ein Austausch von Nährstoffen bzw. ein Abtransport von Stoffwechselprodukten statt. Bei sehr tiefen Temperaturen spricht man von einer „Cryobiose“, was soviel wie einer Kältestarre entspricht. Flüssiges Wasser jedoch, und sei es auch nur ein Mikrofilm, welcher dunkle Partikel bzw. ein Konglomerat von mineralischem und organischem Material umhüllt, kann die mikrobielle Aktivität wieder initiieren. Subglazial findet man zum Teil sogar anaerobe Mikroorganismen, welche ihre Energie auch chemolithotroph, d.h. aus der chemischen Umwandlung anorganischen Materials, gewinnen können.

Allein durch den mechanischen Druck, welcher auf eine Zelle während des Gefrier- und Tauprozesses einwirkt, wird von der Zellmembran gleichzeitige Stabilität und Flexibilität gefordert. Beides erhält sie durch einen erhöhten Einbau bestimmter Lipide, und zwar der ungesättigten cis-Fettsäuren. Die Ausstattung eines Organismus mit verschiedenen Lipiden gibt somit auch Auskunft über dessen Lebensbedingungen. All diese speziellen Anpassungen wie Gefrierschutzproteine, Pigmente und Lipide spielen nicht nur für das Bestehen der glazialen Lebensgemeinschaften, sondern auch für die Nutzung in der Biotechnologie eine interessante Rolle.

\section{Die Lebensgemeinschaften \\ in Schnee und Eis}

Algen

Die hochalpine Flora besteht neben den hinreichend bekannten Vertretern der Blütenpflanzen (Kap. 6), auch aus zahlreichen unauffälligeren Arten der „niederen Pflanzen“. Darunter sind in Gebirgslebensräumen vor allem die Algen, Leberund Laubmoose zu verstehen, welche an gletschernahen und anderen exponierten Pionierstandorten gehäuft auftreten. Als weitere dominante Lebensform gehören hier die Flechten erwähnt (als Symbiose von Algen und Pilz), sowie auch die Cyanobakterien, welche als Prokaryonten jedoch nicht zu den Algen gehören.

Im unmittelbaren Gletschervorfeld sind, abgesehen von bakteriellen Lebensgemeinschaften, Bodenalgen die Erstbesiedler des frisch ausgeaperten anorganischen Substrates. Obwohl makroskopisch meist nicht erkennbar, weil diese Mikroorganismen in der oberen Gesteinsschicht fein verteilt wachsen, spielen sie eine wichtige Rolle bei der initialen Bodenbildung unmittelbar nach dem Gletscherrückzug.

Der tschechische Algenforscher Hans Ettl war im 20. Jahrhundert mehrmals in Obergurgl auf Besuch. Ihm verdanken wir einen ausführlichen Bericht über die Algenflora von Tirol (Ettl 1968), in dem nicht nur zahlreiche Artenfunde aus dem Raum Obergurgl dokumentiert wurden, 
sondern etliche, neu entdeckte Spezies zum ersten Mal beschrieben wurden. Ettl konzentrierte sich dabei aber auf Habitate wie Kleingewässer, Felsbewuchs oder alpine Böden, während die Vegetation auf sommerlichem Schnee und Eis nur einen kleinen Raum seiner Forschungen einnahm und vor allem auf Proben aus dem Raum Kühtai in den nördlichen Stubaier Alpen fußte.

In diesem Abschnitt wird jene wenig bekannte Gruppe von Mikroalgen beschrieben, die sich auf den speziellen Lebensraum „nasser Altschnee“ bzw. „feuchte Gletscheroberflächen" angepasst haben (die Algen anderer alpiner Lebensräume werden in Kap. 6, Gärtner, besprochen). Es handelt sich hier um Kälte liebende (psychrophile) bzw. Kälte tolerante einzellige Grünalgen (Chlorophyta), die ausschließlich auf diesem Substrat vorkommen und sich außerhalb nicht vermehren können. Schnee- und Eisalgen sind ein weltweites Phänomen und man findet sie nicht nur in den Alpen und anderen Hochgebirgen der Erde, sondern auch in den polaren Küstengebieten, wo ähnliche Bedingungen herrschen. Eine (aus heutiger Sicht) historische Zusammenfassung über das Vorkommen dieser extremophilen Organismen lieferte die Ungarin Elisabeth Kol (1968). Obwohl sie wahrscheinlich nie in Tirol war, beschrieb sie lokales, jedoch fixiertes Algenmaterial, welches ihr von anderen KollegInnen (gesammelt H. Ettl, überreicht von F. Wawrik) vermittelt wurde (Kol 1970). Ausgehend von diesen toten Zellen können die z.T. vagen Beschreibungen von Kol bezüglich Plausibilität und Reproduzierbarkeit heutigen Ansprüchen leider nicht mehr genügen. Heutige Funde lassen sich schwer mit ihren Daten korrelieren. Aktuelle Übersichten zur Thematik, mit einer Betonung auf Ökologie und Physiologie, bieten Hoham und Duval (2001) sowie Komárek und Nedbalová (2007).

Über die Auswirkung der Klimaerwärmung auf Schnee- und Eisalgen der Alpen gibt es noch keine Studien. Es kann jedoch von einer Gefährdung von Schneealgen in niederen alpinen Lagen ausgegangen werden, falls es dort keine Schneefelder mehr geben sollte, die bis in den Sommer überdauern. Eisalgen wiederum sind auf die Präsenz von Eis angewiesen, womit durch den aktuellen Gletscherrückzug die potentiellen Lebensräume immer kleiner werden.

\section{Schneealgen („Roter Schnee“)}

Viele Bergwanderer haben schon einmal Roten Schnee bemerkt, doch nur den wenigsten ist wohl bewusst, dass es sich dabei um eine massenhafte Ansammlung von Mikroalgen handelt (welche man ja gemeinhin in Gewässern erwartet). Irrtümlich werden derartige Schneefärbungen oft für angewehten Saharastaub oder anthropogene Verschmutzungen gehalten 
(diese Phänomene gibt es natürlich auch, sind aber seltener und verursachen niemals eine lebhaft rosarote Färbung, die auch mehrere $\mathrm{cm}$ in die Tiefe geht). Einen Überblick über die historischen „Verwirrungen" bezüglich des färbenden Prinzips gibt Werner (2007).

Roter Schnee kommt im Ötztal an geeigneten Stellen häufig vor (z.B. Rotmoostal). Er kann sich in sommerlichen Altschneefeldern entwickeln, welche in Seehöhen ab etwa 2000 m von Mai weg anzutreffen sind. Je höher die Lage, desto später kann die Färbung auftreten (Juni, Juli) bzw. sich in kühlen Sommern sogar bis zum Einbruch des nächsten Winters halten (September, Oktober). Bei den Färbungen handelt es sich meist um kleinräumige, wenige Quadratmeter große Vorkommen, wobei diese vor allem in Senken, Rinnen oder flachen Schneefeldern auftreten, wo die Populationen während der Schmelze nicht rasch durch Schmelzwasser ausgewaschen werden und sich Wasser im Schnee länger halten kann. In einer Saison mit besonders starker Färbung (z. B. im Jahre 2009 mit zahlreichen Mitteilungen aus dem ganzen Alpenraum) kann der Rote Schnee durch optimale Niederschlags- und Temperaturbedingungen besonders gut gedeihen (d.h. viel Neuschnee im Winter, langsames kontinuierliches Abtauen im Sommer). Dann findet man die Zellen auch an exponierten Standorten wie Steilhängen oder Kuppen, die in anderen
Jahren i.d.R. weiß bleiben. Eine weitere Bevorzugung erfahren generell sonnenexponierte Südhänge, weil dort durch die Wärmeeinwirkung der Schmelzwassergehalt im Schneekörper höher ist. Wie alle Lebewesen sind auch Schneealgen für ihre Lebensvorgänge auf flüssiges Wasser angewiesen. Friert das Schneefeld während der Nacht oder während eines sommerlichen Kälteeinbruches durch, so überleben diese Organismen aufgrund ihrer Anpassungen in Form eines Zystenstadiums. Neben dem Tolerieren zahlreicher Gefrier-TauZyklen im Milieu bestehen weitere physiologische Anforderungen bezüglich der Adaptierung an niedrige Nährstoffgehalte und an Strahlungsstress durch sehr helle oder sehr dunkle Bedingungen. An der Oberfläche können durch Reflexionen an den Schneekristallen besonders hohe Strahlungen auftreten (insbesondere im UV-Bereich), während Zellen, die weiter in der Tiefe situiert sind mit rasch (logarithmisch) abnehmender Sonnenenergie im Schneekörper zurecht kommen müssen.

Sommerschnee ist ein kleines Ökosystem, in dem die Schneealgen durch ihre Photosynthese den Platz der Primärproduzenten einnehmen. Der Vorteil, der durch die Eroberung dieses speziellen Standorts gewonnen wurde, ist faktische Konkurrenzlosigkeit, denn andere Algen können hier nicht gedeihen. Auf heterotropher Seite sind am Standort Bakterien, Schneepilze (z.B. Chionaster nivalis) und 
bei besonders guten Bedingungen auch Bodenciliaten zu erwähnen, welche von der Präsenz der Algen profitieren.

Das zeitliche Auftreten von Schneealgen hängt stark mit der Saisonalität im Gebirge zusammen und ist in Abb. 1 für Chloromonaden vereinfacht dargestellt. In diesem Zusammenhang muss ergänzt werden, dass diese Organismen einen komplexen Lebenszyklus besitzen (Ettl et al. 1983), bei dem die Zellen ihre Morphologie in Anpassung an die sich ändernden Umweltbedingungen stark verändern können, und gewisse Stadien treten auch nur zu ganz bestimmten Zeiten auf.

$\mathrm{Zu}$ Beginn der Schneeschmelze entsteht flüssiges Wasser im Schnee. Dies, zusammen mit der stärker und länger andauernden Sonneneinstrahlung, ist ein Signal für die Auskeimung der Zysten aus dem Vorjahr, welche auf der Bodenoberfläche überwintert haben. Dabei erfolgt eine interne Zellteilung (Mitose und Meiose) zu vier Flagellaten. Die Zystenwand bricht auf und die Schwärmer sind in der Lage, im Wasserfilm, der sich zwischen den gra-

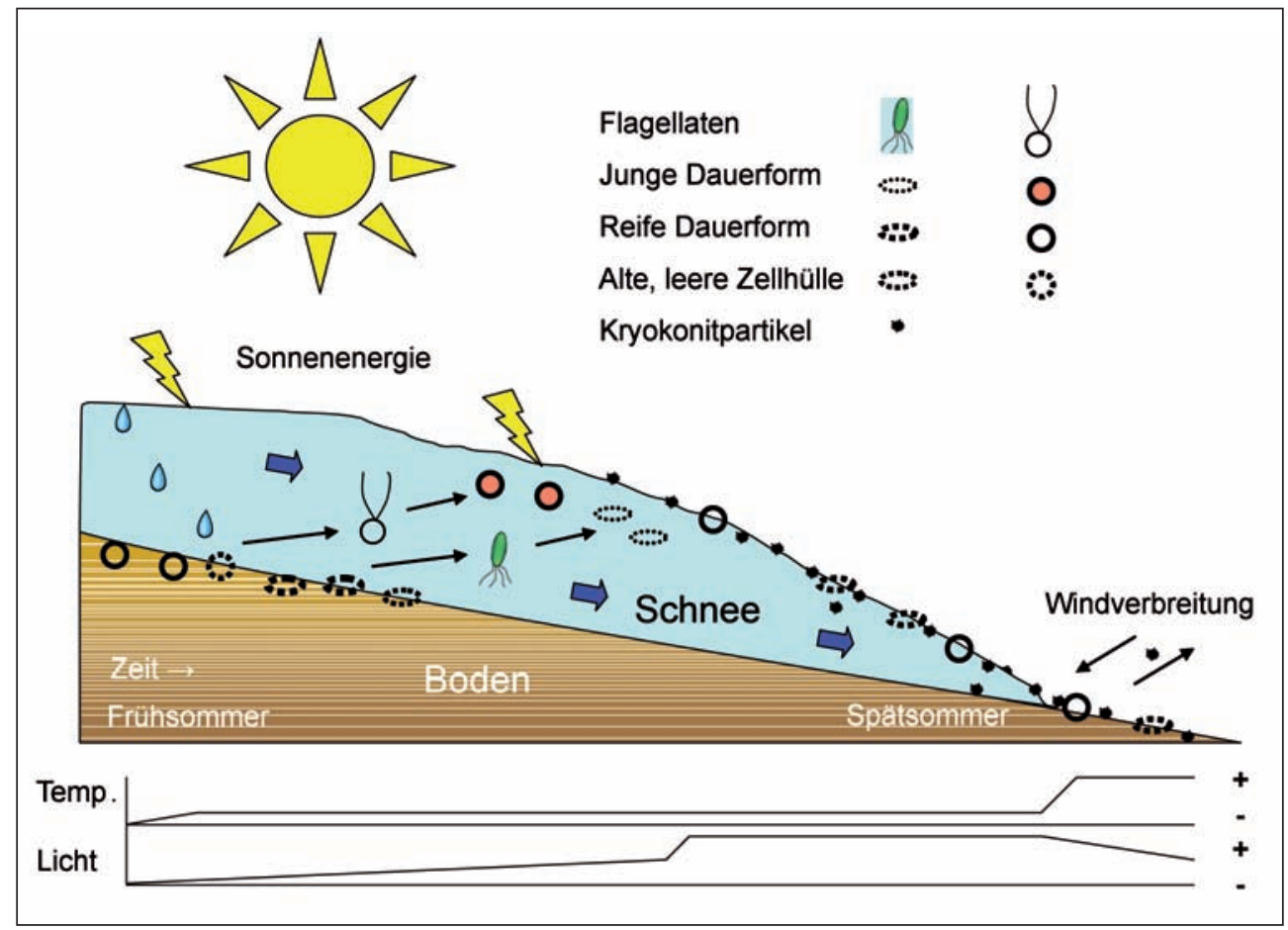

Abb. 1:

Schematischer Lebenszyklus alpiner Schneealgen im Laufe der Saison. Die zeitliche Abfolge erfolgt von links nach rechts. Die Kurven im unteren Bereich symbolisieren die sich dabei verändernden Temperaturund Lichtverhältnisse (weitere Erklärungen im Text). 
nulären Schneekristallen u.a. durch Kapillarkräfte hält, empor zu schwimmen. $\mathrm{Zu}$ diesem Zeitpunkt, meist im April, ist die Schneeoberfläche noch vollkommen weiß (weshalb diese Stadien im Feld fast nie gefunden werden). Die Flagellaten schwimmen nicht bis zur Oberfläche, sondern nur so weit, bis ausreichend Licht vorhanden ist, um weitere Zellteilungen (= vegetativ) oder meiotische Verschmelzungen (= generativ) durchzuführen. Im Anschluss an diese rasche Vermehrung, wahrscheinlich innerhalb weniger Tage, erfolgt ein Abwurf der Geißeln und eine Umwandlung in junge Zysten (auch als Dauerstadien bezeichnet), welche durch die fortwährende Schneeschmelze später passiv an die Oberfläche gelangen (Mai bis Juni) und somit erst dann die Färbung verursachen. Dort sind sie weder mobil noch finden weitere Teilungen statt, doch aufgrund des fortwährend aktiven Stoffwechsels (Remias et al. 2005) sind sie in der Lage, an Größe zuzunehmen und massiv Reservestoffe einzulagern. Dabei handelt es sich nicht oder nur in geringem Maß um die bei Grünalgen geläufige Chloroplasten-Stärke, sondern v.a. um Fette und sekundäre Carotinoide (v.a. Astaxanthin), die sich im Cytoplasma in Form von Fetttropfen anhäufen. Letztere verursachen die Orange- oder Rotfärbung dieser Zellen, obwohl es sich eigentlich um Grünalgen handelt. Über die Rolle der Sekundärcarotinoide wird vielfach diskutiert: Die häufigsten Argumente geben ihnen eine Funktion beim Schutz des Chloroplasten vor Starklicht, als potente Antioxidantien für den intrazellulären Stressschutz (z.B. gegen Radikale) oder als physiologische Möglichkeit, die überschüssige photosynthetische Energie in stickstofffreie Reservestoffe umzuwandeln. Schließlich können die rot gefärbten Schneeflächen im Spätsommer zart nach Wassermelone riechen, was den biologischen Ursprung der Färbung auch ohne Lichtmikroskop plausibel macht. Vermutlich handelt es sich dabei um volatile Spaltprodukte der Carotinoide, die ab einer gewissen Konzentration nicht weiter eingelagert werden können.

Die Zysten müssen bis zum Ende der Schneeschmelze ausgereift und dadurch robust für sich ändernde Umweltbedingungen sein, denn wenn die Zellen auf den Boden gelangen (meist Juli, August), ändern sich die Temperaturen dramatisch: während im Schnee ziemlich konstant 0 bis $0,5^{\circ} \mathrm{C}$ vorherrschen, können alpine Böden bei Sonneneinstrahlung sehr warm werden. Die Zysten müssen dort Trockenheit aushalten und werden zu Winterbeginn wieder eingeschneit. In dieser Hinsicht sind verdickte Zellwände als mechanischer Schutz und ein verringerter Wassergehalt durch die Fetteinlagerung von Vorteil. Vor Winterbeginn kann durch starke Winde eine Fernverbreitung der im Staub befindlichen Zellen durch Aufwehung stattfinden. Dies ist wahrscheinlich ein wichtiger Faktor für die häufige Verbreitung dieser Organismen in kalten Regionen der Erde. Durch Wind wird 
auch feiner Gesteinsstaub aus der Umgebung auf die Schneeflächen aufgetragen, der Altschnee (und v.a. auch nackte Gletscher, siehe nächster Abschnitt) „dreckig“ ausschauen lässt. Im Zusammenhang mit Schnee- und Eisökosystemen werden diese Partikel als Kryokonit bezeichnet. Sie sind im Schnee die einzige wesentliche Quelle für anorganische Nährstoffe.

Die genaue Zahl der Arten, die im Schnee vorkommen, ist unbekannt. Ihre Systematik liegt noch im Argen, da viele der Zysten sehr ähnlich ausschauen und eine differenzierte Beschreibung im Lichtmikroskop oft sehr schwierig ist. Roter Schnee in der Antarktis oder Arktis schaut auf dem ersten Blick fast identisch aus wie jener aus dem Raum Obergurgl (Abb. 2). Derartige rote, runde Zellen mit Durchmessern von 10 bis $30 \mu \mathrm{m}$ werden gewöhnlich in einer Sammelart, Chlamydomonas cf. nivalis, zusammengefasst. In Tirol sind noch zwei weitere Arten anzutreffen, die oberflächlich gelblich-orangen bis hellrosa (und in der Tiefe grünlichen) Schnee verursachen können, nämlich Chloromonas nivalis und Chloromonas brevispina. Bei diesen beiden Spezies, deren spindelförmige, grün-orange gefärbte Zysten ornamentierte Oberflächen besitzen, handelt es sich wahrscheinlich ebenfalls um Sammelarten. Sie sind jedoch, vor allem als Reinvorkommen, deutlich seltener anzutreffen als die erstgenannte „Leitart“ aus dem Roten Schnee.

Darüber hinaus gibt es noch Sonderstandorte, die aufgrund der unterschiedlichen
Ökologie „alternativen“ Roten Schnee verursachen können. In diesen Fällen ist die makroskopische Färbung die gleiche, im Lichtmikroskop sind die Zellen jedoch nicht kreisrunde Zysten, sondern z. B. länglich-oval oder, bei deutlich größeren Maßen (30 bis $50 \mu \mathrm{m})$, oval und mit mehrschichtiger Zellwand. Erstere sind typisch für Roten Schnee, der auf Gletschern statt auf Böden vorkommt. Hier fällt die Gefahr der Erwärmung am Standort nach der Schneeschmelze weg, weshalb die Zysten nicht ruhend sind, sondern auch während

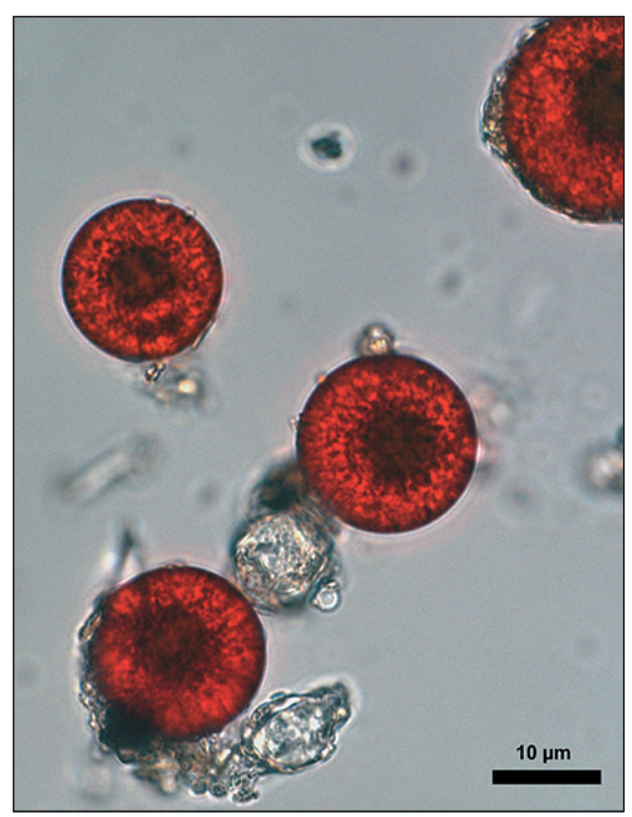

Abb. 2:

Chlamydomonas cf. nivalis (Chlamydomonadales) aus dem hinteren Rotmoostal. Diese Art verursacht Roten Schnee im Rotmoos als auch auf der Hohen Mut. Der dunkle zentrale Bereich besteht aus dem Chloroplasten, welcher durch die cytoplasmatischen Sekundär-Carotinoide überdeckt ist. (Foto: D. Remias) 
des restlichen Sommers flagellatenartige Sporen bilden. Zweitere finden sich v.a. im Schneematsch über der Eisoberfläche von zugefrorenen Hochgebirgseen. Der Lebenszyklus ist noch unbekannt, da die Zellen nach dem Auftauen in das Seesediment absinken. Diese Form wird meist den wenig bekannten bzw. schlecht beschriebenen Spezies wie Chlainomonas rubra oder Chlamydomonas bolyaiana zugeordnet (Ettl et al. 1983).

Gegenwärtig sind international Bemühungen im Gange, diese Algen aufgrund molekularer Daten zu unterscheiden und, falls möglich, in Form von Reinkulturen $\mathrm{zu}$ isolieren und in Folge den Lebenszyklus aufzuklären, was bislang bei einigen Arten aufgrund erfolgloser Kultivierversuche noch nicht gelungen ist.

\section{Eisalgen}

Eines der wahrscheinlich exotischsten und am wenigsten bekannten Habitate für Grünalgen befindet sich auf der Oberfläche von Gletscherfeldern. Auch hier handelt es sich um hoch spezialisierte Arten, die bislang nur von diesem Habitat bekannt sind. Im Gegensatz zum Roten Schnee sind derart besiedelte Eisflächen mit dem freien Auge sehr schwer bis fast gar nicht zu erkennen, weil die Zellen bestenfalls eine schwärzlich-dunkelbraune Färbung verursachen, die im Glanze des Sonnenlichtes einen leichten Dunkelviolett-Stich einnehmen kann. Kryokonit, ein komplexes Gemisch aus feinsten anorganischen und organischen Partikeln, verleiht ausgeaperten Gletschern auch ohne Eisalgen eine fast identische Färbung. Von daher ist die Forschung auf ein gutes Feldmikroskop angewiesen, mit dem das Vorhandensein von Zellen vor Ort überprüft werden muss.

Die Eisalgen der Alpen entstammen der Gruppe der Jochalgen (Zygnemaphyceae), und es handelt sich bei den aus dem Raum Obergurgl bekannten Beständen ausschließlich um zwei Varietäten

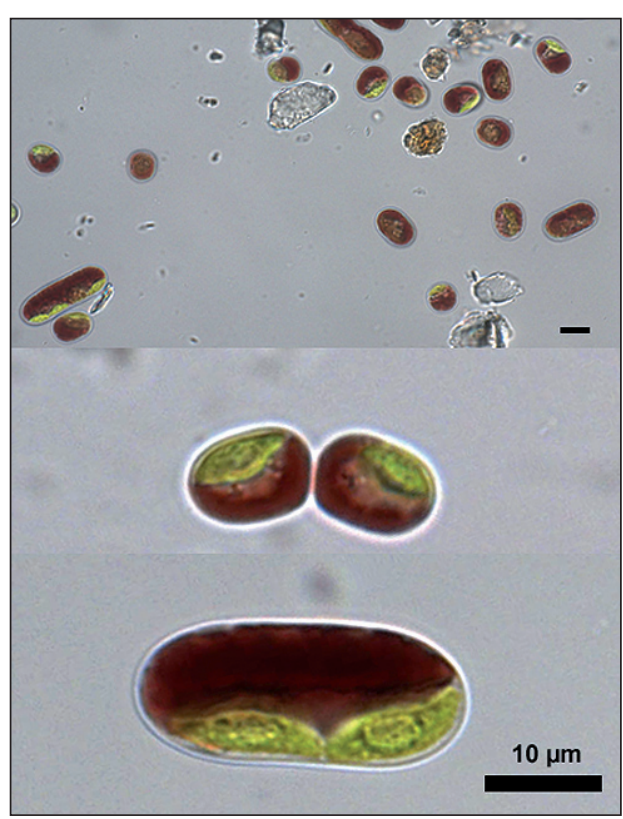

Abb. 3:

Mesotaenium berggrenii (Zygnematales) ist ein obligater Bewohner von permanenten Eisflächen und wurde auf mehreren Gletschern des Ötztals gefunden. Das braune Sekundärpigment unbekannter Natur ist in den Vakuolen gespeichert. Die kleineren, kürzeren Zellen gehören der var. alaskana an, die in Tirol dominierend ist. (Foto: D. Remias) 
der Art Mesotaenium berggrenii (Abb. 3, Remias et al. 2009). Feldproben besitzen im Lichtmikroskop eine unverwechselbare grün-braune Färbung, die einerseits durch den Chloroplasten und andererseits durch einen unbekannten vakulären Sekundärstoff verursacht wird. Von letzterem ist bislang nur eine hohe UV-Absorption bekannt. Die kleinere Form, var. alaskana, wurde erstmals aus Nordamerika beschrieben (Kol 1968). Sie ist daran zu erkennen, dass sie vor der Zellteilung zwei Chloroplasten besitzt und danach nur mehr einen. Die etwas größere Standard-Form hat jeweils die doppelte Chloroplastenzahl, ist jedoch in den Tiroler Alpen bislang nur als Beimischung zur var. alaskana bekannt. Bislang sind nur drei lokale Standorte entdeckt worden, nämlich der Gurgler Ferner (mit massiven Vorkommen südlich dem Hochwildehaus zwischen Mitterkamm und Schwärzenkamm), der Tiefenbachferner und der Sulztal Ferner in den Stubaier Alpen. Eine Tiroler "Gletscherinventur" im Sinne dieser Organismen ist noch ausständig, aber es darf angenommen werden, dass viele weitere Standorte bislang schlicht übersehen wurden. Wie bei den Schneealgen handelt es sich bei den Eisalgen um ein weltweites Phänomen, denn derartige Jochalgen sind auch aus dem Himalaya und den Polargebieten bekannt. Es könnte sich hier letztlich ebenfalls um eine Sammelart aus eng verwandten Vertretern von Mesotaenium handeln. Eine zweite Art aus dieser Gruppe, Ancylonema nordenskiöldii, zeichnet sich durch die Bildung mehrzelliger, unverzweigter Fäden aus. Letztere wurde in Tirol noch nicht gefunden und scheint nur auf den allerhöchsten Gletschern der Alpen (Mt. Blanc, siehe Kol 1968) und in hocharktischen Gebieten (z.B. Spitzbergen) vorzukommen.

Die Jochalgen auf Eis unterscheiden sich von herkömmlichen Schneealgen in ihrer Ökologie und in ihrem Lebenszyklus. Da diese Artengruppe keinerlei bewegliche Stadien besitzt, kann sie nicht in eine schmelzende Schneedecke einwandern. Daher leben sie permanent auf der vereisten Gletscheroberfläche und sind darauf angewiesen, dass der winterliche Schnee wegschmilzt bzw. die Decke dünn genug wird, um ausreichend Licht für die Photosynthese durchzulassen. Weiters sind sie für aktive Stoffwechselvorgänge auf den dünnen Wasserfilm angewiesen, der die Gletscheroberfläche im Hochsommer bedeckt. Man findet $M$. berggrenii bevorzugt auf trockeneren Stellen am Eis, die eine krispe Oberfläche besitzen. Mulden oder Rinnen sind weniger geeignet, da sie dort leichter ausgewaschen werden können. Auch in Kryokonitlöchern kommen sie wahrscheinlich nur sekundär vor. Interessanterweise bestehen die Populationen nur aus zartwandigen, vegetativen Zellen, die sich während der Sommersaison beständig teilen. Offensichtlich nehmen diese keinen Schaden durch Gefrier- und Auftau-Vorgänge oder der erhöhten UVStrahlung im Hochgebirge. Robuste Zystenstadien, wie bei den Chloromonaden 


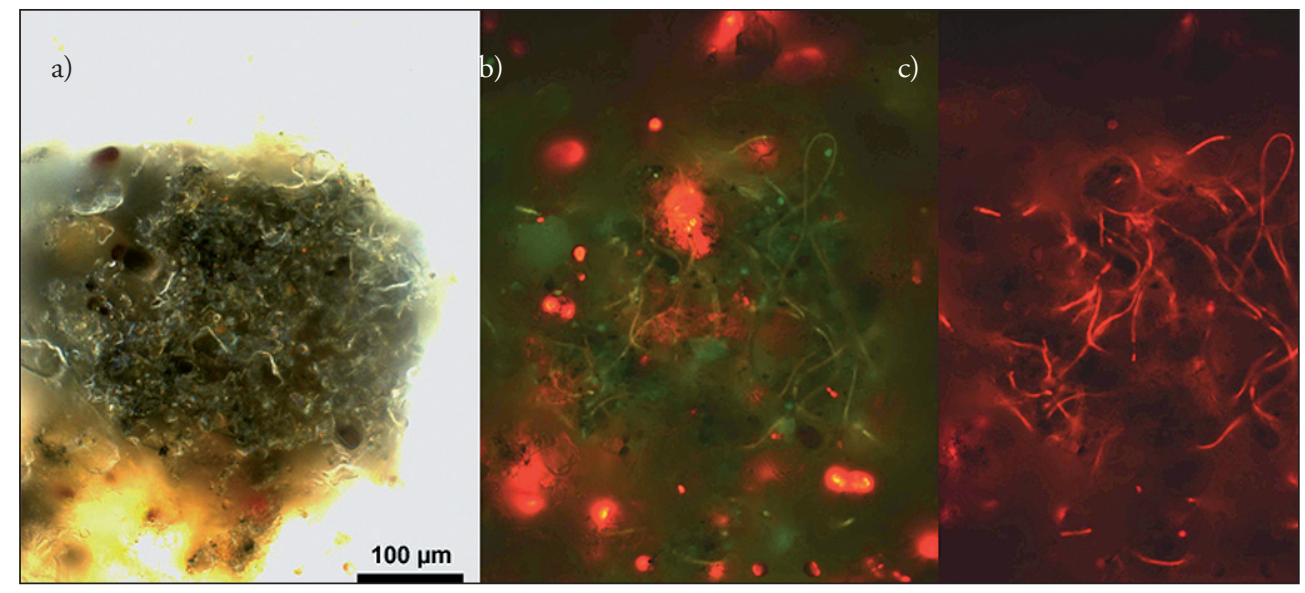

Abb. 4 a-c:

Kryokonitpartikel (Durchmesser zirka 0,2 mm) im Lichtmikroskop. a) Hellfeld-Aufnahme; b) Fluoreszenzaufnahme (Blauanregung): Mesotaenium Autofluoreszenz in rot, prokaryontische Fäden schwach grünlich; c) Fluoreszenzaufnahme (Grünanregung), nur sehr geringe Autofluoreszenz des Chlorophylls, nun sind aber Zellfäden der Prokaryonten sehr gut (rot) zu erkennen. (Foto: D. Remias)

des Roten Schnees üblich, kommen nicht vor, wenngleich Zygotenstadien beschrieben wurden. Diese wurden in Tirol noch nicht beobachtet.

Ähnlich wie Schnee stellen auch Gletscheroberflächen kleine, höchst spezialisierte Ökosysteme dar. Neben $M$. berggrenii findet man noch fädige, wahrscheinlich photoautotrophe Prokaryonten, die jedoch stets nur im Inneren der Kryokonitpartikel vorkommen (Abb. 4). Das gesammelte Eismaterial enthält auch schwarze „Gletscherflöhe“ (Collembola) von 2 bis $3 \mathrm{~mm}$ Länge. Es ist jedoch nicht belegt, dass sie Algenzellen fressen. Das gleiche gilt auch für einige nur gelegentlich im Habitat beobachtete „Protozoa“. In manchen Fällen befinden sich auf Gletschern sowohl Eis- als auch Schneealgen. Dabei handelt es sich jedoch um zwei zeitversetzte Ökosysteme: zuerst entwickelt sich der Rote Schnee, und nach dessen Abschmelzen kommen die ruhenden Zysten auf der Gletscheroberfläche zu liegen. Dann, meist im August und im September bis zu den ersten Kälteeinbrüchen, ist für wenige Wochen die „Saison“ der Eisalgen, die den Rest des Jahres inaktiv eingefroren sind. 
Kryokonite als mikrobieller

\section{Lebensraum}

Gletscherschnee und -eis sind an ihrer Oberfläche ständigen Verunreinigungen ausgesetzt, welche entweder aus der Atmosphäre oder durch Transport mit supraglazialem Schmelzwasser eingebracht werden. Auch Staub von angrenzenden freiliegenden Hängen, kleinste Gesteinsbruchstücke bis gröberer Hangschutt von Felswänden oder auch über weite Strecken durch die Luft transportiertes organisches Material lagern sich auf der Eisund Schneeoberfläche des Gletschers ab.
Durch die Sonneneinstrahlung erwärmen sich die dunklen Partikel, schmelzen somit sukzessive in das Eis ein (Abb. 5) und lassen dabei zylinderförmige oder auch zuweilen recht ungewöhnlich geformte Vertiefungen im Eis zurück. Diese Vertiefungen werden als Kryokonitlöcher bezeichnet (Abb. 6).

Das Phänomen des Einschmelzens von Verunreinigungen in das darunter liegende Eis beschrieb erstmalig Adolf Erik von Nordenskjöld im Rahmen seiner Forschungsreise im Jahre 1870 auf das grönländische Inlandeis. Seine ursprüngliche Annahme war, dass es sich dabei um Ansammlungen von Meteoritenstaub han-

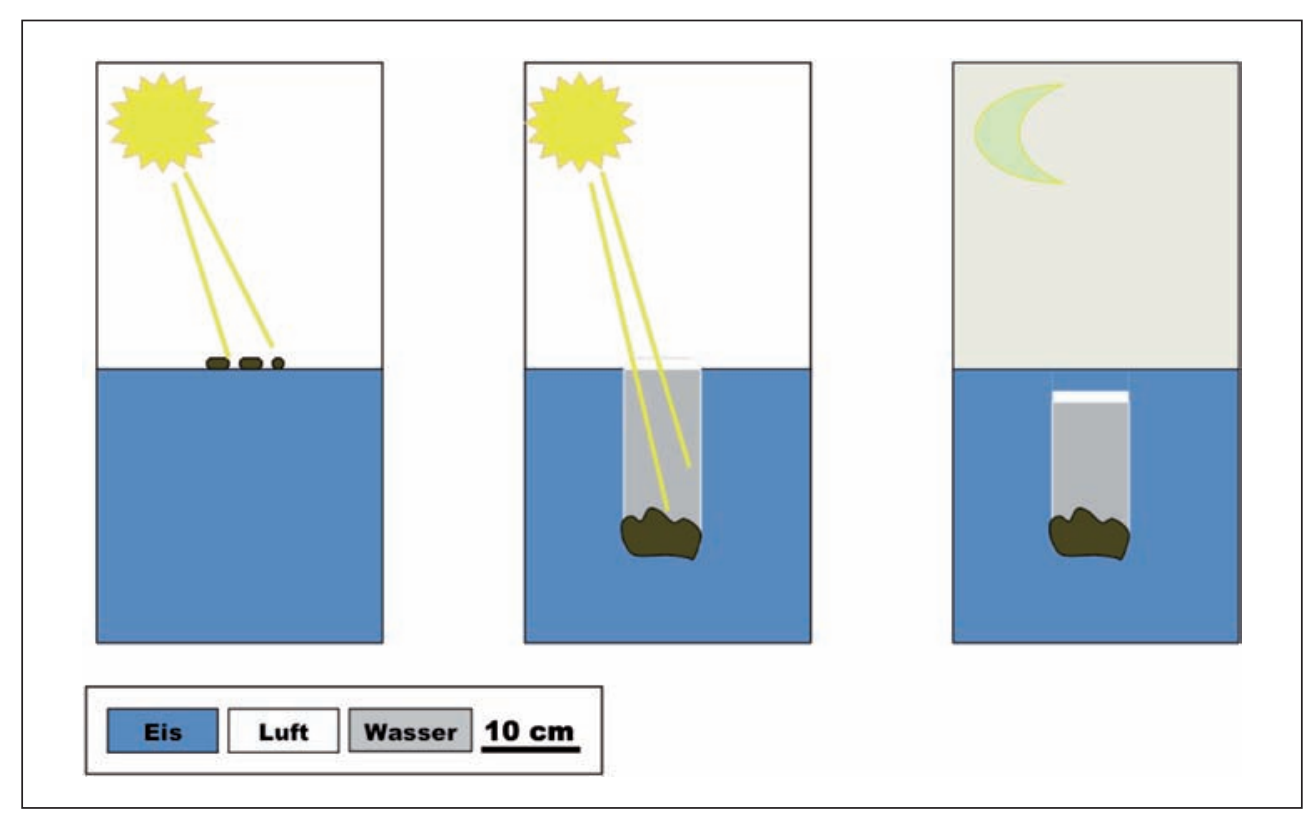

Abb. 5:

Schematische Darstellung der Bildung eines Kryokonitloches: dunkles Material (organischen und anorganischen Ursprungs) wird auf der Eisoberfläche deponiert, absorbiert Sonnenenergie und schmilzt sich in das Eis, indem es einen wassergefüllten Schmelzwassertrichter mit einer sedimentbedeckten Sohle hinterlässt. 


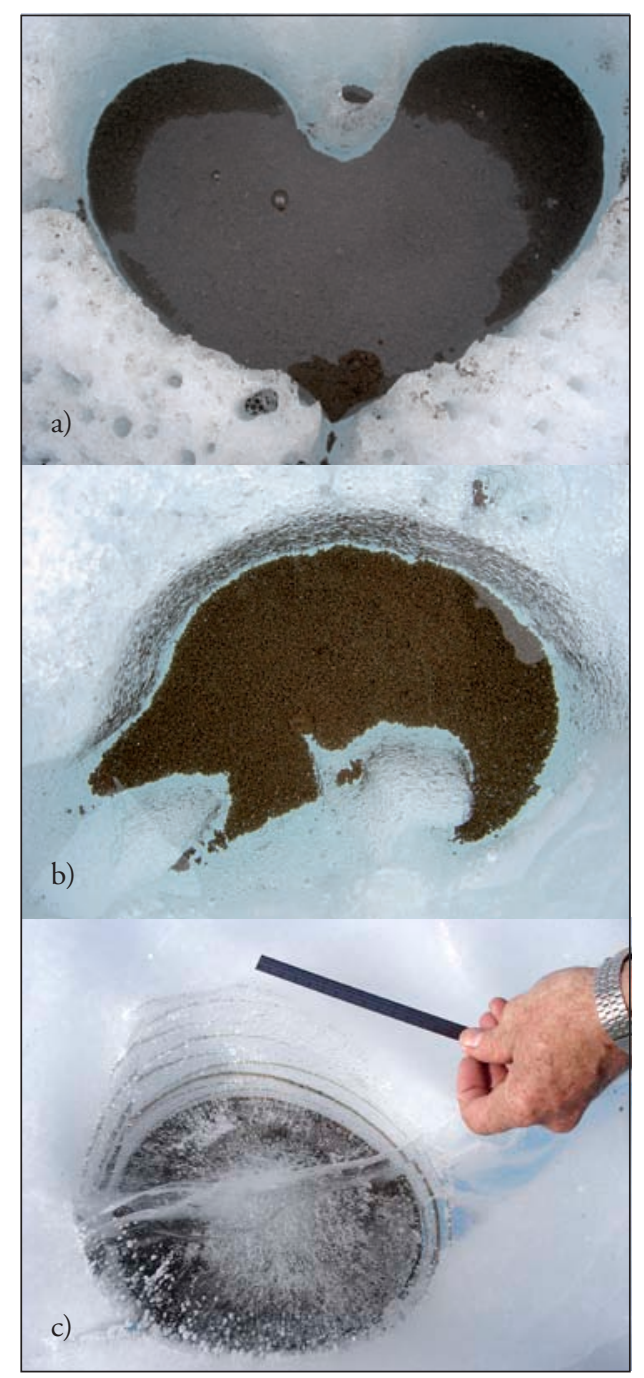

Abb. 6 a-c:

a) und b) Kryokonitlöcher außergewöhnlicher Form; c) Kryokonitloch mit Eisbedeckung (Foto: B. Sattler)

delt. Der Begriff Kryokonit wurde somit von Nordenskjöld geprägt und stammt aus dem Griechischen: „kryos“ steht für
„Frost“ oder „Eis“, das Wort „konia“ kann mit „Staub“ übersetzt werden.

Anhängig von der Lage der Gletscher können die Kryokonite beträchtliche Flächen der Gletscher überziehen (Takeuchi et al. 2001, Säwström et al. 2002). Im Falle des Rotmoosferners konnte eine Bedeckung mit Kryokonitmaterial bis zu maximal $28 \%$ festgestellt werden (Fitz 2005), wodurch auch die Albedo der Gletscheroberfläche verändert wird. Diese Fläche stellt ein wichtiges Teilgebiet des Rotmoosferners dar und spielt im Zusammenhang mit der Erwärmung und dem Gletscherrückgang eine bedeutende Rolle bei der Ablation. Eine Verringerung der Albedo hat direkten Einfluss auf den Energiehaushalt des Gletschers. Auf Grundlage meteorologischer Parameter wie auftreffende und abgegebene kurzund langwellige Strahlung, Windverhältnisse, Temperatur und Luftfeuchtigkeit lassen sich Wärmehaushaltsrechnungen erstellen (Takeuchi et al. 2000). Sie geben Aufschluss darüber, in welchem Ausmaß verringerte Albedo zum Abschmelzen der Eisflächen beitragen kann.

In den Alpen wurden diese so genannten Kryokonitlöcher erstmals von Otto Steinböck beschrieben, welcher sich über ihren ungemein regelmäßigen Bau und die meist kreisrunde Öffnung, welche wie ausgestanzt wirkte (Steinböck 1936), erstaunt zeigte. Diese Vertiefungen im Eis verhalten sich wie Sedimentfallen und akkumulieren organisches (Pollen, Pflan- 
zenbruchstücke, verfrachtete Insekten, etc.) und anorganisches Material (Staub lokalen bzw. regionalen oder weiter entfernten Ursprungs). Aufgrund der höheren Strahlungsabsorption der enthaltenen Teilchen bleibt sowohl die Sohle als auch das überliegende Wasser meist in einem flüssigen Zustand (Abb. 6 a, b), kann jedoch auch mit Schnee bedeckt oder sogar mit einem Eisdeckel über den Tag-NachtZyklus oder über die Wintermonate versiegelt sein (Abb. $6 \mathrm{c}$ und Abb. 5).

Die Entwicklung der Kryokonitlöcher ist abhängig vom Ort der Deposition in Verbindung mit Intensität und Dynamik von Einstrahlung, Temperatur, Niederschlag und Ablation und korreliert negativ mit der Hangneigung. Ihre Lebensdauer reicht von wenigen Tagen bis hin zur endgültigen „Konservierung“ aufgrund eines dauerhaften Frierzustandes, wie es über den Winter oder über längere Perioden in Polargebieten vorkommen kann. In Meereseis können Zellen in den feinen Kanälen leben, die sich zwischen den Eiskristallen bilden (Junge 2002). Die Rhythmik der Jahreszeiten und die damit verbundenen Temperaturschwankungen im Jahres- wie auch im Tagesverlauf prägen Kryokonite in ihrer Entwicklung. Die hohen Temperaturen während der Ablationsphase haben positive Auswirkungen auf Nährstoffzufuhr durch Schmelzwasser und Umsatzraten der Primär- und Sekundärproduzenten, können sich jedoch auch negativ auswirken, indem übermäßig viel von der Eisoberfläche abschmilzt und somit biogenes Material ausgeschwemmt wird. Vorhandene Kryokonitlöcher mit bereits angesammeltem Sediment können für das transportierte Material jedoch auch eine Falle darstellen, in welcher nicht nur Partikel abgelagert werden, sondern auch gelöste Substanzen an bereits vorhandene Partikel absorbieren, wie das z.B. für Radioisotopen aus Atombombenversuchen und dem Tschernobyl-Unfall nachgewiesen wurde (Tieber et al. 2009). Verglichen mit den chemischen Eigenschaften von Eiskernen des Rotmoosferners kann in den Kryokonitlöchern bei verschiedenen Ionen eine Anreicherung in der Konzentration festgestellt werden. So findet man z.B. für $\mathrm{NH}_{4}^{+}-\mathrm{N}$ einen Anreicherungsfaktor von 2,3, während $\mathrm{HCO}_{3}^{-}$um den Faktor 6,1 angereichert werden kann (Fitz 2005). Typisch dabei ist die Ausbildung so genannter "granules“, ein aus dem Englischen übernommener Begriff, welcher am ehesten mit „Korn“ übersetzt werden könnte. Granules sind kornartige Strukturen mit einem Durchmesser von 0,1 bis $3 \mathrm{~mm}$, bestehend aus kleinsten mineralischen Bruchstücken, hauptsächlich in Verbindung mit fädigen Cyanobakterien („Blaualgen“). Derartige Granules sind auch aus dem Fließgewässerbereich bekannt (Droppo et al., 1997) und, sofern die Vertiefung von Schmelzwasser durchflossen ist, durchaus vergleichbar.

Die anhaftenden Cyanobakterien bilden mit den heterotrophen Bakterien netz- 
artige Schichten aus (Abb. 4 a-c), deren Ausmaß und Zusammensetzung schlussendlich die Farbe des Kryokonites beeinflussen (Takeuchi et al. 2001). Je nach Anteil an aktiver oder bereits abgestorbener organischer Substanz erscheint das Sediment braun (wenig organische Substanz) bis hin zu schwarz, was auf einen hohen Anteil organischer Substanz hinweist, welche bereits mikrobiell abgebaut und umgewandelt wurde.

Die Granules stellen für die beschriebene Biozönose ein geeignetes Mikrohabitat dar, in welchem - trotz ausgeprägtem Nährstoffmangels des Schmelzwassers - zu bestimmten Zeiten Photosynthese, Fixierung von $\mathrm{N}_{2}$ und auch Ab-/Umbau organischer Substanz möglich ist. Inmitten der von Nährstoffarmut geprägten Situation eines Gletschers stellen Kryokonitlöcher somit „Oasen“ dar, in welchen Mikroorganismen vergleichsweise gute Lebensbedingungen finden.

\section{Biologische Komponenten}

Etablieren können sich auf der Gletscheroberfläche nur Arten, die auf ganz spezielle Weise an diesen Lebensraum angepasst sind. Während die ersten Beschreibungen der Primärproduzenten aus den Anfängen der Erforschung kalter Ökosysteme überliefert sind (Nordenskjöld 1870, Wittrock
1885), gibt es inzwischen eine Reihe an Publikationen, welche die Lebensgemeinschaften innerhalb eines Kryokonitloches beschreiben, wie z.B. De Smet und van Rompu (1994,) Margesin et al. (2002), Müller und Pollard (2004), Hodson et al. (2007), Anesio et al. (2009).

Wie und von welchen Organismen die Eisoberfläche besiedelt wird, hängt von vielen Faktoren ab. Neben der geographischen Lage, der Geologie, physikalischen Parametern wie Partikelbeschaffenheit, Strahlung, Exposition und den meteorologischen Bedingungen spielen die Eigenschaften des Bodens der unmittelbaren Umgebung eine große Rolle. Die Beschaffenheit sowie der Entwicklungsgrad eines Bodens bzw. der umgebenden Vegetation bestimmen als Quelle organischen Materials die Besiedelung grundlegend mit. Der Transport abgestorbener biogener Substanz wie auch aktiver Organismen erfolgt wie bereits erwähnt mit atmosphärischen Einträgen. Feinste Partikel in der Atmosphäre in Verbindung mit Wasser können bereits ein Lebensraum für Mikroorganismen sein. Sattler et al. (2001) zeigten, dass über die Luft, in Wolkentröpfchen transportierte Mikroben trotz widrigster Bedingungen (wie Temperaturen unter $0^{\circ} \mathrm{C}$ und hoher UVStrahlung) aktiv und sogar zu Reproduktion befähigt sein können. Grundlage bildet die relativ gute Nährstoffversorgung (hoher Gehalt an Kohlenstoff und Stickoxiden) durch Anheftung an Partikel wie 
Staub, Ruß oder Pollen in Verbindung mit Wasser aus stark unterkühlten Wolkentröpfchen. Aber auch Bakterien und Mikroalgen selbst können die Ausbildung derartiger Aerosole initiieren, indem diese als Kondensationspunkt vorhandener Luftfeuchtigkeit oder auch als Ausgangspunkt für die Bildung von Eiskristallen dienen. Sie werden als IN (ice nucleators, also Auslöser von Eiskristallbildung) bezeichnet (Morris et al. 2008).

Die Lebensgemeinschaften der Algen und Cyanobakterien stellen sowohl quantitativ als auch hinsichtlich der Produktivität den weitaus größten Anteil biologischer
Vorgänge innerhalb dieser Systeme dar. Dies lässt sich unschwer auch aufgrund der großflächig auftretenden Färbung vor allem älteren Schnees und Firns erkennen, welche, je nach dominanten Organismengruppen und deren spezifischer Pigmentierung - mannigfaltig sein kann (rot, grün, braun bis schwarz) und praktisch in allen vergletscherten Regionen vorkommt (Psenner et al. 2003).

Schnee- und Eisflächen sind jedoch nicht nur Lebensraum für Schneealgen. Die von den Primärproduzenten bereitgestellte organische Substanz bildet einen guten Nährboden für Mikroorganismen,

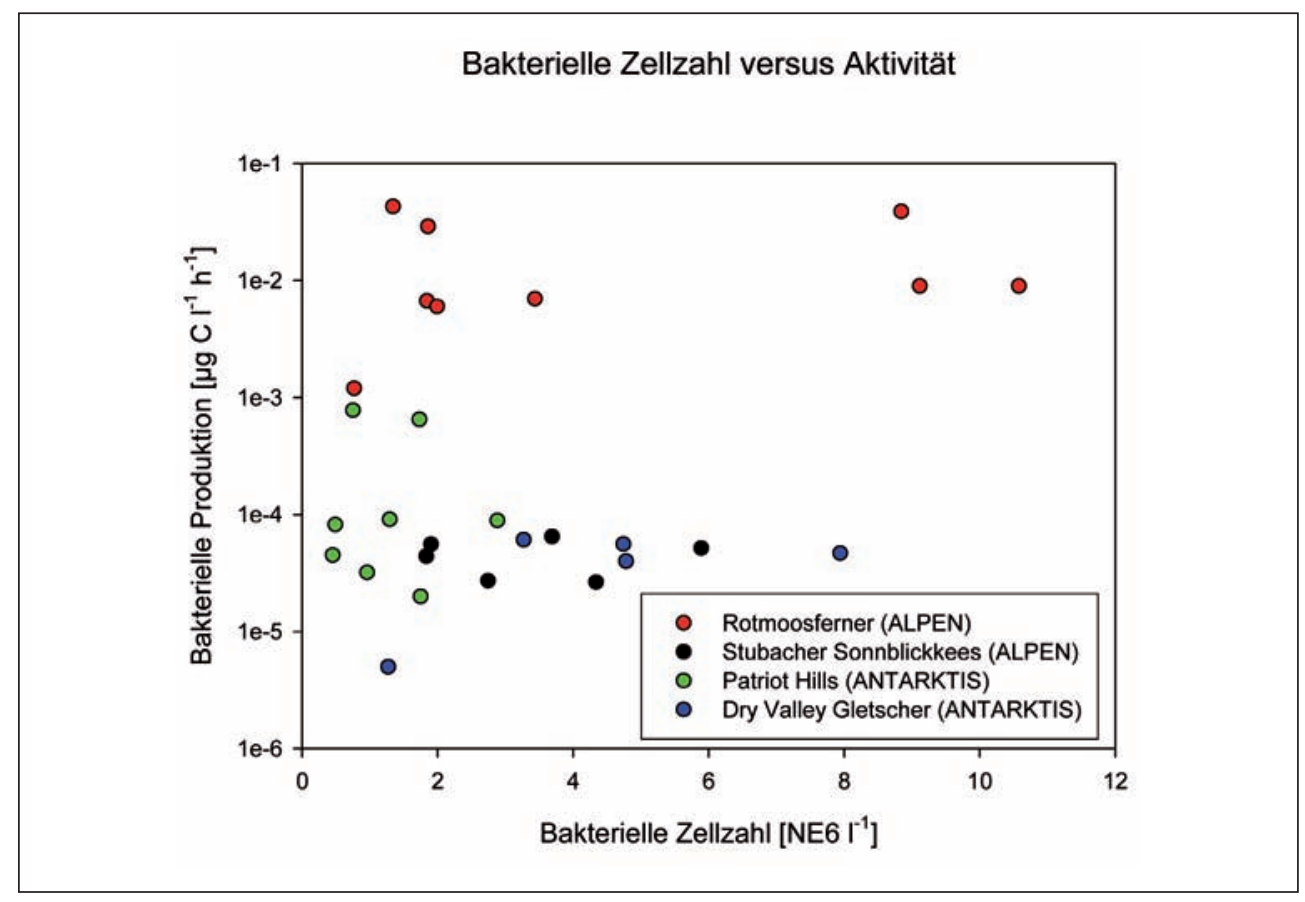

Abb. 7:

Vergleich der bakteriellen Zellzahl versus Aktivität in alpinen und antarktischen Gletschern (Sediment der Kryokonitlöcher) 
welche als Bestandteil der Nahrungsnetze in den Kryokonitlöchern leben. Innerhalb der so genannten GLIMCOs (,glacier ice microbial communities") findet man Viren, Bakterien, Pilze, Algen, aber auch eukaryotische Einzeller bis hin zu Tieren - abhängig von der geographischen Position. Diese mikrobiellen Gemeinschaften sind jedoch äußerst wichtig für den Kohlenstoffhaushalt eines Gletschers, vor allem bei Freiwerden des organischen Kohlenstoffes während der Ablationsperiode. Im Vergleich zu polaren Gletschern findet man in Bezug auf das Verhältnis von Zellzahl zu Aktivität die weitaus höchsten Kohlenstoffproduktionsraten (Abb. 7).
Interessanterweise konnte auf der Gletscheroberfläche des Rotmoosferners eine Saisonalität des Verhältnisses zwischen Auto- und Heterotrophie festgestellt werden. So erkennt man im Frühsommer, wenn der Sonnenstand noch niedriger ist, ein Überwiegen der Heterotrophie (d.h. Abbau organischer Substanz), welches dann im Hochsommer wechselt zur Autotrophie (Aufbau organischer Substanz durch Photosynthese). Später im Herbst, wenn die Sonne wieder niedriger steht, kippt dieses Verhältnis wieder (Abb. 8). Einen unerwarteten Befund zu diesem Thema lieferte eine Untersuchung von Kryokoniten in arktischen Gebieten (Anesio et al. 2009), die zeigte, dass

\section{Alpen (24 hTag/Nacht)}

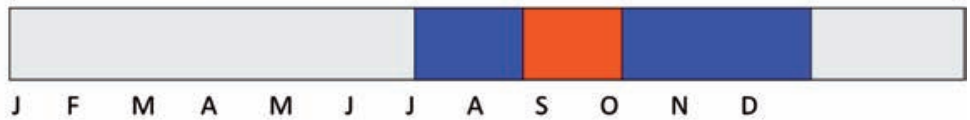

Arktis

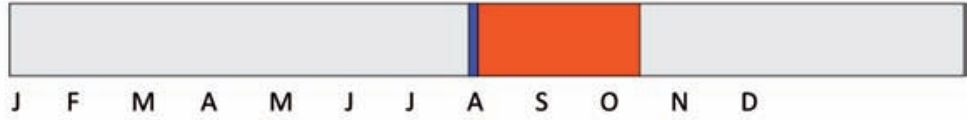

Antarktis

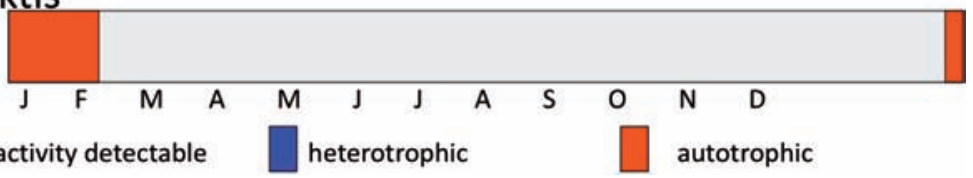

Abb. 8:

Saisonales Verhältnis zwischen Auto- und Heterotrophie auf alpinen (am Beispiel des Rotmoosferners), arktischen und antarktischen Gletschern 
Kryokonite - im Gegensatz zu fast allen Gewässern der Welt, die in Summe heterotroph sind - als autotrophe Systeme beschrieben werden können, d.h. dass die Photosynthese gegenüber der Respiration überwiegt.

Einzellige eukaryotische Organismen aus dem Alpenraum wurden bereits von Steinböck (1957) beschrieben. Im Sediment von Kryokonitlöchern sowie in oberflächigen Kryokoniten konnte er sowohl Ciliaten als auch Bärtierchen (Tardigrada, Macrobiotus sp.: jetzt klebelsbergi) und Rädertierchen (Rotifera, Gattung Philodina) nachweisen. Das massenhafte Vorkommen von Tardigraden wurde auch von Dastych et al. (2003) bestätigt. In Proben aus 44 alpinen Kryokonitlöchern aus dem Rotmoosferner konnte er insgesamt über 4.500 Vertreter des Bärtierchens Hypsibius klebelsbergi Mihelčič (siehe Abb. 9) zählen, welches sich unter anderem auch durch einen hohen Gehalt an Trehalose vor der Kälte schützen kann. Die meist vegetarischen Tardigraden sind eine besondere Organismengruppe, da sie zu den wahren Überlebenskünstlern zählen. Sie können Perioden ohne Sauerstoff ebenso problemlos überdauern wie extrem tiefe Temperaturen. Fällt die Temperatur sukzessive ab, so können sie ihre Extremitäten einziehen und über mehrere Jahre sogar in einem so genannten Tönnchenzustand überdauern. Diese Daseinsform nennt man, wie bereits eingangs beschrieben, Cryobiose, wobei tieftemperaturaktive Komponenten aktiv werden, welche Gefrierschutz-Substanzen, wie z. B. Zucker, herstellen. Zusätzlich schützen Gefrierschutzproteine die Zellmembran vor der Zerstörung durch die Eisnadelbildung. Ihre Temperaturtoleranz bewegt sich in den Extrema von $-270^{\circ} \mathrm{C}$ auf $+150^{\circ} \mathrm{C}$. Thaler (1999) beschreibt in seiner $\mathrm{Zu}$ sammenfassung nivaler Invertebraten der Alpen auch den Gletscherfloh (Isotoma

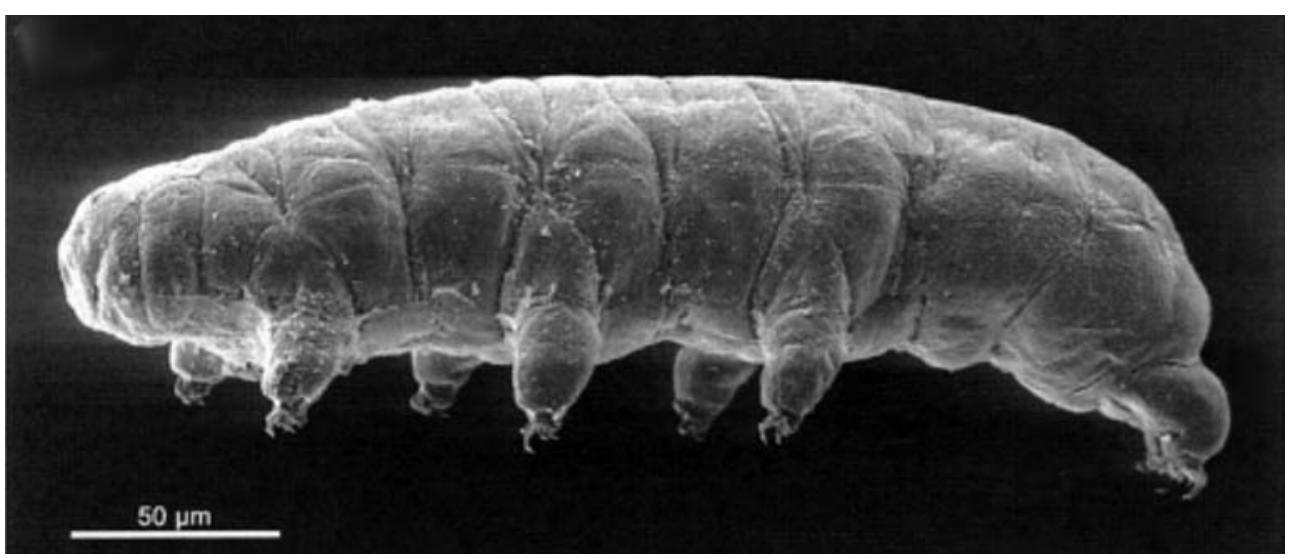

Abb. 9:

Hypsibius klebelsbergi Mihelčič, lateral (Dastych et al. 2003) 
saltans) als dauerhaften Bewohner der Eisund Schneeoberfläche.

Glaziale Systeme bieten somit ausreichend Habitatmöglichkeiten für angepasste Gemeinschaften, welche gleichermaßen sensibel auf Veränderungen reagieren. Die dramatischste Veränderung ist der Verlust des Lebensraumes, wenn Schneefelder oder große Eisflächen abschmelzen. Marginale Schmelzprozesse führen $\mathrm{zu}$ einer vermehrten Verfügbarkeit von flüssigem Wasser, was die Aktivität wiederum fördern kann. In funktioneller Weise sind glaziale Ökosysteme jedoch äußerst wertvoll für daran angrenzende Nischen, speziell in Hinblick auf das Ausmaß der $\mathrm{CO}_{2}$-Fixierung und Produktion von gelöstem Kohlenstoff. Eine Größenordnung, welche bislang im globalen Kontext weit unterschätzt worden ist (Anesio et al. 2009).

\section{Literatur}

Anesio, A.M., Sattler, B., Hodson, A.J., Fritz, A. \& Psenner, R. (2009) High microbial activities on glaciers: importance to the global cycle. Glob. Change Biol., doi: 10.1111/j.1365-2486.2008.01758.x

Dastych, H., Kraus, H. \& Thaler, K. (2003) Redescription and notes on the biology of the glacier tardigrade Hypsibius klebelsbergi Mihelčič, 1959 (Tardigrada), based on material from the Ötztal Alps. Austria. Mitt. hamb. zool. Mus. Inst., Band 100, S. 73-100.

De Smet, R.W.H. \& van Rompu, E.A.

(1994) Rotifera and Tardigrada in some cryoconite holes on a Spitsbergen (Svalbard) glacier, Belgian Journal of Zoology, 124: 27-37.

Droppo, I.G., Leppard, G.G., Flannigang, D.T. \& Liss, S.N. (1997) The freshwater floc: A functional relationship of water and organic an inorganic floc constituents affecting suspended sediment properties. Water, Air and Soil Pollution 99: 43-54.

Ettl, H. (1968) Ein Beitrag zur Kenntnis der Algenflora Tirols. Ber. nat.-med. Ver. Innsbruck 56: 177-354.

Ettl, H. (1983) Chlorophyta I: Phytomonadina. In: Süßwasserflora von Mitteleuropa, Vol. 9., Ettl H., Gerloff J., Heynig H. \& Mollenhauer D. (eds.), Gustav Fischer Verlag, Stuttgart, Germany, 807 S.

Fitz, G. (2005) Kryokonite alpiner Gletscher. Dipl. Universität Innsbruck, 124 S.

Hodson, A., Anesio, A.M., Tranter, M., Fountain, A., Osborn, M., Priscu, J.C., Laybourn-Parry, J. \& Sattler, B. (2007) Glacial Ecosystems. Ecological Monographs, 78: 41-67.

Hoham, R.W. \& Duval, B. (2001) Microbial Ecology of Snow and Freshwater Ice with Emphasis on Snow Algae. In: Snow Ecology, Jones et al. (eds.), Cambridge University Press, New York, 168-228. 
Junge, K. (2002) Bacterial abundance, activity and diversity at extremely cold temperatures in Arctic sea ice. Ph.D. Univ. Washington, $106 \mathrm{~S}$.

Kol, E. (1968) Kryobiologie I, Kryovegetation, In: Elster, H.J., Ohle, W. (eds.) Die Binnengewässer, Band 24, Schweizerbart, Stuttgart, $216 \mathrm{~S}$.

Kol, E. (1970) Vom roten Schnee der Tiroler Alpen. Annales Historico-Naturales Musei Nationalis Hungarici 62: 129136.

Komárek, J. \& Nedbalová, L. (2007) Green cryosestic algae. In: Cellular origin, life in extreme habitats and astrobiology (volume 11): algae and cyanobacteria in extreme environments, part 4: phototrophs in cold environments, J. Seckbach (eds), Springer, Dordrecht, 323-344.

Lang, L. (1927) Gletschereis. Kosmos. Gesellschaft der Naturfreunde Franckh'sche Verlagshandlung, Stuttgart.

Margesin, R., Zacke, G. \& Schinner, F. (2002) Characterization of heterotrophic microorganisms in Alpine glacier cryoconite, Arctic, Antarctic, and Alpine Research, 34: 88-93.

Morris, C.E., Sands, D.C., Bardin, M., Jaenicke, R., Vogel, B., Leyronas, C., Ariya, P.A. \& Psenner, R. (2008) Microbiology and atmospheric processes: an upcoming era of research on bio-meteorology. Biogeosciences Discuss. 5: 191-212.

Mueller, D.R. \& Pollard, W.H. (2004) Gradient analysis of cryoconite ecosystems from two polar glaciers, Polar Biology, $27,66-74$.
Nordenskjöld, A.E. (1870) Redegörelse för en Expedition till Grönland ar 1870. Öfv. kgl. Vetensk.-Akad. Förh. 10.

Remias, D., Lütz-Meindl, U. \& Lütz, C. (2005) Photosynthesis, pigments and ultrastructure of the alpine snow alga Chlamydomonas nivalis. Eur. J. Phycol. 40: 259-268.

Remias, D., Holzinger, A. \& Lütz, C. (2009) Physiology, ultrastructure and habitat of the ice alga Mesotaenium berggrenii (Zygnemaphyceae, Chlorophyta) from glaciers in the European Alps, Phycologia 48: 302-312.

Psenner, R., Wille, A., Priscu, J.C., Felip, M., Wagenbach, D. \& Sattler, B. (2003) Extremophiles: Ice Ecosystems and Biodiversity, In: Knowledge for Sustainable Development. An Insight into the Encyclopaedia of Life Support Systems, UNESCO Publishing-Eolss Publishers, Vol. III, pp 573-598, Oxford, UK.

Sattler, B., Puxbaum, H. \& Psenner, R. (2001) Bacterial growth in supercooled cloud droplets. Geophys. Res. Letters 28(2): 239-242.

Säwström, C., Mumford, P., Marshall, W., Hodson, A. \& Laybourn-Parry, J. (2002) The microbial communities and primary productivity of cryoconite holes in an Arctic glacier (Svalbard $\left.79^{\circ} \mathrm{N}\right)$. Polar Biol 25: 591-596.

Steinböck, O. (1936) Über Kryokonitlöcher und ihre biologische Bedeutung. Zeitschrift für Gletscherkunde 24: S. 1-21. 
Steinböck, O. (1957) Über die Fauna der Kryokonitlöcher alpiner Gletscher. „Der Schlern“, Athesia, Bozen, 31.

Takeuchi, N., Koshima, S., Yoshimura, Y., Seko, K. \& Fujita, K. (2000) Characteristics of cryoconite holes on a Himalyan Glacier, Yala Glacier Central Nepal. Bull. Glaciol. Res. 17: 51-59.

Takeuchi, N., Kohshima, S., Goto-Azuma, K. \& Koerner, R.M. (2001) Biological characteristics of dark colored material (cryoconite) on Canadian Arctic glaciers (Devon and Penny ice caps). Reprinted from Memoirs of National Institute of Polar Research, Special Issue, Nr. 54: 495-505.

Thaler, K. (1999) Nival invertebrate animals in the East Alps: a faunistic overview. In: Margesin R. \& Schinner, F. (eds), Cold Adapted Organisms. Springer-Verlag, Berlin, Heidelberg, New-York, 165-179.

Tieber, A., Lettner, H., Hubmer, P., Sattler, B., \& Hofmann, W. (2009) Accumulation of anthropogenic radionuclides in cryoconites on Alpine glaciers. J. Environ. Radioactivity 100: 590-598 doi:10.1016/j.jenvrad.2009.04.008.

Werner, P. (2007) Roter Schnee oder die Suche nach dem färbenden Prinzip, Akademie Verlag, Berlin, $91 \mathrm{~S}$.

Wittrock, V.B. (1885) Über die Schnee- und Eisflora, besonders in arktischen Gegenden. Studien und Forschungen von A.E. Nordenskjöld. Brockhaus, Leipzig.

\section{Verzeichnis der AutorInnen}

Hieronymus Dastych

Zoologisches Institut und

Zoologisches Museum, Martin-Luther-King-Platz 3, 20146 Hamburg, Deutschland

Dastych@zoologie.uni-hamburg.de

Cornelius Lütz

Universität Innsbruck, Institut für Botanik

Sternwartestr. 15, 6020 Innsbruck, Österreich

Cornelius.Lutz@uibk.ac.at

Roland Psenner

Universität Innsbruck

Institut für Ökologie,

Technikerstr. 25, 6020 Innsbruck, Österreich

Roland.Psenner@uibk.ac.at

Daniel Remias

Universität Innsbruck

Institut für Botanik

Sternwartestr. 15, 6020 Innsbruck, Österreich

Daniel.Remias@uibk.ac.at

Birgit Sattler

Universität Innsbruck

Institut für Ökologie

Technikerstr. 25, 6020 Innsbruck, Österreich

Birgit.Sattler@uibk.ac.at 
F. Nagl, B. Erschbamer

\section{Vegetation und Besiedelungsstrategien}

Die Nomenklatur der Arten richtet sich nach Fischer et al. (2008).

Tab. A1:

Stetigkeitstabelle für die Vegetationstypen des Gletschervorfeldes (2.300-2.450 m Meereshöhe) und der angrenzenden Seitenhänge (bis 2600 m Meereshöhe). Daten aus Raffl et al. (2006a).

Spalte 1: artenarmes Pionierstadium

Spalte 2: artenreiches Pionierstadium

Spalte 3: frühes Sukzessionsstadium

Spalte 4: Übergangsstadium

Spalte 5: Initialrasen

Spalte 6: Initialrasen mit Kobresia myosuroides

Spalte 7: Caricetum sempervirentis

Spalte 8: Caricetum curvulae

Spalte 9: Rieselfluren mit Carex frigida

\begin{tabular}{|c|c|c|c|c|c|c|c|c|c|}
\hline & 1 & 2 & 3 & 4 & 5 & 6 & 7 & 8 & 9 \\
\hline Saxifraga aizoides & V & IV & IV & IV & I & II & . & . & $\mathrm{V}$ \\
\hline Saxifraga oppositifolia & V & V & $\mathrm{V}$ & III & II & II & . & . & . \\
\hline Artemisia genipi & II & IV & III & I & I & I & . & . & . \\
\hline Linaria alpina & III & IV & IV & I & I & I & . & . & . \\
\hline Arabis alpina & I & III & II & II & I & . & I & . & . \\
\hline Sedum atratum & . & II & II & II & I & I & I & I & . \\
\hline Cetraria cucullata & . & I & I & I & I & . & I & I & . \\
\hline Draba aizoides & . & I & I & . & I & . & . & . & . \\
\hline Antennaria carpatica & . & I & . & I & I & I & I & I & . \\
\hline Sempervivum arachnoideum & . & I & . & I & I & . & . & . & . \\
\hline Cerastium uniflorum & I & II & IV & IV & II & I & I & I & \\
\hline Minuartia gerardii & . & II & IV & I & III & III & I & I & \\
\hline Arabis caerulea & I & II & III & II & I & I & . & . & . \\
\hline
\end{tabular}


F. Nagl, E. Erschbamer

\begin{tabular}{|c|c|c|c|c|c|c|c|c|c|}
\hline & 1 & 2 & 3 & 4 & 5 & 6 & 7 & 8 & 9 \\
\hline Festuca pumila & I & I & III & I & I & I & I & . & $\mathrm{V}$ \\
\hline Arenaria ciliata & . & I & II & I & I & I & . & . & . \\
\hline Trisetum spicatum & . & I & II & II & I & I & . & . & . \\
\hline Pritzelago alpina & . & I & I & I & I & . & . & . & . \\
\hline Botrychium lunaria & . & . & I & . & I & I & I & . & . \\
\hline Cetraria nivalis & . & I & I & I & I & I & I & I & . \\
\hline Salix serpyllifolia & . & . & I & I & I & I & I & I & . \\
\hline Thamnolia vermicularis & . & I & I & I & I & . & . & . & . \\
\hline Saxifraga exarata & . & . & I & I & I & I & I & . & . \\
\hline Marchantia polymorpha & . & . & I & I & . & . & . & . & . \\
\hline Alectoria ochroleuca & . & . & I & I & I & . & . & . & . \\
\hline Tussilago farfara & . & . & I & I & I & . & . & . & $\mathrm{V}$ \\
\hline Saxifraga androsacea & . & . & I & . & I & . & . & . & . \\
\hline Cryptogramma crispa & . & . & I & . & . & . & . & . & . \\
\hline Solorina saccata & . & . & I & . & . & . & . & . & $\mathrm{I}$ \\
\hline Poa alpina & I & IV & V & $\mathrm{V}$ & $\mathrm{V}$ & $\mathrm{V}$ & I & II & . \\
\hline Agrostis rupestris & . & . & I & $\mathrm{V}$ & IV & I & I & III & . \\
\hline Trifolium pallescens & I & II & V & $\mathrm{V}$ & $\mathrm{V}$ & $\mathrm{V}$ & I & I & I \\
\hline Saxifraga bryoides & I & III & III & V & IV & II & I & I & . \\
\hline Oxyria digyna & I & I & II & $\mathrm{V}$ & I & . & . & . & . \\
\hline Stereocaulon alpinum & . & III & IV & IV & IV & II & . & I & . \\
\hline Sagina saginoides & I & I & II & IV & II & II & . & I & . \\
\hline Racomitrium canescens & . & III & IV & IV & III & II & I & I & II \\
\hline Luzula spicata & I & I & I & IV & IV & IV & I & I & I \\
\hline Leucanthemopsis alpina & . & I & I & IV & III & II & I & IV & . \\
\hline Gnaphalium supinum & . & I & II & IV & II & I & I & III & . \\
\hline Salix herbacea & . & . & II & IV & III & III & I & II & III \\
\hline Luzula alpinopilosa & . & . & I & IV & II & I & I & III & I \\
\hline Cardamine resedifolia & I & I & I & III & II & I & I & I & . \\
\hline Veronica alpina & . & I & II & III & II & I & . & I & . \\
\hline Geum reptans & . & . & I & III & I & . & . & . & . \\
\hline Taraxacum sp. & . & . & I & III & I & I & I & I & . \\
\hline Saxifraga seguieri & . & . & I & II & I & . & . & . & . \\
\hline Ranunculus glacialis & . & . & . & II & . & . & . & . & . \\
\hline Gentiana verna ${ }^{1)}$ & . & . & I & I & . & . & . & . & . \\
\hline Cerastium cerastoides & . & . & . & I & I & & . & . & . \\
\hline
\end{tabular}




\begin{tabular}{|c|c|c|c|c|c|c|c|c|c|}
\hline & 1 & 2 & 3 & 4 & 5 & 6 & 7 & 8 & 9 \\
\hline Comastoma tenellum & . & . & I & I & I & I & . & . & . \\
\hline Epilobium anagallidifolium & . & . & I & I & I & . & . & . & . \\
\hline Pedicularis kerneri & . & . & I & I & I & I & . & . & . \\
\hline Androsace alpina & . & I & I & I & I & I & I & . & . \\
\hline Primula glutinosa & . & . & . & I & I & . & . & I & . \\
\hline Saxifraga stellaris & . & . & . & I & . & . & I & . & II \\
\hline Primula hirsuta & . & . & I & I & I & I & I & I & . \\
\hline Salix hastata & . & . & I & I & I & . & . & . & . \\
\hline Juniperus communis ssp. nana & . & . & . & I & I & I & I & I & . \\
\hline Coeloglossum viride & . & . & . & I & I & . & I & I & . \\
\hline Huperzia selago & . & . & . & $\mathrm{I}$ & I & . & . & . & . \\
\hline Oreochloa disticha & . & . & . & I & $\mathrm{I}$ & . & I & I & . \\
\hline Achillea moschata & . & . & II & I & IV & IV & I & I & . \\
\hline Euphrasia minima & . & . & II & IV & IV & III & IV & IV & IV \\
\hline Erigeron uniflorus & . & I & II & I & III & II & I & I & I \\
\hline Festuca halleri & . & I & I & I & III & II & IV & III & . \\
\hline Cetraria islandica & . & I & I & I & III & II & IV & $\mathrm{V}$ & II \\
\hline Sibbaldia procumbens & . & I & I & I & II & I & I & II & . \\
\hline Sempervivum montanum & . & I & I & I & II & II & I & II & . \\
\hline Cladonia pyxidata & . & I & I & . & II & I & III & II & I \\
\hline Scorzoneroides helvetica & . & . & . & . & II & . & III & $\mathrm{V}$ & . \\
\hline Cladonia sp. & . & . & I & . & II & II & I & III & . \\
\hline Minuartia sedoides & . & . & . & . & II & I & I & I & I \\
\hline Sedum alpestre ${ }^{1)}$ & . & . & . & I & I & I & . & I & . \\
\hline Potentilla aurea & . & . & . & I & I & I & IV & $\mathrm{V}$ & . \\
\hline Polytrichum sp. & . & . & . & . & I & I & . & . & . \\
\hline Cirsium spinosissimum & . & . & I & I & I & I & I & I & I \\
\hline Phyteuma hemisphaericum & . & . & . & I & I & I & IV & IV & . \\
\hline Veronica fruticans & . & . & I & . & I & I & I & . & . \\
\hline Phleum alpinum agg. & . & . & I & I & I & I & I & I & II \\
\hline Cladonia arbuscula & . & . & I & . & I & . & III & III & . \\
\hline Cetraria ericetorum & . & . & I & . & I & I & . & . & . \\
\hline Senecio incanus ssp. carniolicus & . & . & . & I & I & I & . & . & . \\
\hline Peltigera spuria & . & . & . & . & I & . & . & . & . \\
\hline Doronicum clusii & . & . & . & I & I & . & I & I & . \\
\hline Soldanella pusilla & . & . & . & . & I & I & I & IV & . \\
\hline
\end{tabular}


F. Nagl, E. Erschbamer

\begin{tabular}{|c|c|c|c|c|c|c|c|c|c|}
\hline & 1 & 2 & 3 & 4 & 5 & 6 & 7 & 8 & 9 \\
\hline Veronica bellidioides & . & . & . & . & I & . & II & II & . \\
\hline Peltigera aphthosa & . & . & . & . & I & . & . & . & . \\
\hline Hieracium lactucella & . & . & . & . & I & I & . & . & . \\
\hline Geum montanum & . & . & . & . & $\mathrm{I}$ & . & III & IV & . \\
\hline Minuartia biflora & . & . & . & . & $\mathrm{I}$ & . & . & . & . \\
\hline Lecanora polytropa & . & . & . & . & I & . & . & . & . \\
\hline Psoroma hypnorum & . & . & . & . & I & . & . & . & . \\
\hline Nardus stricta & . & . & . & . & I & I & III & II & . \\
\hline Peltigera sp. & . & . & . & . & I & . & . & . & . \\
\hline Selaginella selaginoides & . & . & . & . & $\mathrm{I}$ & I & I & I & IV \\
\hline Solorina crocea & . & . & . & . & I & . & . & . & . \\
\hline Rhododendron ferrugineum & . & . & . & . & I & I & I & I & . \\
\hline Empetrum hermaphroditum & . & . & . & . & I & . & I & I & . \\
\hline Hieracium alpinum & . & . & . & . & I & . & . & . & . \\
\hline Cladonia ecmocyna & . & . & . & . & I & . & . & . & . \\
\hline Vaccinium gaultherioides & . & . & . & . & I & . & I & I & . \\
\hline Mutellina adonidifolia & . & . & . & . & I & . & II & $\mathrm{V}$ & . \\
\hline Avenella flexuosa & . & . & . & . & I & . & I & I & . \\
\hline Peltigera rufescens & . & . & . & . & I & . & . & . & . \\
\hline Cladonia squamosa & . & . & . & . & I & . & I & I & . \\
\hline Cladonia uncialis & . & . & . & . & I & . & I & I & . \\
\hline Minuartia recurva ${ }^{1)}$ & . & . & . & . & I & . & . & . & . \\
\hline Bellidiastrum michelii & . & . & . & . & I & . & I & . & II \\
\hline Saussurea alpina & . & . & . & . & I & . & I & . & . \\
\hline Barbilophozia sp. & . & . & . & . & I & . & . & . & . \\
\hline Juncus triglumis & . & . & . & . & I & . & . & . & II \\
\hline Primula farinosa & . & . & . & . & I & . & . & . & . \\
\hline Silene vulgaris & . & . & . & . & I & . & . & . & . \\
\hline Dryopteris filix-mas & . & . & . & . & I & . & . & . & . \\
\hline Campanula barbata & . & . & . & . & I & . & II & I & . \\
\hline Gentianella rhaetica & . & . & . & . & I & . & III & I & . \\
\hline Draba dubia & . & . & . & . & I & . & . & . & . \\
\hline Potentilla crantzii & . & . & . & . & I & . & . & . & . \\
\hline Ranunculus montanus & . & . & . & . & I & . & I & I & . \\
\hline Peltigera venosa & . & . & . & . & I & . & . & . & . \\
\hline Loiseleuria procumbens & . & . & . & . & I & . & I & I & . \\
\hline
\end{tabular}




\begin{tabular}{|c|c|c|c|c|c|c|c|c|c|}
\hline & 1 & 2 & 3 & 4 & 5 & 6 & 7 & 8 & 9 \\
\hline Baeomyces rufus & . & . & . & . & I & . & . & I & . \\
\hline Carex brunnescens & . & . & . & . & I & . & . & . & . \\
\hline Arenaria biflora & . & . & . & . & I & . & . & . & . \\
\hline Carlina acaulis & . & . & . & . & I & . & . & . & . \\
\hline Cladonia rangiferina & . & . & . & . & I & . & I & I & . \\
\hline Psora decipiens & . & . & . & . & I & . & . & . & . \\
\hline Oxytropis halleri & . & . & . & . & I & . & . & . & . \\
\hline Umbilicaria cylindrica & . & . & . & . & I & . & . & . & . \\
\hline Solidago virgaurea & . & . & . & . & I & . & . & . & . \\
\hline Leontopodium alpinum & . & . & . & . & I & . & . & . & . \\
\hline Lloydia serotina & . & . & . & . & I & . & . & . & . \\
\hline Kobresia myosuroides & . & . & I & I & II & V & III & I & III \\
\hline Campanula scheuchzeri & . & I & III & II & $\mathrm{V}$ & $\mathrm{V}$ & IV & III & V \\
\hline Persicaria vivipara & . & . & II & III & III & $\mathrm{V}$ & IV & IV & $\mathrm{V}$ \\
\hline Leontodon hispidus & I & I & II & I & IV & $\mathrm{V}$ & III & II & IV \\
\hline Silene acaulis s. lat. & I & I & IV & II & IV & $\mathrm{V}$ & $\mathrm{I}$ & II & IV \\
\hline Agrostis alpina & . & . & I & . & II & IV & IV & I & IV \\
\hline Anthyllis vulneraria ssp. alpicola & . & I & I & . & I & IV & I & . & IV \\
\hline Myosotis alpestris & . & . & I & I & I & IV & I & I & . \\
\hline Trifolium badium & . & . & . & III & III & III & I & I & $\mathrm{V}$ \\
\hline Trifolium pratense ssp. nivale & . & . & I & . & I & III & II & I & III \\
\hline Androsace obtusifolia & . & . & I & . & I & III & I & III & . \\
\hline Saxifraga paniculata & . & I & I & . & II & III & I & . & . \\
\hline Artemisia mutellina & . & I & II & II & II & II & . & . & . \\
\hline Galium anisophyllon & . & . & . & I & I & II & II & . & . \\
\hline Carex sempervirens & . & . & . & . & I & II & IV & II & I \\
\hline Carex capillaris & . & . & . & . & I & II & . & . & $\mathrm{V}$ \\
\hline Alchemilla vulgaris agg. sensu LGME & . & . & I & II & II & II & II & II & I \\
\hline Carex atrata & . & . & . & I & I & II & . & . & I \\
\hline Salix helvetica & I & . & I & I & I & II & I & . & . \\
\hline Thymus praecox ssp. polytrichus & . & . & I & I & I & II & I & . & . \\
\hline Parnassia palustris & I & . & I & I & I & I & I & I & III \\
\hline Bartsia alpina & . & . & I & I & I & I & I & I & . \\
\hline Juncus trifidus & . & . & . & I & I & I & II & II & . \\
\hline Deschampsia cespitosa & . & . & I & I & I & I & I & II & $\mathrm{V}$ \\
\hline Luzula multiflora s.str. & . & . & . & I & I & I & II & I & II \\
\hline
\end{tabular}


F. Nagl, E. Erschbamer

\begin{tabular}{|c|c|c|c|c|c|c|c|c|c|}
\hline & 1 & 2 & 3 & 4 & 5 & 6 & 7 & 8 & 9 \\
\hline Anthoxanthum alpinum & . & . & . & I & I & I & IV & IV & . \\
\hline Antennaria dioica & . & . & . & . & I & I & . & . & . \\
\hline Gentiana orbicularis/brachyphylla ${ }^{2)}$ & . & . & . & I & I & I & I & I & . \\
\hline Carex parviflora & . & . & . & . & I & $\mathrm{I}$ & . & . & II \\
\hline Avenula versicolor & . & . & I & . & I & $\mathrm{I}$ & $\mathrm{V}$ & IV & . \\
\hline Salix retusa & . & . & I & I & I & $\mathrm{I}$ & I & $\mathrm{I}$ & II \\
\hline Oxytropis lapponica & . & . & I & . & I & I & . & . & . \\
\hline Cerastium fontanum agg. & . & . & . & . & I & I & I & . & . \\
\hline Festuca nigricans & . & . & . & . & I & I & II & II & II \\
\hline Lotus corniculatus var. alpicola & . & . & . & . & I & I & II & I & . \\
\hline Astragalus alpinus & . & . & . & . & I & I & I & . & I \\
\hline Gentiana nivalis & . & . & I & . & I & I & $\mathrm{I}$ & . & . \\
\hline Carex curvula ssp. curvula & . & . & . & . & I & I & I & IV & . \\
\hline Pyrola minor & . & . & . & . & I & I & I & I & . \\
\hline Gnaphalium hoppeanum & . & . & I & . & I & I & . & . & . \\
\hline Pinguicula leptoceras & . & . & . & . & I & I & I & I & $\mathrm{V}$ \\
\hline Arctostaphyllos uva-ursi & . & . & I & . & I & I & II & I & . \\
\hline Carex nigra & . & . & . & . & I & $\mathrm{I}$ & . & . & . \\
\hline Draba fladnizensis & . & . & . & . & I & I & . & . & . \\
\hline Juncus jacquinii & . & . & . & . & I & I & II & I & II \\
\hline Hieracium villosum & . & . & . & . & I & I & I & I & . \\
\hline Asplenium viride & . & . & . & . & I & I & . & . & . \\
\hline Thesium alpinum & . & . & . & . & I & I & . & . & . \\
\hline Luzula lutea & . & . & . & . & . & I & I & I & . \\
\hline Salix reticulata & . & . & . & . & . & I & . & . & II \\
\hline Polystichum lonchitis & . & . & I & . & I & I & . & I & . \\
\hline Gentiana bavarica & . & . & I & . & I & I & I & . & IV \\
\hline Homogyne alpina & . & . & I & . & I & $\mathrm{I}$ & I & III & . \\
\hline Carex bicolor & . & . & . & . & I & I & . & . & II \\
\hline Hieracium glaciale & . & . & I & . & I & $\mathrm{I}$ & . & . & . \\
\hline Helianthemum nummularium ssp. grandiflorum & . & . & . & . & I & I & . & . & . \\
\hline Viola biflora & . & . & . & . & I & I & I & I & . \\
\hline Carex ornithopoda & . & · & . & . & I & I & . & . & . \\
\hline Salix breviserrata ${ }^{1)}$ & . & . & . & . & . & I & . & . & . \\
\hline Pedicularis tuberosa & . & . & . & . & . & I & . & . & . \\
\hline Calluna vulgaris & . & . & . & . & . & $\mathrm{I}$ & II & . & . \\
\hline
\end{tabular}




\begin{tabular}{|c|c|c|c|c|c|c|c|c|c|}
\hline & 1 & 2 & 3 & 4 & 5 & 6 & 7 & 8 & 9 \\
\hline Fulgensia fulgens & . & . & . & . & . & . & I & . & . \\
\hline Pulsatilla vernalis & . & . & . & . & . & . & II & I & . \\
\hline Vaccinium vitis-idaea & . & . & . & . & . & . & II & I & . \\
\hline Silene rupestris & . & . & . & . & . & . & I & I & . \\
\hline Potentilla grandiflora & . & . & . & . & . & . & I & I & . \\
\hline Hedysarum hedysaroides & . & . & . & . & . & . & I & I & . \\
\hline Festuca nigrescens & . & . & . & . & . & . & I & I & . \\
\hline Cladonia gracilis & . & . & . & . & . & . & I & I & . \\
\hline Alchemilla fissa & . & . & . & . & . & . & I & I & I \\
\hline Tortella tortuosa & . & . & . & . & . & . & I & I & I \\
\hline Carex frigida & . & . & . & . & . & . & . & . & $\mathrm{V}$ \\
\hline Drepanocladus sp. & . & . & . & . & . & . & . & . & $\mathrm{V}$ \\
\hline Sanonia uncinata & . & . & . & . & . & . & . & . & $\mathrm{V}$ \\
\hline Alchemilla glabra & . & . & . & . & . & . & . & . & IV \\
\hline Philonotis tomentella & . & . & . & . & . & . & . & . & IV \\
\hline Epilobium alsinifolium & . & . & . & . & . & . & . & . & II \\
\hline Agrostis gigantea ${ }^{1)}$ & . & . & . & . & . & . & . & . & II \\
\hline
\end{tabular}

1) Diese Taxa waren teilweise nicht eindeutig bestimmbar, daher ist die Angabe mit Vorsicht zu betrachten.

2) Ein Großteil der bisherigen Angaben von G. brachyphylla im Rotmoostal ist vermutlich auf eine Verwechslung mit G. orbicularis zurückzuführen.

3) Im Gebiet kommt vor allem Silene acaulis ssp. exscapa vor, jedoch waren nicht alle Individuen eindeutig auf Unterartniveau bestimmbar. 
F. Nagl, E. Erschbamer

Tab. A2:

Stetigkeitstabelle für die Schwemmbereiche am Talboden (Spalte 1, 2.380-2.385 m Meereshöhe) und die Feuchtstandorte im Bereich der orographisch rechten Seitenmoräne (Spalte 2, 2.482-2.488 m Meereshöhe) des Gletschervorfeldes im Rotmoostal (Nagl 2009 unpubl.).

\begin{tabular}{|c|c|c|}
\hline & 1 & 2 \\
\hline Trifolium badium & $\mathrm{V}$ & . \\
\hline Persicaria vivipara & V & . \\
\hline Cirsium spinosissimum & V & . \\
\hline Juncus triglumis & V & . \\
\hline Alchemilla fissa & V & . \\
\hline Salix herbacea & IV & . \\
\hline Carex bicolor & IV & . \\
\hline Carex bipartita & IV & . \\
\hline Silene acaulis s. lat. & II & . \\
\hline Comastoma tenellum & II & . \\
\hline Carex atrata & II & . \\
\hline Gnaphalium hoppeanum & II & . \\
\hline Parnassia palustris & II & . \\
\hline Deschampsia cespitosa & V & III \\
\hline Phleum commutatum & V & III \\
\hline Taraxacum sp. & V & III \\
\hline Tussilago farfara & V & III \\
\hline Veronica alpina & $\mathrm{V}$ & III \\
\hline Arabis caerulea & IV & III \\
\hline Cerastium uniflorum & IV & III \\
\hline Saxifraga aizoides & $\mathrm{V}$ & $\mathrm{V}$ \\
\hline Epilobium anagallidifolium & V & $\mathrm{V}$ \\
\hline Poa alpina & V & $\mathrm{V}$ \\
\hline Sagina saginoides & $\mathrm{V}$ & $\mathrm{V}$ \\
\hline Trisetum spicatum & IV & $\mathrm{V}$ \\
\hline diverse Moose & IV & $\mathrm{V}$ \\
\hline Poa laxa & II & $\mathrm{V}$ \\
\hline Epilobium alsinifolium & ${ }^{\circ}$ & $\mathrm{V}$ \\
\hline Arabis alpina & . & $\mathrm{V}$ \\
\hline Saxifraga oppositifolia & . & III \\
\hline Artemisia genipi & . & III \\
\hline
\end{tabular}


Tab. A3:

Stetigkeitstabelle für die Vegetationstypen im Bereich der Liebener Rippe (2.780-2.940 m Meereshöhe, Nagl 2009 unpubl.)

Spalte 1: Elynetum myosuroides

Spalte 2: Sauerbodenrasen

Spalte 3: Androsacetum alpinae

Spalte 4: Hygrocaricetum curvulae

Spalte 5: Sesleria ovata-Gesellschaft

\begin{tabular}{|c|c|c|c|c|c|}
\hline & 1 & 2 & 3 & 4 & 5 \\
\hline Agrostis alpina & III & . & . & . & . \\
\hline Astragalus australis & III & . & . & . & . \\
\hline Gentiana nivalis & III & . & . & . & . \\
\hline Arabis caerulea & II & . & . & . & . \\
\hline Botrychium lunaria & II & . & . & . & . \\
\hline Carex rupestris & II & . & . & . & . \\
\hline Doronicum clusii & II & . & . & . & . \\
\hline Avenula versicolor & II & . & . & . & . \\
\hline Agrostis rupestris & II & . & . & . & . \\
\hline Oxytropis lapponica & II & . & . & . & . \\
\hline Juncus trifidus & II & . & . & . & . \\
\hline Phyteuma hemisphaericum & II & II & . & . & . \\
\hline Veronica bellidioides & II & II & . & . & . \\
\hline Kobresia myosuroides & $\mathrm{V}$ & III & . & . & . \\
\hline Campanula scheuchzeri & IV & II & I & . & . \\
\hline Gentiana orbicularis & IV & . & . & . & $\mathrm{V}$ \\
\hline Festuca pumila & IV & . & . & . & I \\
\hline Salix serpyllifolia & IV & I & . & . & I \\
\hline Veronica alpina & II & I & II & . & . \\
\hline Sibbaldia procumbens & II & I & II & . & . \\
\hline Sagina saginoides & II & . & I & . & . \\
\hline Sedum atratum & II & . & I & . & . \\
\hline Saxifraga seguieri & II & . & II & . & III \\
\hline Carex parviflora & III & II & I & . & I \\
\hline Comastoma tenellum & III & II & II & . & $\mathrm{V}$ \\
\hline Draba hoppeana & $\mathrm{I}$ & I & III & . & II \\
\hline
\end{tabular}


F. Nagl, E. Erschbamer

\begin{tabular}{|c|c|c|c|c|c|}
\hline & 1 & 2 & 3 & 4 & 5 \\
\hline Saxifraga bryoides & I & $\mathrm{V}$ & $\mathrm{V}$ & $\mathrm{V}$ & . \\
\hline Luzula spicata & I & $\mathrm{V}$ & $\mathrm{V}$ & $\mathrm{V}$ & . \\
\hline Poa molinerii & I & III & . & . & . \\
\hline Oreochloa disticha & . & III & I & . & . \\
\hline Pedicularis kerneri & . & IV & I & . & . \\
\hline Trifolium pallescens & . & IV & . & . & . \\
\hline Festuca intercedens & II & $\mathrm{V}$ & II & I & . \\
\hline Potentilla frigida & . & $\mathrm{V}$ & III & . & . \\
\hline Carex curvula & II & III & . & IV & . \\
\hline Primula glutinosa & . & IV & III & $\mathrm{V}$ & . \\
\hline Saxifraga exarata & . & III & IV & . & . \\
\hline Androsace alpina & . & . & IV & . & . \\
\hline Gentiana bavarica & I & III & IV & IV & . \\
\hline Poa laxa & . & $\mathrm{I}$ & $\mathrm{V}$ & $\mathrm{V}$ & . \\
\hline Ranunculus glacialis & . & I & $\mathrm{V}$ & III & . \\
\hline Sesleria ovata & I & . & . & . & $\mathrm{V}$ \\
\hline Artemisia genipi & I & I & II & . & $\mathrm{V}$ \\
\hline Comastoma nanum & . & . & . & . & III \\
\hline Salix herbacea & II & II & I & $\mathrm{V}$ & I \\
\hline Leucanthemopsis alpina & II & III & III & $\mathrm{V}$ & . \\
\hline Persicaria vivipara & $\mathrm{V}$ & III & I & $\mathrm{V}$ & . \\
\hline Saxifraga oppositifolia & IV & I & IV & . & $\mathrm{V}$ \\
\hline Cerastium uniflorum & IV & . & $\mathrm{V}$ & . & V \\
\hline Trisetum spicatum & II & $\mathrm{V}$ & IV & II & V \\
\hline Minuartia gerardii & IV & $\mathrm{V}$ & III & . & V \\
\hline Euphrasia minima & $\mathrm{V}$ & $\mathrm{V}$ & II & . & $\mathrm{V}$ \\
\hline Poa alpina & IV & IV & IV & V & III \\
\hline Arenaria ciliata & III & $\mathrm{V}$ & IV & $\mathrm{V}$ & $\mathrm{V}$ \\
\hline Erigeron uniflorus & IV & $\mathrm{V}$ & IV & II & IV \\
\hline Silene acaulis s. lat. & IV & $\mathrm{V}$ & IV & $\mathrm{V}$ & V \\
\hline Minuartia sedoides & III & $\mathrm{V}$ & $\mathrm{V}$ & $\mathrm{V}$ & $\mathrm{V}$ \\
\hline diverse Flechten & $\mathrm{V}$ & $\mathrm{V}$ & $\mathrm{V}$ & $\mathrm{V}$ & $\mathrm{V}$ \\
\hline diverse Moose & $\mathrm{V}$ & $\mathrm{V}$ & $\mathrm{V}$ & $\mathrm{V}$ & V \\
\hline Antennaria carpatica & I & . & . & . & . \\
\hline Geum montanum & I & . & . & . & . \\
\hline Cardamine resedifolia & $\mathrm{I}$ & . & . & . & . \\
\hline
\end{tabular}


Anhang Kapitel 6 I Pflanzliche Sukzessionen im Gletschervorfeld

\begin{tabular}{|c|c|c|c|c|c|}
\hline & 1 & 2 & 3 & 4 & 5 \\
\hline Potentilla aurea & I & . & . & . & . \\
\hline Arabis alpina & I & . & . & . & . \\
\hline Leontodon hispidus & I & . & . & . & . \\
\hline Gnaphalium hoppeanum & I & . & . & . & . \\
\hline Bartsia alpina & I & . & . & . & . \\
\hline Mutellina adonidifolia & I & . & . & . & . \\
\hline Carex capillaris & I & . & . & . & . \\
\hline Campanula cochleariifolia & I & I & . & . & . \\
\hline Lloydia serotina & I & I & . & . & . \\
\hline Veronica fruticans & I & I & . & . & . \\
\hline Artemisia mutellina & I & I & . & . & . \\
\hline Leontopodium alpinum & I & I & I & . & . \\
\hline Scorzoneroides helvetica & . & I & . & . & . \\
\hline Taraxacum sp. & . & . & I & . & . \\
\hline Sedum alpestre & . & . & I & . & . \\
\hline Gnaphalium supinum & . & . & I & . & . \\
\hline Salix helvetica & . & . & I & . & . \\
\hline Pritzelago alpina ssp. brevicaulis & I & . & . & . & I \\
\hline
\end{tabular}


F. Nagl, E. Erschbamer

Tab. A4:

Stetigkeitstabelle für die Nardus stricta-Gesellschaft im Bereich des Schönwieskopfes (2.275-2.320 m Meereshöhe, Nagl 2009 unpubl.).

\begin{tabular}{|l|l|}
\hline Nardus stricta & V \\
Potentilla aurea & V \\
Scorzoneroides helvetica & V \\
Mutellina adonidifolia & V \\
Anthoxanthum alpinum & V \\
Geum montanum & V \\
Euphrasia minima & IV \\
Soldanella pusilla & IV \\
Homogyne alpina & IV \\
Phyteuma hemisphaericum & IV \\
Luzula sudetica & IV \\
Festuca rubra agg. & IV \\
Polytrichum sp. & IV \\
Carex curvula & IV \\
Carex nigra & III \\
Cetraria islandica & III \\
Festuca halleri & III \\
Cladonia arbuscula & III \\
Gnaphalium supinum & III \\
Poa alpina & III \\
Veronica alpina & II \\
Ranunculus montanus & II \\
Leucanthemopsis alpina & II \\
Luzula spicata & II \\
Carex sempervirens & II \\
Hieracium pilosum & II \\
Avenula versicolor & II \\
Phleum rhaeticum & II \\
Arenaria biflora & II \\
Cerastium cerastoides & II \\
diverse Moose & II \\
\hline
\end{tabular}


Anhang Kapitel 6 | Pflanzliche Sukzessionen im Gletschervorfeld

Campanula scheuchzeri

Cardamine alpina

Sibbaldia procumbens

Agrostis capillaris

Arnica montana

Agrostis rupestris

Deschampsia cespitosa

Potentilla erecta

Soldanella alpina

\begin{tabular}{ll|} 
I \\
I \\
I \\
I \\
I \\
I \\
I \\
I \\
I \\
\hline
\end{tabular}


G. Gärtner

\section{G. Gärtner}

\section{Zur Kryptogamenflora im Rotmoostal}

Tab. A1

\section{Algen aus dem Rotmoos}

aus den Arbeiten von W. Schmidle, Nomenklatur nicht aktualisiert!

W. Schmidle (1895): Beiträge zur alpinen Algenflora.- Österr. B. Z. 45: 249-253, 305-311, 346-350, 387-391, 454-459.

W. Schmidle (1896): Beiträge zur alpinen Algenflora.-Österr. B. Z. 46: 20-25, 59-65, 91-94.

Microspora pachyderma Lagerh.

Pediastrum integrum Naeg. fo. polygonae

Pediastrum tricornutum var. alpinum (nov.var.!) fo. simplex

$$
\text { fo. evoluta }
$$

Pediastrum angulosum var. arenosum Racib.

Pediastrum tetras (Ehrenb.) Ralfs

Scenedesmus variabilis var. ecornis Franzé

Ophiocytium parvulus (Perty) A. Br.

Pleurococcus angulosus (Corda) Menegh.

Hyalotheca dissiliens var. tatrica Rac.

Closterium juncidum Ralfs

Closterium striolatum Ehrenb.

Closterium pritchardianum var. alpinum (nov. var.!)

Closterium abruptum forma brevior West

Closterium venus Kützg.

Closterium rostratum Ehrenb.

Penium margaritaceum (Ehrenb.) Bréb.

Penium cylindrus var. subtruncatum nob. (!)?

Penium polymorphum Perty

Penium digitus Bréb.

Penium navicula fo. apicibus rotundata Wille

Penium crassiusculum De Bary

Penium oblongum De Bary

Penium naegelii Bréb. 
Tetmemorus brébissonii (Menegh.) Ralfs

Tetmemorus granulatus fo. basichondra n. fo.(!)

Tetmemorus levis Ralfs

Tetmemorus minutus De Bary

Dysphinctium palangulae var. De Bary

Dysphinctium cucurbita (Bréb.) Reinsch

Dysphinctium notabile (Bréb.) Hansg.

Dysphinctium speciosum (Lund.) Hansg.

Dysphinctium speciosum var. tumidum nov. var.(!)

Dysphinctium sinuosum (Lund.) Hansg.

Dysphinctium pericymatium (Nordst.) Schmidle

Dysphinctium parvulum (Breb.) Schmidle

Dysphinctium microsphinctum var. crispulum (Nordst.) Schmidle

Dysphinctium holmiense var. integrum (Lund.) Schmidle

Pleurotaeniopsis cucumis (Corda) Lagerh.

Xanthidium armatum var. supernumerarium n. var.(!)

Cosmarium leve var. undulatum Schmidle

Cosmarium carrolense R. et B.

Cosmarium tinctum var. intermedium Nordst.

Cosmarium gothlandicum var. cambrense Turn.

Cosmarium crenulatum Naeg.

Cosmarium impressulum var. integrata Heimerl

Cosmarium impressulum var. alpicola nov. var. (!)

Cosmarium crenatum Ralfs

Cosmarium pseudopyramidatum fo. major Ld.

Cosmarium minutum Delp.

Cosmarium regnesii var. montanum Schmidle

Cosmarium orthopunctulatum spec. nov.(!)

Cosmarium portianum var. calvum nov. var. (!)

Cosmarium pachydermum forma

Cosmarium perforatum var. üporosum Gutw.

Cosmarium netzerianum nov. spec. (!)

Cosmarium subochthodes Schmidle

Cosmarium conspersum Ralfs

Cosmarium praemorsum diverse formae

Cosmarium amoenum Bréb.

Cosmarium retusiforme var. alpinum nov. var.(!) 
G. Gärtner

Cosmarium sexnotatum var. tristriatum (Lütkemüller) Schmidle

Cosmarium osteri nov. spec. (!)

Cosmarium caelatum var. spectabile Nordst.

Cosmarium hexastichum Lund.

Euastrum insigne Hassall

Euastrum ansatum (Ehrenb.) Ralfs

Euastrum elegans fo. scrobiculata Lütkemüller

Euastrum elegans ad var. bidentata Naeg.

Micrasterias crenata Bréb.

Micrasterias rotata (Grev.) Ralfs

Micrasterias denticulate (Bréb.) Ralfs.

Micrasterias papillifera var. verrucosa nov. var. (!)

Staurastrum dejectum fo.

Staurastrum dickiei forma parva

Staurastrum intricatum forma

Staurastrum heimerlianum Lütkemüller

Staurastrum nigrae-silvae Schmidle

Staurastrum scabrum Bréb.

Staurastrum polytrichum var. alpinum Schmidle

Staurastrum trapezicum var. campylospinosum Schmidle

Staurastrum spongiosum var. cumbricum Bennet?

Staurastrum muticum Bréb.

Staurastrum insigne Lund.

Staurastrum pygmaeum Bréb.

Staurastrum varians fo.

Staurastrum muricatiforme spec. nov. (!)

Staurastrum dilatatum Ehrenb,

Staurastrum controversum fo.

Staurastrum gurgeliense spec. nov. (!),

Staurastrum megalonotum fo. hastata Lütkemüller

Staurastrum margaritaceum fo. minor Heimerl 
Tab. A2

\section{Moosbelege des Herbars „Forschungsinstitut für Hochgebirgsforschung“ Obergurgl (Sammler der Belege großteils auf den Kapseln NICHT vermerkt, nur zum Teil NACHWEISLICH von W. Maurer bzw. von D. Müller )}

Datum der Belege. SÄMTL: zw. Sept. 1958, Aug. 1959 und Sept. 1960

Grundfelder d. florist. Kartierung: alle im Grundfeld Nr. 9132, mit Ausnahme der Belege „Weg z.Ramolhaus" die bereits bei Höhen über $2500 \mathrm{~m}$ in 9131 liegen.

\section{Laubmoose}

Abietinella abietina, Gaisbergtal, Hang Kirchenkogel, 2500 m, 7.9.58

Amblyodon dealbatus c. fr., Elynetum, Granatenwand, Gaisbergtal, 2700 m leg. W. Maurer, 7.8.59

Amphidium mougeottii, Felsnische, Bärenhoppet, Rotmoostal, 2500 m, 17.9.58

Andreaea frigida, Fels, Hintere Putzach, Ramolweg, 2530 m, 17.8.60

Andreaea nivalis, zus. m. Solenostoma sphaeroc., Polytr. Norveg., Anthelia juratzk.,Schmelzwasserrinne, Gaisbergtal, Hang d. Kirchenkogels, 2600 m, 6.9.58

Andreaea petrophila, var., Gaisbergt., Hang d. Kirchenkog., überrieselt. Schiefer, 2500 m, 7.9.58 Angstroemia longipes c.fr., mit Brya , Sand, Gletschervorf., Rotmoostal, keine Höhenang., 24.9.58 Anoectangium compactum, feuchte Schieferspalten, Bärenhoppet, Rotmoostal, 2500 m, 17.9.58 Anomobryum filiforme, Spritzwasser, Tribesbach, über Brücke z. Ramolweg, 2100 m, 16.6.61 Atrichum undulatum, feuchte Erde, Obergurgl, 1900m, 13.9.58

Aulacomnium palustre, Polytr. Strictum-Bult, Grasheide, Nederbod.,Gaisbergt. 2300 m, 4.9.58

Bartramia halleriana c. fr, bei Obergurgl, Felsspalte, ohne Höhenang., 20.9.58

Bartramia ithyphylla c. fr., Grasheide, Rotmoos, Mittelrippe im Ferner z.Liebener Sp., 2900m, 6.9.58

Blindia acuta, Quellsumpf, Gaisbergtal, Neederboden, 2300 m, 4.9.58

Brachythecium glaciale, Hangmulde, Gaisbergtal, Hang d. Kirchenkogels, 2500m, 6.9.58

$$
\text { -,- - -, ， Block an Schmelzwasserbach, Weg z. Ramolhaus, 2400-2500 m, 9.8.59 }
$$

Brachythecium reflexum, feuchter Boden, Gurgler Tal, „Die Barste“, 1900 m, 26.9.58

Brachythecium rivulare, Bachbett unter Alnus vir., Obergurgl, Gärtle, 2100 m, 14.9.58

Brachythecium salebrosum, Felsplatte in Bach, Aufstieg z. Seenplatte, 2000m, 14.8.59

$$
\text { -,- } \quad \text {-,- ～， Gaisbergtal, Hang d. Kirchenkogels, } 2500 \text { m, 6.9.58 }
$$

Brachythecium starkei, Boden u. Äste v. Rhododendr., Pirchhüttbühel, bei 2000m, 14.8.60

Bryum alpinum, überrieselt. Stein, Rotmoos, 2300 m, 12.8.60

Bryum argenteum, Steinmauer, Bundessportheim,18.9.58

Bryum bimum c.fr., Wasser einer Quelle, Rotmoostal, Gletschervorfeld, 17.9.58

Bryum duvalii, Quellsumpf, Ausgang d. Zirmeggenkares, 2700 m, 13.9.58 
Bryum elegans, Humus an Felsen, Rhodendronheide, Pirchhüttbühel, 2000m, 14.8.60

Bryum schleicheri c. fr., Quellwasser, Rotmoostal, Gletschervorfeld 2300m, 7.9.58

Calliergon sarmentosum Quellsumpf, Gaisbergtal, Neederboden, 2300 m, 4.9.58

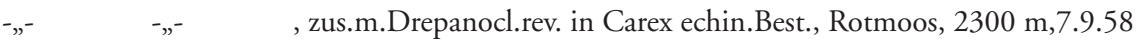

Calliergon stramineum, Quellsumpf, Gaisbergtal, Neederboden, 2300 m, 4.9.58

Calliergon trifarium, Schlammbod.in Hangwasserrinne m.Car.echin., Rotmoos,2300m,16.9.58

Camptothecium nitens, überrieselt. Rasen, Obergurgl, in der Barste, 1900m, 13.9.58

Campylium protensum, Gaisbergtal, Neederboden, 2300m, 4.9.58

Campylium stellatum, Quellaustritt, Bärstleite (über d.Ramolweg), 2200m17.6.61

Catoscopium nigritum c.fr., Elyna.-Rinne, Gaisbergtal, Granatenwand, 2700 m, 7.8.59

Ceratodon purpureus, Brandstelle, Obergurgl, Gärtle, 2100 m, 14.9.58

Climacium dendroides, Rasen am Bachrand, Obergurgl, Gärtle, 2100 m,14.9.58

Conostomum boreale c.fr., Erdnische unt.Rhododendr., Gaisbergt., Neederboden 2300m,4.9.58

Coscinodon cribrosus c.fr., Granatglimmerschief., Gaisbergt., Granatenwand, 2800m,11.8.60

Cratoneurun decipiens, überrieselte Felswand, Gaisbergt., Hang d.Kirchenkog., 2500m, 6.9.58

Cynodontium gracilescens c.fr., Königstal Schlucht 2000 m, leg.W. Maurer, 14.8.60

Cynodontium polycarpum c.fr., Felsbank am Bach, Gurglert., b.Obergurgl,kein.Höhenang.20.9.58

Desmatodon latifolius c.fr., Obergurgl, Zirmegg 2300 m, 13.9.58

Dicranella cerviculata, Torfwand, Rotmoos 2300 m,17.9.58

Dicranella subulata, Grasheide, Weg z.Ramolhaus 2700m, 13.8.59

Dicranoweisia crispula c.fr., Blöcke, Gaisbergtal, Neederboden 2300 m, 4.9.58

Dicranum bonjeanii, auf Sph.nemor.Bult in Flachmoor, Ausg.Zirmeggenkar, 2700m,13.9.58

Dicranum elongatum Zwergstr.heide, Obergurgl, Pirchhüttbühel 2000m, 14.8.60

Dicranum fuscescens var. congestum, Zwergstr.h., Zirbenwald Obergurgl, 1900m,1.8.59

Dicranum fuscescens + Ptilidium ciliare, Rasen, Ramolweg bei 2700m, 17.8.60

Dicranum scoparium c.fr., unter Vaccinien, Obergurgl, Gärtle, 2100 m, 14.9.58

Dicranum undulatum, Zwergstr.h., Gurgler Tal, Eingang z.Rotmoostal, 2300m, 30.9.58

Diobelon squarrosum, Quellsumpf, Gaisbergtal, Neederboden 2300m, 4.9.58

Diphyscium foliosum c.fr., Erdhöhlungen in Rhododendreten, Pirchhüttbühel 2000m,14.8.60

Distichium capillaceum c.fr., Felsspalte, Gaisbergtal 2400m, 4.9.58

Ditrichum homomallum c.fr., Erde in Rhododendretum, Pirchhüttbühel 2000m, 14.8.60

Dolichotheca seligeri, unter Aln. vir., Tribes Bach zw.2000 und 2100m, 16.6.61

Drepanocladus exannulat.var. purpurascens, Quellsumpf, Gaisbergt. Neederbod.2300m,4.9.58

Drepanocladus exannulat. fo. rotae, Flachmoortümpel, Rotmoos, 2300m,7.9.58

Drepanocladus intermedius, in Carex echinata Best., Rotmoos, 2300m, 7.9.58

Drepanocladus revolvens, in Carex echinata Best., Rotmoos 2300m, 7.9.58

Drepanocladus uncinatus var., Gaisbergtal, Neederboden $2300 \mathrm{~m}$, 4.9.58 
Drepanocladus vernicosus, nasser Rasen, Talstation „Hohe Mut Lift“, 2000m, 16.9.58

Encalypta ciliata c.fr., Schieferklüfte, Gaisbergtal, Granatenwand 2500 m, leg.Maurer,7.8.59

Encalypta rhabdocarpa c.fr., Rotmoostal, Bärenhoppet 2500m, 17.9.58

Erythrophyllum recurvirostrum, Sandaufschüttung, rechte S.d.Gurgler Ache, Brücke z.Ramolweg., $1900 \mathrm{~m}, 15.6 .61$

Eurhynchium pulchellum, Fels a.d. Straße, Pirchhütte, 1900m, 14.8.60

Fissidens adianthoides, überrieselt.Boden b.Quellaustritt, Rotmoos, $2400 \mathrm{~m}, 17.9 .58$

Funaria hygrometrica, Brandstelle, Aufstieg Beilstein 2000m, 13.8.58

Grimmia alpestris c.fr., Gaisbergtal, älteres Gl.vorfeld, $2400 \mathrm{~m}, 7.8 .59$

${ }_{-,}^{-} \quad-$ - c.fr., Gaisbergtal, 2350m, 4.9.58

Grimmia elatior, Obergurgl, untere Brücke z.Seenplatte, 14.6.59

Grimmia funalis, Rotmoostal, „unter den Wasserfällen“, keine Höhenang., 24.9.58

Grimmia elongata, Stockkogel, 2800m, auf Fels, 5.8.59

Grimmia incurva c.fr.,Blockhalde, Zirmeggenkar,2600m, 14.8 .59

Grimmia torquata, Schieferfels, rechte S.d.Gurgl.A., Brücke z. Ramolweg 1900m, 15.6.61

Grimmia unicolor, Felskluft, Rotmoost.am Weg z. Ferner, b.d.Wassereintritt.in d.Moos,12.8.60

Hedwigia ciliata, an trock. Besonnt. Block, Obergurgl Ort, 14.8.60

Heterocladium heteropterum, Zirmeggenkar, 2700m, 14.8.59

Heterocladium squarrosulum , Zirbenw., Gurgler Tal „Auf der Kaser“, 2000m, 16.9.58

Homomallium incurvatum, Gaisberg, unter Mutsattel, 2500m, 8.8.59

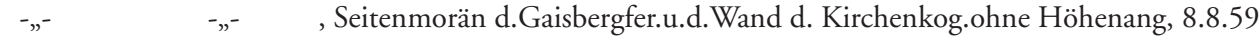

Hydrogrimmia mollis, auf steinen im Abfl. D.Itlsees, Seenplatte $2650 \mathrm{~m}, 13.9 .58$

Hygrohypnum alpinum, Abfl. Itlsee, Seenplatte, 2700m, 13.9.58

Hygrohypnum palustre, c.fr., Gurgler Ache, Felsw.üb. Mittelwasserlinie, 1900 m, 26.9.58

Hylocomium pyrenaicum, Gaisbergt., Neederboden, 2300m, 4.9.58

Hylocom. splendens, Vaccinium, Obergurgl, Gärtle 2100m, 13.9.58

Hylocom.spl. var. groenlandicum, Grasheid., Gaisbergt., Hang d.Kirchenkg. 2500m,6.9.58

Hymenostylium curvirostre c.fr., (Gymnostom.rec.), trief.Fels, Granatenwd. 2600m, 11.8.60

Hypnum cupressiforme var. subjulaceum, Gurgler Tal, Gärtle, 2100m, 13.9.58

Hypnum hamulosum, grasiger Grat, Rotmoos, Hang unt.Mutsattel, keine Höhenang., 10.8.59

Hypnum revolutum, Nardetum, Rotmoost. Mittelrip.im Ferner z.Liebener Sp.,2600m,6.9.58

Kiaeria falcata, Schmelzwasserrinne, Gaisbergt., Hang d. Kirchenkogels, 2600 m, 3.9.58

Kiaeria starkei c.fr., Schneeboden, Timmelsjoch, 2600m, 10.8.59

Lescurea decipiens, Gaisbergtal, Hang d.Kirchenkogels, 2550m, 6.9.58

Lescurea denudata (=?Pseudoleskea), Block in Grash., Gaisbergt., Neederbod. 2300m,4.9.58

Lescurea mutabilis Granatenwand, 2700m, 11.8.60

Leucodon sciuroides, Felsspalte, Gurgler Heide, 2300m, 9.8.60 
G. Gärtner

Meesea trichodes c.fr., Gaisbergtal, Neederboden 2300m, 4.9.58

Mielichhoferia nitida, Ramolhaus, 3000m, 15.8.59

Mniobryum albicans, Schmelzwasserrinne, Seenplatte 2700m, 13.9.58

Mniobryum albicans var. glaciale, Rotmoostal, Gletschervorfeld, ohne Höhenang., 24.9.58

Mnium marginatum, Rhododendretum, Pirchhüttbühel, 2000m, 14.8.60

Mnium pseudopunctatum, Gaisbergtal, neederboden, 2300m, 4.9.58

Mnium punctatum, an der Gurgler Ache, 1900 m, 14.8.60

Mnium stellare, unter Rhododendron, Pirchhüttbüghel, 2000m, 14.8.60,

Myurella tenerrima, Gaisbergtal, Hang d.Kirchenkogels, 2500 m, 7.9.58

Oligotrichum hercynicumGaisbergtal, Neederboden, $2300 \mathrm{~m}$, 4.9.58

Oncophorus virens c.fr., Quellsumpf, Gaisbergtal, Neederboden, 2300m, 3.9.58

Oreas martiana, Felsspalte, Rotmoostal, Mittelrip.im Ferner z.Liebener Sp., 2900m,6.9.58

Orthothecium chryseum, in Rasen v. Distich.cap., Gaisbergt.Hang d.Kirchenk., 2400m,6.9.58

Orthothecium intricatum, Gaisbergtal, Hang d.Kirchenkogels, 2400m, 6.9.58

Orthotrichum alpestre c.fr., bei Brücke zum Beilstein, 1900m, 13.8.60, leg. W. Maurer

Orthotrichum killiasii c.fr., Kalkphyllit, Granatenwand 2800m, 7.8.59

Paraleucobryum enerve, Rhododendronheide, Schwärzenkamm, 2700m, 9.8.59, leg. W.Maurer

Philonotis seriata c.fr., Quellsumpf, Itlsee, 2650m, 13.9.58

Philonotis tomentella c.fr., Quellsumpf, Gaisbergtal, Nederboden 2300m, 4.9.58

-,- $\quad$-,- m. Brutästen, zus. m. Plagiop.oed., in Curvuletum, Felsrippe im Ferner z.Lb.sp. $2600 \mathrm{~m}, 7.9 .58$

Plagiopus oederi c.fr., zus. m. Philon. tom.,Rotmoost., Felsrip.im Fern.z.Lieb.Sp., 2600m,7.9.58

Plagiothecium denticulatum, c.fr., Gurgler Tal, „Die Barste“, 1900m, 26.9.58

Plagiothecium roeseanum, unter Grünerlen, KönigstalSchlucht bei 2000m, leg. W.Maurer,14.8.60

Pleurozium schreberi, Vaccinien, Obergurgl, Gärtle, 2100m, 13.9.58

Pogonatum urnigerum c.fr., Rhodendretum, Wegrand, Aufstieg z.Gaisbergtal, 2200m,Sept.58

Pohlia cruda, Obergurgl, Gärtle, 2100m, 14.9.58

Pohlia gracilis, Gletschervorfeld, Gaisbergt., 2400m, 6.9.58

Pohlia nutans, Neederboden, Gaisbergt. 2300m, 15.8.60

Pohlia polymorpha, Gurgler Tal Gärtle, $2100 \mathrm{~m}, 13.9 .58$

Pohlia proligera, zus.m.Dicranell cervic., Torfwand, Rotmoos, Bachanriss 2300m, 7.9.58

Polytrichum alpinum c.fr., Gurgler Tal, Die „Barste“, 1900m, 13.9.58

Polytrichum attenuatum, Gurgler Tal, „Brenner“, 2000m, 16.9.58

Polytrichum commune, hinter Haus Rochus, Obergurgl, 1900m, Sept.60

Polytrichum juniperinum c.fr., Obergurgl, Gärtle, 2100m, 14.9.58

Polytrichum norvegicum c.fr., mit Anthel.jur, Andr.niv., Racom. sudet.Schmelwasserr., Gaisb.t. Hang d. Kirchenkogels, 2600m, 7.9.58 
Polytrichum piliferum c.fr., Gaisbergtal, Seitenmoräne unter Kirchenkogel, 2400m, 4.9.58

Polytrichum strictum, auf Sph.nemor.Bult, Moor, Ausgang Zirmeggenkar, 2700m, 13.9.58

Pseudoleskea atrovirens, Gaisbergtal. Granatenwand 2700m, 11.8.60

Pterygoneurum ovatum c.fr., m. Stegonia lat.in Elynetum, Gaisbergt.,Granatenw.2700m,7.8.59

Pterigynandrum filiforme var. decipiens, Obergurgl, Gärtle, 2100m, 13.9.58

Pterigynandrum filiforme fo.filescens, Gurglertal, „Die Barste“, 1900m, 26.9.58

Ptilium crista-castrensis, Grünerlen, Königstalschlucht bei 2000m, leg.W.Maurer, 14.8.60

Racomitrium aciculare, am Bach aus dem Lehnerkar bei 2000m, 16.6.61

Racomitrium canescens ?fo.tortuloides, Schwemmsand, Rotmoost., Gle.vorf. 2400m,6.9.58

Racomitrium fasciculare, Gurgler Tal „Die Barste“, 1900m, 26.9.58

Racomitrium heterostichum var. affine, an nassem Fels, „Hintere Putzach“, Ramolweg 2500m, 17.8.60

Racomitrium lanuginosum, Zirmeggenkar 2700m, 13.9.58

Racomitrium sudeticum, mit Polytr.norv., Anthel.jur.u.Andr.niv., Schmelw.rinne, Gaisb.t., Hang

d. Kirchenkogel, $2600 \mathrm{~m}, 7.9 .58$

Rhabdoweisia fugax c.fr., Obergurgl, Gärtle 2100m, 14.9.58

Rhodobryum roseum, Wiese, and.dGurgler Ache, 1900m, leg.D. Müller, 15.8.60

Rhytidiadelphus triquetrus, Vaccinietum, Gärtle, 2100m, 13.9.58

Rhytidium rugosum, Grasheiden, Gaisbergt, Hang.d.Kirchenkogels 2500m (!), 6.9.58

Splachnum pedunculatum, Rindermist, Neederboden Gaisbergt., $2300 \mathrm{~m}, 6.9 .58$

Schistidium papillosum, re.Ufer.d.Gurgl.Ache bei Brücke z.Ramolweg, 1900m, 15.6.61

Stegonia latifolia c.fr., m.Pterigoneurum ov., Elynetum, Granatenwand $2700 \mathrm{~m}, 7.8 .59$

Syntrichia norvegica, Bruchsteinmauer, Bu.sportheim Obergurgl, 18.9.58

Syntrichia ruralis, Gletschervorfeld, Rotmoos, $2300 \mathrm{~m}, 7.9 .58$

-„- $\quad$ Stützmauer, in der Barste $1900 \mathrm{~m}, 14.9 .58$

Tayloria froelichiana c.fr., Hohe Mut Sattel, 2500m, 28.9.58

Tayloria lingulata c.fr., Torf, Timmelsjoch 2600m, 10.8 .59

Tetraphis pellucida, Moderholz, Gurgler Tal, „Auf der Kaser“, 2100m, 16.9.58

Timmia austriaca, unter Rhododendron, Pirchhüttbühel, 2000m, 14.8.60

Timmia bavarica, dunkle Felssp., Hang d,Kirchenkogels, 2400m, 7.9.58

Tortella inclinata, Sanderfläche Gletschervorf., Gaisbergtal $2400 \mathrm{~m}, 4.9 .58$

Tortella tortuosa, Sanderflä, Gle.vorfeld, Gaisbergfern., 2400m, 4.9.58

Trichodon cylindricus c.fr., Sand am Bach, re.S.d.Gurgler Ach.,Brücke Ramolweg.,1900m, 15.6.61

Weisia crispata, Zirmeggenkar, 2700m, 14.8.59 
G. Gärtner

\section{Lebermoose}

Anthelia julacea, Gaisbergtal, Neederboden 2300m, 4.9.58

Anthelia juratzkana, Elynetum,Mittelri.im Rotmoosfer.z. Liebener Sp., 2900 m,6.9.58

Barbilophozia barbata und Barb. Hatscheri, bei Obergurgl, keine Höhenang., 20.9.58

Barbilophozia floerkei, Vaccinien im Zirbenw.,Gurgler Tal, „Auf der Kaser“, 2100m,16.9.58

Barbilophozia hatscheri, Obergurgl, Gärtle, 2100m, 14.9.58

Barbilophozia lycopodioides, unter Rhodendron, Gaisbergt., Neederboden, 2300m, 4.9.58

$$
\text { -„- } \quad \text {-,- } \quad \text { var. parvifolia, b. Obergurgl, 20.9.58 }
$$

Bazzania tricrenata zus.m.Barbiloph.hatscheri, Blockhalde, Obergurgl, Gärtle 2100m, 14.9.58

Blasia pusilla, Obergurgl, am Lobbach 1900m, 13.9.58

Blepharostoma trichophyllum, Felsspalten, Gaisbergt., Hang d.Kirchenkogels, 2600m,6.9.58

Calypogeia neesiana, Zirbenwald, Gurgler Tal, „Brenner“, 2000m, 16.9.58

Calypogeia trichomanes, Gaisbergt., Neederboden, 2300m, 4.9.58

Cephalozia bicuspidata, Zirbenwald, „Auf der Kaser“, 2000m, 16.9.58

Cephalozia lammersiana, Zirbenwald, Gurgler Tal, „Brenner“, 2000m, 18.9.58

Diplophyllum taxifolium, Obergurgl, Gärtle, 2100m, 14.9.58

Fimbriaria lindenbergiana, Schneebod.Gaisbergt., Hang Mutsattel (üb.S.mor.)2500m,7.9.58

Frullania dilatata, Form m.unverd.Zellecken, bei Obergurgl, 20.9.58

Frullania jackii, in Anoectangium -rasen, Rotmoost., Bärenhoppet, 2500m, 17.9.58

Frullania tamarisci, zw.Racomitr.lan., Rotmoostal, Am Hangerer, 2700m, 26.9.58

Gymnocolea inflata, Torf, Flachmoor, Ausgang d.Zirmeggenkares, 2700m, 13.9.58

Gymnomitrium concinnatum, Gaisbergt., Hang d. Kirchenkogels, 2600m, 7.9.58

Gymnomitrium coralloides, Zirmeggenkar, 2700m, 13.9.58

Gymnomitrium obtusum, Gaisbergt., Hang. d.Kirchenkogels, 2600m, 7.9.58

Harpanthus flotowianus var. uliginosa, Gurgler Tal, „Auf d.Kaser“, 2100m, 16.9.58

Isopaches decolorans c.fr., feucht.Erde, Solenostoma u.Psora überwachs., Seitemor.unter Kirchenkogel, $2400 \mathrm{~m}, 6.9 .58$

Lophocolea minor, Obergurgl, nördl.Ortsende, Wiese, 1900m leg.W.Maurer, 14.8.60

Lophozia alpestris, Rhododendretum, Aufstieg z.Gaisbergtal, 2200 m, 17.8.60

Lophozia incisa, Torf, Gaisbergt., Neederboden, 2300m, 4.9.58

Lophozia ventricosa, Zirbenwald, Gurgler Tal, Brenner, 2000m, 16.9.58

Lophozia wenzelii, zw. Sphagnen auf Bülten in Flachm., Ausg.Zirmeggenkar,2700m,13.9.58

-„- $\quad$ - „- (rev.J.Saukel,15.6.82), Schneeboden, Seenplatte, 2700m, 13.9.58

Madotheca cordeana, Gurgler Tal, „Die Barste“, 1900m,26.9.58

Marchantia polymorpha var. alpestris, Wiesenboden, Gurgler Tal, „Die Barste“, 1900m,26.9.58

Marsupella aquatica, Quellmoor, an Stein, Gaisbertgal, Neederboden, 2400m, 7.8.59 
Marsupella revoluta, m. Grimmia funalis an überries.Felswd., Rotmoostal, „Unter d.Wasserfällen“, keine Höhenangabe, 24.9.58

Moerkia blyttii, Erdhöhlung, Ramolweg bei 2500m, 17.8.60

Mylia anomala var., nasser Torf, Flachm.m.Gymnocolea infl., Ausg.Zirmeggenkar 2700m,13.9.58

Nardia compressa, tw.submers, Quellmoor, Gaisbergtal, Neederboden 2300m, 4.9.58

Nardia geoscypha, Grasboden, Gaisbergtal, Neederboden 2400m, 11.8.60

-„- $\quad$-,- $\quad$, Zwergstr.heide, Aufstieg Ramolhaus, 2400m 13.8.59

Nardia insecta, Rhododendretum, Aufstieg z.Gaisbergtal, 2100m, 17.8.60

Nardia scalaris, Quellmoor, Gaisbergtal, Neederboden $2300 \mathrm{~m}, 4.9 .58$

Pellia neesiana, Rhododendron, Pirchhüttbühel, 2000m, 14.8 .60

Plagiochila asplenioides fo, Gaisbergt., Hang d.Kirchenkogels, 2400m, 6.7.58

Plectocolea obovata, feuchte Rinne unt.Vacc.im Zirbenw., Gurgler T. „Brenner“,2000m, 18.9.58

Pleuroaclada albescens, m.Polyt.norv.u.Lophoz.opacif., Schneebo.Seenpl. Itlsee $2650 \mathrm{~m}, 13.9 .58$

Ptilidium ciliare, Obergurgl, Gärtle, 2100m, 13.9.58

Radula complanata, an Stein, Obergurgl, nördl.Ortsende, leg. D. Müller, 14.8.1960

Radula lindbergiana, Rotmoostal, Bärenhoppet 2500m, 17.9.58

Riccardia pinguis, zw.Philonotis an Quellaustr., Rotmoos, 2300m, 17.9.58

Riccia breidleri, toniger Seeboden, Soomsee, 2550m, 13.9.58

Saccobasis polita, Gaisbergtal, Neederboden, 2300m, 6.9.58

Scapania subalpina, Bachufer, Weg z.Ramolhaus, $2000 \mathrm{~m}, 13.8 .59$

Scapania uliginosa, Quellsumpf, Aufstieg z.Ramolhaus, 2700m, 13.8.59

Scapania undulata var. densa, Schlammboden, Rotmoos, 2300m, 17.9.58

Solenostoma crenulatum, zw. Rhododendron, Pirchhüttbühel, $2000 \mathrm{~m}, 14.8 .60$

Solenostoma sphaerocarpum c.fr., m. Andreaea niv.u.Anth.jur., Schmelzwasserrinne, Hang d.

Kirchenkogels, $2600 \mathrm{~m}, 6.9 .58$

Sphenolobus minutus, Obergurgl, Gärtle, 2100m, 14.9.58

Tritomaria exsecta,z.Tl., Grasheide, Obergurgl, Gärtle, $2100 \mathrm{~m}, 14.9 .58$

Tritomaria quinquedentata, Gaisbergtal, Hang.d.Kirchenkogels $2500 \mathrm{~m}, 6.9 .58$

-,- $\quad$-,- $\quad$, Gurgler Tal, „Die Barste“, 1900m, 26.9.58

\section{Sphagnen}

Sph.auriculatum, Flachmoorgraben, Seenplatte, Zirmeggenkar, 2700m, 13.9.58

Sph. compactum, in Trichophorumrasen, Ausgang Zirmeggenkar, $2700 \mathrm{~m}, 13.9 .58$

Sph. fuscum, Zwergstrauchheide m. Calluna, Ramolweg b. Manigenbach, 2250m, 18.8.60

Sph. girgensohnii, Vaccinien, Zirbenwald, Gurgler Tal, „Auf der Kaser“, 2100m, 16.9.58 
G. Gärtner

Sph. inundatum, in Carex echin.best. zus.m.Call.stram.u.Drep.revolv.,Rotmoos,2300m, 7.9.58

Sph. magellanicum, auf Sph.nemor.Bult in Quellsumpf, Zirmegg 2300m, 13.9.58

Sph. nemoreum var., Quellsumpf in Nardetum, Gaisbergt., Neederboden 2300m, 3.9.58

Sph. robustum, Zwergstrauchheide, Eingang z. Gaisbergtal 2300m, 17.8.60

Sph. squarrosum, unter Vacc.im Zirbenw., Gurgler Tal, „Auf der Kaser“, 2100m, 16.9.58

Sph. subbicolor, unter Vacc.im Zirbenwald, „Auf der Kaser“, 2100m, 16.9.58

Sph. subsecundum, in nassem Carex echin.bestand, Rotmoos, $2300 \mathrm{~m}, 17.9 .58$

Sph. teres, überschwemmt.Rasen, Wiesenbach, „In der Barste“, 1900 m, 13.9.58 
Tab. 3

\section{Laubmoose im Rotmoostal}

Liste zusammengestellt aus Belegen im Herbar des Universitätszentrum-AFO sowie im Herbar des Institutes für Botanik der Universität Innsbruck -IB beziehungsweise nach div. Geländeprotokollen von W. Maurer 1958-1960, M. Jochimsen 1961-63, R. Lübenau-Nestle 1993 und des Verfassers.

Anmerkung: die Liste enthält nur tatsächlich im Rotmoostal gefundene und/oder belegte Arten und ist keineswegs vollständig! Nomenklatur nach den Originalbelegen, in Klammer die neue Nomenklatur nach Grims (1999), Grolle \& Long (2006) und Köckinger et al. (2008).

Amphidium lapponicum

Amphidium mougeotii, Felsnische, Bärenhoppet, Rotmoostal, 2500 m,17.9.58

Aongstroemia longipes, Alluvionen im Gletschervorfeld

Bartramia ithyphylla c. fr., Grasheide, Rotmoos,Mittelrippe im Ferner z.Liebener Sp.,2900m,

Brachythecium salebrosum

Bryum alpinum, überrieselt. Stein, Rotmoos, 2300 m, 12.8.60

Bryum bimum (= B. pseudotriquetrum var. bimum) c.fr., Quelle, Rotmoostal, Gletschervorfeld,

Bryum schleicheri c.fr., Quellwasser, Rotmoostal, Gletschervorfeld 2300m, 7.9.58

Calliergon trifarium (=Pseudocalliergon t.), Hangwasserrinne m.Carex echin., Rotmoos

Dicranella cerviculata, Torfwand, Rotmoos $2300 \mathrm{~m}$,

Dicranum palustre (=bonjeanii),

Dicranum undulatum (= D. polysetum), Zwergstr.h., Gurgler Tal, Eingang z.Rotmoostal

Ditrichum flexicaule

Drepanocladus exannulata (= Warnstorfia e.) fo. rotae, Flachmoortümpel, Rotmoos

Drepanocladus intermedius (= Warnstorfia intermedia), in Carex echinata Best., Rotmoos, 2300m,

Drepanocladus revolvens (= Scorpidium rev.), in Carex echinata Best., Rotmoos $2300 \mathrm{~m}$

Encalypta rhabdocarpa c.fr., Rotmoostal, Bärenhoppet

Fissidens adianthoides, überrieselt.Boden b.Quellaustritt, Rotmoos

Funaria hygrometrica

Grimmia commutata

Grimmia funalis, Rotmoostal, „unter den Wasserfällen“, keine Höhenang

Grimmia unicolor, Felskluft, Rotmoost.am Weg z. Ferner, b.d.Wassereintritt.in d.Moos

Hygrohypnum dilatatum, Gletschervorfeld Rotmoosferner

Hypnum hamulosum

Hypnum revolutum, Nardetum, Rotmoost. Mittelrip.im Ferner z.Liebener Sp.,

Kiaeria starkei 


\section{G. Gärtner}

Mniobryum albicans var. glaciale (=Pohlia wahlenbergii var. glacialis) Rotmoostal, Gletschervorfeld, ohne Höhenang

Oreas martiana, Felsspalte, Rotmoostal, Mittelrip.im Ferner z.Liebener Sp., 2900m

Palustriella commutata (= Cratoneuron commutatum )

Plagiopus oederi (= P. oederiana) c.fr., Rotmoostal., Felsrippe.im Ferner z.Liebener Sp.,

Pohlia commutata ( $=$ P. drummondii)

Pohlia proligera, zus.m.Dicranell cervic., Torfwand, Rotmoos, Bachanriss $2300 \mathrm{~m}$

Pohlia rothii (= P. andalusica)

Polytrichum juniperinum, auf Sandböden der Gletschervorfelder

Polytrichum norvegicum (= P. sexangulare) c.fr., mit Anthel.jur, Andr.niv., Racom. sudeticum im

Schmelzwasser

Racomitrium canescens ( $=\mathrm{R}$ canescens subsp. canescens)

Racomitrium canescens ?fo.tortuloides, Schwemmsand, Rotmoost., Gle.vorf.

Syntrichia ruralis, Gletschervorfeld, Rotmoos, 2300m

Tortella tortuosa

\section{Lebermoose}

Anthelia juratzkana, Elynetum,Mittelrippe im Rotmoosferner z. Liebener Sp.,

Conocephalum conicum, an Hangwasserrinne ins Rotmoos

Frullania jackii, in Anoectangium -rasen, Rotmoost., Bärenhoppet, 2500m

Frullania tamarisci, zw.Racomitr.lan., Rotmoostal, Am Hangerer, 2700m

Lophozia decolorans, sandiger Schneeboden im Gletschervorfeld

Marsupella revoluta (= Apomarsupella r.), an überries.Felswd., Rotmoostal, „Unter d.Wasser-

fällen", keine Höhenangabe

Radula lindenbergiana, Rotmoostal, Bärenhoppet $2500 \mathrm{~m}$

Riccardia pinguis (= Aneura p.), zw.Philonotis an Quellaustr., Rotmoos, 2300m

Scapania undulata var. densa, Schlammboden, Rotmoos, $2300 \mathrm{~m}$

\section{Sphagnen (Torfmoose):}

Sph. inundatum, in Carex echin.best. zus.m.Call.stram.u.Drep.revolv.,Rotmoos, $2300 \mathrm{~m}$

Sph. subsecundum, in nassem Carex echin.bestand, Rotmoos, $2300 \mathrm{~m}$ 
Tab. A4

\section{Flechten im Rotmoostal}

Auszug aus Hofmann et al. 1988, die Funde sind nicht auf das Gletschervorfeld beschränkt, sondern umfassen das gesamte Tal inkl. Seitenhänge!

Anzina carneonivea (Anzi) Scheidegger

Buellia insignis (Naeg. Ex Hepp) Th. Fr.

Caloplaca cerina (Ehrh. Ex Hedw.) Th. Fr. var. cerina

$$
\text { -“- _ _ _ - - var. muscorum (Massal.) Jatta }
$$

Candelariella vitellina (Ehrh.) Müll. Arg.

Carbonea vitellinaria (Nyl.) Hertel

Cetraria islandica (L.) Ach.

Cladonia arbuscula (Wallr.) Flotow

Cladonia deformis auct.

Cladonia furcata (Huds.) Schaerer

Cladonia macrophyllodes Nyl.

Cladonia phyllophora Hoffm.

Cladonia pleurota (Floerke) Schaerer

Cladonia rangiferina (L.) Web. ex Wigg.

Cladonia sulphurina (Michaux) Fr.

Cladonia uncialis (L.) Wigg.

Fulgensia bracteata (Hoffm.) Räs. subsp. deformis (Erichs.) Poelt

Icmadophila ericetorum (L.) Zahlbr.

Lecanora crenulata (Dickson) Hook.

Multiclavula corynoides (Peck) Petersen

Peltigera rufescens (Weiss) Humb.

Polyblastia cupularis Massal.

Porpidia crustulata (Ach.) Hertel \& Knoph

Porpidia tuberculosa (Sm.) Hertel \& Knoph var. rubescens ad int.

Psoroma hypnorum (Vahl) Gray

Rhizocarpon geographicum (L.) DC

Rinodina mniaraea (Ach.) Koerber var. mniaraea

Rinodina mniaraea (Ach.) Koerber var. mniaraeiza (Nyl.) H. Magn.

Solorina bispora Nyl. var. bispora

Stereocaulon alpinum Laurer

Xylographa parallela (Ach.) Behlen \& Desberg 


\section{R. Türk, B. Erschbamer}

\section{Die Flechten im Gletschervorfeld des Rotmoosferners}

Tab. A1: Liste der im Gletschervorfeld des Rotmoosferners aufgefundenen Flechtenarten (Moränen der Gletscherstände 1981-1858). Die Bezeichnungen der Substrate bedeuten: bry - moosbewohnend, deb Detritus bewohnend, sil - Silikat bewohnend, sil Fe - Schwermetall-Silikat bewohnend, ter - Boden bewohnend.

\begin{tabular}{|c|c|c|c|c|c|c|c|}
\hline Art & Substrat & 1981 & 1971 & $1956 / 57$ & 1923 & 1858 & $\begin{array}{c}\text { Felsblock } \\
1923\end{array}$ \\
\hline Acarospora peliscypha & sil & & & & + & + & \\
\hline Acarospora sinopica & sil Fe & & & & + & + & \\
\hline $\begin{array}{l}\text { Acarospora smaragdula } \\
\text { var. lesdainii }\end{array}$ & sil Fe & & & & & + & \\
\hline Acarospora veronensis & sil & & + & + & + & & \\
\hline Arthrorhaphis alpina & ter & & & & + & & \\
\hline Aspicilia caesiocinerea & sil & & & & & + & \\
\hline Bacidia bagliettoana & deb & & & & + & & \\
\hline Bellemerea alpina & sil Fe & & + & + & + & + & \\
\hline $\begin{array}{l}\text { Bellemerea } \\
\text { cinereorufescens }\end{array}$ & sil Fe & & & + & & + & \\
\hline Bellemerea subsorediza & sil Fe & & & + & & & \\
\hline Caloplaca holocarpa & deb & & & & + & & \\
\hline Caloplaca stillicidiorum & bry, deb & & + & + & & & \\
\hline Candelariella aurella & epi & & & & + & & \\
\hline Candelariella coralliza & sil & & & & & & + \\
\hline Candelariella vitellina & sil deb & & + & & + & + & + \\
\hline Cetraria ericetorum & ter & & + & & & + & \\
\hline Cetraria islandica & ter & & & & + & + & \\
\hline Cetraria muricata & ter & & & & & + & \\
\hline $\begin{array}{l}\text { Cladonia cervicornis } \\
\text { ssp. cervicornis }\end{array}$ & ter & & + & & + & & \\
\hline Cladonia fimbriata & ter deb & & + & & & & \\
\hline
\end{tabular}


Anhang Kapitel 6 I Pflanzliche Sukzessionen im Gletschervorfeld

\begin{tabular}{|c|c|c|c|c|c|c|c|}
\hline Art & Substrat & 1981 & 1971 & $1956 / 57$ & 1923 & 1858 & $\begin{array}{c}\text { Felsblock } \\
1923\end{array}$ \\
\hline Cladonia macroceras & ter & & + & & & + & \\
\hline Cladonia pocillum & ter & & & & + & & \\
\hline Cladonia pyxidata & ter & & + & + & + & + & \\
\hline Cladonia symphycarpa & ter & & + & & + & + & \\
\hline Flavocetraria cucullata & ter & & & & & + & \\
\hline Flavocetraria nivalis & ter & & & & + & + & \\
\hline $\begin{array}{l}\text { Fulgensia bracteata ssp. } \\
\text { deformis }\end{array}$ & ter & & + & & & & \\
\hline Hypogymnia physodes & sil & & & & & + & \\
\hline Lecanora dispersa & $\mathrm{cal}$ & & & & + & & \\
\hline Lecanora polytropa & sil & & + & + & + & + & + \\
\hline Lecanora rupicola & sil & & & & & + & \\
\hline Lecidea atrobrunnea & sil & & & & & + & \\
\hline Lecidea confluens & sil & & & & & + & \\
\hline Lecidea lapicida & sil & & & & & + & + \\
\hline $\begin{array}{l}\text { Lecidea lapicida var. } \\
\text { pantherina }\end{array}$ & sil & & & & & + & + \\
\hline Lecidea lithophila & sil & & & & & & + \\
\hline Lecidea silacea & sil Fe & & & & + & + & \\
\hline Lecidella carpathica & sil & & & & & + & \\
\hline Lecidella stigmatea & sil & & & & & + & \\
\hline Lecidella wulfenii & deb & & + & & & & \\
\hline Lepraria cacuminum & bry & & & & & + & \\
\hline Lepraria neglecta & bry & & & & & + & \\
\hline Melanelia stygia & sil & & & & & & + \\
\hline Miriquidica garovaglii & sil & & & & & + & \\
\hline $\begin{array}{l}\text { Mycobilimbia } \\
\text { berengeriana }\end{array}$ & ter deb & & & & + & + & \\
\hline $\begin{array}{l}\text { Mycobilimbia } \\
\text { hypnorum }\end{array}$ & deb bry & & & & & + & \\
\hline $\begin{array}{l}\text { Myxobilimbia } \\
\text { microcarpa }\end{array}$ & bry & + & & & & & \\
\hline
\end{tabular}


R. Türk, B. Erschbamer

\begin{tabular}{|c|c|c|c|c|c|c|c|}
\hline Art & Substrat & 1981 & 1971 & $1956 / 57$ & 1923 & 1858 & $\begin{array}{c}\text { Felsblock } \\
1923\end{array}$ \\
\hline Peltigera didactyla & ter & + & + & & & & \\
\hline Peltigera lepidophora & ter & & + & & & + & \\
\hline Peltigera rufescens & ter & + & + & + & + & + & \\
\hline Physcia dubia & sil & & & & + & + & + \\
\hline $\begin{array}{l}\text { Pleopsidium } \\
\text { chlorophanum }\end{array}$ & sil & & & & & & + \\
\hline Polyblastia cupularis & sil & + & & & & & \\
\hline Polysporina simplex & sil & & & & & & + \\
\hline Porpidia crustulata & sil & & + & & + & + & \\
\hline Porpidia macrocarpa & sil & & & & & + & \\
\hline Protoparmelia badia & sil & & & & & + & \\
\hline Pseudephebe minuscula & sil & & & & & & + \\
\hline Pseudephebe pubescens & sil & & & & & & + \\
\hline Pseudevernia furfuracea & sil & & & & & & + \\
\hline Pycnothelia papillaria & ter & & + & & & & \\
\hline $\begin{array}{l}\text { Rhizocarpon } \\
\text { geographicum }\end{array}$ & sil & & + & + & + & + & + \\
\hline $\begin{array}{l}\text { Rhizocarpon } \\
\text { polycarpum }\end{array}$ & sil & & & + & & & \\
\hline $\begin{array}{l}\text { Rinodina mniaraea var. } \\
\text { mniaraea }\end{array}$ & deb & & + & & & & \\
\hline Solorina spongiosa & ter & + & & & & & \\
\hline Sporastatia testudinea & sil & & & & & + & + \\
\hline Stereocaulon alpinum & ter & & + & + & + & + & \\
\hline Strereocaulon nanodes & sil Fe & & & + & + & + & \\
\hline Thamnolia vermicularis & ter & & & & + & + & \\
\hline Umbilicaria cylindrica & sil & & & & + & + & + \\
\hline Umbilicaria decussata & sil & & & & + & & + \\
\hline $\begin{array}{l}\text { Umbilicaria } \\
\text { nylanderiana }\end{array}$ & sil & & & & & & + \\
\hline Umbilicaria polyphylla & sil & & & & & + & + \\
\hline Xanthoria elegans & sil & & & & & + & + \\
\hline
\end{tabular}




\section{Füreder}

\section{Hochalpine Flusslandschaft Rotmoos}

Tab. 2:

Die benthische Fauna verschiedener Teillebensräume der Rotmoosache. Die Zuckmücken (Chironomidae) als dominierende Großgruppe sind mit ihren mittleren relativen Häufigkeiten (in Klammer die minimalen und maximalen Werte in den Einzelproben) angegeben. Darunter sind die in den Teillebensräumen ebenfalls vorkommenden Taxa (in Klammer ihre mittleren relativen Häufigkeiten) gelistet.

\begin{tabular}{|c|c|c|c|c|}
\hline \multicolumn{5}{|c|}{ Gletscherbach - Rotmoosache } \\
\hline Mikrohabitate & Grobblöcke & Lithal & Lithal (ufernah) & Psammal \\
\hline $\begin{array}{l}\text { Relative Häufigkeiten } \\
\text { (min-max) }\end{array}$ & $\begin{array}{c}95.7 \\
(86.2-100)\end{array}$ & $\begin{array}{c}79.9 \\
(39.9-93.0)\end{array}$ & $\begin{array}{c}73.4 \\
(21.7-98.1)\end{array}$ & $\begin{array}{c}63.2 \\
(0-100)\end{array}$ \\
\hline \multirow[t]{22}{*}{ Chironomidae } & Brillia modesta & Brillia modesta & Corynoneura sp. & Corynoneura sp. \\
\hline & Corynoneura sp. & Chaetocladius sp. & Diamesa bertrami & Diamesa cin./zernyi-Gr. \\
\hline & Diamesa cin./zernyi-Gr. & Corynoneura sp. & Diamesa cin./zernyi-Gr. & Diamesa juv. \\
\hline & Diamesa juv. & Diamesa bertrami & Diamesa juv. & Diamesa latitarsis-Gr. \\
\hline & Diamesa latitarsis-Gr. & Diamesa cin./zernyi-Gr. & Diamesa latitarsis-Gr. & Eukiefferiella tirol./brev-Gr. \\
\hline & Eukiefferiella fuldensis & Diamesa juv. & Eukiefferiella fuldensis & Micropsectra sp. \\
\hline & Orthocladiinae juv. & Diamesa latitarsis-Gr. & Heleniella sp. & Orthocladiinae juv. \\
\hline & Orthocladius rivicola-Gr. & Eukiefferiella fuldensis & Krenosmittia sp. & Pseudodiamesa branickii \\
\hline & Parametriocnemus stylatus & Eukiefferiella minor/fittkaui & Orthocladiinae juv. & Pseudokiefferiella parva \\
\hline & Tanytarsini juv. & Eukiefferiella tirol./brev-Gr. & Orthocladius rivicola-Gr. & Thienemanniella sp. \\
\hline & & Micropsectra sp. & Parorthocladius nudipennis & \\
\hline & & Orthocladiinae juv. & Pseudodiamesa branickii & \\
\hline & & Orthocladius frigidus & Thienemanniella sp. & \\
\hline & & Orthocladius rivicola-Gr. & Tvetenia bavarica & \\
\hline & & Orthocladius sp. & Tvetenia calvescens & \\
\hline & & Parametriocnemus stylatus & & \\
\hline & & Parorthocladius nudipennis & & \\
\hline & & Pseudodiamesa nivosa & & \\
\hline & & Pseudokiefferiella parva & & \\
\hline & & Stilocladius montanus & & \\
\hline & & Thienemanniella sp. & & \\
\hline & & Tvetenia bavarica & & \\
\hline \multirow[t]{6}{*}{ Andere Taxa (\%) } & Oligochaeta $(<1)$ & Oligochaeta $(0,5)$ & Nematoda $(<0,1)$ & Nematoda (1) \\
\hline & Tardigrada $(<0,2)$ & Acari $(<0,1)$ & Oligochaeta $(<0,2)$ & Gastropoda $(<0,3)$ \\
\hline & Harpacticoida $(0,5)$ & Harpacticoida $(1,4)$ & Harpacticoida $(0,5)$ & Oligochaeta $(<1)$ \\
\hline & Nematoda (1) & Cyclopoida $(<0,1)$ & Ostracoda $(<0,1)$ & Tardigrada $(<0,2)$ \\
\hline & Cyclopoida $(<0,2)$ & Ostracoda $(<0,1)$ & Cladocera $(<0,1)$ & Oribatida $(<0,2)$ \\
\hline & Collembola $(<0,1)$ & Cladocera $(<0,1)$ & Collembola $(<0,3)$ & Harpacticoida (24) \\
\hline
\end{tabular}


L. Füreder

\begin{tabular}{|c|c|c|c|c|}
\hline Gletscherbach - Rotm & sache & & & \\
\hline Mikrohabitate & Grobblöcke & Lithal & Lithal (ufernah) & Psammal \\
\hline \multirow[t]{13}{*}{$\begin{array}{l}\text { Relative Häufigkeiten } \\
\text { (min-max) }\end{array}$} & $\begin{array}{c}95.7 \\
(86.2-100)\end{array}$ & $\begin{array}{c}79.9 \\
(39.9-93.0)\end{array}$ & $\begin{array}{c}73.4 \\
(21.7-98.1)\end{array}$ & $\begin{array}{c}63.2 \\
(0-100)\end{array}$ \\
\hline & Rhithrogena juv. $(<0,1)$ & Collembola $(<0,2)$ & Baetis alpinus + juv. $(3,1)$ & Ostracoda $(<0,3)$ \\
\hline & $\begin{array}{l}\text { Rhabdiopteryx } \\
\text { alpina }(<0,1)\end{array}$ & Baetis alpinus + juv. $(2,2)$ & $\begin{array}{l}\text { Rhithrogena loyolea } \\
+ \text { juv. (17) }\end{array}$ & $\begin{array}{l}\text { Helophorus glacialis } \\
+ \text { juv. }(<0,3)\end{array}$ \\
\hline & Helophorus glacialis $(<0,1)$ & $\begin{array}{l}\text { Rhithrogena loyolea } \\
+ \text { juv. (13) }\end{array}$ & $\begin{array}{l}\text { Rhabdiopteryx alpina } \\
+ \text { juv. }(2,3)\end{array}$ & Rhypholophus sp. + juv. (4) \\
\hline & Empididae $(<0,1)$ & $\begin{array}{l}\text { Rhabdiopteryx alpina } \\
+ \text { juv. }(5,1)\end{array}$ & $\begin{array}{l}\text { Protonemura sp. } \\
+ \text { juv. }(<0,3)\end{array}$ & \\
\hline & Dicranota sp. $(<0,1)$ & Protonemura sp. + juv. $(0,8)$ & Capnial Leuctra juv. $(<1)$ & \\
\hline & Rhypholophus juv. $(<0,2)$ & Capnia vidua $(<0,1)$ & Plecoptera juv. $(3,5)$ & \\
\hline & & Capnial Leuctra juv. $(0,1)$ & Helophorus glacialis $(<0,1))$ & \\
\hline & & Empididae $(0,2)$ & Limnephilidae juv. $(<0,1)$ & \\
\hline & & Dicranota sp. $(<0,2)$ & Empididae sp. $(0,2)$ & \\
\hline & & Rhypholophus juv. $(0,1)$ & Rhypholophus sp. + juv. (3) & \\
\hline & & Prosimulium sp. $(<0,1)$ & Prosimulium sp. $(<0,1)$ & \\
\hline & & Ceratopogonidae $(<0,1)$ & & \\
\hline Gesamttaxazahl & $9(2-16)$ & $22(16-30)$ & $17(8-26)$ & $6(2-16)$ \\
\hline
\end{tabular}


Tab. 3:

Die benthische Fauna eines nicht-gletscherbeeinflussten Baches (Schönwiesbach) in 3 Teillebensräumen (Quellbereich, Schnelle, Gumpen). Die Zuckmücken (Chironomidae) als dominierende Großgruppe sind mit ihren mittleren relativen Häufigkeiten (in Klammer die minimalen und maximalen Werte in den Einzelproben) angegeben. Darunter sind die in den Teillebensräumen ebenfalls vorkommenden Taxa (in Klammer ihre relativen Häufigkeiten) gelistet.

\begin{tabular}{|c|c|c|c|}
\hline \multicolumn{4}{|c|}{ Quellbach - Schönwiesbach } \\
\hline Mikrohabitat & Quellbereich & Schnelle & Gumpen \\
\hline $\begin{array}{l}\text { Relative Häufigkeiten } \\
\text { (min-max) }\end{array}$ & 72.6 & $\begin{array}{c}51.4 \\
(31.4-71.3)\end{array}$ & 65.4 \\
\hline \multirow[t]{18}{*}{ Chironomidae } & Corynoneura sp. & Brillia modesta & Diamesa cin./zernyi-Gr. \\
\hline & Diamesa cin./zernyi-Gr. & Corynoneura sp. & Heterotrissocladius marcidus \\
\hline & Diamesa juv. & Diamesa cin./zernyi-Gr. & Micropsectra attrofasc--Aggr. \\
\hline & Orthocladiinae juv. & Diamesa juv. & Orthocladiinae juv. \\
\hline & Orthocladiinae "COP" & Diamesa lat./steinboecki-Gr. & Orthocladius frigidus \\
\hline & Paratrichocladius nivalis & Krenosmittia sp. & Orthocladius sp. \\
\hline & Parorthocladius nudipennis & Micropsectra attrofasc.-Aggr. & Parakiefferiella sp. \\
\hline & Pseudokiefferiella parva & Orthocladiinae juv. & Paratanytarsus sp. \\
\hline & Thienemanniella sp. & Orthocladius frigidus & Paratrichocladius nivalis \\
\hline & & Orthocladius sp. & Pseudodiamesa branickii \\
\hline & & Parakiefferiella sp. & Pseudokiefferiella parva \\
\hline & & Paratrichocladius nivalis & Thienemanniella sp. \\
\hline & & Parorthocladius nudipennis & \\
\hline & & Pseudokiefferiella parva & \\
\hline & & Rheocricotopus effusus & \\
\hline & & Smittia sp. & \\
\hline & & Thienemanniella sp. & \\
\hline & & Tvetenia bavarica & \\
\hline \multirow[t]{8}{*}{ Andera Taxa (\%) } & Crenobia alpina (21) & Crenobia alpina $(<0,1)$ & Nematoda $(9,7)$ \\
\hline & Oligochaeta $(<0,1)$ & Nematoda $(<0,1)$ & Oligochaeta $(5,1)$ \\
\hline & Hydrachnellae $(<0,1)$ & Orbatida $(<0,2)$ & Tardigrada $(10,3)$ \\
\hline & Leuctra rosinae $(0,1)$ & Hydrachnellae $(2,5)$ & Orbatida (2) \\
\hline & Leuctra juv. $(0,4)$ & Harpacticoida (15) & Hydrachnellae $(0,3)$ \\
\hline & Perlodidae juv. $(0,7)$ & Ostracoda $(1,1)$ & Harpacticoida $(4,8)$ \\
\hline & Limnephilidae juv. (5) & Collembola $(1,2)$ & Ostracoda $(2,3)$ \\
\hline & Drusus monticola $(0,1)$ & Baetis alpinus + juv. $(0,6)$ & Leuctra juv. $(<0,1)$ \\
\hline
\end{tabular}


L. Füreder

\begin{tabular}{lccc}
\hline Quellbach - Schönwiesbach & & & \\
\hline Mikrohabitat & Quellbereich & Schnelle & Gumpen \\
$\begin{array}{l}\text { Relative Häufigkeiten } \\
(\text { min-max) }\end{array}$ & 72.6 & 51.4 & 65.4 \\
\hline
\end{tabular}

\begin{tabular}{cll} 
Empididae juv. $(<0,1)$ & Rhithrogena loyolea + juv. $(1,6)$ & Limnephilidae juv. $(<0,1)$ \\
& Brachyptera juv. $(0,1)$ & \\
& Protonemura sp. $(1,8)$ & \\
& Leuctra rosinae $(0,4)$ & \\
& Leuctra alpine $(<0,1)$ & \\
& Leuctra juv. $(<0,1)$ \\
& Dictyogenus fontium $(0,8)$ \\
& Perlodidae juv. $(<0,1)$ & \\
& Helophorus glacialis $(<0,1)$ \\
& Limnephilidae juv. $(<0,3)$ \\
& Empididae sp. + juv. $(1,3)$ & \\
\hline & 56 & 26 \\
\hline
\end{tabular}


Tab. 4:

Die benthische Fauna eines aquatischen-terrestrischen Übergangbereiches in 5 Teillebensräumen (Quellbereich, Moos, Algen, Detritus und Tümpel). Die Zuckmücken (Chironomidae) sind mit ihren mittleren relativen Häufigkeiten (in Klammer die minimalen und maximalen Werte in den Einzelproben) angegeben. Darunter sind die in den Teillebensräumen ebenfalls vorkommenden Taxa (in Klammer ihre relativen Häufigkeiten) gelistet.

\begin{tabular}{|c|c|c|c|c|c|}
\hline \multicolumn{6}{|c|}{ Quellgespeister Bach mit Überflutungstümpel } \\
\hline Mikrohabitat & Quellbereich & Moos & Algen & Detritus & Tümpel \\
\hline $\begin{array}{l}\text { Rel. densities } \\
\text { (min-max) }\end{array}$ & $\begin{array}{c}19.1 \\
(18.1-20.2)\end{array}$ & $\begin{array}{c}15.1 \\
(9.1-23.4)\end{array}$ & $\begin{array}{c}4.3 \\
(3.6-5.0)\end{array}$ & $\begin{array}{c}41.1 \\
(27.2-54.9)\end{array}$ & $\begin{array}{c}10.8 \\
(7.3-20.9)\end{array}$ \\
\hline \multirow[t]{13}{*}{ Chironomidae } & Chaetocladius sp. & Chaetocladius sp. & Chaetocladius sp. & Corynoneura $s p$. & Corynoneura $s p$. \\
\hline & Corynoneurasp. & Corynoneura sp. & Corynoneura sp. & Diamesa juv. & Diamesa juv. \\
\hline & Krenopelopia sp. & Krenopelopia binotata & Krenopelopia binotata & Diamesa cin./zernyi-Gr. & Micropsectra sp. \\
\hline & Krenosmittia sp. & Krenopelopia sp. & Krenopelopia sp. & $\begin{array}{l}\text { Heterotrissocladius } \\
\text { marcidus }\end{array}$ & Neozavrelia sp. \\
\hline & $\begin{array}{l}\text { Micropsectra } \\
\text { attrofasc-Gr. }\end{array}$ & $\begin{array}{l}\text { Metriocnemus } \\
\text { hygropetricus-Gr. }\end{array}$ & $\begin{array}{l}\text { Metriocnemus } \\
\text { hygropetricus-Gr. }\end{array}$ & Krenopelopia sp. & Orthocladiinae juv. \\
\hline & Orthocladiinae juv. & Micropsectra sp. & Neozavrelia sp. & Micropsectrasp. & Tanytarsini juv. \\
\hline & $\begin{array}{l}\text { Parametriocnemus } \\
\text { stylatus }\end{array}$ & Orthocladiinae juv. & Orthocladiinae juv. & Orthocladiinae juv. & Tanytarsus lugens-Gr. \\
\hline & $\begin{array}{l}\text { Parorthocladius } \\
\text { nudipennis }\end{array}$ & Orthocladius sp. & $\begin{array}{l}\text { Parametriocnemus } \\
\text { stylatus }\end{array}$ & Orthocladius sp. & \\
\hline & Rheocricotopus effusus & Parametriocnemus stylatus & Rheocricotopus effusus & Paratanytarsus sp. & \\
\hline & Tanypodinae juv. & Pentaneurini juv. & Tanytarsini juv. & Pseudodiamesa nivosa & \\
\hline & Tanytarsini juv. & Rheocricotopus effusus & & Rheocricotopus effusus & \\
\hline & Thienemanniella sp. & Tanytarsini juv. & & Tanytarsini juv. & \\
\hline & Tvetenia bavarica & Tvetenia bavarica & & Tvetenia bavarica & \\
\hline \multirow[t]{13}{*}{ Andera Taxa (\%) } & Crenobia alpina (13) & Crenobia alpina $(1,2)$ & Crenobia alpina $(1,1)$ & Crenobia alpina $(3,4)$ & Crenobia alpina $(<0,1)$ \\
\hline & Nematoda $(7,6)$ & Nematoda (13) & Nematoda $(3,3)$ & Nematoda (10) & Nematoda (61) \\
\hline & Sphaeridae $(<0,2)$ & Sphaeridae $(<0,3)$ & Sphaeridae $(<0,2)$ & Sphaeridae $(1,8)$ & Gastropoda $(<0,2)$ \\
\hline & Oligochaeta (14) & Oligochaeta (7) & Oligochaeta $(6,7)$ & Oligochaeta (10) & Oligochaeta $(3,4)$ \\
\hline & Tardigrada $(<0,1)$ & Tardigrada $(1,2)$ & Tardigrada $(<0,1)$ & Tardigrada $(1,7)$ & Tardigrada $(6,5)$ \\
\hline & Oribatida $(2,7)$ & Oribatida $(13,5)$ & Oribatida $(17,8)$ & Oribatida $(6,2)$ & Oribatida $(2,6)$ \\
\hline & Actinetida $(<0,3)$ & Actinetida $(0,1)$ & Gamasidae $(<0,1)$ & Actinetida $(<0,3)$ & Actinetida $(0,1)$ \\
\hline & Hydrachnellae $(1,3)$ & Hydrachnellae $(9,3)$ & Hydrachnellae $(6,1)$ & Hydrachnellae $(4,8)$ & Gamasidae $(<0,1)$ \\
\hline & Harpacticoida $(18,4)$ & Harpacticoida $(27,6)$ & Harpacticoida (37) & Harpacticoida $(9,3)$ & Hydrachnellae $(4,9)$ \\
\hline & Cyclopoida $(0,1)$ & Cyclopoida $(<0,1)$ & Cyclopoida $(<0,1)$ & Cyclopoida $(<0,1)$ & Harpacticoida $(0,2)$ \\
\hline & Ostracoda (11) & Ostracoda $(10,4)$ & Ostracoda $(21,3)$ & Ostracoda $(10,5)$ & Cyclopoida $(1,3)$ \\
\hline & Baetis juv. $(0,5)$ & Plecoptera juv. $(0,4)$ & Cladocera $(0,8)$ & Leuctra juv. $(<0,1)$ & Ostracoda $(6,6)$ \\
\hline & $\begin{array}{l}\text { Protonemura sp. } \\
+ \text { juv. }(<0,1)\end{array}$ & $\begin{array}{l}\text { Helophorus glacialis } \\
(<0,2)\end{array}$ & Plecoptera juv. $(<0,1)$ & Plecoptera juv. $(0,9)$ & $\begin{array}{l}\text { Helophorus glacialis } \\
(<0,1)\end{array}$ \\
\hline
\end{tabular}


L. Füreder

\begin{tabular}{|c|c|c|c|c|c|}
\hline \multicolumn{6}{|c|}{ Quellgespeister Bach mit Überflutungstümpel } \\
\hline Mikrohabitat & Quellbereich & Moos & Algen & Detritus & Tümpel \\
\hline \multirow[t]{8}{*}{$\begin{array}{l}\text { Rel. densities } \\
\text { (min-max) }\end{array}$} & $\begin{array}{c}19.1 \\
(18.1-20.2)\end{array}$ & $\begin{array}{c}15.1 \\
(9.1-23.4)\end{array}$ & $\begin{array}{c}4.3 \\
(3.6-5.0)\end{array}$ & $\begin{array}{c}41.1 \\
(27.2-54.9)\end{array}$ & $\begin{array}{c}10.8 \\
(7.3-20.9)\end{array}$ \\
\hline & $\begin{array}{l}\text { Dictyogenus } \\
\text { fontium }+ \text { juv. }(<0,1)\end{array}$ & Empididae $(<0,3)$ & $\begin{array}{l}\text { Helophorus glacialis } \\
(0,6)\end{array}$ & $\begin{array}{l}\text { Helophorus glacialis } \\
(0,3)\end{array}$ & $\begin{array}{l}\text { Limnephilidae juv. } \\
(<0,1)\end{array}$ \\
\hline & Plecoptera juv. (1) & Dicranota sp. $(<0,1)$ & $\begin{array}{l}\text { Limnephilidae juv. } \\
(<0,1)\end{array}$ & $\begin{array}{l}\text { Limnephilidae juv. } \\
(<0,1)\end{array}$ & Tipulidae $(<0,1)$ \\
\hline & $\begin{array}{l}\text { Helophorus glacialis } \\
(<0,2)\end{array}$ & Rhypholophus sp. $(<0,1)$ & Empididae $(<0,2)$ & Empididae $(<0,2)$ & Ceratopogonidae $(0,7)$ \\
\hline & $\begin{array}{l}\text { Limnephilidae juv. } \\
(<0,3)\end{array}$ & Tipulidae $(<0,1)$ & $\begin{array}{l}\text { Ceratopogonidae } \\
(0,7)\end{array}$ & Ceratopogonidae $(0,1)$ & \\
\hline & Empididae $(0,1)$ & Ceratopogonidae $(0,5)$ & & & \\
\hline & Dicranota sp. $(0,4)$ & & & & \\
\hline & Prosimulium sp. $(<0,1)$ & & & & \\
\hline Gesamttaxazahl & $53(50-56)$ & $57(56-60)$ & $48(48-48)$ & $46(42-50)$ & $30(28-32)$ \\
\hline
\end{tabular}


E. Rott, D. Gesierich, N. Binder

\section{Lebensraumtypen und Diversitätsgradienten lotischer Algen in einem Gletschereinzugsgebiet}

Tab. A1:

Gesamtartenliste der benthischen Algen an den untersuchten Probenstellen im Rotmoostal inkl. Einstufung der Arten; Rote Liste der Kieselalgen (RL) nach Lange-Bertalot (1996); Rote Liste der Zieralgen nach Lenzenweger (1999a); Trophiewerte (TW) nach Rott et al. (1999); 1 - vom Aussterben bedroht, 2 - stark gefährdet, 3 - gefährdet, G - Gefährdung anzunehmen, R - extrem selten, V - zurückgehend, * - derzeit nicht als gefährdet anzusehen, ${ }^{* *}$ - mit Sicherheit ungefährdet, $\bullet$ - im Gebiet zu erwarten, D - Daten mangelhaft (modifiziert aus: Gesierich, D. \& E. Rott (2004) Benthic algae and mosses from aquatic habitats in the catchment of a glacial stream (Rotmoos, Ötztal, Austria). Ber. nat.-med. Ver. Innsbruck 91: 37-42.)

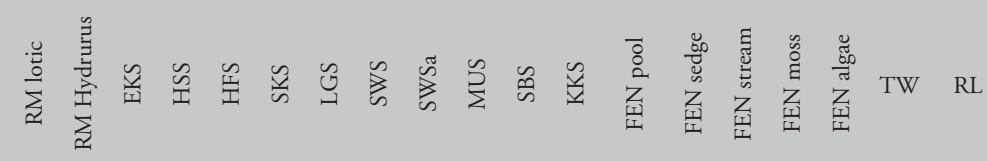

Cyanophyceae

Ammatoidea normanni

$\mathrm{X}$

Ammatoidea simplex

Aphanocapsa sp.

Aphanothece saxicola

Aphanothece stagnina

Calothrix fusca

Calothrix sp.

Chamaesiphon fuscus

Chamaesiphon incrustans

Chamaesiphon investiens

Chamaesiphon minutus

Chamaesiphon polonicus

Chamaesiphon rostafinskii

Chroococcus sp.

Clastidium rivulare

Clastidium setigerum

Dichothrix gypsophila

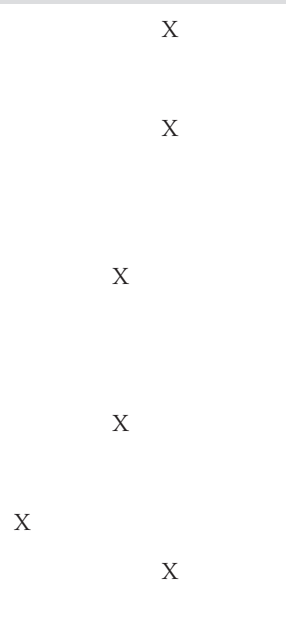

x

X

X

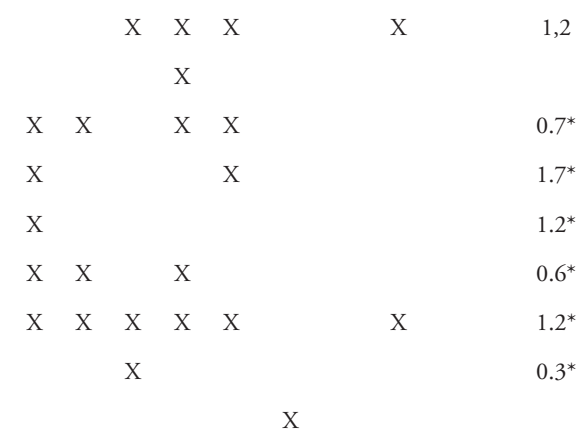

$\begin{array}{lllll}\mathrm{X} & & & & 0.8^{*} \\ \mathrm{X} & \mathrm{X} & \mathrm{X} & \mathrm{X} & 0.4^{*} \\ & & & & 1.2^{*}\end{array}$


E. Rott, D. Gesierich, N. Binder

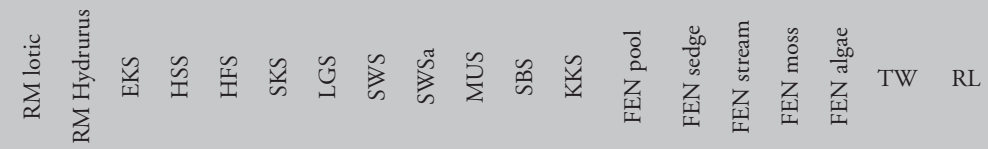

\section{Entophysalis sp.}

Gloeocapsa alpina

Gloeocapsa dermochroa

Gloeocapsa sanguinea

Homoeothrix fusca

Homoeothrix gracilis

Homoeothrix janthina

Homoeothrix varians

Hydrococcus rivularis

Lyngbya martensiana

Nostoc sp.

Oscillatoria sancta

Phormidium autumnale

Phormidium incrustatum

Phormidium subfuscum

Phormidium uncinatum

Pleurocapsa minor

Pseudanabaena sp.

Schizothrix sp.

Siphononema polonicum

Stigonema mamillosum

Synechococcus sp.

Tolypothrix penicillata

Woronichinia sp.

Xenococcus sp.

\section{$\mathrm{X}$}

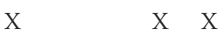

$\mathrm{X} \quad \mathrm{X} \quad \mathrm{X}$

$\mathrm{X}$

$\mathrm{X}$

X

$x \quad x \quad X$

$\mathrm{X} \quad \mathrm{X} \quad \mathrm{X}$

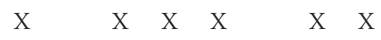

X

$\mathrm{x}$
X $\quad 0,6$

$1.1^{*}$

X $\quad 1,2$

0,6

$0.8^{*}$

$1.5^{*}$

X
$1.4^{*}$

$1.7^{*}$

\section{L}




\begin{tabular}{|c|c|c|c|c|c|c|c|c|c|c|c|c|c|c|c|c|c|c|c|}
\hline & 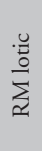 & 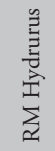 & $\frac{\mathscr{v}}{\not I}$ & $\tilde{n}$ & 至 & $\tilde{w}$ & $\mathscr{3}$ & $\tilde{s}$ & 芯 & $\sum_{\Sigma}^{\infty}$ & $\tilde{\omega}$ & $\ddot{v}$ & 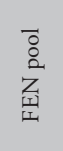 & 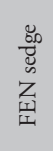 & 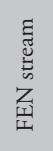 & 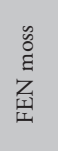 & 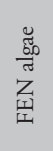 & TW & RL \\
\hline Achnanthes cf. grischuna & $\mathrm{X}$ & & & & & & & & & & & & & & & & & & * \\
\hline Achnanthes cf. kryophila & & $\mathrm{X}$ & & & & & & & & $\mathrm{X}$ & & & $\mathrm{X}$ & $\mathrm{X}$ & $\mathrm{X}$ & $\mathrm{X}$ & $\mathrm{X}$ & & 3 \\
\hline Achnanthes cf. saccula & $\mathrm{X}$ & & & & & & & & & $\mathrm{X}$ & & & $\mathrm{X}$ & $\mathrm{X}$ & $\mathrm{X}$ & $\mathrm{x}$ & $\mathrm{x}$ & 0,6 & . \\
\hline Achnanthes cf. stewartii & & & $\mathrm{X}$ & & & $\mathrm{X}$ & & $\mathrm{X}$ & & $\mathrm{X}$ & & & & & & & & & . \\
\hline Achnanthes cf. subatomoides & & $\mathrm{X}$ & $\mathrm{X}$ & & & & & $\mathrm{X}$ & & & & & $\mathrm{X}$ & & $\mathrm{X}$ & $\mathrm{X}$ & $\mathrm{X}$ & $2.1^{*}$ & V \\
\hline Achnanthes didyma & & & & & & & & & & & & & $\mathrm{X}$ & $\mathrm{X}$ & $\mathrm{X}$ & & & & 3 \\
\hline Achnanthes flexella & & & & & & & & $\mathrm{X}$ & & & & & $\mathrm{X}$ & & & & & 0,3 & 3 \\
\hline Achnanthes helvetica & $\mathrm{X}$ & $\mathrm{X}$ & $\mathrm{X}$ & $\mathrm{X}$ & $\mathrm{X}$ & $\mathrm{X}$ & & $\mathrm{X}$ & & $\mathrm{X}$ & & $\mathrm{X}$ & $\mathrm{X}$ & $\mathrm{X}$ & $\mathrm{X}$ & $\mathrm{X}$ & $\mathrm{X}$ & $0.6^{*}$ & $*$ \\
\hline Achnanthes sp. & & & & & & & & & & & & & $\mathrm{X}$ & $\mathrm{x}$ & $\mathrm{X}$ & $\mathrm{X}$ & $\mathrm{x}$ & & \\
\hline Achnanthes laevis & $\mathrm{X}$ & $\mathrm{x}$ & $\mathrm{X}$ & & $\mathrm{X}$ & $\mathrm{X}$ & $\mathrm{X}$ & $\mathrm{X}$ & & $\mathrm{X}$ & $\mathrm{X}$ & & & & & & $\mathrm{X}$ & 1,2 & $*$ \\
\hline Achnanthes lanceolata & $\mathrm{X}$ & $\mathrm{X}$ & & $\mathrm{X}$ & $\mathrm{X}$ & & & & & & $\mathrm{X}$ & $\mathrm{X}$ & & & & & & $3.3^{*}$ & ** \\
\hline $\begin{array}{l}\text { Achnanthes lanceolata ssp. } \\
\text { frequentissima }\end{array}$ & $\mathrm{X}$ & $\mathrm{X}$ & & $\mathrm{X}$ & $\mathrm{X}$ & & & & & & & & & & & & & $2.8^{*}$ & ** \\
\hline Achnanthes minutissima & $\mathrm{X}$ & $\mathrm{x}$ & $\mathrm{X}$ & $\mathrm{X}$ & $\mathrm{X}$ & $\mathrm{X}$ & $\mathrm{X}$ & $\mathrm{X}$ & $\mathrm{X}$ & $\mathrm{X}$ & $\mathrm{X}$ & $\mathrm{X}$ & $\mathrm{X}$ & $\mathrm{X}$ & $\mathrm{X}$ & $\mathrm{X}$ & $\mathrm{X}$ & $1.2^{*}$ & ** \\
\hline $\begin{array}{l}\text { Achnanthes minutissima } \\
\text { var. jackii }\end{array}$ & $\mathrm{X}$ & & & & & & & & & & & & & & & & & 1,2 & $\mathrm{D}$ \\
\hline Achnanthes petersenii & $\mathrm{X}$ & $\mathrm{X}$ & & $\mathrm{X}$ & & $\mathrm{X}$ & $\mathrm{X}$ & $\mathrm{X}$ & $\mathrm{X}$ & $\mathrm{X}$ & $\mathrm{X}$ & & & $\mathrm{X}$ & & & & 0,6 & 3 \\
\hline Achnanthes pusilla & & & & & & & & & & & & & $\mathrm{X}$ & & & & & 0,6 & 3 \\
\hline Achnanthes scotica & & & $\mathrm{X}$ & $\mathrm{X}$ & $\mathrm{X}$ & $\mathrm{X}$ & & $\mathrm{X}$ & & $\mathrm{X}$ & & & & $\mathrm{X}$ & $\mathrm{X}$ & $\mathrm{X}$ & $\mathrm{X}$ & & $\mathrm{R}$ \\
\hline Adlafia bryophila & $\mathrm{X}$ & $\mathrm{X}$ & & & $\mathrm{X}$ & & & & & $\mathrm{X}$ & & & $\mathrm{X}$ & $\mathrm{X}$ & $\mathrm{X}$ & $\mathrm{X}$ & $\mathrm{X}$ & 1,3 & \\
\hline Adlafia minuscula & $\mathrm{X}$ & $\mathrm{X}$ & & & & & & $\mathrm{X}$ & & & $\mathrm{X}$ & & $\mathrm{X}$ & & & & & 1,1 & \\
\hline Adlafia suchlandtii & & & $\mathrm{X}$ & & & & & $\mathrm{X}$ & & & $\mathrm{X}$ & & $\mathrm{X}$ & $\mathrm{X}$ & $\mathrm{X}$ & $\mathrm{X}$ & $\mathrm{X}$ & 0,6 & $\mathrm{~V}$ \\
\hline Amphipleura pellucida & & & & & & & $\mathrm{X}$ & $\mathrm{X}$ & & & & & & & & & & 2,1 & $*$ \\
\hline Amphora cf. veneta & & & & & & & & & & & $\mathrm{X}$ & & & & & & & 3,8 & ** \\
\hline Amphora inariensis & $\mathrm{X}$ & $\mathrm{X}$ & & & & & & & & $\mathrm{X}$ & $\mathrm{X}$ & & & & & & & $2.1^{*}$ & 3 \\
\hline Amphora libyca & & & & & & & & $\mathrm{X}$ & & & & & & & & & & $3.5^{*}$ & ** \\
\hline Amphora pediculus & $\mathrm{X}$ & & $\mathrm{X}$ & $\mathrm{X}$ & $\mathrm{X}$ & & & $\mathrm{X}$ & & & $\mathrm{X}$ & $\mathrm{x}$ & & & & & & $2.8^{*}$ & ** \\
\hline Aulacosira sp. & & & & & & & & & & $\mathrm{X}$ & & & $\mathrm{X}$ & $\mathrm{X}$ & $\mathrm{X}$ & $\mathrm{X}$ & $\mathrm{X}$ & & \\
\hline Brachysira brebissonii & $\mathrm{X}$ & $\mathrm{X}$ & & $\mathrm{X}$ & $\mathrm{X}$ & & & $\mathrm{X}$ & & & & & $\mathrm{X}$ & $\mathrm{X}$ & $\mathrm{X}$ & $\mathrm{X}$ & $\mathrm{X}$ & 1,1 & * \\
\hline Caloneis hyalina & & & & & & & & & & & & & $\mathrm{X}$ & & & & & & \\
\hline Caloneis silicula & & & & & $\mathrm{X}$ & $\mathrm{X}$ & & & & & $\mathrm{X}$ & & $\mathrm{X}$ & & & & & 2,5 & $*$ \\
\hline Caloneis tenuis & & $\mathrm{X}$ & & & & & & & & $\mathrm{X}$ & $\mathrm{X}$ & & $\mathrm{X}$ & $\mathrm{X}$ & $\mathrm{X}$ & $\mathrm{X}$ & $\mathrm{X}$ & 1,1 & G \\
\hline Cavinula cf. intractata & & & & $\mathrm{X}$ & $\mathrm{X}$ & & & & & & & & & & & & & & \\
\hline Chamaepinnularia mediocris & & & & & & & & & & & & $\mathrm{x}$ & $\mathrm{x}$ & $\mathrm{X}$ & $\mathrm{x}$ & $\mathrm{x}$ & $\mathrm{x}$ & 0,6 & $\mathrm{~V}$ \\
\hline
\end{tabular}


E. Rott, D. Gesierich, N. Binder

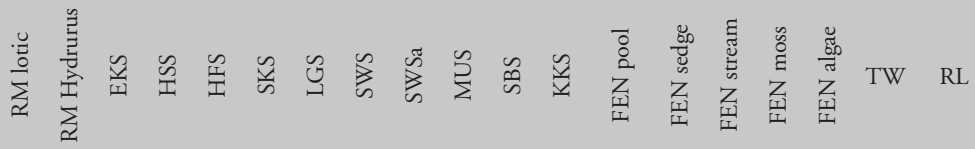

Chamaepinnularia schauppiana

\section{Cocconeis pediculus}

Cocconeis placentula

Cyclotella sp.

Cymbella affinis

Cymbella amphicephala

Cymbella aspera

Cymbella cistula

Cymbella delicatula

Cymbella ehrenbergii

Cymbella naviculacea

Cymbella naviculiformis $\quad \mathrm{X} \quad \mathrm{X}$

$\frac{\text { Cymbella subaequalis }}{\text { Cymbella subcuspidata }}$

Denticula tenuis

Diadesmis gallica var.

perpusilla

Diatoma ehrenbergii

Diatoma hyemalis

Diatoma mesodon

Diatoma vulgaris

Diploneis boldtiana

Diploneis cf. elliptica

Diploneis cf. petersenii

Diploneis marginestriata

Diploneis marginulata

Diploneis oblongella

Encyonema neogracile var. tenuipunctatum

Encyonema alpina

Encyonema caespitosa

X

Encyonema cf. vulgare

Encyonema falaisensis

X X

$\mathrm{X}$

X X

X

X
X

$\begin{array}{rrrrrrrrrrr}X & X & X & & & & X & X & & \\ & & & X & X & X & & X & X & X\end{array}$

X

X X

$\begin{array}{llll}X & X & X\end{array}$

$\mathrm{X} \quad \mathrm{X} \quad \mathrm{X}$

X

X

X

$0.7^{*} \quad *$

X

X

$1,1 \quad \mathrm{~V}$

$1,7 \quad \mathrm{~V}$

X

$2,3 \quad \mathrm{~V}$

X

$0.3^{*} \mathrm{G}$

$2,2 \quad \mathrm{~V}$

$\mathrm{X}$

$\mathrm{X} \quad \mathrm{X} \quad \mathrm{X} \quad 3$

$\begin{array}{llllllllll}\mathrm{X} & \mathrm{X} & \mathrm{X} & \mathrm{X} & 1,8 \quad *\end{array}$

$\mathrm{X} \quad \mathrm{X} \quad \mathrm{X} \quad \mathrm{X}$

$\begin{array}{lllllll}X & X & X & X & X & 1,0 & G \\ X & X & & & & \end{array}$

$\begin{array}{lllllllll}X & X & X & X & X & X & X & X\end{array}$

$\begin{array}{lll}\mathrm{X} & \mathrm{X} & 1.4^{*}\end{array}$

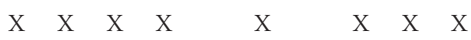

$\begin{array}{llllll}\mathrm{X} & \mathrm{X} & \mathrm{X} & \mathrm{X} & 1,2 \quad * *\end{array}$

$\mathrm{X}$

$1.6^{*} \quad * *$

$x$
$x$

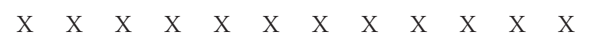

$\mathrm{X} \quad \mathrm{X} \quad \mathrm{X}$

$0.7^{*} \quad *$

X

$2,0 \quad \mathrm{D}$

$\mathrm{X}$

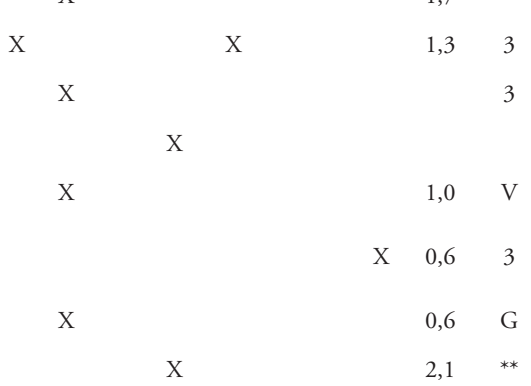

$\mathrm{X} \quad \mathrm{X}$

$\mathrm{X}$

$\begin{array}{llllll}X & X & X & X & X & X\end{array}$

X X

$\begin{array}{llllllll}X & X & X & X & X & 0.4^{*} & G\end{array}$ 


\begin{tabular}{|c|c|c|c|c|c|c|c|c|c|c|c|c|c|c|c|c|c|c|c|}
\hline & $\frac{\stackrel{u}{0}}{\sum_{\beth}}$ & 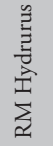 & $\frac{\tilde{y}}{y}$ & $\tilde{\approx}$ & 岂 & $\tilde{v}$ & $\mathscr{S}$ & 绾 & s్ & $\stackrel{n}{\Sigma}$ & ڤै & $\mathscr{y}$ & 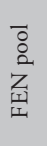 & 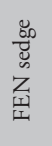 & 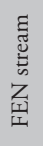 & 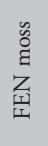 & 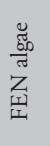 & TW & RL \\
\hline Encyonema fogedii & $\mathrm{X}$ & $\mathrm{X}$ & & & & & & $\mathrm{X}$ & & & & & & & & & & & \\
\hline Encyonema gaeumannii & & & & & & & & & & & $\mathrm{X}$ & & $\mathrm{X}$ & $\mathrm{X}$ & $\mathrm{X}$ & $\mathrm{X}$ & $\mathrm{X}$ & 0,6 & \\
\hline Encyonema minutum & $\mathrm{X}$ & $\mathrm{X}$ & $\mathrm{X}$ & $\mathrm{X}$ & $\mathrm{X}$ & $\mathrm{X}$ & $\mathrm{X}$ & $\mathrm{X}$ & & & & $\mathrm{X}$ & & & $\mathrm{X}$ & & & $2.0^{*}$ & * \\
\hline Encyonema neogracile & $\mathrm{X}$ & $\mathrm{X}$ & & & & & & & & & & & $\mathrm{X}$ & $\mathrm{X}$ & $\mathrm{X}$ & $\mathrm{X}$ & $\mathrm{X}$ & & \\
\hline Encyonema perpusilla & & & & & & & & & & & & & $\mathrm{X}$ & $\mathrm{X}$ & $\mathrm{X}$ & $\mathrm{X}$ & $\mathrm{X}$ & 0,5 & \\
\hline Encyonema silesiacum & $\mathrm{X}$ & $\mathrm{X}$ & & & & & $\mathrm{X}$ & $\mathrm{X}$ & & $\mathrm{X}$ & $\mathrm{x}$ & $\mathrm{X}$ & $\mathrm{X}$ & $\mathrm{X}$ & $\mathrm{X}$ & $\mathrm{X}$ & $\mathrm{X}$ & 2,0 & * \\
\hline Encyonopsis cesatii & & & & $\mathrm{x}$ & & & & $\mathrm{X}$ & & $\mathrm{X}$ & & & & $\mathrm{X}$ & $\mathrm{X}$ & $\mathrm{X}$ & $\mathrm{X}$ & 0,6 & * \\
\hline Encyonopsis microcephala & & & & $\mathrm{x}$ & $\mathrm{X}$ & & $\mathrm{X}$ & & & & & & $\mathrm{X}$ & & & & $\mathrm{X}$ & $1.2^{*}$ & * \\
\hline Encyonema lange-bertalotii & $\mathrm{X}$ & $\mathrm{X}$ & & & & & & & & & & & & $\mathrm{X}$ & & & & & \\
\hline Epithemia sp. & & & & & $\mathrm{x}$ & & & & & $\mathrm{X}$ & $\mathrm{X}$ & & & & & & & & \\
\hline Eunotia\#3 JÖ & & & & & & & & & & & & & & $\mathrm{X}$ & $\mathrm{x}$ & $\mathrm{x}$ & $\mathrm{X}$ & & \\
\hline Eunotia arcus & & & & & & & & $\mathrm{X}$ & & $\mathrm{X}$ & & & & & & & & 1,1 & \\
\hline Eunotia bilunaris & & & & & & & & & & & & & $\mathrm{X}$ & $\mathrm{X}$ & $\mathrm{X}$ & $\mathrm{X}$ & $\mathrm{X}$ & 0,7 & 2 \\
\hline Eunotia cf. groenlandica & & & & & & & & & & & & & $\mathrm{X}$ & & & $\mathrm{X}$ & & & . \\
\hline $\begin{array}{l}\text { Eunotia } \mathrm{cf} . \\
\text { pseudoparalleloides }\end{array}$ & & & & & & & & & & $\mathrm{X}$ & & & & & & & & & . \\
\hline Eunotia curtagrunowii & & & $\mathrm{X}$ & & & $\mathrm{X}$ & & & & & & & $\mathrm{X}$ & & $\mathrm{X}$ & $\mathrm{X}$ & & & \\
\hline Eunotia exigua & $\mathrm{X}$ & $\mathrm{X}$ & $\mathrm{X}$ & $\mathrm{X}$ & $\mathrm{X}$ & & & & & $\mathrm{X}$ & & & $\mathrm{X}$ & $\mathrm{X}$ & $\mathrm{X}$ & $\mathrm{X}$ & $\mathrm{X}$ & $0.5^{*}$ & $* *$ \\
\hline Eunotia incisa ",borealis" & $\mathrm{x}$ & $\mathrm{X}$ & $\mathrm{X}$ & & & $\mathrm{X}$ & & & & $\mathrm{X}$ & & & $\mathrm{X}$ & $\mathrm{X}$ & $\mathrm{X}$ & $\mathrm{x}$ & $\mathrm{X}$ & & * \\
\hline Eunotia inflata & & & & & & & & & & & & & $\mathrm{X}$ & & $\mathrm{X}$ & & & & \\
\hline Eunotia islandica & & & & & & & & & & & & & $\mathrm{X}$ & & & & & & $\mathrm{D}$ \\
\hline Eunotia pectinalis & & & & & & & & & & & & & & $\mathrm{X}$ & $\mathrm{X}$ & $\mathrm{X}$ & & 1,1 & $\mathrm{~V}$ \\
\hline Eunotia tetraodon & & & & & & & & & & & & & & & $\mathrm{X}$ & & $\mathrm{X}$ & & 2 \\
\hline Eunotia valida & & & & & & & & & & & & & $\mathrm{X}$ & & & & & & \\
\hline Fragilaria arcus & $\mathrm{X}$ & $\mathrm{X}$ & $\mathrm{X}$ & $\mathrm{X}$ & $\mathrm{X}$ & $\mathrm{X}$ & $\mathrm{X}$ & $\mathrm{X}$ & & $\mathrm{X}$ & $\mathrm{X}$ & $\mathrm{X}$ & & & $\mathrm{X}$ & & & $1.0^{*}$ & $* *$ \\
\hline Fragilaria brevistriata & $\mathrm{X}$ & $\mathrm{X}$ & & & & & & & & & & & & & & & & $3.0^{*}$ & $* *$ \\
\hline $\begin{array}{l}\text { Fragilaria capucina var. } \\
\text { austriaca }\end{array}$ & & $\mathrm{X}$ & & $\mathrm{X}$ & $\mathrm{X}$ & & $\mathrm{X}$ & $\mathrm{X}$ & & $X$ & $\mathrm{X}$ & & $\mathrm{X}$ & & $\mathrm{X}$ & $X$ & & $0.5^{*}$ & G \\
\hline $\begin{array}{l}\text { Fragilaria capucina var. } \\
\text { capucina }\end{array}$ & $X$ & $\mathrm{X}$ & & & & & & & & $\mathrm{X}$ & & & & & & & & 1,8 & $* *$ \\
\hline $\begin{array}{l}\text { Fragilaria capucina var. } \\
\text { vaucheriae }\end{array}$ & $\mathrm{X}$ & $\mathrm{X}$ & & & & & & $\mathrm{X}$ & & $\mathrm{X}$ & & & & & & & & $1.8^{*}$ & ** \\
\hline $\begin{array}{l}\text { Fragilaria construens } \mathrm{f} \text {. } \\
\text { binodis }\end{array}$ & & & & & & & & $\mathrm{X}$ & & & & & & & & & & 2,3 & $*$ \\
\hline $\begin{array}{l}\text { Fragilaria construens } \mathrm{f} \text {. } \\
\text { venter }\end{array}$ & & & & & & & & $\mathrm{X}$ & & $\mathrm{X}$ & & & $\mathrm{X}$ & $\mathrm{X}$ & $\mathrm{X}$ & $X$ & $\mathrm{X}$ & 2,3 & ** \\
\hline
\end{tabular}


E. Rott, D. Gesierich, N. Binder

\begin{tabular}{|c|c|c|c|c|c|c|c|c|c|c|c|c|c|c|c|c|c|c|c|}
\hline & 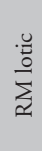 & 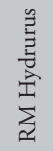 & $\begin{array}{l}\mathscr{y} \\
y \\
y\end{array}$ & $\stackrel{\tilde{A}}{\tilde{I}}$ & 岂 & $\frac{\approx}{\omega}$ & S్త & $\tilde{s}$ & 芯 & $\sum_{\Sigma}^{\infty}$ & $\approx$ & $\tilde{y}$ & 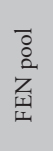 & 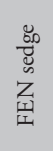 & 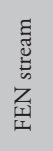 & 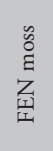 & 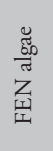 & TW & RL \\
\hline Fragilaria exigua & & & & & & & & & & & & & $\mathrm{X}$ & $\mathrm{X}$ & & & & 0,6 & \\
\hline Fragilaria gracilis & $\mathrm{X}$ & $\mathrm{X}$ & $\mathrm{X}$ & & $\mathrm{X}$ & & & $\mathrm{X}$ & & $\mathrm{X}$ & $\mathrm{X}$ & & $\mathrm{X}$ & $\mathrm{X}$ & $\mathrm{X}$ & $\mathrm{X}$ & $\mathrm{X}$ & & \\
\hline Fragilaria oldenburgiana & & & & & & & & $\mathrm{X}$ & & & & & & $\mathrm{X}$ & & & & & $\mathrm{D}$ \\
\hline Fragilaria pinnata & $\mathrm{X}$ & $\mathrm{X}$ & & $\mathrm{X}$ & $\mathrm{X}$ & & & $\mathrm{X}$ & & & $\mathrm{X}$ & & $\mathrm{X}$ & $\mathrm{X}$ & & & & $2.2^{*}$ & ** \\
\hline Fragilaria tenera & & & & & $\mathrm{X}$ & & & & & & & & & & & & & 1,0 & $\mathrm{~V}$ \\
\hline Fragilaria ulna & $\mathrm{X}$ & & & & $\mathrm{X}$ & & & $\mathrm{X}$ & & & $\mathrm{X}$ & & & & & & & $3.5^{*}$ & $*$ \\
\hline Fragilaria virescens & & & & & & & & $\mathrm{X}$ & & & & & & & $\mathrm{X}$ & & & 1,4 & $\mathrm{~V}$ \\
\hline Frustulia crassinervia & & & & & & & & & & & & & & & & & $\mathrm{X}$ & 0,4 & $\mathrm{~V}$ \\
\hline Frustulia saxonica & & & $\mathrm{X}$ & $\mathrm{X}$ & $\mathrm{X}$ & $\mathrm{X}$ & & & & $\mathrm{X}$ & & & $\mathrm{x}$ & $\mathrm{X}$ & $\mathrm{X}$ & $\mathrm{x}$ & $\mathrm{x}$ & 0,4 & $\mathrm{~V}$ \\
\hline Frustulia sp. & $\mathrm{X}$ & $\mathrm{X}$ & & & & & & & & & & & & & & & & & \\
\hline Gomphonema \#4 JÖ & & & & & & & & & & & & & $\mathrm{X}$ & $\mathrm{X}$ & $\mathrm{X}$ & $\mathrm{X}$ & $\mathrm{X}$ & & \\
\hline Gomphonema amoenum & $\mathrm{X}$ & $\mathrm{X}$ & & & & & & $\mathrm{X}$ & & & & & $\mathrm{X}$ & & $\mathrm{X}$ & $\mathrm{x}$ & $\mathrm{X}$ & 0,4 & 3 \\
\hline Gomphonema anglicum & & & & & & & & & & $\mathrm{X}$ & & & & & & & & & \\
\hline Gomphonema angustum & $\mathrm{X}$ & $\mathrm{X}$ & & & & & & & & & & & & & & & & $1.0^{*}$ & $\mathrm{~V}$ \\
\hline Gomphonema clavatum & $\mathrm{X}$ & $\mathrm{X}$ & & & & & & & & $\mathrm{X}$ & & & $\mathrm{X}$ & $\mathrm{X}$ & $\mathrm{X}$ & $\mathrm{X}$ & & & * \\
\hline Gomphonema coronatum & & & & & $\mathrm{X}$ & & & & & & $\mathrm{X}$ & & & & & & & & 3 \\
\hline Gomphonema exilis & & & & & & & & & & & & & $\mathrm{X}$ & & $\mathrm{X}$ & $\mathrm{X}$ & & & \\
\hline Gomphonema hebridense & & & & & & & & & & & & & $\mathrm{X}$ & $\mathrm{X}$ & $\mathrm{X}$ & $\mathrm{x}$ & $\mathrm{x}$ & 0,9 & $\mathrm{~V}$ \\
\hline Gomphonema micropus & $\mathrm{X}$ & $\mathrm{X}$ & $\mathrm{X}$ & $\mathrm{X}$ & $\mathrm{X}$ & $\mathrm{X}$ & & & & & $\mathrm{X}$ & $\mathrm{X}$ & & & & & & 2,0 & * \\
\hline $\begin{array}{l}\text { Gomphonema olivaceum var. } \\
\text { minutissimum }\end{array}$ & $\mathrm{X}$ & $\mathrm{X}$ & & & & & & & & & & & & & & & & $1.2^{*}$ & $*$ \\
\hline Gomphonema pala & & & & & & & & & & & & & $\mathrm{X}$ & $\mathrm{X}$ & & & & & \\
\hline Gomphonema parvulius & & & $\mathrm{X}$ & & $\mathrm{X}$ & $\mathrm{X}$ & & & & $\mathrm{X}$ & & & $\mathrm{X}$ & $\mathrm{X}$ & $\mathrm{X}$ & $\mathrm{X}$ & & & \\
\hline Gomphonema sp. & & & & & & & & $\mathrm{X}$ & & & & & $\mathrm{X}$ & $\mathrm{X}$ & $\mathrm{X}$ & & & & \\
\hline Gomphonema sphaenovertex & & & & & & & & & & & & & $\mathrm{X}$ & & & & $\mathrm{X}$ & & \\
\hline Gomphonema tergestinum & & $\mathrm{X}$ & $\mathrm{X}$ & $\mathrm{X}$ & $\mathrm{X}$ & $\mathrm{X}$ & $\mathrm{X}$ & & & & $\mathrm{X}$ & $\mathrm{X}$ & & & & & & $1.4^{*}$ & G \\
\hline Gomphonema truncatum & & & & & & & & & & & & & & & $\mathrm{X}$ & & & 1,9 & $*$ \\
\hline Hantzschia amphioxys & $\mathrm{X}$ & & & & & & & & & & $\mathrm{X}$ & & & & & & & $3.6^{*}$ & $* *$ \\
\hline Hygropetra balfouriana & & & & & & & & & & $\mathrm{X}$ & & & $\mathrm{X}$ & $\mathrm{X}$ & & & & 0,6 & $\mathrm{R}$ \\
\hline Luticola acidoclinata & & & & $\mathrm{X}$ & & & & & & & & & & & & & & 2,9 & \\
\hline Meridion circulare & $\mathrm{X}$ & $\mathrm{X}$ & & $\mathrm{X}$ & & & & & & & $\mathrm{X}$ & $\mathrm{X}$ & & & $\mathrm{X}$ & & & $2.5^{*}$ & ** \\
\hline Navicula angusta & & & & & & $\mathrm{X}$ & & $\mathrm{X}$ & & $\mathrm{X}$ & & & & & & $\mathrm{x}$ & $\mathrm{x}$ & 0,6 & 3 \\
\hline Navicula cari & & $\mathrm{X}$ & & & & & & & & & & & & & & & & 2,6 & ** \\
\hline Navicula cf. scutelloides & & & & & & & & & & & & & & & $\mathrm{X}$ & & & 2,7 & \\
\hline
\end{tabular}


Anhang Kapitel 8 I Aquatische Lebensräume

\begin{tabular}{|c|c|c|c|c|c|c|c|c|c|c|c|c|c|c|c|c|c|c|c|}
\hline & 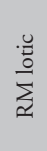 & 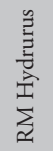 & $\underset{v}{\mathscr{y}}$ & $\stackrel{\mathscr{I}}{\tilde{I}}$ & 岂 & $\ddot{n}$ & 心 & $\tilde{s}$ & 芯 & $\sum_{\Sigma}^{n}$ & జै & $\ddot{v}$ & 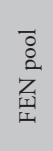 & 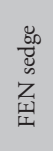 & 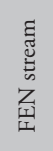 & 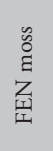 & 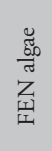 & $\mathrm{TW}$ & RL \\
\hline Navicula cryptocephala & & $\mathrm{X}$ & & & & & & & & & & & & & & & & $3.5^{*}$ & $* *$ \\
\hline Navicula cryptotenella & $\mathrm{X}$ & $\mathrm{X}$ & & & & & $\mathrm{X}$ & & & & $\mathrm{X}$ & & & & & & & $2.3^{*}$ & \\
\hline Navicula exilis & & & $\mathrm{X}$ & $\mathrm{X}$ & $\mathrm{X}$ & & & & & $\mathrm{X}$ & $\mathrm{X}$ & & $\mathrm{X}$ & $\mathrm{X}$ & & $\mathrm{X}$ & & 2,0 & G \\
\hline Navicula heimansoides & & & & & & & & & & & & & $\mathrm{X}$ & & & & & & 3 \\
\hline Navicula radiosa & & & & $\mathrm{X}$ & & & & & & $\mathrm{X}$ & $\mathrm{X}$ & & $\mathrm{X}$ & & & & & 0,6 & $* *$ \\
\hline Navicula tripunctata & & & & & & $\mathrm{X}$ & & & & & & & & & & & & $3.1^{*}$ & $* *$ \\
\hline Navicula trivialis & $\mathrm{X}$ & $\mathrm{X}$ & & & & & & & & & & & & & & & & 3,3 & $* *$ \\
\hline $\begin{array}{l}\text { Naviculadicta } \\
\text { bremensiformis }\end{array}$ & & & & & & & & & & & & & $\mathrm{X}$ & $\mathrm{X}$ & $\mathrm{x}$ & $\mathrm{x}$ & & & 3 \\
\hline Neidium affine & $\mathrm{X}$ & $\mathrm{X}$ & & & & & & & & & & & $\mathrm{X}$ & $\mathrm{x}$ & $\mathrm{X}$ & & & 0,6 & $\mathrm{~V}$ \\
\hline Neidium affine var. linearis & & & & & & & & & & & & & & & $\mathrm{X}$ & & & & \\
\hline Neidium affine var. longiceps & & & & & & & & & & & & & $\mathrm{X}$ & & & & & 0,6 & G \\
\hline Neidium bisulcatum & & & & & & & & & & & & & $\mathrm{X}$ & & $\mathrm{X}$ & & & 0,6 & 3 \\
\hline Nitzschia acidoclinata & & & & & $\mathrm{X}$ & $\mathrm{x}$ & & & & & $\mathrm{X}$ & & $\mathrm{x}$ & $\mathrm{x}$ & $\mathrm{X}$ & & $\mathrm{X}$ & 2,3 & $*$ \\
\hline Nitzschia alpina & & & & & & & & $\mathrm{X}$ & & & $\mathrm{x}$ & & $\mathrm{x}$ & & $\mathrm{x}$ & & $\mathrm{X}$ & 0,6 & G \\
\hline Nitzschia cf. tubicola & $\mathrm{X}$ & $\mathrm{X}$ & & & & & & & & & & & & & & & & 3,4 & * \\
\hline Nitzschia fonticola & $\mathrm{X}$ & & & $\mathrm{X}$ & & & & & & & & & & & & & & 1,9 & ** \\
\hline Nitzschia gracilis & & & & & & & & $\mathrm{X}$ & & & $\mathrm{X}$ & $\mathrm{X}$ & $\mathrm{X}$ & $\mathrm{X}$ & & & $\mathrm{X}$ & $2.5^{*}$ & * \\
\hline Nitzschia hantzschiana & & & & $\mathrm{X}$ & & $\mathrm{X}$ & & $\mathrm{x}$ & & & $\mathrm{X}$ & & $\mathrm{x}$ & $\mathrm{x}$ & & $\mathrm{x}$ & $\mathrm{X}$ & 2,0 & * \\
\hline Nitzschia perminuta & $\mathrm{X}$ & $\mathrm{X}$ & & $\mathrm{X}$ & & & & $\mathrm{X}$ & & & $\mathrm{X}$ & $\mathrm{X}$ & $\mathrm{X}$ & $\mathrm{X}$ & $\mathrm{X}$ & $\mathrm{X}$ & $\mathrm{X}$ & 2,3 & * \\
\hline Nitzschia pura & $\mathrm{X}$ & $\mathrm{X}$ & & & & & & & & & & & $\mathrm{x}$ & & & & & $1.9^{*}$ & * \\
\hline Nitzschia subacicularis & $\mathrm{X}$ & & & & & & & & & & & & & & & & & 2,9 & $\mathrm{R}$ \\
\hline Pinnularia acidoclinata & & & $\mathrm{X}$ & & & & & & & & & & & & & & & & \\
\hline Pinnularia biceps & & & & & & & & & & & & & $\mathrm{x}$ & $\mathrm{x}$ & & & & & \\
\hline Pinnularia borealis & $\mathrm{X}$ & $\mathrm{X}$ & & & & & & & & & & & & & & & & 1,9 & $* *$ \\
\hline $\begin{array}{l}\text { Pinnularia borealis var. } \\
\text { sublinearis }\end{array}$ & & & $\mathrm{X}$ & & & & & & & & & & & & & $\mathrm{X}$ & & & \\
\hline $\begin{array}{l}\text { Pinnularia divergentissima } \\
\text { var. minor }\end{array}$ & & & & & & & & & & & & & & $\mathrm{X}$ & & $\mathrm{X}$ & $\mathrm{X}$ & & $\mathrm{D}$ \\
\hline Pinnularia flexuosa & & & & & & & & & & & & & $\mathrm{X}$ & & & & & & . \\
\hline Pinnularia irrorata & & & & & & & & & & & & & $\mathrm{x}$ & & & & & & \\
\hline Pinnularia microstauron & $\mathrm{X}$ & $\mathrm{X}$ & & & & & & & & & & & $\mathrm{X}$ & $\mathrm{X}$ & $\mathrm{x}$ & & & 1,0 & V \\
\hline Pinnularia neglectiformis & & & & & & & & & & & & & & $\mathrm{X}$ & & & & & \\
\hline Pinnularia notabilis & & & & & & & & & & & & & & $\mathrm{X}$ & & & & & G \\
\hline
\end{tabular}


E. Rott, D. Gesierich, N. Binder

\begin{tabular}{|c|c|c|c|c|c|c|c|c|c|c|c|c|c|c|c|c|c|c|c|}
\hline & $\frac{\underline{\underline{z}}}{\sum_{\Omega}}$ & 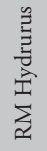 & $\ddot{v}$ & $\tilde{气}$ & 点 & w & 心్త & 多 & 䠌 & $\sum_{\Sigma}^{\infty}$ & $\tilde{\omega}$ & $\ddot{v}$ & $\begin{array}{l}\overline{0} \\
\stackrel{0}{\circ} \\
z \\
z \\
\text { ⿶. } \\
\end{array}$ & 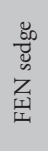 & 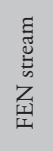 & 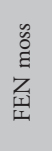 & 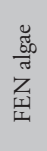 & TW & RL \\
\hline Pinnularia obscura & & & & & $\mathrm{X}$ & $\mathrm{X}$ & & $\mathrm{X}$ & & & & & $\mathrm{X}$ & $\mathrm{x}$ & $\mathrm{X}$ & $\mathrm{X}$ & $\mathrm{X}$ & 2,0 & $* *$ \\
\hline Pinnularia ovata & & & & & & & & & & & & & $\mathrm{X}$ & & & & & & \\
\hline Pinnularia permicrostauron & & & & & & & & & & & & & $\mathrm{X}$ & & & & & & \\
\hline Pinnularia pisciculus & & & & & & & & & & & & & & & & $\mathrm{X}$ & & & \\
\hline Pinnularia stidolphii & & & & & & & & & & & & & $\mathrm{X}$ & & & & $\mathrm{X}$ & & \\
\hline Pinnularia subcapitata & & $\mathrm{X}$ & & & & & & & & & & & & & & & & & * \\
\hline $\begin{array}{l}\text { Pinnularia subcapitata var. } \\
\text { subrostrata }\end{array}$ & & & $\mathrm{X}$ & & $\mathrm{X}$ & & & & & & & & $\mathrm{X}$ & $\mathrm{X}$ & & $\mathrm{X}$ & $\mathrm{X}$ & & * \\
\hline Pinnularia submicrostauron & & & & $\mathrm{X}$ & & & & & & & & & & & & & & & $\mathrm{D}$ \\
\hline $\begin{array}{l}\text { Pinnularia tirolensis var. } \\
\text { julma }\end{array}$ & & & & & & & & & & & & & $\mathrm{X}$ & $\mathrm{X}$ & & & & & \\
\hline Pinnularia viridiformis & & & & & & & & & & & & & & & & & $\mathrm{X}$ & & G \\
\hline Pinnularia viridis & & & & & & & & & & & & & $\mathrm{X}$ & & $\mathrm{X}$ & & & 1,3 & * \\
\hline Reimeri sinuata & $\mathrm{X}$ & $\mathrm{X}$ & & $\mathrm{X}$ & $\mathrm{X}$ & $\mathrm{X}$ & & $\mathrm{X}$ & & $\mathrm{X}$ & & $\mathrm{X}$ & & & & & & $2.1^{*}$ & $* *$ \\
\hline Sellaphora laevissima & & & & & & & & & & & & & & $\mathrm{X}$ & & & & 1,1 & $\mathrm{~V}$ \\
\hline Sellaphora pupula & & & & $\mathrm{x}$ & $\mathrm{x}$ & & & & & & & & $\mathrm{X}$ & $\mathrm{x}$ & $\mathrm{X}$ & $\mathrm{X}$ & & $3.7^{*}$ & $* *$ \\
\hline Stauroneis prominula & & & & & & & & & & & & & $\mathrm{X}$ & & & & $\mathrm{x}$ & & \\
\hline Surirella sp. & & & & & & & & & & & & & & & & & $\mathrm{x}$ & & \\
\hline Tabellaria flocculosa & $\mathrm{X}$ & $\mathrm{X}$ & & $\mathrm{X}$ & $\mathrm{X}$ & & & $\mathrm{X}$ & & & & $\mathrm{X}$ & $\mathrm{X}$ & $\mathrm{X}$ & $\mathrm{X}$ & $\mathrm{X}$ & $\mathrm{X}$ & $0.8^{*}$ & ** \\
\hline \multicolumn{20}{|l|}{ Chlorophyceae } \\
\hline Gongrosira debaryana & & & & & & & & $\mathrm{X}$ & & & & & & & & & & $2.1^{*}$ & \\
\hline Gongrosira incrustans & & & & & & & & & & & $\mathrm{X}$ & & & & & & & $1.8^{*}$ & \\
\hline Haematococcus pluvialis & & & & & & & & & & & & & $\mathrm{X}$ & & & & & & \\
\hline Microspora sp. & & & & $\mathrm{X}$ & & & & & & & & & & & $\mathrm{X}$ & & $\mathrm{X}$ & & \\
\hline Oedogonium sp. & & & & & & & & $\mathrm{X}$ & & $\mathrm{X}$ & & & & & $\mathrm{X}$ & & $\mathrm{X}$ & & \\
\hline Oocystis solitaria & & & & & & & & & & & & & $\mathrm{X}$ & & & & & & \\
\hline Pediastrum tetras & & & & & & & & & & & & & $\mathrm{X}$ & & & & & & \\
\hline Sphaerobotrys fluviatilis & & & & & & & & $\mathrm{X}$ & & & & & & & & & & $3.1^{*}$ & \\
\hline Stigeoclonium sp. & & & & & & & & & & & & & & & & & $\mathrm{X}$ & & \\
\hline \multicolumn{20}{|l|}{ Zygnematophyceae } \\
\hline Closterium closterioides & & & & & & & & & & & & & $\mathrm{X}$ & & & & & & 3 \\
\hline Closterium lunula & & & & & & & & & $\mathrm{X}$ & & $\mathrm{X}$ & & & & & & & & \\
\hline Closterium striolatum & & & & & & & & & & & & & $\mathrm{X}$ & $\mathrm{x}$ & & & & & 3 \\
\hline Cosmarium botrytis & & & & & & & & & & & $\mathrm{X}$ & & & & $\mathrm{X}$ & & & & 3 \\
\hline
\end{tabular}




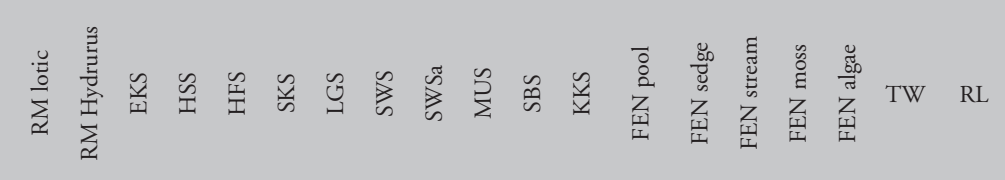

Cosmarium difficile

Cosmarium impressulum var. alpicolum

Cosmarium margaritiferum

Cosmarium novae-semliae

X

var. sibiricum

Cosmarium ochthodes

Cosmarium subcostatum

var. minus

Cosmarium vexatum var. concavum

Euastrum ansatum var. pyxidatum

Euastrum bidentatum

X X

Euastrum denticulatum

X

X

Euastrum inerme

Euastrum verrucosum var. alatum

Micrasterias denticulata

Micrasterias denticulata var angulosa

X X

Micrasterias papillifera

X X

Mongeotia ovalis

X X

Mougeotia sp.

Penium cylindrus

Penium sp.

$\mathrm{X}$

Penium spirostriolatum

Sphaerozosmasp.

$$
\text { X }
$$

Spirogyra sp.

X X

X

Staurastrum crenulatum

X

X

3

Staurastrum monticulosum

X

Staurastrum orbiculare var. ralfsii 
E. Rott, D. Gesierich, N. Binder

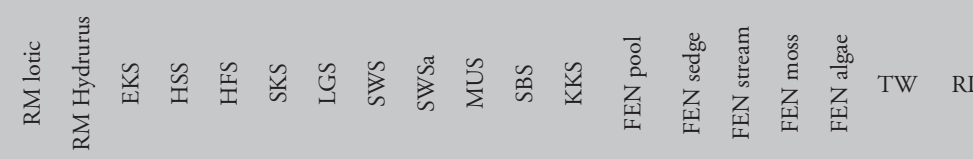

Staurastrum pyramidatum

$$
\text { X }
$$

Staurastrum teliferum var.

ordinatum

$\mathrm{X}$

Tetmemorus granulatus

X

Zygnema sp.

X X

X $\quad X \quad X$

Dinophyceae

Gloeodinium montanum

X X

Rhodophyceae

Chantransia sp.

\begin{tabular}{|c|c|c|c|c|c|c|c|c|c|c|c|c|c|c|c|c|c|}
\hline Vaucheria sp. & & & & & & & & & $\mathrm{X}$ & & & & & & & & \\
\hline Artenzahl Kieselalgen & 63 & 61 & 27 & 38 & 48 & 27 & 14 & 50 & 6 & 41 & 46 & 19 & 89 & 65 & 68 & 60 & 57 \\
\hline $\begin{array}{l}\text { Artenzahl Nicht- } \\
\text { Kieselalgen }\end{array}$ & 2 & 4 & 2 & 3 & 8 & 2 & 3 & 29 & 15 & 12 & 26 & 18 & 35 & 10 & 11 & 5 & 13 \\
\hline Gesamtartenzahl & 65 & 65 & 29 & 41 & 56 & 29 & 17 & 79 & 21 & 53 & 72 & 37 & 124 & 75 & 79 & 65 & 70 \\
\hline
\end{tabular}

Xanthophyceae 


\section{U. Peintner, R. Kuhnert}

\section{Pilze und mikrobielle Gemeinschaften im Gletschervorfeld}

Tab. A1:

Pilztaxa des Rotmoostales (Vegetationsperioden 2005-2007)

saprobe Pilze (SAP), Ektomykorrhiza Pilze (ECM), lichenicole Pilze (LICH), parasitische Pilze (PAR),

$\left(^{*}\right)$ alpine Taxa, $\left(^{\circ}\right)$ aus der alpinen Zone bekannt, (!) erstmals in der alpinen Zone festgestellt

\section{Pilztaxa des Rotmoostales}

$\begin{array}{cl}\text { ECM } & \begin{array}{l}\text { Ektomykorrhiza } \\ \text { Pilze }\end{array} \\ \text { LICH } & \text { lichenicole Pilze } \\ \text { PAR } & \text { parasitische Pilze } \\ \text { SAP } & \text { saprobe Pilze } \\ * & \text { alpine Taxa } \\ \circ & \text { aus der alpinen Zone bekannt } \\ ! & \text { erstmals in der alpinen Zone festgestellt }\end{array}$

Basidiomycota

Agaricales

$\begin{array}{lllll}\text { SAP } & ! & \text { Agaricus } & \text { porphyrhizon } & \text { P.D. Orton } \\ \text { SAP } & \circ & \text { Agaricus } & \text { silvicola } & \text { Vittad. } \\ \text { SAP } & \circ & \text { Agrocybe } & \text { praecox } & \text { (Pers. : Fr.) Fayod } \\ \text { ECM } & ! & \text { Alnicola } & \text { alno-betulae } & \\ \text { SAP } & \circ & \text { Arrhenia } & \text { acerosa } & \text { (Fr.) Kühner } \\ \text { SAP } & \circ & \text { Arrhenia } & \text { auriscalpium } & \text { (Fr.) Fr. } \\ \text { SAP } & \circ & \text { Arrhenia } & \text { griseopallida } & \text { (Desm.) Watling } \\ \text { SAP } & \circ & \text { Arrhenia } & \text { latispora } & \text { (J. Favre) Bon \& Courtec. } \\ \text { SAP } & \circ & \text { Arrhenia } & \text { lobata } & \text { (Pers.) Kühner \& Lamoure ex Redhead } \\ \text { SAP } & \circ & \text { Arrhenia } & \text { obatra } & \text { (J. Favre) Redhead, Lutzoni, Moncalvo \& } \\ & & & \text { Vilgalys } & \text { (D.A. Reid) Redhead, Lutzoni, Moncalvo \& } \\ \text { SAP } & \circ & \text { Arrhenia } & \text { obscurata } & \text { Vilgalys } \\ & & & \text { Arrhenia } & \text { spathulata } \\ \text { SAP } & \circ & \text { trigonospora } & \text { (Fr.) Redhead } \\ \text { SAP } & * & \text { Arrhenia } & \text { (Lamoure) Redhead, Lutzoni, Moncalvo \& } \\ & & & \text { Vilgalys }\end{array}$


U. Peintner, R. Kuhnert

\begin{tabular}{|c|c|c|c|c|}
\hline SAP & $\circ$ & Arrhenia & velutipes & $\begin{array}{l}\text { (P.D. Orton) Redhead, Lutzoni, Moncalvo \& } \\
\text { Vilgalys }\end{array}$ \\
\hline SAP & $\circ$ & Bovista & nigrescens & Pers. \\
\hline SAP & & Bovista & $s p$ & \\
\hline SAP & $\circ$ & Calyptella & capula & Quél. \\
\hline ECM & & Clavaria & cf. argillacea & Fr. \\
\hline ECM & $\circ$ & Clavulinopsis & vernalis & (Schwein.) Corner \\
\hline SAP & $*$ & Clitocybe & candicans var. dryadicola & Lamoure \\
\hline SAP & $\circ$ & Clitocybe & festiva & J. Favre \\
\hline SAP & $*$ & Clitocybe & festivoides & Lamoure \\
\hline SAP & $*$ & Clitocybe & lateritia & J. Favre \\
\hline SAP & $\circ$ & Clitocybe & marginella & Harmaja \\
\hline SAP & $*$ & Clitocybe & nuoljae & Lamoure \\
\hline SAP & $*$ & Clitocybe & paxillus & Gulden \\
\hline SAP & $\circ$ & Clitocybe & phyllophila & (Pers.) P. Kumm., ss. Kuyper \& Bellu \\
\hline SAP & $\circ$ & Clitocybe & suaveolens & (Schumach.) P. Kumm. \\
\hline SAP & $\circ$ & Clitopilus & scyphoides & (Fr.) Singer \\
\hline SAP & $\circ$ & Collybia & aquosa & (Bull.) P. Kumm. \\
\hline SAP & $\circ$ & Conocybe & juniana var. subsejuncta & Hauskn. \\
\hline SAP & $\circ$ & Coprinus & martinii & J. Favre \\
\hline ECM & $*$ & Cortinarius & adalbertii & J. Favre \\
\hline ECM & $*$ & Cortinarius & albonigrellus & J. Favre \\
\hline ECM & * & Cortinarius & alpinus & Boud. \\
\hline ECM & * & Cortinarius & bresadolae & Schulzer ss. Lamoure \\
\hline ECM & * & Cortinarius & caesionigrellus & Lamoure \\
\hline ECM & $*$ & Cortinarius & chrysomallus & Lamoure \\
\hline ECM & $*$ & Cortinarius & comatus & J. Favre \\
\hline ECM & $\circ$ & Cortinarius & comptulus & M.M. Moser \\
\hline ECM & $*$ & Cortinarius & diasemospermus & Lamoure \\
\hline ECM & * & Cortinarius & gausapatus & J. Favre \\
\hline ECM & * & Cortinarius & galerinoides & Lamoure \\
\hline ECM & $\circ$ & Cortinarius & helvelloides & (Bull.) Fr. \\
\hline ECM & * & Cortinarius & binnuleus var. favreanus & Bon \\
\hline ECM & * & Cortinarius & inops & J. Favre \\
\hline ECM & $*$ & Cortinarius & levipileus & J. Favre \\
\hline ECM & * & Cortinarius & minutulus & J. Favre \\
\hline ECM & $*$ & Cortinarius & obtusus cf. & (Fr.) Fr. \\
\hline ECM & $*$ & Cortinarius & oreobius & J. Favre \\
\hline
\end{tabular}


Kapitel 9 | Pilze und mikrobielle Gemeinschaften im Gletschervorfeld

\begin{tabular}{|c|c|c|c|c|}
\hline ECM & $*$ & Cortinarius & pauperculus & J. Favre \\
\hline $\mathrm{ECM}$ & $*$ & Cortinarius & phaeochrous & J. Favre \\
\hline ECM & * & Cortinarius & phaeopygmaeus & J. Favre \\
\hline ECM & * & Cortinarius & rusticellus & J. Favre \\
\hline $\mathrm{ECM}$ & * & Cortinarius & stenospermus & Lamoure \\
\hline $\mathrm{ECM}$ & * & Cortinarius & subfusisporus & Bon \\
\hline $\mathrm{ECM}$ & $*$ & Cortinarius & subtilior & J. Favre \\
\hline ECM & * & Cortinarius & tenebricus & J. Favre \\
\hline $\mathrm{ECM}$ & & Cortinarius & $s p$ & \\
\hline SAP & $\circ$ & Cuphophyllus & ochraceopallidus & (P.D. Orton) Bon \\
\hline SAP & $\circ$ & Cystoderma & carcharias & (Pers.) Fayod \\
\hline SAP & $\circ$ & Entoloma & asprellum & (Fr.) M.M. Moser \\
\hline SAP & $\circ$ & Entoloma & atrosericeum & (Kühner) Noordel. \\
\hline SAP & $\circ$ & Entoloma & bipellis & Noordel. \& T. Borgen \\
\hline SAP & $\circ$ & Entoloma & cetratum & (Fr.) M.M. Moser \\
\hline SAP & $\circ$ & Entoloma & conferendum & (Britzelm.) Noordel. \\
\hline SAP & $\circ$ & Entoloma & flocculosum & (Bres.) Pacioni \\
\hline SAP & $\circ$ & Entoloma & formosum & (Fr.) Noordel. \\
\hline SAP & $\circ$ & Entoloma & infula & (Fr.: Fr.) Noordel. \\
\hline SAP & o & Entoloma & juncinum & (Kühner \& Romagn.) Noordel. \\
\hline SAP & $\circ$ & Entoloma & lividocyanulum & (Kühner) M.M. Moser \\
\hline SAP & $\circ$ & Entoloma & papillatum & (Bres.) Dennis \\
\hline SAP & $\circ$ & Entoloma & porphyrophaeum & P. Karst \\
\hline SAP & $\circ$ & Entoloma & prunuloides & (Fr.) Quél. \\
\hline SAP & $\circ$ & Entoloma & sericatum & (Britzelm.) Sacc. \\
\hline SAP & $\circ$ & Entoloma & sericellum & (Fr.) P. Kumm. \\
\hline ECM ? & $\circ$ & Entoloma & sericeum & (Bull.) Quél. \\
\hline SAP & $\circ$ & Entoloma & serrulatum & (Pers.) Hesler \\
\hline SAP & & Entoloma & $s p$ & \\
\hline SAP & $\circ$ & Flagelloscypha & dextrinoidea & Agerer \\
\hline SAP & $\circ$ & Galerina & calyptrata & P.D. Orton \\
\hline SAP & $\circ$ & Galerina & clavata & (Velen.) Kühner \\
\hline SAP & $\circ$ & Galerina & pseudomycenopsis & Pilát \\
\hline SAP & $\circ$ & Galerina & vittiformis & (Fr.) Earle \\
\hline SAP & & Galerina & $s p$ & \\
\hline ECM & * & Hebeloma & alpinum & (J. Favre) Bruchet \\
\hline ECM & $\circ$ & Hebeloma & candidipes & Bruchet \\
\hline
\end{tabular}


U. Peintner, R. Kuhnert

\begin{tabular}{|c|c|c|c|c|}
\hline ECM & $\circ$ & Hebeloma & collariatum & Bruchet \\
\hline ECM & $\circ$ & Hebeloma & crustuliniforme & (Bull.) Quél. \\
\hline ECM & * & Hebeloma & marginatulum & (J. Favre) Bruchet \\
\hline ECM & $\circ$ & Hebeloma & mesophaeum & (Pers.) Quél. \\
\hline ECM & $\circ$ & Hebeloma & nigellum & Bruchet \\
\hline SAP & $*$ & Hemimycena & ochrogaleata & (Favre) Moser \\
\hline SAP & 。 & Hygrocybe & chlorophana & (Fr. : Fr.) Wünsche \\
\hline SAP & * & Hygrocybe & citrinopallida & (Smith \& Hesler) Kobayasi \\
\hline SAP & $\circ$ & Hygrocybe & coccineocrenata & (P.D. Orton) M.M. Moser \\
\hline SAP & $\circ$ & Hygrocybe & conica & (Schaeff.: Fr.) Fr. \\
\hline SAP & $\circ$ & Hygrocybe & conicopalustris & R. Haller Aar. \\
\hline SAP & $\circ$ & Hygrocybe & helobia cf. & (Arnolds) Bon \\
\hline SAP & $\circ$ & Hygrocybe & insipida & (J.E. Lange ex S. Lundell) M.M. Moser \\
\hline SAP & $\circ$ & Hygrocybe & laeta var. laeta & (Pers.) P. Kumm. \\
\hline SAP & $\circ$ & Hygrocybe & mucronella & (Fr.) P. Karst. p.p. \\
\hline SAP & $\circ$ & Hygrocybe & pratensis & (Pers. : Fr.) Murrill \\
\hline SAP & $\circ$ & Hygrocybe & pseudoconica var. tristis & (Pers.) Bon \\
\hline SAP & $\circ$ & Hygrocybe & substrangulata & (P.D. Orton) P.D. Orton \& Watling \\
\hline SAP & 。 & Hygrocybe & xanthochroa of & (P.D. Orton) M.M. Moser \\
\hline SAP & 。 & Hygrocybe & $\begin{array}{l}\text { virginea var. } \\
\text { ochraceopallida }\end{array}$ & (P.D. Orton) Boertm \\
\hline SAP & $\circ$ & Hygrocybe & pratensis & (Pers.) Murrill \\
\hline SAP & $\circ$ & Hygrocybe & turunda $c f$. & (Fr. : Fr.) Karst \\
\hline SAP & $\circ$ & Hygrocybe & virginea & (Wulfen) P.D. Orton \& Watling \\
\hline SAP & $\circ$ & Hypholoma & elongatum & (Pers.) Ricken \\
\hline SAP & $\circ$ & Hypholoma & subfusisporum & (F.H. Møller) M.M. Moser \\
\hline SAP & $\circ$ & Hypholoma & myosotis & (Fr.) M. Lange \\
\hline SAP & & Hypholoma & $s p$. & \\
\hline ECM & * & Inocybe & albidodisca & Kühner \\
\hline ECM & $\circ$ & Inocybe & aurea & Huijsman \\
\hline ECM & $*$ & Inocybe & canescens & J. Favre \\
\hline ECM & $\circ$ & Inocybe & dulcamara Gruppe & \\
\hline ECM & * & Inocybe & egenula & J. Favre \\
\hline ECM & * & Inocybe & favrei & Bon \\
\hline ECM & $\circ$ & Inocybe & fraudans & (Britzelm.) Sacc. \\
\hline ECM & * & Inocybe & frigidula & Favre \\
\hline ECM & * & Inocybe & fulvipes & Kühner \\
\hline
\end{tabular}


Kapitel 9 | Pilze und mikrobielle Gemeinschaften im Gletschervorfeld

\begin{tabular}{|c|c|c|c|c|}
\hline ECM & $*$ & Inocybe & $\begin{array}{l}\text { fuscomarginata var. } \\
\text { leucolepis }\end{array}$ & Kühner \\
\hline ECM & $*$ & Inocybe & geraniodora & J. Favre \\
\hline ECM & * & Inocybe & giacomi & J. Favre \\
\hline ECM & $\circ$ & Inocybe & inodora & Velen. \\
\hline ECM & * & Inocybe & johannae & Kühner \\
\hline ECM & $\circ$ & Inocybe & lacera & (Fr. : Fr. ) P. Kumm. \\
\hline ECM & $\circ$ & Inocybe & leucoblema & Kühner \\
\hline ECM & * & Inocybe & leucoloma & Kühner \\
\hline ECM & $*$ & Inocybe & luteipes & J. Favre \\
\hline $\mathrm{ECM}$ & $*$ & Inocybe & maculipes & J. Favre \\
\hline ECM & * & Inocybe & obscurobadia & (J. Favre) Grund \& D.E. Stuntz \\
\hline $\mathrm{ECM}$ & $!$ & Inocybe & ochroalba & Bruyl. \\
\hline ECM & * & Inocybe & oreina & Favre \\
\hline ECM & $\circ$ & Inocybe & praetervisa & Quél. ss. Favre \\
\hline ECM & $\circ$ & Inocybe & praetervisa f. luteophylla & Bon \& Jamoni \\
\hline ECM & $!$ & Inocybe & pseudodestricta & Stabgl \& J. Veselský \\
\hline ECM & $\circ$ & Inocybe & pseudohiulca & Kühner \\
\hline ECM & * & Inocybe & rufofusca & (J.Favre) Bon \\
\hline ECM & $\circ$ & Inocybe & soluta & Velen. \\
\hline ECM & * & Inocybe & striaepes & Kühner \\
\hline ECM & $!$ & Inocybe & striata & Bres. \\
\hline ECM & * & Inocybe & substellata & Kühner \\
\hline ECM & * & Inocybe & substraminipes & Kühner \\
\hline $\mathrm{ECM}$ & * & Inocybe & tenerella ss. Favre & (J. Favre) J. Favre \\
\hline ECM & $\circ$ & Inocybe & tenerella cf. (ovalispora) & \\
\hline ECM & $*$ & Inocybe & tetragonospora & Kühner \\
\hline ECM & $!$ & Inocybe & umbrina & Bres. \\
\hline ECM & $\circ$ & Inocybe & vulpinella & Bruyl. \\
\hline ECM & & Inocybe & $s p .(1)$ & \\
\hline ECM & & Inocybe & $s p .(2)$ & \\
\hline ECM & $\circ$ & Laccaria & montana & Singer \\
\hline ECM & $\circ$ & Laccaria & pumila & Fayod \\
\hline ECM & $\circ$ & Laccaria & tetraspora & Singer \\
\hline SAP & $\circ$ & Lacrymaria & glareosa & (J. Favre) Watling \\
\hline SAP & $\circ$ & Lepiota & $a l b a$ & (Bres.) Sacc. \\
\hline SAP & & Lepista & $s p$. & \\
\hline
\end{tabular}




\begin{tabular}{|c|c|c|c|c|}
\hline $\mathrm{LICH}$ & $\circ$ & Lichenomphalia & grisella & $\begin{array}{l}\text { (P. Karst.) Redhead, Lutzoni, Moncalvo \& } \\
\text { Vilgalys }\end{array}$ \\
\hline LICH & & Lichenomphalia & alpina & $\begin{array}{l}\text { (Britzelm.) Redhead, Lutzoni, Moncalvo \& } \\
\text { Vilgalys }\end{array}$ \\
\hline SAP & $\circ$ & Lycoperdon & marginatum cf. & Vittad. \\
\hline SAP & $\circ$ & Lycoperdon & umbrinum & Pers. \\
\hline SAP & & Lycoperdon & $s p$ & \\
\hline SAP & $!$ & Macrocystidia & cucumis & (Pers.) Joss. \\
\hline SAP & $\circ$ & Melanoleuca & leucophylloides cf. & (Bon) Bon \\
\hline SAP & & Melanoleuca & $s p$ & \\
\hline SAP & $\circ$ & Mycena & pura & (Pers.) P. Kumm. \\
\hline SAP & & Mycena & $s p$ & \\
\hline SAP & $\circ$ & Mycenella & salicina & (Velen.) Singer \\
\hline SAP & $*$ & Ompablina & pseudomuralis & Lamoure \\
\hline SAP & $\circ$ & Omphalina & favrei & Watling \\
\hline SAP & $\circ$ & Omphalina & hepatica & (Fr. : Fr.) P. D. Orton \\
\hline SAP & $\circ$ & Omphalina & kuehneri & Lamoure \\
\hline SAP & $\circ$ & Omphalina & rivulicola & (Favre) Lamoure \\
\hline SAP & & Omphalina & $s p$ & \\
\hline SAP & o & Panaeolus & acuminatus & (Schaeff.) Quél. \\
\hline SAP & o & Panaeolus & papilionaceus & (Bull.) Quél. \\
\hline SAP & $\circ$ & Panaeolus & semiovatus & (Sow.) S. Lundell \& Nannf. \\
\hline SAP & o & Phaeogalera & stagnina & (Fr.) Pegler \& T.W.K. Young \\
\hline SAP ? & o & Pleurotellus & hypnophilus & (Pers.) Fayod \\
\hline SAP & o & Psilocybe & merdaria & (Fr.) Ricken \\
\hline SAP & $\circ$ & Psilocybe & semilanceata & (Fr.) P. Kumm. \\
\hline SAP & * & Psilocybe & velifera & (J. Favre) Singer \\
\hline SAP & o & Psilocybe & montana cf. & (Pers.) P. Kumm. \\
\hline SAP & & Psilocybe & $s p$. & \\
\hline SAP & o & Rickenella & fibula & (Bull.ex Fr.) Raithelh. \\
\hline SAP & o & Stropharia & caerulea cf. & Kreisel \\
\hline SAP & $\circ$ & Stropharia & pseudocyanea f. ochrocyanea & (Bon) Noordel. \\
\hline SAP & $\circ$ & Stropharia & semiglobata & (Batsch : Fr.) Quél. \\
\hline
\end{tabular}


Kapitel 9 | Pilze und mikrobielle Gemeinschaften im Gletschervorfeld

\section{Cantharellales}

ECM Clavulina rugo

\section{Geastrales}

SAP $\quad$ Geastrum

SAP $\quad \circ \quad$ Geastrum

\section{Russulales}

$\mathrm{ECM} *$ Lactariu

$\mathrm{ECM} \quad * \quad$ Lactarius

ECM $\quad * \quad$ Lactarius

ECM * Lactarius

ECM !? Lactarius

ECM $\quad * \quad$ Russula

ECM * Russula

ECM * Russula

ECM * Russula

$\mathrm{ECM} \quad * \quad$ Russula

Sebacinales

ECM ! Sebacina

ECM ! Sebacina

ECM

Sebacina

\section{Thelephorales}

$\begin{array}{llll}\text { ECM } & \circ & \text { Thelephora } & \text { caryopyllea } \\ \text { ECM } & ! & \text { Tomentella } & \text { sp. (1) } \\ \text { ECM } & ! & \text { Tomentella } & \text { sp. (2) }\end{array}$

Ascomycota

Pezizales

$\begin{array}{lll}\text { SAP } & \circ & \text { Geopora } \\ \text { ECM } & \circ & \text { Helvella } \\ \text { ECM } & * & \text { Helvella }\end{array}$

minimum

kotlabae?

brunneoviolaceus

nanus

pseudouvidus

robertianus

rufus

emetica var. alpestris

nana

norvegia

oreina

saliceticola

epigaea

incrustans

$s p$.

sp. (2)
(Bull.) J.Schröt.

Schwein

V.J. Stanek

M.P. Christ.

J. Favre

Kühner

Bon

(Scop.: Fr.) Fr.

Singer

Killerm.

D.A. Reid

Singer

(Singer) Kühner ex Knudsen \& T. Borgen

(Berk. \& Broome) Bourdot \& Galzin (Pers.) Tul. \& C. Tul.

(Schaeff.) Pers.

(Boud.) Torre

(O. Weberb.) Massee

T. Schum. 
U. Peintner, R. Kuhnert

$\begin{array}{lllll}\text { SAP } & \circ & \text { Neottiella } & \text { aphanodictyon } & \text { (Kobayasi) Dissing, Korf \& Sivertsen } \\ \text { ECM ? } & \circ & \text { Peziza } & \text { cf. badia } & \text { Pers. } \\ \text { SAP } & \circ & \text { Scutellinia } & \text { kerguelensis } & \text { (Berk. : Hook) O. Kuntze } \\ \text { SAP } & \circ & \text { Scutellinia } & \text { hyperborea } & \text { T. Schumach. } \\ & & & & \\ & & \text { Helotiales } & & \text { Eckblad } \\ \text { SAP } & * & \text { Geoglossum } & \text { alpinum } & \text { (W. Phillips) Dennis } \\ \text { ECM ? } & & \text { Hymenoscyphus } & \text { repandus } & \text { Raitv. } \\ \text { SAP ? } & \circ & \text { Hyalopeziza } & \text { latispora } & \\ & & & & \text { (Bals.-Criv.) Vuill. } \\ \text { PAR } & & \text { Bypocreales } & & \text { (Alb. \& Schwein.) Tul. \& C. Tul. } \\ \text { PAR } & \circ & \text { Hypomyces } & \text { rosellus } & \\ & & & & \end{array}$

